
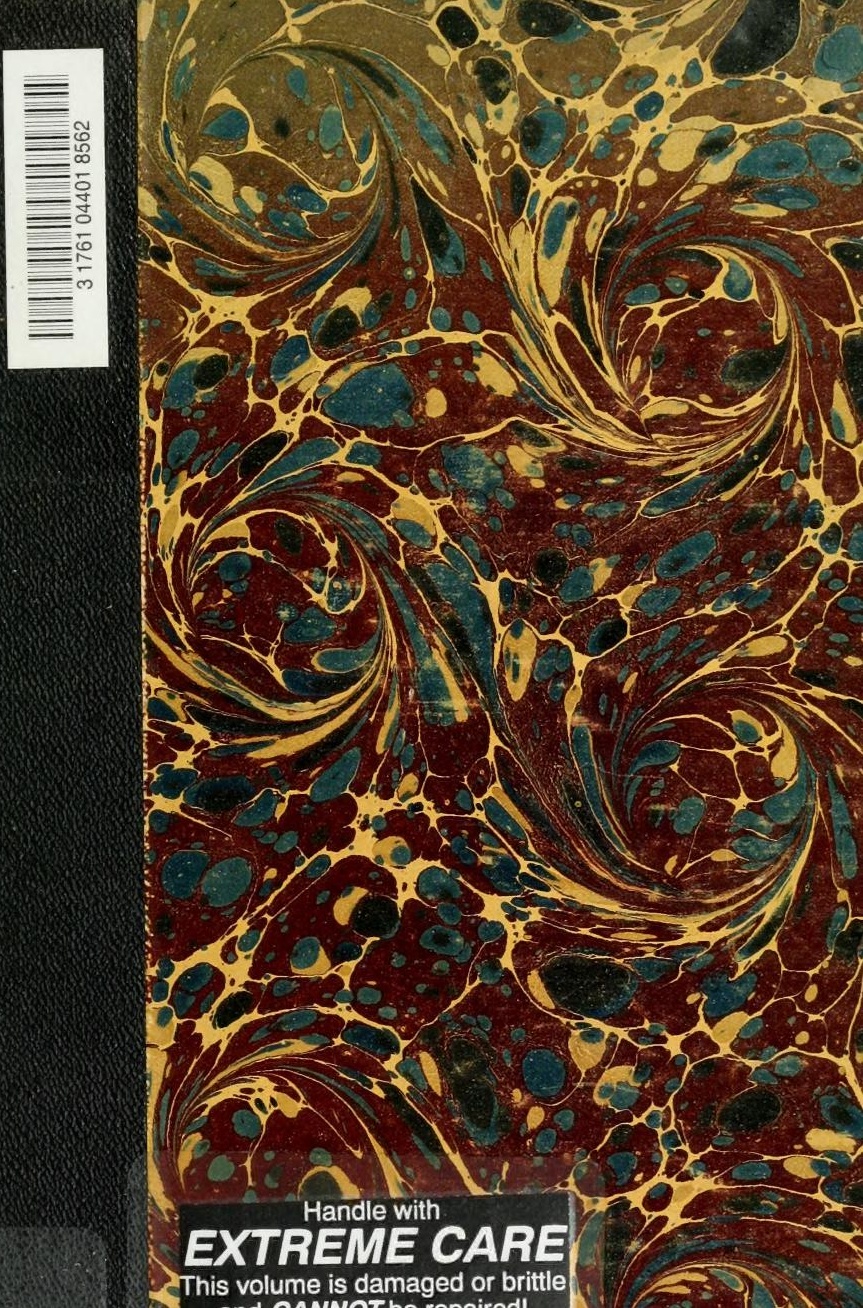


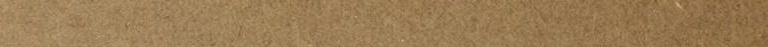


or 



\title{
DIE PILZE BÖHMENS.
}

ERSTER TEIL.

\section{ROSTPILZE (UREDINALES).}

\author{
BEARBEITET
}

VON

Ph. Dr. FRANZ BUBÁK,

ORD. PROFESSOR DER BOTANIK UND DER PFLANZENKRANKHEITEN AN DER KÖNIGL.

LANDWIRTSCHAFTLICHEN AKADEMIE IN TÁBOR.

ARCHIV DER NATURWISSENSCHAFTLICHEN LANDESDURCHFORSCHUNG VON BÖHMEN. XIII. BAND. NRO. 5.
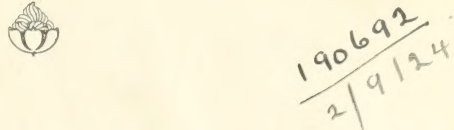

PRAG.

IN COMMISION BEI FR. R̉IVNÁC. - DRUCK VON DR. ED. GRÉGR A SYN 1908. 

SEINER HOCHWOHLGEBOREN HERRN

\section{HERRN J. E. KABÁT,}

EM. ZUCKERFABRIKSDIREKTOR,

MEINEM LIEBEN MITARBEITER IN FREUNDSCHAFTLICHER ERINNERUNG

WIDME ICH DIESES BUCH. 


$$
\begin{aligned}
& \text { QK } \\
& 608 \\
& \text { CaB8 } \\
& 1908
\end{aligned}
$$




\section{Vorwort.}

Nach langjährigem Studium der böhmischen Pilze, mit welchen ich mich schon seit dem J. 1890 beschäftige, übergebe ich der Offentlichkeit den ersten Teil der böhınischen Pilzflora und zwar die Rostpilze, die ich besonders in d. J. 1896 und 1898-1901 eingehend studiert habe.

Der zweite Teil, welcher bald folgen soll, wird die Phycomyceten, Ustilagineen und Tilletiineen enthalten. Die weiteren Bände (3., 4. und 5.) werden die Basidiomyceten, Ascomyceten und Fungi imperfecti behandeln.

$\mathrm{Zu}$ allen diesen Gruppen hat sich während der vielen Jahre ein sehr reichhaltiges Material in meinen Sammlungen angehäuft. Es stammt teils aus den Händen meiner botanischen Freunde, von welchen ich besondnrs den eifrigen Mykologen Herrn Dir. J. E. K a bát in Turnau hervorhebe, hauptsächlich ist es aber mein eigenhändig gesammeltes Material, welches von unzähligen Exkursionen in Böhmen zusammengetragen wurde.

Sehr wertvolle Beiträge erhielt ich auch von folgenden Herren: Professor Dr. J. Velenovský, A. Weidmann, Direktor der Knabenvolksschule in Wittingau, $\dagger$ G. Wagner, Lehrer in Schmilka in Schandau in Sachsen, W. Krieger, Lehrer in Königstein a./E. in Sachsen, † MUDr. J. M üh $1 \mathrm{~b}$ a $\mathrm{ch}$ in Chotébor, Doz. Dr. K. Domin in Prag. † Ph. C. Th. Novák in Prag. Sehr nennenswerte Beiträge lieferten in den letzten Jahren die Herren: † Lehrer J. Houska in Lenešic, F. M a l o c h, Bürgerschullehrer in Pilsen, V: V o dák, Bürgerschullehrer früher in Pardubic, jetat in Dobruška, wie auch Herr Prof. Fr. M a t ou s chek, früher in Reichenberg, jetzt in Wien.

Alle litterarischen Beiträge, welche die Pilıflora Böhmens betreffen und welche alle in der historischen Éinleitung aufgeführt sind, exceptierte ich immer mit grösster Vorsicht, denn bei vielen ist das wissenschaftliche Niveau sehr gering. Näheres über diese Sache kann man entweder in der oben citirten Einleitung oder bei einzelnen Arten fiuden.

Von grösseren Sammlungen, die ich durchgeseheu habe, wären besonders zu nennen: Die mykologisehen Sammlungen des böhmischen Museums in Prag, der k. k. deutschen Universität daselbst, der k. k. Gymnasien in Jičín und Jungbunzlau, des k. k. Hofmuseums in Wien, wie auch einige kleinere Privatsammlungen.

Jene Pilze, die ich auf den angeführten Standorten selbst gesammelt habe, sind mit(!) versehen; wo dasselbe Zeichen hinter dem Namen des Sammlers steht, zeigt es an, dass ich dus Material von dieser Lokalität gesehen habe. 
Lange Jahre - fasst beinahe ein halbes Jahrhundert - lag das mykologische Studium bei uns brach, es war Niemand da, der sich entschlossen hätte, wenigstens eine Partie dieser interessanten Pflanzenklasse zu bearbeiten, anderseits nahmen diesbezügliche Arbeiten Leute vor, die keine genügende botanische Vorbildung hatten, es waren dies kurz und gut nur Dilettanten, welche nichts anderes als irgend eine Kompilationsarbeit von schlecht bestimmten Arten geleistet haben.

Eine weitere Ursache war auch ein grosser Mangel an Litteratur, denn nicht nur die mykologische, sondern auch die kryptogamische Litteratur überhaupt wurde von den sechziger Jahren des vorigen Jahrhundertes angefangen, systematisch in allen öffentlichen Bibliotheken vernachlässigt, indem nur das gekauft wurde, was die massgebenden Persönlichkeiten zu ihren Studien brauchten.

Endlich gibt es weder in Prag noch in Böhmen überhaupt eine öffentlich zugängliche mykologische Sammlung, in welcher die grossen Exsikkatenwerke von Sydow, Vestergren, Krieger, Allescher, Brinkmann, D. Saccardo, Ellis et Everhart etc. zu finden wären.

Die einzige grosse Sammlung in Böhmen überhaupt ist meine eigene, in welcher circa 15.000 Species in circa 300.000 Exemplaren aus allen Pilzklassen vertreten sind.

Bei solchen Umständen nimmt es nicht Wunder, wenn Jemand angefangen hat sich mit dem Studium der Pilze zu befassen, er bald alle Lust zur weiteren Arbeit verlieren musste, als er auf die grossen Schwierigkeiten in der Beschaffung der Litteratur und des Vergleichnugsmaterials gestossen ist.

Ich hoffe, dass durch den vorliegenden ersten Teil der böhmischen Pilzflora, das erste abgeschlossene mykologische Werk in Böhmen überhaupt, wenigstens einige Freunde der Naturwissenschaft zum eifrigeren Studium der Pilze angeregt werden. Ich bin jederzeit gerne bereit, einem jeden Interessenten bei diesem Bestreben beihilflich zu sein.

Meinen wärmsten Dank schulde ich hauptsächlich Herrn Prof. Dr. Ant. Frič, welcher meine Studien auf allerlei Art beförderte. Unterstützungen zu meiner Arbeit erhielt ich von der löbl. böhm. Kaiser Franz Josefs Akademie in Prag und von dem löbl. Komité für Landesdurchforschung von Böhmen. Ich danke auf dieser Stelle beiden genamnten Korporationen dafür aufs innigste.

Die vorliegende deutsche Ausgabe (die böhmische erschien Ende 1906) enthällt auch alle diejenigen Funde der böhmischen Uredineen, welche von mir und meinen Freunden im J. 1907 gemacht wurden. Ebenso wurden auch in derselben alle Arbeiten, die im Jabre 1907 erschienen, berücksichtigt.

TÁBOR, im Januar 1908 . 


\section{Historische Entwicklung des mykologischen Studiums in Böhmen.}

Die Anfänge des mykologischen Studiums in Böhmen sind an den Namen des Philip Maximilian Opiz gebunten, welcher, wei auch aus den im böhm. Museum befindlichen bisiccaten ersichtlich, schon vor dem J. 1sin Pilae sammeit. und bestimmte.

Allerdings sind schon riel früher zwei Publikationen in Prag erschienten welche auch Beiträge zur Systematik unıl Kilasifikation der Pilze enthielten, beile sind aber mit der geschichtlichen Entwidilung des mylougrischen studiums im unseren Vaterlande keineswegs verbunden. Es sind dies J. A. Scopulis: Dissertu. tiones ad scientiam naturalem pertinentes aus d. J. 1772 und "Introductio ad historiam naturalem" aus d. J. 1777.

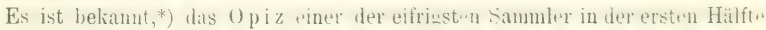
des vorigen Jahrhumlertes war. Er betrieh seinte Taitigkeit nicht nur in den Platnerogamen, sondern auch in den Kryptogamen.

Schon im J. 1816 veröffentlichte er in Röhling's „Flora Deutschlands“ anhangsweise und im J.1n17 in Pras selbständig ein lerzeichuiss der hryptogam.n Deutschlands, welche nach den Substraten zeordnet sins. unter dem Titel:

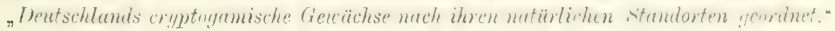
In diesem Verzeichnisse betimen sich auch einige Anraben üher böhmi-che I'ilat. welche zwar mit einem Stermhen i", versehen sind, loch fehlen die standurtsangaben bei ihnen ganz und gar.

Sehr bald verstand es Opiz eine ansehnliche Reihe von botauischen Sammlern um sich zu gruppieren, die er aneiferte auch dic kungi zu sammeln. Es waren dies besonders: Johann Graf $\mathrm{Chotek}$, welcher in der

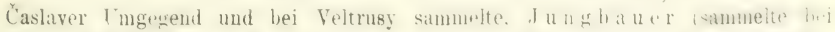

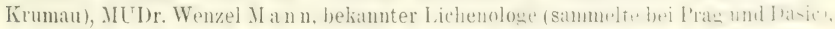
Jurist $M \ddot{0} \mathrm{rk}$ Von $M$ örkenstein (sammelte bei Strašic), Kajetan Nenning (bei Hohenfurt), Quadrat (bei Prag) und viele andere.

In Jahre 1818 gründete $O$ piz seine Tauschanstalt für Naturalien, als erste diesartige Institution ïherhaupt. Die ersten Antinge derselhen waren aiemlich

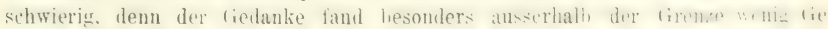
fallen. Dies dauerte allerdings nicht lange, denn in kurzer Zeit wurden alle

*) Siehe auch V. Maimald's Geschichte der Botanik in Böhmen, Wien und Leipzig. 1900. 
Sehranken gebrochen und sein Gedanke fand bald viele Anerkennung und nach uud nach entstanden ähnliche Anstalten auch anderwärts.

Durch die genaunte Tauschaustalt wurde die Sammeltätigkeit in Böhmen in besonderem Maasse gefïrdert. allerdings waren es in ersten Reihe die Phauerogamen, welche hier die grösste Berücksichtigung fanden.

Ausser den obengenamuten Männern versammelte $\mathrm{O}_{\mathrm{p} \text { i z }}$ in der ersten Periode seiner Tauschanstalt weitere botanischen Ailepte um sich, die auch für ihn sammelten, wie Ramisch, Ta usch, Malý, Presl, Erxleben, Beneš, Steinreit e r, K l e mens, A h s b as, Jir ás ek, Spring s eld, Sýkora, Konrád, etc.

Die von diesen Männeru gesammelten Pilze wurden von $O \mathrm{p}$ i z bestimmt und durch seine Tauschanstalt gelangten sie in private und iffentliche Sammlungen nicht nur in Böhmen, sondern in ganz Mitteleuropa.

Ehenfalls im . 1. 1818, gah O piz eine Sammluug von Kryptogamen aus. Sie besteht aus $:$ Heften ,je 25 Sprecies), in welchen auch einige Pilze enthalten sind und trägt den Namen ${ }_{n}$ F lor a c ryptog a m c a B o e m i a e.*)

Im J. 1821 übergab IUDr. J. V. Krombholz dem Drucke ein Verzeichniss der essharen Pilze, die im J. 1,20 in Pras äffentlich foilgehoten wurden unter dem Titel. "Conspectus fungorum esculentorum, qui per decursum anni 1820 Pragae publice vendebantur."

Der eifrige Opiz stellte im J. 1823 naç circa 10jähriger botanischer Tätigkeit ein Verzeichniss der brihmischen Phanerogamen und Kryptogamen: Böheims phanerogamische und kryptoganische Gewächse", welches auch Pilze enthillt, leider wrisstenteils wirder ohue Standortsangaben. Bei einigen Species siud auch neben den Standortsangaben die betreffenden Sammler hauptsächlich die Teilnehmer seiner Tauschanstalt, angeführt.

Im demsellnen Jahre gründete O pi z eine periodische Zeitschift: Naturalientausch de's F. .I. () piz, welche als Hauptorgan seiner Tauschanstalt dienen sollte. Ausserilem anthielt sie anch verschieden" Abhandlumgen, Rezensionen. Aufrufe etc

Es erschienen von derselben in freien Zeitrüumen von J. 1823 bis zum J. 182x im Ganz'n 12 Hefte, von welchen die letzten einen geänderten Titel und zwar . laträge zur Naturesehirhte" führen. In lieser Zeitschrift sind auch einige kleinere Berichte, Sotizen und miliologische Artilielchen, wie noch weiter unten ausführlicher dargelegt wird, enthalten.

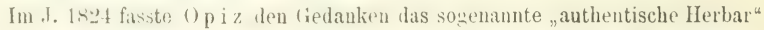
zu grümden, welehes jederman zugïnglich sein sollte, damit sich die Naturforscher die Prioritiit ilırer Funde (hesser nener Arten) sichern könnten. Er bestätigte zunleich in seinem Orwan den Empfang aller lieitritge für dieses Herbar, damit anch das hotanische Puhlikum auf die betreftenden Entdeckungen aufmerksam gemacht und hiedurch zu weiteren Forschungen angeifert werde.

I as authentische Herbar hefand sich in der Opizschen Wohnung und war nur Jerlezman zuninglich. In demselben befand sich auch eine ansehuliche

*) Siche F. Mfatouschete in Verhandlnngen d.k. k. Zool. bot. Gesellschaft Wien 1900 pag.

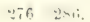




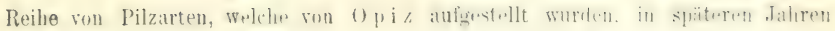
auch viele neue Spezies von Corda und einigen anderen Mykologen.

In J. 1826 begegnet man zum erstenmale dem Namen von August Karl Josef Cord a, damals einem achtzehnjährigen, Jünglinge und zwit in rim. lim.

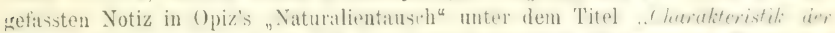

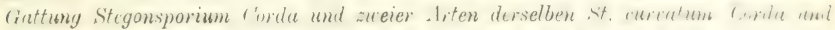
st. rotumium Corda (1. c. pg. 45s-459). In dieser ['eriole fime (orda an im sthellen Tempo sich mykologische Kenutuisse anzueignen, wovon besmders zwei Manm-krigt..

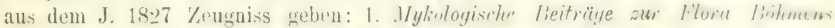
in welcher die Gattungs- und Art-I)iannosen, wie anch Standortsanabben f rkon

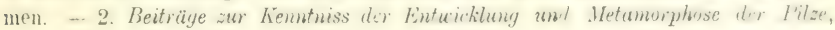

Zu dieser Zeit fühlen Corda und Opiz zugleich bei den böhmischen botanikern einen Mangel an Lust zu mykolonischeu Studien. dem an-ser dusti

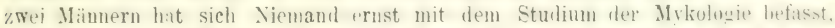
nur mykologisches Material wurde für sie ofters aresammelt. (p)iz sant in seinem Aufrufe vom 11. Februar 1.27 (Naturalientausch 1) 472): Ein grosser Tuil der angebenden Botaniliex fühlt eine wewisse Art Widerwillen gruen das Studium der Mykologie." In weiteren Keilen fortert or dite sammler auf, beim Anlesrn von mykologischen Sammlungen auch auf elegante Ausstattung zu achten.

Kurz darnach wentet sich wieder Corda zu den Botanikern in Böhmen indem er sie zur Pflege des mykolngischen Studiums anmifert. Er ruft folgunler massen: „Meine Herren! liei dem jetzt so hohen Stamle dep phäungamisehen fortamik, dem unermïdeten Streben durch Tausch seine Kimntnisse zu bereichran. hei so genauer [uterscheidung iler Arten, bei den daburch erzengten fortwihrmidn neuen Entiledkungen in unserem geliebten Vaterlande, den vom Per-run +riffueten,

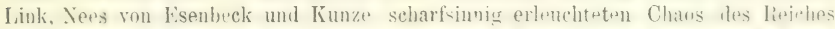
der Schwämme, kamm ich nicht einsehen, warum diesen Theil der Intanik rie-w Herren Vatuforseher Böhmens so ganz vernachläsigen: Sind schwämme und l'ils.

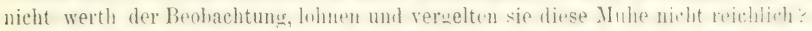

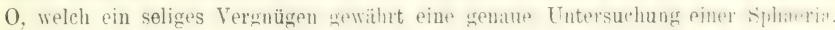
eines Thamnidium..." etc. und zum Ende: "Ahmte nur jeder Herm Opiz, Dr. Mann, Jungbauer und Herrn Nenning nach, o! wie bald wäre unser werthes Vaterland in dieser Hinsicht aufgeklät, denn jeder. welcher tessm Xindel- m !

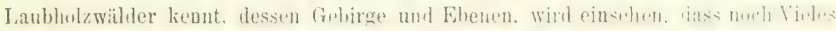
zu thun übrig ist und was gethan wurde, haben wir ja nur einzig und allein den

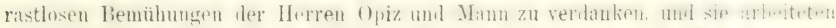

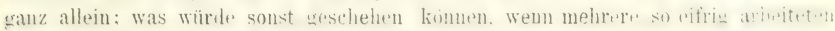
und keine Mühe, kein Hinderniss scheuten! - Dies ist mein und des peehrten

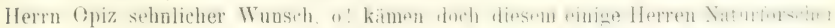
nach, wïrle bald Herr Opiz und ich durch Thaten überzengt, dass diese Worte nicht fruchtlos waren und sind."

Ich zitiere diese Stellen aus Corda's Aufrufe wörtlich, damit Ćorda’s jugend-

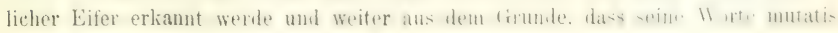
mutandis bis heutzutage giltig sind. 
Im J. 1828 veröffentlichte Krombholz in der Monatszeitschrift der Vaterlïndischen (iesellschaft des böhmischen Museums die Abhandlung: „l'eber eine neue Morchelart ${ }^{2}$, in welcher er eine neue Marchelspezies - Morchella bohemica - und eine anilere seltene Art - Morchella hybrida - beschreibt und abbildet. Die Tafel ruiht gewiss von Corda.

In demselben Jahre publizierte Corda nur kleinere mykologische Notizen; 1. Erineum*) P'raesensianum Corila (Opiz, Beitrïge zur Naturgeschichte 1828, pg. 660), 2. Syloma violaceum Corda (1. c. p. 662).

Auch folgende drei mykologischen Notizen Eck's*it) sind auf Corda zurïckzuführen :

1. Sporotrichum compactum Eck (1. c. 1). 598).

2. Cenangium Cordae Eck (1. c. pg. 658).

3. Eck: Über Ilea (Fries) Corda em. und Kosteletzkya Corda (1. c. pg. 671).

In dieser Zeit arbeite Corda schon an seinen Pilzen für Sturm's Flora Iientschlands, und schon im Jahre 19.9 erschien ein Band (III. Abteilung, 2. Band) mit 64 liolorierien 'Tafeln. Der zweite liand (III. Abteilung, 3. Band) wurde im Jahre 1837 ausgegeben.

Ein merkwürdiges Ereigniss in dex mykologisehen Litteratur dieser Perionle waren Krombholz's ,Naturgetreue Abbildungen and Beschreibungen der essbaren, schädlichen und imdächtigen schuämme. I)as Werk, von welchem das erste Heft im J. 1837 erschien, wurde erst im J. 1846 vollendet, Das nötige Pilzmaterial, (hauptsicblich von Huppilzen), für die Abbildung liess Krombholz in zahlreichen Bezirken Böhmens in grosen Massen sammeln und entweder frisch oder konserviert einsenden. Krombholz erlebte selbst nut die Herausgabe von sieben Heften, denn er starb schon im J. 1842. Nach seinem Tode führte die Redaktion des Werkes Zobel.

Corda, welcher von Krombholz in seinen Studien sachlich und materiell unterstiitat wurde, verfertinte für sein Werk mikroskopische I)tails. wie auch zahlreiche l'ilzabhilungen und übte anch rinen niclit unbedeutenden Einthass auf den Text aus.

Das Krombholz sehte Werk, welches auf 34 Folio Tafeln eine srosse Anzahl von verschieleuen, hauptsäthlich ter fleischigen Pilzspezies darstellt, war seiner Zeit sehr geachtet. Leider versitumte anch Kromhholz sehr oft die Standorte anzugeben, indem er sich auf alluemeine Verhältuisse, in welchen die oder jene Pilzart rorkommt, beschrïnkte.

In den J. 1831-1835 sammelte Corda allmählich das Material für seine "Icones l'ungorum" und deswegen besitzten wir ans dieser l'eriode von ihm keine mýkologische Arbeit. Man kennt hier nur seinem Vurtrag gehalten am 1!?. September im J. 1833 in der Vexsummlung der dentschen Naturforscher und Aerzte in Breslau "l̈ber Michelïs Intheren der Fleischpilze" . iehe Flora oder botanisehe Zeitung 1834 , pg. $113-115)$.

") Damals waren Erin e $\mathrm{m}$ und Phy lle rium noch für Pilze gehalten; jetzt wissen wir von denselben, dass sie von parasitichen Milbenarten aus den Gattungen Phytoptus (Kriophyes) verursacht werden.

**) E ck Josef, war in J. 1828 Magistratskonzipist; er sammelte in der Umgegend von Prag. 
Lirst im Jahre 1836 veröffentlichte er in Weiten weber's "Beitrig zur zuesammten Natur- und Heilwisseuschaft" (I. Band, 1. Heft, pg. 80) „M/yliologische Beiträge" in welchen er die Gattungen, Doratomyces Corda, Epicoceum Link und

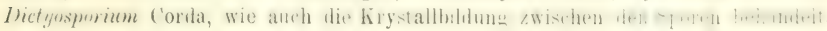

In folgenden Jahre (1837) erschien endlich der I. Teil seines Monumentalwerkes "lcones Fungorum hucusque cognitorum". Die weiteren liande erschienen: II. (1838), IIi. (1839), IV. (1840), V. (1842). Das Erscheinen des YI. I3andes

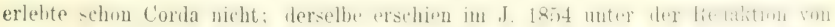
Dr. J. B. ZobeI. "Icones Fungorum" gehören zu fundamentalen mykologischen

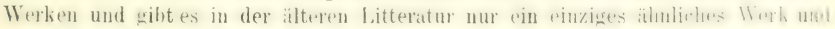
zwar 'I'ulasne's "Selecta fungorum Carpologia" (1861-1865). Corda war der

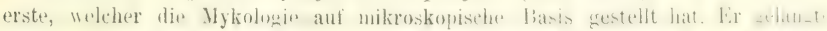

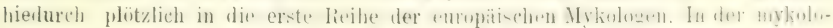

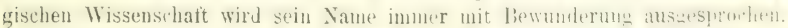

Sein Werk ${ }_{n}$ Icones $^{u}$ ist noch heute ein wertvolles Buch, welches kein Mykologe enthehren kann. Dawon gibt die Ausuabe der cwei anastatischen Xentruh. (Friedländer in Berlin) genügendes Zeugnis.

Zugleich mit dem dritten Teile der "Icones" erschien Corda 's "Frachtflora europäischer Schimmelbildungen" und im nächsten Jahre deren

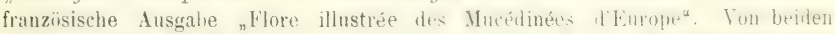

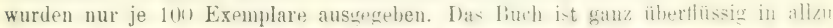
grossem Format gebalten, so dass fichleiden in der ersten Auscabre seiner Lotanik pg. 165. mit vollem Recht das Werk "sinnlos verschwenderisch ${ }^{\star}$ neunt. Auf 25) Tafeln von wrossem Folioformat ist immer anit Ausuathme der Tafel VIII. nu. je ein Pilz abgebildet. Alle angefühten Arten - allerolings in kinimerem .Yasstabe - konnten sehr leicht auf 2-3 Tafeln desselben Formates reproduziert werden. Denselben Vorwurf kam man auch manchen Tiafeln dex [rones liumenum machen, besonders jenen des sechsten Bandes.

Im Jahre 1842 veröffentlichte $\mathrm{Cor}$ a seine Anlcitung zum Studium der Mykologie". Dieses Buch hat drei Abteilungen. In der ersten ist die myko-

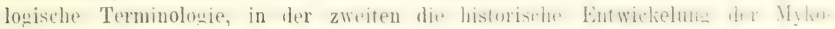

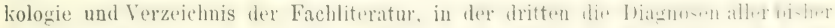

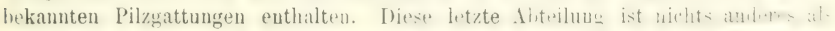
eine Wiedergabe der I. Abteilung aus dem V. Bande seiner lcoues Fungurum.

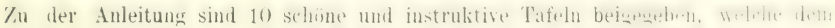

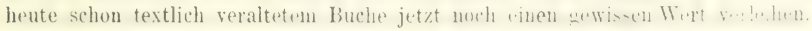

Corda bescküftigte sich auch wit Phytopathologie und verifflentlichte zwei Abhandlungen über parasitische Pilze:

1. Beitrag zur Kenntnis der Brandarten der Cerealien und

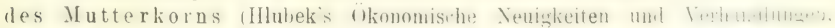
Prag 1846). In dieser Arbeit beschreibt der Autor auch eine neue lirandart Uredo Secalis Corda, eine seltene Brandart des Kornes, die, wie bekannt, jetzt Tilletia Secalis (Corda) heisst.

2. Beiträge zur Kunde der Kartoffel in Beziehuug auf ihre Organisation und Krankheiten. (Daselbst 1847.) 
Sehr willkommen war den bihmischen Botanikern, die sich auch mit Mykolunie beschittigten, der im .I. 1 int erschienene zweite band vom I'resl's Werke "Vseobecny rostlinopis" (Allgemeine Botanik), in welchem pg. 1852-1995 auch eine systematische Bearbeitung der wichtinsten Pilce enthalten war. Iu dieser Partie. die allerdings nur Kompilation ist, denn Pres! beschäftinte sich nicht wit Pilzen, ist auch lieioe Riüclisicht aut die Verhreitung der Pilze in Böhmen renommen, dafür wurle aber hier die bähmische mykologische Terminologie geschattien, deren man sich noch heute berlient. Nirh gründlicher als in dem oben genannten wurle aber die mykologishe Terminologie in seinem spüteren Werke

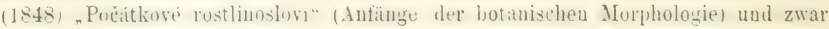
pg. $212-238$ bearbeitet.

Im J. 1849 verschwand Corda ganz geheimnisroll mit dem Schiffe „Victoria", auf dem er von einer Forschungsreise aus Texas heimkehrte. Im August 1849 schiffte er sich in New-Orleans ein, das Schiff wurde aber nach einigen Wochen in westimischen Waisern menschenleer nefunden. Was mit der Besatzung und mit len l'assagieren übrhaut geschah. bleiht his bente unaufrehlant.

Mit Corda verschwand der einzige, auf wissenschaftlicher Grundlage

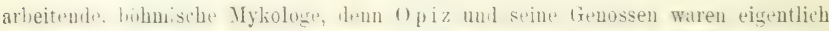
nur simmler, welche die Pllze nur mit Hile der Lupe hestimmten. Die allgemein bekannte Richtung der Opiz'schen schnle äusserte sich hauptsitchlich darin, dass fast eine jede Varietät und Form zur Species erhohen wurle. Da diese neuen Arten von () 1 i z gewrihnlich uhm. Diagnost publizirt oler nu serteilt wurten. so

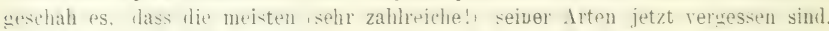

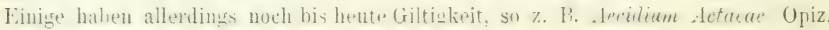
Aecilium Sweertiae Opiz usw.

Nach Corda's Tode war Opiz der einzige, welcher hie und da irgend welche mylolonische Notiz publizirte. So im J. 1s.il veroffentlichte er im Lotos zwei neue Arten von Hericium. In Jahre 1852 erschien von ihm der bekannte

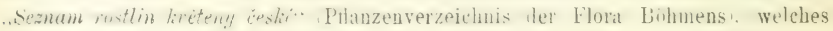
auch alphabetisch zusammeurestellte Enumeration ler bisher aus Bohmen bekaunt gewordenen Pilze enthält, allerdings wieder ohme Standortsangaben.

Schon lange Jahre vorher sammelte Opiz eifrig Material für seinen, Nomen-

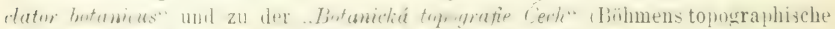
lotanik, welche anch Pilze suthielten. Beile Werke bliehen aher im Manuskript.

In den Jiliren $1851-56$ publizirte $0 \mathrm{piz}$ im Lotos: ,Uebersicht der auf

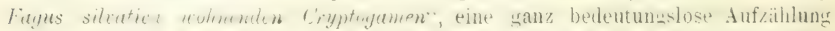

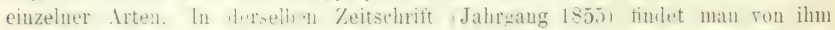

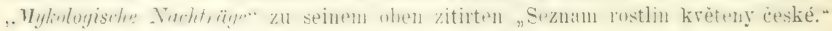
Im J. 1856 reröffentlicht er, wieder in Lotos, ,Eimige neue böhmische Pilze d. i. eine Beschreibung vou vier neuen Basidiomyceten.

$\mathrm{Zu}$ dieser Zeit beginuen einige Mïnner sich mit rollem Ernste mit der Mytologie zu hushattigen. Es waren dies hir ho her, (hirurg in Kaplitz. Peyl.

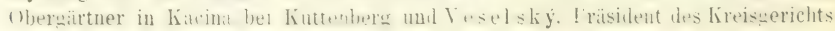
in Kuttenberg.

Von diesen schätze ich besonders Peyl am höchsten. 
Kirchner veröffentlichte im Lotos im J. $1856^{\circ}$ "Beschreibung einiger newen und im südlichen T'eile des Budweiser Kreises seltener vorkommenden Pilze". In

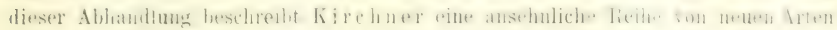
Der grösste 'T'eil derselben wurde aber sehon früher von verschiedenen IIykologen beschrieben, was Kirchner, der die betreffende Literatur nicht besass, nicht

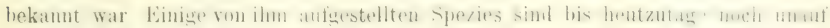
geklärt und es scheint mir, dass sie auf eine falsche Bestimmung des Nährsubstrates zurückzuführen sind. Es sind dies besonders die Arten: Uredo Ajugae Kirchner, Aecidium Succisue Kirchner, Uredo Nasturtii Kirchner (nach der Be-

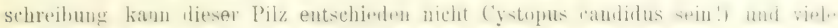
andere.

In demselben Jahre (1856) erschien die erste Arbeit von Veselsk $y$ "Verzeicheis der l'ilze Böhmens" und zwar in der Bsterreichischen botanischen

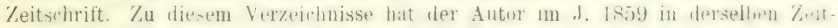
schrift noch Nachträge veriffentlicht Die tenannten Verseichnisse siml für die Pilztlora von Böhmen wichtin und zeigen zurleich, wie Veselsky bei der liegrenzung der einzelnen Arten behutsam vorging.

Im J. 1857 publizirt Opiz im Lotos eine einzige Notiz, in welcher er den

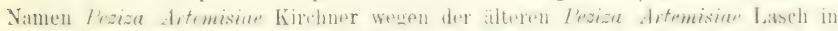
Peziza Kirchner Opiz ändert. In demselben Jalırgange teilt Dr. Gintl ein

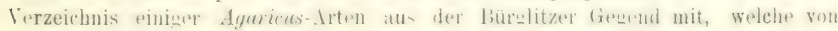
Rabenhorst bestimmt wurden.

Im J. 1857 übergibt Peyl in derselben Zeitschrift der Öffentlichkeit seine erste Arbeit "Beschreibung ciniger neuen Pilze", die sich bis in den nächsten

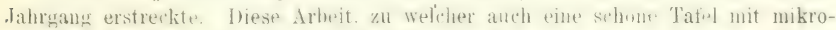

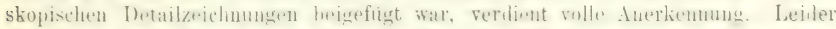

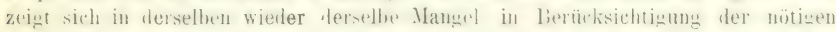
Literatur. Ausser diesem Artikel veröffentlichte Peyl im J. 1865 im Lotos eine

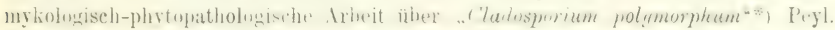

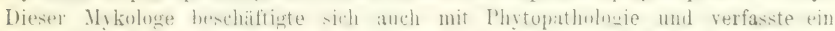

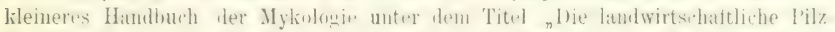
kunde für Landwirte, Forstmämer, (iürtner und ILausfrauen" (Prag 18ẗ̈. bei Calve).

Zu den letzten Arheiten von Opiz gehören im Lotos 1857 nDie Schmarotzer unserer Georyinen", tue lufzähluns von l'ilzen auf (ierorgiuen und daselhst eine

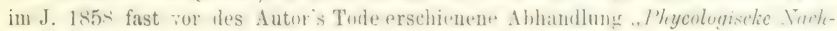

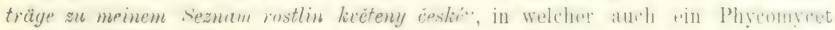
Achlya prolifera Cienk aufgefülırt wird.

Durch den Tw 0 pizs phielt die systematische botanik in liohmen einen grossen Verlust. denn Opiz war mech im sreisen Alter ein sehr Heissiger sumuler ron kiryptogamen und Phameroramen und er verstand es auch die jüugere (itente.

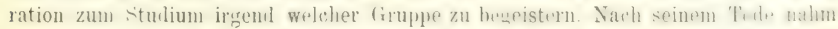
auch die sehr blühende Tauschtitigkeit in Böhmen ihr Ende.

*) Ist identisch mit Fusicladium pirinum Fuckel, relches als Conidienform zu Venturia pirina Fuckel gehört. 
Von den späteren Arbeiten wäre besonders nennenswert K i r ch n e r's im J. 1862 im Lotos erschienene Abhandlung "Die Pilzsucht der Insekten", in wolcher all, damals bekanten entomiphthoren Pilze aufgezählt werden. Die in Böhmen gefundenen derartigen Pilze werden hier ebenfalls respektiert.

In der Periode von J. 1862-1875 begegnet inan in den Zeitschriften keine mykologische drheit, drm alie diejenigen, welche sich nit der Mykologie beschäftigt hahen sind entwerler gestorben oder haben das Studium derselben aufgegeben. Man kamn hier nur eine kleine Notiz von Mahner im Lotos 1874 „Ein neuer Trüffelfundort in Böhmen6" erwähneu.

Weun wir die uanze 0 piz'sche Lera überblicken, so finden wir, dass ausser Corda und vielleicht noch $\mathrm{Krombholz}$ und Peyl die übrigen Mykologen eigentlich mo l'ilzsummler waren. Wenn wir dann weiter den Umstand erwägen, dass diese Mianner ïher die nötige Literatur nicht verfügten und infolgedessen von dem jeweiligen Stande der mykologischen Systematik keine Uebersicht hatten, unil weiturhin, lass sie ihre funde hauptsichlich nur mittelst der Lupe bestiumten, so müssen wir zugeben, dass die Resultate ihrer Forschungen für unseren Zweck nur einen sehr prohlematischen Wort besitzen. Nur in dem Falle, wenu das betreffende Material noch erhalten und brauchbar ist, kann man ihre neuen Arten und Funde respektiren.

Von späteren Sammlern nenne ich ausser den schon angeführten noch Sachs, Hennevogel, Karl, Štika, Laube, Schöbl, Fierlinger etc.

Was die alten Sammlungen betrifft, so kimn ich auch über diese referieren. In der botanischrn Abteilung des königlichen böhmischen Museums in Prag ist eine sehr urusse Anzahl von böhmischen Pilzen vorhanden, von welchen leider viele durch ierschiedene Insekten seh. gelitten haben. Dieselben stammen grösstenteils aus () p i is Tauschanstalt, und waren fasst alle in seinem Herbar einverleiht. Ausserim hrimlen sich in den renamnten Sammlungen eingereiht: Yeselskýs mykolugisches Herhar, einige Pilzarten von Peyl, Kirchner, Hoffmann und anderen. Den Pilzen, welche Corda gesammelt hat, fehlen die Standortsangaben. Denselben Fehler hegring (orda anch in seinen Icones fungorum. Da er von sehr vielen Leuten aus dom Auslando. Material zum Bectimmen bekam, so kann man für die böhmische Pilzflorit nur joue Arten akzeptieren, bei welchen Standortsangahe vorhanden ist.

Dats Herhatrimm von Peyl befindet sich in den Simmlungen der k. k. böhm. Realschule in liarolinenthal; sein mykologischer Teil representiert eine ansehnlichr Reihe von Fascikeln. Ausser den Arten, welche Peyl boi Kačina gesammelt hat und rom welchen wieder sehr viele keine Standortsangaben aufweiseni finden wir in dieser Sammlung dieselben Species, welche auch im böhm. Museum aufbewahrt werden.

Im Naturalienkabinet des k. k. (iymmasiums in J un g b unz la u befindet sich eine kleine Sammlums nach dem † Dr. W im mer, welche nur aus ausgetauschten Arten besteht. Klein ist die mykologische liollektion des k. k. Gymnasium in Jičin.

Im Herbarium des Dr. Baur in Smíchov habe ich eine Reihe von Pilzen aus der Gegend von Biolnm. Leipa gefunden, welche daselbst Prof. Dr. Schiffner fresammelt hat. Darunter befinden sich einige seltene Pilzarten. Ziemlich viele 
böhmische Pilze liegen im Herbar d. k. k. Il ofun seums in Wien. In lirünn*) be-

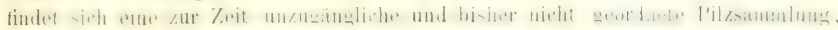
welche ron Ka lmus zusammengestellt wurde und ein Exemplar der oben angeführten Exsiccatensammlung von Opiz.**) Kirchner's Pilze befinden sich bei seinem Sohne in Wien.

Alle genannten Sanmlungen - ausser jener des k. k. Hofmuseums in Wien -

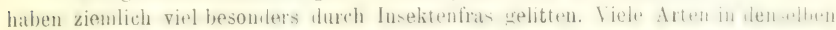
sind entweder steril oder es wurilen ihre Sporen gänzlich von verschiedenen In.

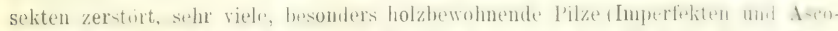

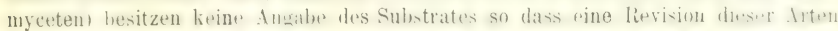

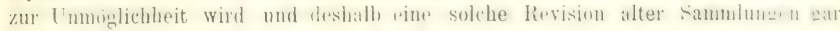
nicht lohnend erscheint.

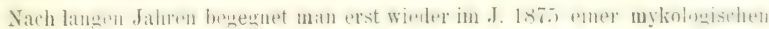

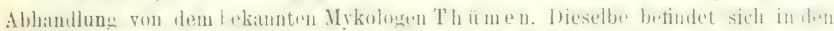
Verhamdlumsen il. k. k. zoul. botan. liesellschaft in Wien und fuldrt den Titel ..limi-

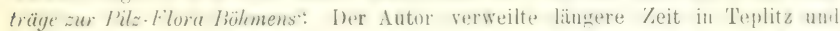
unternahm von dort aus zahlreiche Exkursionen in den Landstrich $=$ Aussig a. E. und Kommotau, wie auch in das Erzgebirge. Obzwar 'T'h ümen's Ilrbar in Bukarest durch Brand vernichtet wurde, befmden sich doch moch fast. von allen seiuen Arten Belere in seinen Exsiccatenwerken: Fingi austraci, Hubarium mycologicum-oeconomicum und Mycotheca universalis.

Im J. 1883 publizirte im Lotos Paul Hora, damals Assistent der botani.

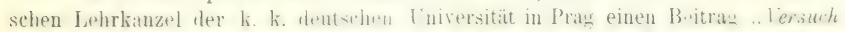
einer Flora ton /'ilsen: In demsilhen betinden sich ausser der Phanermanten anch Kryptogamen und von diesen auf S. 88-90 Pilze.

Sehr wichtig und wertvoll sind Beiträge von Dr. J. Schrïter, dem behanuten Autor des leider nicht ganz vollemileten Werkes . Pilar rom whlesinn"

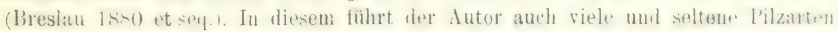
aus dem livesengebirge und seinen Vorlagen an, die er zumeist sellsst gesammelt hat.

Die Beiträge vom Lehrer $\mathrm{Schwa}$ b, welche im Lotos veröffentlicht waren,

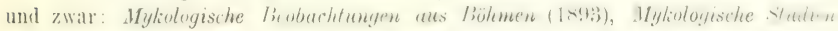
im Böhmerwalde im J. 1892 (1894) und Mykologische Mitteilungen aus Böhmen (1895), kaun man nur mit höchster Vorsicht benützen, weil der Autor mit der Mykologie lieineswegs so weit vertraut war. dass er - ausserdem mit der motigen

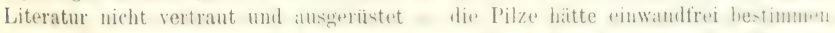
kimmen. Er wayte es anch einige neue Arten besmoters in ler polymorplien riatounf Russula***) aufzustellen. die von allen Myliolowen wit litelit innoriert weriten.

Cypers publizierte in den Verhandlungen der zool. bot. Gesellschaft in Wien in den J. 1893 und 1896 zwei Verzeichnisse der Pilze aus dem Riesengebirge und seinen Vorlagren.

*) Sammlungen des Naturforschenden Vereines.

*) Kiaiser Franz Josefs Museum.

** Schwalb, Das Buch der Pilze, Wien 1891 pg. 
Im J. $18: 4$ veriffentlichte Prof. A. Bernard in Tibor im Jahresprogramme des dortigen (iymmasiums eine Zusammen-tellung der böhmischen Gasteromycetes unter dem Titel ${ }_{n}$ Houby brichatkovité".

Ein wichtiger Beitrag zur Pilzthora Ibohmms ist Lehmann's „Terzeichnis ron Hutpilzen, die in der I Imyebuny ron Iieburriu und Friedland in Böhmen 189s

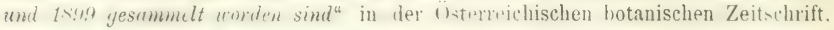
Wien 1900. Fast alle Spezies wurden von Prof. Paul Heunigs, Kustos am kiinigl. hotan. Museum in Berlin bestimmt, was dirses Verzeichnis wertooll matht.

Kleinere mykologische Abhandlungen findet man auch iu manchen Jahrgängen der Zeitschrift „Vesmír" (Prag).

Von denjenigen Männern, die sich jetzt in Böhmen mit Mykologie besohaftigen oder beschifficten. nenne ich noch nachtriglich folgende: Wridmann,

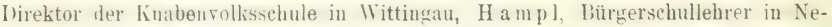
tolic, † MUTr. Mühlbach in Chotebor, † Prof. Kriźek in Chrudim, Vodák, Bürrersehullehrer in Dohruski, M a loch, ito. in P'ilsen, $\leftarrow$ Houska, ato. in Lenešic, wie auch meinen hochverdienten Mitarbeiter und Freund H. J. E. Kabát, em. Zuckerfabriksdirektor, jetzt in Turnau.

In dieser historischen Einleitung iberging ich mit Stillschweigen alle solche Handbüher, die esshare und griftige Pilze behamleln, da sie geröhnlich nur Kompilkationen simd von Leuten, die keineswers Fachmänner sind, ja oft von Leuten, die aus allen miglichen Fächern kompilieren. Solche Bücher hahen keinen Wert, besonders nicht für die mykologische Systematik.

Ausser liturarischen Besträgen und Belegen in verschiedenen Herbarion erscheinen als sehr rgiebige tuellen für die Kenntnis de’ böhmischen Pilze auch einige Exsiccatenwerke. Die Th tïmen'schen P'ilzsammlungen wurden schon oben erwähnt. Von den jetzt erscheinenden kommen hier in Betracht: $\mathrm{R}$ abenhorst's - Winter - Pazschke, Fungi europaei, Vestergren's "Micromycetes rariores. (Stockholm, Lerner's (Wien) "Flora austrohangarica", das Exsiceatenwerk des k. u. k. Hofmuse ums in Wien "Cryptogamae exsiccatae". Sydow's "Lredimeen. L'stulayineen. P'otomyceten und I'hycomyceten und Kabat und Bubilis . Fungi imperfecti exsiccati für alle diese Sammlungen hahen $\mathrm{K}$ abát und ich sehr zahlreiche böhmische Pilze geliefert. 


\section{Rostpilze (Uredinales).}

Die Rostpilze sind l'arisiten hauptsibchlich auf Phanerogamen, denn von den Kiryptogamen befallen siu verhältnismässig nu einige Irten aus der Giruppe der farne. D as 11 y celi um ist fidig. verzweint, vielzellig und verbreitet sich intercellular, indem e's in einzelne Zellen uur mit kleinen Hamstorien eindringt, steltener wäthst das Mycel selbst auch in den Zellenraum ein es ist damn intracellular. Sporen (basidiosporen oder Sproridien) entwickeln sich gewöhnlich zu vier auf einem P'rom y col i um, welches mit einigen (querwinden versehen lst. I)as Promycelium entsteht aus der Chlamydospore (Teleutospore oder Winterspore) und ist entweder exogen d. i. ganz frei, oder endogen und dam dringen nur die Stielchen (Sterigmata) hervor.

Ausser den Sporidien und Teleutosporen entwickeln sich noch Konidien, wie auch noch Chlamydosporen von einem anderen Typus, nämheh Aecidiospo-

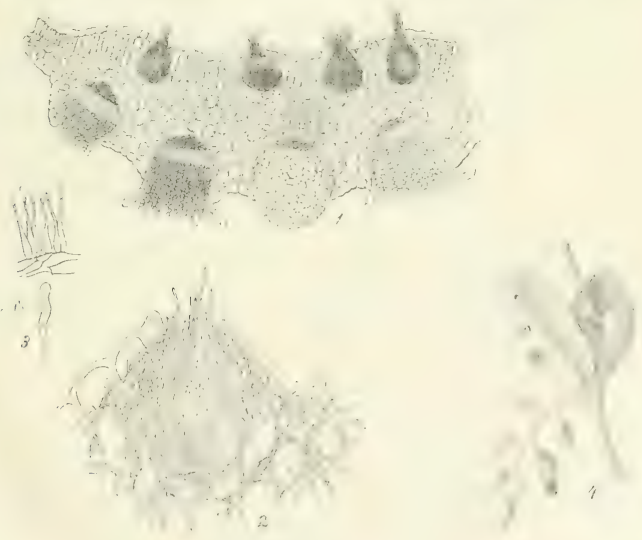

Abb. 1. Puccinia graminis P'ers. 1. Schnitt durch ein Blatt von Berberis velgnris; oben Spermogonien, unten Aecidien. 2. Durchschnitt eines Spermogoniums. 3. Stück einer Spermogonienwand, mit Stielchen und Spermatien. 4. Aestchen von Berberis, mit Aecidien (1. nach Sachs, „2. nach Tavel). 
ron und Uredosporen (Stylosporen), welche nur Keimschläuche entwickeln, die in die Nährpflanze eindringen.

Die Aecidien und die Uredosporen werden oft vou Spermogonien (Pykniden) hegleitet, in welchen sich Spermatien (Pylinosporen) entwickeln. Die Spermatien spielen keine lolle bei der eigentlichen Vermehrugg der Uredineen.
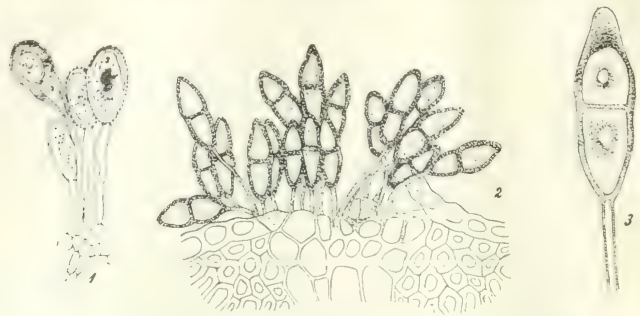

Abb. 2. Puccinia greminis Pers. 1. Gruppe von Uredosporen. 2. Durchschnitt eines Teleutosporen. lagers. 3. Stark vergrösserte Teleutospore (1, 2 nach De Bary, 3 nach Eriksson).

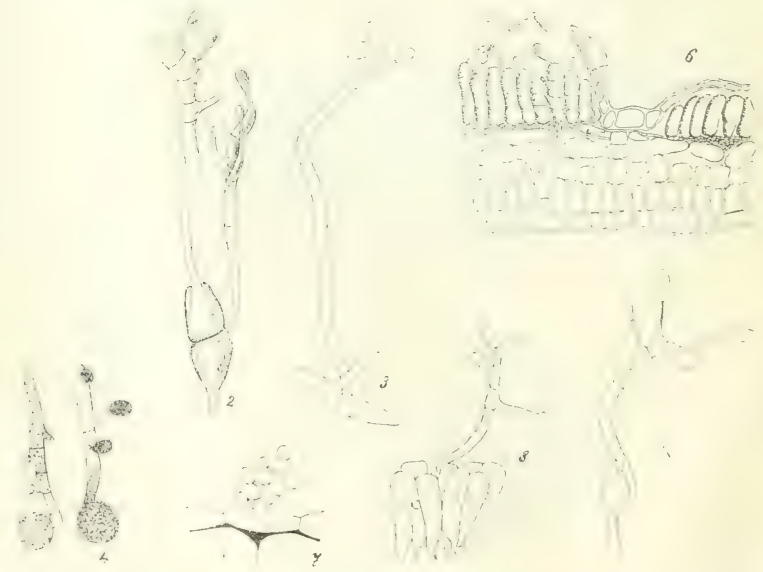

Abb. 3. Teleutosporenkeimung bei verschiedenen Gattungen: 1. Uromyces Fabae. 2. Puccinia graminis. 3. Aymnosporangium Sahinae. 4 Endoplyjllum Secti. 5. Coleosporium Senecionis. 6. Ochropsora Sorbi. 7. Gronartium asclepiadenm. 8. Melampsoridium betulinum. (Nach Tulasne, Plowright, Dietel). 
Man findet also bei den Rostpilzen ausser den Sporidien und Teleutosporen noch: 1. Speruation; 2. Aecidiosporen entweder mit Pseudoperidium (Aecidium, Roestelia), oder ohne dieses (Cateoma), kettenweise gebildet; 3. Uredosporen, welche einzeln auf kürzeren oder Jängeren Stielen entstelien.

Die Uredineen sind deshalb pleomorplie l'ilze. Die gemannten Sporen entwickeln sich ontweder nur auf einer Pthaze - a utoecische Arten, oder sie entwickeln sich anf zwei in ganz verschiedene Ordnungen gehörigen l'flanzen - heteroecische Arten.

Je nach dem, welche Sporenformen sich entwickeln, teilt man die Rostpilze in:

1. Eu-Typus (Eu-Puccinia, Eu-Uromyces), bei welchem noch allle 4 genannten Sporenformen sich entwickelu.

2. Opsis - Typus (Pucciniopsis, Uromycopsis), welchen die Uredosporen fehlen.

3. B rachy-Typus (Brachypuccinia, Brachyuromyces) nur mit Spermogonien. Uredo- und Teleutosporen.

4. Hemi-Typus (Hemipuccinia, Hrmiuromyces), welcher nur Urelo- und Teleutosporen besitzt. Mir scheint diese Gruple unatiirlich, denn es gehören hicrher nur solche Arten, leren vollstandige bntwicklung hisher unhekannt ist.

5. Micro-Typus (Mikropuccinia, Microuromyces), bei welchem nur Teleutosporen ausgebililet weriten, die rist nach der Winterperiode keimen. Squermogonien fehlen hier oft.

6. Lepto-Typus (Leptopuccinia, Leptouromyces) nut mit 'l'eleutosporèn, welche sofort nach der Reife keimen und Sporidien produzieren.

In diesem I. 'Teile der böhmischen Pilztlora werden im ganzen 310 Arten aufgezählt, von welchen 20 von mir aufgestellt wurden.

\section{Orduung: Pucciniaceae.}

Teleutosporen gewöhulich gestielt, seltemer stiellos, einzelliz. o.ler eimrihis

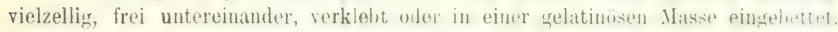
Sporidien auf exogrnem Promycelium. Aecilien mit P'seudneridien, seltener nhme. dieselben. Uredosporen auf Stielen befestigt.

\section{Familie: Puccinieae.}

Teleutosporen 1-2 zellig, gewöhnlich untereinander frei, seltener verkleht.

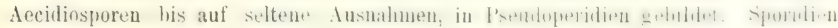
nierenförmig.

1. Teleutosporen einzellig, gestielt, untereinander frei . . . . Uromyces.

2. Teleutosporen einzellig, sitzend, in Schichten gebildet . . . Schroeteriaster.

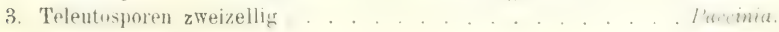




\section{Gattung: Uromyces. Link.}

Spermogonien lirugformig, vingesenkt, mit kegelformiger Mündung, welche aus sterilen Stielchen gebildet ist

Aecidien mit Pseudoperidien; Aecidiosporen ohne Keimporen.

Uredosporen in staubigen Häufchen, die anfangs von der Epidermis hedekt sind, einzeln auf Stielun gehilitet, mit einigen mehr oder weniger sichtharen Keimporen, stachlig oder mit kleinen Wärzchen beleckt.

Teleutosporen in festen ofler staubigen Lagern, die zuerst von der Lpidermis bedeckt, dann aber nackt sind, einzellig, seltener vereinzelt zweizellig (Ur. ambiguus), einzeln auf ihren Stivehen gehildet, mit emem scheitelstindigen Keimporus.

Sporidien bilateral, fast nierenförmig, auf Sterigmaten eines vierzelligen, exogenen Promycels entstehend.

I. Euuromyces. Alle Sporenformen entwickelt: Teleutosporen keimen erst im Frühjahre.

1. Auteuuromyces. Alle Sporenformen auf einer Wirtspflanze.

a) Teleutosporenglatt.

a) T'eleutosporenstiele fest.

1. Tromyees Fabae (Persion) De Bary, - Uredo Fabae Persoon. - Uromyces Orobi Winter. - Puccinia Orobi Kirchuer in Lotos 1856, pg. 181.

Spermononien auf der Oberseite gelhlicher Flecke grupppiert oder unterseits zwischen den Aecidien vereinzelt, sehr klein, honiggelb.

Aecidien auf gelblichen Flecken blattunterseits, in kleinen, lockeren (iruppen, manchmal auch hie ud da vereinzelt. Psendoperidien klein, circa $0.4 \mathrm{~mm}$ breit, niedrig. gelh, mit breit zurückgebogenem, zerschlitztem Rande; Pseudoporidienzellen von sehr verschiedener Form, bis $36 \mu$ lang, $2.2, \mu$ breit, in fast regulären Reihen stehemd. Sporen lugligreifurmig, bis länglich-polyëdrisch. $17 \cdot 5-265 \mu$ lang, 15,5-2.2 $\mu$ breit, dünwandig, dicht- und feiuwarzig, mit orangerotem Inhalte.

Uredolascr auf hejden Blattseiten verteilt, rundlich, auf den Blattstielen länglich, einzelne Lager anch auf gelblichen fleckeben oder zuweilen auch kreisförmig usestellt, bald nackt. iraum, staubig; Sporen kuglig, eiförmig, ellipsoidisch, 22-3:3 " lang, ") () 24 $\mu$ lireit, galbhraun, entfernt stachlig, mit :3-4 Keimporeu.

Teleutosporenlager wie bei den Uredosporen, aber fest, spaltförmig aufreissend; Sporen eiformig, ellipsoidisch oder länglich, $31-14 \mu$ lang, $20-33 \mu$ breit, hellkastanienlraun, glitt, am Scheitel abgerundet oder verjüugt, daselbst his 1:) $\mu$ dick und dunkler, unten grisstenteils in den festen, lirïtigen, bis 95 $\mu$ langen, gelbbrïunlichen Stiel verjüngt.

Aecidien von Mitt. Mai bis Ende Juni, Uredosporen von Juni bis August, Teleutosporen von Juli bis zum Eude der Vegetationsperiode auf.

Lathyrus tuberosus: Prag (Hoffuann)! Kaiserwiese bei Smíchov (Hoser, Opiz)! Rothenhaus bei Komotau (Roth)! Teplitz (Thümen)!

Orobus albus: Geiersberg und Hanenstein im Erzgebirge (Herb. Peyl)! 
Orobus montanus: T'eplitz (Thümen, fungi austriaci Nr. 1130)! Berg Wostray bei Aussig (Wagner)! Geltsch (Podpèra und Wilhelm)!

Orobus uiger: Raldotin bei Prag! lierg Wawein bei Lohositz! Wäliter bei Dymokur!

Orobus vernus: Sv. Prokop bei Prag (Opiz)! Zahoraner Schlucht bei I)avle! Mühlhausen (Kahrít)! Sehr oft im manzen böhm. Mittelgebirge und zwa bei Brüx, Bilin, Teplit», Leitmeritz, Aussin, Levín! Rothenhaus hei Komotan (Ienth)! Reichenbers (Niegmund)! Turnau, Kabát)! Chotuc bei Křinec! Kačina (P'eyl)! Holín bei Irobruska (Vodik)! Tábor! Kaplitz (Kirehner als I'ucrinia ()robi liirchner)! Krumau (Jungbauer)!

Vicia eracea: Kaiserwiese bei Smíchov (Opiz im Herbar des böhm. Museums als C'aeoma ptychospermum Opiz)! Prag (Heunevogl)! Habstein (Kabát)!

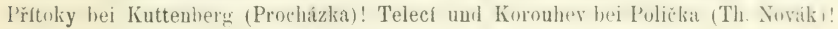
Plavo bei Budweis! Wittingau (Weidmann)!

Vici a Faba: Ueberall auf dieser kultivierter Pflanze verbreitet.

Vicia sat iva: Ebenfalls.

Vicia sepium: Ebenfalls auf dieser Nührptlanze viel vorbreitet.

Auf Vicia cracca kommt auch der heteroecische Uromyces Pisi vor, welcher feimpunlitierte Teleutosporen auf feinen, hellen Stielen besitzt.

Uromyces Orobi (Persoon) Plowright), welcherneuerdings von Jordi (7entralblatt für Bakteriologie und Parasitenkunde II. Abt., Bd. XI (190:3) wieder von der vorliegenden spezies abgetrent warde, stellt nur eine biologische Form dar.

2. Uromyces Ervi (Wallroth) Plowrinht. - Aeridium Ervi Wallroth. Puccinia Ervi Opiz in schedis et in Seznam pg. 139.

A ceidien auf heiden lilattseiten in kleinen (iruppen gestellt oder einzeln zerstreut. Pseudoperidien weiss, anfangs halblougelig, dann walzeuförmig. ziemlich lang, mit weissem, zerschlitztem und zurüchgebogeuem Ramdr; Pseudoperidicnzellen in dentlichen Feihen. rundlich oder polygonal, fast isodiametrisch. Sporen

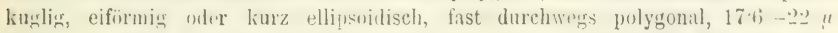
laug, $13-17 \cdot 5$ " breit, mit dünner, dichter und sehr feinwarziger Membran und orangefarbigem Inhalt.

Uredolager zimmtbraun, auf den Blättern oder auf Blattstielen zwischen den Aecidien zerstreut, staubig; Sporen kuslis, eiförmign ndex kurz ellipsuiliseh. 22-31 $\mu$ lang, 20-22 $\mu$ breit, gelbbraun, zerstreut, kurz stachelig, mit 2 Keimporen.

Teleutosporenlawer auf den Blittern zerstrent. rumblich onler lïndich, auf den Blattstielen und stengeln verlïngert, anfamss ron der Epidermis beileclit, später nackt, schwarz, fest. Sporen sehr verschiedenartig, eiformig, ollipsoidi-ch,

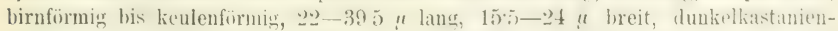

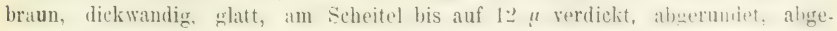
stutzt oder in eine stumpfe spitze verjünst, unten abgerumlet oder verjunat: Stiel dick, fest, brïunlich, bis $70 \mu$ lang. 
Aecidien und Teleutosporen rou Juni his Oktober, Uredosporen in selb. stïndigen Lagern ziemlich selten ausgebildet.

Ervum hirsutum: Michle (Opiz)! Generálka (Opiz 1852 unter dem Vamen Puccinia Ervi ()pizı! Podlužany bei Roždalovic! Rovensko nicht selten! - Sedlčan (Th. Novák)! Wittingau (Weidmann)!

Uromyces Erri ist mit Uromyces Fabae verwand, aber ron demselben linlänglich rerschieden, besonders in biologiseher Hinsicht. Die Aecidiosproren son Uromyces Erri rufen bei der Infektion auf der Nähnptlanz+ wieder Aecidien hervor. Inies goschirht fast die eanze Vegetationszeit hindurch. Die Uredosporen befinden sich wahrscheinlich im Stadim des Aussterbens.

3. Tromyces Phaseoli Persoon) Winter - Eredo appendiculata $\alpha$ ) Phaseoli Persoon. - Uromyces a ppendiculatus Link.

Spermogonien in kleinen, gelblichen Gruppen.

A ecidien: Flecke auf der Blattoberseite, klein, $2 \mu$ breit, gelb; Pseudoperioden aut der Unterseite der Flecke sparsam in kreisformigen, dichten Gruppen, seltrner oberseits, niedrig, weiss. unregelmässig zerschlitzt; Psendoperidienzellen in vertikalen Reihen. sehr verschieden geformt. Sporen polygonal und zwar liuglig, eiförmig, ellipsoidiseh oder länglich, $20-35, \mu$ lang, $155-22 \mu$ breit, mit kleinen Wärzchen dicht besetzt.

Uredolager rundlich, auf beiden Blattseiten verteilt, manchmal auch ringfömis um eil zentrales Häufchen herumgestellt, zimmthraun, staubig. Sporen kuglis, vifumis, ellipsoidisch oder lïnslich, $24-3950$ " lang, 16-2. " hreit, hellhraun, mit dünner, entfernt kleinstachliger Membran, mit 2 wenig deutlichen, aequatorial liegenden Keimporen.

Teleutosporenlager wie bei dem Uredosporen, aber schwarzbraun, oft zusammentiessend, staubig. Sporen liuglig, eiformig, ellipsoidiseh, $26 \% 5$ bis $: 750$ " lanı. 2.9-265 " breit, dunkelkastanienbraun, dickwadig, glatt, beiderseits abgerundet, an scheitel mit breiter, abserumdeter, bis 4.5 " boher Papille. Stiel dick, fest, längeı als die Spore.

Aecidien von Mai bis Aurust, Uredo- und Teleutosporen von Juni bis zum Ende der Vegetationsperiode.

Phaseolus vulgaris: Prag (Wolfner, Hennevogl)! Nusle (Opiz als Puceiuia Plasuoli (Ppiz)! Kolin , Veselský)! Kačina (Peyl)! Kuttenberg (Veselsky)! Tepl, Kimmail)! Teplitz (Thümen)! Herruskretschen (Wagner)!

4. Uromyces Silenes (Schlechtendal, Fucliel. - Ca eoma silenes Schlechteudal. - Uromyces in aequialtus Lasch.

Spermogonien honiggelb, zwischen den Aecidien zerstreut.

Aecidien auf der Blattunterseite auf gelben Flecken in rundlichen frrųurn Lestellt, auf den Blattuerven unit Blattstielen in länglichen Gruppen. l'sumbperidion gelblich, walzenfimis, manchmal sehr verlïngert, wit weissem mirıelmässiz zerschlitztem, zurückehogenem Rande; Pseudoperidienzellen von sehr verschiedener Form, polygonal, oft rom rechtechigen Umrisse, in vertikalen 


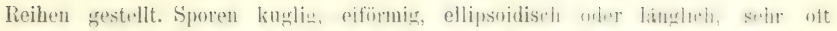

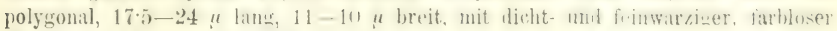
Membran und orangefarbigem Inhalte.

Uredolager über die Blätter zerstreut, oft auf gelblichen oder violetten Flecken is rundlichen (irupuen, won rundlicher form, hraun, hald nacki unit staubig; Sporen kuglig oder eiförmig, 22-28.5 $\mu$ lang, $20-2 \pm \mu$ breit, hellkastanienbraun, mit dicht- und feinwarziger Mcmbrau und $3-4$ il himpuren.

Teleutosporenlager auf den Blättern auf gelben oder violetten Flecken, ringformir um ein urösseres zentrales Hitufchen gestellt, anf den strngreln in verlingerten Gruppen, rundlich oder limolich, shuar, fest: cporen kusliz.

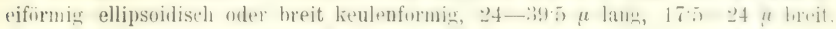
dunkelkastanienbraun, dickwandig, yat, am siheitel his auf 11 u veruliekt, daselbst dunkler, abgerunlet orler seltener in sine hreite, stumpfe spitze rerjunert. unten abgerumet oder in den Stiel plutzhich verjüngt; stiel fest, ohen briunlich. bis $90 \mu$ lang.

Aecidien von Mai bis Mitte Juni, Uredosporen von Mai bis September, 'Teleutosporen von Juli bis zum Ende der Vegetationsperiode.

Silene nutans: Radotín bei Prag! Mühlhausen a. E., Schelesen bei Liboch, Wopparnertal (Kabit)! Herrnskretschen (Wagner)! Klein-ikial und Vazovec bei Turnau (Kabát)! Rovensko! Kolin (Veselský)! Wittingatu (Weid$\operatorname{mann})$ !

5. Uromyces Polyani (Persoon) Fuckel. - Puccinia l'olygoni Persom.

Spermogonien honigrelb, auf der (Jberseite der Flecke gruppiert oder zwischen den Aecidien zerstrent.

Aecidien auf rundlichen gelben Flecken, meist blattunterseits, in dichten rundlichen (iruppen ouler auch über die libitter einzeln zerstreut, seltener und spärlich blattoherseits. Pseudoperidien aufangs halbliugelier, dann lang walcenfirmig, vom Shattgewebe oft abgetrennt, mit weissem, geralem, frin zorschlitztem Rande: Pseudoperidien zellen ron sehr verschiedener Go-talt. meistens polyedrsch bis 33 " lang, 22.2 $\mu$ hreit, in regeluässigen, vertikalen lieihen gestellt suren

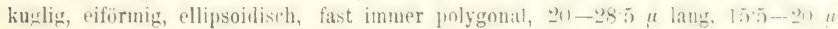
breit, dünnwandig, dicht- und feinwarzig, mit orangefarbigem Inhalt.

Uredolager beiderseits auf den Blittern ziemlich dicht verteilt oder zerstreut, manchmal auch rings um ein grosseres Häutchen gestellt, rumblich mite hesonders auf den Steugeln - linglich, balit nackt, zusammentliesenul, hram, stauhis:

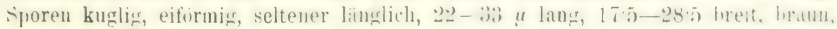
dickwandig, dicht- und feinwarzig, mit 3-4 Keimporen.

Teleutosporenlager beiderseits auf den Blättern dicht verteilt oder anch nur zerstreut, rundlich, auf den Stengeln rerlingert umb lieihen lnhimd, endlich den Stengel ganz orler streckenweise hedeckend, bald nacht, shwar. test;

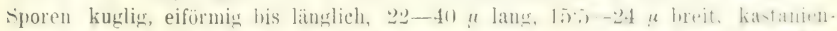

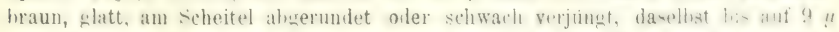
verdickt und dunkler, unteu abgerundet oder plitslich in don s(l ! langen, haunlichon festen Stiel verjüngt. 
Spermogonien schon fou Mitte April, Aecidien von Ende April bis Mai, Urelosporen fon Mitte Mai his knde August, Tentusporen von Mitte Juni bis zum Ende der Vegetationsperiode.

Polygonum ariculare: Ein sehr rerhreiteter liostpilz, welcher besonders auf dürren, überwinterten Stenceln auffallend ist. deoidien rufen auf den Blittern purpurrote Flecke.

B) Teleutosporenstiele zart, abfallend.

6. Iromyees Armeriae (Schlechtemlal) leveillés - ('aenma Armeriae Schlechtendal. - Uromyces Armeriae Léreillé. - Uredo Limonij aut. p. p.

Spermogonien zwischen den Aecidien zerstreut oder gruppiert, honigbräunlich.

A ecidien auf den Blättern in kleinen unregelmässigen Gruppen; Pseudoperidien anfangs halbkugelis. spater walzenformig, ziemlich hoch, mit weissem,

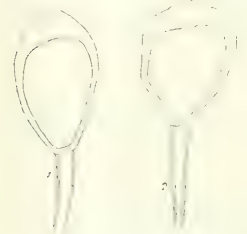

Abb. 4. Telentosporen von Uromyces Armeriae. tief und unregelmässig zerchlitztem, nicht zurückgebogenem Rande; Pseudoperidienzellen sehr verschieden, bis $44 \mu$ lang, $22 \mu$ breit, in unregelmässigen, vertikalen Reihen stehend. Sporen kuglig, eiförmig oder länglich-polygonal, $24-33 \mu$ lang, $17.5-22 \mu$ breit, sehr dickwandig, fein- und dichtwarzig, mit orangefarbigem Inhalt.

Uredolager an den Blättern, hauptsächlich aber auf den Stengeln, rerlängert, von der aufgeblasenen Epidermis lange bedeckt, dann spaltförmig oder unregelmässig zerschlitzt, staubig, oft zusammenfliessend, zimmtbraun; Sporen kuglig oder kurz eiföruig, seltener ellipsoidiscb, 20-33 $\mu$ lang, 20-28.5 $\mu$ breit, hellbraun, dichtwarzig, mit 2 Keimporen.

Teleutosporenlager rundlich oder länglich, auf den Blàttern nur zerstreut, anf den Stengeln verlingert und oft zusammenfliessend, schwarzbraum, staubig; Sporen neistens kuglig, eiförmig. keulenfoming. seltener länglich. 28:5-37.5 $\mu$ lang, 24-31 "1 hreit, kastanienluaun, dickwandig. shatt, am Scheitel bis auf 8 " verdicht, daselhst dunkler und abgerundet orler in eine breite. stumpfe, oben fast farbluse spitze verjünst, untrn ahserumbet oder plötzlich in den Stiel verjüngt; derselbe zart, farblos, leicht abfallend, so lang oder kürzer als die Spore.

Aecidien von Mitte April, Urensporen ron Mai, Telentosporen hauptsächlich im Herbst.

Armeria vulgaris: Sadskä, Velenka! Chržín bei Welwarn (Kabát)! (nter-lieřkovic! Aussig (Thümen, fungi austriaci Nr. 386)! Thammühle hei Hirsehberg (Kabait)! Herrnskretschen (Wagner). Tábor! 
Mit dieser Art wurde früher auch der Uromyces von Statice Limonium vereinigt und zwar unter dem Namen Uromyces Limonii (DC.) Léveillé.

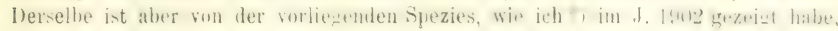
gitinzlich verschieden,

†. Uromyces Trifolii repentis ('astagne). Lindruth. Aneidinm Trifolii repentis Castagne. - Uromyces Trifolii Autt. p. p.

Spermogonien beiderseits, auf den Blättern in der Mitto der Aecidien gruppiert, hellbraun.

A ecidien meistens blattunterseits ringförmig gestellt, auf den Nerven und Blattstielen in vertingerten Gruppen; die befallenen Stellen immer versh hivelen artis gekrummt und rerunstaltet. Psembperidien klein, niedrig, anfans halhkugelig, später walzenfürmig, mit weinsem. zurickgehnuem, fein/erschlitım Rande; Pseudoperidionzellen in rertikalen lieihen stehend. Sporen kuglis, eifiming bis länslich, immer pulyedriseh. 165-24 " lan- 11 17\% u hreit, mit farbloser. fein und dichtwarziger Membran und orangefarbigem Inhalt.

U red o I a ger beiderseits auf den Blättern gleichmässig verteilt oder nur zerstreut, rundlich his länglich, teilweise fon der unregelmitsig zersiblitzten Epirlemis bedeckt, zimmthraun, stauhig. Sporen kuglig, eiformie. 2.) 26\% "t lang $20-265 \mu$ breit, braun, genährt stachlig, mit $2-4$ Keimporen.

Teleutosporenlager wie die Uredolager aber dunkelbraun, auf den

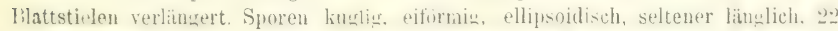
bis $3: 3$ " ame, $17 \div 5-2.2$ " hreit. dunkelkastanienbaun, glatt, ziembich dickwandig, am Scheitel ahgerunlet oder wenig verjüngt, nicht verliclit, mit einer niedrigen, hreiten, hyalinen Kappe, unten abserundet orler plïtzlich in den stiel rujument derselbe kürzer als die Spore, farblos, abfallend.

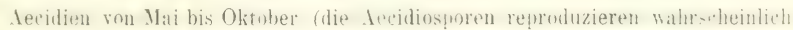
wieder Aecidien!), Uredosporen von Juni bis August, Telentosporen von Juni bis zum Ende der Vegetationsperiode.

Trifolium repens: Vyšehrad! Kolín (Ve- selský)! Pardubice (Vodík)! Welwarn (Kabát)! Osseg bei Teplitz (Thümen)! Rovensko!

Uromyces Trifolii repentis wurde früher von allen Autoren als eigene Spezies nicht unterschieden. Erst $\mathrm{Lindroth}$ (Liro) trennte denselben von Uromyces Trifolii ab. (Siehe Vestergren, Micromycetes rariores selecti Nr. 1063 (1906) und Lind roth, Kulturversuche mit finnischen Rostpilzen I., p. 11-15). Aus seinen Versuchen $\mathrm{Nr}$. 81-82 scheint hervorzugehen, dass die

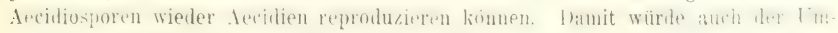
stand übereinstimmen, dass sich die Uredosporen nur spürlich entwickeln.

*) $\mathrm{B}$ u bák Fr.: Einige neue oder kritische Uromyces-Arten. Sitzungsberichte d. krinigl. böhm. Gesellschaft der Wissenschaften in Prag 1902, XLVI., pg. 4.-6. 
8, Uromyces Geranii (De Candolle) Otth et Wartmann. - Uredo Geranii De Candolle. - Uromyces Geranii Otth et Wartmann.

Spermogonien honinbran, tross, 130-150 „ im Durchmesser, zwischen den Aecidien ziemlich zahlreich zerstreut.

A ecidien sehr zahlreich auseebldet. auf den Blattspreiten in rundlichen oder unregelmässigen, oft bis :2 cm langen, schwielenartigen Gruppen, auf den Blattstielen federkielartige Verdickungen herrorrufeni. Pseudoperidien dichtstehend. anfanıs halbkuglig, später mit ruudlichem Loch geüffnet; Pseudoperidienzellen, gleichuässig dick; Sporen kuglig, eifirmig, ellipsuidisch oder seltener lïnglichpolyedricch, 22-23 4 lanm, $155-24 u$ breit, mit farbloser, licht- und feiuwarziger Membran und orangefarbigem Inhalt.

Uredolager auf den Blättern beiderseits zerstreut, rundlich, dunkelbraun;
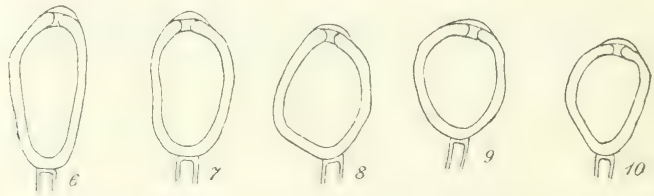

Abb. 5. Teleutosporen von Uromyces Geranii von Geranium palustre.

Sporen kuglig nder eiformig, "2.2-28, 22-24 " breit, kastanienbraun, ihre Membran mit feinen, zerstreuten Stacheln und mit 1 seltener 2 Keimporen.

Teleutosporenlager auf gelben oder purpurruten Flecken blattunterseits zerstreut, lilein, schwarzbraun, fest. Sporen eiförmi bis ellipsoidisch, seltener länglich. :3R-40 " laus, $1 ! 1-2$ tion ! breit, dunkelbraun, glatt, am Scheitel mit farbloser, stumpfliegelfurmiger. Kappe, unteu mit kurzem, farblosem, leicht abfallendem Stielchen.

Aecidien Fnde Iai bis Ende Juni, Lredosporen ron Juni bis September, Teleutosporen vun Juli bis in den Wiuter. Oft alle drei Sporenformen zugleich im Fruhjahre.

Geranium columbinum; Teplitz (Thümen)! Böhmisch Leipa (Schiffner im Herbar Dr. Baur)! Turnau (Kabát) Louñovice (Stejskal)!

Geranium dissect um (bisher nur Uredo): Turnau (Kabát)! St. Prokop bei Prag (noch am 5. Oktober nur Uredo)!

Geranium palustre: Revnice bei Prag (Th. Novák)! Bei Prag schon Lenes (Herb. d. dentsch. Lniversitiit daselbst)! Cibulka Opiz)! Kokorín bei Liboch 
(Kabat, 'Th. Novák)! Mseno bei Libochovic! Kost hei Sohotha (Kabait)! linsenslan! Taschov bei Ieitmeritz! Klein I'riesen bei Aussig! Tetsehen IWagner. Selunhorn bei Bodenbach!

Geranium pratense: Teplitz (Thümen). Hartal (Cypers). Zahostice bei Chýnov!

(ieranium silvaticum : Johamesbal (schroter, I)omiu)! Teplits. Thumen,, Fungi Iustriaci Nr. 381, 9.4i)! \%echarund an lieilherge im Erzabirue lirimer).

9. Uromyees Kabatianus bubak - Uromyces Geran i Winter, Sartrilu etr. Uromyces Geranii Beck in Kerner's Flora austro-hungarica. Nr. 373.

Spermogonien spärlich, gross, houiggelb, später dunkler, in der Mitte der Flecken auf beiden Blattseiten.
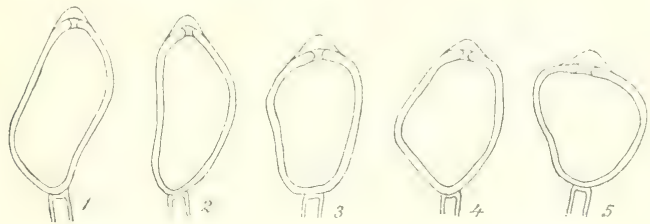

Abb. 6. Teleutosporen vou Lromyces Kabatianus von Geranium pyrenaicum.

Aecidien blattunterseits auf rundlichen, zelblichen Flecken rundliche

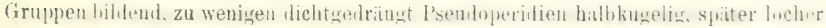

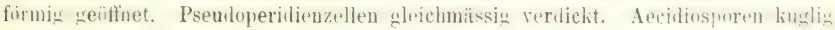

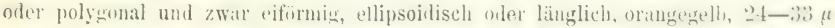
lang. $18-26.5 \mu$ breit, mit gelblicher, dicht- und feinwarziger Membran.

Uredolager blattunterseits auf gelben Flecken kreisförmig gruppiert, selten zerstrent, chokoladenbrann, staubies: Iredosproren kuglig uler seltener m. farmig, 22-20; "

Teleutosporenlager auf gelben oder kitrmimoten Flecken auf der unteren

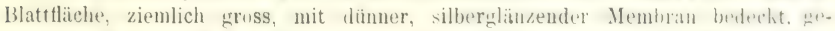
wohnlich kreiaformig uruppiert, bald zusimmenfliessend, braun, statuhig; Telento-

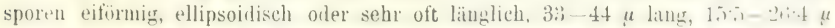
breit, hellbrann, glatt, am scheitel mit einer ziemlich hohen, hyalinen, kingefinmigen Papille. Stiel kurz und hyalin, leicht abreissend.

Accidien von Mitte April bis Ende Mai, Uredosporen von Mai bis November, Teleutosporen von Oktober bis Fnde Dezember.

Geranium pyrenaicum: In Prager Gärten z. B. Klamovlia (Kabát)! Kinsky'scher Garten! In Pras wurle diese Spezies schon fom liteher wrammelt 
und zwar unter dem falschen Namen Puccinia Geranii Corda. - Kaplitz (Kirchner 1842 als Aecidium Gerauii DC)!

Die vorliegende Art wurde früher von allen Autoren von Uromyces Geranii nicht unterschieden. Beide sind aber genü̈reud morphoiogisch verschieden.

10. Uromyces Valerianae (Schumacher) Fuckel. - Uredo Valeriana Schumacher - Uromyces Valerianae Fuckel.

Spermogonien ziemlich gross, beiderseits auf den Blättern zwischen den Aecidien zerstreut, oder in deren Mitte gruppiert, honigbraun.

A e ciditan blattunterseits in lockeren, gewöhnlich kreisfömigen, gelblichen Flecken, auf den Nerven Blattstielen und Stengeln in uuregelmässigen, verlängerten Gruppen. Die befallenen Partien sehr oft verunstaltet. Pseudoperidien anfangs halbkugelig, dann zylindrisch, ziemlich niedrig, breit geöffnet, mit unregelmässig zerschlitztem Rande. Sporen polvëdrisch, isodiametrisch, 22-24

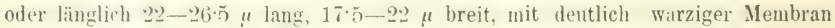
und oraugefarbigem Inhalte.

Uredolager hlattoberseits zerstreut older auf gelben, unregelmässigen Flecken „ruppiert, seltener hlattunterseits, zimmtbraun, rundlich, manchmal zusammenfliessend; Uredosporen kuglig, 22-26 $\mu$ im Durchmesser oder eifurmig bis ellipsoilisch, 26--33 " lang, 22-2-28.5 $n$ breit, hellbraun, entfernt stachlig, mit 2-3 Keimporen,

Teleutosporenlager blattunterseits, klein, lange von der grauen, glänzenden Epidermis bedeckt, blasenförmig, zerstrent oder in dendritische, von den Nerven hegrenzte Gruppen zusammenfliessend, sohr spät nackt und dann brauu, staubig'; Sporen fast kuglig bis ellipsoidisch, $2(1-33, " 3$ lang, $15 \cdot 3-22, u$ hreit, hellbraun, glatt, am Sicheitel mit breitem, von einer flachen Papille bedecktem Keimporus; Stiel farblos, bis $11 \mu$ lang, abfallend.

Aecidien von Mitte Mai bis Mitte Juni, Uredosporen bis Mitte August, Teleutosporen von August bis zum Ende der Vegetationsperiode.

Valeriana dioica: Pořičan! Tetschen (Wagner)! Nemschen bei Aussig! Harta bei Ilohenelbe (Cypers)! Trautenau (I'astor)! Slané bei Semil! Bora und Studené hei Rorensko! Chotéhoŕ (Mühlbach)! Tábor! Kạ̣litz (Kirchner als A eci.

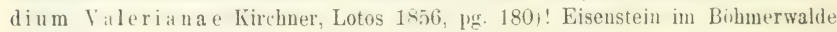
(Krieger).

Valeriana officinalis: Bei Prag (Opiz im Herbar des böhm. Museums)!

11. Uromyees Betae (Persoon) Tulasne. - Uredo Betae Personn. - Uromyces Betae Tulasue.

Spermogonien honigbraun, in der Mitte der Aecidien oder zwischen denselben zerstreut.

A ecidien auf heiden Blattseiten auf gelben, rundichen oder länglichen Gruppen, kreisformig gestellt oiler umregelmässig zerstrent. I'seudoperidien gelh, tief eiugesenkt, anfangs hallhugelig. spaiter wit rundlicher ïfinung. mit niedrigem, 
unregelmaissig zerschlitztem, weissem liande. P'sendoperidienzellen sehr unregermïssig, 22-38 $\mu$ lang, 17-27 $\mu$ breit. Sporen immer polyëdrisch und zwar

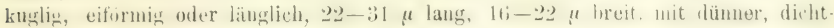
und feinwarziger, farbloser Membrin und orangefarbigem Inhalte.

L redolager rundlich oder länglich. unregelmässig auf bevilen Iblattieiten zerstreut oder kreisformig gruppiert, zimmtbraun, von der zerrissemen Epintermis

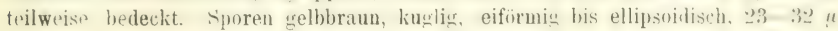
lang, $17-24 \mu$ breit, mit entferntstehenden Stacheln besetzt, mit 2 aequatorialen Keimporen.

Teleutosporenlager auf beiden Blattseiten zerstreut, rundlich oder länglich, von der Epidermis teilweise bedeckt, dunkelbraun. Sporen kuglig, eiförmig oder länglich, 25-32 $\mu$ lang, 18-24 $\mu$ breit, mit dunkelkastanienbrauner, am Scheitel wenig verdickter Membran und daselbst mit hellerer, bis $2 \mu$ hoher, abgerundet kegelformiger Papille versehen; Stiel so lang wie die Spore, abfallend.

Aecidien Ende April und im Mai, Uredo. sporen von Juni, Teleutosporen im Herbst.

Beta vulgaris: Vršovice bei Prag (Opiz 1836)! Nusle (Opiz 1839)! Bylany bei Böhm. Brod! Chrudim (Boh. Procházka)! Kaěina (Peyl)! Vtelno bei Mělník! Welwarn (Kabát, Aecidien 1./V.)! Komotau (Thümen in Fungi austriaci Nr. 387): Teplitz (derselbe)! Ujezd unterhalb der Ruine Trosky! Kyselorsko bei Turnau (Kiabát)! Vysoké Veself (Kabait)! und gewiss viel verbreitet, besonders dort, wo Zuckerrübe seit längerer Zeit kultiviert wird.

Aecidien werden seltener gefunden und kommen hauptsïchlich auf jungen Keimptlanzen, hauptsïchlich aber auf Sämlingen vor. Blätter, welche von Uredosporen und Telentosporen befallen sind,
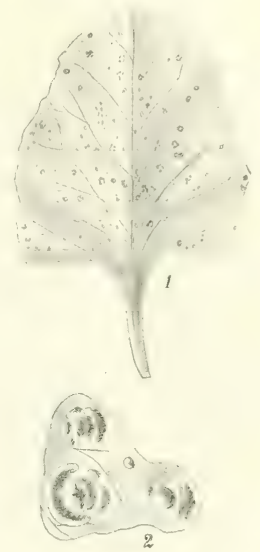

Abb. 7. Uromyces Betae: 1. Ein vom l'ilze befallenes Blatt. Uredo- und Teleutosporenlazer vergrossert (nach I)ietel). werden gelb, welken und endlich veräürren gänzlich. Wenn viele oder sämtliche Blätter einer Pflanze befallen sind, dann sinkt anch der Ertrag, denn die Rübe bleibt klein.

b) T'eleutosporen warzig.

\section{Uromyces Acetosae Schroeter.}

Spermogonien gelb, zwischen den Aecidien zerstreut.

A ecidien auf rundichen, $1-3 \mathrm{~mm}$ breiten, purpurroten Flecken gruppiert; auf der Oberfäche der Flecken dichter, auf der Unterseite locker stehend. Pseudoperidien weisslich, klein, niedrig, anfangs halblugelig, später zylindrisch, oft zusammengedrückt und endlich vom lilattrenehe lospeliost, mit unregelmässig zersehlitztem, nicht zurückgehonenem Rando; I'spulopurilien- 
zellen unregelmässig polyëdrisch. nicht in veutlichen Reihen. $2 * 2-35 \mu$ lang, 16 bis $22 \mu$ breit. sporen kuglig-polyedrisch ndor kugliz-länglich. 15-5-24 "u laug, $154-17.6$ " breit. mit dïnner, farbloser, sehr feiuwarziger Memhran und orangefarbigem Inhalte.

Uredolager anf beiden Blattseiten regelmässig zerstreut, klein, zimmtbraun, bald nackt und staubig, von einem roten Hofe umgehen. Sporen liuglig, eiförmig bis länglich, $17.5-28.5 \mu$ lang, $17.5-24 \mu$ breit, mit brauner $2-3 \mu$ dicker, fein- und dichtwarziger Membran, mit 2-3 Keimporen.

Teleutosporenlager auf beilen Blattseiten, gewohnlich zwischen den Uredolacrem zerstrent, oder um ein zentrales Uredohäufchen ringförmig stehend, schwarz, fest Sporen kunlis ode: keulentirmig, 23-33 $\mu$ lang, 20-24 mit dicker, dunkelkatstanienbrauner Membran; dieselbe mit reihenfürmig und dicht gestellten Wärzchen bedeckt. am Scheitel $4-0 \mu$ dick, daselbst zweischichtig. Stiel etwa halb so lang wie die Spore, abfallend. (Siehe Abbildung 11, VI.)

Aecilien in Mai, Uredosporen und Teleutosporen von Juni bis Oktoher. In Mittel- und Nordeuropa zerstreut.

Rumex Acelosa: Herrnskretschen, Tetschen (Wagner); Graupen bei Teplitz (Thumen, Fungi austriaci Nr. 391)! Neratovic! Mẻsic bei Tábor! Lomnitz a. d. Lužnic (Weidmann)!

decidien dieses Pilzes dürfen nicht wit diejenigen ron Pucciaia Trailii Plowright rerwechselt werden. Sporen der letztgenannten Art sind fast farblos. Uredosporen kïnnten wieder mit den Uredosporen von Puccinia Acetosae (Schumacher) verwechselt werden; diese sind aber entfernt stachlig und besitzen 2 Keimporen.

2. Heteruromyces. Spermogonien und Aecidien auf einer - Uredo- und Teleutosporen auf zweiter, in eine ganz andere Familie gehörigen Wirtspflanze.

a) Teleutosporen glatt.

13. Uromyces Dactylidis Otth. - Uromyces Dactylidis Schroeter p. p - A ecidium Ranuncula cearum De Candolle p. p.

Spermogonien auf gelben Flecken blattoberseits, honigbraut, blattunterseits und auf den Nerren zwischen Aecidien zerstrent.

A ecillien auf gelben, schwach blasig aufgetriebenen, kreisförmigen, auf den Blattstielen in länglichen, zusammenfliessenden Gruppen. Pseudoperidien niedrig, breit, mit grelbem Rande, sehr fein zerschlitzt; Pseudoperidienzelleu sehr verschiedenartig, ahgerundet oder polyedrisch, entweder isodiametrisch, bis $35 \mu$ breit, oder länglich, $35 \times 22 \mu$, in unregelmässigen Reihen stehend. Sporen kuglig oder eiförmig, schwach polyëdrisch, $17 \cdot 5-26.5 \mu$ lang, $13-24 \mu$ breit, mit farbloser, dichtwarziger Membran und orangefarbigem Inhalte.

Uredolager rostbraun, beiderseits auf den Blättern zerstreut, stricbfömig, zwischen den Nerven liegend, der Lïnge nach aufreissend und staubig. Sporen kuglig, eiförmig, $265-33$ " lang, 22-265 " breit, gelbbraun, mit fein- und entferntstachliger Membran und vielen $(7$. (1) Keimporen; Inhalt orangefarbig. 
'Teleutosporenlager blattunterseits, strichförmig, lings und quer,

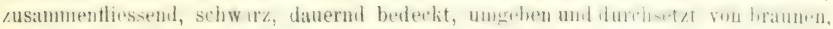

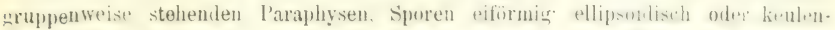

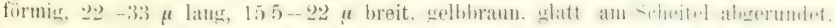
abgestutzt, manchmal auch in eine stumpefe Spitze verjünet, davelhst verifickt. unten abgerundet oder in den Stiel verjüngt; derselbe fest, brïunlich, so lang witz die Spore.

Aecidien von Mai bis Mitte Juni, Uredosporen von Juni bis Oktober, Teleutosporen von Ende Juni bis zum Winter.

A ecidien a uf Ran unculus bu lbosus: Sv. Matěj bei Prag (Opiz)! Kopanina! Zahoranertal hei Iawle! In ler Strasse vou Odripes zum Vosknswla!

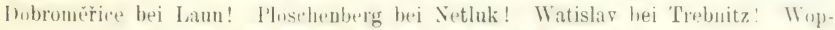
parnertal bei Lobositz! 'Teplitz (Thümen)! Aussig (Wagner)!

Ranunculus lanuginosus: Turnau (Kabát)! Leschtine bei Klein priesen! Geltsch (Opiz)! Pelzdorf bei Hohenelbe (Cypers)! Tábor!

Uredo- und Teleutosporen auf Dactylis glomerataVrané bei Prag! Neratovic! Welwarn (Kabát)! Rovensko!

Uromyces Dactylidis Otth ist mit Uromyces Poae verwandt uud wird von manchen Autoren mit demselben vereinict. Er ist aber von demselben durch arossere Uredosporen, wie auch hiologisch verschiesten. Zwischen den Uredosporen findet man keine Paraphysen.

14. Uromyces Poae Rabenhorst. - Uromyces I) actylidis Schröter p. p. A ecidium Ranunculacearum D. C. p. p.

spermogonien honig gelb, blattoberseits in ziemlich grossen Gruppen oder auch zwischen den Aecidien blattunterseits zerstreut.

A ecidien auf weisslichen, blasenartigen Flecken in dichten, rundlichen, aut den Blattstielen in länglichen Gruppen. Pseudoperidion tief im Blattgewebe eingesenkt, wenig die Obertliche überragend, mit fein und fast regrelmïssig zerschlitztem Rande; Pseudoperidienzellen poly iddrisch, isodianetrisch (35 $u$ ) bis länglich (35 > $22 \mu$ ). annähernd reihenförmig. Sporen polyedrisch und zwar meistens von kugliger, seltener. eifömiger oder ellipsiodischer Form, 15)-2x5 loser, dicht warzenförmigen Membran und orangerotem Inhalte.

Uredolager auf gelben Flecken auf beiden Blattseiten zwischen den Nerven zerstreut, strichförmig, läuss geöfnet, gelbbrann, staubig. Sporen buglin: seltener eiformig bis ellipsoidisein, $155-24$ lawo, $15 \overline{5}-20 u$ breit, hellgelh, finund entferntstachlig, mit vielen $(4-9)$ Keimporen. Zwischen den Sporen manchmal Paraphysen.

T e leut osporen lag er hauptsächlich blattunterseits, seln klein, strichformis. zwischen deu Nerven liegend, oft in längero Reihen zusammenfliessenul, sidwwar, dauernd bedeckt, umgeben und durchsetzt von braunen, grupenteise stehmen

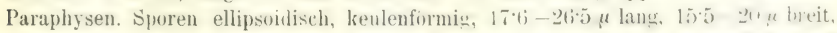
gelbbraun, am Scheitel abgerundet oder abgestutzt, daselbst etwas verificio. und kastanienbraun, unten abrerundet oder keilförmie in den hräunlichen. trsten, wie die Spore langen Stiel verjüngt. 
Aecidien von Mitte April bis Ende Mrai, Ureilosporen von Mitte Mai, Teleuto. sporen von Mitte Juni bis zum Ende der Vegetationsperiode.

A ecidien auf Ranunculus bulbosus, ficaria und repens überall in niedrigeren Lagen verbreitet.

Ranunculus auricomus: Wäldchen am Fusse des Chotuc bei Křnec! 'Teplitz (Thümen)! Mariaschein (Wiesbaur)! Kestrany bei Písek! Tábor!

Ranunculus nemorosus: Hammerstein bei Reichenberg (Matouschek)! Zahơ̌anertal bei Davle! Tábor!

Uredo- und Wintersporen auf Poa pratensis, nemoralis (hier Uredo mit Paraphysen) und a n n a viel verbreitet.

15. Uromyces Festucae Sydov - A e cidium Ranunculacearum De Candolle p. p.

spermograirn mul Aecidien wie bei den rorangehenden zwei Arten (Siehe Abbild. 9. III.).

Uredolayer auf gelben Flecken blattoberseits, länglich vier anch ziemlich verlingert, hald natkt. mangefarbig, stabig; Sporen kuglig. piformig his ellipsoidisch, 20-31 " laug, 175-2.2 $\mu$ breit. mit gelblichel, fein stachlicher Membrau, $6-8$ in zwei Etagen gestellten Keimpuren und wit oraugefarbigem Inhalte.

Teleutosporenlager auf denselben oder dunkleren Flecken oft rings um die Lredolager kreisformig gestellt, blattuberseits, klein, länglich, schwarzbrauu, nmgeben oler durchsetzt son Gruppen hrauner Paraphysen, Sporen umgekehrt eiturmig oder biruformi-, seltener lïnglicb, 20-33 4 lang, 175-2:2 hreit, am Siheitel abgerumlet, ahgestutzt orler (oft einseitig) verjüngt, zum Stiel keilfürmig verschnälert, mit gelbbrauner, am Scheitel dunklerer, nicht oler nur schwach verdickter Membran; Stiel bräunlich, bis $35 \mu$ lang.

Aecidien im Mai auf $R$ an unculus bulbosus: Lužnicetal bei Tábor!

Uredo und Teleutosporen von Ende Mai auf Festuca ovi na: Daselbst.

Festuca sp.: Kuchelbad bei Prag (Horal in Syclow's Uredineen Nr. 46.)!

De'n grnetischen Zusammenhang habe ich im J. 1905 durch Infelitionsrersuche bewiesen.

Ursprünglich ist diese Species ron Sydov ron Festuca rubra aufgestellt worden. Von Uromyces Ranunculi-Festucae Jaap (kommt nicht in Böhmen vor) ist sie hauptsiichlich durch kiuzere Telentosporen verschieden.

16, Uromyces graminis (Niessl) Dietel - Capitularia graminis Niessl. Uromyces Dactylidis Winter. - A ecidium Seseli Niessl.

Spermogunien auf beiden 1Blattseiten in der Mitte der Aecidien, gelblich, circa $100 \mu$ breit.

A ecidien beiderseits anf gelben Flecken, auf den Blattstielen kurze Verdickungen herrorrufend. I'seuloperidien reiss, lang wal enfömig, mit unregehnïssig zersihlitztem, leicht abfallendem Rande. I'seudoperidienzellen polyedrisch, in der

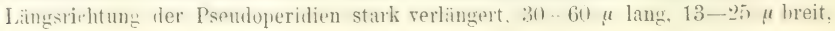




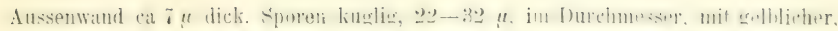

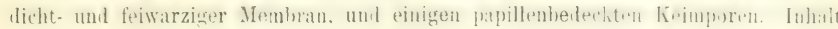
orange.

Uredolager blattoberseits, klein, strichförmig, bald nackt, rotbraun, stau-

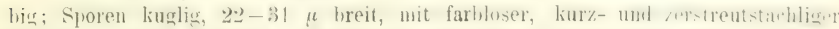

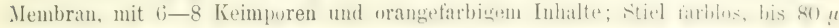
lang; Paraphysen fehlen.

Teleutosporenlager blattoberseits oder auf den Blattscheiden, klein.

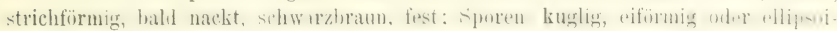
disch, 24-35 $\mu$ lang, 22-26.5 $\mu$ breit, braun, glatt, am Scheitel bis $11 \mu$ dick, abrerundet oder seltener wenig in eine stumpt-konische spitze serjungt, dissellin, donlielkastanienbraun, unten abgermelet wher in den fexten, wedblichen, his l:an "t langen Stiel verjüngt.

Aecidien iu der zweiten Hälfte Juni und anfangs Juli auf s'eseli g la uc um, Uredo und Teleutosporen his zum Ende der Vergetationsperiode auf II lica i. i 1 i a $t$ at.

Bisher nur unterhalb dem Herferhause zwischen Kühelbau und Radotir bei Prag.

Der geuetische Zu*ammenhang der decidien mit dum Iromyces wurde von mil in J. 1904 bewiesen.

17. Uromyces Scirpi (Castague) Lawerheim. - Uredo Scirpi Cartagne Uromyces lineolatus (Desmaziéres) Winter. - Uromyces Scirpi Lager heim nec Burrill.

Spermogo nie n honignelh, beiderseits auf den Flecken und and den Blattstielen.

A e cidien auf gelben Flecken in unregelmässigen oder rundlichen Gruppen blatunterseits ouler auf den Blattstielen. Psemboperidien zimulich hoch, wa,

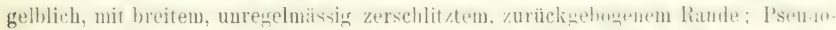

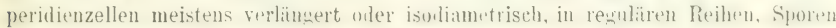

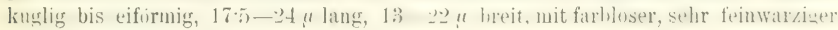
Membran und orangerotem Inhalte.

Uredolager auf gelbbraunen Flecken, strichförmig, zwischen den Nerven

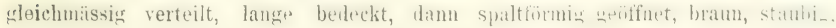
Sporen kuglig, eiförmig bis lang ellipsoidisch, 22-35 $\mu$ lang, $17.5-22$ breit, hellbraun,-entferntstachlig, mit 2-3 Keimporen.

Teleutosporenlager kleiu, rundlich oder länglich, in langen, strich.

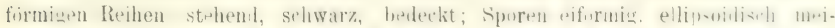

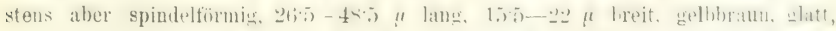

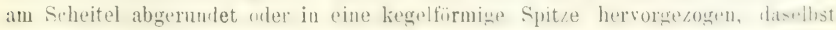
dunkler und oft bis zu $9 \mu$ verdickt, unten in den festen, bis $90 \mu$ langen, im oberen Teile bräunlichen Stiel verjüngt.

Aecidien im Juni, Uredosporen von Ende Juni, Teleutosporen von August, beide bis zum Vegetationsende. 
A ecidien in Böhmen auf Umbelliferen:

Berula angustifolia (Aecidium Berulae Bubák); Welwarn 2.9.6. 1900 Kabát)! Zwischen Manderscheid und Velenka (20.6. 1901 !

Daucus carota (Aecidium carotinum Bubák): Bei dem Žehuner Teich zusammen mit den Aecidien auf Pastinaca sativa (4/6. 1900)!

Pastinaca sativa (A ecidium Pastinacae Rostrup). Welwarn (Kabát)! Zwischen Manderscheid und Velenka mit Aecidium Berulae Bubik! Beim Žehuňer Teiche! Srpina bei Počerad!

Uredo- und Teleutosporen auf Scirpus maritimus: Prag (Hoffmannn)! Vršovice $\left(O_{p i z}\right)$ ! Velenka, Zitovlice. Krinec! Welwarn, Vysolí Veselí (Kabát)! Brüx (Štika); Wittingau (Weidmann)!

Durch Infektionsversuche wurde von Ka bát bewiesen, dass A ecidium Berula Bubák zu Lromyces Scirpi gehört. Belege betinlen sich in meinem Herbar.

A ecidium carotinum Bubák fand ich auf einigen blätern von Daucus carota in unmittelbarer Nähe des Aecidiums auf Pastinaca.

Auf Berula findet man nur selır kleine decidiengruppen, oft sogar nur vereinzelte Pseudoperidien. Sehr oft sind atuch submerse Blätter infizielt um es biliten sich auch in diesem Falle regelmässige Aecidien aus.

18. Uromyces Rumicis (Sthumacher) Winter - Uredo Ru u ic is s.humacher-. Aecidium Ficariae Persoon p. 1).

Spermogonion honiguelb, blattuherseits gruppenweise oder auch zwischen den Aecidien blattunterseis zerstreut.

A ecidien auf den Blättern auf weision. Hasenformigen Flecken, in dichten. rundlichen, auf den Blattstielen verlïugerten (iruppen. Pseudoperidien tief eingesenkt, wenig über die Blattoberfläche hervorragend, mit fein-und fast regelmässig zerschlitztem Rande; Pseudoperidienzellen pmlyëdrisch, isodiametrisch, ca 35 $\mu$ im Durchmesser oder länglich, $35 \mu \times 22 \mu$, fast in Reihen stehend. Sporen polyëdrisch, meistens luglig, seltener eiformig bis ellipsoidisch, 15- $28 \%$ " lang, 13-22 breit, mit farbloser, dichtwarziger Membran und oraugerotem Inhalte.

Uredolager beiderseits auf den Blittern auf gelben oiler braunen, lileinen. rundlichen Flecken dicht steheni, kleiu, rundlich, ball nackt, liraun. staubig und zusammentliessend, selten kreisfrimig steheud. Sporen liuglig oder kirz eifirmig. 19-265 4 lang, 20-24 $\mu$ breit, mit dünuer, hellbrauner, entferntstachliger Membran und zwei Keimporen.

Teleutosporenlager wie bei Uredo schwarzbraun bis schvarz, fest;

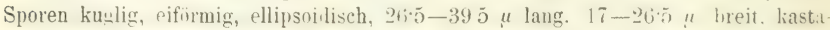
nienbraun, dickwandig, "latt, am Scheitel abgerundet und daselhet mit einex niedrigen, flachen oder niedrig konischen, hyalinen Papille. unten abgerundet oder manchmal in den leicht abfallenden Stiel verjüngt. Siehe Abbiliung 11, IV.,

Aecidien anfangs April bis Ende Mai auf Ranunculus Ficaria.

Uredosporen vou Juni, Teleutosporen ron Mitte Juli auf

Rumex aquaticus: Suchdol bei Prag (Th. Novák)! Kolín (Veselský), Habstein (Kabát)! Reichenber!̀ (Siegmund)! 
R u mex la y d rola path u m; Libiš bei Neratovic!

R $u \mathrm{mex}$ m aximus: Hertine im Bielatale!

R u m ex obtusifolius: Auf dieser Wirtspflanze viel verbreitet.

Auf vergilbten Blättern sind die Sporenlager von grünen Höfchen umgeben.

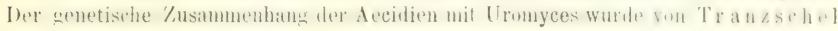
im J. 1904 bewiesen.

19. Uromyces Veratri De Candolle - A ecidium Cacaliae Thimen -. A e cidium Adenostylis Sydow.

Spermog o n i e n auf der Oberseite der Flecke in der Mitte der Aecidien gruppiert, honiggelb, sehr kleiu, tief eingesenkt.

A e cidi e n auĩ der Unterseite der gelblichen, später brïunlichen und gelb

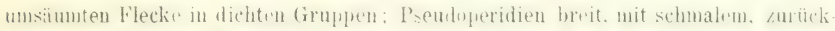

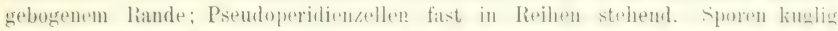

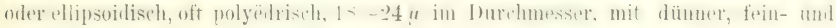
dichtwarziger Membran und hellgelbem Inhalte.

Ur odol a ger blattunterseits reichlich entrickelt, rundlich oder länglich,

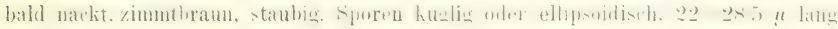
20-24 $\mu$ breit, mit brauner, entferntstachliger Membrau und zwei im Wasser stark aufquellenden und mit uiedrigen Papillen bedeckten Keimporen.

Teleutosporenlager blattunterseits zerstreut, rundlich oder lïnglich,

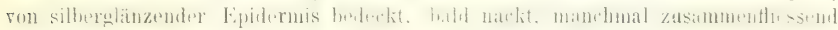

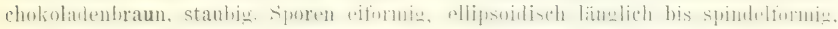
$24-395 \mu$ lang, $15-22 \mu$ breit, glatt, kastanienbraun, am Scheitel mit stumpfkegelformiger, hyaliuer, bis 7 " hoher Papille; stiel lirätig. fest, bräunliel, su lanse wie die Spore.

Aecidien im Juli und August auf

A denosty les albifrons: Riesengebirge, Rehhorn, Glatzer. Schueeberg.

Uredo- und Teleutosporen von Juli bis zum Vegetationsende auf

Veratrum Lo beli an um: im Riesengebirge, an Rehhorn bei Schatzlar und an Glatzer Schneeberge sehr verbreitet.

Uromyces Veratri kommt nur im Gebirge vor. Der genetische Zusammenhang zwischen den Aecidien und Uromyces wurde im J. 1904 von Tran z s hel bewiesen.

b) Teleutosporen punktiert.

20. Uromyees Pisi (Persoon) De Bary. - Uredo appendiculata $\beta$ ) Pisi Persoon. - Aecidium Euphorbiae P'ersoon p. p.

Spermogonien houigbraun, sehr zahlreich auf den Blïttern vor den Aecidien entwickelt, konisch hervorragend, wohlriechend.

A ecidien gleichmässig über die ganze Blattunterseite rerteilt; Pseudoperidien weiss, tief eingesenkt, breit und niedrig, mit fein- und regelmässig zer-

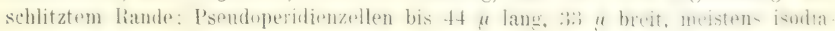


metrisch oder länglich, gelblich, aut der Innenseite $6.5, "$ verdiclit. Fporen puly-

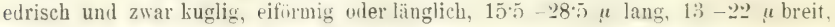
ziemlich dickwandig, dicht- und feinwarzig, mit orangefarbigem Inhalte.

Uredolager blattunterseits, seltener blattoberseits, verteilt, rundlich, bald wackt, dunkelbraun und staubiy; Sporen kuglig bis ellipsoidisch, 22-34.5 " laug, $20-24 \mu$ breit, braun, entferntstachlig: Keimporen 4-5, mit niellrigen. farblosen Papillen bedeckt.

Teleutosporenlager blattunterseits, seltener blattoberseits, rundlich. schwarzbraun bis schwarz. staubig. oft zusammenfliessend; Sporen kuglig, eifurmig
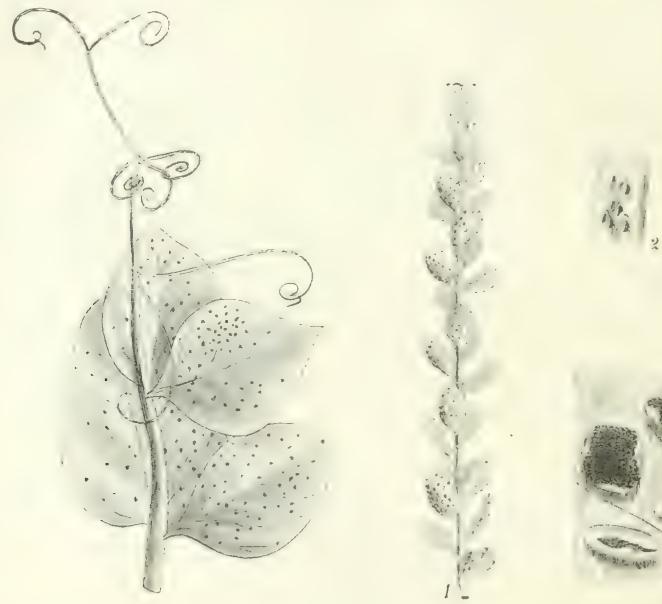

Abb. 8. Uromyces Pisi. Links ein Stückchen einer Erbsenpflanze mit dem Pilze. 1. Euphorbia cyparissias mit Aecidien. 2. Vergrösserte Pseudoperidien. 3. Stark vergrösserte Teleutosporenlager. (Nach Dietel.)

bis länglich, 22-2-35 $\mu$ lang. $155-26, \mu$ breit, dunkelkastanieubraun, mit feinen, nadelartigen Findrücken, beiderseits abgerundet, am Scheitel zuweilen nit niedriger. breiter, hyaliner Papille oder nur schwach verdickt: Stiel selu zart, farblos, abfallend, bis $50 \mu$ lang.

Aecidien von Mitte April bis zum Juni auf:

Euphorbia cyparissias sehr verbreitet.

Euphorbia esula ebenfalls verbreitet.

Euphorbia virgata: Klomin, Krinec! 
Uredo-und Teleutosporen auf:

Lathyrus pratensis: Sazena bei Welwarn (Kabát)! Turuau (derselbe)! Aussig (Wagner)! Eulau bei Tetsehen (Thümen, fungi austriaci 3r8)!

Lathyrus sativus: Klobuky bei Peruc!

Lathyrus silvestris: Radbuzatal bei Pilsen (Hora)! Ridlá im BrdyGebirge (Domin)! Tábor!

Pisum sativum: Auf dieser kuitivierter Nährpflanze verbreitet.

Das Mycel der Aecidien überwintert im Rhizom und im Frühjahre dringt es in alle neuen Triebe, die gïnzlich rerunstaltet werden. Sie zeichnen sich besonders durch schlanken Wuchs aus, wobei auch die Blatter fleischiger werden. Auf Euphorbia cyparissias sind dieselben läger als auf gesunden Pflanzen, bei Euphorbia esula und virgata, aber eiformig ouler fast rundlich. Der Zusammenhang des Uromyces Pisi mit den Aecilien vou Euphorbia cyparissias wurde von mehreren Autoren, mit den Aecidien von Euphorbia esula von Klebahn bewiesen. Die Zugehörigkeit der Aecidien von Euphorbia virgata ist noch zu beweisen.

21. Uromyces Fischeri Eduardi Magnus. - Uromyces Pisi Autt. 1. 1). Uromyces Jordian us Magnus nec Bubák.

Tredolager meistens blattoberseits, seltener blattunterseits, auch auf I3lattstielen und Stengeln ziemlich reichlich verteilt, sehr klein, rundlich oder auf den Blattstielen und Stenreln länglich, bald nackt, staubig, braun. Sporen kuglig oder ('ifürmig, $22 \mu$ lang, $2(1)-2 \cdot 2 \mu$ breit, mit hellgelbbrauner, fein- und entferntstachliger Membran und 4-5 Keimporen, die mit ziemlich stark aufquellbaren Höfchen versehen sind.

Teleutusporenlager wie die Uredolager, aber dunkelbraun. Teleutosporen eiförmig bis ellipsoidisch, $22-33 \mu$ lang, $22-24 \mu$ breit, mit dunkelbrauner, fein- und dichtwarziger Membran, am Scheitel abgerundet und daselbst mit Hacher, hyaliner Papille, unten mehr viler weniger verjüngt; Stiel kurz, hyalin, leicht abfallend.

Uredo von Juni, Teleutosporen von August auf

Vicia crace a: Mašov bei Turnau (Kabát)!

I h habe schon in der bohmischen Ausgabe des forliegenden Werkes pg. 35 (1906) auf die Unterschiede zwischen den Formen von Uromyces Pisi auf Pisum s ativum und Vicia cracca hingewiesen. Später wurde die Lorm ron Vicia cracea von Ma:nus (1907) als selbststindige Art aufgestellt, aber keine eigentliche I)iagnose derselben regeben. Die vorliegende Beschreibung ist nach den böhmischen Exemplaren entworfen.

Die Aecidien kommen wahrscheinlich auch auf Euphorbia-Arten vor. 
c) Teleutosporen mit lcistenförmigen Verdiclinngen.

20. Uromgces Medicaginis falcatae (De Candolle) Winter. Uredo Fabate var. Medicaginis fal catae De Candolle. - U romyces striatus Schroeter. - Puccinia Loti Kirchner, Lotos 1856, pg. 181. - Aecidium Euphorbiae Persoon p. p.

Spermogonien und Aecidien wie bei Uromyces Pisi; die befallene Pflanze (nach Schröter) niedrig, Blätter breit, verdickt.

Uredolager rundlich oder länglich, gewöhnlich blattunterseits, gleichmissig verteilt, seltener blattoherseits zerstreut, zimmtbraun. bald naclit und staubiu.

Sporen kuglig, eiförmig, ellipsoidisch, 15.5-24 $\boldsymbol{u}$ lang, $155-20 \mu$ breit. braun. entfernt stachlig, mit $3-4$ Keimporen, die mit kleinen, farblosen Papillen und kleinen Höfchen versehen sind.

Teleutos p orenlager wie bei den Uredolagern, dunkelbraun, bald nackt Sporen kuglig, eiförmig bis ellipsoidisch, 175-26.5 $\mu$ lang, $155-20 \mu$ breit, kastamenbraun, mit lïnlichen. schwach wellenfwimigen Leisten besetzt. heiderseits ahgeruadet, am Scheitel mit flacher, nushriger, hyaliner Papille, unten mit kurzem. farblosem, leicht abfallendem, bis $6 \%$ u breitem Stiele.

Aecidien im Mai und Juni auf

Euphorbia cyparissias sehr verbreitet.

Uredosporen von Juni, Teleutospreren von Juli, beide sporentormen bis zum Ende der Vegetationsperiode auf

Medicago falcata: Lieben (Opiz)! Tejuka (Th. Novák)! Kosoř! Ka¿ina (Peyl)! I)vakačorice bei Pardubic (Vodák)! Welwarn (Kabat)! Wiesen hei V̌setat! Rovensko! Habstein! Teplitz (Thümen)!

M e di c a go minima: Welwarn (Kabát)!

Medicago sativa: Kaiserwiese bei Prag (Opiz)!

Trifolium agrarium: Welwarn (Kabát)! Rovensko!

Trifolium arvense: Sehr oft bei Prag (Opiz, Fischel, ipse)! Kolín (Veselský)! Rovensko! Teplitz (Thümen)! Wittingau (Weidmanı)!

Das Aecidium-Mycel perenniert wie bei den Aecidien ron Uromyces Pisi.

\section{Uromyces Viciae craceae Constantineanu.}

Uredola ger gewöhnlich blattoberseits, rundlich, klein, zerstreut, bald nackt, hellbriun. Sporen kuglig oder eiformig, $21-24,4$ limg, $175-2.24$ breit. mit gelbbraumer, teinwarziger Membran und mit $4-$. s stark aufquellenilen und behöften Keimporen.

Teleutosporenlager hauptsächlich blattoberseits, zerstreut, klein, rundlich oder elliptisch, auf den Stengeln elliptisch bis lïurlich, bald nackt, schwarzbraun, staubig. خporen eiformig, hirnfirmigy oder ellipsoidisch, $22-26 \%$ "l lang, $165-20 \mu$ breit, am Scheitel abgerundet und daselbst mit einer hyalinen, abgerundet konischen, $2-3 \mu$ hohen Papille, unten gewöhulich in den kurztn. hyalinen, abfallenı.n Stiel verjüngt. Membran hellbraun mit linnsverlautenden, gewöhnlich anastomosierenden Leisten besetzt. 
Uredosporen von Juni, Teleutosporen von Ende Juli auf

Ervum lens: Welwarn (Kabát)! Nové Dvory bei Kolín (Veselský)! Kačina (Peyl)! Elbeteinitz (Veselský)!

Ich schliesse mich der Meinung von Magnus an, dass der vorliegende l'ils mit l'rom yees. I i cian. raccat Constantineamu morpholouisch idontiseh ist. I)ie Aecidien bewohnen gewiss wieder Fuphorbia-Arten.

"1. Iromyes Euphorbiac-corniculati Jordi Aecidium Euphorbiat Person p. p. - Puccin i a L oti Kirchner.

Spermogonien und A e cidien wie bei Uromyces Medicaginis falcatae.

Uredolager blattunterseits zerstreut, sonst wie bei Uromyces Astragali; Sporen kuglig oder ellipsoidisch, 18-25 $\mu$ lang, 17-23 $\mu$ breit, mit hellbrauner, zerstreut stachliger Membran und 2-5 Keimporen.

'Teleutosporen blattunterseits, dunkelbraun bis schwarz; Sporen knglig, eiformig oder hirnformig. 1s "

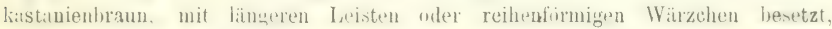
mit kurzem, hyalinem Stiele. Vštat!

Aecidien von Mitte April bis Juni auf Euphorbia cyparissias:

Uredosporen von Mai, Teleutosporen von Ende Juli, beide bis in den IVinter anf

Lotus corniculatus: Kaplitz (Kirchner als Fuccinia Loti Kirchner)! Vsetat!

Lotus tenuifolius: Srpinawiesen bei Seidowitz!

Diese Spezies wurde von Jordi auf Grund von Infektionsrersuchen wie

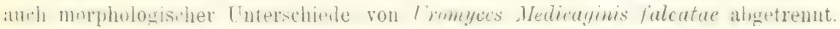

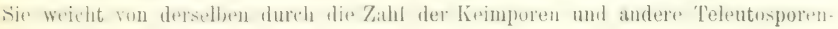
skulptur betrïclitlich ab.

25). Uromyces Astragali (Opriz) Saccarto, - Uredo Astragali Opiz in Sezuam rostlin květeny české 1852, pg. 151. - Uredo a cuminata Kirchner in Lotos 1856, pg. 179. - Uromyces Euphorbiae-Astragali Jordi.

Spermogonien und A ecidien wie bei Uromyces Medicaginis falcatae.

Uredolager blattunterseits zerstrent, rundlich, bald nackt, zimmtbraun,

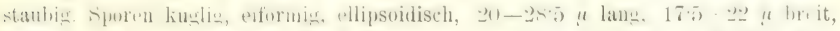

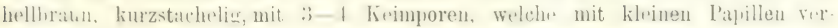
sehen sind.

Teleatosporenlager blattunterseits dichtstehend, hattobersent nur sehr zerstrent, rundlich, auf den libatstielen und stengeln länglich, schwarhoram. bald nar.ht und stauhig. Sporen linglig, eitwmis, ellipsoidisch. lämglich oder auch levilförmig, $20-31 \mu$ lang, $15 \cdot 5-22 \mu$ breit, beiderseits abgerundet, zuweilen unten schwah verjungt, hellkastanionhram. mit niedrigen, hem Stiol shwath berläu- 


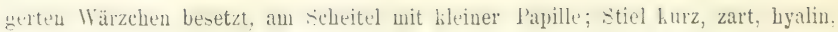
abfallend.

Aecidien von Mitte April bis Ende Mai auf

Eunhorbia cyparissias: 'Tábor!

Uredosporen von Juni, Teleutosporen von Juli auf

Astragalus austriacus: Welwarn (Kabát)!

Astragalus cicer: Im Herbarium des böhmischen Museums in Prag liegen Exsikkaten ans dem J. 1stti ats Bohmen (Hoser, Hoffmanu): leider ohne Standortsangabe.

Astragalus glycyphyllus: Noré Dvory bei Kuttenberg (Veselský)! Jačna (Peyl)! sundinka hei Pardubic Vodaks! Tumau , Kahat): Bila bei Bühm. Aicha! Harta bei Hohenelhe (Cypers); Küuigswald hei T'eplitz (Thümen, fungi austriaci $\mathrm{Nr}$. 381)!

A stragalus O nobrychis: Sazená bei Welwarn (Kabát)!

Oxytropis pilosa: Troja $($ piz, 1856)! Sr. Prokop bei Prag (Hora, in Sydow's Uredineen Nr. 401).

Der genetische Zusammenhang zwischen den Aecidien und dem Tromyces wurde von Jordi festgestellt.

26. Cromyces Jordianus Bubak. - Uromyces Astragali Jordi nec

Uredolager blattoherseits, seltener blattunterseits, hellbraun, bald naclit, staubig. Syoren kuglig, eitrirmig orler ellipsoidisch, $18-20 \dot{\mu}$ im Durchmesser oder $20-28 \mu$ lang, $17-23 \mu$ breit, hellbraun, kurzstachlich, mit $6-8$ Keimporen, welche mit kleinen Papillen versehen sind.

Teleutosporenlager wie bei der vorangehenden Spezies, jedoch die Wärzchen ein wenig grösser und dichter stehend.

Aecidien bisher unbekannt, aber wahrscheinlich auf Euphorbia-Arten.

Uredosporen von Juni, Teleutosporen von Juli auf

Astragalus exscapus: Radobyl bei Leitmeritz (Hora in Sydow's Urediueen Nr. 156)! Kreuzberg bei Liebshausen! Rannayerberg bei Laun (Wiesbaur)!

Die Nomenklatur dieser Art wurde ron mir in Anuales mycologici Vol. III. (1905), pg. 217 ff. richtiggestellt,

II. Iromycopsis. Nur Spermogonien, Aeciulien und Telentosporen entwickelt; die letzten erst im Frühjahre keimfähig.

a) Teleutosporen glatt.

27. Cromyces Behenis (De Caudolie) Lnger. - A ecidium Be henis De Candolle.

A ecidien bejilerseits auf den Blittern auf gellen oder viuletten, rundlichen Flecken, in kleineren oder grösseren Girupen. Pseudoperidien welb, ziemlich verlingert, oft rom Blattwewbe abgesmdert, mit zurückgebogenem, fuinzerschlitztem Rande; Pseudoperidienzellen sehr rariahel. meistens polyedrisch, ca 3" „u lang, 


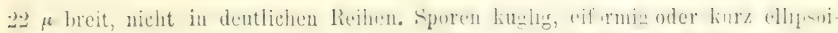

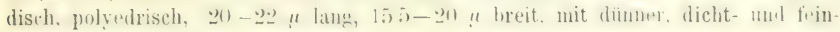
warziger Membran und orangerotem Inhalt.

Teleutosp orenlager rundlich oder länglich, oft, besonders an den Stennelu, reihenformig zusammentliessend, von der silberglänzenden Epidermis lange bedeckt, daun naclit, shwarz, fest. sporen kuglig oder breit eiformig, ollipandisch, braformig, keilformig, $265-44 \mu$ lang, $17-25 \cdot 5 \mu$ hreit, dunkelkistanienbrıun, watt, an Scheitel abmerundet, ahgestutzt oder seltener verjüngt, liaselhst his $11 \mu$ dick und dunkler, unten abgerundet oder in den bis $70 \mu$ langen, festen, oben bräunlichen Stiel verjüngt.

A ecidien vor Mitte Juni und mit den Teleutosporen bis zum Ende der Vegetationsperiode auf

Silene inflata: Mirovice bei Welwarn (Kabát)! Počáply bei Pardubic (Vodili)! Dolánky bei T'umau (Kabit)! Reichenbern (Fiegmumt als decidium stel-

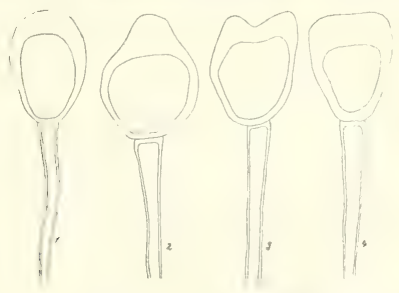

Abb. 9. T'eleutosporen von Uromyces Behenis.

lariae Opiz)! Katharinaberg bei Reichenberg (Kabát)! Teplitz (Thümenı; Herruskretschen (Wagner); St. I'eter und spindelmühle im Riesengebirqe (Schroetr.). Tábor!

Diese Spezies ist dadurch biologisch interessant, dass das sporidiengreborent Mycel Aecidien und Teleutosporen bilidet und dass dip Aecidien durch die granze Vegetationsperiode wiederholt werden (Dietel).

2R. Uromyces Scrophulariae (I)e (andolle) Winter. - Aecidi u u S croph hI a riae De Candolle. Aecidien.

Spermogon ie n honiwzelb, vereiuzelt orler fruppenweise zwischon iten

A $\theta$ cidien blattunterseits anf gelblichen oder violetten Flecken zerstrmut. Pseudoperidien halbkugelig, selb, tief eingesentit, mit rundlicher oder lituzheher, unregelmïssiger Oeffuung und weissem, umregelmitssig zerschlitztem, batd athallendem

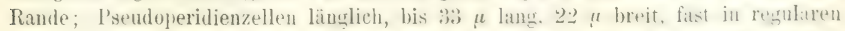

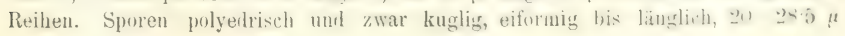




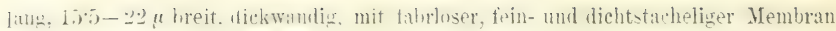
und orangerotem Inhalt.

Tele u tosporenlager zugleich mit den Aecidien aus demselbem Iycel ent-

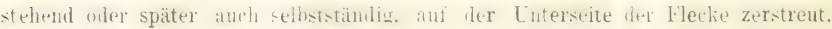

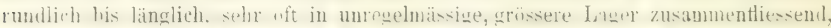
auf dem Stengel Ferlänert und dichte. linglich fruplen biliteml. lange ron der

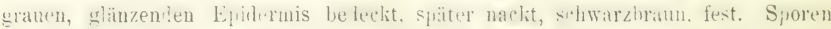

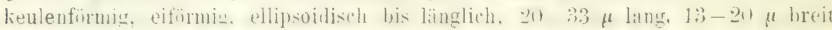

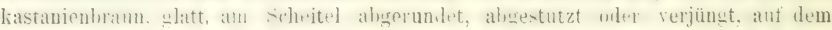

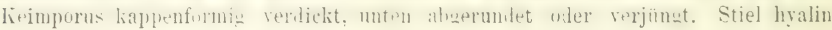
fest, bis $40 \mu$ lang.

Aecidien von Juni bis zum Herbst, Teleutosporen vou Juni bis zum Winter auf

Scrophularia nodosa: Gross-Skal! Turnau, Dolánky bei Turnau (Kabít)! Nové Dvory bei Kuntenberg (Veselský)! Tábor !

Uromyces Scrophulariae besitzt nach D i e tel wiederholte Aecidienbildung.

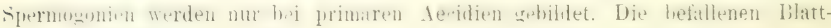
spreiteo, Blattstiele und Stengel sind stark gekrümmt uad verdiclit.

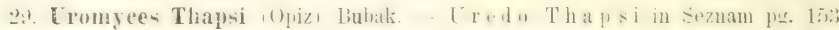
(1952) et in exsicc. - A ecidium Thapsi Opiz in schedis 1849 ! - Uromy ces Verbasci Niessl.

Spermogon i en zwischen den decidien zerstreut, honiggelb.

A e cidien blattunterseits auf gelblichen, zerstreuten, oder gleichmässig

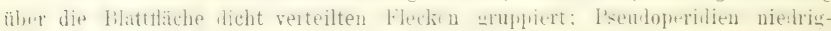

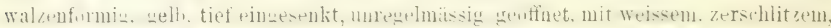

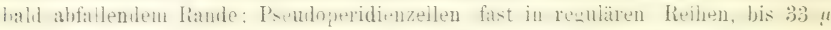
lang, $22 \mu$ breit; Sporen polyedrisch und zwar kuglig bis eiförmig, 17.5-22 $\mu$

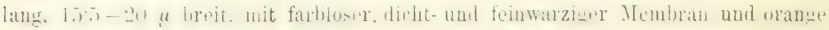
rotem Inhalte.

Teleutosporenlager wie bei Uromyces Scrophulariae, sehr lilein; Sporen ebenfalls, $22-32 \mu$ lang, $13-17 \cdot 5 \mu$ breit.

Aecidien von Juni bis zum Winter, Teleutosporen von Juli bis zum Vegetationsende auf

Verbaseum Thapsus: Baumgarten bei Prag (Opiz, August 1849, als Aecidium Thapsi Opiz in Herb. d. böhm. Museums in Prag; als Uredo Thapsi Opiz im Herbar d. k. k. bot. Abteil. d. k. k. Hofmuseum in Wien! Kačina (Peyl)!

Uromyces Thapsi ist mit der vorangehenden Spezies rerwandt, bildet aber lieine Deformationen.

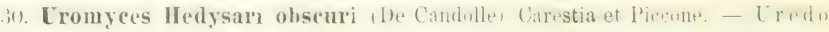
Hedysari obscuri De Candolle. - Uromyces Hedysari obscuri Carestia et Piccone. - Uromyces Hedysari Fuckel. - Uromyces Hedysari obscuri Winter. 
Spermogouien nur bei primären decidien, honiggelb, in kleinen Gruplen blattunterseits zwisehen den Aecilien

Aecidien (p rimäre) blattunterseits auf gelblichen, unregelmässigen Flecken, in kleinen, rundlichen oder länglichen Gruppen, oft dicht aneiuander gedringt und dann zusammengedriickt oder auf Blattstielen und Stengeln;

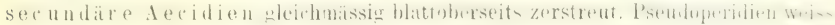

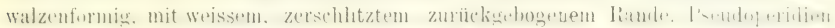

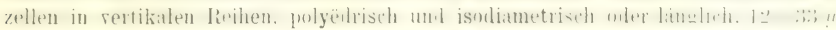
lanı, 11 -22 $и$ breit. Sporen polyëdrisch, sehr verschieden, kuglig, eiförmig, elli psoidisch oder länglich, $15-24 \mu$ laug, $12-175 \mu$ breit, mit dünner, hyaliner, fein- und dichtwarziger Membran und orangerotem Inbalt.

Teleutosporenlager klein, rundich oder lïuglich, blattoberseits, sel-

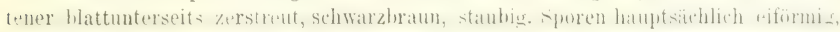
ellipsoidisch bis lïnglich, $20-40 \mu$ lang, $11-17.5 \mu$, hellkastanienbraun, dicht-

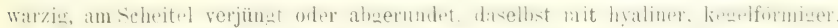
breit abgerundeter oder abgestutzter, $2-5 \mu$ hoher Papille, unten verjüngt, seltener abgerundet; Stiel halb so lang oder lïnger als die Spore.

Aecidien im Juni und zugleich mit denselben oder später auch die Telentosporen auf

Hedysarum obscurum: T'eufelsgarten im Riesengebirge (Pax).

Pax sammelte daselbst, nur Aecidien. Meine Diagnose ist nach Dietel's Exsikkaten aus den Tanern (Kitprunertal, anworfen. Dich demselhen Lutor besitzt auch diese Spezies wiederholte Aecidienbildung,

\section{Uromyces minor Schröter. - Uromyces Trifolii Winter p. p.}

Spermogonien honiggelb, auf der Oberseite von gelblicher Flecke.

A ecidien blattunterseits auf gelblichen, umegelmässigen Flecken dicht eruppiert, auf den Hanptnerven und biattstielen in verlänerten. his 1 an. langen

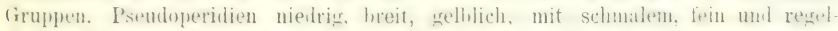

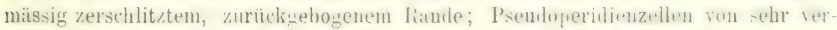

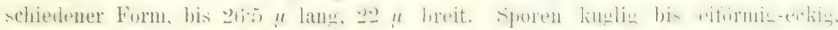
13-17.5 $\mu$ lang, $1 \mathrm{I}-155$ breit, dünawandig, dicht- und feinwarzig, mit orangerotem Inhalt.

Teleutosporenlager blattunterseits, seltener blattoberseits umregelnässig

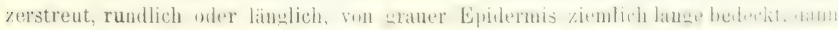

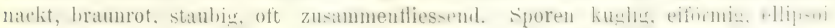
disch oder länglich, 175-31 $\mu$ lang, $13-20 \mu$ breit, kastanienbraun, dickwandig, glatt onler mit kleinen zerstreuten oder hie und da reshenformig stedenden 11 . 1 \%

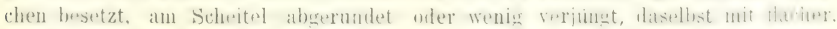

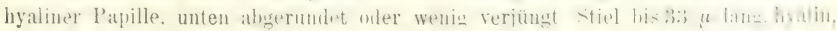
zart, abfällig.

Aecidien im Juni mit erster Generation der Teleutosporen zugleich aus dem. selben Mycel; die zweite (aecidiengeborene) Generation von Mitte Juli bis Oktober auf 
Trifolium montanum: Dóblice bei Prag (Opiz 1826)! Stern (Eck, im Herbar des botan. Instit. d. deutsch. Inivers. in I'ray)! Modraner Schlucht! Mühlhausen a. E.. Berg Wawč́n bei Radositz nächst Lobositz! Berg "Hora" bei Merzkles! An Fusse des Radelsteius au der Skalitzer Strasse! Radolýl und Welbine hei Leitmeritz! Vazovec bei Turnau (Kabát)! Tábor!

c) Teleutosporen mit leistenförmigen V'erdickungen.

32. Cromyces Erythronii the ('amblle) Passerini. - A e c i d i u m E r y th ro. ni De Candolle. - Caeoma Erythronii Corda. - Uromyces Erythron i i Winter, De 'Toni p. p.

Spermogonien auf beiden Blatttlïchen unregelmässig zwischen den Aecidien gruppiert, honiggelb.

A ecidien auf kleinen Flecken in abgerundeten, oft auch verlängerten und zusammentliessenden Gruppen blattunterseits und auf den Blattstielen, seltener
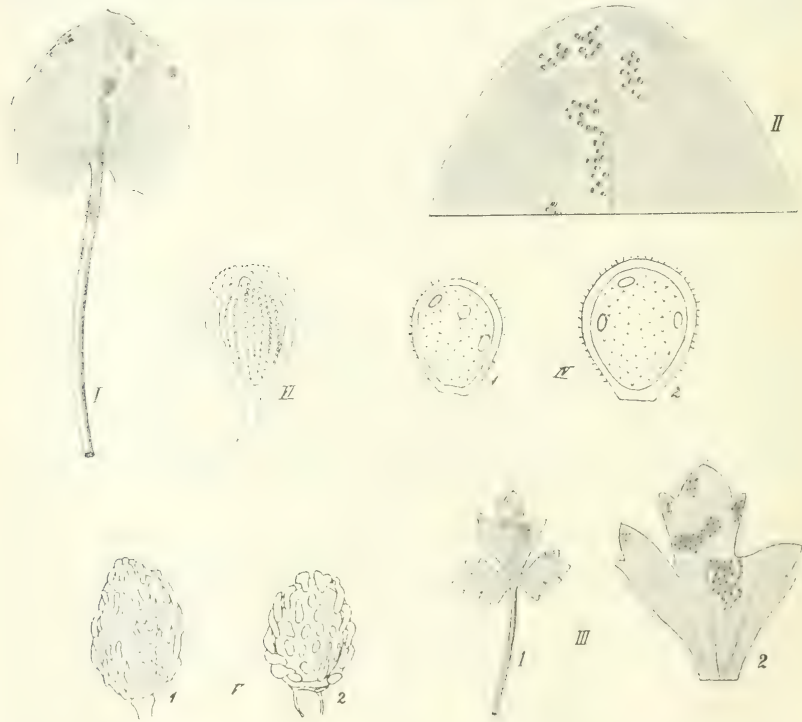

Abb. 10. I. Uromyces Ficariae auf Ficaria verna. - II. Aecidien von Uromyces Erythronii aut Erythronium deus canis. - III. Aecidien von Uromyces Festrcae auf Ranunculus bulbosus. - IV. Uredosporen von Uromyces Rumicis. - V. Teleutosporen von Uromyces scutellatus. - VI. Telentosporen von Uromyces Acetosae. (IV-VI nach Magnus. 


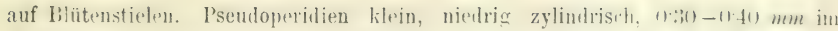
I) urchmesser, weiss, mit fein zerschlitztem. zuritchgehogenem Raude. l'senduperi-

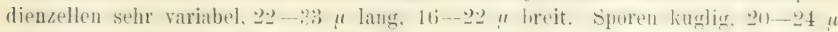
im Durchmesser oder länglich 20-33 4 lang. 15 - 24 " hreit, wft polyedrisch. mit dïnuer, farbloser, dichtwarziger Membran und orangerotem luhalte.

Teleutosporen I a g r auf bleichen Flecken auf den Blättern gruppiert oder ïber die nanze Blattobertlïche gleichnäissis verteilt, chokoladenbratun, staubius. Teleutosporen kuglig, ellipsoidisch. $24-395$ " lang. $175-265 \mu$ breit, wit hraumer, dïnner Membran. welche mit geschliuselten und verästelten Längsleisten iresetzt ist, am Scheitel abgerunlet und mit schmaler, walzenformiger Papille vistehen. unten nur selten verjüngt; Stiel bis $28 \mu$ lang, oben $7 \mu$ breit, farblos, vergänglich.

Aecidien im April und Mai, Teleutosporen im Mai auf

Erythronium dens can is: Medník bei Davle! Daselbst wird dieser Pilz schon von Corda in Icones fungorum Tom. II, pg. 2, Tab. VIII. fig. 10 . angegeben, allerdings mit falscher Bezeichnumg "Moldautal oberhath Prag ". lier Standort liegt oberhalb des Flusses Sázava.

W inter, Schröter und De Toni (in Saccardo's, Sylloge) und nach diesen fast alleneuere Mykologen vereinigen unter dem Namen Uromyces Ery. throni diesen Pilz und jenen von Lilium. Scilla u. s. w. Beide siud aher, wie ich in den Sitzungsberichten d. kön. bïhu. (tesellsch. der Wissenschaften nachsewiesen habe, gänzlich verschieden.

33. Uromyces Lilii (Link) Fuckel. - Caeuma Lilii Link in Linne, spec. plant. Ed. VI. Vol. VI, pars. 2, pg. 8. - Urom y ces Li i i i Fuckel. - Uromyces Erythronii Winter, Schröter, De T'oni p. p.

Spermogonien zwischen Aecidien zerstreut, gelbbraun.

A ecidien aut gelben. of zusammentliessenden Flecken aut der lilattoberseite gruppiert oder verteilt, tief eingesenkt, pustelformin, gelh, gross, his $1 \mathrm{~mm}$ im Inrchmesser, durch ein zentrales, wewännlich unregehnïssiges Loch geiftinet und mit sehr unregehmissig zerschlitztem, nicht umgebogemem Ranl versehen. Psendoperidienzelle’n gross, bis 50 " lang, 33 " breit. Sporen eiformiщ, ellipsoidisch, länglich. $2 .-37 \cdot 5$ " lang, 20-26.5 " hreit, mit ziemlich dicker, farbloser, dicht- und fein warziger Membran und orangerotem Inhalt.

Teleutosporenlager auf beiden Blattseiten, rundlich oder lïnglich auf Blattstielen sehr verlängert, von bald gesprengter Epidermis bedeckt. dunkelhraun, staubig. Teleutosporen litglig, eifürmig, ellipsoilisch bis länglich, :31 51)

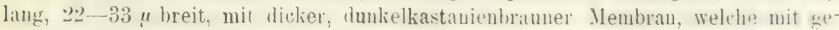
schlïnelten und reritstelten Längsleisten hesleckt ist, an Scheitel abgerundet nnd mit habliugdiger oder konischer, hyaliuer Papille versehen, unten abgeruudet oder seltener verjüngt. Stiel lïnger als die Spore, zart, lyaliu, sehr verginglich.

Aecidium im Mai, Telentosporen etwas später, aher ans demselben Mreel, endlich nur Teleutosporen auf

Lil ium c a n d i d um : Kačina (Peyl) in Herbarium d. königl. böhm. Museums (nur Teleutosporen)! 
III. Brachyuromyees. Sur Spermognien, [redo- unl Teleutosporen ausgebildet; die letzten keimen erst in Frühjahre

Aus dieser tiruppe ist bisher in Böhmen kein Repriisentant aufgefumlen worden. Migrlicherweise wehort hierher vielleicht irmendeine Art der nächstfolgeuden Gruppe.

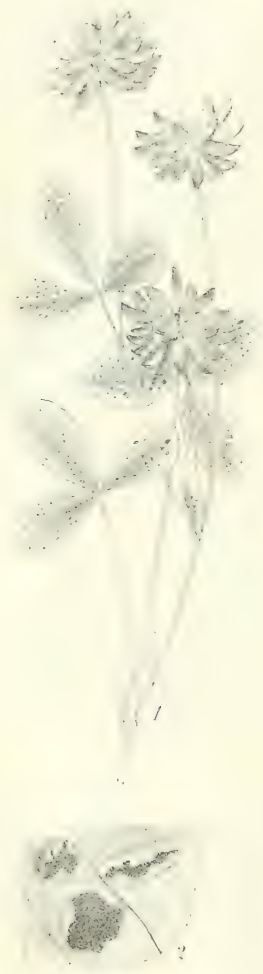

Abb. 11. Uiomyces Tritolii.

1. Trifolium hyluillum wit dem Pilze. - 2. T'cleatosnorenlager stark vergrossert. (Nach I) ietel.)
IV. Heminromyees. Nur Uredo- und Teleutosporen ausgebildet; die letzten keimen erst im Frühjahre.

(Walırscheinlich nur eine unnatürliche Gruppe, in welche solche Arten eingereiht sind, deren ganze Entwicklung nicht bekannt ist. Das gilt besonders von den auf Papilionaceen vorkommenden Arten.)

( ) Teleutosporen glatt.

35. Uromyces Trifolii (Hedwiğ fil.) Léveillé. Puceinia Trifolii Hedwig fil. - Uromyces Trifolii Léveillé.

Uredolager beiderseits auf den Blättern gleichmässig verteilt oder nur zerstreut, rundlich bis länglich, von unregelmässig zerschlitzter Epidermis teilweise bedeckt, zimmtbraun, staubig. Sporen kuglig, eiförmig, 22-26.5 „ lang, 20 bis $265 \mu$ breit, braun, mit kräftigeren und mehr (als bei Uromyces Trifolii repentis) entfernten Stacheln besetzt, mit 5-7 Keimporen.

Teleutosporenlager wie die Uredolager, aber schwarzbraun, auf den Blattstielen verlängert. Sporen kuglig, eiförmig, ellipsoidisch, seltener länglich, $22-33 \mu$ lang, $17 \cdot 5-22 \mu$ breit, dunkelkastanienbraun, glatt oder mit vereinzelten Wärzchen, oben abgerundet oder schwach verjüngt, daselbst mit einer niedrigen breiten, hyalinen Papille, unten abgerundet oder plötzlich verjüugt; Stiel kürzer als die Spore, farblos, verg̈̈nglich.

Uredosporen von Juni bis August, Teleutosporen von Juli bis zum Ende der Vegetationsperiode auf

Trifolium frag if e r u m: Welwarn (Kabát)! Křnec! Podulší bei Jičín!

Trifolium hybridum: Wiesen bei Všetat! Welwarn (Kabát)! Hrádek bei Auscha! 


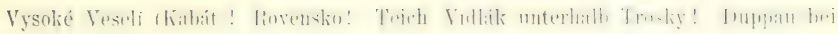
Karlsbal (Wiesbaur)!

Trifolium pratense: Habstein (Wagner)! Dobruška (Vodák)!

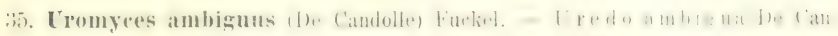
dolle. - Uromyces ambigus Fuckel.

U redolager blattoberseits zerstreut oder in langen Reihen zwischen den Nerven, verlïngert, der Länge nach oder anch quer zusammentliessend, von welb.

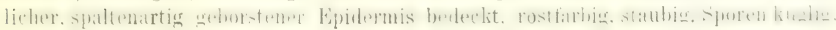
eiförmig oder ellipsoidisch, 20-35 $\mu$ lang, 17-26\% $\mu$ breit, mit hyaliner, feinwarziger Membran und 6-7 Keimporen.

Teleutosporenl a ger dicht und gleichmïssig auf den Blättern verteilt,

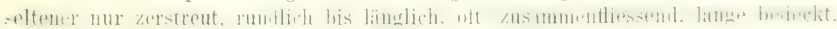
endlich nackt, kastanienbraun. Sporen sehr unregelmässig und zwar eiförmig, ellipsoidisch oder lïnglich, immer mehr oder weniger eckig, auch keulen- oter birnförmig, 24-10 $\mu$ lang, 20--2t $\mu$ breit, am Scheitel abgerundet, abgestutzt oler

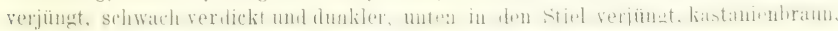
glatt. Stiel bis $40 \mu$ lang, zart, ziemlich dauterhaft.

Uredosporen im Mai, Teleutosporen von Mitte Mai bis Ende August auf

Allium scorodoprasum: Chotuc bei Křinec! Dymokurer Wälder!

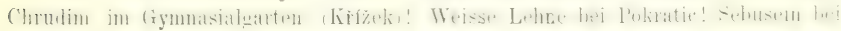
Leitmeritz!

Allium rotundum: Chotuc bei Křnec!

In dem Materiale von Dymokur habe ich eimmal eine zweizellige Teleutospore $(46 \mu \times 24 \mu)$ beobachtet.

b) Teleutosporen warizig.

36. Uromyces caryophyllinus (Schrank) Schroeter. - Lycoperdon earyophyllinum Schrank. - Uromyces Dianthi Niessl.

Uredolager pustelförmig (besonders auf Diantbus caryophyllus gross),

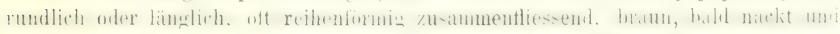
staubig. Sporen kuglig, ellipsoidisch, 22-375 $\mu$ laug, $1855-26.5 \mu$ breit, sehr

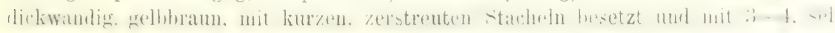
tener 5 aequatorialen oder iu der oberen Sporenhälfte gelegenen Keimporen.

Teleutosporenlager wei bei den Uredosporen, lange bedeckt, dunlielbraun. Sporen fast kuglig, eiförmig oder ellipsoidiseh, $22-375 u$ lang, $17 . \overline{5}-2 \pm \mu$ breit, kastanienbraun, dickwandig, sehr feinwarzig, am Scheitel mit breiter briun-

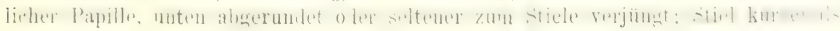
$1 / 2$ Spore.

Uredosporen von Juni, T'eleutosporen ron Juli auf

D i a n th us caryophy 11 us: Prag (Opiz im Herbar d. böhm. Museums nur Uredosploren!

Hariot hält die Uredoform von Dianthus caryophyllus für selbstständige Form - Uredo Dianthi Hariot. 
37. Uromyes Onobrychidis (Desmaziéres) Léveille. - C redo a nobry chii Desmaziéres in Catalogue plant. omiss. p. 25 (1813). - Urom yces O nobryc h i d is Léveillé in Disposit. meth. Uredinearum (1841). - Urom y ces Genistae tin ctoria e Winter, De Toni et alii p. p.

U redolager auf beiden BlattHächen verteilt, rundlich oder länglich, anfan-i von der Epilermis heleckt. bald aber nackt, bram. staubig und oft zusammentliessenil, anf den Bluttstielen und Stengeln verlängert, lange bedeclit, enılich durch einen länglichen Riss geuffnet; Spuren kuglig, eitrirmig, ellipsoillisch, 2.2 bis $33 \mu$ lang, $17 \cdot 5-24 \mu$ breit, hellbrauu, entfernt stachlig, mit 3 Keimporen.

Teleutosporenlager zwischen den Uredolagern spärlich entwickelt,

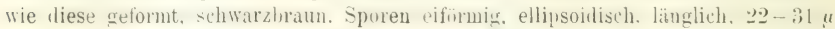
lang, $175-20 \mu$ lreit, mit kastanienhrauner. lüumer, feinwarziger itrocken untersucht!) Membran. am Scheitel abgerundet uni ciu wenig verdickt, daselbst dunkler und wit deutlichen heimporen versehen, unten abgerundet oder in einen kurzen, farblosen, leicht abreissenden Stiel verjüngt.

Eredosporen ron Juni his in len Winter, Teleutosporen ziemlich selten entwickelt und zwar erst im Herbst auf

On obryehis vicia folia: Kaiserwiese bei Smíchov (Hoser)! Karlstein (Hura in Sydows Crenlineen Nr. ״̈! Welwarn , Kabit)! Mlechrosty bei Kralup !

Die vorliegende Art wurde früher von den neueren Autoren entweder mit Uromyces Genistae tinctoria eder mit Uromyces Trifoli vereinigt.

38. Cromyces lupinicolus lmbali - Licaeoma Lupini Hoffmann in schedis.

Credolager auf rundlichen, britublichrn Flecken blattunterseits einzeln oder in kleineu fruppen verteilt, rumllich. zimmtbraun, staubig. sporen kuglig. 20-24 $\mu$ lang, $15 \cdot 5-20 \mu$ breit, mit gelbbrauner, dünner $(1 \mu)$, feinwarziger Membran und $2-3$ Keimporen.

Teleutosporenlager wie bei den Uredosporen aber braun. Sporen selten kuglig. meisteus eformig, ellipsoidisch bis keilformig verlängert, $24-35 \mu$ lang, 13-20 $n$ breit, am Scheitel abgenundet um daselbst ifters mit einer dimmen Papille versehen, unten gewihnlich iı einen kurzen Stiel verjünst, mit hellbramer, etwa $2 \mu$ dicker und feinwarzigerMembran.

Uredo- und Teleutosporen im Sommer auf

Lupinus sp.: Prag (Hoffmann) - im Herbarium d. königl. Mfuseums in Irag als Dicaeom a Lupini Hoftimann.

39. Uromyces Ononidis Passerini. - Uromyces Anthyllidis Hariot p. p. - Uromyces Genistae tinctoriae Winter p. p.

Uredolager auf beiden Blattflächen zerstreut oder um ein zentrales, grösseres Haufehen lireisformig gruppiert, zimmtbraun: Sporen kuglig, eiförmig bis kurz ellipsoidisch. $2(1-31$ " lang, $175-2.2 \mu$ breit, mit hellbrauner, bis $2 \cdot 5 \mu$ 
dicker, zerstreut feiustacheliger Membran; Keimporen 2-4 (gewïhnlich 3), aussen mit dicker, dentlicher Papille, innen mit aufyuellendem Höfchen versehen.

Teleutosporeulager rundlich, schwarzbraun, auf beiden Blattllïchen zerstreut und von derher, später gespaltener Epidermis bedeckt. Sporen kuglis, eiförmig bis kurz ellipsoidisch, 2.2-33 $\mu$ lang, $20-22 \mu$ breit, dunk lkastanienbraun. auf beiden Polen abgerundet, dicht mit grösseren Wärzchen besetzt; Stiel kräftig, abfallend, kürzer als die Spore.

Uredosporen von Juui, Teleutosporen von September, beide bis zum Vege. tationsende auf

Ononis spinosa: Pelc be: Prag (Op)iz, November 1849)! Welwarn (Kabát)! Sadská!

Müller meint im Zentralblatt für Bakteriologie und Parasitenkunde, II. Abt.. XVII. Band, p. 211, dass zu dieser Art das A ecidium Eu ph or b i a e Gerardiante E. Fischer gehint. Ich hetone hier aher, das auf den angeführten Standorten des Uromyces, auch in der Nähe, Euphorbia Gerariliana überhaupt nicht rorkommt.

40. Uromyces Anthyllidis (Greville) Schroeter - Eredu Anthyllidis Greville. - Uromyces Anthyllidis Schroeter.

Uredolager auf beiden Blatttlächen zerstreut, mauchmal sehr dicht gruppiert oder um ein zentrales, grösseres Häufchen kreisfömig nestellt, rundlich ołler länglich, bald nackt und staubig. Sporen inmere fast kuglig, 22-285 " lang, 22-24 $\mu$ breit, mit $ٌ \mu$ dicker, blasskastanienbrauner Membran, mit kurzen, zerstreuten Stacheln und mit 4-8 Keimporen, welche mit niedricren, hyalinen Papillen, innerlich mit kleinen Höfchen versehen sind.

Telentosporenlager zwischen den Uredolagern, denselhen gleich, aber dunkelbraun. Sporen meistens kuglig, selten eiförmig bis ellipsoidisch, $22-28, u$ lang, 175-22 $\mu$ breit, beiderseits abgerundet, am Scheitel oft mit niedriger, hyaliner Papille, mit dunkelkastanienbrauner, 3 ॥ dicker, mit grösseren Wärzchen bedeckter Membran. Stiel bis $33 \mu$ lang, vergänglich.

Uredosporen von Juni, Teleutosporen von Ende Juli, beide Sporeuarten bis Ende Oktober auf

Anthyllis vulneraria: Prag (Hennevogl)! liaumgarten (Th. Nuvális: Welwarn (Kabát)! Rovensko! Roudné bei Turnau (Kahit)! Chočiny bei Chýnov!

41. Uromyces fienistae tinctoriae (Persoon) Winter em. - L redo a p pendiculata var., Genistae tinctoriae Persoon. - Uromyces Genistae tinctoriae Winter p. p.

Iredolager blattunterseits zerstreut, rundlich, klein, hellbraun, hald nackt und staubig. sporen kuglig, eiförmig, ellipsoiıliseh, 2.2-31 " lang. 20-20(; hellbraun, ziemlich dickwandig, feinstachelig, mit $3-6$ Keimporen, dir nit niedrigen, farblosen Papillen bedeckt sind.

Teleutosporenlager blattunterseits zerstreut, klein, rundlich, hlattoberseits durch kleine, gelbliche Flecke markiert, bald nackt und clunkelhraun, balı Dr. Bubák, Die Piize Böhmens. 
zusammenfliessend. Watthherseits nur vereinzelt. Sporen kuglis. eiförmir, ellipsoi-

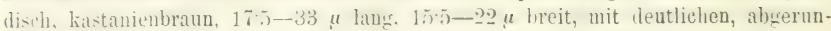
deten, hie und da in liurze Leisten zusummentlesenden Wärchen besetzt, beiderseits alwrumdet, unten seltener in den kurzen, farblosen, leicht alfallenden Stiel verjüngt.

Uredosporen vou Juni bis September, Telentosporen ron Juli bis zum Verge. tationsende auf

Cyt isus biflorus: "Dolečka" bei Leitomischl (Th. Norák)!

Cytisus capitatus: Kounice bei Böhm. Brod (Židlický)!

Cytisus Laburnum: Prag (Opiz, Kalmus, Weitenweber)! Kaisergarten

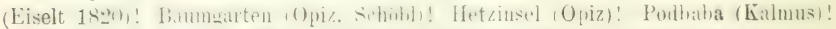

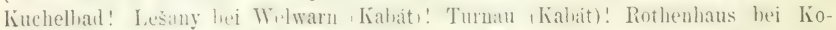

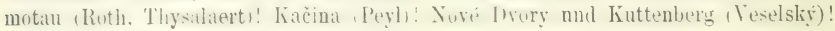
Tloskor bei Neveklor (Eck)!

Cyt isus nigricans: Šárka bei Prag (Vávra)! Michle (Kalmus)! Woppar-

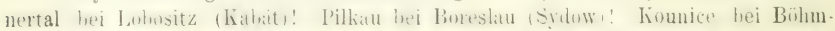

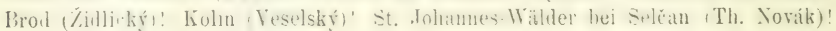
Tábor! Krumau (Jungbauer)!

Genista tinctoria: Kuchelbad bei Prag (Opiz 1849)! Rothenhaus bei Komotau rachs)! Pilkau bei boreslau (Sydon): Herrnsketschen (Wagner)! Rojau bei Krumau! Kaplitz (Kirchner)! Chlum bei Dobruška (Vodák)!

Galega officinalis: Pardubic (Opiz)! im Herbarium des königl. böhm.

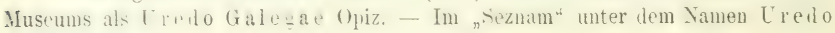
Galegi Opiz.

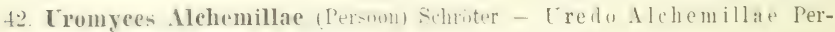
soon. - Trachyspora Alehemillae Fuckel.

Uredolager rundlich oder länglich, minienrot, strahlenförmig auf der unanzeu blattunterseite verteilt, meistens in derselhen Richtung zusammentliessend,

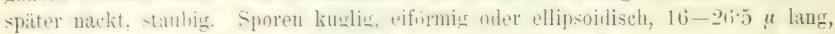
16-2.2 " lreit, mit himer, farbloser, kurzstabliger Membran und orangerotem Inhalt.

Teleutosporenlager kastanienbraun, wie bei den Uredosporen oder über die Blattunterstite zerstreut und dam kl+in. rundlich. Syoren kuglig, eifümig

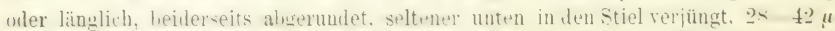

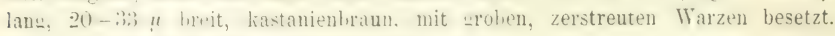
Stiel zart, bis $40 \mu$ lang, leicht abfallend.

Uredosporen rum Ende April his zum Juli, im Gebirge nnch im September, Telentosporen in iden Tredolitern sihon im Mai und sthstimdig bis zum Ausust, im Gebirge bis zum Ende der Vegetationsperiode auf

Alchemilla vulgaris im ganzen Lande und im Gebirge verbreitet, bei Prag seltener. In lifesenubirge. auf lem riatrer Simeeberge, im Bohmerwalde, Erzgebirge und böhm. Mittelgebirge gemein.

Alchemilla fissa: Kessel im Riesengebirge! 
I) Blätter werden in der Weise deformiert, dass lie Iblattspreite kleiner, die Blattstiele aber verlängert werlen. Das Mycel peremiert im Rhizom und dringt jedes Jahr in die Blïtter ein, die es in der erwähnten Weive deformiert. Jene Blätter, die durch die Uredosporen infiziert werden, sind ganz nomal ausprebildet und die Teleutosporenhüufchen sind auf ihnen nur zerstreut.

V. Mierouromyees. Nur Teleutosporen werden ausgehildet, welche erst im nächsten Frühjahre keimen. In den Teleutosporenlagern findet man oft auch vereinzelte Uredosporen, niemals aber selbständige Uredolager.)

43. Iromyees Ficariae ischumacher) Léveille. - L redo Fic ariate Sinmacher. - Uromyces Ficariae Léveillé.

T'eleutosporenlager auf beichen, ruudlichen orler verlängerten l'lecken sruppiert, rundlich oder länglich, anfangs bedeckt, daun mit rundlichem Loch gtiffinet, endlich gan\% nackt, zusammenfliessend und staubig; auf den Blattstielen in länglichen, verschiedene Verdickungen und lirümmungen verursachenden Gruppen. Sporen kuglig, aiförmig, ellipsoidisch, birnförmig oder lïnglich-spindelförmig, 2.: bis $40 u$ laug, 175-26.5 $\mu$ breit, kastanienbraun, glatt, am Scheitel mit bräunlicher, hreit kegelfömiger, his s̆ "l hoher, alygerundeter Papille, unten in den kurzen, bis $7 \mu$ breiten, hyalinen, abfallenden Stiel verjüngt.

Iredosporen in juugen T'eleutosporenlawern, kuglig, ellipsoidisch, birn-

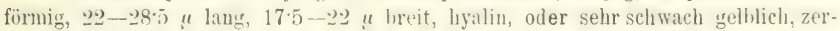
streut stachelig.

Von Mitte April bis Ende Mai auf

Fi c aria verna: Prag (Kratzmann)! Klamovka! Cibulka! Baumgarten (Beneš)! St. Prokop! Troja! Sarka (J. Opiz)! Roztoky! Dolany bei Lihsice! Kúchelhad! Radotín, Radotinertal! V'senory (Podpéra)! Cernošice! Solopisky! Rohlin! Larlstein! st. Ivan! Zwischen Mavle und Pikovice! Lochovicer Park I)omin)! Welwarn (Kahát)! Kačiua (Peyl)! Voškovrch bei I'odéhrarl! Velenka, Sadskit! Lenešice (Houska)! Rotheuhaus bei Komotau (Roth)! Teplitz (Thümen)! Harta (Cypers)! Háj hei Pilsen (Malorh)! Taibor! Sobèslav (Stejskal) und rewiss sonst mehr verbreitet.

Ficaria verua var. calthaefolia: Janegg bei Dux (Wiesbaur).

14. Uromyces Gageae beck. - I rom y ces $O$ r u it hog a 1 i Winter, schriter et alii non Léveillé.

Telentosporenlager auf beiden Blattlichen zerstrent, rumblich his elliptisch, von feiner, silbergrauer, bald sich länes spalteniler Epirlermis heiplit. staubig, dunkelhraun. Sporen liuglig-eiformio, ellipsoidisch, 22, , -39. his 2455 " breit, dunkelkastanienbraun, dickwandig, glatt. auf lubilen Pulen alug. rundet, selten unten in len Stiel verjünt. am sideritel mit einer his 45 " hwhen, farblosen Papille. Stiel $t_{2}-{ }_{3}$ der Sporenlïnge errelchend, zart, farblos. Ieicht abreissend.

Von Mitte April bis Mitte Mai auf

Gagea lutea: Prag (Opiz)! Baumgarten (Corlau! Kunirsaal (Iracht)! 
Zwischen Karlstein und St. Iran ofters! Weltruser Park (Kabát)! Chotuc bei Krinec! Yošlovreh bei Podebrad! Kolín (Veselský)! Milaverberg bei Laun ! Krumau (Jungbauer)!

Gagea pratensis: Tábor!

Wie schon der Autor selbst im Cryptosamae exsiceatae Musei Vindobonensis Nr. 18 angibt, ist die vorliegende Spezies von Uromyces Ornithogali L é r. durch breit ellipsoidische, glatte, unten wewhnlich abgerundete Sporen ver. schieden.

Th üm en füht in den Verhandlungen der zool-hotan. Gesellschaft 1875, py. 535 aus Buhmen auch Iromyces acutatus Fuckel und zwar vou Bühmiseh Aicha auf Allium olesaceum auf. Ich lionnte den Pilz, welcher ron Be nes gesam.

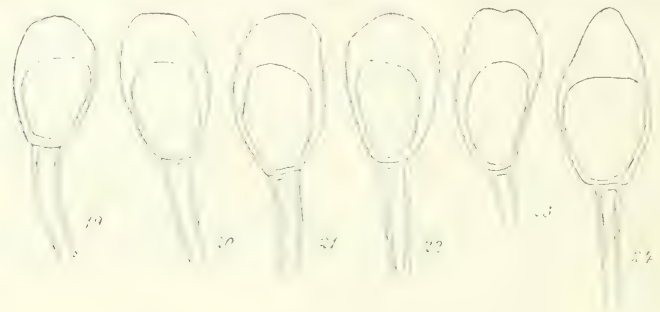

Abb. 12. Teleutosporen von Uronyces Solidaginis.

melt sein sollte. selhst nicht untersuchen. (Fiehe wegen Uromyces a cut a tus auch meine Bemerkmuen in den Sitzungsberichten d. k. höhm. Ges. 1. Wiss., Prag 1902, Nr. XLVI, pg. 22.)

45. Iromyces Cacaliae (De Candolle) Unger. - Puccinia Caca liae De Candolle. - Uromyces Cacaliae Unger.

Telentosporenlager auf der Tnterseite gelblicher, über die Blattflitche zerstreuter Flecke, dicht gruppiert, rundlich, bald nackt unil in grossere, his $5 \mathrm{~mm}$ breite Lager zusammenfliessend, dunkelbraun, staubig. Sporen eiförmig. ellịsoidisch bis spindelformír verlingert, 24-395 stanienbraun, glatt, am Scheitel mit einer bis t; $\mu$ hohen. kegelformigen Papille, unten abgerundet oder manchmal in den breiten, farblosen, wie die Spore langen, leicht abreissenden Stiel verjüngt.

Eine Gebirgsart, die im Juli zu finden ist auf

Adenostyles Alliariae: Riesengebirge, auf der böhmischen rie auf schlesischer Seite: Elbfallbaude, E.beruml, Weisswassergrund, Riesenurund!

Mit Uromyces Cacaliae wurde früher auch das Aecidium, welches auf Adenostyles vorkmmt. genetisch verhumlen. E. Fischer zeinte aher im J. 189, dass zwischen heiden Sprorenformen lein Zusammenhang besteht. Tranzsclie bewies daun später, dass dieses Aecidium zu Uromyces Veratri gehört. 


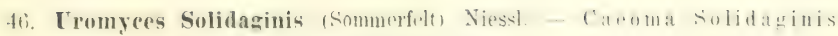
Sommerfelt.

Tele utosporenlager blattunterseits, seltener blattuhrseits, auf rumbli-

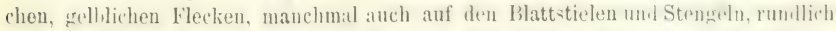
oler linglich, bald nackt, in ziemlich grosse (bis $11.5 \mathrm{~cm}$ ) (iruphen dichterelriugt, schwarz, fest. Sporon ellipsoidisch bis breit keulenförmig (jumes, unreife sporen auch spindelfömig), $265-395 \mu$ lim $15 \%-22 \mu$ hreit, am Siheitel bis 13 " dick, diselbst breit aboerundet, ahgestutzt oder nur weuig verjüngt, gegrn den Stiel zusammengezogen, glatt, :-lhhrau, am Scheitel kastanientraun; Stiel st rk, etwa wie die Spore lang, bei derselben $6.5 \mu$ breit hyalin, ziemlich fest.

Von Juli bis Ende August auf

Solidago virgaurea var. alpestris in böchsten Lagen der Sudeten : Hohes Rad (Schroeter); zwischen Riesenbaule und Prinz Heiurichsbaude! Glatzer Schneeberg (Schroeter).

47. Iromyces Phyteumatum (De (andolle) Unger: - Puceinia Phyteumarum De Candolle. - Uromyces Phyteumatum Unger.

Teleutosporenlager unterseits, stellenweise, oder über die ganze Blattspreite gleichmaissig verteilt, rundich, bald nackt, kastanieubraun, staubig und zusaumentliessend. Sporen kuglig, eifirmig, ellipsoidisch, $2 \cdot 2-4 \cdot 2 \mu$ lang, $15 \cdot 5-2+\mu$ breit, duukelkastanienbraun, glatt, an scheitel bis $11 \mu$ dick, daselbst heller, ab)gerundet oder in eine stumpfe Spitze vorgezogen, unten abrerundet, seltener plötzlich in den Stiel vr rü̈nt; derselbe lïrzer als die Spore, bis y $\boldsymbol{u}$ dick, farblos, leicht sich ablösend.

Von Mai bis Ende Juli im Gebirge und im Hügellande auf

Phyteuma spicatum: Aubachtal bei Neuhaus nächst Görkau (Wiesbaur)! Gottesgab (Krieger), Keilberg (Wagner), sosau bei Karlsbad (Bock? im Herbar. d. k. k. naturhist. Hofmuseums in IVien)! (teorgswalde, Johannesbar bei Trauteuau (Neumann im Herhar. d. höhm. Museums iu Prag)! Benecko bri Starkenbach! Zackenfall im Riesengebire (Nichooter). Rissengrund! - Babina bei Leitmexitz!

4׳. Uromyces Scillarum (freville) Winter. - Ured o Scillaru m Greville. - Uredo Hyacinthi Opiz in schelis et in Seznam pg. 15). - Iromyces Scillar u Winter.

Teleutosporenlager auf bleichen. ellinsoidischen oder rundlichen Flecken auf beiden Blattfiichen gruppiert; die inneren Lager orinunuslus, die ïusseren oft elliftische Figuren bildend; einzelne Layer rumdlich oder lïnglich, von gesprengter Epidermis teilweise bedeckt, dumkelbraun, staubin, oft in groussere homplexe zusammenfliessend. Sporen breit eifürmin, ellipsoidisch, keulenfurmig ader länglich, oft polyëdrisch, 20-375 ! lany, $13-22$ ! breit, hellkastanienhraun, dümnwandig, slatt, when abgestutzt, abgerundet oder verjüngt: Stiel farblos oder manchmal bräunlich, ziemlich dick, bis $33 \mu$ lang, leicht abfallend. 
Von Mitte Mai bis Ende Juli auf

Il us cari comosum; Leitmeritz (Wagner).

Muscaritenu iflorum: Podbaba bei Prag (Beneš, Opiz)! und zwar auf den Ahhüngen gegenüber Selc! Roztoky! Brüx (Štika)! Zlatnikerherg hei Bilin! Milayerber bei Laun! Langer Berg hei Solan! Radobýl bei Leitmeritz!

In jungen Lagern findet man nach $J$ uel (Bulletin de la Soc. Myc. de France 1901, pg. 250) zuweilen vereinzelte $20-27 \mu$ breite. farblose, feinstachelige Uredosporen.

b) Teleutosporen grobwarzig.

49. Uromyces apiosporus Haszlinsky. - Uromyces Primulae Schröter p. p. - Uromyces Primulae integrifoliae Winter p. p. - Uromyces Primulae min imae E. Fischer.

Teleutosporenlager blattoherseits, zerstreut oder gruppiert, rundlich oder länglich, von graner Epidermis lange bedeckt, dann nackt, teilweise zusammentliessend, dunkelkastanieubraun, staubig. Sporen kastanienbraun, kuglig, eiförmig, ellipsoidisch bis hirnförmig, $24-4 t \mu$ lang, 22-25.5 $\mu$ breit, am Scheitel abgerundet oder schwach in eine breite, stumpfe Spitze verjüngt, daselbst stark verdickt und heller, unten abgerundet, seltener in den Stiel verjüngt: Membran mit groben, halbkugeligen Warzen besetzt; Stiel fast so lang wie die Spore, bis $65 \mu$ lang, farblos, leicht abfallend.

Von Anfang Juli bis Ende August auf

Primula minima im Riesengehirge: Brumenberg (schon schröter) und zwar an Abhange zur Wiesenbaude! Gr. Ḱessel (Domin)! Kkleine Schneegrube (Schröter, Domin)! - Früher auch in dem ehemaligen hotanischen Garten in Swichov (Hora 1890)!

Das Mycel dieser Gebirgsart perenniert und dringt im Frühjahre in die neuen Sprossen und bildet deshalb gewöhnlich auf allen Blättern der befallenen Sprosse Teleutosporenlager aus.

50. Tromyces scutellatus (Schrauk) Léreillé. - Lycoperdon scutellatum Schrank. - U romyces Kalmusii Saccardo.

Spermogonien gross, anfangs halbkugelig, später konisch, gelblich oder orange, blattunterseits zwischen den Aecidien mehr oder weniger zerstreut.

T'eleutosporenlager blattunterseits dicht verteilt, rundlich oder länglich, polsterformig, von dünner, grauer Epidermis bedeckt, bald nackt, schwarzhraun, staubig, zusammenfliessend, oft eine zusammenhängende Schicht bildend; Sporen kuglig, eifurmig, ellipsoidisch oder länglich, 22-33 $\mu$ lang, 17'5-24 $\mu$ breit, dunkelkastanienbraun, mit grossen, lïnglichen, reihenförmig gestellten Warzen bedeckt, am Scheitel abgerundet, etwas verdickt und daselbst mit gröberen Warcen bedeckt, unten in den breiten und der Länge der Spore gleichenden, farblosen, abfallenden Stiel verjüngt. (Siehe Abbildung 10, V.)

Uredosporen in Teleutosporenlagern nur vereinzelt, kuglig, ellipsoidisch, lïnglich, hellbraun, dickwandig, feiustachelig, mit 1-3 Keimporen. 
Auf verschiedenen Euphorbia-Arten im Mai und Juni.

En p horbi a c y par is s i s: Žižlor (Opizals Uredo Euphorbiae eyparissiae Opiz)! Závist! Homole bei Vrané! Davle! Všenory (Beneš)! Tuchoměřce

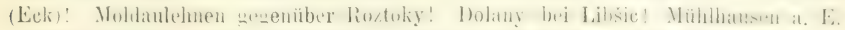

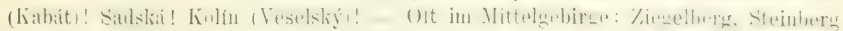

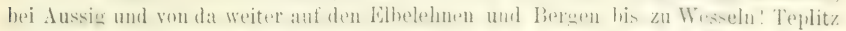

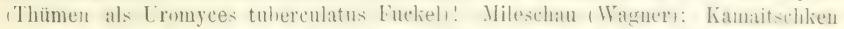

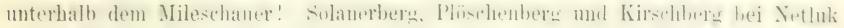

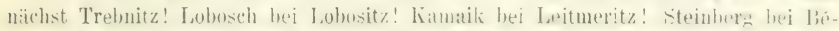
loschitz! Johamnesherg bei liolusoruk! Derer Mili bei Laun! lieorgsherg! Vrionicer

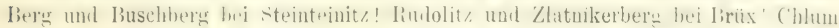
bei Manětín (Bauer)! (Kabát)!

Euphorbia esula: Zwischen Letky und Žalow! Hled’sebe bei Weltrus

Euphorbia Gerardiana: Mühllausen a. E. (Kabát)! Hledsebe bei Weltrus (Kabát)!

Dats Myeel überwintert in dem lihizom nud dringt jelles Jahr in alle neuen Sprossen ein und deformiert dieselben derart, wie tie Aucidien zu Uromyces Pisi und Uromyces Medicaginis falcatae. Uromyces Kalmusi Saccardo, welcher auf Grumb der Exemplare atus der Prager Umengemd (legit líalmus) aufgestellt wurle, halte ich nach den orisinalen aus der Haud de; II. P'. Sydow nur für Uromyces scutellat us. (Siehe auch bubak: Einige nene und kritisehe Uromyces Arten. Sitzungsherichte 1. kgl. hoihm. Gesellsch. 1. Wiss. Prag 1902, XLVI, pg. 10-11.)

VI. Lepturomyces. Nur Telentosporen ausgebililet, welche sofurt lieime 1 (Aus dieser Gruppe ist aus dem Gebiete bisher keine Art bekannt.)

\section{Schroeteriaster.}

Die Entwicklung bisher nur teilweise bekannt.

Uredosporen wie bei der Gattung Uromyces.

Teleutosporen in festen, liusenformigen, daterud von der Fpidermis bedekten Lagern, einzellig, hïchstens in 4-5 Schichten ähereinauder liegrend, zusammengeklebt. Keimporus undeutlich.

\section{Schroeteriaster alpinus (Schroeter) Magnus - Urom yces a lpinus Schroeter.}

Uredo lager auf beiden Blattseiten auf gelblichen, oben kiuminrot umsïumtent Flecken einzeln oder zu wenisen zerstrent wher aber fast fleichmibiving verteilt. klein, rundlich, bald natclit, staubig, zimmtbraun; sposen liumlig bis ellipsindisch 20-31 $\mu$ lang, 18-2: $\mu$ breit, mit gelbbrauner, stachliger Membran um 4 heimporen.

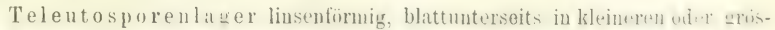
seren, gewöhlich, dichten (iruppen, dauernd von der Epidermis b-ukctkt. s.hwarzbraun, etwa $1 \mathrm{~mm}$ hreit; Sunren dicht verkleht, ellipsnidisch, eitiirmis mier keulen- 
förmig bis in 5 Schichten ühereinander gelagert, beiderseits abgerundert oder wenig verjüngt, 20-35 $\mu$ (seltener bis $40 \mu$ ) latg, $11-15 \mu$ (seltener bis $20 \mu$ ) breit, mit gelblicher Membran, am Scheitel mit bis $9 \iota$ hoher, hyaliner, abgerundeter oder konischer Papille, mit orangerotem Inhalte, stiellos.

Uredosporen von Juli, Teleutosporen von August auf

Rumex alpin us nur in Riesengebirge: Krausebauden! Spindelmühle (Hennings). Neue schlesische Baude (Schöter et ipse)!

Der Entwickelungsgang ist bisher unbekannt. Th üm en führt in seinem Ver. zeichnisse der Pilze Böhmeus (Verhanılungen d. zool.-bot. Gesellsch. Wien, Bd. XXV, pg. 535) ein Aecidium von $R u m e x$ alpinus auf, welches von $O$ piz bei Hohenelbe gesammelt sein sollte
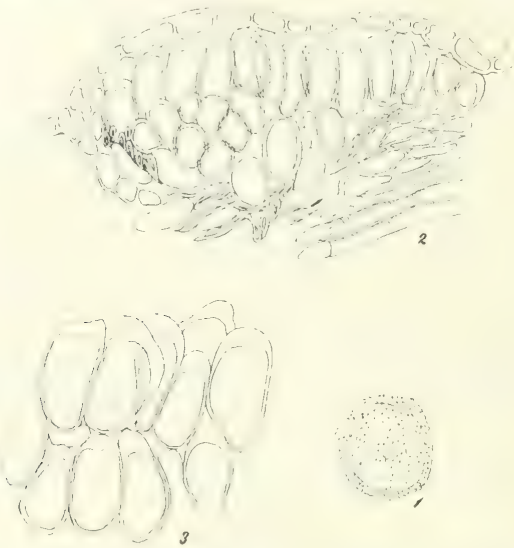

Abb. 13. Schrocteriaster alpinus. 1. Eine Uredospore. 2. Schnitt durch ein Teleutosporenlager.

3. Zwei Etagen von Teleutosporen.

Ob dieses Aecidium hierher oder nur zu Puccinia Phragmitis gehört. ist allerdings noch fraglich.

Die Teleutosporen sind dicht zusammengeklebt und weil sich immer neue und neue Sporen aus der Basalschicht entwickeln, so entstehen auf diese Weise 4-5schichtige Iager.

\section{Puccinia Persoon.}

Spermogouien wie bei Uromyces.

A ecidien ebenso; nur bei einigen Arten fehlt das Pseudoperidium und anstatt dessen sind die Aecidien an der Aussenseite von einem H y p h $\mathrm{nm}$ ant el umgeben. 
Uredosporen wie bei Uromyces.

Teleutosporen ebenfalls, aber zweizellig (ausuahmsweise 1-, 3- bis mehrzellig).

Sporidien wie bei Uromyces. (Siehe Abbildung 1, 2 und :3, 2.)

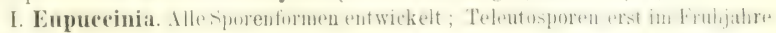
keimfähig.

1 Anteupucinia. Alle Sporenformen auf derselben Wirtspftanze.

a) Teleutosporen glatt.

a) Teleutosporenstiele fest, uicht abfallent.
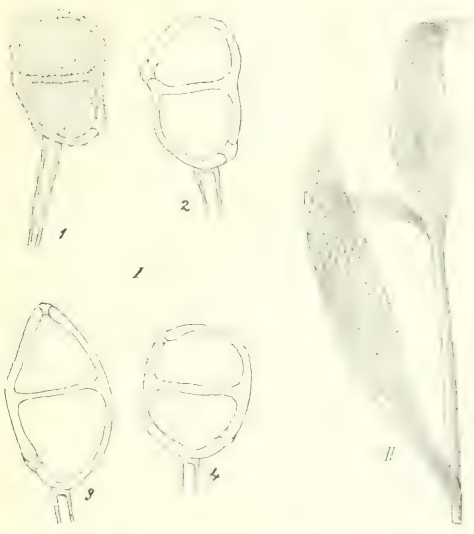

Abb. 11. I. $(1-4)$ Puecinia Willemetiae, Teleutosporen. - II. Aecilieu von Puccinia Bupleuri falcati auf Bupleurum falcatum. - III. Telentospore ron Puccinia Saxifrajae. - IV. Teleutosporen von Puccinia Sorghi, - V. Teleutosporenlager ron Puccinia Asparagi.

\section{Puceinia Asparagi De Candolle.}

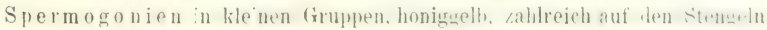
verteilt.

A ecidien in länglichen Gruppen; Pseudoperidien klein, niedrig, walzen-

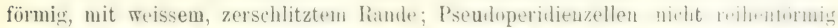

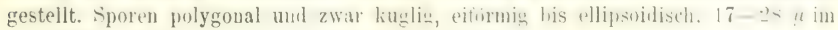
Durchmesser, feinwarzig, mit orangerotem Inhalte.

Uredolager zimmtbraun, linnglich, selhmal, lame budeclit; simm knolig oder eiformig, $20-30$ " latug, 17 - 25 " hreit, hellhaun, mit dicht- und feinwarziger Membran und 4 Keimporen 
Teleutosporenl ager rundlich oder länglich, bedeckt, dann uackt, schwarzbram bis schwarz; Sporen ellipsuidisch his keulenfurmig, am Scheitel ahgerumlet oller abgestutzt, daselhst rerdickt und dunkler, unten abgerundet vder in den Stiel verjüngt, bei der Querwand sehr wenig oder „rar nicht eingeschnürt, 30-5ะ „u lang. 17-26 " breit, kastanienhraun, glatt, untere 7.elle gewihnlich heller; Stiel fert. bräunlich, bis $160 \mu$ lang. (Siehe Abbild. 14, 5).

Aecidien im Mai, I redosporen ron Juni, Telentosporeu von Juli auf Stengeln und Aesten von

Asparagus officinalis: Prag (Forster, Hoffmann, Reiser, Quadrat Weitenweber)! Welwarn, Turnau (Kabat)! Harta bei Hohenelbe ('ypers).

\section{Puceinia Thesii (Desvaux) Chaillet.}

Spermogonien zwischen den Aecidien verteilt, honiggelb.

A ecidien auf beiden Blattseiten gleichmissin verteilt oder manchmal in rundlichen bis länglichen Gruppen; Pseudoperidien walzenförmig, nit weissem, umgebogenem, zerschlitztem Rande; Pseudoperidienzellen aul der Aussenseite his $15 \mu$ dick: sporen kuglig bis länglich, gewöhnlich eckig, feinwarzi lang, $13-18 \mu$ breit.

Uredolager über die ganze Ptlanze unregeimaissig verteilt, rundlich bis lïnglich, lange bedeckt, braun, staubig; Sporen kuglig bis breit ellipsoidisch, 20 bis $2 * \mu$ lang, $20-24 \mu$ breit, mit gelbbrauner, fein warziger Membran und $4-5$ Keimporen.

Teleutosporenlager wie bei den Urelosporen, oft auch verlängert, fest, schwarz; Sporen ellipsoidisch, eifurmig oder lïnglich, beiderseits ahgerundet oder seltener verjüugt, bei der Querwind eingeschnürt, 33-52 " lang, $20-26 \mu$ breit, mit kastanienbrauner, glatter, am Scheitel stark verdickter (bis $10 \mu$ ) Membran; Stiel kräftig, gelblich, lang, nicht abfallend.

Aecidien im Mai, Uredosporen von Juni, Teleutosporen von Juli auf

Thesium lin o phyllum: Hügel Loreta bei Jičín!

Thesium pratense: Prar (Hennevogl nach Thümen). Neubrunu bei Mader im Böhmerwalde!

\section{Puccinia Melianthi Schweinitz.}

Spermggronien honiggelb, in kleineren oder grösseren, rundlichen oder unregelmässigen Gruppen.

A ecidien entweder in kreisförmigen oder dichten Gruppen auf der Unterseite von gelblichen, rundlichen oder liuglichen Flecken. Pseudoperidien niedrig: mit umgebogenem zerschlitztem Rande; Sporen polygoual und zwar kuılig bis länguich, 21-28 $\mu$ lang, 18-21 $\mu$ breit, mit düner, fein- und dichtwarziger Membran und orangerotem Inbalt.

Ure dolag er blattunterseits, seltener blattoberseits zerstreut, rundlich, bald nackt, stauhig, braun; Sporen kuglig, eiförmig bis ellipsoidisch, 24-29 $\mu$ lang, $17-22 \mu$ breit, nit hellbrauner, stachliger, mit 2 Keimporen versehener Membran. 
Tele u o sp oren lag or blattunterseits, seltener blattoherseits zerstrent wher stellenweise gruppiert, rundlich, klein, bali nackt, schwarzhatum, fest: Sporen eiförmig, ellipsoidisch, keulenfirmig oder lïnglich, am Scheitel abrerundet, seltener verjüngt, zum Stiele gewöhnlich verjüugt, bei der Querwand milssig eingeschnürt, $35-60 \mu$ lang, 20-28 $\mu$ hreit, mit kastinienhramer, glatter, an Scleeitel bis $8 \mu$ dicker und hellerer Membran; Stiel hyalin, kriiftig, bis 100 $\mu$ lang, nicht abfallend.

Aecidien selten, Lredosporen von Juli, Teleutosporen von August anf

Helianthus annuus: (iross-Skal bei Turnau! Turnau (iKabit)! Niedergrund bei Tetschen (Wagner) und gewiss auch anderwïrts.

Puccinia Helianthi verbreitete sich in den letzten 25 Jahren von Russlituid aus über ganz Europa. In Russland tritt sie sehr oft epidemisch auf und verdirbt die jungen Kulturen.

55. Puceinia punctata Link. - Pu c e in i a G a l i i autt. nou Persoon. honiggelb.

Spermogonien auf beiden Blattseiten, in kleineren oder grisseren Gruppen,

A ecidien hauptsächlich blattunterseits, seltener blattoberseits, nicht selten auch auf den Stengeln, gewöhnlich auf rötlichen bis violetten Flecken locker gruppiert; Pseudoperidien niedrig, mit schmalem zurückgehogenem, zerschlitztem Raude, 250-350 $\mu$ im Durchmesser; Pseudoperidienzellen rhombisch im Durchmesser, aussen $65-10 \mu$ dick; Sporen polygonal und zwar kuglig, eiförmig bis ellipsoidisch, 17-26.5 $\mu$ lang, 13 - 2 ) $\mu$ breit, mt fein- und dichtwarziger Membran und orangerotem Inhalte.

Uredolager zugleich mit Aecidien aus demselben Mycel auf beiden Blattseiten und dann ziemlich gross, von blasenförmig aufgetriebener Epidermis bedeckt, später zusammenfliessend oder aecidiengeboren und damn blattunterseits, zerstreut, klein, rundlich, hald nackt, hraun, staubig; Sporen kuglig, eiförmig, seltener ellipsoidisch, $20-28.5 \mu$ lang, 15.5-22 $\mu$ breit, mit hellhrauner, entferntstachliger Membran und 2, seltener 3 Keimporen.

Teleutosporenlager blattunterseits oder stengelhewohnend, rundlich oder länglich, bald nackt, polsterförmig, fest, schwarz; Sporen keulenförmig bis ellipsoidisch, am Scheitel abgestutzt, abgerundet oder verjüngt, zum Stiel keilförmig verjüngt, bei der Querwand deutlich eingeschnïrt, 37-66 $\mu$ lang, glatt, braun, obere Zelle am Scheitel bis $13 \mu$ dick, dunkler, $17 \cdot 5-26.5 \mu$ breit, untere heller, $13-22 \mu$ breit; Stiel kürzer oder länger als die Spore, kräftig, nicht ahfallend.

Aecidien im Mai und Juni, Tredosporen oft zugleich mit denselhen aus demselben Mycel oder selbständig von Juni, Teleutosporen ron Juli auf

Galium Mollugo: Überall verbreitet.

Galium verum: Ebenfalls.

Galium uliginosum: Studené bei Rovensko!

Galium silvestre: Nové dvory bei Kolín (Veselský)!

Galium palustre: Kačiua (Peyl)! Reichenberg (Siegmund)! 
Aus dem sporidiengehorenem Mycel bilden sich oft zugleich mit den Aeridien anch Uredolager, manchmal folgen den Spermogonien nur die Uredolager, so dass die Aecidiengeneration nicht ausgebildet wird.

\section{Puceinia Galii silvatiei Otth.}

Spermogonien auf beiden Blattseiten oder nur auf einer derselben; in kleinen Gruppen, orangegelb.

A ecidieu hlattunterseits auf relben Flecken, seltener blattoherseits in lockeren, ärmlichen (iruppen zerstreut, oft auch einzeln; Pseudoperidien niedrig, klein, $170-350$ im [)urchmesser, mit weissem, umgehogenem, zerschlitztem Rande; Pseudoperidienzellen im Durchschnitte rhombisch, aussen dicker; Sporen polygonal und zwar kugelig, eiförmig oder ellipsoidisch. $20-24 \mu$ lang, 15-20 $\mu$ breit, mit dicht- und feinwarziger Membran.

Uredulager gewönulich hattunterseits oder stengelbewolnend, klein, rundlich oder länglich, bald nackt, staubig, hellbraun; Sporen gewöhnlich kuglig, auch eiförmig bis ellipsoidisch, $-0-26.5 \mu$ lang, $17-22 \mu$ breit, mit hellbrauner, entfernt stachliger Membran und 2, seltener 3 Keimporen.

Teleutosporenlager blattunterseits verteilt, klein bis mittelgross, oft zusammenfliessend, auf den Stengeln mehr oder wenicrer rerlängert, bald nackt, fest schwarz, schwach glänzend; Sporen keulenförmig, am Scheitel abgestutzt, algerundet oder verjüngt, zum Stiel keilfürmig verjüngt, bei der Querwand wenig eingeschnürt, 33-48 $\mu$ lang, kastanienbraun, glatt, obere Zelle am Scheitel 11 bis $16 \mu$ dick, $17 \cdot 5-28 \mu$ breit, untere heller, $13-17 \cdot 5 \mu$ hreit; Stiel liräftig, kürzer bis länger als die Spore, nicht abfallend.

Juli auf

Aecidien im Mai und Juai, Uredosporen von Juni, Teleutosporen von

Galium silvaticum: Mühlhausen a. E. (Kabát)!, Raudnic (Thümen)! Gross Wostray hei Aussig (Wagner). Creltschberg! Rožđ̊alovic! Vysoké Veself (Kabát)! Kolín (Veselský)! Kačina (Peyl)! Jaroměr (Knaf)! Halín bei Dobruška (Vodák)! Tábor!

Aus dem sporidiengeborenen Mycel bilden sich oft zugleich mit den Aecidien auch Urelolager, vereinzelt auch Teleutosporenlager; manchmal folgen den Spermogonien sofort Uredolager. In diesem Falle werden Aecidien entweder gar nicht ausgebildet oder es entstehen nur vereinzelte Pseudoperidien,

\section{Puccinia Asperulae cynanchicae Wurth.}

Spermogon i en auf Stengeln oder Blättern, kuglig bis birnförmig, honig gelb.

A ecidien auf beiden Blattseiten und auf Stengeln, karminrot umsäumt; Pseudoperidien schüsselförmig, mit weissem, wenig aus dem Blattgewebe hervorragendem Rande; Pseutoperidien in regulären Reihen, auf der Aussenseite $6-9 \mu$ dick; Sporen polygonal und zwar kuglig bis ellipsoidisch, 17-2.2 $\mu$ lang, 15-18 breit, mit dünner, feinstachliger, farbloser Membran.

Uredolager auf beiden Blattseiten und auf Stengeln, sehr zerstrent, rundlich, bald nackt, staubiu, hellbraun; Sporen kuglig oder eckig, 24-31 $\mu$ lang, 19-24 $\mu$ breit, mit brauner, stachliger Membrau und 2 Keimporen 
Teleutosp or enlager wie bei Uredosporen, fest, schwarz, gewölbt; Sporen

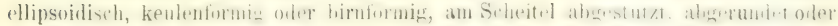
verjüigt, zum Stiel gewöhnlich verjüngt, $40-55 \mu$ lang, obere Zelle $17-24 \mu$,

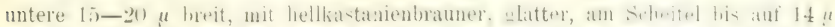

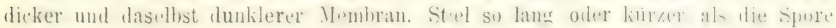
bräunlich, nicht abfallend.

Aecidien im Mai, Uredosporen im Juni, Teleutosporen von August auf ('Thümen)!

Asperula cynanchica: Volovice bei Welwarn (Kabát)! Aussig

\section{Puccinia Asperulae odoratae Wurth.}

Spermogonien bisher nicht gefunden.

A ecidien blattunterseits in kleinen Gruppen; P'seudoperilien schüsselformis, mit weissem, wenig aus dem Blattrewebes hervorbrechendom Rande; Premloperidienzellen in regulitren Reihen, anssen $6-8$ " dick: Sporen knglig. Mlipsoidich oder polygonal, 14-21 $\mu$ breit, mit dïnner, warziger Membran.

Eredolager meistens blattunterseits, zerstreut, sehr klein, auf den Stengeln strichformig, hellbram; Sporen kuglig, ellipsoidisch oder birnfirmig, $18-30$, im Durchmesser, mit braner, feiustachelger Membran und 2 Kémporen.

Tele utosporenl ager blattunterseits zerstrent, seltener uruppint, klein, rundlich bis länglich, lange bedeckt, auf den Stengeln pollinzert. schmarzbran; Sporen ellipsoidisch, birnförmin orter keulenformis, an Scheitel ahzerundet wher gerwöhnlich verjüngt, zım Stiel verjungt, bei der (Querwand schwach eingeschnitrt, 30--52 $\mu$ lang, $17-21 \mu$ breit, mit hellgalhbraner Membran, an Scheitel heller und daselbst bis $11 \boldsymbol{u}$ dick; Stiel so lang oder külzer als die Spore, byalin, nicht abfallend.

Aecidien im Mai, Uredosporen von Juni, Teleutosporen von September auf Asperula odorata: Kačina (Peyl)!

\section{Puccinia coaetanea Bubák.}

Spermogonien gross, honigbräunlich, auf beiden Seiten der Flecke im ziemlich grossen, dichten Gruppen, oft die Blattspitzen ganz bedeckend.

A ecidien auf der Blattunterseite, auf gelben, rötlichen oder violetten

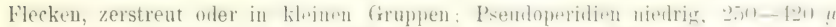

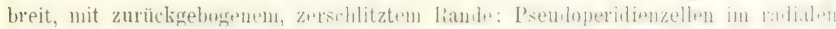

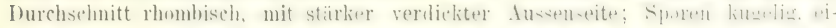

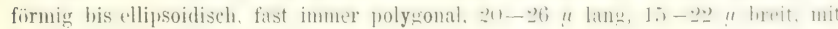
dicht- und feinwarziger Membran.

Uredolager aufangs aus demselben Mycel wie die Aecidien, beiderseits

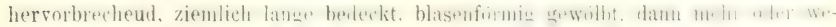

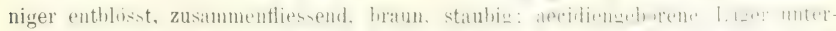

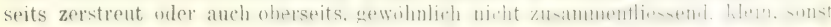
wie die vorigen; Sporen kugelig, eiförmig bis ellipsoidisch, 2.)-285 4 (seltener 
$31 \mu$ ) lang, $20-24 \mu$ breit, mit hellbrauner, feinstacheliger Membran und $2-3$ Keimporen.

Teleutosporenlaøer gewöhnlich unterseits, entweder aus demselben Mycel wie Aecidien und Uredosporen orler aus uredogeborenem Mycel und dann auch auf den Stengeln und Aesten, ziemlich gross, rundlich oder lïnglich, bald nackt, oft zusammenfliessend, schwarz, kompakt, schwach glänzend; Sporen gewribnlich keulenförmig, oben abgestutzt, abgeruudet oder verjüngt, in den Stiel keilformir verschmälert, in der Mitte etwas eingeschuiurt, 42-62 $\iota$ lang, mit glatter, kastanienbrauner Membran; obere Zelle am Scheitel bis auf $18 \mu$ verdickt, daselbst dunkler, 2()$-285 \mu$ breit, untere Zelle $175-22 \mu$ breit; Stiel läuger oder kürzer als die Spore, ziemlich dick, nicbt abfällig; Keimporus der Basalzelle oft mit breiter, hyaliner Papille.

Aecidien-, Uredo- und Teleutosporen im Mai und Juni zunleich aus demselben Mycel, selbstïndige Tredo- und Teleutosporenlager von Juni auf

As perula galioides: Plöschenberg bei Netluk nächst Trebnitz (21. Mai 1902, Aec.. Ur. und Tel., 26. VI. Ur. und Tel.)!

Die vorliegende Art ist durch grosse Spermogonien, grïssere Uredosporen welche mit :-3 Keimporen versehen sind, durch grössere Teleutosporen, wie auch durch die biologischen Verhältnisse von den verwandten Arten verschieden.

\section{Puccinia Calthae Link.}

Spermogonien honiguelb, in kleinen Gruppen beiderseits auf den Flecken.

A ecidien blattunterseits in kleinen Gruppen auf gelblichen Flecken oder in länglichen Gruppen auf den Blattstielen; Pseudoperidien niedrig, mit umgebogenem Raude, grob zerschlitzt; Pseudoperidienzellen eiformig bis länglich, fast in re„nulären Reihen; Sporen polygonal-kuglig, feinwarzig, $21-28 \mu$ im l)urchmesser.

Iredolager meistens blattoberseits verteilt, klein, rundlich, bald nackt, braun, staubig: Sporen liuglig bis ellipsoidisch, hellbraun, 26-35 $\mu$ lang, 20-25 $"$ breit, entferntstachlig, wit 2 Keimporen.

Teleutosporenlager meistens blattunterseits verteilt oder stellenweise kreisförmig stehend, anfangs hedeckt, dann nackt, klein, schwarz, fest; Sporen ellipsoidisch, keulenfömis, spindelfurmig, beiderseits verjüngt, bei der (Querwand nicht oder nur wenig eingeschnürt, 31-46 $\mu$ laug, 15-22 $\mu$ breit, mit hellbrauner glatter Membran; Keimporus der Scheitelzelle scheitelständig, jener der Basalzelle dicht an der Querwand, beile mit dicker, hyaliner Papille; Stiel krättig, bis $75 \mu$ lang, farblos, nicht abfällig.

Aecidien im Juni, Uredosporen rou Mitte Juni, Teleutosporen von Juli auf

Caltha palustris: Wiesen bei Ovéary nnd Park in Kačina (Peyl)! Telecí bei Policka (Novák)! Oft im Erzgehirge: Neustadt, Kalkofen, Ullersdorf! Oberbrand bei Joachimstal! Gottesgab und Böhmisch Wiesental (Waguer); Kechgrund (Sydow)! Fuss des Keilberges (Krieger)!

Puccinia Calthat ist von Puccinia Zopfii durch kleinere, hellere, glatte Teleutosporen und lange, feste Stiele verschieden. 
B) T'eleutosporenstiele zart, abfullend.

\section{Puceinia Porri (Sowerby) Winter.}

A ecidien auf beilen Seiten von gelblichen Flecken, in olliptischm tiruppen oder kreisformig gestellt; Pseuloperidien niedriz- mit weissem, wenig umgebugen'm, zerschlitztem Rande: Psendoperidienzellen auf der Aussenseite bis 7 u dick;

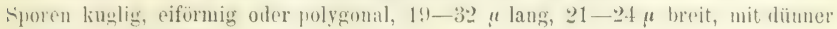
feinwarziger Membran.

Iredolager auf heiden Blattseiten, gewöhnlich auf bleichen Flecken, zerstent oder manchmal in lïnglichen Gruppen, lange bedeckt, rundlich bis langlich, dann nackt, staubig, rostgelb; Sporen kuglig bis ellipsoirlisth, 28-32 4 latms, 21 bis $2 \Omega^{3} \mu$ breit, mit hellbrauner, entferntstachliger Membran und 3 , mit niedrigen, breiten Papillen versehenen Keimporen.

Teleutosporenlager wie bei Uredosporen, schwarz, von grauer Epidermis lange beleckt, oft, besonders um the Uredolager herum, zusammenfliessend; zweizelligre Sporen kenlenfömig oler länglich, am scheitel abgerunlet oder wenï. verjüngt, zum Stiele verschmïlert, bei der Querwand schwach eingeschnürt, $35-46 \mu$ lang, 2(1-24 $\mu$ breit, mit brauwer, glatter, am Scheitel $3-4 \mu$ dicker Membran; einzellige Sporen birnformig orler ellipsoidisch, am Scheitel abyestutzt oder abgerundet, $26-42 \mu$ lang, 18-2+ $\mu$ breit; Stiel kurz, farblos, ahfillig.

Aecidien im Mai und Juni, Tredosporen von Juni, Teleutosporen von Juli auf

Allium fistulosum: Prag (Kalmus)!

Allium porrum: Prag (Quadrat)!

Allium sativum: Welwarn (Kabát)!

Allium schoenoprasum: Welwarn, Turnau (Kabát,! Reichenberg criegmund)! von Tetschen bis zu Hernskretschen auf (len Elbufern (Thümen, Wagner)! in Tábor!

Allium sibiricum: Riesengrund im Riesengebirge! Botanischer Garten

\section{Puccinia Gentianae Strauss.}

Spermogonien honiggelb, zwischen den Aecidien zerstreut.

A ecidien blattunterseits oiler auf den Stengeln, auf gelblichen, rumilichen oder länglichen Flecken, in unregelmässigen, lockeren oder dichteren Gruppen ; Psendoperidien niedrig, mit weissem, zerschlitztem Rande; Sporen polyedrisch, linglig bis ellipsoidisch, 16-23 " lang, 14-17 " breit, mit dünner, fein- und dichtwarziger Membran und orangerotem Inhalt.

Uredolager hauptsächlich blattoberseits, zerstreut, manchmal anch kreis. fömigr stehend, l:lein, rundlich, hrann; Sporen kuglig, eifïrmig bis ellipsoidisth,

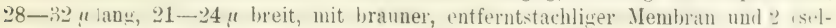
tener 3) Keimporen.

Teleutosporen lager wie bei den Uredosporen, schwarbraun, stanligin; Sporen fast kuglig bis ellipsoidisch, beiderseits abgerundet, bei der (querwam kaum eingeschuürt, $\$ 3-42 \mu$ lang, $26-31 \mu$ breit, glatt, dunkelkastanienbraun: sitiel farblos, kürzer als die Sprore; Keimporus der sicheitelzelle scheitelstimdig, 
seltener seitwäts stehend, jener der Basalzelle unterhalb der Querwand, beile mit niedrigen, hyalinen Papillen.

Juli auf

Aecidien im Juni. Uredosporen ron Enle Juni, Telentosporen von Ende

Gentiana cruciata: Krumau, Hohenfurth (Jungbauer 1818)!

\section{Puccinia Sweertiae (Opiz) Winter.}

Spermogonien ziemlich gross, honiggelb, auf beiden Blattseiten in kleinen Gruppen.

A ecidien auf der Unterseite von gelben ode: brauen Flecken in rundlichen, kleinen, auf den Blattstielen und Nerven in verlängerten Gruppen; Pseudoperidien anfangs gewölbt, mit rundlicher Oeffnuug, dann niedrig schüsselfurmig, mit ungebogenem, zerschlitztem Rande; Pseudoperilienzellen in undeutlichen Reiben, auf der Aussenseite bis $11 \mu$ dick, auf radialem Durchschnitte abgerundet-rhombisch; sporen immer polyedrisch und zwar kuglig, eiförmig, ellipsoidisch, 20 - 28 " lang, 17 -2:2 $\mu$ breit, mit dicht. und feinwarziger Membran und orangerotem Inhalte.

Uredolager (nach Winter) kugliy, hellbraun, fein punktiert, $19-26 \mu$ im Durchmesser.

Teleutosporenlager blattoberseits, entweder auf schwarzen AecidienHeclies oder zerstreut, klein, rumulich, lange bedeclit, selten zusammenfliessend, dunlielbraun; Sporen ellipsoirliseh, eiförmig, manchmal auch länglich, öfters polyedrisch, beiderstits aburundet oder zum stiel zuweilen ein wenig rerjüngt, bei der (Juerwand wenig oder gar nicht eingeschnürt, 35- $-48 u$ lang, $24-35 \mu$ breit, mit hellkastanienbrauner, ulatter Membran: Stiel fein, farblos, abfällig, bis 44 ulang; Keimporus der Scheitelzelle oft ein wenig heraboriickt, jener der Basalzelle unterhalb der (מuerwand oderetwas herabgeschoben, heide mit kleinen, farblosen Papillen.

Aecidien im Juli, Teleutosporen im August anf

Sweertia perenn is: Im Riesengebirge ziemlich verbreitet, z. B. Elbfallbaude, Elbewiese, bei ler Prinz Heinrichlaude oberhalb der Bergschmiede, Riesengrund, Teufelsgarten etc.

IV inter beschreibt auch die Uredosporen. Es muss hier aber hervorgehohen werden, dass weder $S y d o w$ und Fischer, noch ich, obzwar wir alle reichliches Material zu Verfü_un hatten, niemals diese Sporen gesehen haben. Ihre Existenz ist deshalb fraglich.

\section{(i4. Puccinia nigrescens Kircher. - Pucinia obtusa Schroeter.}

Spermogonien honiggelb, in kleinen Gruppen auf beiden Seiten der Flecke oder auf den Nerren und Blattstielen zwischen den Aecidien.

A ecidien in dichten Gruppen aufder Unterseite ron rötlicher oder gelblicher Fecke, auf den Blattspreiten in rumilichen und oft blasenförmigen, auf den Nerren und Bla!tstielen in länglichen und verschielene Deformationen verursachenden Gruppen; Pseudoperilien unregelmäsig, tief eingesenkt, wenig herrorragend, unregelmässig seriffuet, mit zersehlitztem, selten umgeb)genem liande: Sporen kuslis, eifürmig, 


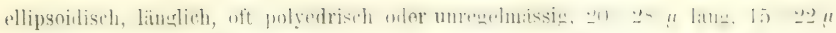
breit, mit dicht- und feinwarziger Membran und orangerotem Iuhalt.

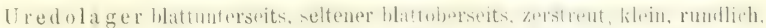

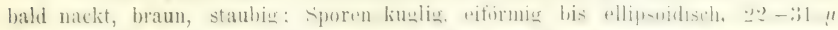
lang, $17-26$ " 3 Keimporen.

Teleutosporenlager wie bei den Uredosporen, schwarz, staubig; Sporen ellipsoidisch his länglicil. heiderseits ahgermudet oder manchunal zum itiel verjüngt, bei der Querwand eingeschnürt, 37-44 $\mu$ breit, lang, 22-31 $\mu$ mit. licker, kastanienbrauner, glitter, am scheitel bis s "dicker Mrmbran, "ler mit breiter, hellerer Papille versehen; Stiel kurz, zart, farblos, abfällig. Juli auf

Aecidien im Mai und Juni, Uredosporen von Juni, Teleutosporen von

Salvia verticillata: Ziemlich verbreitet.

Puccinia Betonicae Corda in Icones fungorum II., p. 5, tab.|VIII., fig. 21. ist auch nur Puccinia nigrescens.

\section{Puccinia Soldanellae (De Candolle) Fuckel.}

Spermogonien auf beiden Blattseiten oder nur blattunterseits, stark gewölbt, honiggelbbraun.

A ecidien auf der ganzen Blattunterseite oder nu stellenweise, gleich-

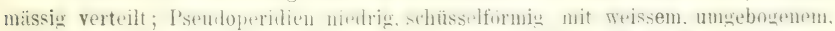

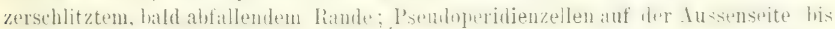
10 " dick; Sporen kuglig, eiförmig bis ellipsoidisch, oft polyëdrisch, 22-28 $\mu$ lang, 17-22 $\mu$ breit, mit dünner, feinmarciger Nembran.

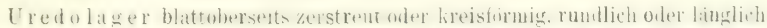
ziemlich lange bedeckt, hatun, staubig: fyoren kuglin, eifoming bis ellipsolisch, hellbraun, stachlig, 24-35 $\mu$ lang, 18-26 $\mu$ breit; Nembran $3 \mu$ dick, mit 3 Keimporen.

Teleutosporenlager wie bei den Uredosporen, schwarzbran; Sporen

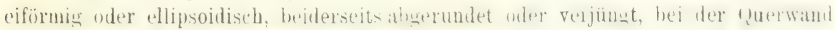

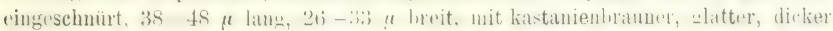
Membran; Keimporus der Sthritelzelle manchmal cin wenin herahgertickt. jemr ter Basalzelle in verschiedener Lage von der Querwand bis zum stiele, beide mit

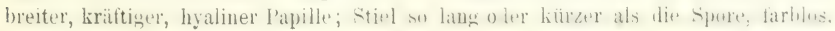
abfüllig.

Alle drei Stadien fast zugleich im September auf

Soldanella montana: Nur im Böhmerwalde und zwar am Wege vom

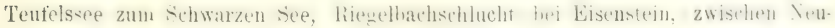
brunn und der Ahornsäge!

Das Aecidiummycel ïberwintert im Rhizom und dringt jedes Jahr in die

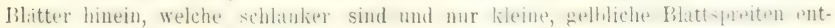
wickeln. 


\section{Puccinia Violae (Schumacher) De Candolle.}

Spermogonien an der Oberseite der Flecke, honiggelb.

A ecidien auf alleugrünen Teilen, anf den Llättern oft auf blasenfümigen Flecken in rundlichen Gruppen, auf den oft verdickten orler nekrümmten Blattstiplen und Stengeln in verlängerten Gruppen; I'seuloperidien nieligs, mit umselngenem, zerschlitztem Rande; Pseudoperidienzellen auf der Aussenseite bis 10 " dick; Sporen kuglig bis ellipsoidisch, polyëdrisch, $16-24 \mu$ lang, $10-18 \mu$ breit, mit düuner, diclit- und feinwarziger Membran.

Uredolager blattunterseits zerstreut oder zuweilen kreisförmig, klein rundlich, bald nackt, staubiq, zimmtbraun ; Sporen kuglig bis ellipsoidisch, 2()$-28 \mu$ lang, 17-2: $\mu$ heit, mit hellbramer, stachliger Membran und „2 Keimporen.

T'eleutosporenlager wie bei den Uredosporen, dunkelbraun, staubio; Sporen ellipsoidisch, beiderseits alogerundet, bes der querwand wenig oder gar nicht eingeschnürt, 211-40 $\mu$ l:mg, 15-20) $\mu$ lreit, mit kastanienbrauner, glatter Menbran; Stiel kurz, hyalin, abfillig: Keimporus der basalzelle zuweilen ein wenig herabgerückt, bẹide mit niedrigen, farblosen Papillen.

Aecidien im Mai und Juni, Uredosporen im Juni, Teleutosporen von Juli auf

V iola canina: Kiefernwälder bei Poričan! Volovice bei Welwarn (Kabát)! Rovensko! Leitmeritz, Teplitz (Wagner)! Wopparnertal bei Lobositz!

Viola collina: Kuchelbad, Radotín, St. Ivan! Unter-Beřkovic! Wetterstein bei Sychrov!

Viola hirta: Auf dieser Nührptlanze verbreitet!

Viola mirabilis: Mühlhausen a. E. (Kabit)!

Viola odorata, Riviniana, silvestris: Sehr verbreitet.

Auf verschiedenen kultivierten Viola-Arten in Duppau bei Karlsbad und in Mariaschein (Wiesbaux)!

\section{Puceinia Silenes Schröter.}

Spermog onien in kleinen Gruppen, honiggelb.

A ecidien blattunterseits auf hellgelben Flecken, in kleinen, rundlichen Gruppen: Pseudoperidien niedrig, mit weisem, zerschlitztem Rande; Sporen liuglig. polyedrisch bis ellipsoidisch, $17-26 \mu$ lang, $14-20 \mu$ breit, mit feinwaraige Membran und oraugerotem Inhalt (nach Schröter und Sydow).

Urodolager atuf beiden blattseitn zerstreut, rundlich, of um ein griosseres Häufchen mehr oder weuiger liresformig gestellt, balll nackt, staubig, zusammenfliessend, zimmtbraun; Sporen gronstenteils kuglig, oft auch eiförmig his ellipsoidisch, 22-28 " lang, 17-24 $\mu$ breit. lellbraun, entfernt-stachlig, nit $3-4$, von niedrigen Papillen bedeckten Keimporen.

Teleutosporenlager wie bei den Uredosporen, dunkelbraun, staubig; Sporen ellipsuilisch, lïnglich, beiderseits abgerundet, bei der Querwand schwach verjüngt, 26-42 $\mu$ lang, 20-26 $\mu$ breit, mit hellkastanienbranner, glatter Memhran; Stiel kurz, farblos, abfillig; lieimporus der Basalzelle in rerschiedenen Latren von der (Querwand his zum Stiel, beide mit kleiner, hyaliner Papille.

Aecidien im Juni, Uredosporen im Juli, Teleutosporen von August auf

Melandryum pratense: Welwarn (Kabát)! 
68. Puccinia Epilobii tetragoni (1)e (andolles Wiuter. -. Hi cateom a Epi lobii Opiz in schedis 1818. - Puccinia tenuistipes Opiz in schedis 1853.

Spermogonien zwischen den Aecidieu zerstreut, honiggelb, später dunkler.

Aecidien über die ganze Blattunterseite oder nur stellenweise gleichmässig verteilt, vereinzelt anch blattoberseits; Psendoperidien schiisselfirmin, mit umgebogeaem, ziemlich breitem, groh zerschlitztem Ramle; Sfrnen länglich-pniyedrisch, $17-26,4$ lang, $15-22 \mu$ breit, mit feinwarziger, ungleichmässig dicker Nembran und orangefarbigem Inhalt.

Uredolager blattunterseits vereinzelt oder stellenweise oder aber über

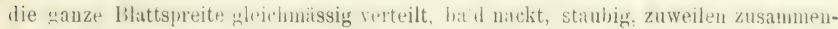

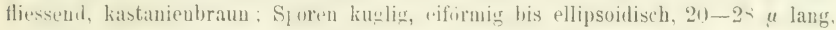
$15-25 \mu$ breit, mit brauner, stachliger Jembran und 2 Keimporen.

Teleutosporenlager wie bei Uredosporen schwarzbraun; Sporen eifömig bis ellipsoidisch, beiderseits abgerundet, hei der Querwand mässig eingeschnürt, 24-35) $\mu$ lang, 14-21 " hreit, mit hellhrauner, "nlatter, an Scheitel bis 5 ") dicher Membrin; Stiel kur\%. zart, hyalin: Kuimporus der basalzelle hei der Querwand oder um $1 / 2$ herabgerückt. Juli auf

Aecidien im Mai und Juni, Uredosporen von Juni, Teleutosporen von

Epilobium hirsutum: Sárka (Opiz)! St. Prokop! Radotín! Ounétic

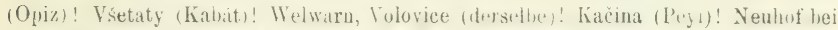
Koln (Veselsk!)! Muhelisa bei Gablonz a. X. (Matouschels)! Hracholusky hei Rau initz

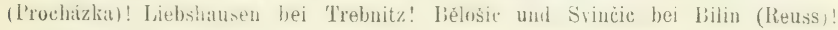
Podersam (Reichharit)!

Epilobium montanum: Zahoranertal bei Davle! Turnau (Kabát)! Herruskretschen (Whgner)! Hopfenhere bei bodenhach! Mürkenher: und Grapen hei Teplitz (Thümen)! liotenhaus hei Komotan (Rinth)! Tiborl Glatzer schneberg (Schröter).

Epilobium obseurum! Tábor!

Epilobium roseum: Fugau (Karl)! Aecidien unter dem Namen Aecidiu m angallidis Karl auf Veronica Anagallis!

Dits Mycel durehdringt die ganze Nithrpflan/. und derformiert diesolbe. Von I'uccinia Epilobi i I)C. Unterscheidet sich dir vorliegende Art durch flatte, am Scheitel verdickte Teleutosporen.

09. Puccinia Apii Desmazieres. - Puccinia bullata Aut. 1). p. - U redo Apii Opiz 1836 in schedis.

Spermogonien blattunterseits, gewilumlich in der Mitte der Aecidien gruppiert, braunrot.

Aecidien auf gelblichen Flecken hattunterseits in klein-11. rundlichen

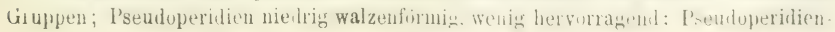


zellen in regelmässiøen Reihen, länglich, 20-31) $\mu$ lans. $10-2+\mu$ hreit; Sporen kugligeckig, ellipsoidisch, dicht und feinwarzig, $17-23 \mu$ breit.

Uredolager hauptsibchlich blattunterseits, klein, zerstreut oder in kleiuen oft ringfirmigen Grup!en, braun, staubin; sporen eiformig his ellipsoidisch, $23-32 \mu$ lans. 19-25 $\mu$ breit, mit hellbraumer, an Sicheitel stark verilicliter Membran und 3 Keimporen.

Teleutosporenlager hauptsächlich blattunterseits, grösser als die Uredulager, rundich. von Erater Epilermis bederlit, bith nackit und staubig, schwarz-

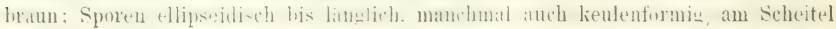
abgerundet, zum Stiel verjüngt, bei der Querwanil wenig eingeschnürt, $32-55 \mu$ lang, 16-23 $\mu$ breit, mit brauner oder hellbrauner, glatter Membran; Keimporus

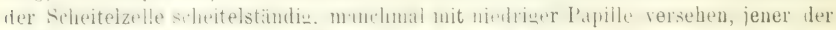
basalzelle tief nah unten rerschulien; stiel leieht ahfallend. forblos. so lang wie die Spore.

Aecidien im Mai, Uredosporen von Juni, Teleutosporen von Juli auf

Apium graveolens: Bei Prag (Opiz 1836, Corda 1844)! Lenešic (Houska)! Tetschen (Thïmen) und gewiss auch anderwärts.

70. Puecinia Bupleuri faleati (I). Candolle, Winter. - Aecidium Bupleuri Opiz l)eutschl. kryptog. Gewïclise 1816. pg. 35.

Spermogonien auf beiden Blattseiten zwischen den Aecidien verteilt oder auch selbstständig, honiggelbbraun, $100-160$ ) $n$ breit.

A ecidien blattunterseits (seltener blattoberseits) gleichmïsig verteilt

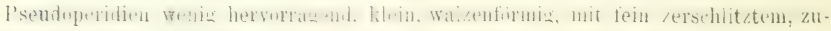

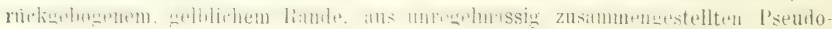
peridienzellen bestehend; Sporen knglig ołer ellipsoidisch, $18-24 \boldsymbol{\mu}$ breit, mit dicht- und feinwarziger Nembran und orangerotem Inhalte. (Siehe Abb. 14, II)

Uredolager hauptsïchlich blattunterseits auf kleinen gelblichen Fleckchen

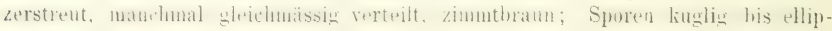
soidisch, 19-2 $4 \mu$ lang, $17-22 \mu$ breit, mit gelbbrauner, gleichmä̈ssig dicker dichtstachliger Membrau und 4 (manchmal 3 oder 5 ) Keimporen.

Teleutosporenlager wie bei den Uredosporen, von gruer Epidermis

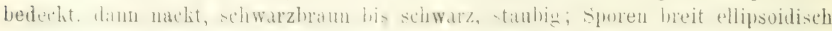
oder eifömig, beiderseits abgerundet, bei der Querwand wenjg oder gar nicht eingeschnürt, $26-33 \mu$ lang, $22-20 \mu$ breit, mit brauner, glatter Membran; Keim-

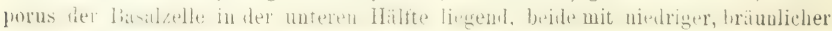
Papille; Stiel zart, hyalin, leicht abfallend.

Aecidien im Mai und Juni, Uredosporeu nur sehr wenig entwickelt, 'Teleutosporen von August auf

Bupleurum falcatum: Kuchelbad, Radotín, Kosoŕ, Karlstein, Dolany

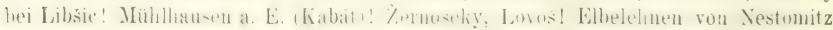
bis zum Ziègenberge! Stadic (Wiesbaur)! Teplitz (Thümen). Peruc, Chrastín, Šebin! 
I) as Aecidiunmyeel überwintert im lihizom und im Irihjałre dringt es in die ganze Ptlanze ein, fruktifiziert gewöhulich ant allen lilïtern, die dann hellgrün und schmialer siod; die befallenen T'riebe blïhen gewöhnlich nicht.

b) Teleutosporen wehr oder wemiger warzig.

(a) Iseudoperidien entuiclielt.

*) Das Aecidiummycel durchdringt die ganze Nïhrpflanze.

\section{Puccinia Crepidis Schröter.}

Spermogonien honiggelb, auf beiden Blattseiten, manchmal auch am Stencel zwischen den Aecidien zerstrent.

A ecidien über die ganze Blattseite fast gleichmässig verteilt, alle Blätter

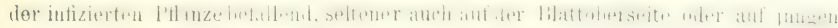
Stengeln; Pseudoperidien niedrig, breit, mit umgebogenem, schmalem, feinzer-

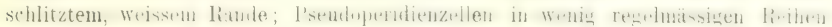
Sporen kugligeckig oder eiförmig, $20-25 \mu$ lang, $16-20 \mu$ breit, gelblich, feinwarzig.

Uredosporeu auf beiden Blattseiten, klein, rundich, zimmtbraun, staubig. Sporen kuglig, ellipsoidisch oder eifömig, 20-25 $\mu$ lang, $16-20 \mu$ breit, mit hellbrauner Membran und 2-3 Keimporen.

Teleutosporenlager meistens blattunterseits oder auf den Stengeln,

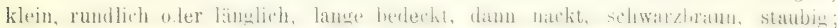

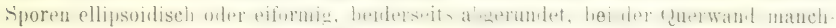
mal schwach eingeschnït, $20-30 \mu$ lang, 17-22 $\mu$ breit, mit kastanienbrauner,

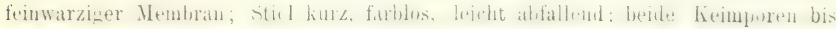
zur $1 / 2$, jener der Basalzelle manchmal noch tiefer herabgerückt.

Aecilien anfangs Mai und mit ihuen aus demselben Mycel auch die Uredound Telentosporen; selbstandige Uredo- und Teleutosporenlager von Juni auf

Crepis tectorum: Sct. Ivan bei Beraun! Iradisko bei Sadskí! Uha bei

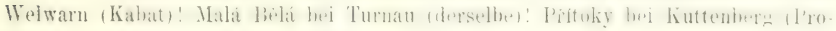
cházka)! Wesseln bei Aussig̣! Tábor!

Crepis virens: Herruskretschen (Thümen).

Das Aecidiummycel durchdringt die ganze Pflanze, die verkümmert und zur Blüte nicht gelangt; die befallenen Blätter sind blass und rorlängert.

\section{7:- Puecinia Barkhausiae rhoeadifoliae liubik in M.sterr. Imtan \%enthin $1902 \mathrm{Nr}, 2$,}

Spermogonien zwischen den Aecidien selı zerstreut, klein, gelb und bald verschwindend.

A e cidien auf der gauzen Blattunterseite regelmässig verteilt, seltener auch auf der Blattoberttäche, hier aber nur spärlich entwickelt, blass, niedrig, bis $66 \mu$

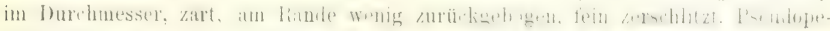

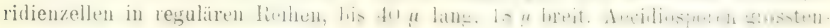
teils eiformig oder ellipsoidisch, $17 \cdot 5-32 \mu$ lang, $13-20 \mu$ breit, seltener eckig und 
isodiametrisch, $175-20 \mu$ im Durchmesier. Membrau feinbörnig, Inhalt gelborange.

Uredolager run ilich, dunkelbraun. bald natit; Lredospmren kuglig bis

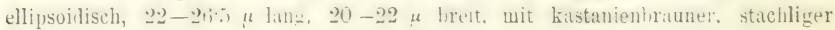
Membran und zwei etwas oberinalb der Mitte der Spore liegenden límporen.

Teleutosporenlager rundlich oder elliptisch, schwarzbraun, staubig;

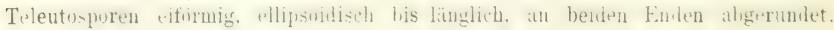
$265-44 \mu$ lang, $22-31 \mu$ breit, (gewöhnlich $33-40 \mu$ lang und $22 \mu$ breit). lieimporis der Sheitelzelle scheitelstudig. stltener tin weuir herahgerückt, derjenige der ba-alzell bis zur Hoifte herabgeschohen: Membran katanientraun, fein punktiert; Stiel so lang oder länger als die Spore, zart und hyalin.

Aecidien von Mitte Mai bis Mitte Juni, Uredosporen von Ende Mai bis zum Winter, Teleutosporen von Juli auf

Barkhausia (Crepis) rhoeadifolia: St. Prokop, lysučany bei Prag! Auf den Lehnen ron Selc bis zur Podbaba! - Im Bielatalo bei Welbine!

Inas Aecidiummvel durchiriant die ganze P'Hauze, welche infulgedessen nicht zur Blüte gelangt; die atedilientrigeuden Biatter simi shmäler als die gesumien, ziemlich Ferlingert und wenig geliphlit. Ton I'uctinia C'repidis Schriter unterscheidet si.h der vorhesemde liz dureh grössure Aeciliosporen und durch die Farbe der Uredo- und Teleutosporen.

\section{Puccinia Podospermi De Candolle.}

S permogonien blattoberseits zerstreut, honiggelb.

Aecidirn üher die samze Blattunterseite sleichmassig verteilt, auch auf den Involucrablïttern. schüssulfrimi-, mit weissem, zurüch-ebngenem. grobzerschlitztem Rande; Psendoperidienzellen auf ler Innenseite $7-11$ " dick: Spmren

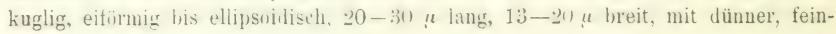
warziger Membran.

Credolager auf beiten Blattseiten rerstreut. runtlich, bald naclit, staubig; braun; Sporen kuglig oule! eiformig. seltener ellipsoilisch, $24-32 \mu$ lang. $22-24 \mu$ hreit, mit liätiger, brauns. entfernt stachliger Membran uu I உै von niedrigen, hyalinen Papillen bedeckten Keimporen.

Teleutosporenlager wie bei den Uredospuren. schwarzbraun, staubig; Sporen luglig-nlipsolulisch bis ellipsondiseh, beilerseits abgerunder, bei der (quer-

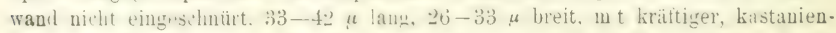
brauner, eatfernt warciger Jembran. auf kurcem, zartem, farblosen Stiel; Keimporen um $1 / 3-1 / 2$ herabgerückt.

Aecidien im Mai und Juni, Uredo- und Teleutosporen von Juni auf

Podospermum Jacquinianum: Hlubočepy bei Prag (Schiffner)! Lenešic (Houska)!

Podospermum la ciniatum: Radotín bei Prag! Welwarn (Kabát)! Libochovic! Jičln!

Das Aechliummycel durhhdrinet die franze Nahrptanze und üherwintert in der Wurzel. 
** Das Accidiummycelgist lokalisiert.

74. Puccinia Lampsanae (Schultz) Fuckel.

Spermogonien honiggelb, anf der Oberseite der Flecke gruppiert, seltener unterseits zwischen den Aecidien; Spermatien $4-45 \times 2-4 \% u$.

A ecidien anf der Unterseite roter, blasenförmiger Flecke oder auf den

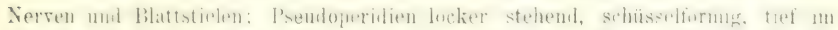

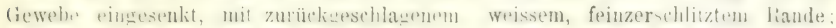

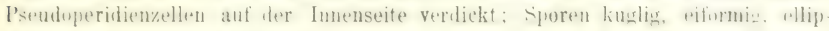
soidisch, manchmal polyedrisch, 15-28 $\mu$ lang, 13-26 $\mu$ breit, mit farbloser, dicht- und feinwarziger Membran und orangerotem Inhalte.

Uredolager hauptsïchlich blattunterseits, auch auf den Stengeln, klein, rumblith, bald nakt. zusammentliessent, staubis, cimmthraun; Sporen kunlis bis

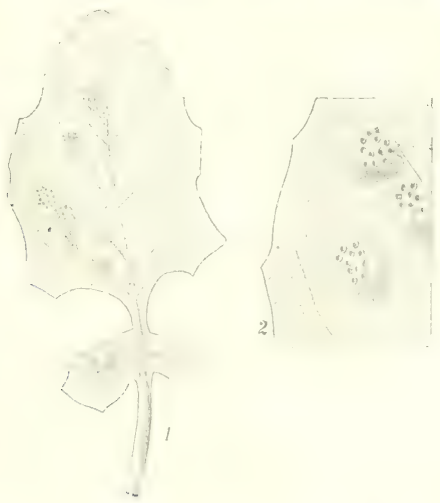

Abb. 15. Aecidien vo Puccinia Lampsanae auf Blättern von Lampsana commuis.

ellipsoidisch, 17-24 $\mu$ lanı, 15-1s $\mu$ breit, mit hellbraumer, feinstachliger . Membran und ¿ papillenlosen Keimporen.

Teleutosporenlager wie bei den Uredosporen, schwarzbraun, staubig;

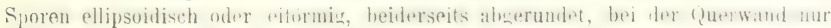
seiten eingeschnürt, $20-33 \mu$ lang, $16-26 \mu$ breit, mit kustanienbrauner, sehr feinwarziger Membran; Stinl kurz, farblos, oft sehinf seitwats sitzrud; he humms der Scheitelzelle newionlirh seitwäts verschoben, jener der basillexile um \%. herabgerückt, beide ohne Papillen.

Aecidien oft schon von Antaug März bis zum Mai, Credospuren fon Mitte Mai, Teleutosporen von Juni auf

Lampsan a communis: Sehr verbreitet. 
Vom Aecidium lampsanicolum Tranzschel sind die Aecidien der vorliegende Spezies durch die auf der Innenseite verdickten Pseudoperidienzellen und durch leicht sich loslösende Aecidiosporen verschieden.

\section{Puccinia major Dietel.}

Spermogonien beiderseits auf den Flecken, honiggelbbraun.

A ecidien blattunterseits auf gelben oder roten, rundlichen Flecken, auf den Nerven und Blattstielen in lïuglichen Gruppen, dichtstehend; Pseudoperidien niedrig, mit weissem, zurückgeschlagenem, zerschlitztem Raule; Psendoperidienzellen kuglig-polyedrisch bis länglich, 20-26 $\mu$ langr, $13-22 \mu$ breit, mit ungleichmässig dicker, dicht- und feinwarziger Membran.

Uredosporen auf beiden Blattseiten auf gelblichen Flecken zerstreut, bald nackt, staubig, zimmtbraun; Sporen kuglig. eiförmig bis lïnglich, 22--29 $\mu$ lang, $17-24 \mu$ breit, mit gelbbrauuer, $2-25 \mu$ dicker, stachliger Membran und 2 bis 3 Keimporen.

Teleutosporen wie bei den Uredosporen, schwarzhraun, ziemlich lange bedecht, daun nackt, staubig; Sporen ellipsoidisch orler eiförmig, auf beiden Enden abgerundet, selten unten verjüngt, bei der Querwand wenig eiugeschuürt, $33-44 \mu$ lang, 22-33 $\mu$ breit, mit kastanieubrauner, feinwarziger Membran; Keimporus der Scheitelzell" bis zu $1 / 2$, oft bis zur (Yueswand heraligerütit, jener der Basalzelle in der oberen Hälfte; Stiel kurz, hyalin, abfallend.

Aecidien im Mai und Juni, Uredosporen im Mai, Teleutosporen von Juli auf Crepis paludosa: Ziemlich verbreitet.

\section{Puccinia Crepidis granditlorae Hasler.}

Spermogronien auf beiden Blattseiten, von den Aecidien umschlossen, erst honigfarben, dann rot, vor den Aecidien hervorbrechend.

A ecidien meist blattunterseits, seltener wherseits und dann gewöhnlich einzeln, auf weinroten, gelb umrandeten Flecken ziemlich gedrängt, meist in vielzähligen, ruudlichen, an den Blattnerven und Stielen läuglichen Gruppen. Pseudoperidien niedrig, becherförmig, mit weissem, schwach zurücligeschlagenem, feinzerschlitztem Rande. Pseudoperidienzellen nicht in regularen Reihen, auf der Aussenseite nach unten übereinandergreifend; äussere Wand dünn, innere verdickt (5 $\mu)$, fein warzig. Sporen kuglig, polyedrisch-kuglig oder ellipsoidisch, 16-26 $\mu$ lang, $16-21 \mu$ breit, mit dünner, feinwarziger Membran und orangerotem Inhalte.

Uredolager auf gelblichen Flecken, auf beiden Blattseiten unregelmässig zerstreut, klein, zimmtbrann. Uredosporen ellipsoidisch oder kuglig, $21-30 \mu$ lang, $20-26 \mu$ breit, mit gelbbrauner, bis $3 \mu$ dicker, feinstacheliger Membran (Stachelabstand circa $2 \mu$ ). Keimporen $2-3 \mu$, aequatorial oder unregelmässig angeordnet, ohne oder mit schwach entwickelter, farbloser Kappe.

Teleutosporeula'ger blattbeiderseits auf gelben Fleckchen, punktförmig $(1 / 2 \mathrm{~mm})$, braunschwarz, staubig; Teleutosporen ellipsoidisch, biruförmig oder oval, $\left.26^{\circ}-41\right) \mu$ lang, 19-20 $\mu$ breit, kastanituluaun, feiuwarzig (Warzenabstand circa 
$2 \mu$ beiderseits ahgerundet, selten gegen den Stiel verjüngt, in der Mitte nicht oder nur schwach eingeschnürt, am Scheitel nicht verdickt.

Keimporus der Scheitelzelle meist in der obrer Zellhalfre, derjenige der Basalzelle häufig in der Mitte, beide obne oder mit mïssig entwickelter I'apille. Stiel sehr kurz, hyalin, abiallend.

Aecidien anfangs Mai, Uredospo:en vou Mitte Mai, Telentosporen von dusust anf

Crepis grandiflora: Elbewiese (Schröter); Glatzer Schneeberg!

Bei der Reabeitumg der böhmischen Rostpilse habe ich den vorliegemben Pilz als Puccinia Crepidis grandiflorae n. sp. beschrieben. Später habe ich dieselbe wieder zu Puc cinia m a jor Dietel gezoren, da mir die Cnterschiede zu gering schienen. Neuerilings wurde dieser Pilz von II asler*) auf Grunil von Kulturversuchen für eine selbständige Spezies erliat. Die voliegen le Iriagnos verdanke ich auch seiner Liebenswür rigkeit

\section{Puccinia Crucheti Hasler.}

Spermogonien auf beiden Blattseiten, kugrelförmig, circa $130 \mu$ breit, rot; Mündungshyphen $23 \mu$ vorragend.

A ecidie n blattunterseits, seltener blattoberseits und dann gewöhnlich einzeln, auf gelben oder roten Flecken, in rundichen oder unregelmiissig geformten, an den Blattnerven uud Blattstielen in länglichen Gruppen. Pseudoperidıen niedrig, becherförmig, mit weissem etwas zurückgehogenem, fein zerschlitztem Rande; Psendoperidienzellen in regelmässigen Reihen angeorinet, auf der Aussenseite nach unten ïbereinandergreifend; äussere Mumbran dïnn. innere verdickt ( $6 \mu$ ), feinwarzig; Aecidiosporen kugelig, polyedrisch-kugelig oder eirund, $16-21 \mu$ lang, $13-16 \mu$ breit, selten bis $23 \mu$ lang, $20 \mu$ breit; Membran dünn, feinwarzig; Inhalt orange.

U redo lager auf gelblichen Flecken blattunterseits, seltener blattoberseits oder am Stengel, klein, zimmtbraun; Sporen kuglig, polyedrisch-kuglig oder ellipsoidiscb, 19-26 $\mu$ lang, 19-21 $\mu$ breit, mit hellbrauner, dünner (höchstens $2 \mu$ ), feinstachliger Membrin (Stachelibstand höchst+ns $2 \mu$ ); Keimporen meist 2, aequatorial, selten 3 , kappenlos.

Tele utosporenlager auf gelben Flecken blattunterseits, seltener blattoberseits oder am Stengel, punktfirmig ( $1 / 2 \mathrm{~mm}$ ), bramschwarz. Sporen ellipsoidisch, eiförmig, selten birnförmig, $21-37 \mu$ lang, $16-25 \mu$ breit, braun, feinwarzig (Abstand $2 \mu$ ) beiderseits abgeruudet, in der Mitte schwach eingeschuürt; Keimporus der Scheitelzelle bis zu \%/3 herabgerückt, häufig am Scheitel, jener der Basalzelle unregelmässig gestellt, beide ohne oder mit schwach entwickelter Papille. Stiel kurz, hyalin, abfällig.

Aecidien im Mai, Uredo im Juni, Teleutosporen von Juli auf

Crepis succisaefoli a: Babina bei Leitmeritz, Tábor!

Die vorliegende Art wurde von $\mathrm{Hasler}$ 1. c. (siehe die vorangehende Spezies) anf Grund seiner Kulturversuche aufgestellt. Die Liannose wurde mir fon demselben bereitwilligst mitgeteilt.

*) Zentralblatt für Bakteriologie und Parasitenkunde, II. Abt., XXI. Bd. (Jena 1908) Heft $16 / 16$, pg. 510 . 


\section{Puccinia Intybi (Juel) Sydow.} der Flecke.

Spermogonien honiggelbbraun, in kl inen Gruppen auf der Oberseite

Aecidien auf der Unterseite von lileiner, rundlicher, selblicher, rötlicher oder brauner Flecke, in lileinen Grupten, oft wur $2-3$ ales nur vereinzelt; Psen-

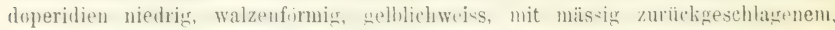
zerschlitztem Raude; Sporen polyulriseh und $z$ war kuglig bis ellipsoidisch. $18-2+\mu$ lang, $15-20 \mu$ hreit, mit dümer, dicht- und feinwarziger Membran und orangerotem Inhalt.

Uredolager hauptsächlich hattoberseits zerstreut, sehr klein, rundlich, staubig, zimmtbraun ; Sporen kuglig, eiformig ofters elliqsoidisch, $24-29 \mu$ lang, $18-24 \mu$ breit, mit gelbbrauner oder brauner, bis $2.5 \mu$ dicker, entfernt stachligur Membran und 3 Keimporen.

T e le utosporenlager wie bei den Uredosporen, schwarzbraun; Sporen eiförmig, ellipsoidisch, seltener länglich, beislerseits abyerundet, bei der Querwand nicht oder nur wenig eingeschuürt, $26-40 \mu$ lang, 18-26 $\mu$ breit, mit kastanienbrauner, feinwarziger Membran; Stiel kurz, farblos; Keimporus der Basalzelle in der Mitte, beide mit niedrigen, hyalinen Käppchen.

Aecidien ron Mitte Mai bis Ende Juni, Uredosporen von Mitte Juni, Teleutosporen von Juli auf

Crepis praemorsa: Radotin bei Prag, Karlstein! Lešany bei Welwarn (Kabrit)! "Hora" bei Semice nächst Lysá! Berg Wawčn bei Trebnitz!

\section{Puceinia praecox Bubák. - A ecidi um praecox Bubák.}

Spermogonien beiderseits zwischen den Aecidien zerstreut oder gruppiert, honiggelbbraun.

Aecidien auf beiden Ilattseiten auf gelblichen oder rötlichen, gewöhnlich unregelmässigen, se'tener rundlichen Flecken, oder auf deu Nerven: Pseudoperidien niedrig, mit zurücligebogenem, zerschlitztem Iiande; Psendoperidienzellen elliptisch

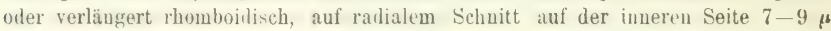
dick; Sporen polyedrisch und zwat kuglig, eiföruig bis länglich, $17 \cdot \bar{j}-31 \mu$ lang, $175-22 \mu$ breit, mit farbloser, dicht- und feinwarziger Membran und orangerotem Inhalte.

Uredolager auf beiden Ilattseiten oder auf den Stengeln verteilt oder zerstrent, bald nackt, staubig, brann; Sporen kuglis, piformig his mllipsoidisch, 22-3:3 $и$ lang, 2()$-2 !) \mu$ breit, mit brauner, fntfernt stachliger Membran und 2 (seltener 3) Keimporen.

Teleutosporenlager wie bei den Uredosporen, auf kleinen, gelbliclien Fleckchen stehend, schwarbluan, stanbig; Sporen breit, ellipsisliseh oder eiförmig, 30-46 $\mu$ lang, 24-31 $\mu$ breit, beiderseits abgerundet, bei der Querwand wenig oder gar nicht eingeschuiut; Mombran kastanienhaun, foinwarzig: bejie Kein. poren bis um $1 / 2$ und mehr herabgerückt; Stiel kurz, hyalin, abfällig.

Aecidien Ende März und im April rewohnlich auf den Blattspitzen, Uredosporen von Mai, Teleutosporen von August auf

Crepis biennis: Ziemiich verbreitet. 


\section{Puecinia Willemetiae Bubák.}

Spermogonien in kleinen Gruppen zwischen den Aecidien.

A ecidien blattunterseits rings un die Spermogonien; l'sendoperidien niedrig, mit kaum zurückgeschlagenem Rande; Sporen polyedrisch und zwar kuglig oder fast kuglig, 18-2: $\mu$ im Durchmesser, dicht. und feinwarzig.

Uredolager auf violetten, kleinen Fleckchen auf beiden Blattseiten sehr zerstreut, rundich oder länglich, sehr klein, $02-0.5 \mathrm{~mm}$ breit, bald naclit; Sporen kuglig oder eiförmig, $22-26.5 \mu$ lang, 17.5-2.2 $\mu$ breit, hellbrïunlich, dichtund feinwarzig.

Teleutosporenlager wie bei den Uredusporen, schwarz; Sporen ge-

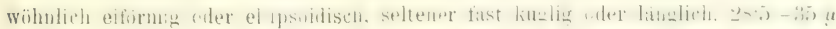
lang, 20-24 $\mu$ breit, beiderseits abgerundet, bei der Querwaul wenig oder gar

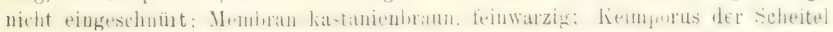

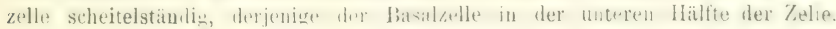
beide mit schwach entwickelter Papille versehen. Stiel fast so lang wie die Spore. (Siche Abb. 14, I.)

Aecidien im Juni, Uredosporen und 'Telentosporen von Juli auf

Willemetia hieracioides: Hammern, Spitzberg und Eisenstein im Böhmerwalde!

\section{Puccinia Menthae Persoon.}

Spermogonien hongrgulhbraun, spiter dunlielbraun, beiderseits auf den Flecken stehend oder nur zwischen den Aecidien in kleinen Gruppen.

A ecidien auf den Blattstielen, Stengeln in verlängerten Gruppen, verschichene leformationen hervorrufeml, aut der Blattunterseite auf runllichen, grelben oiler purpurroten l'lecken; I'seudoperidien hreit, niedriz. unregelmässig sich öfnend, nicht zurückgeburn, groh serschlitzt; sponen sehr variabe', kugliz, eiformig, ellipsoidisch, läglirh, oft polvedrisch, 20-38 $\mu$ lang, $13-22 \mu$ breit. mit hellgelbbrauner, fein- und dichtwarziger Membran.

Uredolager blattunterseits zerstreut oder in ringfirmigen (iruppen auf kleinen, gelblichen Fleckchen orter anch ohne dieselben, klein. rundlich oder länglich, bald nackt, manchmal zusammentliessend, staubig, hellzimutbraun; Speren kuglig, eiförmig bis ellipsoidisch, $20-28 \mu$ lang, $17 \cdot 5-22 \mu$ breit, mit hellgelber, feinstacheliger Membran.

Teleutosporenlager wie bei den Uredosporen, schwarz; Sporeu breit

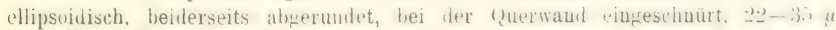

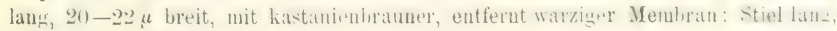
zart, farblos, abfällig; Keimporen mit niedrigen Kappen.

Aecidien von Mai bis Mitte Juni, Uredosporen im Juni, 'Teleutosporen im Juli auf

C'alamintha Acinos: Kosor, Kuchelbad, Zárist bei Prag! Neratovic (Kabát)! Rovensko! Lenešic (Houska)!

Clinopodium, vulgare: Cibulka (Opiz)! Kuchelbad, Zítvist, Koda bei Tetín, Stechovic! Mühlhausen a. K. (Kabit)! Teplitz (Thümen)! Trusliy. Ruren-kn! 
Harta hei Hohenelbe (Cypers)! Korouher bei Polička (Th. Nurák)! I) hurušk (Vodák)! Tábor! Wittingau (Weidman)! Krumau (Jungbauer)!

Mentha arvensis: Ueberall verbreitet!

Mentha aquatica: St. Prokop (Opiz)! und Selz bei Prag! Roždalovic! Mentha capitata: Neratovic, Všetat! Welwarn (Kabát)!

Mentha hortensis: Turnau (Kabat)!

Mentha piperita: Rovensko!

Mentha rotundifolia: Welwarn (Kabát)! Gross Skal! Holic!

Mentha silvestris: Verbreitet!

Aus Böhmen sind von allen Nährpflanzen die Aecidien bekaunt. Sehr interessant verhält sich diese Puccinia-Art auf Calamintha Acinos auf warmen Silurfelsen iler Prager Umgegend \%. B. bei Ku helbail und liosor. Dort kamn man schon Mitte April auf üherwinterten Blittern zahlreiche Uredosproren finden, die entweder in alten Teleutospurenlapern sich neu ausbilden oder rings um dieselben in selbstandigen Lagern, aus dem üherwinterten Mycel entstehen. Erst Mitte Mai erscheinen Aeridien, als sich schon vordem durch nene Infelition mittelst Iredosporen neut, zerstreute Uredolager mehmals wiederholt ausgebilitet hatten.

\section{Puceinia Zopfii Winter.}

Spermogonien auf beiden Seiten der Flecke, honiggelbbraun.

A ecidien auf der Unterseite von bleichen, rundlichen Flecken, in rundlichen Gruppen oder ringformig stehend, auf den Blattstielen in länglichen (rruppen; P'seudoperidien schüsseltörnig, mit zurücligehogenem, zerschlitztem Rande; I'seudoperidienzellen aussen $\tau$ - $\mu$ verdicht: Sporen polyedrisch und zwar kuglig bis ellipsoidiseb, 20-24 $\mu$ im Durchmesser, mit dünner, tein- und dichtwarziger Membran.

Uredolager hauptsächlich blattunterseits, auf kleinen, grellen bis braunen Flecken, klein, rundlich, bald nackt, braun, staubigr; Sporen kuglig bis ellipsoidisch, $22-32 \mu$ lang, 2()$-25 \mu$ hreit, mit hellbrauner, stachliger Membran und $2-3$ Keimporen.

Teleutosporenlager meistens blattoberseits, sonst wie die Uredolager, schwarzbraun. staubig; Sporen ellipsoidisch his länglich, beiderseits abgerumdet oder in den Stiel rerjüngt, bei der Querwand wenig eingeschuirt, 35-55 $\mu$ lang, 22--35 $\mu$ breit, mic $4 \mu$ dicker, kastanienbrauner, feiuwarziger oder oft fast undeutlich warziger Membran; Stiel kurz, hyalin, abfallig; beide lieimproren mit farblosen Kappen bedeckt. Juli auf

Aecidien im Mai und Juni, Uredosporen von Juni, Teleutosporen ron

Caltha palustris: Rovensko! Hirschberg, Bölmm, Leifua (Wagner) Prihraz bei Münchengraetz (Kiblat)! Tábor und Planá a. L.! Oft im Bühmerwalde vom Osser über Spitzberg bis zum Eisenstein! Arber! Nenbrunn! Ahornsäge! 
Von Puccinia Caltha hauptsächlich durch breite, dickwandige, warzige T'eleutosporen verschieden.

13. Pseudoperidien fehlen.

\section{Puceinia Cirsii eriophori Jacky.}

Spermogonien blattoberseits einzeln oder in Gruppen, seltener blattoberseits, ziemlich gross, rotbraun.

Cacom a auf der Unterseite gelber, oft purpurrot umsiumter Flecke, einzeln, seltener in kleinen Gruppen, ohne Pseudoperidien, nur von einem Hyphen-

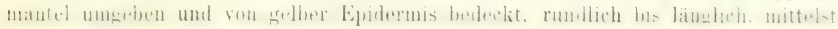

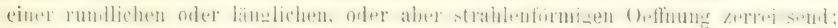

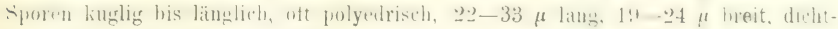
warzig, mit schwach orangefarbigem Inhalt.

Uredolager blattoberseits, klein, rundlich, oft zusammentliessend, bald

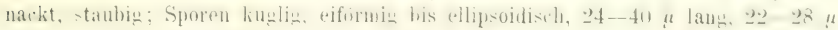
hreit. mit helliastauientrauner, bon ziemlich entferntotelendion. Janeen sacheln besetater Membran. Kipimporen $; 3$, seltener 4, mit hyalinen, stark anfipellenden Kappen besetzt.

Teleutosporenlager auf beiden Blattseiten, meistens aber blattoberseits, rundlich, bald nackt. att zusammentlesseme, schwarkhaun his schwarz: Sym-

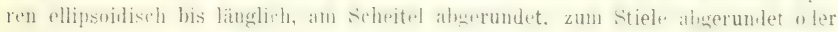
verjüngt, bei der Querwand wenig oder gar nicht eingeschnürt, $37-44 \mu$ lang, $24-28 \mu$ breit, mit kastanienbrauner, feinwarziger Membran; Stiel kurz, liriftig hyalin. Keimporus der oberen Zelle scheitelständig, oder nur wenig seitwärts verschoben, derjenige der Basalzelle dicht an der Querwand, beide mit hyalinen Kappen.

Caeoma von Jitte Mai bis Mitte Juni, Uredosporen von Juni, Teleutosporen von Juli auf

Cirsium eriophorum: Izadotín bei Prag! Mühlhausen a. E. (Kabát)! lioštál bei Trebnitz, Strádonic bei Peruc!

Von der nächstfolgenden Art dadurch verschieden, dass sie auf Cirsium lanceolatum nicht ibergeht, wie auch durch die Lage des Keimporus in der Scheitelzelle der Teleutosporen.

\section{Puceinia Cirsii Ianceolati Schröter.}

Spermogonien blattoberseits zerstreut oder in ärmlichen fruppen, honigbraun, halbkuglig.

C a e $0 \mathrm{ma}$ wie bei der vorangehenden Art, oft auch blattoberseits; Sporen

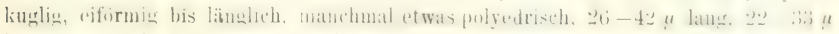
breit, sonst wie bei Puccinia Cirsii eriophori.

Uredolager wie bei der voraugehenden Spezies, oft nuch blattunterseits; Sporen ebenfalls, $24-33 \mu$ lang, $24-28 \mu$ breit, mit 3 Kieimporen, die mit hyalinen, stark aufquellenden Kappen versehen siud. 
Teleutos porenlager wie bei der vorangehenden Art, meistens aber hlattheiderseits; Sporen ebenfalls, $33-49 \mu$ lang: 201)-24 " breit: Keimporus der wheren Zelle scheitelstänig oder bis zur Querwand herabgerickt, derjenige der Basallzelle dicht an der Querwand, beide mit hyalinen Kappen.

Caeoma Enle April bis Mitte Juni, Cretusporen Mitte Mai. Teleutosporen von Juli auf

Cirsium lanceolatum: Ziemlich verbreitet.

\section{Puccinia Lactucarum Sydow.} honiggelb.

Spermogonien auf der Oberseite oder auch Unterseite gelber Flecke,

A ecidien blattunterseits auf gelben Flecken (Lactuca quercina) oder auf len Nerven, blattstiplen und Stengwn in rerlingarten, die hefillenen Trile verdrebenden Gruplen. tief eingesunkt, pustelfimis sewiilht, mit runblicher Oeffnung,

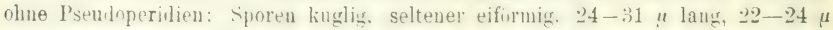
breit, hellgell, mit farhloser, dicht- and feinwarziger Membran und orangerotem Inhalt.

Uredosporen auf beiden Blattseiten, hauptsächlich blattunterseits, auf geblichen Fleckehen oder in mullichen, kleiturn (iruppen, rundich, bald nackt hellbranu, staubie; sporen ellipsoidisch uley fast kuglig. 17--24 u lang, 15-22 u hreit. mit hellgelher, entfernt stachliger Membran: Keimporen 3-4, mit kräftigen, breitell, stark aufquellenden Kappen.

T+leutusporeulaner rumilich. hauptsächlin blattunterseits (manchmal gleichuassiz) verteilt, schwarzhraun, staubiz. auf ien äbrigen PHancenteilen rerlitmert und of zusammentliessend: Sporen ellipsomistl. beiderseits abgerundet bei der Querwand nur selten eingeschnürt, 33-42 $\mu$ lang, 24-31 $\mu$ breit, mit

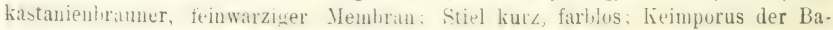
salzelle gewöhnlich in der Mitte der Zelle.

Aecidien im Mai, Uredosporen von Juni, Teleutosporen teils zugleich mit deu Atcidien aus demselben Yriel, spater (Juui, aus den Lredosporen entstehend auf

Lactuca perennis: Kuchelbad (Opiz)! Auf den Lehnen zwischen Selc

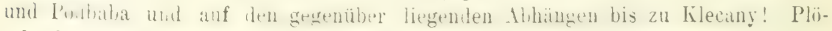
schenberg bei Netluk nïchst Trebnitz! Dreikreuzberg bei Leitmeritz!

Lactuca quercina: Kuchelbad! Koda bei Tetíu!

-6. Puccinia Chondrillae Corda - Puccinia IIyeelis Opiz Sezuam pg. 138. - Puccinia Prenanthis (Persoon) Lindroth.

Spermogonien honiggelb, auf der oberen Seite der Flecke oder unten zwischen den Aecidien verteilt.

A ecirlien hlattunterseits auf ge blicles: odtr purpurroten Flecken, telten auch rereincelt blattwiersits, in kleweren oder grisseren Gruppen, manchmal auch auf de: 1Blattstielen. blisenfiiimig onter ialbkuglig, spriter mit rundicher Oeffunng. 


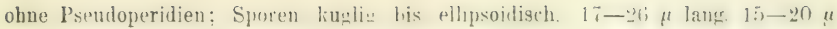
breit, mit fein- und dichtwarziger Membran.

Iredolager hauptsählich hactunterseds zerstreut, aut molhlichen Flackchen, ruudlich, bald nakt. hellzimmthraun, staubig; Sporen kuglin noler fast kuslig, 17-24 " lang, 15-20 "u hreit, mit hellgelber, entfernt stachliger Membran. Keimporen $3-4$, mit stark gewölbten, bis $18 \mu$ breiten Kappen.

Teleutosporenlager wie bei den Uredosporen, schwarz, staubig; Sporen ellipsoidisch, oft asymetrisch, beilerseits abgerundet, bei ler (Querwand nicht zusammengeschnürt, $21-38 \mu$ lang. $18-2+4$ hreit, mit gellibrauner, undeutlich feinWatrigres Membran; Stiel kurz, alffilligr, hyalin. Leimporus der obren Zelle

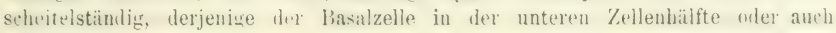
anderwärts. Juli auf

Aecidien anfangs Mai, Uredosporen ron Ende Mai, Teleutosporen von

Lactuca muralis: In Nadelwäldern und an Bachufern bis circa $1000 \mathrm{~m}$ ziemlich zahlreich.

\section{Puccinia Prenanthis purpureae (Persoon) Lindroth.}

Spermogonien honiggelb, ziemlich gross, zwischen den Aecidien au beiden Blattseiten.

A ecidien auf der Unterseite von rundichen, gelhen oder gelblich-purpurrote. Flecken, in rundlichen oder an den Norsen linglichen Gruples, anfangs grwiblht, dann in der Mitte mit rundlicher Ocffnung, gelblich, olne Psemlopreridien.

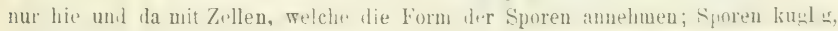
seltener eiförmig, $15-22 \mu$ lang, $13-17.5 \mu$ breit, mit farbloser, feinwarziger Membran und orangerotem Inlalt.

Lredolager blattunterserts auf kleinew, gelhlichen Flechen zerstreut, kilein.

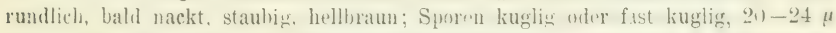
lan:, 175-2.2 $\mu$ hreit, mit entfemt stachliger Membran; Keimporen 3 (seltener 4), mit stark aufquellenden Kappen.

Teleutosporenlager wie bei den Uredosporen, schwarzbraun, staubig; Sporen eifirmig oder ellipsodisch, beiderseits abgerundet, bei dre Querwand wenig oder gar nicht eingeschnürt, 26-44 $\mu$ lang, 20-26 $\mu$ breit (seltener bis $33 \mu$ breit) mit hellkastanienhrauner, feinwarziner Membran; Stiel kur\%, hyalin, abfillin: Keimporus der oberen Zelle scheitelständig oflor manchmal bis zur Querwand herabgerückt, derjenige der Basalzelle bis um die Hälfte verschoben.

Aecidien von Juli, Uredo- und T'eleutosporen kurz nach denselben auf

Prenanthes purpurea: Ziemlich verbreitet, besonders in den unteren Lagen des Riesengebirges, Glatzer Schnepherges, des Bohmerwaldes und des Erzgebirges. Sie steigt bei uns bis zu 1200-1300 m hoch.

\section{Puccinia Mulgedii Sydow.} zerstreut.

Spermogonien honiggelb, rings um die Aecidien blattbeiderseits

Aecidien auf der Unterseite kleiner, gelblicher Flecke in ärmlichen 
Gruppen, oft auch einzeln, sonst wie bei Puccinia Prenanthis purpureae; Sporen kuglig bis ellipsoidisch, $15-24 \mu$ lanı, $13-20 \mu$ breit, mit farbloser, feinwarziger Membran und orangerotem Inhalt.

Uredolager wie bei Puccinia Prenanthis purpureae; Sporen $20-24 \mu$ lang, $17 \cdot 5-22 \mu$ breit.

Teleutosporenlager ebenfalls; Sporen $26-40 \mu$ lang, $22-265 \mu$ breit.

Aecidien im Juli und mit ihnen oder erst nachher Uredo- und Teleuto. sporen auf

Mulgedium alpinum: Sehr oft im Riesengebirge, wo sie bis zu Neuwelt herahsteigt! Glatzer Schneeberg! Keilberg im Erzgebirge (Wagner); Zechengrund (Sydow)! bei Gottesgab)! In Böhmerwalide: Arber (Krieger); Deffernik und Lakka!

c) Teleutosporen mit netzförmig verbundenen Leisten besetzt.

\section{Puccinia aromatica Bubák.}

Spermogonien beiderseits zwischen den Aecidien, eingesenkt, hellgelb.

A ecidien blattunterseits auf gewolbten Flecken, oft an den Nerven oder auf Blattstielen und Stengeln, dicht gruppiert, anfangs von der Epidermis bedeckt, später oberflächlich, mittelst eines länglichen Spaltes geöffnet, öfters zusammenfliessend; Pseudoperidien wenig entwickelt und von einem Hyphenmantel umgeben; Pseudoperidienzellen hyain, unregelmässig gereiht und nur schwach zusanmenhängend. Sporen kuglim oder eiförmir, 19-2+ 4 lang, 15-22 4 breit, mit hyaliner. dichtwarziger Membran und orangerotem Inhalt.

Uredolager blattunterseits oder auf den Blattstielen und Stengeln, ziemlich gross, zimmtbraun, bald nackt und staubig; Sporen breit ellipsoidisch oder eiförmig ellipsoidisch, $21-28 \mu$ lang, $17-23 \mu$ breit, mit $2.5 \mu$ dieker, gelbbrauner, stachliger Membran und 3 Keimporen.

Teleutosporen entweder in den Uredolagern oder später in selbständigen, kleinen, rundlichen, schwarıen Lagern blattunterseits, auf den Blattstielen umd Stengeln; Sporen ellipsoilisch, breit ellipsoidisch oder eifurmig ellipsoidisch, beiderseits abgerundet, bei der Querwand wenig eingeschnürt, 26-34 $\mu$ lang, 19 - 24 " breit; Membran $4 \mu$ dick, braun, mit netzfömig verbundenen Leisten verseben; Stiel kurz, zart, hyalin.

Aecidien im Mai, Uredo- und Teleutosporen von Juni auf

Chaerophyllum aromaticum: Perue! Smečno, Turnau (Kabát)! Reichenberg (Siegmund 1840)! Hořičky bei Böhm. Skalic (Kabát)!

\section{Puceinia Chaerophylli Purton.}

Spermog onien hellgelb, tief im Gervebe eingesenkt.

A ecidien blasenförmig, blattunterseits in dichten, rundlichen Gruppen, auf den Blattnerven und Blattstielen oft lileine Deformationen herrorrufend; Pseudoperidien schwach entwickelt. später mit rundlicher, zentraler oeffuung. Sporen kugligpolyedrisch bis ellipsoidisch, 18-35 $\mu$ lang, 11i-26 $\mu$ breit, mit ziemlich grobwarziger Membrau uud orangerotem Inhalt. 
Fredolater b blattunterseits zerstreut. klein, rumblich, zimmtbraun, stanbig: Sporen kuglig, eiformig oiler ellipsoidisch, 20-30 $\mu$ lang, 1--25 $\mu$ breit, mit gelblicher his gelbbraumer, entfarnt stachliger Membran und 3 Kémporen.

Teleutosporenlager wie bei den Uredosporen, staubic. schwarzhraun, auf den Blattstielen und Stengeln verlämgert: Sporen eiformig, pllipsoidisch bis lïnglich, beiderseits sewöhnlich abgerundet, zum Stiel manchmal wenig verjüngt. bei der Querwand mehr oder weniger eingeschnürt, $24-36 \mu$ lang, 16 - 2 i $\mu$ breit; Iembran relbłraun oder hraun, mit netzformig verbundenen Leisten besetzt; Stiel lurz, zart, farblos oder schwach zelblich, so lang wie die Spore; Kimporus der Basalzelle bis um $\% / 3$ herabgerückt, beile mit kleiner, fast undeutlicher Papille. Juli auf

Aecidien von Mitte Mai, Uredosporen von Juni, Teleutosporen von

Cerefolium silvestre: Ziemlich verbreitet.

Chaerophyllum hirsutum: Deutsch Bielau bei Poliěka (Tb. Novák), Zwischen der Iiiesenbaude und Prinz Heinrichsbaule im Erzgehirge idecidien 12. Juli)!

Chaerophyllum temulum: Teplitz (Thümen)!

Myrrhis odorata: Eisenstein im Böhmerwalde und zwar bei den Wirtschaftsgebäuden an Finse des Panzers (Hora)! Petzer! und Krummhübel im Riesengebirge (Sydow).

91. Puccinia Pimpinellae (Strauss) Martius, - Aecidium P'impinellae Kirchner im Lotos 1856, p. 180.

Spermogonien zwischen den Aecidien zerstreut oder gruppiert, blattbeiderseits, gelblich.

A ecidien in kleineren oder grösseren Gruppen auf den Blattspreiten und Nerven, manchmal auch auf den Blattstielen, ofters kleine Hypertrophien verursachend; Pseudoperidien sanz eingesenkt, seltener hervorragend und dann glinzendweiss, unregelmässig zerschlitzt; Pseuloperidienzellen nicht in regelmässigen Iieihen; Sporen kugliq bis ellipsoidisch, hellgelblich, 22-29 $\mu$ lang, $20-26 \mu$ breit. feinwarzig.

Uredolager hauptsächlich blattunterseits zerstreut oler verteilt, klein rumdlich, bald nackt, manchmal zusammenfliessend, zimmtbraun; Sporen kuglig, eiformig bis ellipsoidisch, 22--32 u lang, $21-27 \mu$ breit, mit brauner, stachligri Membran; lieimporen 2 (seltener 3), mit niedrigen, hyalinen Kappen.

Teleutosporenlager wie bei den Uredolagern, schwarzbrau bis schwarz, auf den Stengeln verlängert, staubig; Sporen ellipsoidisch, beiderseits abgerundet. bei der Querwand mehr oder weniger eingeschnürt, $27-37 \mu$ lang, $19-25 \mu$ breit, mit brauner, leistenförmig-netzförmiger Membran; Stiel kürzer oder länger ats die spore, hyalin oder schwach selblich; Keimporus der Basalzelle um $2 / 3-4$ herabgerückt.

Aecidien im Mai, Uredosporen von Juni, Teleutosporen von Juli auf

P'impinella magna: Mśeno bei Budin. Woptrarnertal bei Lohosit $\angle$ liabat)! Teplitz (Thümen)! Herrnskretschen (Thümen), Untergrund bei Tetschen (Wagner)! 'T'urnau (Kabát)! Johannesbad (Domin)! 
Pimpinella Saxifraga: Hoch Veselí (Kabát)! Kolín (Veselský)! Neratovic! Ula, Welwarn (Kabat)! Rownaj bei Rauinitz (Prochazka)! Teplitz (Thümen). Rothenhaus hei Komotau (Loth)! Lomnitz a. L. (Weidman)! Vsechoy bei Tahor!

\section{Puccinia Cicutae Lasch.}

Spermogonien zwischen den Aecidien zerstreut, blass.

A eridien hasenfömig, tief eingesenkt, fruplenweise anf den Blattotielen, Stengeln und Blattnerven, im Umrisse elliptiseh his lïnolich; P'seudoperidien nur schwach entwickelt, nis hervorragend; sporen kuglig his ellipsidisch, 17-26; $\mu$ lang, $10-20 \mu$ breit, mit farbloser, dicht- und feinwarziger Nembran.

Uredolager blattunterseits auf hellgrünen Flecken zerstreut, klein, rundlich, bali nackt. hellhraun, staubig; Sporen kuglig, eiformis his ellipsoidisch 19-2! $\mu$ lang, $14-2.2$ " hreit, mit gethlicher oder hellhauner, entfernt stachliger Membran und 3 Keimporen.

Teleutosporenlager wie bei den Uredolagern, schwarbliaus, stauhig, auf

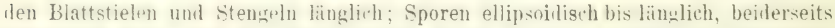
abgerumlet wier unten manchmal rerjüngt, hei der Querwand deutlich eingeschnürt,

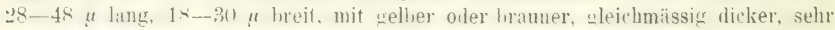
verschieden konturierter Membran und zwar dieselle warzenfirmig- leistenförmig oder netafirmig oder fast glatt; Stiel kurz, zart, hyalin, abti lig; Keimporus ıler oheren Zelle scheitelstïndig, derjenige der Basalzelle um $\%$ - $\%$, her.ıhgerürkt.

Aecidien von Mitte Juli und mit denselben zugleich oder nach ihnen die Eredusporen und Teleutosporen, die letzten besonders aher im August und September anf Cicuta virosa: Habstein (Kabát)!

2. Heteropuccinia. Spermogonien unl decidien auf einer, Uredo- und Teleutoşnoren auf zveiter, in eine ganz undere Orilnung zugehörigen Nährpflanze.*

a) Teleutosporen glatt.

a) Teleutosporenlager fest, dauernd bedeckt bleibend.

*) Teleutosporengruppen in rinzelnen Layern von braunen I'traphysen umgeben.

93. Puccinia dispersa Eriksson. - Puccinia dispersa Eriksson et Henuing forma specialis, Secalis Eriksson et Henning.

Spermogonien honigbraun, später fast schwarz, auf buiden Fleckenseiten in ziemlich reichlichen Gruppen oder zerstreut.

A ecidien auf der Unterseite, seltener Oberseite rundlicher oder länglicher. andher his orangefarbiger. his $1.5 \mathrm{~mm}$ hreiter Electie oder auch auf den

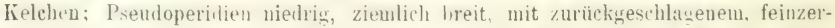
schlitztem liande; Sporen polyedrisch und zwar kuglig bis lïnglich, $20-31 \mu$ lang. $15-22 \mu$ breit, mit dicht- und feinwarziger Membran.

Uredolager elliptisch bis länglich, $0.5-1.7 \mathrm{~mm}$ lang, $025-0.85 \mathrm{~mm}$ breit, meistens hlattolerseits zerstreut oder fast gleichmissig vertelt, hald nackt, rostIraun, staubig; sporen kuglig oder ellipsoidisch, $22-31 \mu$ lang, $22-2-26 \mu$ hreit,

*) Ich reihe hier auch solche Arten ein, deren Aecidien bisher unbekannt sind, welche aber ganz sicher heteröcischer Natur sind. 
mit brïunlicher, stachliger Membran, $8-10$ Keimporen und orangefarbigem Inhalt.

Teleutosporenlager hauptsächlich blattunterseits und auf den blatt. scheiden, verlïngert, gruppiert, manchmal auch quer zusammenfliesseml, dauernd hedeclit, scliwarzhraun; Sporen gruppenweise von bramen Parifysen umgeben länglich bis keulenformig, am Stheitel abgerundet, abgestutat oder schief hervor-

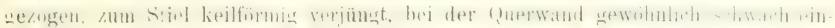
greschnürt, 40-57 $\mu$ lang, obere Zelle 14-2.2 $\mu$, untere 12-17 $\mu$ breit; Memhran glatt, hellbraun, am Scheitel dunkler; Stiel kurz, gelblich oder bräbnlich.

Aecidien Eude Juli his zum Winter auf

Lycopsis arvensis: Welwarn (Kabat)! Kokorín! Böhm. Leipa (Schiffner)! Rovensko! Harta bei Hohenelbe (Cypers)! Selčan; Svojanov bei Polička (Th. Novák)! Trebon̆ (Weidman)! und gewiss auch auderwärts.

A nchusa officinalis: Kaiserwiese bei Prag (Hennevogl)! Zahoŕanertal

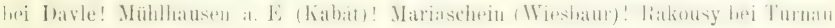
(Kabát)!

Uredo von Mai, hauptsächlich aber von Juni, Teleutosporen von Juli auf

Secale cereale: Ueberall verhreitet.

Die vorliegende Rostart erscheint in Böhmen alljährlich und beschädigt den

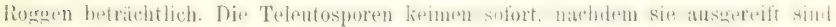
und ihre Sporidien infizieren dann Lycopsis und Anchusa.

Morfologisch ist Puccinia dispersa mit Puccinia triticina gleich, diese besitzt aber erst im Frühjahre auskeimende Teleutosporen.

Von Puccinia glumarum unterscheidet sie sich sogleich durch die Farbe der Uredolager.

94. Puceinia bromina Eriksson. - Puccin ia Symphti-Bromorum Fritz Miiller.

Spermogonien auf der Oberseite, seltener Unterseite der Flecke in kleinen Gruppen, honiggelh.

Aecidien blattunterseits, auf den Kelchen und Stengeln auf gelben Fle-

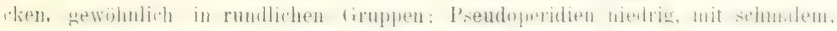

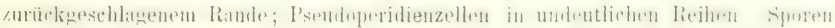
polyedrisch und zwar kuglig bis länglich, orangegelb, warzig, 19-29 $\mu$ lang, $17-24 \mu$ breit.

Ured ol ager rostbraun, blattoberseits zerstreut, seltener blattunterseits, klein, länglich; Sporen kuglig, gelblich, 18-30 $\mu$ im Durchmesser; stachlig; Membran bräunlich, mit 7-10 Keimporen.

T'eleutosporenlager blattunterseits, seltener blattoberseits, $0.5-0.7 \mathrm{~mm}$

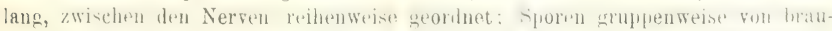

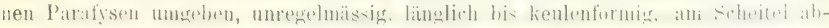

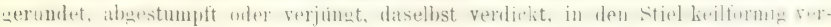
schmälert, $45-70 \mu$ lang, $14-18 \mu$ breit, mit hellbrauner, glatter Nembran; Stiel kurz, fest, liyalin. 
Aecidien im Mai und anfangs Juni auf

S y mpliyt um officinale: Hetzinsel (Beneš, Opiz)! und Kaiserwiest hei Prag (Schohl)! Ttefansüherfuhr hei Mélnik! Kolín (Veselslý)! Reichenberg (Siegmund)!

Uredosporen ron Eude Mai, Teleutosporen von Juli auf

B r o u us comm ut a us: Welwarn (Kabát)!

Brom us mollis: Sehr verbreitet.

B rom us secalinus: Selčan (Th. Novák)!

Bromus sterilis: Roztok und Selc bei Prag! Welwarn (Kabát)!

Bromus tectorum: St. Prokop bei Prag! Welwaru (Kabát)! Lenešic (Houska)!

95. Puccinia triticina Eriksson.

Uredolager meistens hattoherseits verteilt oder zerstreut, auch auf den Blattscheideu und Stengeln, $1-2 \mathrm{~mm}$ lang, $(0.5-1) \cdot 8 \mathrm{~mm}$ hreit. hald nacht, rost-
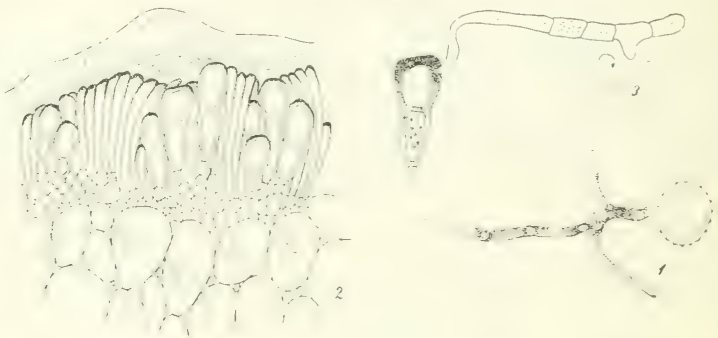

Abb. 16. Puccinia triticina. - 1. Keimende Uredospore. - 2. Schnitt durch ein Teleutosporenlager. - 3. Keimende Teleutospore mit Sporidien (Nach Eriksson).

hraum, stauhig; Sporen ligglig his ellipsoidisch, 20-2s "t lang. 17-24 " hreit, mit brauner, stachliger Membran und 8-10 Keimporen.

Teleutosporenlager meistens hattunterseits. auch auf Blattscheiden und Stengeln, lïnglich, hedeckt. schwarzbraun; Sporen gruppenweise von braunen Parafysen umgeben, länglich his keulevfürmig, am Scheitel abgestutzt, ahgerundet oder verjüngt, zum Stiel keilförmig verschmälert, hei der Querwand schwach eiugeschnürt. $30-45 \mu$ lang, 12-2) $\mu$ hreit, mit hrauner, glatter, am Scbeitel schwach verificliter Membran; Stiel kurz, bräunlich.

Uredosporen im Juni, Teleutosporen von Juli auf

Triticum vulgare: Sehr verbreitet und den Weizen ebenfalls stark beschädigend.

Von Puccinia dispersa ist sie durch kleinere Teleutosporen, die erst im Frühjähre keimfühig sind, verschieden. 


\section{Puccinia dactylidina Bubák.}

Uredosporen blattbeiderseits, klein, $1 / 4-3 / 4 m m$ lang, $0.1-0.2 m m$ breit,

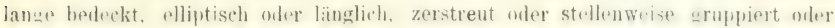
zwisehen den Nerven in kurzen Reihen. spriter nackit, rosthaun, stauhier; Sporm

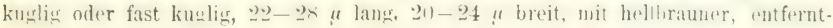
und feinstachliger Membran, mit $8-10$ wenig deutlichen Keimporen.

Teleutos poren lager blattbeiderseits, meistens aber blattunterseits, klein, $11.15-0.75 \mathrm{~mm}$ lang, rundich, elliptisch ader verlangert, üher das Iblatt ulewh. mïs:irr verteilt oder stellenweise sruppiert, oder zwischen den Nerven reihenweise. mauchmal auch zusammentliessend, dauernd bedeckt, fest, schwarz; Sporen uruppenweise von braunen Parafysen umgeben, von sehr versehiedener Form, meistens keulenfirmig, au Scheitel abgestutzt, abgerumdet oder hervorgezogen, daselbst schwalı verdickt und dunkler, zum stiel keilenförmig verjüugrt, bei der Querwand melır orler weniger eingeschnürt. 30-55) $\mu$ lang, die ohere Zelle öfters kürzer als die untere, $18-28 \mu$ breit, die untere $9-22 \mu$ breit, mit glatter, an der unteren Zelle hellgelhhauner, an der oheren hrauner Jemhran; Stiul liurz, fest, bräunlich bis hraun; Keimpren manchmal mit breiten, niedrigen Papillen. Einzellige Teleutosporen mehr oder weniger hänfig.

Uredo- und Teleutosporen im August auf

Dactylis glomerata: Radič bei Selčan ('Th. Novák)! Chotèboŕ (Mühlbach)!

Puccinia dactylidina ist mit Puccinia dispersa verwandt, von derselben aber, wie auch von anderen verwandten Arten ibrch kleine Sporenlager, wie auch breitere Teleutosporen verschieden.

97. Puccinia Agropyri Ellis et Fverhart. - A ecidium (: le mat id is I). Candolle - Puc cinia (il e mat id is Lagerhem in Urediueae herharii El. Fries, pg. 54.

Spermogonien blattoberseits in der Mitte der Flecke gruppiert oder blattunterseits $\mathrm{zwischen}$ den Aecidien, houiggelb.

A ecidien anf gelben Flecken in kleineren oder grösseren Gruppen blattunterseits. I'seudoperidien ziemlich hoch, weiss, orange, mit breitem. zurücky-'schlagenem, zerschlitztem, weissem Rande: Pseudoperidienzellen in vertikalen leihen, im Dorehschnitte viereckig oder pulygonal, sehr dickwandig, bis 3"; "lang, \$1 $\mu$ breit, oft mit oramefarbugem Inhalt. Spoten kuglie, eiformig oder ellipsoidisch. 21)-31 4 lann, 2()-2.2 $\mu$ hreit, mit dicht- und feinwarziger Membran und orangerotem Inhalt.

Ured o l a ger hauptsächlich blattoberseits, schmal, länglich oder strichformis, lange herleckt, später längs gesaltem, braumot; sporen kuglig oder eiformus. seltener ellipsoidisch, 22-31 $\mu$ laug, $175-265 \mu$ breit, mit brauner, ziemlich dicker, entferntstachliger Membran, 6-7 Keimporen; Stiel lang, nach oben erweitert.

T'e leutosporenlager blattunterseits oder auf den Blattscheiden, klein, länglich his strichformig. oft zusimmentliessend, dauernd von der fipidernis h. deckt. schwar,; sporen gruppenweise ron hellbranen, zusimmengelilesten l'ara- 
fysen ungehen, walzen- oder kinlenfümig, nit auch unregulmässit, $395-6 t j u$ lang, $175-265 \mu$ breit, in der Mitte mehr oder weniger eingeschuürt; die obere

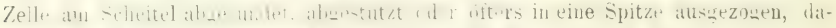

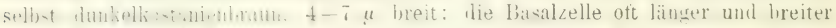

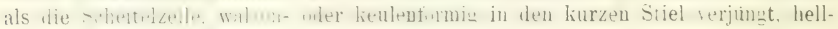
braun; Membran hei dem Stiele oft ziemlich verdickt.

Aecidien im Juni und Juli anf

Clematis recta: Prag (Forster, Hoser, Opiz)! Podbaba (Opiz)! Chra-

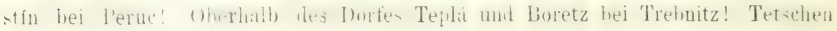
(Kanl im Herl). Peyl)!

Uredosporen im Juli und August, Teleutosporen von Juli bis in den Winter auf

Agropyrum repens: Oberhalh des Dorfes Teplá bei Trebuitz!

Der Zusammenhang der Aecidien mit den Uredo- und Teleutosporen wurde von $\mathrm{D}$ ietel (Oesterr. bot. Zeitschr. 1892, pu. 261-263) bewiesen.

\section{Puccinia persistens Plowright.}

Spermogonien orangerot, in kleinen Gruppen auf beiden Seiten der Flecke.

A ecidien battunterseits auf rotbramen. blasenformig gewillen Fleclien, vereinzelt atheh blattuherseits, in dichten. kleineren oler grusseren Gruplen. auf

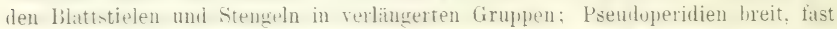
trichterfirmin. gelhorange. anfangs mit rob zershlitzten, weissem, abtäligem Rande. ynater werilen die einzeln’n Zipfel nochmals in schmälere, wenig zurück-

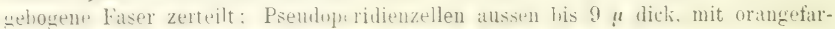
higem Inhalt: sporen pulyedrisch uni zwar kuglis, eiformig, ellipsodisch, seltener lïnglich. 211-31 " lans. $17-2.2, "$ breit, mit dicht- und feinwarziger Membran.

Uredolager elliptisch, länglich bis kurz strichförmig, blattoherseits, rost-

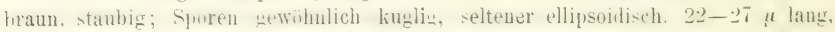
17-22 $\mu$ breit, mit feinstachliger Membran und oraugefarbigem Inhalt.

Teleutos poreulager hlattunterseits. lünlich bis strichförmig, oft dicht gruppiert, lange heleckt, fest, schwarz; Sporen gruppenweise von braumen Parafysen umpelien, ron sehr versehiedener form und zwar keulen-, spindelfurmig, länglich, schmal walzenförmig, 40-77 / lang. hei der Querwand fewohnlich nicht eingeschnür, helloglh, ohere Zelle kurz keilformig, ellipsoidisch oder viereckig, kürzer, sulten länger als die Bisalzelle. 11-2-2 " hreit. am seheitel his $9 \mu$ dick

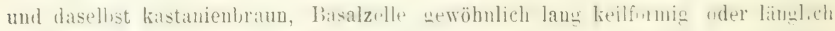
bis walzenförmig, $9-13 \mu$ breit, beim Stiele mit dickerer Membran; Stiel kurz, fest.

Aecidien im Mai auf

Thalictrum minus: Berg Lobosch hei Lohositz!

Uredosporen ron Juni, Teleutosporen ron August auf

Triticum repens: Berg Lobosch hei Lobositz!

Der genetische Zusammenhang der Aecidien mit den Uredo- und Telentosporen wurde von Plowright und E. Fischer bewiesen. 
99. Puccinia glumarum (Schmidt) Eriksson et Henning.

Spermogonien und A ecidien bisher unbekannt.

Uredolager $0.5-1 \mathrm{~mm}$ lang, $0.3-0.4 \mathrm{~mm}$ breit, blattbeiderseits oder auf den Blattseheiden, in Reihen (bis $7 \mathrm{~cm}$ lang) stehend. manchuat cusammmflies-end, auf den Spelzen auf der inneren Seite, stanbig, zitrongoll, ; soren kuglig his cllipsoidisch, 17-30 " lang. 15-20 " hreit, mit farbloser, "ntfernt stathliger Membran, 8-10 (manchmal sogar 12) Keimporen und orangerotem Inhalt.

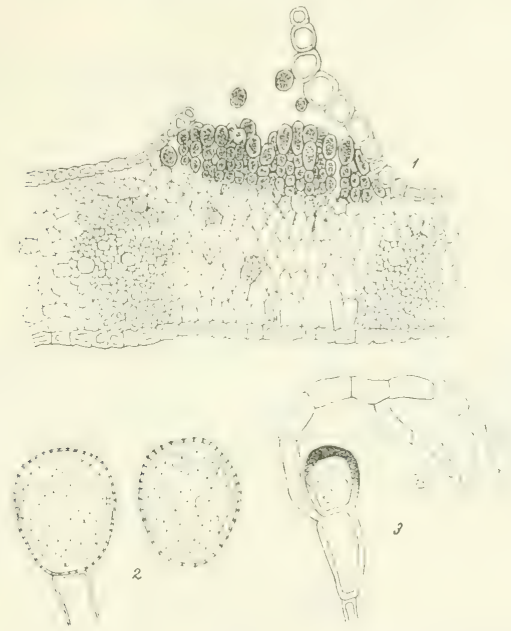

Abb. 17. Puecinia glumarum. - 1. Schnitt durch eiu Uredolager am Veizenblatte. - 2. Verurosserte l'redosporen mit Keimpuren. 3. Keimende T'eleutospore mit Pro nycelinm und poridieu. (Nach Eriksson).

T'eleutosporenlager blattunterseits, oder auf den Blattscheiden und

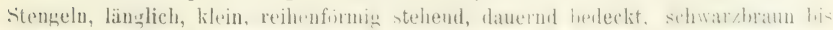

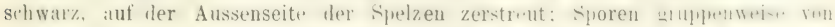

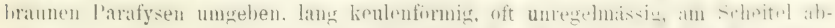
gestutzt, ahgerundet oler verjüngt. dastellsst $4-6$, oft his 111 u dick 1 m. dunkler,

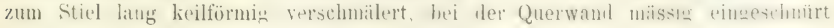
30-70 $\mu$ lang; obere Zelle 16--24 $\mu$, untere $9-12 \mu$ breit, mit brauner, glatter Membran; Stiel kurz, bräunlich, fest; Promycelium gelb.

Uredosporen von Juni, Teleutosporen von Juli auf

Elymus europaens: Duppau bei Karlsbad (Wiesbaur)! 
Secale cereale, Triticum vulgare: Ueberall häufig!

Hordeum vulgare, Triticum repens: Schon seltener!

Calamagrostis epigeios: Chlum bei Dobruška (Vodák)!

Die vorliegende Spezies kommt auch auf Triticum caninum vor.

Eriksson unterscheidet folgende Spezialformen:

f. sp. Tritici auf Triticum vulgare.

f. sp. Secalis anf Secale cereale.

f. sp. Hordei auf Hordeum vulgare.

f. sp. Elymi auf Elymus arenarius.

f. sp- Agropyri auf Triticum repens.

Puccin ia gl umarum verursacht alljährlich in Böhmen grossen schaden am Getreide. Besonders im J. 1904 trat sie im südlichen und südwestlichen Böhmen epidemisch vor und verursachte enormen Schaden.

\section{Puccinia Triseti Eriksson.}

Uredolager meistens blattoberseits, $05-1 \mathrm{~mm}$. laug, (1):3-05 mm. breit, zerstreut, gelbbraun oder gelb; Sporen kuglig bis ellipsoidiseh, 17-28 $\mu$ laug, $17-20 \mu$ breit, stachlig, gelblich.

Te leutos porenlager blattunterseits, rundlich bis länglich, zerstrent oder stellenweise gruppiert, dauernd beleckt, schwarz, fest; Sporen gruppenweise ron braunen Parafysen umgeben, länglich bis keulenförmig, am Scheitel abgestutzt, abgerundet bis verjüngt, zum Stiel keilformig verschmälert, bei der Querwand wenig oder gar nicht eingeschnürt, 30-45 $\mu$ lang, $16-22 \mu$ breit, wit brauner, glatter, am Scheitel dickerer Membran; Stiel kurz, brïunlich, fest.

Uredosporen von Juni, Teleutosporen sehr selten von September auf

Trisetum flavescens: Vrané und Okrouhlo bei Davle! Revnice (Th. Novák)!

\section{Puceinia holcina Eriksson.}

Uredolager klein, länglich, $1-3 \mathrm{~mm}$. lang, $05-1) .8 \mathrm{~mm}$. breit, besonders blattoberseits zerstreut oder gruppiert, gelbbraun, staubig; Sporen kuglig bis ellipsoirlisch, $20-28 \mu$ breit, gelbl)raun, mit bräunlicher, stachliger Membran.

Teleutosporenlager klein, schwarzbraun bis schwarz, blattbeiderseits zerstreut, auf den Blattscheiden lieihen bildend, lauerud bedeckt; Sporen gruppenweise von braunen Parafysen umgeben, hreit keulenförmig, am Scheitel abgerundet. abgestutzt oder schief vorgezogen, bei der Querwand wenic oder war nicht eingeschnürt, zum Stiel keilfürmig verschmälert, 32-54 $4 \mathrm{lang}, 16-255 \mu$ breit, mit brauner, glatter Membran; Stiel kurz, gelblich oder bräunlich.

Uredosporen von Juni, Teleutosporen von Juli auf

Holcus mollis: Selčan (Th. Novák)! Semín bei Pardubic (Vodáli) und gewiss auch anderwärts.

Die Aecidien sind bisher unbekannt; der Pilz kommt auch in anderen Ländern auf Holcus lamatus ror: 


\section{Puceinia Poae trivialis Bubáli}

Uredosporen blattoberseits zerstreut, rundlich oder litiglich, bald nackt,

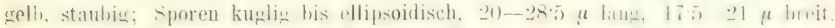
mit stachliger Membran und orangefarbigem Inhalt.

Teleutosporenlager blattunterseits, elliptisch bis kurz strichförmigr.

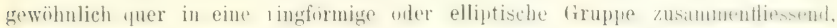
danernd bedeckt, schwarz; Sproren gruppenweise von hraunen Pitralysten umpebun.

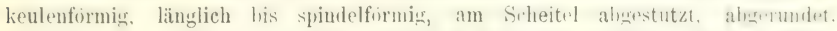
meistens aher verjüngt, zum Stiel gewohulich keilfomig verjüngt, bei der (1uer. wand manchmal zusammengezogen, :5-5s gelhbrauner, am Scheitel dunklerer uni dasellrst $4.5-11 \mu$ diclier Membran; Stiel kurz, bräunlich, nicht abfällig.

Uredosporen im Mai, Teleutosporen von Juli auf

Poa trivialis: Welwarn (Kabat)!

Diese Puccinia vom Typus der Puccinia glumarum unterscheidet sich von allen verwanden Arten hauptsïhlich dureh die Teleutosporentiger, welche in ringförmige Gruppen zusammenfliessen.

\section{Puccinia perplexans Plowright.}

Spemogouien klein, honiggelb, in kleinen Gruppen blattbeiderseits.

Aecidien auf der Unterseite gelblicher Flecke in rundlichen, auf den Blattstielen verläugerten (iruppen: Psendoperidien dicht mruppiert, ineit, nit zurïckueschlagenem, sehr fein zerschlitztem Rande; Sporen polychlisch-kugliz oler ellipsoidisch, $20-26 \mu$ lanm, 15-20 $\mu$ hreit. wit dicht- und feinwarziger Membran und orangerotem Inhalt.

Uredolager blattbeilerseits serstreut. Alptisch lis linglich, hie und da

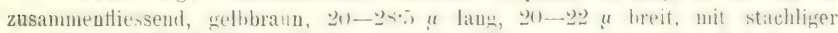
Membran und $6-8$ in zwei Kreisen liegenden Keiniporen; zwischen den sporen zahlreiche keulenförmige oder kopfförmige Parafysen.

Teleutosporenlager blattunterseits, schwarz, fest, dauernd bedeckt, sunst wie bei den I redosporen; Sporen eruppenweise von hramen Parafystn umgebeu, von sehr verschiedener Form, himformin, länlich, keulouformig, am Scheit abgerundet, abgestutzt oder manchmal verjünt, zum Stiel mehr orlor wenigry

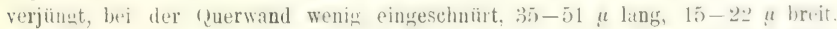
mit glatter, hellka-tanienfrauner, an scheitel dunklerer und wenis repilichiter. beim stiel manchmal dickerex und intensiver nefirlten Membran; Stiel kur. hralin oder brïunlich.

Aecidien ron Ende April bis anfaugs Mai auf

Rauuculus acer: Roztoky bei Prag! Welwarn, Hoch Veseli (Kabát)!

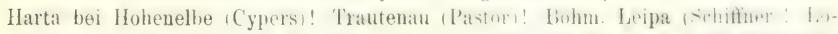

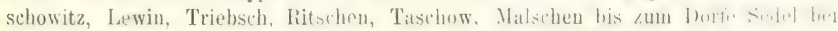
Aussigr! Nemschen bei Aussig: Duppau low Karishad (Wiesbauer)! Whioty und P'intovka bei Tábor! 
Uredosporen ron Juni, Teleutosporen von August auf

Alopecurus pratensis: Welwarn (Kabát)! Sejkořice, Křečovice, Rovensko! Isihm. Matha bei P'olic a. M., Wichstadtl bei Grulich! Vlécỉ důl bei Tábor! Chočiny bei Chýnov!

Der genetische Zusammenhang der Aecidien mit Puccinia wurde von Plowright bewiesen.

\section{Puccinia pygmaea Eriksson.}

Uredolager gewöhnlich blattunterseits auf gelblichen Fleckchen, klein, länglich bis strichformin, reibenfomig zwischen den Nerven stehend oder zerstreut, manchmal zusammentliessend, orangrelb, staubig; Sporen liuglig bis ellipsoidisch, $19-29 \mu$ lang, $17-20 \mu$ breit, gelblich, stachlig, mit $x-10$ Keimporen in zwei Kreisen.

Teleutosporenlag er blattunterseits, klein, elliptisch bis länglich, danernd hedeckt, schwarz; Sporen gruppenweise von braunen Parafysen umgeben, lienlenförmig, am Srheitel ahgestutzt, alggerundet viler seitwärts vorgezogen, zum Stiel keilformig verschmälert, hei der Querwand weniz oder gar nicht eingeschnürt, $31-42 \mu$ lang, 15-20 $\mu$ breit, mit hellbranner, am Scheitel schwach verdickter und dunklerer, beim Stiele ebenfalls verdickter Membrau; Stiel kurc, farlilos.

Uredosporen im August und September, Teleutosporen von Oktober auf

Calamagrostis arundinacea: Waltersdorf bei Ober.Politz in der böhm.-sächs. Sehweiz (Krieger)!

Calamagrostis Halleriana: Im Erzgebirge bei Pressnitz und Schmiedeberg (Wanner)! Bohmerwald: Klammerloch, Sihwarzer See, von Defferuik bis zum Lakka-See, Rachel!

Aecidien bisher unbekannt

105. Puceinia Agrostidis Plowright. - A ecidium Aquilegiate Persoon. Puccinia Aquilegiae (Persoon) Lagerheim.

Spermogonien auf der Oberseite gelblicher, verdickter, oft violett umsäumter Flecke orler auf derer Unterseite zwischen den lecidien locker stehend, klein, honiggelb.

A ecidien blattunterseits auf blasenformign Flecken in ziemlich dichten. rundlichen, selten unregelmässigen tiruppen; Pseudoperidien nithig, hreit, mit schmalem, wenig zurïcligeschlagenem, selnr fein zerschlitztem Rande; P'sendoperidienzellen in annihermi reunlären, vertikalen Reihen, polyëhrisch, isodiametrisch oder nur wenig verlängert, bis $33 \mu$ lang, $26 \mu$ breit; Sporen immer abgeruudet und zwar eiformis, ollipoidiseh bis linglich, $155-265 \mu$ latug, $13-20) \mu$ breit, mit farbloser, fein- und dichtwarziger Membran und orangerotem Inbalt.

Uredolager blattbeiderseits atuf lieinen, länglichen, gelben Flecken verteilt, lïnglich oder strichformï, etwa $1 \mathrm{~mm}$. lanı, hellorange; Sporen liuglig, eiformi.,

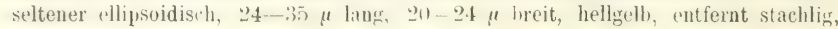
mit 5-s Keimporen. 
Tele utosporenlager blattunterseits, klein, länglich bis verlängert strich-

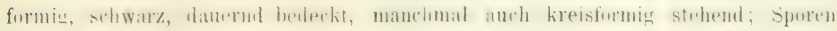
zylindrisch oder keulenförmig, 44-66 $\mu$ lang, 175-24 $\Perp$ breit, in der Mitte

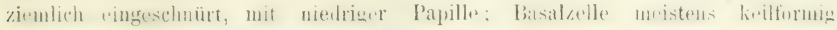

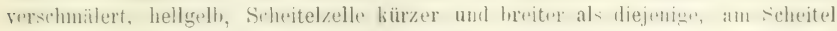

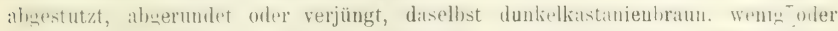
gar nicht verilickt einzelne Sporengruppen von hellbranten, festzusammenhängenden Parafysen umgeben.

Aecidien im Mai und Juni auf

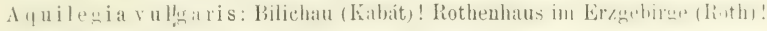
Langenau bei Hohenelbe (Cypers)! Chotěboř (Mühlbach)!

Uredosporen vou Juni, Teleutosporen von Mitte Juli auf

Agrostis vulgar is: Chotěbor (Mühlbach)!

Der genetische Zusammenhang der Aecidien mit Puccinia wurde von Plowright festgestellt.

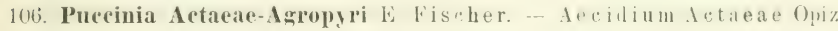
in Seznam prag. 111 et in schedis 1818.

Spermogonien gelbbraun, auf beiden Seiten der Flecke in ihrer Mitte gruppiert.

Aecidien blattunterseits aut gelben, $7-8 \mathrm{~mm}$ grossen Flecken locker verteilt, manchual auch in 1--2 Kreisen. Pseudoperidien gelloweiss. Wenic zurülireschlagen und zerschlitzt: Psemilopridienzellen in unregelmässigen Reiben; s, mren kinglin-polyëlrisch oiler elhısoblisch, mit dïnner. farhloser, feiu- und dichtwarziger. $16-26 \mu$ langer, $15--20 \mu$ breiter Membrau und hellgelbem Inhalt.

Uredolager blattoberseits, selten und nur vereinzelt auch blattunterseits, zwischen den Nerven liegend, wenig rorlugert. balil nackt, braun, staubig; ; poren

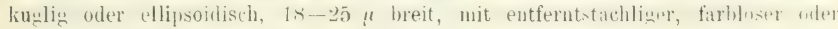
hellgelblicher Membran und 3-5 Keimporen.

Teleutosporenlager blattunterseits, kurz strichförmig, manchmal der Iänge nach zusammentliessend, zwischen den Nersen reihenweise liemont, lams. bedeckt, schwarz; Sporen gruppenweise von braunen Parafysen umgeben, sehr variabel, keulenforuig, birnformig, seltener auch ж)lindrisch, oft ungleichseitiz. am Scheitel abgerundet, abgestut/t oler eimseitig vorgezogen, auf der lasis almuthlinh in den Stiel verschmälert, bei der Querwand wenig oder gar nicht eingeschniirt, 32-45 $\iota$ lang, 14-25 $\mu$ breit, mit dünner, glatter, hellkastanienbrauner, an Scheitel $3-6 \mu$ dicker und dunklerer Membran; Stiel kurz, fest.

Aecidien im Juni und Juli auf

A ctaea spicata: Geltsch bei Lewin (Opiz, 12. Juni 1s18)! Osseg bei Teplitz (Thüwen)! Rothenhaus (Roth 1849)! Mariaschein (Wiesbaur)!

Uredosporen von Juli, Teleutosporen von August bis zum Vegetationsende auf

Triticum caninum: Zahoranertal bei Davle! Turnau (Kabsit)! Chlum bei Dobruški (Vodák)! 
107. Puccinia Arrhenatheri (Klebahn) Eriksson. - A ecidium uraveolens Shuttleworth.

Spermogonien blattbeiderseits zerstreut.

Aecidien üher die sanze Blattuuterseite gleichmässig zerstreut, mauchmal auch auf den Früchten; Pseudoperidien kurz zylindrisch oder becherförmig, mit schmalem, zur ückgeschlagenem, xerschlitztem Rande; Pseudoperidienzellen in mehr oter weniger dentlichen Reihen, fest verbunden. Sporen polyedrisch, und

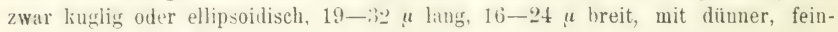
und dichtwarziger Membran.

U red o la ger meistens blattoberseits, seltener blattunterseits, klein, rundlich oder lünglich. manchmal zusammentliessend, golduelh: Sporen kuglig oder eiförmig, gelblich, 19-30 4 lang, 19-26 $\mu$ breit, mit zahlreichen lieimporen und vermischt mit keulen- oder kopfförmigen, bis 80 " langen, oben 11$)-14 \mu$ breiten Parafysen.

Teleutosporenlatger klein, strichfirmig, schwarz, lange bedeckt; Sporen gruppenweise von schlanken, braunen Parafysen umgeben, länglich oder keulenformig, am Siheitel abgerundet oder abgestutzt, zum Stiel rerjüngt, bei der Querwand nicht oder nur wenigr eingeschnürt, $30-45 \mu$ lang, $18-24 \mu$ breit, mit flatter, grelbbrauner, am Scheitel dunklerer und dickerer Membran; Stiel hyalin, kurz, fest.

Aecidien im Mai ; ihr Mycel überwintert in den infızierten Trieheu und dringt im Früljahre in neue Aeste, die in kurze Hexenbesen verwandelt werden, und fruktifiziert auf ihren allen Blättern.

Berberis vulgaris: Kinsky'scher Garten in Prag (Kalmus)! Welwarn (Kabát)!

Uredosporen von Juni, Teleutosporen von Juli auf

Arrhenatherum avenaceum: Welwarn (Kabát)! Reichenberg (Matouschek)!

108. Puccinia simplex (Körnicke) Eriksson et Henning.

Uredolager sebr klein, $0.3-0.55 \mathrm{~mm}$ lang, $0 \cdot 1-0 \cdot 2 \mathrm{~mm}$ breit hauptsächlich blattoberseits zerstrent, zitronengelh, staubig; Sporen kuglig, eiförmig bis ellipsoidisch. 21)-33 " lang, 17-22 $\mu$ brest, mit gelbbrauner, entferntstachliger Mem bran und 8-10 Keimporen.

Teleutosporenlager hauptsächlich blattunterseits und auf den Blattscheiden, klein, elliptisch bis länglich, dauernd bedeckt, schwarı; Sporen gruppenweise von braunen. am Scheitel erweiterten Parafysen umgrhen, gewöhnlich einzellig, une -elmitssig keulenformig, 30-46 " laug, 17-2.2 " breit, seltener zweizellig, keulenformig oder länglich, 40-ht " lang, 15-24 " breit, bei der Querwand schwah ein„eschnürt, beiderlei sporen am Scheitel abserumdet oder verjünt, zum Stiel keilforming verschmälert, mit hellkastanienbrauner, am Scbeitel 4 -s "I dicker und dunklerer Ifembran: Stiel kurz, brann, nicht abfillig. (Abb. 1s. V, 1-2). 
Ureilosporen von Juni, T'eleutosporen im Juli auf

Hordeum distichum, vulgare, hexastichum und zeocrithon allgemein verbreitet.

Aecidien bisher unbekannt.

** Teleutosporen ohne Parafysen.

Zwischen den Uredosporen Parafysen vorhanden.

\section{Pnecinia Poarum Nielsen.}

\section{honiggelbbraun.}

spermogonien hattheiderseits auf gelben Flecken in kleinen irupuen,

A ecidien auf der Unterseite gelber oder rotvioletter, rundlicher Flecke in kleineren oder grösseren rundlichen Gruppen; Psendoperidirn ziemlirh
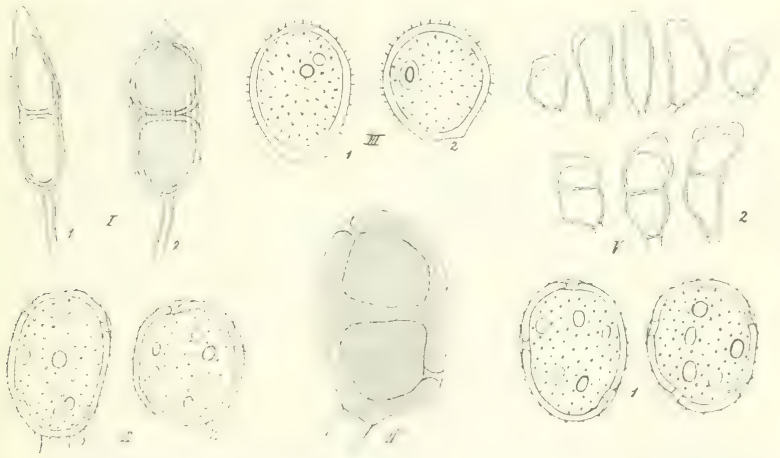

Abb. 18. Teleutosporen von Puccinia Chrysospleniz, 1. forma persistens, 2. forma fragilipes. II. Uredosporen von Puccinic dispersa. - III. Uredosporen von Puccinia Acelosae. - IV. Teleutosporen von Puccinia Carthami. - Puccinia simplex: 1. Uredosporen, 2. einzellige unà zweizellige Teleutosporen. (I. nach Dietel, II.+V. nach Klebahn, HI. nach Mignus).

dicht gruppiert, niedrig walzenformig, mit weissem, zurückgeschlagenem, zersehlitztem Rande; Pseudoperidienzellen aussen bis $10 \mu$ dick; Sporen liuelig his ellipsoidisch, fast immer polyeibisch, 18-28 " lang, 16-20 " breit, mit lünner, feinwarziger Membran.

Uredolager bhattoberseits oder auch aut den Bhattseheiden, klein. rumllich oder elliptisch, gelborange; Sporen kuglig oder effirmig, selten ellipsoidiseb, $22-28 \% \mu$ lang, $175-22 \mu$ breit, mit hyaliner oder schwach gelblicher Uembran, ziemlich dichtwarzis, mit $\vec{b}-10$ in zwei lireisen gelergenen lieimporen: zwishen den Sporen keulenförmige oder kolffürmige, s(1 "lange, 22 " breitr, Purafisen.

Teleutosporenlager blattunterseits viler auf den Blattsclutiden. kilein. rundlich, linglich oder strichfümig, zerstrent oder stellenweive srupliert, shwarz, 


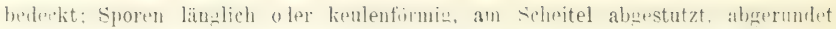
oder verjuingt, bei der Querwand nicht oder nur wenig eingeschnürt, 35-60 $\mu$ lang, $18-24 \mu$ breit, mit brauner, glatter, am Scheitel bis $7 \mu$ dicker Membran; Stiel kurz, schwach bräunlich, nicht ahfällig.

Aecidien von frühem Frühjahre bis zum Winter auf

Tussilago farfara: Gemein!

Uredosporen von Mai, Teleutosporen vou Juli auf

Poa annua, nemoralis, pratensis: Sehr verbreitet.

Poa compressa und trivialis: Schon seltener!

Der genetische Zusammenhang wurde zuerst von $\mathrm{Nielsen}$ festgestellt.

110. Puceinia Baryi (Berkeley et Brome Winter. - Eredo Irachypodi i Opiz in schedis 185 ? !

[redolatger blattoherseits zerstreut od $\mathrm{er}^{2}$ aruppiert, oft reihenweive zwischen den Nerven liemend, strichtirmin, rostgelh, starli staubig: Sporen kuglig his elipsidisch, is-2.) u in Durchmesser. ziemlich dickwanliz. gelblich. fein- und ziem-

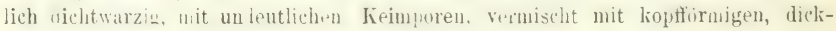
wandigen Parafysen.

Teleutosporenlager blattunterseits, schmal, strichförmig, schrarz, dauerud hederkt. smist wie die Creslolazer; Sporen sehr ungleich, ellipsoidisch, himfirmig. lienlenturmig, an Scheitel abgertutzt oder abgerundet, dasellst verdiclit und dunkler, bei der Querwand schwach eingeschnür, zum Stiel alluahlich verjüngt, 25- $42 \mu$ lang, $15-25 \mu$ breit, init glatter, hellbrauner Membran; Stiel kurz, bräunlich, fest, oft fehlend.

Uredosporen von Juni, Teleutosporen von Juli auf

Brachypodium pinnatum: Kuchelbad und Radotín bei Prag! Míkor bei Mèlnik! Welwarn (Kabát) ! Rovensko!

Brachypodium silvaticum: Cibulka bei Prag (Opiz)! Bohnicer Wald (1) piz)! Kuchelh,ud, liosıi. Radotín! Mühlhausen a. E. Kahat)! Stefansüberfuhr bes Neratorio! Tornau (Kitbit,! Rovensko! Nutzhorn bei Rozdialosic! Teplitz (Thümen)!

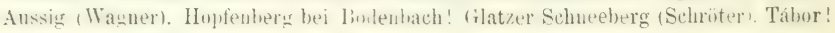
Plavo bei Bulweis!

\section{Puceinia Magunsiana Kömicke - Puccinia serialis Opiz in schedis 1852 .}

Spermogonien honiggelbbraun, bìatcoberseits auf gelblichen Flecken in kleinen Gruppen oder blattunterseits, auf den blatt-tielen und Stengeln zwischen den Aecidien.

Aecidien auf der Unterseite gelblicher Flecke in rundlichen oder unregeimassigen (imuplen, auf den Blattstimlen und Stengeln in rerlangerten firuppen; Pseudoperidien mit zuritcheschlagenem. zer-chlitztem lianle; Psendoperidienzellen aussen his 7 " dick, in mehr oder weniger renelmissigen Reilien; Sporen hugligpolyerisch, bis lämglich-polyedrisch, 14-25 $\mu$ laner, 14-18 $\mu$ breit, mit dünner, dicht- und feinwarziger Membran. 
Uredolager blattbeiderseits verteilt oder zerstreut, klein, linglich, ziem-

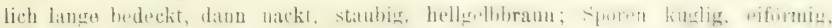

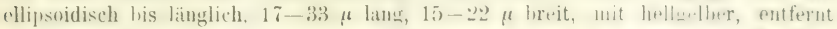
stachliger Membran und umintlichen Keimporen; Sporen mit zahlarichen, kenlen-

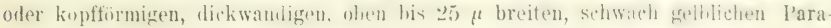
fysen vermischt.

Teleutosporenlager fest, Hach, schwarzbraun, auf beiden Blattseiten, likin, länglich mier liurz strichformin, zestreut oder ziemlich dieht verteilt, auf

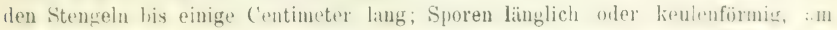
S'heitel abgerundet, seltener ahgestutzt oder verjüngt, zum stiel keilformiz ver schmailert, bei der Querwand schwach eingeschnürt, 35 55 $\mu$ latng. 17 - „2) $\mu$ breit,

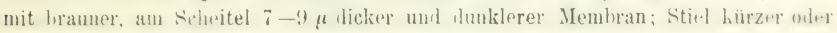
lüuger als die Spore, stark, gelbbraun, nicht abfällig.

Aecidien im Juni auf

Ranunculus repens: Welwarn (Kabát)! Lysá (Th. Novák)! Komárover Teich bei Dymokur und gewiss auch anderwärts.

Nach Plowright, Klebahn und E. Fischer auch auf Ranunculus bulbosus.

Uredosporen von Juni, Teletousporen von Ende Juli auf

Phragmites commuis: Auf feuchteren Wiesen und bei Gewïssern ziemlich verbreitet.

Der genetische Zusammenhang der Aecidien mit Puccinia wurde von Cornu, Plowright und Klebalin festrestellt.

\section{$\square$ Parafysen zwischen den Uredosporen nicht vorhanden. \\ Uredosporen stachlig. \\ $\triangle$ Teleutosporenstiele lang.}

\section{Puccinia Phragmitis (Schumacher) Köruicke.}

Spermogonien weiss, in grossen, lockeren Gruppen blattbeiderseits.

A ecidien gewöhnlich anf der Unterseite gelber oder purpurroter, rundlicher, bis 1 cm. breiter, Gelb, rosenrot oder violett unsitumter I'lecke; P'sendoperidien dichtstehend, nielrig, mit schmal zurïckgescharenem, zerschlitztem Rand; Psendoperidienzellen aussen his 11) $\mu$ dick, in unregrelmissigen Reihen; Sporen kunlig-polyëdrisch, 17-2i $\mu$ im Inurchmesser oder eiformig und ellipsoidisch, $17-26 \mu$ lang, $15-18 \mu$ breit, farblos, fein- und dichtwarzig.

Urodolager elliptisch, fänlich bis strichfomig, battbeilerseits zwisihen den Nerven verteilt orler stellenweise gruppiert, ziemlich atoss, gawnllot, oft zusammentliessend, braun, statubig; Sporen eiformig. wlipsoidisch his lituglich,

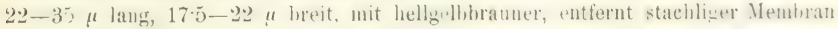
und vier Keimporen.

Teleutosporenlager wie bei den Uredosporen, schwarzbraun, gewölbt,

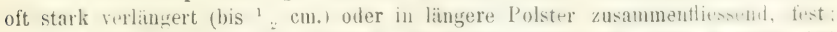
sporen ellipsoidisch bis spindelformig. heiderseits ahgeruntet uder verjumt, hei der Querwand dentlich verjüngt, 40 - iti $\mu$ lang. $175-22 \mu$ breit, mut glatter, 
kastanienbrauner, dick'r. am Seheitel 4-4 $\mu$ verdickter Membran; Stiel 100-2u(1 lang, farblos, fest.

Aecidien im Mai und Juni auf

Rumex aquaticus: Habstein (Kabait)! Brüx (Štika)!

Rumex crispus: Welwaru, Hoch Veseli (Kabat)! Zehuner Teich! Srpina bei Počerail!

Rumex hydrolapathum: Kokořín (Kabát)!

Rumex obtusifolius: Welwaru (Kibait)! Podẻbrad (Opiz)! Rarlowesic bei Libochovic!

Uredosporen von Juni, Teleutosporen von Juli auf

Phragmites communis: Ziemlich verbreitet.

Entscheidende Versuche über die Zugehörigkeit der Aecidien von Rumex Aecidium rubellum Gmeliu) zu dieser Puccivia wurden von Plowright durchgeführt. Thümen führt in Verhandlungen d. zool. bot. Gesellschaft Wien 1875, pag. 535; auch Aecidien von $\mathrm{R} u m$ ex alpinus auf, die von Opiz bei Hohenelbe gesammelt wurdeu. Ob dieselben hierher oder zu Schrocteriaster alpinus gehören, muss erst durch diesbezügliche Versuche festgestellt werden.

\section{Puccinia Trailii Plowright.}

Sp ermogonien honigrelbbraun, oberseits auf den Flecken in dichten Gruppen.

A e c i di e n blattunterseits auf purpurroten, gelb umsäumten, rundlichen Flecken; Pseuloperidien breit, schüsselförmig, mit weissem, zurückireschlagenem Rande; Pseudoperidienzellen auf der Aussenseite $7-10 \mu$ dick; Sporen polyëdrisch und zwar kuglig, ellipsoidisch oder unregelmässig, $15-2.2 \mu$ lang, $15-20 \mu$ breit, mit dünner, warziger Membran.

U red o l a g e r blattbeiderseits zerstrent, elliptisch bis länglich, rostbraun, staubig: Sporen fast kuglig, eiförmig bis ellipsoidisch, 25-35 4 ian breit, mit brauner, stachliger Membran.

Teleutosporenlager blattbeiderseits zerstrent oder stellenweise uruppiert, schwarzbraun his schwarz, $2-4 \mathrm{~mm}$. lang, $0.5 \mathrm{~mm}$. breit, gewolbt, fest; Sporen ellipsidisch bis linglich, 35-50 $\mu$ lang, $20-23 \mu$ breit, beiderseits abgerundet oder schwach verjüngt, bei der (juerwand eingeschnïrt, mit kastanitnbrauner, trocken untersucht feinpunktierter, am scheitel $5-10 \mu$ dicker Membran; Stiel fest, braun, bis $110 \mu$ lang, fest.

Aecidien im Mai auf

Rumex Acetosa: Welwarn (Kabát)! Netolic (Hampl)! Radimovicer und Měsicer T'eiche bei Tábor! Soběslav (Stejskal)!

Uredosporen vou Juni, Teleutosporen von Juli auf

Phragmites com m u is: Slaná bei Semil! Pardubic (Vodák)! Netolic (Hampl)! Radimovicer und Měsicer Teiche bei Tábor!

Der genetische Zusammenhang wurde von $\mathrm{N}$ ielsen, Plowright und K lebahn festgestellt. Von Puccinia Phrasmitis ist die vorliegende Art hauptsäıhlich biologisch, wie auch durch die feinpunktierten Teleutosporen, welch auf langen braunen Stielen befestigt sind, verschieden. 
114. Puccinia graminis Persoon. - A ecidium B e rberidis Persoon.

Spermogon i e $n$ blattoberseits, in der Mitte gelblicher Flecke iu kleinen Gruppen, honiggelbbraun.

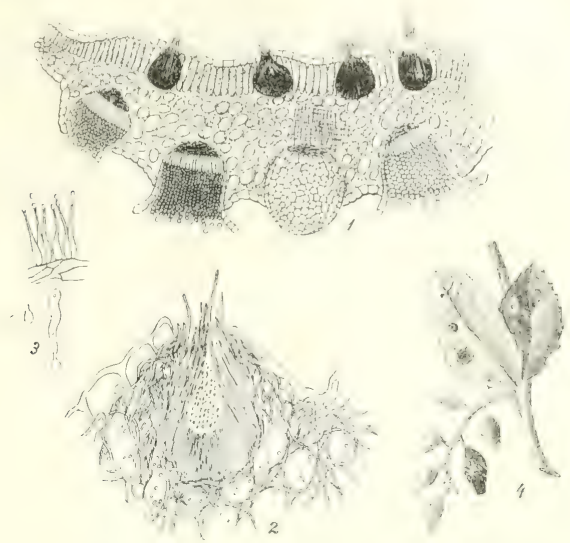

Abb: 19. Puccinia graminis Pers. 1. Schnitt durch ein Blatt von Berleris vulgaris; oben Spermogonien, unten Aecidien. 2. Durchschnitt eines Spermogoniums. 3. Stück einer Spermogonienwand, mit Stielchen und Spermatien. 4. Aestchen von Berberis, mit Aecidien (1. nach Sachs, 2. nach Tavel)
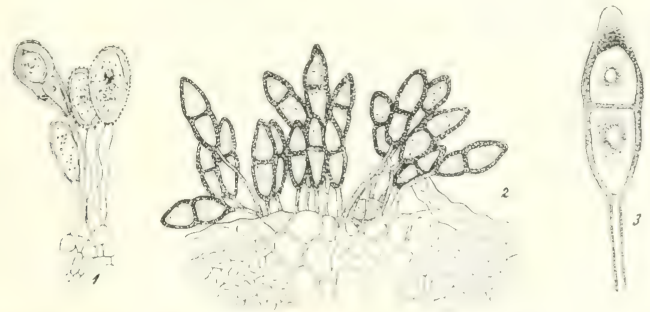

Abb. 20. Puceinia graminis Pers 1. Giuppe yon Uredosporen. 2. Durchschnitt eines 'Teleutosporenlagers. 3. Stark vergrösserte Teleutospore (1, 2 nach De Bary, 3 nach Eriksson).

A e cidien auf der Unterseite gelber bis roter Flecke, in kleinerer oder grösserer Zahl, auch auf den Früchten; I'seurloperidien walzenformigr: l'-eudoperidien zylindrisch. mit zurückgebogenem, zerschlitztem Rande: I'smuloperilieuDr. Bubák, Die Pilze Borhmens. 
zellen in undentlichen Reihen; Sporen kugligpolyëdrisch, 14- ־6 $\mu$ im Durchmesser, mit dünner, glatter oder feinwarziger Membran und orangefarbigem Inhalt.

Ured ol a ger blattbeiderseits, auch auf Blattscheiden und Halmen zerstreut, oder reihenweise, liuglich bis strichfümig, oft zusammeufliessend und dann bis $1 \mathrm{~cm}$. lang, ron geborstener Epidermis bedeckt, rostbraun, staubig; Sporen ellipsoidisch bis läuglich, stachlig, 20-42 $\mu$ lang, $14-22 \mu$ breit, mit brauner, stachliger Membran und 4 (selten 3 oder 5) Keimporen.

Teleutosporenlager wie bei den Uredosporen, schwarz, bald nackt, fest, zusammentliessend; Sporen länglich, spindelförmig oder keulenförmig, oben abgerundet oder verjüngt, zum Stiel verjüngt, bei der Querwand schwach eingeschnürt, 35-60 $\mu$ lang, 12-2: $\mu$ breit, mit kastanienbrauner, am Scheitel $6-10 \mu$ dicker und dunklerer, glatter Membran; Stiel bis $60 \mu$ lang, kräftig, brätunlich.

Aecidien anfangs Mai bis Mitte August auf B e r beris v u lgar is sehr verbreitet; auf Mahonia a qu ifolium habe ich sie aus Böhmen noch nicht gesehen.

Uredosporen von Juni, Teleutosporen von Juli auf allen vier Getreidearteu sehr verbreitet. In feuchten Jahren tritt Puccinia graminis epidemisch auf. Sie kommt auch auf zahlreichen kultivierten und wildwachsenden Grïsern vor und zwar:

Agrostis stolonifera: Bad Wartenberg (Kabát)! Rothenhaus (Roth)!

A grostis vulgaris: Rovensko!

A ven a f a t u a: Karlstein (Hora)! Duppau (Wiesbaur)!

Dactylis glomerata: Wopparnertal bei Lobositz (Kiabát)! Harta (Cypers)! Rovensko! Tábor!

Deschampsia ca espitosa: Wiesen bei Všetat! Welwarn (Kabát)! Unterhalb Lobosch bei Lobositz! P'odhaj bei Bad Wartenberg (Kabát)!

Festuca ar undin a c ea: Welwarn (Kabát)!

P o a a n u a: Welwarn (Kabát)!

Poa nemoralis: Baumgarten bei Prag (Opiz)! Radotín! Wopparnertal bei Lobositz, Turnau (Kabát)!

P o a pratens is: Welwarn (Kabát)!

Triticum caninum: Wopparnertal (Kabát)! Nové Dvory bei Kolín (Veselský)! Rovensko!

Triticum repens: Sehr verbreitet !

Eriksson unterscheidet eine grössere Anzahl von spezialisierten Formen.

115. Puceinia Anthoxanthi Fuckel. - Puccinia Arenae pubescentis Bubák.

U re 101 a ger blattbeiderseits, oben zahlreicher, auf verlïngerten, gelbbraunen, zerstreuten oder gruppierten Flecken, länglich bis strichförmig, bald nackt, rostbraun, staubig; Sporen eiförmig bis ellipsoidiscb, hellbraun, 20-33 $\mu$ lang$15-2 \cdot 2 \mu$ breit, gelbbraun, mit dicker, stachliger, gelblicher Membran und 4 kreuz, weise aequatorial gelegenen Keimporen. 
Teleutosporenlager blattheiderseits verteilt, elliptisch bis langlich. bald nackt, schwarzbraun, später ganz schwarz, fest: Sporen ellipsoidisch, länglich bis keulenförmig. $28-46 \mu$ lang. 15-22 $\mu$ breit, am Scheitel abgerundet oder verjüngt, daselbst stark verdickt und dunkiler, unten abgerundet oder keilfürmig verschmälert, bei der Querwand wenig oder gar nicht eingeschnürt, mit hellkastanienbrauner, glatter Membran; Stiel brïunlich, bis $60 \mu$ lang, fest.

Uredosporen vou Juli, Teleutosporen erst ziemlich spät, grewöhnlich erst im September auf

Anthoxanthum odoratum: Chotèboř (Mühlbach)! Hoch Vesell (Kabát)! Rovensko! Dorf Mladey unterhalb dem Geltschberge! Fuss des Berges "Hora ${ }^{4}$ bei Merzkles! Libiš bei Neratovic! Neratovicer Wiesen! Měsice bei Tábor! Lomnic a. Lużn. (Weidmann)! Spitzberg im Böhmerwalde!

Aecidien bisher unbekannt. Im Riesengebirge fand Kabát auf derselben Nährpflanze einen anderen Rostpilz - Uredo anthoxanthina Bubák. Puccinia Avenae pubescentis Bubák ist zu streichen, da es sich gezeigt hat, dass die Nïhrptlanze nicht Avena pubescens, sondern perennierendes Antho$\mathrm{xanthum} \mathrm{odoratum} \mathrm{ist.}$

\section{Puccinia Phlei pratensis Eriksson.}

Uredolager blattbeiderseits zerstreut oder blattunterseits und auf den Blattscheiden ziemlich dichtstehend, elliptisch, länglich oder kurz strichförmig (1-2 mm.), auf den Blattscheiden oft zusammenfliessend und daun $1 \mathrm{~cm}$. lang und lïnger, seitlich von der Epidermis bedeckt, gelblraun, staubig; Spuren eiförmig, ellipsoidisch, keulenförmig-linglich, $2 \cdot 2-33 \mu$ lang, $15-20 \mu$ breit, mit hellgelbbrauner, am Scheitel schwach verdickter, entferutstachliger Memhin, mit 4 (auch 3 oder 5) Keimporen.

Teleutosporenlager auf den Blattscheiden und Stengeln, $2-4 \mathrm{~mm}$. lang oder lïnger, schmal, schwarzbraun bis schwarz, nackt oder hie und da bedeckt, oft zusammenflessend; Sporen spindel- oder lieulenfürmig, am Siheitel abgerundet oder verjüugt, zum Stiel keilfürmiı verschmälert, hei der Querwand schwach eingeschnürt, 38-52 $\mu$ lang, $14-10 \mu$ breit, mit glatter, kastanienbratuner, am Scheitel bis $8 \mu$ dicker Membran: Stiel stark, britunlich, bis $60 \mu$ lang, fe'st.

Uredosporen von Juni, Telentisporen nur selten aussebilitet oder oft überhaupt nicht entwickelt, so dass der Pil\% mittelst der Uredosporen überwintert. Auf

Phleum pratense: Strahor bei Prag (Th. Novák, im Juni 1900 nur Uredo)! Rakousy bei Turnau (Kabát)!

Morphologisch ist dieser Rostpilz mit P'uccinis gramiuis fast identisch, er bildet aber keine Aecidien auf Berberis vulgaris. (Nach Eriksson.)

\section{Puceinia Sesleriae Reichardt.}

Uredolager strichformig, hauptsächlich blattoberseits, anfangs bedeckt, daun längs geöffnet, rostbraun, staubig; Sporen kuglitg bis ellipsoidiscb, 20-3:30 $\mu$ lang, $18-24 \mu$ breit, mit dicker $(3 \mu)$, entferntstachliger Membran und 4 Keimporen. 
Telentosporenlager wie bei den Uredosporen, schwarz, fest, gewölbt; Sporen birnformig his spindelformig, am scheitel abgerundet oder verjüngt, zum Stiel mehr oder weniger verjüngt, bei der Querwand nur wenig eingeschnürt, $35-60 \mu$ lang, $17--24 \mu$ breit, mit kastanienbrauner, am scheitel bis $11 \mu$ verdickter und duublerer Membran; Stiel kräftig, braun. bis $70 \mu$ lang, fest.

Uredosporen im Juli, Teleutosporen von Ende August auf

Sesleria coerulea: Kosoř bei Prag! Turnau (Kabát)!

Re ich ardt behauptet, dass zu dieser Puccinia die Aecidien ron Rhamnus saxatilis gehören. Dieser Strauch kommt aher auf den hihmischen Standorten, wie auch überhaupt in ganz Buhmen nicht vor. Meine diesbezüglichen Infeltionsversuch $\mathrm{e}^{*}$ ) blieben auch resultatlos.

\section{Puccinia Sorghi sehteinitz. - Puceinia May dis Bérenger.}

Uredulaner hattheiderseits ztrstrent oder hie und da gruppiert, elliptisch oder lïnglich, sewölbt, lange bedeclit, rostbiaun, staubig; Sporen kuglig, eiförmig oder ellipsoidisch. $24-33$ " lang, $20-26$, hreit, mit gelbbrauner, entferut stachliger Membran und 4 , mit niedrigen, hyalinen Kappen bedecliten Keimporen.

Teleutosporen lager wie bei den Uredosporen manchmal bis strichförmig. lange heleclit, dann naclit, gewölbt. schwarz, fest: Sporen ellipsodisch oder lïulich, beriderseits ahgerunlet oder manchmal auch verjügt, hei ler Querwand schwach eingeschnüıt, $30-50 \mu$ lang, 17-24 $\boldsymbol{u}$ breit, mit kastanienbrauner, glatt'r, am Scheitel stark Feriliter. Membran; Stiel hraun, kräftig, kürzer oder länger als die Spore, fest. (Siehe Abb 14, IV.)

Uredo- und Teleutosporen im August auf

Zea Mays: Kacina (Peyl)! Hoch Veselí, Lohositz (Kabát)! Rovensko!

Aecidien kommen nach A r th "r's Versuchen auf $\mathrm{Ox}$ al is-Arten vor. Nach Lellerman's Versuchen sollen die sporidien die Fähigkeit besitzen auch direkt Zea Mays zu intizieren, was allerilings selur bezweifelt werden muss.

Puccinia Sorghi wurde nach Europa aus Amerika eingeschleppt und zuerst (nach Desmazières) in Holland (1837) beobachtet.

119. Puccinia Moliniae Tulasne - Puccinia ne moralis Juel. - A ecidium Melampyri Kunze et Schmidt.

sper:nogonien honigbraun in kleiner Gruppe auf der Oberseite der Flecke.

A e cid ien blattunterseits auf roten Flecken in lockeren Gruppen; Psendoperidien niedrig walzenförmig, mit zurückgeboresem, fein zerschlitztem Rande; Sporen kuglig-polyedrisch, 15-19 $\mu$ im Durchmesser, farhlos, sehr fein- und dichtwarzig.

Uredosporen blattoberseits, länglich oder strichfurmig, oft zusammen-

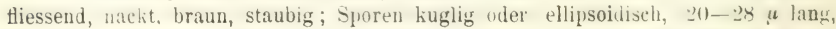
20-24 $\mu$ breit, mit qelbbraumer, sphr dicker, ziemlich grobstachliger Membran und 3 Keimporeu.

Teleutosporen lagger elliptisch. länglich oder strichformig, stark gewilbt, schwarzhraun, blattoberseits, seltener blattunterseits verteilt oder gruppiert, oft

4) Siehe Zentralblatt für Bakteriologie und Parasitenkunde, II. Abteilung, Bd. XVIII, Jena 1907 , pag. 77 . 
verschiedenartig zusammenfliessend, fest; Spuren ellipsoilisch, beiderseits abgerunlet, bei der Querwitnd eingeschnürt, 33-4t $\mu$ lang, 22-24 u breit, mit dicker, kastauienbramer, glatter, am Scheitel stark (bis jo $\mu$ ) verdickter Membran, daselbst mit brüulicher, m.hr oder weniger deutlicher Papille versehen: stiel stark gelblich, sohr lang, fest.

Aecidien im Juni auf

Melam prum pratense. Aus Böhmen habe ich sie bisher noch nicht gesehen.

Uredosporen Mitte Juli bis Mitte August, bald durch Teleutosporen verdriingt atuf

Molinia coerulea: Wiesen bei Neratovic und Všetat! Pŕrhráz bei Müncheneraitz (Kabat)! Hoch Veseli, Welwarn (Kabát)! Kačina (Peyl)! Lomnic a. L. (Weidman)!

Von Rostrup wurde auf Grund wenig verlässlicher Versuche behauptet, dass zu dieser Puccinia die Aecidien von Orchideen (Aecidium Orchidearum 1)uby) gehören. Klebahn zeigte später, dass diese Aecidien mit Puccinia Orchidearum-Phalaridis genetisch zusammenhängen.

Die Zugehorigkeit ler Aecilien von Melampyrum pratense mit den Uredo- und Teleutosporen von Molinia wurde von $\mathrm{J}$ u e 1 festgestellt.

\section{Puccinia Stipac (Opiz) Hora. - A ecidium Thymi Fuckel.}

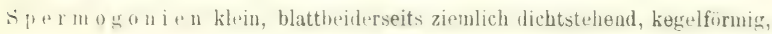
orauge.

A ecidien blattunterseits nur zerstreut oder in kleinen, rundlichen Gruppen dichtstehend, oder die ganze Blattunterserite hedeckend; Pseudoperidien anfangs halblugelig. später mit rundlicher Oeffunng; Pseudoperidienzellen stark verlängert: Sporen kuglig, ellipsoidisch bis länglich, oft polygonal, $22-31 \mu$ lavg, $155-2() \mu$ hreit, oder 17-22 $\mu$ im Iurchmesser, mit dicker, gelbhrauner, feinwarziger Membran.

L red ol a ger blattoberseits, seltener auf Blattscheiden, klein, strichformin. zwischen den Verven liegend, oft der Länge nach zusammentliessend, bald nackt, staubig, rostı ot; Sporen kuglig, 20-265 $\mu$ im Durchmesser onter eiformig, 24-31 lang, 20-24 $u$ breit, orange, feinstachlig, mit vielen (bis 10) Keimporen.

Teleutosporenlager wie bei den Uredosporen, schwarz, gewölbt, fest; Sporen linglich, keulenformig oder spindelförmigr. am scheitel abserundet oder kegelfömig verjüngt, seltener abgestutzt, zum Stiel heilformigr verschmilert, scttener abgerundet, bei der Querwand gewohnlich stark eingeschnürt. 42-8 175-24 $\mu$ lreit, mit glatter, hellkastanicnbraumer, am Scheitel bis 11 u dieker und daselhst dunklerer Membran; Stiel gelblich, his 100 „u lang, fest. ()ft kommen auch einzellize, droizellige und rierzellige Sporen (I'hrammidiun-Typus. wis auch dreizellige (Triphragmium-Typus) und zweizellige (Diorchidium-Typus) vor.

Aecidien im Mai und Juni auf

Thymus pannonicus: Kuchelbad! und vor mir schon im Jabre 1857 Nickerle! Welwarn (Kabát)! 
Thymus praecox Opiz: Hügel Vínek bei Vražkov nächst Raudnitz!

Ausserdem habe ich bei meinen Infektionsversuchen die Aecidien auf Thymus ovatus Mill. und die Spermogonien auf Thymus angustifolius erzielt.

Uredosporen im Juni und Juli, Teleutosporen von Juli auf

Stipa capillata: Kuchelbad! und früher schon im J. 1888 (Hora, damals Assistent an dem botanischen Institute der $\mathrm{k}$. $\mathrm{k}$. deutschen Universität in Prag)! Hügel Vínek bei Vrážkov nächst Raudnitz! Welwarn (Kabát)!

Den genetischen Zusammenhang der Aecidien von Thymus mit der Puccinia auf Stipa capillata habe ich im J. 1902 festgestellt. Später wurde auch von D i edicke bewiesen, dass hierher auch die Aecidien von Salvia silvestris und $\mathrm{Salvia}$ silvestris $X$ pratensis gehören.

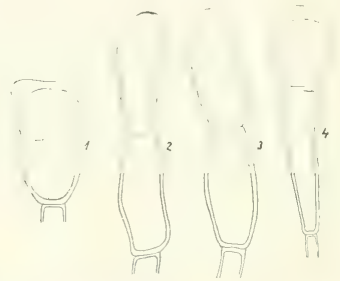

Abb. 21. Teleutosporen von Precinia longissina.

121. Puccinia longissima Schroeter. - E ud op hyllum Sedi (De Candolle) Léveilé. - A e cidium Se di Schroeter.

Spermog on i e n gross, schwarzbraun, kegelförmig, zwischen den Aecidien zerstreut.

A ecidien auf den Blättern des befallenen Triebes entwickelt, mit tief eingesenkten, halbkugelig gewölbten und mit rundlichem Loch geöffneten, randlosen Pseudoperidien; Sporen kuglig bis länglich, gewöhnlich polyedrisch, 22-33 $\mu$ lang $20-31 \mu$ breit, mit farbloser, fein- und dichtwarziger Membran und orangerotem Inhait.

U redolager parallel mit den Nerven blattoberseits, auf rotbraunen oder gelbroten Flecken, seltener auf Blattscheiden, strichförmig, oft der Länge nach zusammenfliessend, bald nackt, staubig, rostbraun; Sporen kuglig, seltener eiförmig bis länglich, $26-40 \mu$ lang, 22-33 $\mu$ breit, mit gelblicher, feinstachliger Membran und orangerotem Inhalt; Stiel bis $66 \mu$ lang, oben aufgeblasen und bis $6.5 \mu$ breit, oft gekrümmt; Keimporen 10 bis mehr.

Teleutosporen lager auf braunen oder rotbraunen Flecken, schwarz, fest, von grauer Epidermis teilweise bedeckt, sonst wie die Uredolager; Sporen sehr verschiedenartig, gewöhnlich lang walzenförmig, länglich oder verlängert keulenförmig, seltener länglich-ellipsoidisch, am Scheitel abgerundet, verjüngt oder 
seltener abgestutzt, daselbst dunkler und bis 11 " diek, 55-12:) " lang, 13-26.5 " breit, obere Zelle ellipsoidisch, lïnglich oder fast zylindrisch, untere langr keulenförmig, länglich oder auch zylindrisch, oft um $1 / 2$ lïnger als die Scheitelzelle: Membran gelbbraun, glatt; Stiel kriftig, bis 22 $\mu$ lang, farblos, fest.

Aecidien von Mitte April bis Mitte Juni auf

Sed um a cre: Lobosch bei Lobositz!

Se d u m bol on i ense: Roztok, St. Prokop, Radotin, Vrané, Loznice bei Trnová! Květná bei Pribram (Domin)! Hledsebe bei Weltrus (Kabat)! Hradisko bei Sadská, Velenka! Schelesen bei Liboch (Kiabát)! Lobosch bei Lobositz, Wopparnertal, Plöschenberg und Kirschberg bei Netluk, Solanerberg bei Trebnitz. - Tábor!

Uredosporen von Mai, Teleutosporen von Juli auf

Koeleria cristata: Tábor!

Koeleria glauca: Kiefernwälder bei Sadská!

Koeleria gracilis: Kuchelbad bei Prag; zwischen Hostin und Liarlstein; Rejkovice bei Lochovic! Kiefernwälder bei Sadská, Hradisko, Velenka! Turnau (Kabát)! Wälder bei Unter-Beřkovic! Lobosch bei Lobositz! Kirschberg bei Netluk!

Der genetische Zusammenhang der Aecidien mit Puccinia wurde von mir durch zahlreiche Infektionsversuche im J. 1902 festgestellt.

\section{$\triangle \triangle$ Teleutosporenstiele kurz.}

122. Puccinia sessilis Schneider. - Puccinia Smilacearum-Digraphidis Klebahn. - A ecidium Convallariae Schumacher.

Spe rmogonien rotbraun, in kleinen Gruppen auf beiden Seiten der Fleckr.

A ecidien auf Blättern oder am Perigon in kleinen unregelmässigen oder rundlichen Gruppen, auf runảlichen oder unregelmässigen Flecken; Pseułoperidien schüsselförmig, mit weissem, umgebogenem, zerschlitztem Rande; Pseudoperidienzellen auf der Aussenseite bis \& $\mu$ dick; Sporen kuglig bis ellipsoidisch, oft polyedrisch, 17-24 $\mu$ lang, $17-22 \mu$ breit, mit feinwarziger Membran.

Uredolager blattbeiderseits zerstreut, klein, rundlich bis länglich, bald uackt, staubig, gelbbraun; Sporen kuglig bis ellipsoidisch, 20-28 $\mu$ lang, $18-24, \mu$ breit, mit hellbrauner, entfernt stachliger Membran und etwa 7 Keimporen.

Teleutosporenlager wie bei den Uredosporen, schwarz, lange bedeckt, manchmal zusammenfliessend; Sporen von verschiedener Form, keulenformig bis länglich, am Scheitel abgestutzt, abgerundet oder verjüngt, zum Stiel mehr oder weniger verschmälert, bei der Querwand deutlich eingeschnürt, $30--45, "$ lanı, 15 - $25 \mu$ breit, mit brauner, glatter, an Scheitel bis $5 \mu$ dicker und dunhlerer Membran; Stiel kurz, fest.

Aecidien im Mai und Juni auf

Couvallaria majalis: Stefansüberfuhr bei Neratovic! Velenka bei Salska: Dymokurer Wälder, besonders bei den Teichen! Nutzhorn bei Roždalovic: Kačina (Peyl)!

Paris quadrifolia: Stefansüberfuhr, Velenka!

I'olygonatum multiflorum: Velenka! Jakobsteich bei Dymoliur! Neu hof bei Kolín, Kačina (Peyl)! 
Smilacina bifolia: Neuhof und Kačina (Peyl)! Harta bei Hohenelbe (Cypers); Tábor! Wittingau (Weidman)!

Uredosporen von Ende Mai, Teleutosporen von Juli auf

Phalaris arundinacea: Stefansüberfubr bei Neratovic! Spojily bei Pardubic (Vodák)! Teiche bei Padrt nächst Rožmital!

Der genetische Zusammenhang zwischen den Aecidien und der Puccinia wurde von Soppitt, Plowright und Klebahn festgestellt.

123. Puceinia Phalaridis Plowright. - L'uccinia A ri-Phalaridis Klebahu.

Spermogonien anf beiden Seiten der Flecke, honiggelb, in kleinen Gruppen

A ecidien blattunterseits auf rundlichen Flecken in dichten Gruppen; P'seudoperidien niedrig, mit umgeborenem, zes'hlitztem Rande; Pseudoperidienzellen auf her Aussenseite bis $8 \mu$ dick; Sporen kuglig-polyedrisch oder eiformig-polyedrisch, 2()$-24 \mu$ lang, 15-2: $\mu$ breit, mit feinwarziger Membran und orangefarbigem Inhalt.

Uredosporen und Teleutosporen wie bei Puccinia sessilis Schneider.

Aecidien im Mai und Juni auf Blättern von

Arum maculatum: Kačina bei Kuttenberg (Peyl)! Belege im Peyl's Herbar in den Sammlungen d. k. k. Realschule in Karolinental.

Uredosporen von Juni, Teleutosporen von dugust auf

Phalaris arundinacea: Aus Böhmen sah ich sie noch nicht.

Der genetische Zusammenhang wurde von Plow right festgestellt.

\section{Puccinia Orchidearum-Phalaridis Klebahn.}

Spermogonien auf beiden Seiten der Flecke in kleinen Gruppen, honiggelb.

Aecidien auf der Unterseite rundlicher, gelber Flecke, ringförmig mler nur gruppitrt; Pseudopertidien niedrig, mit zurückgeschlagenem, grobzerschlitztem Rande; Pseudoperidienzellen in undeutlichen Reihen, aussen bis 10 $\mu$ dick: sporen polyelrisch unil zwar kuglig, 18- 24 $\mu$ im Durchmesser oder thachliuglig und dann bis $28 \mu$ breit, mit dünner, feinwarziger Membran.

Uredo- und Teleutosporen wie bei Puccinia sessilis Schneider. Aecidien im Mai und Juni auf

Listera ovata: Ruine Hrádek bei Auscha (Domin)!

Orchis incaruata: In der Remise zwischen Klomín und Byškovic!

Uredosporen ron Mitte Juni, Teleutosporen von Juli. Aus Bühmen sah ich dieselben noch nirht. (Siehe auch die Bemerkung hei Puccinia Moliniae.)

Der genetische Zusammenhang wurde von Klebahn festgestellt.

\section{Puccinia Cesatii Schroeter.}

Credolager blattbeiderseits, auf braunen Fleckchen, zerstreut oder in kurzen Reihen, länglich bis strichformig, dunkelbraun, staubig; Sporen kuglig. 
$24-31 \mu$ im Durchmesser, mit dicker (5) $\boldsymbol{\mu}$ ), liastanienhranuer, dichtwarzigh Me'm. bran und mit $3-5$ Keimporen; Stiel lang, hyalin.

Teleutosporenlager wie bei Uredosporen, bald nackt, dunkelbraun, fest; Sporen breit ellipsoidisch, beiderseits algerundet, bei der (2n-rwand schwach eingreschnürt, 25-35 $\mu$ lang, 22-28 $\mu$ bıeit, mit kastanienbrauner, an Siheitel stark verdicktor, glatter Membran; Stiel sehr lang, kriftig, hyalin, fest; rinzellige Teleutosporen zahlreich, wenig kleiner als die zwoizelligen.

Uredosporen von Juli, Teleutosporen von August in Uredolagern, später selbständig auf

Andropogon ischaemum: Kuchelbad, Radotfn, hosor! Lysoleje (0piz)! P’oŕlčin, Bühm. Brod! Welwarn (Kabát)! Teplitz (Thümen, Mąrms)! Kamýk im Moldautale (Domin)!

Aecidien bisher unbekannt. Teleutosporen werden ziemlich selten bei uns gebildet.

$\beta$. Teleutosporen buld, seltener erst später nackt.

* Teleutosporen am scheitel mit fingerartigen Auswüchsen.

\section{Puceinia coronata Corda}

Spermogonien blattbeiderseits zwischen len Aecidien, honigrotbraun.

A ecidien in dichten, kleineren oder grösseren Gruppen, auf gelben Flecken blattunterseits, seltener blattbeiderseits, auch auf Blüten und Früchten: Pseudoperidien breit, schüsselförmig, manchmal auch röhrenförmiır, mit schmal zurïckgeschlagenem, feinzerschlitztem Rande; Psendoperidienzellen in urdeutlichen Reihen fest verbunden: Sporen polyedrisch und zwar kuglig bis länglich, 16-24 $\mu$ lang, $14-20 \mu$ breit, ziemlich dickwandig, feinwarzig.

Tredolager klein, orange, meistens blattoberseits und anf Blattscheiden, lïuglich bis kurz strichfömig; Sporen kuglig bis tiförmig, 16-30 $\mu$ lang, $14-24 \mu$ breit, gelblich, mit feinstacheliger Membran nud etwa 10 wenic deutlichen Keim. poren.

Teleutosporenlager hauptsichlich blattunterseits, rundlich oder strichförmig, oft ziemlich lang. quer nicht zusammenfliessend, gewöhnlich schon im Herbst nackit, schwarz, fest; Sporen verschieden gross unl von verschiedeuer Form, gewohnlich keulenförmigr, am Scheitel mit einigen oder mebreren fingerartigen Auswüchsen, zum Stiel verjüngt, in dex Mitte wenig oder gar nicht eingeschnürt, $35-65 \mu$ (manchmal bis $80 \mu$ ) lang, 12-2." " brest mit hellbrauner, an scheitel dunklerer Membran; Stiel liurz, krïftig, fest.

Aecidien von Mitte Mai bis Juli, oft noch im August auf

Frangula alu us: Ueberall sehr verbreitet.

Uredosporen von Juni, Teleutosporen von Juli auf.

Agrostis vulgaris: Kaderavec bei Turnatu (Kabat)! Lnterhalb Waldstrin bei Turnau (Kabát)!

C'a lamagrostis aruu dina (cea: Hoch Veseli (Kabát)! Bilichau (Kabát)! Rachel im Böhmerwalde.

Holcus lanatus: Ueberall auf Wiesen verbreitet. 
Holcus mollis: Rovensko! Turnau (Kabát)! Tábor!

Phalaris arundinacea: Hirschberus (Kabát)! Semin unterhalb Trosky (Kabát)!

Poa pratensis: Rovensko! Teleutosporengruppen nur blattoberseits, alle nackt (18. VIII. 1899).

Triticum rep̣ens: Rothenhaus bei Komotau (Sachs)! Bělá bei Böhm. Aicha!

Ausserdem kommt diese Puccinia (gewiss auch in Böhmen) auf Agrostis stolonifera, Calamagrostis lanceolata. Dactylis glomerata, Festuca silvatica etc vor.

Eriksson und Klebahn unterscheiden folgende Spezialformen, welche schon an bestimmte Nährpflanzen gewöhnt sind und von diesen auf andere überhaupt nicht oder nur sehr schwer übertragbar sind:

f. sp. Calamagrostidis auf Calamagrostis lasceolata.

f. sp. Phalaridis auf Phalaris arudinacea.
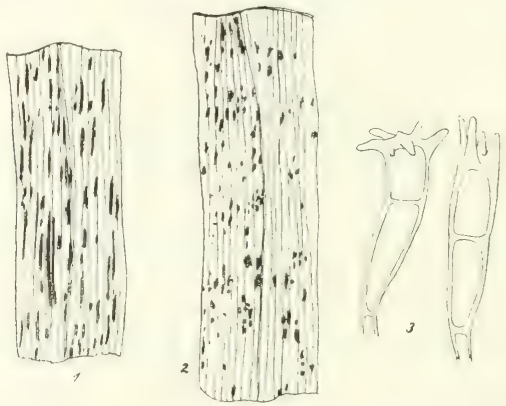

Abb. 22. Puccinia coronata. 1.-2. Teleutosporenlager auf Ilïttern.

3. Teleutosporen (nach Klebahn).

f. sp. Holci auf Holcus lanatus und H. mollis.

f. sp. Agrostidis auf Agrostis vulgaris und Agrostis stolonifera.

f. sp. Agropyri auf 'Triticum repens.

127. Puceinia Lolii Nielsen. - Puccinia coronifera Klebabn. braun.

Spermogonien auf beiden Seiten der Flecke in kleinen Gruppen, honig-

A ecidien in dichten, kleineren oder grösseren Gruppen auf gelhen bis hraunen Blattflecken, seltener auch auf Blüten und Früchten; Pseudoperidien und Sporen wie bei Puccinia coronata.

Uredolager wie bei Puccinia coronata, die Epidermis auf denselben anfangs blasenförmig aufgetrieben. 
Teleutosporenlager wie hei Puccinia coronata, aber breiter und quer zusammentliessend, so dass eine ringtormige oder längliche Gruppe um ein zentrales Uredolager oder um einen gelblichen Fleck herum gehilhtet wird hesonders bei Iolium perenne, Avena sativa, weniger deutlich auf anderen Grïsern, z. F, hei Arrhenatherum). Die Lager bleiben länger bederkt als bei der vorangehenden spezies.

Aecidien von Mitte Mai und im Juni auf

Rhamnus cathartica: sehr verbreitet.

Uredosporen von Mitte Juni, 'T'eleutosporen von Juli auf

Arrhenatherum avenaceum: Wopparnertal bei Milleschau (Kabát)! Avena sativa: Überall sehr verbreitet!

Aven a fatua: Bubenč (Wondrácek)! Duppau (Wiesbaur)! Dobruśkat d lidak ?

Festuca arundinacea: Welwarn (Kabát)!

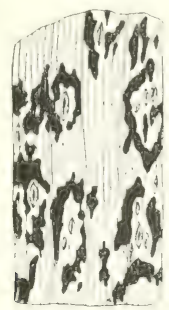

Abb. 23. Teleutosporenlager von Puccinia Lolii um die Uredolager gruppiert. (Nach Klebahn).

Festuca gigantea: Welwarn (Kabát)!

Holcus lanatus: auf Wiesen sehr verbreitet.

Holcus mollis: Rovensko! Turnau (Kabát)!

Lolium perenne: Ueberall sehr verbreitet!

Gramineen vor.

Sie kommt noch auf Alopecurus pratensis, Glyceria aquatica und anderen

Eriksson und Klebahn unterscheiden folgende Spezialformen:

f. sp. A venae auf Avena sativa.

f. sp Lolii auf Lolium perenne.

f. sp. Holci auf Holcus lanatus, H. mollis.

f. sp. Festucae auf Festuca pratensis.

f. sp. Alopecuri auf Alopecurus pratensis.

f. sp. Glyceriae auf Glyceria aquatica

128. Puceinia Erikssonii Bubák nov. nom. - Puceinia Ilelicat Bubak nee Puccinia Melicae (Eriksson) Sydow.

Uredolager klein, ellipsoidisch oder länglich, blattoberseits zwischen den Nerven verteilt, au den Seiten von der Epidermis bedeckt, hellorange. stubin : 
Sporen kuglig oder kuglig viförmig, $13-17.5 \mu$ laug, $13-15.5 \mu$ breit, mit hellgelber, sehr feiustachliger Membran; zwischen den Sporen keulenförmige oder kopfförmige, oben bis $13 \mu$ breite Paraphysen.

Teleutosporenlager blattoberseits, schmal elliptisch bis kurz strichförmig, sehr klein, bald nackt, schwarzbraun; Sporen keulenfurmig oder länglichkeulenförmig, am Scheitel mit fingerartigen Auswüchsen oder nur einfach verjüngt, zum Stiel keilförmig verschmälert, bei der Querwand wenig oder gar nicht eingeschnürt, $30-49 \mu$ lang, hellbraun, obere 7elle $11-155 \mu$, untere $9-13 \mu$ breit, heller; Stiel kurz, fest, bräunlich; einzellige Sporen ziemlich reichlich.

Uredosporen im September, Teleutosporen erst im November auf

Melica nutans: Turnau (Kabát; Uredo 27./9., Teleutosporen 15./11. 1902)! Rovensko (Uredo 4./9. 1896)!

Ich habe diese Puccinia früher mit Puccinia Melicae (Eriksson) Sydow vereinigt. I) a sich aber bei meiner Spezies in den Uredolagern immer Paraphysen befinden, während bei der genannten Eriksson-Sydow'schen Art dieselben gänzlich fehlen, so müssen beide getrennt werden.

Von Puccinia Lolii und Puccinia coronata ist sie hauptsïchlich durch kleinere Sporen beider Generationen verschieden.

\section{Puccinia Festucae Plowright. - Aecidium Periclymeni Schumacher.}

Spermogonien in kleinen Gruppen auf beiden Seiten der Flecke, klein, honiggelb.

A ecidien blattunterseits auf gelben oder braunen, rundlichen Flecken, in rundlichen, oft sehr kleinen Gruppen; Pseudoperidien kurz walzenformig, gelblichweiss, mit kaum zurückpeschlagenem, zerschlitztem Rande; Sporen kuglig bis länglich, oft polyedrisch, 18-28 $\mu$ lang, 17-26 $\mu$ breit, mit gelblicher, ungleichmässig dicker, fein- und dichtwarziger Membran.

Uredola kuglig bis ellipsoidisch, 18-30 $\mu$ lang, 18-21 $\mu$ breit, mit gelber, $1-2 \mu$ dicker, entfernt stachliger Nembran und 6 Keimporen.

Teleutosporenlager hlattoberseits, länglich bis strichformig, anfungs bedeckt, später lïngs gespalten, schwarzbraun; Sporen lang keulenförmig, am Scheitel stark verdickt, mit 4-6 fingerartigen Auswüchsen, seltener einfach verjüngt, zum Stiel gewöhulich keilförmig verschmälert, bei der Querwand schwach eingeschnürt, 35-66 $\mu$ lang, $15-23 "$ "breit, mit hellbıauner, glatter Membran; Stiel kurz, braun, fest, oft verdickt.

Aecidien im Juni auf

Lonicera xylosteum: Wald „Šebin" bei Libochovic (13. VI. 1900)!

Uredosporen von Ende Juni, Teleutosporen von August auf

Festuca duriuscula, ovina, rubra. Bei uns noch nicht gefunden.

*) Teleutosporen oline fingerartige Ausuïchse.

T'eleutosporen glatt.

Teleuiosporenlager fest. 


\section{Puccinia oblongata (Link) Winter.}

Uredolager blattbeiderseits auf braunen, roten oder purpurroten Flecken

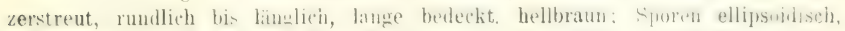
birnfurmig bis keulenfurmig. $24-46 \mu$ lang, $11-20 \mu$ breit, mit starker. whatter, gelblicher Membran.

Teleutosporenlager meistens blattuaterseits verteilt, schwarzbraun, bald nakl, fest, sonst wie die Credolager; Sporen lieulenfirmig oder spindulformin, am sicheitel abgestutzt, abgerundet oller verjünt, zum stiel allmahlirh

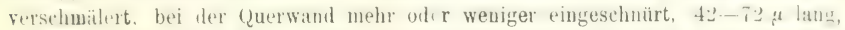
15-24 $\mu$ breit, mit glatter, gelbhrauner, an Scheitel bis 20) $\mu$ dicker und dunlilerer Membran; Stiel krïftig, hyalin so lang oder kürzer wie die Spore, fest.

Uredosporen von Mai, T'eleutosporen von August auf

Luzula vernalis: Tupadol, Ćáslav (Veselský)! Kačina (Peyl)! Bad Wartenbere (liabit)! Rovensko! Harta und Langenau bei Hohenelbe (Cypers)! Herrusliretschen (Wigner); Wald Roudnib bei sedllan (Th. Novik)! Bihm. Kubit/en werselbe)! Spitzberg! Wittingau (Weidman)!

Aecidien bisher unbekannt. Von Puccinia obscura wie durch die Uredosporen als atuh die Teleutosporen sinzlich wrschieden. Die Uredosporen uherwintern oft

\section{Puceinia obseura Schroeter.}

Spermogonien honiggelb, blattbeiderseits zwischen den Accidien locker uruppiert.

Aecidien blattbeiderseits auf gelben oder braunen Flecken ringförmig stehend oder locker uber das Blatt surteilt: Pseudoperilien niendrier, mit weissem.

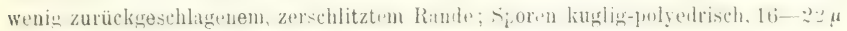
breit, mit feinwarziger Membran und orangerotem Inhalt.

Liedolaner blattbeiderseit-, hauptritchlich aber blattunterseits auf purpur. roten bis yurumschwarzen Flecken, zers:rent, rundich bis läm-lich, langr beleckt, braun, staubig; Sporen kuglig, eiformig, celtener ellipsuidisch, „2) $33 \mu$ langr, 15-24 $\mu$ breit, mit hellbrauner, entfernt stachliger Membran und 2 Keimporen.

Teleutosporenlager blattunterseits, bald uackt, fest, schwarzbraun, sonst wie die Uredolager ; Sporen kenlenformig oder spindelformig, am Selu-itul

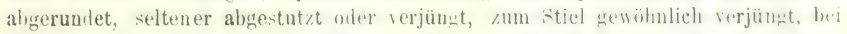
der Querwand mehr oder weniger eingeschnürt, $30-48 \mu$ lang, $14-20 \mu$ breit, mit brauner, glatter, an scheitel bis $9 \mu$ dicker Membran; Stiel welblich oder hyalin, kräftig, etwa so lang wie die spore, fest.

Aecidien im Herbst (September) auf

Bellis perennis: Teplitz (Thümen); Herrnskretschen (Wagner).

Uredosporen vom Herbst bis zum Sommer, Teleutosporen im sinmex und Herbst auf

Luzula campestris: Neratovic! Mühlhasen a. E. (Kabát)! Iloch-Veselí

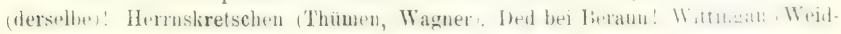
man!! 
Lızula maxima: Im Böhmerwalde zwischen dem Teufelssee und Schwarzen See, zwischen der Seewaud und Osser, Arber, vom Deffernik zum Lakka See, Rachel! - Melzergrund im Riesengebirge (Schroeter).

Luzula pallescens: Ratzkenberg bei Lewin! Turnau (Kabát)!

Luzula vernalis: Kost bei Sobotia; Friedrichstal im Riesengebirge (Kabát)!

Der genetische Zusammenbang wurde vou Plowright festgestellt. Der Pilz erhält sich auch ohne Aecidien, mittelst Uredosporen, die überwiutern.

\section{Puccinia Caricis (Schumacher) Rebentisch.}

Spermogonien honiggelb, zwischen den Aecidien gruppiert oder verteilt.

Aecidien anf Blättern auf rundlichen oder unregelmässigen, verdickten Flecken, auf Blattstielen und Stengeln stark verdiclit und gek ümmte Deformationen bildend; Pseudoperidien becherförmig, dichtstehend am Raude breit zurückgeschlagen und zerschlitzt; Pseudoperidienzellen in Reihen stehend; Sporen kugligpolyedrisch bis eiformig, feinwarzig, $16-24 \mu$ lang, $12-20 \mu$ breit; Inhalt orange.

Uredolager meistens blattbeiderseits, klein, $05 \overline{-1} \mathrm{~mm}$ lang, hellbraun, auf kleinen Flecken oder ohne solche; Sporen kuglig bis eiförmig, $22-31 \mu$ lang, 15-2. $\mu$ breit, oder $20-24 \mu$ im Durchschnitt; Membran hellbraun, entfernt stachlig, mit 3 Keimporen.

Teleutosporeulager blattbeiderseits, rundlich oder etwas länglich (etwa $1 \mathrm{~mm}$ lang), zerstreut oder reihenweise, schwarzbraun, fest; Sporen sehr rerschiedenartig, gewöhnlich keulenförmig, oben abgerundet, abgestutzt oder seitlich vorgezogen, daselbst $5-8 \mu$ dick und dunkler, zum Stiel keilfömig verschmälert, bei der Querwabd eingeschuürt, $35-55 \mu$ lang, $14-24 \mu$ breit, hellbraun, untere Zelle heller, Membran. glatt; Stiel kräftig, gelblich, kürzer als die Spore, fest.

Aecidien im Mai und Juni, manchmal, besonders im Gebirge noch im August auf

Urtica dioica: Sebr verbreitet.

Uredosporen von Juni, Teleutosporen von Juli auf

Carex acuta: Welwarn (Kabát)! Žitovlice bei Roždalovic!

Carex caespitosa: Welwarn (Kabát)!

Carex hirta: Überall sehr verbreitet!

Von Puccinia silvatica unterscheidet sich diese Spezies durch hellere Uredosporen, die mit 3 Keimporen versehen sind, unit durch kürzere Teleutosporen.

\section{Puccinia Pringsheimiana Kleb.}

Spermogonien blattbeiderseits aut den Flecken gruppiert, ziemlich gross honigbraun, auf den Früchten zwischen den Aecidien zerstreut.

A ecidien auf der Unterseite purpurroter oder orangefarbiger Flecke, in fast rundlichen (iruppen, auf den Nerven, Blattstielen, Früchten und jungen Aestchen in verläbgesten Gruplen; Pseudoperidien dichtstehend, niedrig, mit ziemlich stark zurückgeschlagenem, zerschlitztem Rande; Pseuloperidienzellen auf vertikalem Schnitt rhomboidisch, in unregelmässigen Reihen; Sporen kuglig, eiförmig bis 
ellipsoidisch, newöhnlich polyeirisch. 15-22 " lang, $13-14,4$ breit, mit dicht und feinwarziger Membran.

Uredolager hlattunterseits, auf gelben, linglichea Fleclien, hlein, rundlich oder ellipsoidisch, bald nackt, staubiy, hellhraun, manchmal auch der Läuge nach zusammentliessend; Sporen kuglig oder ellipsoidisch, 18-22 $\mu$ lang, $17-21 \mu$ breit, Membran hellbraun, entfernt stachli, mit 3 (seltener 4 ) heimporen.

Teleutosporenlager wie bei den Uredosporen, fest, schwarzbriun; Sporen wie bei Puccinia Caricis, $40-58 \mu \operatorname{lang}, 15-22 \mu$ breit.

Aecidien von Mai bis Juni, seltener noch anfangs Juli auf

Ribes grossularia: Welwarn (Kabát)! Reichenberg (Siegmund)! Clıruilim (Kǐlžek)! Wittingau (Weidman)!

Ausserdem noch auf Ribes rubrum, alpinum, aureum und sanguin eum. Von diesen Nährpflanzen aus Böhmen bisher nicht bekannt.

Uredosporen von Juni, Teleutosporen ron August auf

Carex acuta, stricta, vulgaris, caespitosa. Aus Böhmen sah ich dieselben noch nicht.

Der genetische Zusammenhang wurde von Klebahn festgestellt. Von Puccinia Maguusii Kleb. hauptsächlich durch kürzere Uredosporen verschieden.

\section{Puccinia Magnusii Klebahn.}

Spermogoni en honigbraun, in lockeren Gruppen auf heilen Seiten der Flecke

A ecidien hlattunterseits auf gelben bis roten, rundlichen oder unregelmässigen Flecken in kleinen Gruppen; Pseudoperidien schüsselformig, mit schmal zurückgeschlagenem, fein zerschlitztem Rande; Pseudoperidienzellen in fast regulären Peihen; Sporen kuglig-polyedrisch his eiformig, 17-22 $\mu$ lang, $15-20 \mu$ breit, mit dünner, feinwarziger Membran.

U red ol a ge r hauptsächlich blattunterseits, elliptisch, länglich bis strichförmig, zwischen den Nerven in Reihen stehend, der Länge nach zusammentliessemi, ebenso auch auf den Halmen, rostbraun, an den Seiten von der Epidermis bedeckt, staubig; Sporen meisteus eifurmig und länglich, selteuer kuglig, 228-35 „u lang, $22-28 \mu$ breit, mit $2 \mu$ dicker, hellhrauner, entfernt stachliger Membran, mit 3 (seltener 4) aequatorialen Keimporen.

Teleutosporenlager blattbeiderseits oiler aut den Halmen, rundlich. elliptisch bis strichförmig verlängert, oft zwischen den Nerven reihenweise und dann längs zusammenfliessend, fest, schwarzbraun bis schwarz, an den seiten von der Epidermis bedeckt; Sporen lang keulenförmig bis keulenfömin-linglich, oben abgerundet, abgestutzt oder verjüngt, zum Stiel keilfurmig verschmälert, bei der

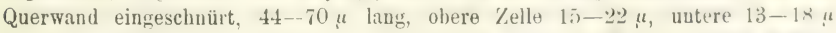
breit, mit gelbbrauner, oben bis $11 \mu$ dicker und dunklerer Membran; Stiel kriattir. bräunlich, halb so lang wie die Spore, fest.

Aecidien im Juni auf Ribes nigrum, alpinum, aureum, sanguineum; aus Böhmen sah ich sie bisher noch nicht.

Uredosporen von Ende Juni, Teleutosporen von Juli auf

Carex riparia: Vršovic bei Prag (Opiz als Puccinia Glyceriae Opiz 1852)! Welwarn (Kabát)! Herrnskretschen (Wagner). 
Der genetische Zusammenhang wurde von Klebahn festgestellt. Nach demselben kommt diese Art auch auf $\mathrm{Carex}$ acutiformis vor.

\section{5̃. Puccinia Ribesii-Pseudocyperi Klebahn.}

Spermogonien blattoberseits in kleinen Gruppen.

A ecidien auf der Unterseite orangefarbiger Flecke; Pseudoperidien schüsselfirmig; Pseudoperidienzellen auf der Aussenseite $3-4 \mu$ dick; Sporen polyedrisch, rundlich bis eiförmig, 19-2* $\mu$ lang, $16-18 \mu$ breit, mit feinwarziger Membran.

Uredolager blattunterseits auf gelben Flecken verteilt, elliptisch, oft in Reihen stehenl, dunkelbraun, staubig: Sporen gewöhnlich ellipsoidisch, $22-33 \mu$ (nach $\mathrm{Kleb}$ a hu bis $37 \mu$ ) lang, $20-24 \mu$ breit, mit dunkelbrauner, stachliger Membran und $3-4$ Keimporen.

Teleutosporenlager wie bei den Uredosporen, gewölbt, schwarzbraun; Sporen keulenförmig, hei ler Querwand wenig eingeschnürt, $40-56 \mu$ lang, obere Zelle 16-22 $\mu$ breit, am Scheitel abgerundet, seltener abgestutzt oder verjüngt, untere Zelle 13-19 $\mu$ breit, in den stiel keilförnig verjüngt; Membran braun, glatt, am Scheitel $7-9 \mu$ dick; Stiel gelblich, bis $25 \mu$ lang, fest.

Aecidien im Juni und Juli auf Ribes nigrum, a ureum, alpinum, s anguineum und Grossularia; aus Böhmen bisher nicht bekannt.

Uredosporen im Juli und August, Teleutosporen von Ende August auf

Carex Pseudocy perus: Kost bei Sobotka (Kabát)!

Der genetische Zusammenbang wurde von Klebahn festgestellt.

\section{Puccinia silvatica Schroeter.}

Spermogonien auf beiden Seiten dex Flecke in kleinen Gruppen, honiggelbbraun.

A ecidien auf der Unterseite gelber, brauner oder purpurroter Flecke in rundlichen, dichten oder lockeren Gruppen, auf den Stengeln oder Scbäften verlïngerte (iruppen bildend; Pseudoperidien schüsselfirmig, niedrig, mit zurückgeschlagtuem, zerschlitztem Rande: Pseudoperidienzell'n in regelmässigen Reihen, aussen bis $s \mu$ dick; Sporen polyedrisch und zwar kuglig bis ellipsoidisch, 15-22 $\mu$ lang, $12-17.5 \mu$ breit, mit dünner, feinwarziger Membran.

Uredolager blattunterseits, klein, elliptisch oder lïnglich, zerstreut, rostbraun; Sporen kuglig, eiformig bis ellipsoidiscb. 22-31 $\iota$ lang, $20-24 \mu$ breit, mit gelbbrauner, feinstachliger Membran und 2 Keimporen.

Teleutesporenlager wie bei den Uredosporen, gewölbt, fest, schwarz; Sporen gewöhnlich keulenförmig, am Scheitel abgestutzt, abgerundet oder selten verjüngt, zum Stiel verschmälert, bei der Querwand mässig eingeschnürt, $35-55 \mu$ lanı, $12-18 \mu$ breit, mit hellbrauner, glatter, am Scheitel bis $11 \mu$ dicker und dunklerer Membran; Stiel krïftig, gelblich, liürzer als die Spore, fest.

Aecidien vou Mai bis zum August auf

Crepis biennis: Unterhalb Voškovrch bei Poděbrad! Žehuněr Teich! Zwischen Sebusein und Tschersing! Jenčic bei Trebnitz! Turnau (Ǩabát)! Kuttenberg (Procházka)! Tábor! Kaplitz (Kirchner)! 
Taraxacum of $\mathrm{icinale:} \mathrm{Verbreitet!}$

Senecio nemorensis: Herrnskretschen (Wagner). I'intovka bei T'ábor!

Senecio Fuehsii: Bei Sedel und Nemschen nächst Jussig! Königswald bei Tetschen (Thümen)! Herruskretschen (Wagner).

Uredosporen von Juni, 'leleutosporen von August auf

Carex brizoides: Bodenbach (Thümen)! Hermskretschen (Vagner). Pintovka hei Tábor (hier zusammen mit Aecidien auf allen ; +rotrn Xilurpultanz-n!

Carex glauca: Welwarn, Bilichau (Kabát)! Rovensko!

Carex leporina: Pelešany bei Turnau (Kabát)! Brada bei Jićfn! Herrnskretschen (Wagner).

Carex pallescens: Velenka bei Sadská! Mühlhausen a. E., Bilichau (Kabát)!

Carex panicea: Welwarn (Kabát)! Rovensko!

Carex pilosa: Pardubic!

Carex rigida: Riesengebirge z. B. zwischen der liesenbaude und Prinz Heiurichsbaude, Abgrunde oherhalb de' Teiche! Koppenplan (Schroeter

Carex Schreberi: Hradisko bei Salská!

Carex silvatica: Aussig, Niedergrund, Herrnskretschen (Wagner).

Der genetische Zusammenhang wurle zuerst von sehroet.r und ditnn ron Klebahn, Wagner, E. Fischer, Bubák und Sydow festgestellt.

137. Puecinia Opizii Bubik - d e cidi um la et ucin um Lilgerheim et Limbroth.

Spermogonien klein, auf der Oberseite der Flecke in kleinen Gruppen oder unterseits zwischen den Aecidien zerstreut.

A e cidien blattunterseits auf rundlichen, $1 / 2-1 \mathrm{~cm}$ breiten, schmutzin rosmroten oder rötlichen, auf Latetnca scariola auch walhen od peridien locker gruppiert, kurz walzenförmic, mit breitem, zurürkgeschlagenem, ziemlich regelmissig zerschlitzten Rande; Pseudoperidienzellen aussen $4-7$ u dirk, in regelmässigen lieihen; Sporen kuglig oder eifurmis, fast immer kuglis, 15\%) his

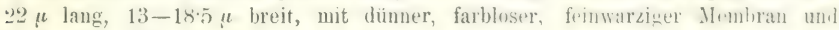
orangerotem Inbalt.

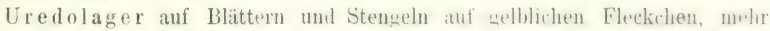
oder weniger zerstreut, klein, ellipsoldisch oder länglich, andanzs bedeckt, spriter längs gespalten und nackt, braun, staubig: Sporeu kuglin. eiformin, ellipsolis h oder lïnglich, $175-33 \mu$ lang, $17 \%$ - 20 breit, mit branner, entfernt stinhlizer Membran und 2 Keimporeu.

Teleutosporenlaner wie bei den Lredolagern, Bläter und Stengel finl

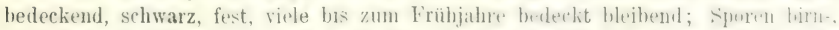

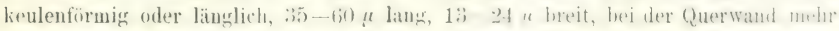

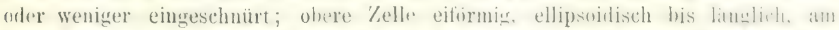

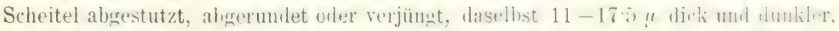
Basalzelle keilformig in den Stiel verschmailert, adhlich. heimpons dor scheited-

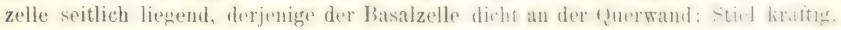
hyalin, so lang wie die Spore, fest. 
Aecidien im Juni und Juli auf

Lactuca muralis: St. Ivan bei Beraun! Unter Berkovic! Jedomelice bei Schlan! Teplitz (Thümen)! Gross Wostray bei Aussigr! Turnau, Bukovina bei Bad Wartenberg (Kabát)!

Lactuca scariola: St. Ivan bei Beraun!

Uredosporen von Juli, Teleutosporen ron August auf

Carex muricata: St. Ivan bei Beraun! Unter-Beřkovic! Jedomělice bei Scblan! Turnau (Kabát)! Chotuc bei Křnec!

Die Afcidien dieser Puccinia sind ron devjenigen der Puccinia Chondrilla durch typisch entwickelte Pseudoperidien verschieden.

Den genetischen Zusammenhang habe ich im J. 1902 festgestellt.

\section{Puccinia caricicola Fuckel.}

Uredolager blattunterseits auf braunen oder gelben Flecken zerstreut oder in kurzen Reihen. klein, rundlich oder strichformis, hellbraun, lange bedeckt; Sporen liuglig, eifrirmig, ellipsoidisch, 26-29 "t lans, 22-26 u breit, hellbraun, stachlig, mit 3 Keimporen.

Teleutosporenlager anfangs in Uredolagern, später selbständig, verlängert, dunkelbraun; Sporen lüuglich bis spiulelfirmig, am scheitel mit breiter. bis 7 " dicker, hellbrauner Papille, nach unten abgerundet oder verjünt, 28-40 " lang, $16-30 \mu$ breit, hellkastanienbraun, untere Zelle heller; Stiel hyalin oder schwach bräunlich, kürzer oder länger als die Spore. Nach Fuckel und Sydow auch einzellige Sporen nicht selten, 23-40 $\mu$ lang, 14-19 « breit.

Uredosporen im August, Teleutosporen zu derselten Zeit mit ihnen vermischt, selbständig erst auf absterbenden Blättern von

C a rex supina: Lešany bei Welwarn (Kabát)! 25. September 1897 Uredosporeu und nur selten zwischen denselben auch Teleutosporen.

139. Puccinia Aecidii Leucanthemi E. Fischer. - Aecidium Leucanthemi De Candolle.

Spermog on ie n blattoberseits auf gelben oder rötlichen, rundlichen Flecken oder blattunterseits zwischen den Aecidien gruppiert, honiggelb.

A ecidien unterseits auf den Flecken iu mehr oder meniger rewelmissicren Kreisen oder unregelmässig gruppiert, manchmal auch, besonders auf den Verven und Stengeln, in verlängerten Gruppen, blattoberseits meistens nur vereinzelt oder in ärmlichen Gruppen. Psendoperidien niedrig und breit, mit breit zurückaeschlagenem, fein und regelmässig zerschlitztem, gelblichem Ramle; Pseudoperidienzellen in vertikalen, fast regelmässigen Reihen, sebr versihiedew, isodiametrisch bis verlängert deltoidisch oder rhomboidisch, bis 5 () $\mu$ lang, $22 \mu$ breit; Sporen immer polyedrisch und zwar meistens kuglig und eifurmig, seltener ellipsoidisch. $15 \%$ bis $22 \mu$ lang, 13-2.) " hreit. mit farbloser, dünner, sehr feinköruiger Membran und orangefarbigem Inhalt.

Uredolager klein, länglich, etwa $0 \cdot 25, \mathbf{2} m m$ laug, fon der Epidermis lanıe bedecht; Sporen kugligr bis eiförmig, 18-21 $\mu$ im Durchmesser, mit farbloser oder 
gelhlicher, von kurzen, knnischen, entfernten Stacholchen besetzter Membran und mit zwei oberhalb des Aequators gelegenen Keimporen.

Teloutosporenlager wie bei den Uredosporen, schwarzhraun; Sporen birnförmig bis keulenförmig, $42-50 \mu$ lang, $18-21$ u breit, am Scheitel oft papillenförmig verjüngt und ungleichseitig, seltener abgerundet, unten in den stiel allmählich verjüngt, bei llor Querwand wenig eingeschnürt; Basalzelle oft länerer und breiter als die Scheitelzelle; Membran braun, glatt, am Scheite $14-17 \mu$ dick; Stiel kürzer oder nur wenig länger als Basalzelle, farblos, fest.

Aecidien im Juni, Uredosporen von Mitte Juni, Teleutosperen von iuli his zum Winter auf

Chrysanthemum Leucanthemum: Bisher nur bei Bilichau (18. $f$. 1899, Kabát)!

Uredo- und Teleutosporen auf $\mathrm{C}$ a rex montana; aus Bohmen sah ich sie noch nicht.

Der genetische Zusammenhang wurde ron F. Fischer bewiesen. Die naichstfolgende Art unterscheidet sich von der vorliegenden durch $1 \mathrm{~mm}$ lange, $1 / 4-1 / 2 \mathrm{~mm}$ breite und stark gewölbte Lager.

\section{Puccinia Caricis montanae E. Wischer.} Flecke.

Spermogonien honiggelb, in kleinen (irupren auf beiden Seiten der

A ecidieu hattunterseits in rundlichen (iruppen auf grelhen. karminrot oder braun umsäumten Flecken; Pseudoperilien nielrig, breit, mit zurücligesthlagenem, unregrelmässig zerschlitztem Rande; Pseuduperidienzellen in regremïsigen Reihen; Sporen kuglig-polyedrisch, 14-18 " im Durchmesser, feinwarzig.

Uredolager blattunterseits, auf gelblichen, verlïgerten Flecken, klein, strichförmig, $1 \mathrm{~mm}$ lang, $1 /{ }_{-1}^{1} \mathrm{~mm}$ breit, stark wewölbt, bald nackt, braun; Spporen kuglig bis ellipsoidisch, 18-25 $\mu$ lang, 18-21 $\mu$ breit, mit brauner, feinund entfernt stachliger Membran und 2 Keimporen.

Teleutosporenlager wie hei den Uredusporen, fest, schwarz; sporen birnförmig, keulenförmig, am Scheitel meistens abgerundet oiler kegelfömig voryezogen, daselbst $10-14 \mu$ dick, unten in den Stiel verjüngt, bei der Querwand schwach eingeschnürt, $36-52 \mu$ lang, $18-24 \mu$ breit, mit brauner, glatter Membran; Stiel so lang wie die Spore, kräftig, hyalin, fest; Keimporus der Scheitelzelle gewöhnlich ein wenig seitwärts verschoben, derjenige der Basalzelle an dter Scheidervand.

Aecidien von Mitte Mai bis Ende Juni auf

Centaurea Jacea: Berg Gross-Wostray bei Aussig!

Uredosporen von Juni, Teleutosporen von Juli auf

Carex montana: Berg Gross-Wostray bei Aussig!

Der genetische Zusammenhang der Aecidien mit Puccinia warde ron E. Fischer festgestellt und später von mir bestättigt. 


\section{Puecinia Sehroeteriana Klebahn.}

Spermogonien loniggelbbraun, in kleinen Gruppen auf beiden Seiten der Flecke.

A ecidien blattunterseits auf ruadlichen, purpurbraunen, trelbumsïumten, $1 \mathrm{~cm}$ breiten Flecken, in rundlichen oder unregelmässigen, dichten Gruppen; Pseudoperidien niedrig, mit umgebogenem, zerscblitztem Rande: Pseudoperidienzellen auf der Aussenseite 6-9 $\mu$ dick; Sporen polyedrisch und zwar kuglig bis eiförmig, $13-20 \mu$ lang, $11-15 \mu$ breit, mit feinwarziger Membran.

Uredolager blattbeiderseits auf gelblichen Flecken, klein, länglich, zerstreut, lange bedeckt, dann nackt, braun, staubig; Sporen kuglig his eiförmig, stachlig, braun, $20-26 \mu$ lang, $15-20 \mu$ breit, mit 2 (uach Klebabn auch 3 ) im oberen $1 / 3$ liegenden Keimporen.

T'eleutos poren la ger hauptsächlich blattoberseits, klein, läglich, schwarz, lange bedeckt, fest; Sporen keilfirmin bis spindelfömig, am siheitel abgestutzt, abgerundet oder verjungt, zum Stiel keilformig verschmälert, bei der Querwand eingesehnürt, 40-55 $\mu$ lang, 18-21 "t breit, mit rellbrauner, glatter, am Scheitel bis $10 \mu$ dicker Membran; Stiel gelblich, so lang wie die Spore, fest.

Aecidien im Mai und Juni auf

Serratula tinctoria: In Bohnicer Walde bei Prag (Opiz 185t)! Wiesen bei Všetat, Liblic und Vavřinec! Drísy bei Všetat (Kabát)!

Uredosporen von Ende Juni, Teleutosporen von Juli auf Carex flava, vulpina. Aus Böhmen sah ich sie noch nicht.

Der genetische Zusammenhang wurde von $\mathrm{Kle}$ b a h $\mathrm{n}$ ermittelt.

\section{Puccinia dioicae Magnus.}

Spermogonien klein, honigbraun, auf beiden Seiten der Flecke in kleinen Gruppen.

A ecidien blattunterseits, seltener auch blattoberseits, auf rundlichen, gelben oder braunen Flecken, in rundlichen oder ringürmigen, $2-5 m m$ breiten Gruppen; Pseudoperidien niedrig, ziemlich breit, weisslich, mit sehmal zurückgeschlagenem und zerschlitztem Rande; Psendoperidienzellen in regelmässigen Reihen; Sporen liuglig-polyedrisch, feinwarzig, 18-25 „4 im Durchmesser, mit orangefarbigem Inhalt.

Uredolager klein, rundlich, liastauienbraun; Sporen kuglig, eiformig bis ellipsoidisch, 18-28 " lang, 20-22 " breit, mit hellbraumer, stachliger Membran und 2 Keimporen.

Teleutosporenlager rundlich oder länglich, etwa so breit wie das Blatt, stark gewolht, hald nackt, fast schwarz, fest; Sporen kenlenformig, am Scheitel abgestutzt oder zugespitzt, oft anch daselbst unregelwässig, zum Stiel keilformig verjüngt, bei der Querwand schwach eingeschnürt, $35-60 \mu$ lang, $14-\vartheta 1 \mu$ breit, mit hellbrauner, glatter, am Scheitel bis $14 \mu$ dicker und dunklerer Membran; Stiel krüftig, gelb, oft so lang wie die Spore, nicht abfällig. 
Aecidien von Mitte Mai auf

Cirsium canum: Wiesen bei Neratovic und Vsetat! Budohostice bei Welwarn (Kabit)! Milleschau im Mittelgebirge! venskio!

Cirsi u m olerace um: Bilichau (Kabát)! Kornhaus bei Schlan! Ro-

(jirsium canum Xolera ceum: Bilichau (Kabát)!

Cirsi um pa lustre: Vśetat! Bilichau (Kabát)!

Uredosporen von Juni, Teleutosporen von Juli auf Rovensko!

Carex Daralliana: Neratovic, Všetat, Velenka! Welwarn (Kabát)!

143. Puccinia paludosa Plowright. - A ecidium Pedicularis Libusth.

S p e r m o g o n i e $n$ loniggelb, in kleinen Gruppen.

A ecidien in rundlichen oder länglichen Gruppen oder auch unregelmässig und dicht gruppiert, auf Blattspreiten. Blattstielen und Stengelu; P'seudoperidien niedrig walzenfurmig, mit weissem, zurüchrebonenem, zerschlitztem Rande;

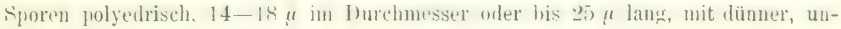
gleichmässig warziger Membran.

Ured ol a g e hauptsiuhlich blattunterseits, auf kleinen, gelblichen Flecken, zerstreut oder stellenweise gruppiert, klein, rundich oder lïuslich, bald nackt, staubig, schwarzbraun; Sproren kuglig oder kurz ellipsoidisch, 20-20 $\mu$ im I)urchmesser oder bis $28 \mu$ lang, mit hellbramer, dicker, entfernt stathliger Membran und drei Keimporen.

Tel e utosporen la ger blattbeiderseits, haupts ächlich aber blattunterseits, kleiu, zerstreut od rer renweise gruphiert, rumblich oder lïnglich, schwarzbraun, hald nackt, fest; Sporen keulenformin, am Scheitel abgerumbet oiler ahigestutz, seltener verjüugt, zum Stiel lieilformiøs verschmillert; untere Zelle gewihnlich

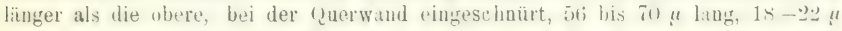
breit, mit qelbbrauner, slatter, an Scheitel bis 11 ॥ dicker und dunklerer Membran; Stiel kräftig, bräunlich, kurz, nicht abfällig.

Aecidien im Mai bis Juli a uf

Pedicularis silvatica: Zinnwald im Erzgebirge (Thümen). Reichen-

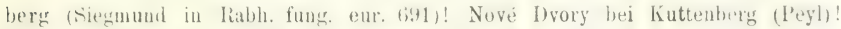
lodenbach (I'eyl in Veselky's "Nachtran ete."). - Aweh l'enek im Herh. d. biohn. Museums, aber ohne Lokalitit.

Uredo- und Teleutosporen von Juli auf

Carex vulgaris; nach Sydow auch auf Carex stricta, fulva, panicea (?). Aus Böhmen sah ich sie noch nicht.

Der genetische Zusammenhang wurde von $\mathrm{Pl}$ o w $\mathrm{right}$ bewiesen.

144. Puceinia uliginosa Juel. - Aecidium Parnassiae Graris.

Spermog on i e n fehlen.

A ecidien blattunterseits auf gelben rundlichen Flecken, in rundichen

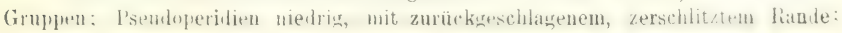


Psembloperidienzellen aussen bis $7 \boldsymbol{\mu}$ dick: Sporen linglig-polyedrisch, $14-18 \mu \mathrm{im}$ Durchmesser, mit feinwarziger Membran.

U red ol ager hlattbeiderseits zerstreut, sehr klein, rundlich oder länglich, grelbbraun, staubig; Sporen kuglig bis eifirmig, 221-25 $\mu$ im Durchmesser, mit brauner, stachliger Membran und 3 Keimporen.

Tele u to s o re n la ger wie bei den Uredolagern, schwarz, fest; Sporen lïnglich oder lïnglich-lieulenfürmig, beiderseits abgerundet oder zum Stiel verjüngt, bei der Querwand schwach eingeschnurt, 30-38 $\mu$ lang, 12-18 $u$ breit, mit kastanienbraun $r$, glatter, am Scheitel bis $8 \mu$ dicker Membran; Stiel farblos, $14-32 \mu$ lang, nicht abfällig.

Aecidien im Juni auf

Parnassia palustris: Bilichau (Kabát)! Zalší bei Vesell a. L.!

Uredosporen von Juli, Teleutosporen von August auf

Carex vu I g ris: Aus Böhmen sah ich sie noch nicht.

Der genetische Zusammenhang wurde von J u el festgestellt.

\section{Puceinia Polygoni Albertini et Schweinitz.}

Spermogonien klein, honiggelb, auf beiden Seiten der Flecke in lockeren Gruppen.

A e c i d i n blattunterseits auf rötlichen bis purpurroten, gelb umsäumten und manchmal zusammentliessenden Fecken gruppiert oder aunähernd kreisförmig gestellt; I'seudoperidien klein, walzenförmig, niedrig, mit zurüchgeschlagenem, fein zerschlitztem Ramde; Pseudoperidienzellen reihenweise stehend, aussen $7-9 \mu$ dick; Sporen kuglig his eiformig, stets polyedrisch, 15-20 $\mu$ lang, 13-18 « breit, feinwarzig.

Uredolager blattunterseits verteilt, seltener blattoberseits, rundlich, bald nackt, machmal zusimmentliessend, braun; sporen ellipsoidisch oder eiförmig, $24-30$ " lang. 15-20 " breit, wit gelbbrauner, entferntstachliger Membrau und 2 Keimporen.

Teleutosporen I g er wie die Uredolager, schwarz, glänzend, bald nirclit, fest, atuf deu Blättern runulich, auf den Stengeln länglich; Sporen ellipsoidisch his keulenfïmig, am Scheitel gewöhnlich abgerundet, weniger abgestutzt oder verjüngt, zum Stiel lieilförmigr rerschmälert, bei der Querwand schwach eingeschnürt, 32-45 " lang, 18-21 " hreit, mit hastanieubrauuer, glatter, am Scheitel stark

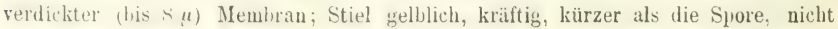
abfällig.

Aecidien im Mai und Juni auf

Geranium pusillum: Dolany bei Libšic! Turnau (Kabát)! und gewiss auch anderwärts.

Uredolager von Ende Juni, Teleutosporenlager von August auf

Polygou m Convolvulus: Ziemlich verbreitet.

Polygonum dum etorum: Krè (Opiz)! und Roztoky bei Prag! Mühlhausen a. L., Welwarn (Kabit)! Reichenberg (Siegmund)! Postelberg!

Der genetische Zusammenhang wurde von $\mathrm{Tr}$ anzschel festgestellt. 
146. Puccinia Polygoni amphibii l'ersoon. - A ecidium sanguinolentum Lindroth.

Spermog on i e n blattbeiderseits in kleinen Grupp en. klein, honigrellorange.

Aecidien auf der. Unterseite von roter bis purpurroter Flerke, wanchma] auch grün umsïumt, oft zusammenfliessend und grössere Blattpartion bederkend; Pseudoperidien in rundlichen oder länglichen Gruppen, oft kreisformig stehend, niedrig, walzenförmig, mit zurückıeschlaøenem, fein zerschlitztem Rande; Pseudoperidienzellen aussen $6-7$ " dick; Spor^n polyedriseh und zwar kuglig, pifürmig his ellipsoidisch, 17-22 $\mu$ lang, $14-20 \mu$ breit, mit feinwarziger Membran.

Uredolager hlattbeiderseits zerstreut oder dichter uruppiert, lilein, rundlich oder elliptisch, bald nackt, zimmtbraun, staubig, ofters zusammentliessend; Sporen kuglis, eiförmig. ellipsoidisch, 25 -28 $\mu$ lang, $18-21 \mu$ breit, mit licker, selbhrauner, entfernt stachliger Membran und 2 Keimporen; Stiel lang, hyalin.

Teleutosporenlager entweder in Uredolagern, und dann nackt; Sporen am Scheitel meistens abgerundet ode! verjüngt; selhständire Lager grewöhnlich blattunterseits, klein, warzenförmig, oft um die Uredolager gruppiert, schwarz, lange bedeckt; Sporen am Scheitel unregelmäissig, öfters abgestutzt; beide Sporenformen ellipsoidisch bis keulenfümigr, zum Stiel verschmälert, bei der Querwand schwach eingeschnürt, 35-52 $\mu$ lang, $16-22 \mu$ breit, mit kastanienbrauner, glatter, am Scheitel bis $8 \mu$ dick; Stiel hyalin, gelblich, fest.

Aecidien im Mai und Juni auf

Geranium pratense: Welwarn, Vysoké Veselí, Dolánky bei Turnau (Kabát)! Jakuber und Komárover Teich bei Dymokur!

Ausserdem wurde von Tranzschel, welcher den genetischen Zusammenhang festgestellt hat, bewiesen, dass die Aecidien ausserdem noch auf Geranium p a lustre vorkommen. Ich erzielte bei meinen Infektionsversuchen Aecidien auch auf Geranium silvaticum.

Uredosporen von Juni, Teleutosporen von Ende Juni auf

Polygonum amphibium: Sehr verbreitet.

\section{Puccinia Rumicis scutati (De Candolle) Winter.}

Uredolager blattbeiderseits, oft auf braunen oder roten Flecken, zerstreut oder mauchmal ringförmig, klein, rundlich, bald nackt, staubig, rotbraun; Sporen viförmig bis ellipsoidisch nder anch länglich, 26-38 $\mu$ lavg, $20-26 \mu$ breit, mit hellbrauner, entfernt stachliger Membran, mit 2-3 Keimporen.

Teleutosporenlager blattheiderseits, auf Blattstielen und Stengeln, lïnglich bis strichförmig, hald nackt, schwarz, fest, gewölbt; sporen ellipsoidiseh bis länglich, am Scheitel abgerundet, zum Stiel verschmälert, bei der Querwand

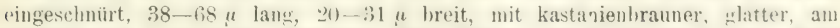
Scheitel bis $11 \mu$ diclier Membran; Stiel kräftim, braun, bis $60 \mu$ lang, nicht abfällig.

Uredosporen im Juli, Teleutosporen von August auf

Rumex s cut at u s: Adersbach (Domin)!

Der Entwicklungsgang unvollkommen bekannt. 


\section{Teleutosporenlager staubig.}

\section{Puccinia argentata (Schultz) Winter.}

Spermogon ien kein, $110(1-180$ " hreit, honiggelb, zwischen den Accidien blattunterseits zerstreut.

A ecidien blattunterseits, auf Blattstielen und Stengeln auf gelben, verdickten liecken in lileineren tiruppen rerteilt oder dieselben ganz bedeckend; l'seudoperidien weiss, anfaugs halbkugelig gewïlbt, endlich hreit zurückgeschlagen und zersthlitzt. ${ }^{1},{ }_{1}^{1 / 2} \mathrm{~mm}$ im 1)urchmesser: Pseudoperidienzellen fast in regulïren Reihen; Sporen polyedrisch-kuglig oder eifurmig, 175---22 u laug. 13-20 breit, mit hyaliner, feinwarziger Membrau und orangefarbigem Inhalt.

Uredolage r blattunterseits, klein, bald nackt, ockergelb oder hellbraun, staubig: Sporen kuglig oder eiturmig, 175-245 $\mu$ lang, 15-20 $\mu$ breit, mit gelblicher oder lräunlicher. entfernt stachliger Nembran und $4-7$ (gewröhnlich 6) Keimporen.

Teleutosporenlager auf der Unterseite gelblicher oder bräunlicher Flecke zerstreut, oft in halhen oder vollkommenen hireisen stehend, bald nackt, manchmal zusammentliessend, dunkelbraun, staubiy; Sporen eiförmig, ellipsoidisch his linglicl, $24-37 \mu$ lang. $13-22 \mu$ breit, beiderseits abgerundet oder verjüngt hei ter Querwand wenin vier war nicht eingeschü̈rt, nit hellkastanienbrauner, glatter, am Scheitel und am Keimporus der Basalzelle mit kegelformiger oder halbliugeliger Papille: stiel zart, farblos, leicht abreissend, so lang oder kürzer wie die Spore.

Aecidien von Mitte April bis Ende Mai auf

A doxa moschatellina: Trnová bei Davle (Th. Novák)! und im ersten Quertale nirdlich you Leznice! Weltrus (Kabat)! Wopparnertal! Teplitz (Thümen). Herrnskretsehen (Wagner). IDittersbach bei Böhmisch Kamnitz (derselbe). Gross Skal! Harta hei Hohenelbe (Cypers). P'intoska und l'ŕlhénice bei Tábor! Duppau bei Karlsbad (Wiesbaur)!

Uredolager von Mai, Teleutosporealager wenig später auf

Impatiens noli tangere: Prag (Masner)! Michle (Opiz)! Lobkovice (Th. Norikı: Weltrus (C'orda, Kabait)! Sidonka bei Ylèlnik! Neuberg hei Junghunzlau (Tieich)! Tupatel bei ('islar (Teselsky̧)! (ilatzer Schneeherg (Schroeter). Oher Mohrau bei Grulich! Gross Slial! Třti hei Böhm. Aicha! Böhm. Leipa (Warnж). Lireuzberg hei Leitmeritz (Ingmus)! Teplitz (Thümen). Peruc! Rothenhaus bei Komotau (Tiuth)! Scblackenwerth IReuss)! P'intovka und Pŕfběnice bei Tábor! Böhmerwald: am Wege von Deffernik zum Lakka-See!

ber genetische Zusaumenhang der decidien mit Puccinia wurde ron mir im J. 1903 und 1904 festgestellt.

1.4:. Puccinia Bisturtae (Strauss) De Candolle. - Puccinia Cari-Bistortae Klebahn. - Puccinia Angelicae-Bistortae Klebahn.

Spermogonien honigbraun, auf beiden Seiten der Flecke gruppiert.

A ecidien auf verdicliten Blattflecken oder Blattstielen, intensiv gelb bis orange, tief im diewehe eingesenkt, oft überhaupt nicbt hervorragend, kuglig oder 
abmeflacht, manchmal sohüssolformige; I'semduperidienzellen in mul-utlichen Reihrn: Sporen kuglig-polyedrisch, 15-20 $\mu$ im 1)urchmesser, feinwarzig.

Uredolager blattunterseits, rundlich, ockerbraun, ball nackit; Sporen kuglig bis ellipsoidisch, feinstachlig, hellgelb, 20-25 $\mu$ lang, $18-20 \mu$ breit.

Teleutosporenlager blattunterseits, rundlich, zerstrent oder in ringfor-

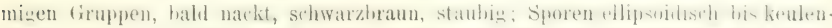

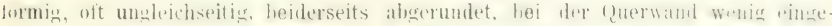

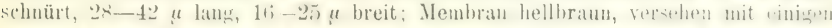

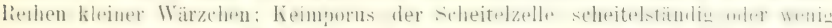

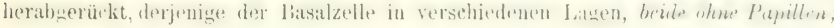
Stiel kurz, farblos, leicht abfällig.

Aecidien im Mai auf

C arum carvi und Angelica silvestris; aus Böhmen sah ich sie noch nicht.

Uredo- und Teleutosporen von Juni auf

Polygonum Bistorta: im l'ale wie auch im Gebirge sehr verbreitet.

Der genetische Zusammenhang wurde von Klebahn und E. Fischer festgestellt. Von Puccinia mammillata Schroeter unterscheidet sich die vorliegende Art dadurch, dass sie auf den Keimporen keine Papillen besitzt.

150. Puccinia Mei-mammillata simalent

Lecidium II ei Sehrueter -

Aecidium Mei mutellinae Winter.

Spermogonien zwischen den Aecidien, honiggelb.

A e idien auf Blättchen, Blattstielen und Stengeln, kltine oder grössere schwielig verdickte. Stellen bildend, dicht gruppiert, hecherformis, randos; sporen

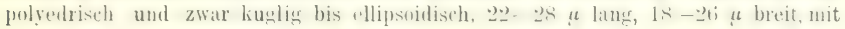
dünner, fein- und dichtwarziger Membran.

Uredolager blattunterseits zerstrent oder stellenweise gruppiert, klein, rundlich, bald natelit, rosthraun, staubig; sporen kughig, eiformig bis allipsoitisch, $21-26 \mu$ lang, 19 -g2 $\mu$ breit; Membran $35 \mu$ dick, walbbram, entfernt stahlin (Distanz $1 \cdot 7-2 \cdot 5 \mu$ ), mit 4 Keimporen.

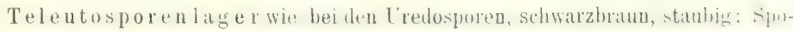

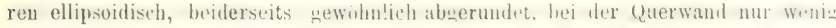

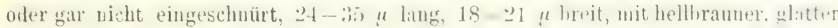
Membran oder nur mit vereinzelten, manchmal reihenweise stehemben Ifarzchen versehen; Stiel kurz, hyalin, abfiblin; Koimporus der sideitelasle scheitalstindiz

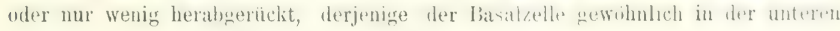
Zellenhälfte, beide mit hoher, hyaliner Papille.

Aecidien im Juli und August auf

Meum mutellina: Glatzer Schneeberg (Schroeter).

Uredo- und Teleutosporen von August auf

Polygonum Bistorta: Glatzer Schneeberg (Schroeter, Bubik, Jacky)!

Der genetische Zusammenhang wurde zuerst von mix vermutet (1900), im J. 1904 dann von Semade a i bewiesen. 
151. Puccinia Angelicae-mammillata kilebhn - A ecidium Bubáki a Juel.

Spermogonien in kleinen Gruppen zwischen den Aecidien oder auch blattoberseits, hellgelb.

A ecidien blattunterseits auf gelblichen Flecken oder auf den Verven, Blattstielen und Stengeln, in kleineren oder grisseren, dichten fruppen; P'seudoneridien schüsselfurmig, mit zurückgeschlagenem, zersthlitztem Rande; Pssudoperidienzellen nicht reihenformig gestellt; Sporen kuglir-polyolirisch, 17-24 4 im Durchmesser, fein und dichtwarzig.

Uredolager wie bei der vorangehenden Art; Sporen liuglig, eiförmig bis ellipsoidisch, 20 :6 $\mu$ lang, 19-24 $\mu$ breit, mit $25 \mu$ dicker, stachliger Membran (Stachelentfernung $2 \cdot 5-3 \cdot 5 \mu$ ), hellbraun, mit 4 Keimporen.

Teleutos porenlager wie bei der vorangehenden Art; Sporen gewöhnlich unregelmissig linglich, seltener ellipsoidisch, heitlerseits abgerundet, bei der Querwand nicht orler nur wenig eingeschnürt, heiderseits ahgerundet, 24-4: " langs: 17-21 $\mu$ hrit; Membran bran, hesetzt mit wenigen, reihenformi stehenden Wärchen: Stiel kurz, hyalin, abfälig; heimporus der Basalzelle dicht beim Stiel, beide mit hoher, farbloser Papille.

Aecidien Ende Mai und anfangs Juni auf

Angelica silvestris: Habstein (Kabait)! Bora bei Rovensko!

Uredosporen von Juni, Teleutosporen von Juli auf Polygonum Bistorta: Habstein (Kabit)! Bora hei Rovensko! Slana und Bořkov bei Semil! Vysoké Veseli (Kabát)! Harta bei Hohenelhe ((ypers)! Wekelsdorf! Teleci bei Policka (Th. Novák)! Dobruška (Vodák)! Rothenhaus bei Komotau (Roth)!

Der genetische Zusammenhang wurde von K lebahn festgestellt, uachdem ich schon vorher denselben vermutungsweise angedeutet habe.

\section{Teleutosporen warzig.}

152. Puccinia Acetosae (Schumacher) Köruicke. - Uredo Acetosae Schumacher. - Puccinia Rumicis Lasch.

Iredolager klein, rundlich, über die ganze Blattspreite verteilt oderzerstrent, auf kleinen, purpurroten Flecken hattbeiderseits, sehr oft korrespondierend, bald nackt, kastamenbraun, staubig. Sporen kuglig, eiförmig oder birntörmig, ?0) bis 31 " lang, 2:-2) 4 breit, braun, entfernt stachlig, mit 2 Keimporen in der oberen Sporenhälfte.

Teleutosporeulager wie bei den Crelosporen aber schwarbraun; Sporen ellipsoidisch, länglich his rerlängert keulenformig, $265-46 \mu$ lang $22-26 \%$ breit, in der Mitte schwach eingeschnüt. kastanienbraun, mit dickwandiger, deutlich warziger Memhran: ohere Zelle abgerundet, am Scheitel wenig rexdickt, untere abverundet oder lieilformig rerschmälert: Stiel hvalin. $11 \mu$ lang, leicht abfaillig.

Credosporen fast das ganze Jahr hindurch, Teleutosporen in niederen Lagren ziemlich selten und arst im Oktober. im Gubirge schon im Juli (Rumex arifolius) auf 
Rumex Acetosa: Sehr verbreitet im Uredostadium; Teleutosporen

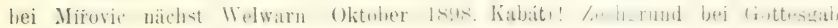
(Wagner).

Rumex Acetosella: Welwarn (nur Uredo, Kabát)!

Rumex arifolius: Hüufig im liesengebirge, so z. I). bei Neuwelt, Elbe-

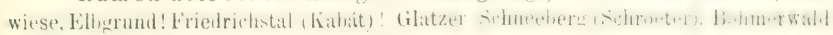
am Wege von Deffernik zum Lakka-See!
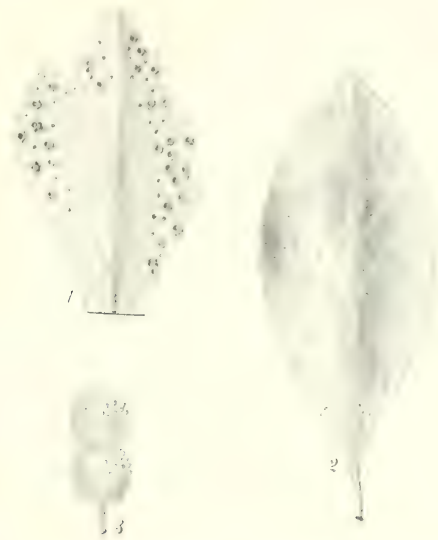

Abb. 24. P'uccinia Pruni spinosae. 1. Aecidien auf Anemone ranunculoides. - פ. Uredo und Teleutosporenleger auf Blattera tor Prunus domestica. - 3. Eine vergrösserte Teleutospore.

\section{Teleutosporen stachlig.}

153. Puceinia Pruni spinosae Persoon. - A e cidium punctat um Persoon.

Spermogonien blattbeiderseits zerstreut, hraun bis schwarzbraun.

A ecidien über die ganze Blattunterseite verteilr, ziemlich entfernt stehend,

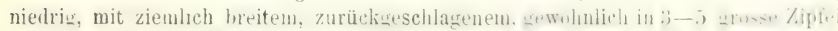

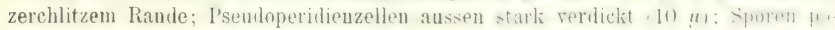
lyedrisch und zwar kuglig bis eiförmig, 16-24 $\mu$ lang, 15.5-17.5 $\mu$ breit, gelbbraun, mit dicht- und feiuwarziger Jembran, an der Iiasalseite bi- 4 , " dick.

Uredolager blattunterseits zerstreut oder dicht gruppiert und dann zu-

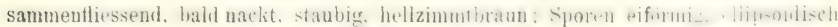

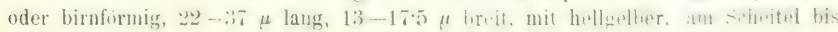


6.5 $\mu$ dicker Membran und உ2 1? Keimporen; zwischen den Sporen zahlreiche kopf förmige, $12-14 \mu$ breite, dickwaudige Paraphysen.

Teleut os p oren lager wie bei den Uredolagern, oft die ganze I3lattunterseite herleckend, schwarzhraun. staubig, manchmal krustenfömig zusammentliesseurl: Sporen beiderseits abgerumlet, bei der lguerwand stark eingeschnürt, 28-4t laus, 17 --26 u breit, heide Zellen gew ihnlich kuglig abgetlacht oder seltener die Basalzelle lieilformir: Membran kastauienhritun, mit niedrigen Stacheln besetzt: Stiel zart, farblos, abfällig.

Aecidien Ende April und im Mai auf

Anemone ranunculoides: Šárka (Kratzmann)! Selc! St. Prokop, Kuchelbad, Radotin. Karlsteiu, St. Ivau! Ouval (Th. Norák)! Velenka bei Sadski, Toskorrch hei Pudélraul, Chotuc hei Kirinec, Iymokur! Kolin (Veselský)! Rorensho! Wopparnertal bei Lobositz, Hoblik und Milayer hei Laun! Brüx (Stika)! Borschen bei Bilin, Mariaschein (Wiesbaur)! und gewiss auch anderwärts.

Uredosporen von Juli, Teteutosporen ron August auf

Prunus armeniaca: Vysoké Veselí (Kabát)!

Prunus domestica: Kire (Corda)! St. Prokop : Kalmus)! Welwarn (Kabsit)! Kolin (Vesefslif)! Kačna (P'eyl)! Pardubie (Vodáli)! Rovensko! Turnau (Kabát)! Harta bei Hohenelhe (Cypers)! Hirschberg. Dittersbath hei Buhm. Leipa, Aussig, (Wagoer); Bodenbach (Thümen): Herenshretschen + Wagner); Woplarsertal hei Lobositz (Kabät)! Lomnitz a. L. (Weidman)! Krumau (Jungbauer)!

Prunus insititia: Mühlhausen a. E. (Kabát)!

Prunus spinosa Vichle (Opiz)! Kuchellad! Jühlhausen, Tysoké Vesulf (Kabát)! Kolín (Veselský)! Sandau (Cypers)!

Der genetische Zusammenhang wurde im J. 1904 von Tranzschel festgestellt.

II. Pucciniopsis. Vur ipermo:nnien. Aecidien und Tetentosporen entwickelt.

\section{Puccinia Passerinii schroeter.}

Spermogonien honigbraun, blattbeiderseits zerstreut.

A ecidien blattbeiderseits gleichmaissig verteilt, auch auf Stengeln und Deckhlättern, seltene' auf Blüten; P'sedoperidien manchmal ziemlich lang walzenfirmig. mit weissem, mässig zurückzeschlagenem, zerschlitztem Rande: Sporen po-

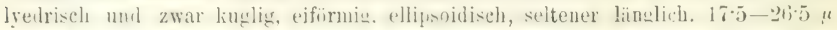
lang, 1:3-231 $u$ breit, mit sehr feinwarziger Membran und orangerotem Inhalt.

Teleutosporenlager auf stengeln, Blättern und Deckblättern verteilt, rundlich his linglich, rou grauer, spiter läng gespaltener Epidermis hedeckt. schwarzbraun, staubie; Sporen gewihnlich ellipsoidisch, heiderseits ahgerundet, bei

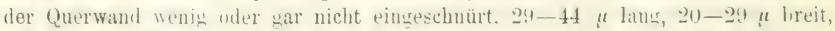
mit kastauienbramer. dicker, warziger, am Scheitel wenig verdickter Membran: Stiel zart, manchmal bis 4" "lang, abfitlig; heimporus der Pasalzelle in der Ilitte oder bald nach when, bald nach unten verschohen. Zwischen den Teleuto. 


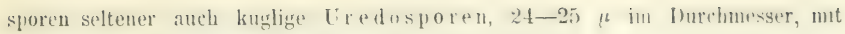
hellgelbbrauner, warziger Membran und 5 Keimporen.

Aecidien im Mai und Juni, Teleutosporen von Juni auf

Thesium ebractoatum: Lřizy hei l'šetat (Kahat)! Velenka bei Sadska!

Das Aecidiummycel durchiringt die ganze Nährptlanze und ïberwintert in Rhizom.

\section{Puccinia Tragopagi (Persoon) Corda.}

Spermogoni on houggrelh, hlattoberseits und an den Stengeln rerteilt.

A ecidien auf der ganzen Blattunterseite oder auf Stengeln; P'sendoperidien gleichmässig verteilt, anfangs pustelformig, dann schüsselförmig. mit weisserm. zurïkgeschlarenem, zerschlitztem Rande; Pseudoperidienzellen aussen stark verdickt; sporen polyedrisch und zwar kuglig bis ellipsoidisch, 20-30 "/ lang, 16 his 24 "t hreit, mit farbloser, dichtwarziger Membran und orangerotem Inhalt.

Teloutosporenlaner klein, rundlich bis lïnglich, blattheiderseits oiler auch auf Stengeln zerstreut, gruppenweise oder fast gleichmïssig verteilt, hald naclit schwarcbraun, staubig; Sporen pllipsoidisch, $26-48$ " laus, 20-35 "3 hreit, heiderseits ahgerundet, hei der Querwand manchmal schwach eingeschnürt, wit kastanienbrauner, warziger Ifembran; Stiel kurz, farblos, abfällig; Keimporus der Scheitelzelle seitlich liegend, derjenige der Basalzelle um $1 / 3^{1 /}$ : herabgerückt, manch. mal mit niediger Papille. Zwischen den Telentosporen manchmal Uredosporen, : 4 bis $30 \mu$ lang, braun.

Aecidien von Mai bis September, Teleutosporen schon Ende Mai auf

Tragopogon pratense ziemlich verbreitet.

Das Aecidiummycel durchiringt die ganze Nahrphtanze und vom Frühjahre his zum Herbst durchzieht es alle neu sich bildende Blätter; die befallenen Pflauzen sind verschiedenartig deformiert, besonders die Inlïtter sind gelblich.

\section{Puccinia Falcariae (Persoon) Fuckel.}

Spermogonien blattheiderseits, hituptsiichlich blattoherseits froichmässign verteilt, konisch hervorragend, houiggelb; Spermatien kuglig-eiformig bis länglich, $3-9 \mu$ lang, $25-3.5 \mu$ breit, gelbbraun.

A eci i i en blattunterseits gleichmässig verteilt; Pseudoperitien weisslich, mit zurückgeschlagenem, tief zerschlitztem Rande: Sporen polyedrisch und zwar kuglig bis länglich, 21-25 " laur, 14-18 " breit, mit düaner, fuin- und dichtwarziger Membran.

Tele utosp oren I a e r hlattbeiderseits zerstreut, rundlich oder limglich, ron geborstener Epidermis teilweise bedeckt, schwarzhraun, staubin; Sporen eifurmis, ellipsoidisch bis lïnglich, beiderseits gewöhulirh ahgerundut, hei der Onur-

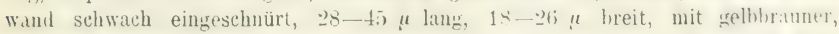
glatter Jembran; Stiel liurz, zart, liyalin, abfillig; Keimporus der liasalıelle heim Stiel oder wenig höher, beide mit kleiner Papille.

Spermogonien von April, Aecidien von Mai, Teleutosporen von Juni auf

Falcaria Rivini: Fast überall, wo die Nährptlanze vorkommt, beson- 
ders die Afrilien selur hututg: die Teleutospuren in geringerer Menge aurgebildet.

Ins Aeviliummycel izberwintert im Rhizom und dringt im Frihjahre in alle Blätter, die dadurch länger, schmäler und bleich werden, ein.

157. Puccinia ambigua (Albertini et Schweinitz) Lagerheim.

Spermogonien auf der Unterseite der Fleeke zwischen den Aecidien zerstreut oder gruppiert, gelb.

Aecidien auf der Cnterseite gelber Flerke zerstreut oder auch vereinzelt mler übte da: ganze Blatt zerstrent, gelhlichweiss, mit zorückgesehlagenem. irohzerschlitztem Ramble; sporen huglig oder polyedrisch, $13-25 \mu$ im 1)urchmesser, mit farbloser, warziger Membran und orangerotem Inhalt.

Teleutasporenlager auf Blattem oler Stengeln, kleiu, rundlich oder lïnglich. manhmal, lesmmlers anf den stengeln zusammentliessenul, ron grauer Epidermis lange beltecht. danu nackt, schwarz, fest; Sporen ron verschiedener Art, ellipsuilisch. lämslich oder lieilfurmis, an Siheitel abgerundet oder oft seitlich vorsezogen. daselhst $5-11$ u dick und dunkler. in ler Mitte weniu eingeschnürt,

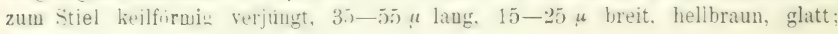
Stiel schwach bräunlich, bis $50 \mu$ lang, fest.

Aecidien im Juni, von Juli dann mit den Teleutosporen zugleich aus demselben Mycel auf

Galium Aparine: Stepanos hei Bilin: Herruskretschen (Wagner), Nove Drory bei Kuttenberg (Veselský)! Radič bei Selčan (Th. Novák)!

Aecidien können wieder Aecidien reproduzieren.

III. Bracligpuccinia. Sur spermogonien. Uredo- und Teleutosporen.

a) Teleutosporen glatt.

\section{5s. Puccinia Čelakovskýana Bubák.}

Spermogonien blattbeiderseits in kleinen Gruppen, honigbraun.

Credosporen: Primäre Lay, r hlattunterseits auf gelben Flecken, ziemlich uross, ringförmig rruppiert, lang, belectit, spitter nackt. of zusammentliessend, dunkelbraun ; solumbire laypr zerstrent. bahl nuckt, haun. staubig; heilerlei Sporen kuglig bis eiförmig, 24-33 $\mu$ lang, 19-25 $u$ breit, oder 20-27 $\mu$ im Durchmesser, mit brauner, stachliger Membran und 2-3 Keimporen.

Teleutosporenlager blattunterseits und auf Stengeln, rundlich bis linglich, bull nackt, schwarz, fert: sporen von versehiedener Form, eiförmig. elli-

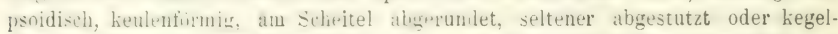
förmig vorgezuen. diselbst stark (5-11 $\mu$, verdiclit und donkler, zum Stiel verjüngt, hei dr. (1)erwand wenig oder gar nicht ringeschnürt, 42-66 $\mu$ lang, $18-26 u$ breit. mit leellkastanienhramer. glatter Membran: Stiel kräftig. hyaliu, bis $44 u$ lang, nicht abfällig.

Primäre [redu rou Mitt* Mai, sehundire vou Juni, Teleutosporen von August auf

Galium ('r u ciata: Prag (Opi $\angle$, Kalmus)! Cibullia. Cernosice, Roblinertal, 


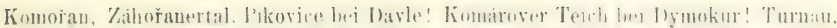
Kost bei Sobotka, Wopparnertal bei Millesehatu (Kabat)! Losehitz hei bilin! Orhk (Domin)!

Die vorliegende Brachypuccinia wurde früher mit Puccinia punctata vereinigt; erst im J. 1898 trennte ich sie von derselben ab.

\section{Puccinia Angelicae (Schumacher) Fuckel.}

Spermogonien zerstreut, gelblich, klein, tief eingesenkt.

Uredosporen: Primäre Lager intensiv gelb, auf Blattstielen und Nerven oder in bleinen Gruppen blattunterseits anf gelhen Flecken, später dunkler, endich dunkelbraun; sekwndëre Layer zerstreut, klein, rundlich, blattheiderseits oder nur blattunterseits. auf kleinen gelblichen lilecken. Sporen aiformig his ellijsondisch, manchmal auch keulenformig, 25-41) 4 lang, 22-2-28 $\mu$ hreit, mit hellhratuner, stachliger, am Scheitel dickerer $(5-10 \mu)$ Membran und 3 Keimporen.

Teleutosporen: Primïre Lager zwischen den Uredolagern, dieselben bald

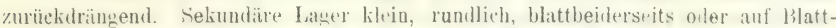
stielen und Steugeln, bahd nackt, schwarz, fest. Sporen ellipsoidisch orler schmal lieulenförmior, manchmal unregelmässig, :3()-45 $\mu$ lang, $15-25 \mu$ breit, oben abgerundet oder wenig verjüngt, zum Stiel gewöhlich verschmälert, lei der duerwand mehr oder weniger eingeschuït, mit brauner, glatter Membratu, an ficheitel war nicht oder nur wenig verdickt, mit kleiner Papille oder ohne derselben; Keimporus der oberen Zelle terminal, derjenige der Basalzelie zu ${ }_{3}{ }^{3} / 4$ herabgerückt; Stiel kurz, farblos, abfällig.

Von Juni bis zum Winter auf Angelica silvestris: Habstein (Kabát, primäre Uredo 8./VI., sekundäre und Teleutosporen 8./VII.)!

\section{Puccinia bullata (Persoon) Winter em.}

Spermog onien in kleinen Gmppen auf Blattzipfeln. Terven oder Blattstielen zerstreut, gelblich.

Ured osporen: Primäre Lager länglich, dunkelbraun, bald von Teleutosporen durchsetzt, auf Nerven oder Blatstitlen, die befallenen Partien verschiedenartig deformierend, in kurze orler auch einige $\mathrm{cm}$ lange Gruppen zusammentlessemal, bald nackt, staubig; sekundäre Lager klein, rundlich, blattunterseits oder hattbeilerseits zerstreut, bran oder dunkelbraun; sporen eiformigr, ellip oidisch wler

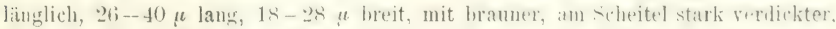
entferntstachliger Membran und $3(-4)$ Keimporen.

T'eleutosporenlager schwarzbraun bis schwarz, auf Blätern rundlich, auf Iilat-tielen und Stengeln verlingert und zusammentliessend, mlintisih his linglich, am Scheitel abgerundet, an der basis abzerundet oder verjüngt. bej der

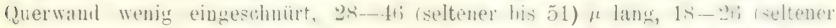
32) |" breit, mit kastanienbrauner, gleichmissig dicker, ulatter, an den liompren papillenformig verdickter Membran: Keimporus dier Basalzelle in der muteren ${ }^{1}$. bis $1 / 3$, manchmal bis beim Stiel; ilerselbe kurz, zart. hyalin, leicht abratlin. 
Primäre Tredo im Mai, sekundite Ende Juni, Teleutosporen zuerst in Ureilolagern, selbständig im August auf

Peucedanum palustre: Habstein. Thammüble bei Hirshberg (Kabuit)!

Seseli hippomarathrum: Radotín! Radobýl bei Leitmeritz!

Sil a us pratensis: Am Fusse des Berges "Hora" bei Merzkles!

Primäre Uredo verursacht Verdickungen und verschiedene Krümmungen der befallenen Partien.

\section{Puccinia Petroselini (De Candolle) Lindroth.}

Spermogonien blattunterseits in kleinen Gruypen zwischen den primären Uredolagern, gelbbraun.

Uredosporen: Primäre Lager klein, rundlich, zimmtbraun, staubig, hauptsitchlich blattunterseits in ringformigen Gruppen oder zerstreut; sekundüre Lager wie die primaren. blattunterseits zerstreut; beile später von Telentosproren, die sich in ihren Lagern ausbilden, dunkel gefärht; Sporen kuglig, eifurmig bis ellipsoidisch, 22-29 " lang, 21-25 "l breit, nit gelbbrauner, stachliger, manchmal ron der Mitte atus glatter, am Scheitel bis i $\mu$ dicker Membrau; Keimporen 3 (seltener 2), mit hyalinen, ziemlich kräftigen Kappen versehen.

Teleutosporenlager wie bei sekundären Uredolagern. braun bis schwarzbreun, auf lilattstivlen und steugeln verlingert, zusammenfliessend, staubig; Sporen eiformig, ellipsoidisch his lïnglich, oft unregelmässig, beiderseits abgerundet oder zum Stiel verjüngt, hei der Querwand wenig eingeschnürt; $28-49 \mu$ lang, $18-25 \mu$ breit, mit briuner, slatter Membran; Stiel kurz, hyaliu, abfälig; Keimporus der Scheitelzelle scheitelstimblir vder nur wenip seitwärts verschoben, derjenige der Basalzelle um $1 / 2-3 /$, herabgerückt, beide mit niedrigen Papillen.

Uredo- und Teleutosporen von Juli auf

A et hus a cy n a pi um: Welwarn, Mühlhausen (Kabát)! Roždalovic! Herruskretschen (Wagner), Teplitz (Thümen).

\section{Puccinia Conii (Strauss) Fuckel.}

Uredosporen: Sekumläre Lager meisteus blattunterseits zerstreut, rundlich, lilein, anf Blattstielen und Nerven grosser und oft zusammenfliessend, zimmtbraun, balı nackt, staubig; Sporen eiförmig bis ellipsoidisch, „4-35 ! lang, 17-26 $\mu$ hreit, mit gelhbrauner, nur in der vheren Hälfte entfernt stachliger und daselbst his lia) u dicker, unten dünner, glatter Vembran und 3 Keimporen.

Teleutosporenlager klein, ruudlich oder elliptisch, blattunterseits, auf Blattstielen und stengelu, lange $50 u$ graner Epilermis bedeckt, daun nackt, schwarzbraun, staubig; sporen eifömig his ellipsoidssch, oft unregrmaissig, an Scheitel ahgerundet, bei dum Stiel ebenfalls oder verschmailert, bei der Querwand wenig oder gar nicht eingeschnürt. 30-49 " lang, 20-30 " breit, mit brauner, glatter Jembran: Stiel kurz, hyalin, leicht abfilligr. Keimporus der oberen Zelle scheitelständig oder nur wenig seitwiuts verschoben, derjenige der Basalzelle dicht bei der Scheidewand, beide mit kleiner, hyaliner Papille. 
Tredosporen im August und mit ihnen zugleich oder anch spriter Teleuto. sporen auf

Coni um maculatum: Nové Dvory und Kačina (Peyl)! Libiš bei Neratovic.

Die Beschreibung der primären Uredolager fehlt noch gan\%. Von verwandten Arten (Puccinia Petroselini, P. Angelicae, P. bullata) ist die vorliegende Surzies hauptsïchlich durch schmale, im unteren Teile glatte Telentospoten verschieden.

\section{Puccinia Athamanthae (De Candolle) Lindroth.}

S p e r m o g o n i e n zerstrent, eingesenkt, gewölbt, gelblich.

Uredos poren: Frimäre Lager auf Blattstielen und Nerven in bis $2 \mathrm{~cm}$ langen Gruppen, verschiedene Hypertrofien und Krümmungen verursachend, dunkel. braun; sekundäre Lager blattheiderseits, klein, rundlich, auf zelblichen, braunen oder roten Flecken; Sporen eiförmig bis ellipsoidisch, $26-40)$ laug, $22-30$ - 3 breit, braun, mit stachliger, am Scheitel $4-9, \mu$ dicker Membran und $3-4$ lieim. poren. -

Te le utospore u lager anfangs in Uredolagern oder später auch selbstständig, klein, rundlich, schwarzbraun bis schwarz, schwach staubig; Sporen eiformig bis lïnglich, am Scheitel ahgerundet, zum Stiel verschmälert, bei der (Querwand wenig oder gar nicht eingeschnürt, $32-45$ " lang, $18-24$ " breit, mit brauner, glatter Membran; Keimporus der Basalzelle um $y_{3}{ }^{t} /{ }_{3}$ herabgerüclit, beide mit niedriger Papille; Stiel kurz, farblos, leicht abfillig.

Primäre Uredosporen Mitte Juni, sekundïre wie auch Telentosporen von Ende Juni auf

Peucedanum Cervaria: Hledsebe, Weltrus (Kabát)! Weisse Lehne bei Leitmeritz! Neschwitz bei Bodenbach!

b) Teleutosporen warzig.

«) Teleutosporenlager staubig.

164. Puceinia Oreoselini (Strauss) Fuckel.

S p ermogon i e $\mathrm{zwischen}$ den primären Uredolagern zerstreut, honiggelh, später braun.

Uredosporen: Primäre Lager auf Blattstielen und Nerven verschicdene, oft einige $\mathrm{cm}$ lange Deformationen hervorrufend, gross, zimmtbraun, später auch Teleutosporen führend und dann schwarzbraun; sekumläre Layer blattunterseits zerstrent, klein, rundlich, braun; Sporen kuglig, efformig bis ellipsoidisch. 26-40 $\mu$ lang, $16-28 \mu$ breit, mit gelbbrauner, stachliger, am Scheitel his $7 \mu$ dicker Membran; Keimporen 3, mit niedrigen, hyalinen Papillen.

Teleutosporenlager meistens blattunterseits zerstreut, seltener zusammentliessend, klein, rundlich, schwarzhraun bis schwarz, staubig; Sporen ellipsoidisch, länglich bis keulenförmig, beiderseits abgerumlet oder manchual zum Stiel verschnälert, bei der Querwand schwach eingeschnürt, 26-4: $\mu$ lang, $19-27 \mu$ 
breit, mit gelbbrauner, locker warziger Membran; Stiel zart, liurz, farblos; Kieimporus der Basalzelle in der unteren Hälfte, beide mit kleinen Papillen hedeckt.

Primäre Uredo anfangs Juni, sekundiire von Mitte Juni, Teleutosporen ron

Mitte Juli auf

Peucedanum Oreoselinum: Wiesen zwischen Neratovic und Libiš ! Velenka und Hradisko bei Sadská! Habstein (Kabát)! Jaroměř (Knat)! Aussig (Thümen, die Nährpflanze falsch bestimmt für Seseli coloratum)!

165. Puccinia Hieracii (Schumacher) Martius.

Spermogonien honiggelbbraun, blattheiderseits, auf Blattstielen oder Stengeln zwischen den Uredolagern oder auf entgegengesetzter Seite.

Uredosporen: Primäre Lager auf Blattspreiten auf rundlichen oder verlängerten, gelblichen oder rötlichen Flecken, kreisförmig oder nur gruppiert, auf Nerven und Blattstielen verschiedene Deformationen bildend, in verlängert'n Gruppen, ziemlich gross, bald nackt, kastanienbraun, staubig. zusammenfliessenu; seliundüre Lager hauptsächlich blattoberseits verbreitet, rumblicb, braun, staubig; Sporen luglig, eiförmig bis ellipsoidisch, $24-29 \mu$ lang, $16-25 \mu$ hreit, mit relbbrauner, stachliger Membran und 2 oberhalb der Mitte liegenden Keimporen.

Teleutosporenlager wie bei sekundïren Uredosporen, auch auf Stengeln, seltener auf Blättern nur gruppenweise, schwarzbraun, staubig; Sporen ellipsoidisch, eiförmig oder birnförmig, oben abıerundet, unten oft verjüngt, bei der Querwand wenig oder gar nicht eingeschnürt, 24-40 $\mu$ lang, 16-24 $\mu$ hreit, mit kastanienbrauner, sehr feinwarziger Membran; Stiel kurz, hyalin; beide Keimporen bis zur Mitte der Zelle herabgerückt.

Primäre Uredo von Mai (manchmal auch im Juli), sekundäre von Juni, Teleutosporen von Juli auf

Hieraci um a 1 pin um: Auparuellen im Riesengebirge! Glatzer Sclneeberg (Schroeter).

H i eracium a uricula: Tŕtice bei Kornhaus!

H jeracium a u $r$ an t i a u $^{\mathrm{m}}$ : Schlingelhaude im Riesengehirge (Schroeter).

Hieraci um boreale: Vrané bei Davle! Eisenbrod (Kabát) ! Teplitz (Thümen).

Hieracium Fritzi i: Weisse Wiese im Riesengebirge (Schroeter).

Hieraci um gland u los o-dentat u m: Kleine Koppe und Brunnenberg im Riesengebirge (Schroeter).

Hieracium laevigatum: Michle (Opiz)! Selc bei Prag! Neratovic! Leschtine bei Klein Priesen!

Hieracium murorum: Ueberall verbreitet.

Hieracium nigrescens: Wiesenbaude im Riesengebirge!

Hieracium Pilosella: Rotstein unterhalb Kozákov!

Hieracium praealtum: Děd bei Beraun!

Hieracium prenanthoides: Weisswassergrund im Riesengebirge (Schroeter)

Hieracium silvaticum: Ziemlich verbreitet! 
Hieracium sudeticum: Elbwiesen im Riesengebirge (Schroeter).

Hieracium tridentat $u$ m: Rösselberg bei Brïx!

H i eracium umbellat um: Kuchelbad (Hora)! Lešany bei Welwarı (liabit)! Wopparnertal bei bobesitz (Kabit)! Toplitz (Thümen! Hornskretseben (derselbe).

166. Puceinia Cichorii (De Caudolle) Bellynk.

Spermogonien und primäre Uredo bisher unbekannt.

Uredosporen: Sekundäre Lager blattbeiderseits oder über die Stengel rerstrent, rumdlich, hald nackt, zimmtbraun, manchmal zusammenfliessend. staubio

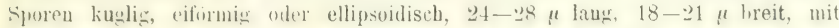
uelbhrauner. entfernt stachliger Membrau und 2 kappenlosen Keimporen.

Teleutosporenlager wie bei den Uredosporen, schwarz, staubig; Sporen ellipsoidisch oder birnfömig, beilerseits abgerundet oder zum Stiel rw schmälırt, hei der (querwand schwach eingeschnürt, 27-38" lang, 19-25 " breit: Nembran gelbbraun, mit feinen entfernt stehenden Warzen besetzt; Stiel liurz. farblos, zart, abfällig; Keimporus der oberen Zelle seitwärts verschoben, derjeniџe der Basalzelle um $1 / 3-1 / 2$ herabgerückt.

Sekumäre Uredosporen (manchmal auch schon Teleutosporen) anfangs Mai, Teleutosporen von Juni auf

C i c h ori um Intybus: Ueberall ziemlich verbreitet!

167. Puccinia Chondrillina Bubak et Sydow. - Uredo chondrilla" Opiz, Seznam 1852, pg. 151.

Spermogonien honiggelb, zwischen den Uredolagern dicht gruppiert, bald vergehend.

Uredosporen: Primüre Lager auf beiden Seiten der jungen Blätter in urossen, dunkelbraunen, riugformig oder unregelmässig gruppierten Lagern, von silbergrauer Epislermis bedeckt, später teilweise nackt, staubig; selundäre Lager ohne Spermogonien, in rundlichen. dunkelbraunen, blattheilerseits zerstreuten, auf Aesten und Stenqeln verlängerten, oft zusammenfliessenden Lagera. Beiderlei sporen

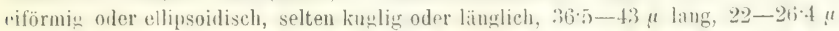
hreit. mit brauner. feinstachliger Membran und zwei oberhalb des lequators lingenden Keimporen.

Teleutos porenlager rundlich oder lïnglich, schwarzbraun, auf Blättern zerstreut, oft zusanmentliessend, auf Stengeh und Aesten zahlreich entwiclielt. oft dieselben krustenfirmis üh+2ziehend, von derber Epidermis hedeckt oder umgehen; Sporen kastanienhrann, eiformier oder ellipsoidisch, manchmal in der Mitte eingeschnürt, $33-46 \mu$ lang, $22-26{ }^{\circ} \mu$ breit, fein und deutlich warzig; Keimporus der oberen Zelle uni $1 / 2$ bis $2 / 3$ herabgerückt, derjenige der Basalzelle in der Mitte gelegen; Stiel oft länger als die Spore.

Primäre Uredosporen von Mitte Mai, sekundäre von Juni, Teleutosporen Ende Juli auf 
Choudrilla juncea in der Prager Umgegend: Letná (Opiz 1849 als Uredo Chondrillae Opiz)! Folimanka (Schobl)! Kuchelbarl, Radotín, Vysočan! Děd bei Beraun; Poř́čan! Mühlhausen a. E. (Kabát)!

\section{Puceinia Taraxaci (Rebentisch) Plowright.}

S p e r m o g o n i en honiggelb, in rundlichen Gruppen.

Ured os p oren: Primäre Lager gewöhnlich grösser als sekundäre, beide blattbeiderseits zerstreut oder oft zusammenfliessend, rundlich bis lïuglich, bald nackt, staubig, dunkelbraun; Sporen kuglig, pifürmig oder ellipsoidisch, $22-28 \mu$ ang, $16-26 \mu$ breit, mit brauner, stachliger Membran und 2 Keimporen.

Teleutosporenlager wie bei den Uredosporen, staubig, schwarzbraun bis schwarz; Sporen ellipsoidisch, seltener eiformig, beiderseits abgerundet, manchmal unten verschmälert, bei der Querwand eingreschnürt, 25-38 $\mu$ lang $16-26 \mu$ breit, mit kastanienhrauner, feinwarziger Membran; Stiel kurz, hyalin, abfällig.

Uredosporen von Juni, Teleutosporen von Juli auf

Taraxacum leptocephalum: Wolwarn (Kabát)!

Taraxacum officinale: Sehr verbreitet.

Taraxacum palustre: Bora bei Rovensko!

\section{Puccinia Leontodontis Jacky.}

Spermogonien in kleinen Gruppen auf beiden Seiten der Flecke, oder nur einerseits, honigbraun, klein.

Uredos poren: Primüre Lager an der Unterseite seltener Oberseite von purpurroter oder brauner, verlängerter Ilattflecke, kleine Deformationen bildend, auch bei Hauptnerven oder seltener auf rundlichen Flecken auf den Blattspreiten einzeln oder in kleinen länglichen Gruppen, ziemlich gross, ron grauer Epidermis bedeckt, dann nackt, dunkelbraun, staubig und zusammentliessend; sckunlüre Lager blattbeilerseits zerstreut, klein, rundlich, zimmtbraun; beiderlei Sporen kuglig oder ellipsoidisch, 25-35 $\mu$ lang, $24-27 \mu$ breit, mit hellbrauner, stachliger Membran und 2 Keimporen.

Teleutosporenlager wie bei den Uredolagern, schwarzbraun bis schwarz; Sporen sehr verschiedenartig, gewïhnlich ellipsoidisch, oder auch eifurmig bis länglich, beiderseits abgerundet, bei der Querwand wenig oder gar nicht eingeschnürt, $30-42 \mu$ lang, $21-27 \mu$ breit, mit kastanienbrauner, feinwarziger Membran; Stiel kurz, farblos, abfälig; beide Keimporen um $1 / 4$ bis $1 / 2$ herabgerückt.

Primäre Uredo in der ersten Hälfte Juni (im Gebirge in der ersten Hälfte Juli), sekundäre Uredosporen und Teleutosporen von Juli auf

Le ontodon has tilis: Medník bei Davle (Primäre Uredo 3./VI.)! I,enešic (Houska)! Teplitı, Niedergrund bei Tetschen, Herrnskretschen (Wagner). 
Leontodon hispidus: Vyšehrad, von Modran bis zu Jarov ofters, Radotin, Selc! Poŕčany, Velenka, Sadskit Mélnkk, Klein Priesen hei Anssig (Primär Uredo 1. VI.)! Weisswasseryrund in Riesengehirge (Primäre Ureito (j. VII.)!

Leontodon autumnalis: Teplitz, Aussig, Herrnskretschen (Waguer).

\section{Puccinia Iypochoeridis Oudemans.}

Spermogonien und primäre Uredosporen wie bei Puccinia Leontodontis, also die Lager dunkelbraun.

Sekundiare L' redolager blattbeiderseits auf kleinen Ilecken zerstreut, matnchnal auch auf Stengeln, klein, staubig, zimmtbraun; Sporen kuglin oder kuglig-

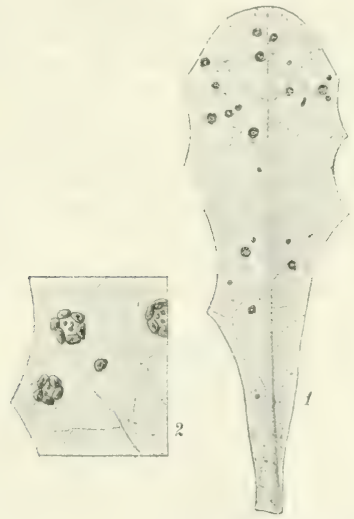

Abb. 25. Puccinia Hypochoevidis. 1. Primäre Uredosporen. 2. Dieselben vergrössert.

eiförmig, 2.2-28 $\mu$ lang, $20-26 \mu$ breit, mit hellkastanienbrauner, sehr feinstachliger Membran und zwei in der oberen Hälfte liegenden, mit kleinen Papillen versehenen Keimporen.

Teleutosporenlager wie bei sekundären Uredolagern, klein, schwarzbraun bis schwarz, staubig; Sporen sehr verschiedenartig, eiförmig, ellipsoidisch. seltener linglich, beiderseits abgerundet oder manchmal zum Stiel verschmilert. bei der Querwand gar nicht oder nur wenig eingesehnürt, 30-42 " lang. 17-24 " breit, mit kastanienbrauner, feinwarziger II mbrau; Stiel kurz, farblos; Keimporen beider Zellen oft bis $1 / 2$ herabgerückt.

Spermogonien und primäre Urerio im Mai, sekundäre von Mitte Mai, Telent(1) sporen von Juli, manchmal aber schon zugleich mit primïren Uredosporen auf 
Hypochoeris ylabra: Dáblicer Berg bei Prang (Opiz)! Neratovic (Domin)! Herrnskretschen ( $W_{\text {agner }}$ ).

Hypochoeris radicata: Pıkovice bei Davle, Rídká bei Mnı́šek! Neratovic, Klomin, Oužic !

\section{Puceinia montivaga Bubák n. sp.}

Spermog on ien honigbraun, blatbeilerseits zwischen primären Ureılolagern in kleinen Gruppen.

Uredosporen: Primüre Lager blattbeiderseits auf rundlichen oder länglichen, purpurroten, of mit schmalem oder breiterem Saume versehenen Flecken, rundlich oder linglich, kreisformig um die spermogonien gestellt, dann nackt, staubig, ringfömig zusammenfliessend, zimmtbraun; selundärc Lager blattbeiderseits, hauptsïchlich aber unterseits zerstreut, sehr klein, hellzimmtbraun, staubig; beiderlei sporen eiformig, ellipsoidisch bis lituglich, 25-33 (manchmal atuch 35) ". lang, 20 -2t; $u$ breit, mit welhbrauner, ziemlich lanstachliger Membran und 2 im oberen Drittel liegenden Keimporen.

Teleutosporenlager den sekundären Uredolagern konform, staubig, schwarz; Spqoren eifömiı. hirnformig bis ellipsoidisch, seltener länulich. beidersfeits abgeruder, selten unten verjüngt, manchmal schwach in der Mitte eingeschnüıt, 33-38 "3 lang, 20-2.4 " breit, mit kastanienbrauner, feinwarziger Membrin; Stiel kurz, hyalin, abfällig; beide Keimporen oft bis um $1 / 3$ herabgerückt.

Spermogonien und primäre Uredo anfangs Juli, sekundäre Uredo- und Teleutosporen Ende Juli auf

Hypochoeris uniflora: Riesengebirge und zwar auf den Abhängen des Gr. Kessels gexen Rochlitz zu: primare Uredo am 6. Juli, sekundire und Telentosporen am 23. Juli 1898! Aupafall und Glatzer Schneebery (Schroeter).

Puccinia montivaga ist mit der vorangehenden Art verwand, von derselben aber durch die form der primären Iredolager, die stets ringförmig gruppiert und zimmthraun sind, durch kleinere Uredo- und Telentosporen verscbieden. Die Uredosporen besitzen ״,, im oberen Drittel gelegene Keimporen, wïhrend bei Puccinia Hypochoeridis dieselben aequatorial liegen.

\section{Puecinia Picridis Haszlinsky.}

Uredolager blattbeiderseits zerstreut oder locker gruppiert, auf gelblichen oder purpurroten Flecken, klein, braun, staubig, manchmal auch zusammenfliessend; Sporen kuglig oder breit tifurmig, $21-27$ "t im Durchmesser oder $24-30 \mu$ lang. $16-20$, breit, mit hellbrauner, feinstachliger Membran und 2 Keimporen.

Teleutosporenlager wie bei den Uredosporen, schwarzbraun, staubig; Sporen eiformig bis ellipsoidisch, heiderseits abgerundet, bei der Querwand wenig oder gar nicht eingeschnürt, $27-35, "$ lang, $18-24$ ! hreit, mit brauner, feinwarziger Jembran: Stiel kurz, bis 16; u lang, hyalin, abfillig: Keimporen um $1 / 3-1 / 2$ herabgerückt. 
Uredosporen von Juni, Teleutosporen ron Juli auf

Picris hieracioidles: Všctat! Welwarn (Kabát)! Rarlobýl bei Leitmeritz! Ratscheberg im Bielatale! Tschöppern bei Brüx! Lenešic (Houska)!

Gewiss eine Brachypuccinia, obzwar primäre Uredo bisher unbekannt.

\section{Puecinia scorzonericola Tranzschel.}

spermogonien blattbediderseits zwischen den Tredolagern in ämlichen Gruppen, honigbraun.

I'redosporen: l'rimäre Layer blattheiderseits anf gelblichen, rundlichen oder länglichen Llecken, kreisfömig eruppiert, zusammentliessend; sekundäre Layer kein, rumblich, blattheilerseits zerstreut, bejderlei staulig, braun; Sporen kuglig his ellipsoidisch, 2.2-33 $\mu$ lang, $1 s-31 \mu$ breit, wit brauner, stachliqer Membran unid 2 (seltener 3) Keimporen.

Teleutusporenlager wie die sekundïrn Uredolager, schwarzbraun bis schwarz, stauhiz; ifters auch Teleutosporen schon in primären und sekumiären Iredulagern: sporen ellipsoilisch oder eifomig, heiderseits abserundet oder manchmal zum Stiel versihmailert, bei der querwand nicht eingeschnürt, 30- 40 u lang, -2-20 $u$ breit. mit kastanienhrauner, teinwarziger Membran; Stiel liurz, zart, lygalin, abfillig: Kimporen in verschiedenen Lagen, meistens in der Mitte dır Zellen.

Primäre Uredo im Juni, sekundäre wie auch Teleutosporen mit ihnen zugleich oder später auf

Scorzonera humilis: Bei Dobronicer Haltestelle nächst Tábor!

\section{Puccinia Bardanae Corda.}

Spermogonien honigbruun, blattoberseits in kleinen Gruppen in den primären Uredolagern.

Uredosporen: Primüre Lager blattoberseits, auf gelblicheu, bis $1 / 2 \mathrm{~cm}$ breiten Flecken ringformig \#e-telit, oft zusammenfliessenil, bald nackt, zinmtbrau, stambig̈; selumdäre Lager blattbeiderseits zerstrent, klein. rundlich, bald nakt,

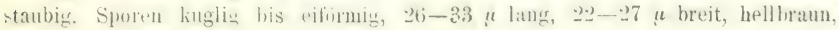
stachlig, mit 3 Keimporen.

Teleutospurenlater wir hei selundiren Tredosporen, sthwarz, staubig;

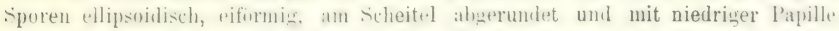
versehen, zur liasis schwach verschmallert, bei der Querwand wenig eingeschnürt,

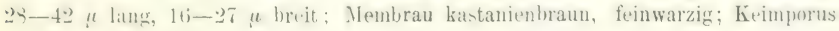
der Basalzelle oft bis $1 / 2$ herabgerückt; Stiel zart, hyalin, leicht abfällig.

Primäre Uredo von Ende April bis anfangs Juni, sekundäre von Mlai, T'e. leutosporen von Juli auf

Lappa major: Praǵ (Hennevogl)! Pardubice (Vodák)!

Lappa minor: Roztok bei Prag!

Lap pa tomentosa: Ueberall sehr verbreitet.

Lappa major $\times$ tomentosa: Bolehoše bei Opočno (Rohlena)! 


\section{Puccinia Jaceae Otth.}

Spermogonien gelblich. später orange, in kleinen Gruppen blattoberseits, seltener blattunterseits und auf Blattstielen.

Uredosporen: Primäre Lager hauptsächlich blattunterseits ringfürmig um die Spermogonien, lastanienbraun, bald nackt, zusammenfliessend und staubig: sekundüre Lager blattunterseits zerstreut, klein, soust wie die primären; Sporen kuglig orler eifrimig, $24-30 \mu$ laug. $16-28 u$ breit, mit brauner, stachliger Memhran und 2 mehr zmu Scheitel gerückten lieimporen, welche mit feinen liapen rersehen sind.

Teleutosporenlager blattunterseits zerstreut, rundich, schwarzbraun, staubig; Sporen eiförmig, ellipsoidisch, beiderseits gewönlich halbkugelig abgerundet, bei der Querwand nicht eingeschuürt, $24-37$ u lang, 15-27 « breit, mit liastanienbrauner, feinwarziger Membran: Stiel liurz, zart, farblos, leicht abfällig; beide Keimporen $1 / 3-1 / 2$ herabgerïckt.

Prnmäre Uredo in Mai, sekundïre von Juni, Teleutosporen son Juli auf

Centaurea Jacea: Überall verbreitet.

\section{Puccinia Centaureae De Candolle.}

Der vorangehenden Art ähnlich, aber mit diesen Unterschieden:

Uredosporen 20-28 $\mu$ lang, $17-24 \mu$ breit, mit 3 aequatorial gelegenen Keimporen.

T'eleutosporen 27-40 $\mu$ lang, $16-25 \mu$ breit, bei der Querwand eingeschuürt; Keimporus der Scheitelzelle $1 / .$, derjenige der Basalzelle $1 / 3-1 / 2$ herabgerückt.

Primaire Uredo im Mai, sekundäre von Juni, Teleutosporen von Juli auf Centaurea $\mathrm{Scab}$ i os a: Überall verbreitet!

\section{Puccinia tinctoriicola Magnus.}

Spermogonien und primäre Uredo unbekannt.

Sekundïre Uredolager blattbeiderseits, zerstreut oder gruppiert, kisin. rundlich, staubig, dunkelbraun; Sporen kuglig bis ellipsoidisch, $28-35$ " lang. 2.2-30 4 breit. mit brauner, dicker, stachliger Membran und 2 Keimporen.

T'eleut osporenlager wie bei den Uredolagern, schwarz; Sporen eiformig, ellipsoidisch, manchmal auch birnfömig, $30-42, \mu$ lang, $26-29$ " breit, beiderseits abgerundet oder unten seltener verschmälert, hei der Querwand manchmal wenigr eingeschuürt, 311-42 " lang, $26-29 u$ breit, mit hellkastanienbrauner, feinwarziger Membrau; Stiel kurz, zart, farblos, leicht abfüllig.

Uredosporen ron Juli, Teleutosporen von September auf

Serratula tinctoria: Mühlhausen (Kabát)! Sadská! Vysolié Veselí (Kabát)!

Wahrscheinlich eine Brachypuccinia. 


\section{Puceinia Cariuorum Jacky.}

Spermogn ien honiphraun, blattbeiderseits zwischen den Creatosporen gruppiert.

Uredosporen: Primüre Lager blattbeiderseits, auf gelblichen Flecken konzentrisch gruppiert, kreisformig zustmmentlessend, zimmtbraun, staubjz; sekundïre I-ayer meistens blattunterseits, auf gelblichen oder undeutlichen Filecken verteilt, klein, bald nackt, zimmtbraun, staubig: Sporen kuglig oder eiformig, 2.) bis 25 $\mu$ lang, 19--24 $u$ breit, hellbraun, stachlig, mit 3 Keimporen.

'T e leut os p o r e n l a g e r wie bei sekundären Uredosporen, schwarz, fest; sporen sehr verschieden, eiformig, ellipsoidisch bis länglich, am scheitel und au! der basis abgerundet, bei der Querwand wenig oder gar nicht eingeschnürt, „25 his \$8 $\mu$ lang, $17-26 \mu$ breit, mit kastanienbrauner, warziger Membran; Keimporus der oberen Zelle scheitelstindig oder um herahgerückt, derjenige der Basial. zelle ebeifalls um ${ }^{1}{ }_{3}$ herahgeschoben, beide mit feiner Papille; Stiel kurz, zart, hyalin.

Primäre Uredosporen im Mai und Juni, sekundäre von Juni, Teleutospreren von Iuli auf

Carduus acanthoides: Welwarn (Kabát)!

Carduus crispus: Prag (Hennevogl)! Weltrus (Kabát)! Wopparnertal (derselbe)! Trebnitz! Elbufer bei Bodenbach!

Carduus nutans: Welwarn (Kabát)!

Carduus personata: Am Fusse des Riesengebirges und zwar bei Dunkeltal, Friedrichstal! Haclielsdorf bei Hohenelbe! Löwengrund bei der Mohornmühle uiichst Trautenau (Domin)!

\section{Puceinia Cirsii Lasch.}

S permogoni e n auf kleinen, gelben, rundlichen Flecken blattbeiderseits in ärmlichen Gruppen, klein, anfangs blass, später honigbraun.

Uredosporen: Primäre Lager in kleinen rundlichen Giruppen blattheiderseits, später kreisforming oder halbkreisformig zusammenfliessend, nackt, zimmtbraun, staubig; selumbäre Lager blattbeiderseits zerstreut, klein, rundlich, bald nackt, staubig; Sporen kurlig, eiformig, ellipsoidisch, 22-2s $\boldsymbol{\mu}$ lang, $19-2 \pm$ " breit, mit hellhrauner, stachliger Membran und 3 bappenlosen oder nur mit winziger Papille versehenen Ḱeimporen.

Teleutosporen I g er auf kleinen, braunen oder gelblichen Flecken, blattbeiderseits, meistens aher blattunterseits zerstrent oder gruppiert, klein, rundlich, schwarz, staubin; Sporen eiformig bis ellip ooidisch, beiderseits ahgerundet oder manchmal auf der Basis wenig verschmälert, bei der Querwand wnig oder gar nicht eingeschnüıt, 25-37 $u$ lang, 17-24 $u$ be eit, mit kastanienbrauner. feinwarziger Membrau; Stiel kurz, farblos; Keimporus der oberen Zelle scheitelständip oder bis ${ }^{1 / \%}$ herabgerückt, derjenige der Basalselle um ${ }^{3}, 3$ herabyeschoben, beide mit kleiner oder gar keiner Papille.

Primäre Uredo von Mitte Mai bis Mitte Juni, sekundire ron Juni. Teleutosporen von Juli auf 
Cirsium c a num: Neratovic, Libiš, Všetat, Velenka! Welwarn (Kabát)! Roždilovic! Rurensko! Reichenher siecmund)! Teplitz (Thümen)! Bodenhach!

Cirsium heterophyllum: Wurzelsdorf am Fusse des Isergebirges! Im Erzgebirge bei Zinnwald, am Keilherge und lichtelberge (Kirieger. Wagner)! Böhmerwald: am Wege von Ober-Moldau zur Schattawa!

Cirsium palustre: Velenka bei Sadská! Habstein (Kabát)!

Cirsium pannonicum: Weisse Lehne bei Leitmeritz! Gross-Wostray bei Aussig!

Cirsium oleraceum: Überall genug verbreitet.

\section{Puccinia Carlinae Jacky.}

spermogonien honigbraun, blattoberseis in kleinen Gruppen in der Sitte der primären Uredosporen.

Uredosporen: Primäre Lager blattoberseits, auf gelblichen, etwa $1 / 2 \mathrm{~cm}$ breiten Flecken, rmoformig stehrnd, oft zusammentlessend, bald nackt, zimmtbraun, staubig; sekundüre Lager blattheiderseits, klein, rundlich, ziendich lange berleckit, dann nackt, bratun, stauhig; beiderlei sporen kuglig bis ellipsoidisch, 24-29 $\mu$ lang, 20-25 $\mu$ breit, mit dicker, hellbrauner, von sehr feinen, schwer sichtbaren Stachelchen besetzter Membran und 3̈ Keimporen.

Teleutosporenlager wie bei sekundiren Uredosporen, schwarzbraun, staubig; Sporen birntörmig bis eiformig, seltener keulenformig oder ellipsoidisch, au Scheitel halbkugelig abgerundet, zum Stiel verschmälert, bei der Querwand wenig oder gar nicht eingeschnürt, 25-35 " lang, 16-20 $\mu$ breit, mit dicker, bramer, warziger Membran: Stiel liur, lyaliu: Keimporus der oberen Zelle um ${ }^{1}$ : derjenige der Basalzelle um ${ }^{1} /$, herabgerückt.

Juli auf

Primare Uredolager in Mai, sekundare fon Ende Mai, Teleutosporen ron

Carlina acaulis: Mašov bei Turnau (Kabát)! Bernardov bei Kuttenberg (Peyl)! Tábor!

Auf Carlina vulgaris kommt Puccinia divergens Bubák vor, welche hauptsichich durch grossere Teleutosporen (40-51 "l lang, 24-3:3 " breit) von der vorliegenden Art verschieden ist. Sie kommt sicher anch in Böhmen vor.

1si. Puccinia suaveolens (Persoon) liostrup. Puceinia obtegrens (Link) Tulasne.

Spermog o n i en blattbeiderseits dicht verteilt, rütlich, wohlriechend.

Uredo- und Teleutosporen: Lager der primüren Generationen über die ganze Blattunterseite rerteilt, oft zusimmentliessemi, anfanıs routlibhksstanienbraun, später schwarzbraun, staubig; Lager der sekundüren Generationen schwarzbraun, blattuntersuits zerstreut, selten zusammenfliessent, staubig. - Ureilosporen kuglin bis ellipsoldisch, $24-28$ " latg, $20-24$ " breit, mit hellbrauner, stachliger Membran: Keimporm 3, mit hyalinen, niedrigen Papillen versehen. - Teleutosporen eifurmin, ellipsoidisch oder birnförmis, beiderstits abgerundet oder mauch- 


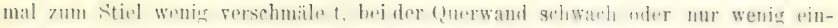
geschnürt, 26-42 $\mu$ lang, $16-25 \mu$ breit, mit brauner, dünner, feiuvarziger

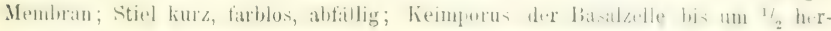
abgerückt.

Primäre Generation im Mai, sekundäro von Juli auf

Cirsium arvense: Sehr gemein !

Dat Myeel der ersten (sporidiengeborener) (ieneration durehzieht die ganze Sibrpflanze, deren alle l'eile verlängert werilen und alle blatter sureulawer tragen; die selinditre (uredogeborene) (ieneration besitzt nur lukalisiertes My.el.

\section{Puccinia Cyani (Schleicher) Passerini.}

Spermogonien anf allen Blättern und Stengeln der befallenen PHanze verteilt, honigbraun.

Uredosporen: P'rimäre Lager über alle Blätter, hauptsächlich unterseits

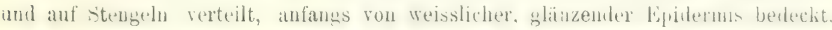
rundlich oder lïnglich, dann nackt, braun, staubig; sekundäre Lager über die Blätter seln zerstreut, sonst wie die primüren; Sporen kuglig, eiförmig, ellipsoidisch, $22-30$ « lang, 19-24 $u$ breit, mit gelbbrauner, fein- und kurzstacheliger Membran und 2 Keimporen.

T'eleutosporenlager zerstrect, manchmal schon mit primären Uredosporen, klein, rundlich, blattbeiterseits, bald nackt, shwarz, staubig; sporen kuglin

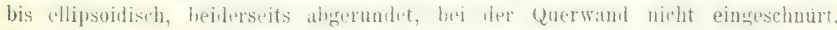
30-35 " lang, 2.2-27 "2 hreit, mit kastanienbauner, sehr feinwarziger Membran: Stiel kurz, hyalin, abfilliw; Keimporus der oberen \%elle un ' ${ }_{3}$, derjenige der basal zelle um $1 / 3-2 / 3$ herabgerückt, beide mit niedrigen Kappen.

Primäre Uredo im Mai, sekundïre von Juni, Telentosporen von Juli auf

Centaurea Cyauns: Prag (Hoffmann)! Kaiserwiese (Forster)! Libice bei Podèbrad! Welwaru (Kabit)! 'Teplitz (Thümen). 'Tábor!

Das Mycel der ersten (sporidiengeborenen) Generation, durchdringt die ganze Nührptlanze. Aus primären Uredosporen entsteht bei der Infektion nur lokalisiertes Mycel, welches nur zerstreute Uredo- und Teleutosporenlager ausbililet.

\section{Puccinia Echinopis De Candolle.}

Uredolager meistens blattunterseits verteilt, rundlich, staubig, zimmt-

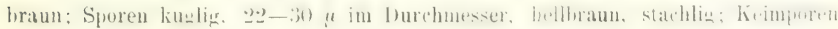
2-4, mit grossen Höfcheu und niedrigen hyalinen Kappen versehen.

Teleutosporenlager blattbeiderseits, ziemlich gross, schwarzbraun bis

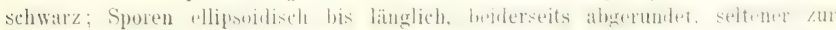
Basis verjüugt, bei der Querwand wenig oder gar nicht eingeschnürt, 35-44

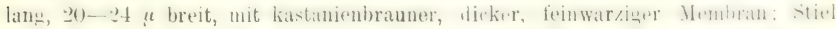
kurz, farhlos, abfallig; Keimporus der oberen \%ellen bis zur 1 , herahteratelit, derjenige der Basalzelle ebenfalls, beide mit sehr niedrigen Papillen. 
Uredosporen im Juni, Teleutosporen von Juli anf

Echinops sphaerocephalus: Zwischen Kuchelbad und Radotín (Opiz)! Košľ̆ (Herb. d. böhm. Museums in Prag)!

Der Entwicklungsgang unrollkommen bekinnt; wabrscheinlich eine Brachy. puccinia. Ich konnte den Pilz am Opiz'schen Standorte nicht finden, obzwar die Nährptlanze daselbst sehr verbreitet ist.

184. Puceinia Carthami (Hutzelmann) Corda. - D i ca e oma Carthami Hutzelmann in schedis et apud Opiz, Seznam pg. 139.

Uredolager blattbeiderseits, meistens blattunterseits, zerstrent, gruppiert oder zusammentliessend, klein, rundlich, kastanienbraun, staubig; Sporen kuglig bis ellpsoidisch, $20-27 \mu$ lang, $16-22 \mu$ breit mit hellkastanienbrauner, feinstachliger Membran und 2 Keimporen.

Teleutosporenlager wie bei Uredosporen, schwarz,stanbig; Sporen breit ellipsoidisch vder eiformig, heiderseits abgerundet, bei der Querwand wenig oder gar nicht eingeschnürt, 28-46 $\mu$ lang, 21-33 $\mu$ breit, mit kastanienbrauner, dicker, von kleinen Wärchen feinpunktierter Membran; Stiel kurz, farblos; Keimporus der oberen Zelle un $1 / 3$, derjenige der Basalzelle um $1 / 2-2 / 3$ herabgerückt.

Carthamus tinct ori us: Kanalgarten (Corda)! Saaz (Hutzelmann)!

Da Carthamustinctorius in Böhmen im Grossen nicht mehr angebant wird, so wird wahrscheinlich diese Puccinia in Böhmen nicht mehr vorkommen. Sie kommt besonders in Aegypten, Ost-Indien und Jipan vor. Der vollständige Entwicke lungsgang ist nicht bekannt, aber nach den verwandtschaftlichen Beziehungen dieser Art zu Puccinia Centaureae wahrscheinlich eine Brachypuccinia.

B) Teleutosporenlager fest.

\section{Puceinia Tanaceti De Candolle.}

Spermogonien und primäre Uredolager bisber unbekanut.

Uredosporen: Sekundäre Layer blattbeiderseits zerstrent, rundlich, braun; Sporen ellipsoidisch, 24-32 $\mu$ lang $16-25$ breit, mit brauner, stachliger Membran und drei, von breiten, hyalinen Kappen bedeckten Keimporen.

'Teleutosporenlager wie bei Uredosporen, fest, schwarz; Sporen ellipsoidisch bis lämglich, am Scheitel abgerundet oder verjüngt, bei der Querwand schwach eingeschnürt, 35--60 $\mu$ lang, 16 - 24 " breit, mit hellkastanienbrauner, :m Scheitel hellerer und stark $(\tau, u)$ verdickter, feinwarziger oder auch glatter Membran; Stiel bis $120 \mu$ laug, farblos, nicht abfallig.

Uredosporen von Juli, T'eleutosporen von Ende August auf

Tanacetum vulgare: Rovensko! Turnau, Vys. Veselí (Kabát)!

Wahrscheinlich eine Brachypuccinia. Von Puccinia Pyrethri unterscheidet sie sich durch kleinere, am Scheitel stark abgerundete, von Puccinia Absinthii durch kleinere Teleutosporen. 


\section{P'uccinia Pyrethri Rabenhorst.}

Uredo layer gewöhulich blattunterseits zerstreut oler verteilt, klen, rundlich nder libnglich, hellbraun, staubig; Sporen kuglig bis ellipsoblisch, 201-33 " lane, $20-26$ " hreit, mit hellhramer, entfernt stachliger Membran; Keimporen 3 , bederkt mit breiter, gewölbter Papille.

Teleutosporenlager gewöhnlich blattunterseits, auf Blattstielen und stengeln, verteilt, manchmal zusammentliessend, rumllich, seltener länglich, hahl nackt, fest, schwarz; Sporen ellipsoidlisch oder lïnglich-ellipsoidisch, beiderseits ahgrerundet, bei der (Querwand schwach ringeschnürt, 40-55 $\mu$ lang, 20-28 $\mu$ hreit, mit kastanienbrauner, dicker, warziger Membran; stiel kriftig, farblos, bis 111 "I lang, nicht abfällig.

Uredosporen im Juni, Teleutosporen von Eude Juni auf

Chrysanthemum corymbosum: Sv. Matěj und Hetzinsel bei Prag (Opiz)! Sv. Ivan bei Beraun! Mühlhausen a. E. (Kabait)! Rożdalovic! Teplitz! ('Thümen)! Lukow bei Bilin! Karlsbad (Reuss)! Selčan (Th. Novák)!

Diese Puccinia unterscheidet sich von Puccinia Tan a ceti durch dickwandige, breitere, am Scheitel fast regelmässig abgerundete Teleutosporen.

\section{Puccinia Absinthii De Candolle.}

Uredolager blattunterseits zerstrent oder stellenweise gruppiert, staubig, rundlich oder lïnglich, rostbraun. Sporen kuglig oder eiförmig, hellbraun, entfernt stachlig, 24-35 $\mu$ lanw, $15-28$ " breit; Keimporen 3 , bedeckt mit breiter, gewiilhter, farbloser Papille.

Teleu tos porenlager hauptsïchlich blattunterseits, nicht selten auch hattoberseits, zerstreut oder in Gruppen, manchmal auch kleinere Gruppen um eine, grössere, zentrale ringförmig gestellt, versehielen gross, runllich, bald nackt, fest, schwarz; Sporen ellipsoidisch, länglich oder kenlenförmig, 37-52 breit, manchmal (auf Artemisia vulgaris) bis $30 \mu$ breit, am scheitel abgerundet, in der Nitte schwach eingeschnürt, zum Stiel allmählich keilförmigr verschmälert, beide Zellen gleich lang oller die untere länger; Membran hell- bis dunkelkastanienhraun, dicht von undeutlichen, auf der Basalzelle allmählich zum Stiel rerschwintenden Warzen besetzt: Keimporus der oberen Zelle scheitelständin, derje nige der Basalzelle dicht unterhalb der Scheidewand, beide mit hellerer, besonders die obere Zelle mit breiter, krïftiqer, warzenförmiger Papille. Stiel farblos, fest, bis $90 \mu$ lang, $8-9 \mu$ breit.

Uredosporen von Juni bis August, Teleutosporen von Juli bis zum Winter auf

Artemisia Absinthium: Prag (Quadrat)! Habstein und Neuschloss (Wagner)! Kunětická Hora (Vodák)! Tábor! Krumau (Jungbauer)!

Artemisia Abrotanum: Kirchhof in Rovensko!

Artemisia dracunculus: Prag (Opiz 1815)! Turnau (Kabát)!

Artemisia vugaris: Ueberall verbreitet.

Iliese Puccinia-Art wurde früher mit Puccisia Tanaceti vereinist, ron Sy dow aber in seinen Uredineen I, Genus Puccinia, wieder abgetrennt. 


\section{Pnecinia Balsamitae (Strauss) Winter.}

Spermogonien auf rundlichen, gelblichen, ${ }^{1}{ }_{2} \mathrm{~mm}$ breiten Flecken blattunterseits, seltener oberseits, honigbraun.

Uredosporen: Primäre Lager auf denselben Flecken wie die Spermogo. nien, blattoberseits, seltener unterseits, ziemlich gross, von glänzeuder Epidermis bedeckt, dann nackt, zimmtbraun; selumdïre Lager blattbeiderseits verteilt oder auch ringförmig steheud, klein, sonst wie die primiren; Sporen kuslig, eiförmig, ellipsoidisch, 28-35 " lang, $26-33 "$ breit, nelbhraun, entfernt stachlig; Keimporen 3, mit starken Kappen versehen.

Teleutosporenlager wie bei sekundären Uredosporen, bald nackt, fast schwarz, staubig; Sporen ellipsoidisch oder länglich, beiderseits abgerundet. bei der Querwand deutlich eingeschnürt, 35-50 $\mu$ lang, 25-28 $\mu$ breit, mit kastanienbrauner, ziemlich dichtwarziger, am Scheitel $6-7 \mu$ dicker Nembran; leimporus der Basalzelle dicht an der Scheidewand; stiel so lang oder länger als die Spore, hyalin, zart, ziemlich lange mit der Spore verbunden.

Primitre Uredo Ende Mai und im Juni, sekundïre von Juui, Telentosporen von Juli auf

Tanacetum Balsamita: Oft in Gärten und auf Friedhöfen z. B. Kanalgarten (Corda 18:5, Fieber, Hoffmann, Helfer)! Vysolé V'eself (Káabit)! Rovensko ! Turnau (Kabát)! Tábor!

In J. 1901 habe ich mittelst Infektionsversuche berriesen, dass diese Puccinia eine Brachyform ist.

\section{Puccinia Chrysanthemi Roze.}

Uredolager meistens blattunterseits, seltener blattoberseits, auf gelblichen oder braunen Flecken, zerstreut oder oft um ein grïsseres, zentrales Lager ringförmig gruppiert, hald nackt, zimmtbraun, zusammentliessend, stanbig; Sporen kuglig, ellipsoidisch, eiformig bis länglich, $22-44 \mu$ lang, $20-26 \mu$ breit, mit hellbrauner, entferut stachliger Memhin; Keimporen 3. mit stark aufquellbaren Kappen versehen.

Teleutosporenlager in Uredolagern (in Japan auch in selbstäudigen Lagern;, ellipsoidisch oter liuglich, beiderseits abgerundet, bei der (guerwand wenig oder gar nicht cingeschnürt, 35-43 " lang, 20-2.) $\mu$ breit, mit kastanienbranner, sehr feinwarziger Nembran; Stiel 35-60 $\mu$ lang. farblos, fest oder abfallig; Keimporus der oberen Zelle scheitelstïndis, derjenige der Iiasalzelle an der Scheidewand; manchmal auch einzellige Teleutosporen entwickelt.

In Glashäusern auf kultiviertem

Chrysanthemum indicum: Prag! Kralup! Frauenberg!

Diese Puccinia wurde nach Europa aus Japan eingeschleppt, etwa im Jahre 1897. Bei uns überwintert sie mittelst der Uredosporen, die anch im Freien die Keimfïhigkeit nicht verlieren. Sie bildet auch zweizellige Crulosporen, die man leicht nach den Stacheln und Keimperen (in der Scheitelzelle $2-3$, in der Basalzelle $0,1-2)$ von den Teleutosporen unterscheiden kann. 


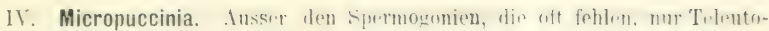
sporen, die erst im Frülijalıre lieimen.

a) Th den T'eleutosporenlagern Paraphysen.

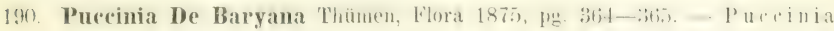
compacta De Bary, Botan. Zeitung 1858, pg. 83, nec Kunze, nec Berkeley. -

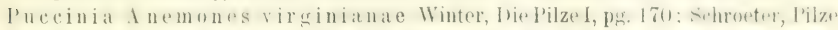

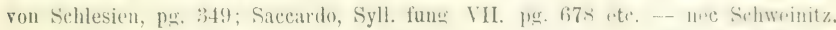

Teleutospureulager auf gelhlichen oder purpurroten, blasentirmin aufgetriebenen Flecken, blattoherseits I Anemone silsestris, oder anf blattstienem, bei

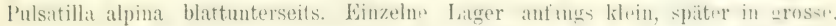
rundlich oder längliche, sthwarze obler schwarzhraune, feste, ron glinzender Eqidermis bedeckte Lager zusammentliessend; sporen länglich, lieulenfurmio order zylindrisch, 42-92 $\mu$ lang, $11-24 \mu$ breit, bei der Querwand eingeschnürt:

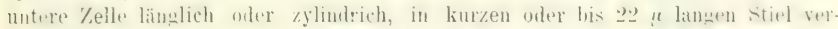
s.hmailert. yelblichbraum. obere Zolle banglich orler viformig, bram, besonders am Siheitel bis sehwarzbraun, daselhst stark rerdickt, aberstutzt, aligerundet oder verjüngt; Sprorengruppen von tremelloiden, braunen, fest verlilehten Paraphysen umgeben.

Von Mitte Mai bis zum Ende der Vegetationsperiode, im Gebirge von Juli auf

Anemone silvestris: Turnau (Kabát)! Bílá bei Böhmisch Aicha, Kirchberg und Plischenberg bei Watislaw! Slavetin bei Peruc (Ilouska)! St. Ivan bei Beraun (Th. Novák)!

Pulsatilla alpina im Riesengebinge: Aupaquellen, Resenbaule, Schneekoppe, Riesengrund!

l'uecinia De Baryana wurle früher mit der norlamerikanischen l'urc in ia A nemones rirginianae schweinitz indentifiziert. Im .J. 1901 habe ieh aber gezeigt, dass sie von derselben ganz verschieden ist.

b) Ohne Paraphysen.

a) Teleutosporen glatt.

\section{Puccinia Liliacearum Duby.}

Spermogonien zwischen Teleutosporenlagern verteilt oder an den Blatt-

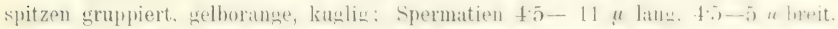
kuglig bis länglich, schwach gelblich.

Teleutosporenlager auf gelblichen, verdickten Blattpartien, meistens auf den Spitzen, halbkugelig gewilht, dicht gruppiert, anfangs von grauer Fintermibedeckit, dann mit rundlicher oder spaltenförmiger ()effinung und die spuren rankenfurmig hervorstossend, später mehr enthlïsst, oft zusammentliessemel, dunkeltram.

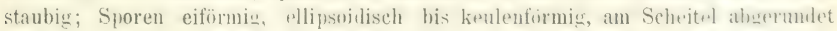
oder stumpf zusespitzt, zum Stiel verschmälert, bei der (jurwaml wenig einge-

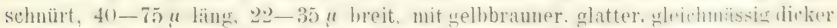
oder seltener am Scheitel dickerer Membran. Stiel kurz, hỵaliu, alifillic. 
Von Mitte April bis Ende Mai auf

Ornithogalum tenuifolium: Häufig in der Prager Umgegend, im Ell,tale, Egergebiete und im Böhmischen Nittelgebirge! Sonst auch bei Welwarn (Kabát)! Všetat! Teplitz (Thümen)! Rosental bei Mariaschein (Wiesbauer)! Herruskretschen (Wagner)!

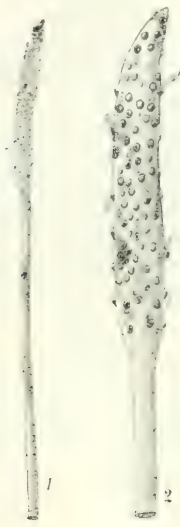

Abb. 26. Puccinia Liliaicarnm. 1. Teleuto-porentragende Blatter. 2. Iiesel

ben vergrössert.

Die Aecidien von Ornithogalum ten u ifolium und 0 . umbellatum gehören wahrscheinlich zu einer heteröischen Uredinee.

\section{Puecinia asarina Kunze.}

Teleutosporenlager blattbeiderseits, klein, rundlich, von grauer Epidermis lange bedeckt, locker in rundlichen Gruppen auf blasenförmig aufgetriebenen, etwa ${ }^{1} / 2 \mathrm{~cm}$ breiten Blattpartien stehend, später zusammenHliessend. Sporen eiförmig, ellipsoillisch, meistens aber spindelförmig, manchmal unregelmässig, am Scheitel mit bis $8 \mu$ hoher Papille, an der Basis abgerundet oder verjüngt, bei der Querwand wenig oder gar nicht eingeschnürt, 28-45 $\mu$ lang, 14-24 $\mu$ breit, mit glatter, hellbrauuer Membran; Stiel kurz, farblos, leicht abfällig. Keimporus der Basalzelle bei der Scheidewand oder etwas herabgeschoben, manchmal mit ciner Papille.

Von Juni bis zum Winter, alte Lager sogar auf uberwinternden Blättern bis zum Frühjahre auf

A s a rum e uropa um: Karlstein, St. Ivan, Koda bei Tetín! Okrouhlo bei Darle! Kačina (Peyl). Pardubic (Opiz, Vodák)! Sofiental hei Nieder Mohren nächst Polic a. M.! Ober Mohrau bei Grulich! Hořičky bei Böhm. Skalic (Kabát)! Rovensko! Parchen bei Böhm. Kamnitz (I)innebier)! Tetschen (Wagner)! Theresienfeld bei Mariaschein (Wiesbaur)! Borschen bei Bilin (Wiesbaur)! Rotenhaus hei liomotau (Roth)! Netolic (Hampl)! Tábor! Kaplitz (Kircbner).

\section{Puccinia Campanulae Carmichael.}

Teleutosporenlager blattunterseits, seltener blattoberseits, auch auf den Blattstielen zerstreut oder dicht gruppiert, balbkugelig gewolht, lange bedeckt. später nackt, rostbrauu, stauhig; Sporen ellipsoidisch bis lïnglich, 2〈-42 $\mu$ lang, 14--20 "u breit, obere Zelle oft breiter als die untere, am Scheitel gewöhnlich abgerundet, selteuer verjüngt, stets mit hellerer, kegelfürmiger, $2-4$ " hoher Papille; Membran dünn, gelbbraun, glatt: Stiel kürzer als die Spore, sehr zart, farblos, al,ällig; Keimporus der oberen Zelle scheitelständig, seltener seitwärts verschoben, derjenige der Basalzelle dicht unter der Scheidewand. 
Im Juli und September auf $1906)$ !

Campanula Scheuchzeri: Grosser Kessel im Riesengebirge (5. VII.

\section{Puecinia conglomerata (Strauss) Schumacher et Kunze.}

'l'eleutosporenlager blattunterseits, seltener oberseits, auf gelben oder rötlichen Flecken, klein, stark gewöht, von gehorstener Epidermis budecht, latstanienbraun, staubig, dichtstehend, endich in unsollkommene Kreise oder rumiliche Lager zusammentliessend; Sporen eiformig. ellipsoidisch bis länglioh, ziemlich umgleich, zum Scheitel verjüngt, zur Basis meistens ahgerundet, bei der (guerwaml

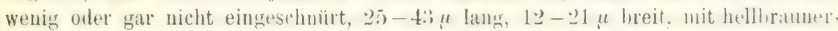
glatter Membran. Stiel hyalio, zart, abfillig; Keimporus der oberen Zelle sifheitelständig, derjenige der Basalzelle bei der (Juerwaul, beide mit kleintu. hỵanen Papillen.

Im Juli und August im Gebirge auf

Homogyne alpina: Im Riesengebirge ziemlich verbreitet am ginzen liamme und auf seinen Abhängen! Gipfel des Glatzer. Schneeberges und Marchquellen! Keilberg im Erzgebirge? (Krieger, Wagner), Hichtelberg (Dydow)! Arber im Böhmerwalde (Krieger).

195. Puccinia caulincola schneder. - Pucciuia Schneideri Schroeter.

Teleutosporenlager auf Stengelı, Blattstielen und Blattspreiten, klein, länglich, lange bedeckt, dann geöffnet, oft zusammentliessend, brann, staubig; sporen ellipsoidisch, beiderseits abgerundet oder manchmal oben verjüngt, bei der Querwand eingeschnürt, 25-38 $\mu$ lang, 15-291" breit, mit pelbhratuer, wlatter, an den Keimporen papillenförmigr verdickter Membran; Stiel lang, zart, farblos, ah). fällig; Keimporus dor oberen \%elle scheitelständig oder wenig herabgerüclit, der. jenige der Basalzelle in verschiedener Lage von der Querwanl his zum Stime.

Von Juli auf

Thymus alpestris: Riesengrund (Domin)!

Thymus chamaedrys: Freibeit bei Trautenau (Domin)!

Das Iycel perenniert wahrselexinlich in Rhizon und dringt jedes Jahr in die neuen Triebe ein, die verlängert werden und gewöhnlich anch nicht blïhen. [)ie befallene Pflanze sieht hexenbesenartig aus,

\section{Puecinia Adoxae Hedwig fil. - Puccinia Adoxae Autt. p. p.}

Teleutosporenlager auf Stengeln, Blattstielen und Blättern gleichmïssig rerteilt oder auf gelben, rumllichen oiler lisolichen Flecken rimeformig uruppiert, klein, rundlich oder elliptisch bis spindelformig, 22-5-44 4 lanz. 1.5 bis

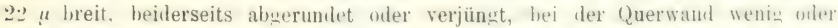

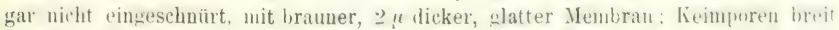
geiiffnet, mit hyalinen, abgerundeten, $2-45$ " hohen P'apillen versehen. Keimporıs der oberen Zelle scheitelstandig, derjenige der Basilzelle dicht an oder unt+rhalh,

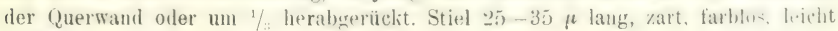
abfällig. 
Von Mitte April bis anfangs Juni auf

Adoxa moschatellina: Teplitz (Thümen). Nieder-Haan bei Osseg (Wiesbaur)! Weltrus (Kabát)!

Ausser diesem Pilze kommen auf Atoxa noch zwei Rostpilze vor und zwar tin isoliertes A ecidium, von welchem ich im J. 1903 nachwewiesen habe, dass es zu Puccinia argentata gehört und zweitens eine Auteupuccinia - Puccin ia albescens (Grév.) Plowr.

197. Puceinia Astrantiae lialchbrenner. - Puccinia astranticola Bubáls.

T'eleutos poren la ger blattbeiderseits auf welblichen oder braunen Flecken in kleineren oder grösseren, dichten Gruppen, selten unregelmässig zerstreut, auf Blattstielen verschiedenartige Líümmunen und Verdickungen verursachend, halbkugelig gewalbt, anfangs son derber Epidermis bedecht, dann mit rundiches ()effumy in der Vitte, staubig, zusammentliessend, chokoladenbram. Sporen eiformigr,

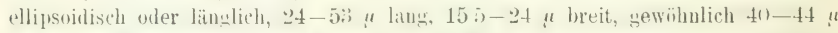
ling, 18-20 " breit, oft stark eckig. in der Witte selten einesescluürt, am Scheitel verjüngt, abgeruniet oder abgestutat; Membrau dunlielbram, glatt; Keimporus der oheren \%elle scheitelstïndig, selten etwas herabgeriickt, derjenige der basalzelle in sehr verschiedenen Lagen son der Querwand his zum Stiele; beide mit nie. driger, etwa ? " hoher l'apile; Stiel halb so lang wie die Spore, zart, farblos, abfällig.

Im Monate Juli auf

Astrantia major: Bilichau (Kabát)! Babina bei Leitmeritz!

198. Puceinia Aegopodii (Schumacher) Link. - Uredo Aegopodii Schumacher. - Puc cin ia Aegopodii Link.

T'leutosporenlager blattheiderseits auf weisslichen, verdickten Flecken in kleinen, rundlichen, auf Nersen und Blattstielen in verlängerten Grupyen, ziemlich Hach, vou dünner Epidermis hedeckt, bald mit länglicher uoregelmässiger Oeftumn, dann zusammentliessend, staubig, schwar\%. Sporen eiformig, ellipsoidisch oder läoglich, oft unregelmässig polyedrisch, 245-4<5 $\mu$ lang. 155-2. $\mu$ breit, gewöhnlich $35-37, \mu>20 \mu$, selten in der Nitte schwach eingeschnürt, mit dunkelkastanienbrauner Membran; obere Zelle gewohnlich am scheitel verjüngt, seltener algerumlet oder alugestut/t. Basalzelle unten abgerundet; Keimporus der oberen \%elle scheitelständig, derjenige der Basalzelle auf der Querwand oler unterhalh derselben, beide mit 2-3 " hoher Papille; Stiel kürzer als die Spore, zart, hyalin, abfällig.

Von Ende April bis Ende Juli auf

A egopodium Podagraria in niedrigeren Lagen, wie auch im Gebirge verbreitet. In der löchsteu I ano sammelte ich sie bei Joachimstal im Erzgebirge.

Von Puccinia Astrantiae unterscheidet sie sich durch die Form der Lager, die Farbe derselhen, wie auch durch die Lage des Keimporus in der Basalzelle. 
ß) Sporen warig.

199. Puccinia fusca (l'ersoms) Winter. - Aecidium fusenm I'ersoun.

Spermogonien blattoberseits oder beiderseits zerstreut, gross, schwarzbraun, später schwarz.

T'eleutosporenlager blattunterseits mehr oder weniger dicht verteilt, rundlich, bald nackt, staubig, oft zusammentliessend, braun: Sporen ans 2 kuslizen orler ollipsoidischen Zellen bestehend, heiderseits abgerundet, hei der Gurwami stark eingeschnürt, 31 - 5n $\mu$ lang, 15-24 $\mu$ breit; Membran hellkastanientraun, mit kriftigen, entfernten Warzen besetzt; Stiel kurz, zart, hyalin. Manchurel anılı einzellige Sporen : $28-33 \times 17-22 \mu$.
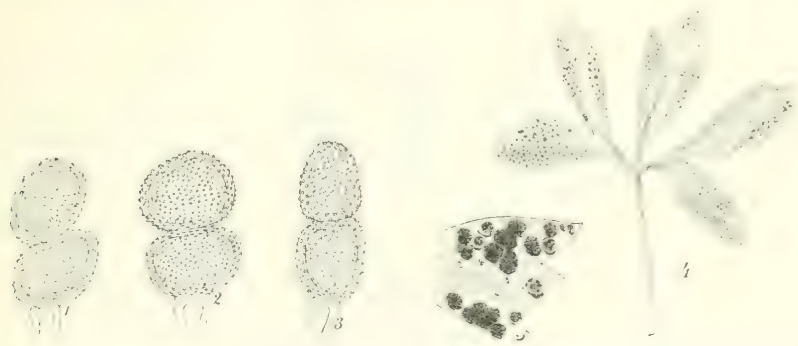

Abb. 27. Puccinia fusca. 1.-3. Telentosporen. 4. Anemone nemorosa mit Teleutosporenlagern.

5. Vergrösserten Teleutosporenlagern.

Von Mitte März bis Ende Juni auf

Anemone nemoros a viel verbreitet.

I)as Mycel überwintert in Rhizom und dringt im Fribjalıre in die Blitter. ein, welche bleicher werden und nur schmale Blattzipfel entwickeln.

200. Puceinia Pulsatillae (0piz) Rostrup. - D i caeoma l'ulsat illatº Opiz. - Puccinia subfusca Holway.

Spermogonien selten entwickelt, blattoberseits, braun.

Teleutosporenlager blattunterseits gleichmässig verteilt, lange von dünner, weisslicher Epillermis bedeckt, damn mit zentraler Oeftumg, fast halt,kurelig rewilbt, staubig, nicht zusammentliessend, schwarzhraum: Sporen von rurschielener Form; obere Zelle gewöhnlich kuglis, untere kugliz his lieilfirmin; Sporen 31-62 " lang, 15-28 $\mu$ hreit, bei der Querwanil stark eingeschmirt, mi. hellkastanienbriuner, in der Basalzelle hellerer, mit liriftigen, entfernt stehenden Warzen besetzter Memhran; Stiel kurz, zart, farhlos; einzellige Sporen 4 ¿<11; $\mu$ 
Von Mitte Mai bis Ende Juli auf

Pulsatilla pratensis: Motol bei Prag (Th. Novák)! Hostín bei Karlstein! Rejkovice bei Lochovic! Im bohm. Mittelgebirge auf Bergen bei Leitmeritz, Aussig, im Bielatale, bei Trebnitz, Bilin usw. ziemlich häufig.

Die biologischen Verhältnisse wie hei der vorangehenden Art. Früher wurde diese Spezies rou neueren Autoren mit Puceinia fusca vereinigt. Im J. 1903 habe ich in Hedwigia gezeigt, dass beide Pilze verschieden sind.

\section{2(11. Puccinia singularis Magnus, - Puecinia l) it umleri Lagerheim.}

Teleutosporenlager hauptsächlich blattunterseits oder auf Blattstielen, seltener blattoherseits, auf rundlichen, gelblichen Flecken, klein, rumdlich, bald aber in grosse. his $2 \mathrm{~cm}$. lange (iruppen zusammenfliessend, nackt, staulig,

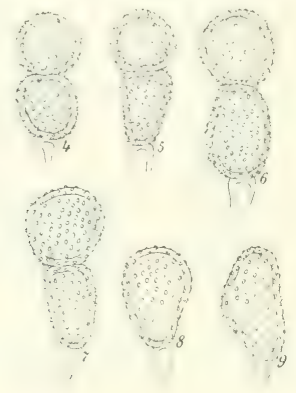

Abb. 28. Teleutosporen von Puccinia Pulsatillae.

dunkelhraun; Sjoren ellipsoilisch his linglich, heiderseits atherundet oder schwach

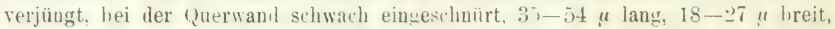
mit kastanienhraumer, feinwarziger Memhran; Stiel zart, farhlos, ahfällig, so lane oder kürzer als die Spore; lieimporus der liasalzelle in Ferschiedener Lage von der Querwand bis zum Stiel, beide mit dicker, hyaliner Papille.

Im April und Mai auf

A nemone ran unculoides: Zwischen Sobochleben und Marschen bei Teplitz (Wiesbaur).

Ich habe keine Belegexemplare gesehen. Nach der Mitteilung des $† \mathrm{P} . J$. W i esbaur wurde der Pilz von Magnus bestimmt.

\section{Puccinia Epilobii De Candolle.}

Teleutosporenlager blattbeiderseits, ofters aber unterseits, klein, rundlich, ziemlich dicht verteilt, bald uaclit, seiten zusammentliessend, rostbraun, 
staubig; Sporen ellipsoidisch oller birnförmis, ziemlich verschiedenartig, beiderseits abgerundet, selten zur. Basis verjüngt, bei der Querwand stark einueschnürt, 28 bis 4" " lans. 20-28 "2 breit, mit hellbruner, feinwarziger, gleichmässig dicker. am Scheitel manchmal mit niedriger, hyaliner Papille versehener Membran; Stiel kurz, farblos, abfillig: Keimporus der Basalzelle manchmal fast bis zum Stielo herabgerückt.

Teleutosporen von Juli auf

Epilobium roseum: Kaplitz (Kirchner)!

Kirchner bestimmte die Nährpflanze für L,ychnis flos cuculi und den Pilz als l'uecinia sp. Die vorliegende Art unterscheidet sich von Puccinia Epilobii tetragoni nicht nur biologisch, sondern auch durch warzige, am Scheitel nicht verdickte Teleutosporen.

\section{Puccinia Ribis De Candolle.}

Tele utosporenlaner blattoberseits auf gelben oder braunen Flecken. ringfömig gruppiert, klein, zusammenfliossend, lunkelbraun, bald nackt, staubig; Sporen ellipsoidisch bis länglich, beiderseits ahgerundet, hei der Querwand eingeschuiut, 25--42 $\mu$ lang, $17--201$ " breit, mit hrauner, warziger Membrau; Stiel kurz, farblos, abfatlig; Leimporus ler basalzelle nahe dem Stiele, beide gewöhnlich mit niedriger, hyaliner, warziger Kappe.

Von August auf

Ribes petratum: Im Riesengrehirge nahe dem Elbfall (Schriiter) uni zirka 1 Stunde unterhalb desselben (Kabát)!

Ribes rubrum: In den Prager Gärten, z. B. im Garten des Grafen Kounic (Corda), liaumgarten (Eck, Kratzmann)! Troja (Schöbl)! Vys. Veseli (Kabat)!

\section{ү) Teleutosporen mit leistenförmigen Verdickungen.}

\section{Puccinia Dentariae (Albertini et Schweinitz) Fuckel.}

Teleutosporenlager hlattunterseits, seltener oberseits, auf Blattstielen und Stengelu, oft stark Verdickungen hervorrufend, bis 25 cm. lang, zusammenflessend, lange von silbergraner lipidermis bedeckt, dann staubig, rostbraun; Sporen meistens länglich, seltener ellipsoidisch, beiderseits abgerunlet oder soltener weni verjüugt, in der Mitte schwach eingeschnürt, $29-46 \mu$ lang, $15-20 \mu$ hreit, mit hellbramer, lïngs nestreifter, an Scheitel papillentirmig verdickter Membran; Stiel burz, hyalin, ziemlich fest, zart.

Im Mai und Juni auf

Dentaria enneaphyllos: Oberbalb der Strasse zwischen Machendorf und Eckersbach bei Reichenberg (Matouschek)!

\section{Puceinia Saxifragae Schlechtendal.}

Teleutosporenlager hlattheiderseits, hauptsächlich aher unterseits, auf sundlichen oder unregelmässigen, gelben, roten oder braunen Flecken, rundlich, 
dichtstehend, zusammentliessend, staubig, dunkelbraun; Sporen eiförmig, ellipsoidisch bis länglich, am Scheitel verjüngt, an der Basis abgerundet oder verjüngt, bei der ()uerwand wenig oder gar nicht eingeschnürt, 26-40 $\mu$ lang, 15-18 $\mu$ breit, mit gelbbramer, längs gestreifter Membran; Stiel kurz, hyalin, abfällig; Keimporen mit halbkugeligen oder kegelfürmigen Papillen bedeckt. (Siehe Abb. 14. III.)

Schon von Mitte April auf

Saxifraga granulata: Polbaba bei l'rag (Corda). Am rechten Elbufer gegenüber Selc! Turnau, Hirschberg (Kabat)! Herruskretschen (Wagner). Pikovice bei Davle (Kabát)! Tábor!

Nach Dietel keimt ein Teil der Teleutosporen sofort nach der Reife.

\section{Leptopuccinia.}

\section{Puceinia Ptarmicae Karsten.}

Teleutosporenlager klein, rundlich, braun oder dunkelbraun, fest, in rundichen, dichten Gruppen, gewöhnlich blattunterseits auf gelben oder rötlichen Flecken, oft zusammenfliessend, von den Sporidien später grau gefürbt: Sporen keulenförmig, an Scheitel abgerundet oder verjüngt, zum Stiel keilförmig verschmilert, bei der Querwand eingeschnürt, 35-57 $\mu$ lang, gelbbraun, glatt, obere Zelle am Scheitel bis $11 \mu$ dick und daselbst dunkler, 175-24 $\mu$ breit, untere Zelle 15-20 $\mu$ breit; Stiel kräftig, im oheren Teile schwach gelblich, bis $66 \mu$ lang, $16 \mu$ breit, dickwandig, nicht abfällig; Keimporus der Basalzelle unterhalb der Querwand, mit ziemlich kräftiger, hyaliner Papille versehen.

Von Juni auf

A chillea Ptarmica: Wald Šejba bei Roždalovic!

\section{Puccinia Millefolii Fuckel.}

Teleut os poren lager rundlich, fest, klein, manchmal auf bleichen Flecken sitzend, blattbeiderseits verteilt, oft zusammenfliessend, braun, von den Sporidien grau gefärbt; Sporen ellipsoidisch oder keulenförmig, an Scheitel abgerundet oder verjüngt, zum Stiel keilförmig verschmälert, bei ler Querwand schwach eingesphnürt, 35-5.) $\mu$ lang, $14.27 \mu$ breit, mit glatter, hrauner, am Scheitel stark verdickter Membran; Stiel krïftig, farblos, nicht abfällig, etwa so lang wie die spore.

Von Juni his zum Winter auf

Achillea millefolium: Welwarn (Kabát)!

A chillea setacea: Komořany bei Prag! Welwarn (Kabát)!

\section{Puceinia Verruca Thümen.}

Teleutosporenlager blattunterseits. auf rundlichen, gelben his braunen gewölbten Flecken, kleiu, halbkugelig, dicht gruppiert, dunkelbraun, fest; Sporen schlank keulenformig, am Scheitel abgerundet orler kegelfümig verjüugt, zum Stiel verschmälert, hei der (unerwand schwach eingeschnürt, 40 -6s $\mu$ lang, 12 bis 
$24 \mu$ hreit, mit hellhrauner, glatter, am Scheitel his $14 \mu$ dicker Memhran; Stiel kräftig, bis $70 \mu$ lang, nicht abfillig, hyalin.

Von Juli auf

Centaurea montana: Niedergrund bei Tetschen (Wagner).

\section{Puceinia Valantiae Persoon.}

T'eleutosporenlager rundlich oder länglich, auf den Blättern und Stengeln einzeln oder ringformig, manchmal auf den Stemeeln in verläuserte, verschiedene Verdickungen und líümungen verursaheme (iruppen zusanmenHiessend, halbkugelig rewillt, fest, helloriau, fon den sporidien gratu gefirbt; sporen spindelformig, heiderseits verjüngt onter manchmal am Scheited abgerundet,

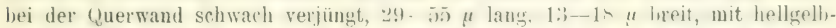
brauner, glatter, am Scheitel bis $9 \mu$ dicker Membran; Stiel his s() $\mu$ lang. farblos, nicht abfällig.

Von Mai bis zum Winter auf

Galium Cruciata: Cibulka bei Prag (Opiz)!

Galium mollugo: Welwaru (Kabát)! Odřepsy bei Poděbrad!

(Krieger)!

Galium saxatile: Gottesgab (Wagner) und Keilberg im Erzgehirge

Galium silvaticum: Mühllıausen a. E. (Kahát)! Tábor!

\section{Pnecinia Veronicae Schröter.}

Teleutosporenlager unterseits auf gelben oder braunen, manchmal zrewilbten Flecken, in rundichen Gruppen, zuweilen auch in kunzentrischen Kreisen, klein, halbkugrelig, dichtstehend, bald nackt, hellhran; Sporen lïnglich-ellipsoilisch bis spindelförmin, am Scheitel aborundet oller rerjüngt, zum Stiel versihmälert, bei der (querwand wenig oder gar nicht eingeschuürt, 29-44 " lang, 10-13 $\mu$ breit, mit schwach gelblicher, glatter, am Scheitel bis $7 \mu$ dicker Membran; Stiel so lang wie die Spore, farblos, fest.

Von Juli auf Blättern von

Veronica montana: Babylon hei liovensku, (iross skal! Hermskretschen (IVagner)!

\section{Puccinia Glechomatis De Candolle.}

Teleutosporenlager fest, klein, halbkugelig, auf braunen oder undrutlirhen, oft auch konvexen Flecken, blatunterseits verteilt oder riugfurmis gruppiert und manchual zusammentliessend, auf Iilattstielen und Stengeln Ferlämert, braun bis selwarzhraun, von den sporidien grau gefitht: Sporen eiformı his ellipsoidisch, am scheitel oder seitwäts mit brauner, algerundeter oder lieger-

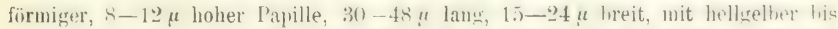
kastamienbrauner, glatter Membran; stiel fest, hyalin, so lang vder lïncer als die Spore.

Durch die ganze Vearetationsperiole, im Winter auch auf äherwinternden Blättern von 
Glechoma hederaceum: Ueberall ziemlich verbreitet.

In der Vegetationsperiode werden hellere Polster gebildet und ihre Sporen sind sofort keimfähig; zum Ende der Vegetationsperiode entstehen dann, gewöhnlich in Kreisen, schwarzbraune Lawer, deren Sporen erst im Frühjahre keimen.

\section{Puceinia anmularis (Strauss) Winter. - Ured o a n $\mathrm{u}$ l a r is strauss.}

T'eleutosporenlager entweder einzeln üher die Bläter zerstreut oder in kreisförmigen firuppen anf der Unterseite gelblicher oder brauner Flecke, anfanıs klein, $\nabla$ on der Epidermis hedeckt, später nackt, zusammentliessend, hraun: Sporen ellipsoidisch, länglich bis spindelfömig oder auch zylindrisch, $30-60 \mu$ lang, 13-22 $\mu$ hreit, sehr hell gelhhraun, in der Mitte gewöhnlich mehr oder weniner eingeschnürt, obere Zelle liäufig breiter und länger als die Basalzelle, am Scheitel his $11 \mu$ dick, alıerundet oder in eine fast farblose, oft seitwärts gebogone Spitze verjüngt, untere Zelle keilfürmig verschmälert; Stiel his $95 \mu$ lang, fest, hyalin.

Von Mai bis zum Ende der Vegetationsperiode auf

T e u c r i m cham a d rys nur in wärmsten Gegenden: Lehne gegenüher Kinsoř hei Radutin, Kuchelbad! Hedsehe hei Weltrus (Kahát)! Lohosch bei Lohositz!

\section{Puccinia grisea (Strauss) Winter.}

Teleut osporenlager auf braunen oder schwarzbraunen, rundlichen Flecken blattunterseits, oder auch auf Blattstielen, ringförmig um ein zentrales Lager stehend oder gruppiert, hellhraum, hald narkt, fest; Sporen länglich his spindelförmig, am scheitel abgerundet, verjüngt, zum Stiel gewïnlich verschmälert, bei der Querwand wenig oder gar nicht eingeschnürt, 35-55 " $\operatorname{lang}, 12-18 \mu$ hreit, mit sthwach gelhlicher, glatter, am Scheitel und am unteren Keimporus his 11 " dicker Membran; Stiel lang, kräftig, hyalin, nicht abfällig; Keimporus der Basalzelle dicht bei der Querwand.

Von April bis zum Vegetationsende auf

(ilobularia Willkommii: Waldlehnen zwischen Raudnitz und Kalešov (20. VI. 1902)!

\section{Puceinia Thlaspeos Schubert.}

Teleutosporenlager sehr dicht, blattunterseits, auch auf Kelch- und Kronenblïttern, rundlich. grewölbt, fest, braun; Sporen ellipsoidisch bis länglich, manchmal auch keulenförmig, an Scheitel ahgerundet oder verjüngt, zum Stiel gewöhnlich verschmälert, bei der Querwand schwach eingeschnürt, $35-44 \mu$ lang, $15-18 \mu$ breit, mit glatter, gelhlicher bis gelbbrauuer, am Scheitel bis $s \mu$ dicker Membran; Stiel manchmal bis $70 \mu$ lang, hyalin, nicht abfällig.

Von Anfang Mai bis zum Winter auf

Arabis hirsuta: Wiesen bei V'setat (Hora in Sydow s Uredineen Nr. 443)! Wiesen bei Velenka! 
Thlaspi alpestre: Zahoranertal bei d)arle. Seitental hinter Leznice gegen

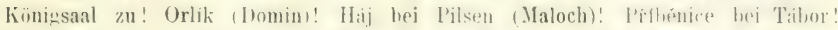
Katharinaberg bei Reichenbers Matouschek)! Herrnsketschen IThimen, Kriener,

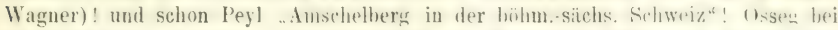
Dux (Thümen). Keilherg und Fichtelher: im Erzgebirge (IVasner)! I)uppan hei Karlsbad (Wiesbaur)!

Ias Mycel üherwintert und dringt in Friihalıre in alle neuen Triebe ein, die es deformiert, so dass sie kurz bleiben, wihlond die Blitter mor klein und gelblich werden.

\section{Puccinia Arenariae (Schumacher) Winter.}

'Teleutosporenlager rundlich oder länglich, auf den Blättern zerstreut oder gruppiert, oft riugformig stehend, auf den Stengeln in verlangerten firmpen, hellbraun, später dunkler, von den Sporislien grau getirbt, fest: Sporen ellipsoidisch, lïnglich-spintelformig oder keulenformig, am Scheitel meistens verjüngt orler fast zugespitzt, an der Basis abgerundet ofler allnibhlich in don Stin verschmälert,

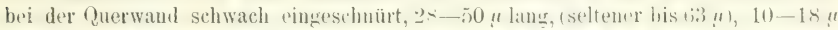
breit, mit glatter, helgelber, am Schutel bis 10 u dicker Memhan; Stiel hyalin, bis $140 \mu$ lang, nicht abfällig.

Die ganze Vegetationsperiode hindurch; alle Lager lianu man auch im Wrinter, z. B. auf Stellaria Holostea finden.

Arenaria serpyllifolia: Budohostice bei Welwarn (Kabát)!

Dianthus barbatus: Prag (Opiz, Hotfinann)! Prribram (Domin)! Rotenhaus bei Komotau (Roth)!

Cerastium triviale: Teplitz (Thümen, Wagner). Wittingau (Weidmann) !

II a la chium a quaticum: Turnau, Kost bei Sobotka, Welwarn (Kabát)! Kaplitz (Kirchner).

Melandryum silvestre: Kost bei Sobotka (Kabat)! Neuwelt! Herrnskretschen (Wagner). Hammerstein bei Reichenberg (Matouschek)!

Mo ehringia trinervia: Sehr verbreitet.

Sagina procumbens: Rovensko! Kost bei Sobotka (Kabát)! Riesenarund und Cirenzbauden im Riesengebirge (Schroeter. Tibor! Kaplitz (Kirchner).

Stellaria gram in ea: Herrnskretschen (Wagner); Langenau bei Hohenelbe (Cypers).

Stellaria Holostea: Cibulka, Stern bei Prag! Mühlhausen (Kabát)! Aussig (Thümen). Herruskretschen (WVagner). Tábor!

Stella ria media: Š́rka bei Pragr (Corda). Welwarn (Kabát)! Raudnitz (Thümen). Gross Skal! Hoch Veseli (Kabit)! Lolin (Veselsky). Harta bei Ilohenelbe (Cypers). Aussig (Thümen).

Stellaria nemorum: Viel verbreitet. 
216. Puccinia Herniariae Unger 1836. - Puccinia Herniariae Kirchner 1856.

Teleutosporen auf Blättern und Stengeln, stark gewölht, fest, im Umrisse rundlich oder länglich, anfangs braun, später schwarzbraun, oft in grössere, kompakte Polster zusammenfliesseme; Sporen ellipsoidisch, lüuglich oder spindelförmig, beiderseits abgerundet oder verjüngt, bei der Querwand schwach eingeschnürt, 30-44 $\mu$ lang, $11-165 \mu$ breit, mit hellgelblicher, glatter, am Scheitel 3-4 $\mu$ dicker Membran; Stiel kriftig, his $110 \mu$ lang, schwach gelblich oder hyalin, nicht abfällig.

Von Juni bis zum Winter, überwinternde Lager bis zum Frühjahre auf

Herniaria glabra: Klein Rohozec bei Turnau (Kabát), Kaplitz (Kirchner).

217. Puccinia Spergulae De Candolle. - Puccinia Spergulae Kirchner, Lotos 1856, p. 182.

Teleutosporenlager auf Blittern, Stengeln, Aesten, Blütenstielen und Kelchen, rundich oder linglich, stark gewoilht, oft zusammentliessend, hraun bis schwarzbraun, von den Sporidien später grau gefübt; Sporen spindel-oder keulenformig, am Scheitel abgerundet oder verjüngt, zum Stiel verschmälert orler manchmal abgerumlet, hei der Querwand mïssig eingeschniurt, $30-52 \mu$ lang, $12-1 \leftarrow \mu$ breit, mit hellgellbramer, slatter, an Scheitel bis ? " Membran; Stiel bis $90 \mu$ lang, krüftig, bräunlich, nicht abfällig.

Von Juni bis zum Winter auf

Spergula arvensis: Záhoŕi und Bor bei Rovensko! Roudné bei Turnau (Kabát)! Teplitz (Thümen). Wittingan (Weidman)! Goldenkron bei Krrumau (Jungbauer bei Kirchner 1. c.).

\section{Puccinia Malvacearum Montagne.}

Trleutosporenlager rundlich, halblugelig gewölbt, nackt, fest, hellbraun, später dunkler, blattunterseits, auf Blattstielen und Stengeln verteilt: Sporen aiförmig. ellipsoidisch oler liurz spindelförmiø, beiderseits gewöhnlich rerjüngt, seltener oben abgerundet, bei der Querwand eingeschnürt, 35- $70 \mu$ laug, $17-24 \mu$ breit, mit hellgelber, glatter, am Scheitel stark verdickter Membran: Stiel kräitig, bis $150 \mu$ lang, hyalin, nicht abfällig.

Von März bis zum Winter, alte Lager auch im Winter auf

Althaea officinalis: Herrnskxetschen (Wagner) Tábor!

Althatea rosea: Welwarn, Hoch Veseli (Kabat)! Rovensho! Ilerrnskretschen, Dittershach bei Bühm. Kamnitz (Wagner). Mariaschein und Kulm bei Karbitz (Wiesbaur)! Hlinsko! Bernardice bei Tábor! Tábor!

Althaea rosea var. nigra: Botan. Garten in Tábor!

II lva r:tundifolia: Hoch Veself (Kabat)! Hermskretschen (Wagner)! Thammühle bei Hirschberg (Kabát)! Soběslav! 
Malva silvestris: Müblhausen a. E. (Kabat)! Iohositz! Wopparnertal (Kabát)! Stěpánorice (16./:3.!), Tjezd uud lioketnice bei Jurensko! Solčan (Th. Novák)! Č́ernice bei Pilsen (Maloch)! Náchod bei Tábor!

Malva vulgaris: Welwarn (Kabát)! Herrnskretschen (Wagner).

I)iese Pucrinia-Art wurle nach Guropa aus (hile eingeschleppt und ersehien zum erstenmale in J. 1 sis? in spanien, woher sie sich in kurzer Zeit üher nanz Europa verbreitet hat.
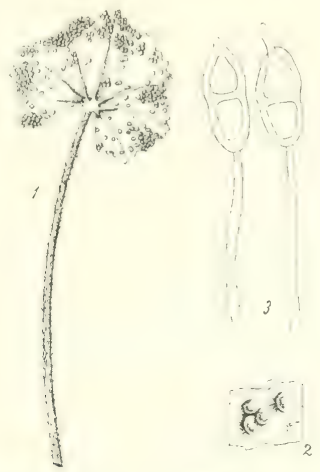

Abb. 29. Puccinia Malucaram. 1. Teleutosporenlager auf Malva rotundifolia. 2. Dieselben vergrössert. 3. Teleutosporen, die rechte im Keimungsstadium.

\section{Puccinia Cireaeae Persoon.}

T'eleutosporenlager fest, von zweierlei Art: klein, halbkugelig, hellhrann, in kleineren oder grösseren rundlichen Gruplen, unterseits auf gelblichen Flecken dicht rruppiert, spaiter zusammenfliessend; ihre Sporen sofort keimfïlig, mit hellbrauner Membran; Lager der zweiten Art werden rrst später webildet, meistens auf Blattnerven und Stengeln, länglich, dunkelbraun; Sporen ellipsoidisch his spindelförmig, am Scheitel abgerundet oder in eine hohe (12 $\mu$ ) kegelformige Papille verjüngt, zum Stiel verschmälert, bei der Querwanil schwah eingeschnürt. 25-4i) $\mu$ lang, 8-14 " breit, glatt, "rst im Fribjahre lieimfähig; Stiel fest, hyaliu so lang oder länger als die Spore.

Von Juli bis zum Winter auf

Circaea alpina: Wittingau (Weidman)! Herruskretschen (Wagner)!

Circaea intermedia: Kaplitz (Kirchner)! Frimburg bei Hrádek nächst Schüttenhofen (Vodák)!

Circaea lutetiana: Weltrus (Graf Chotek)! Nové Dvory bei Kuttenberge (Veselský)! Kačina (P'eyl)! Bühm. Leipa (Schiffner)! Schatzlar I(ferhard)! 


\section{Puccinia Chrysosplenii Greville.}

Teleutosporen von zweierlei Art: 1. forma persistens Dietel. Lager klein halbkugelin, gewohnlich blattunterseits in lireisformigen Gruppen, hellbraun. fest; Sporen spindelformis, an Scheitel in eine hohe $(9, u)$. kegelformige Papille übergehend, unten abgerundet oder in den Stiel versehmälert, hei der (Luerwand schwarh eingeschnürt, 28-40 $\mu$ lang, 11-1i) $\mu$ breit, mit glatter, schwach gelhlicher Membran: Stiel fest, hyalin, his 4) $\mu$ lang; Keimporus der oberen Zelle scheitelstündig, derjenige der lasalzelle dicht unter der sicheidewand: Sporen gleich nach der Reife keimfähig.

2. forma fragilipes Dietel. Lager blattoberseits in ruudlichen Gruppen oder zerstreut, zimmtbraun, staubig; Sporen ellipsoidisch bis länglich, beiderseits abgerunclet oller verjüngt, am Scheitel mit aufresetzter, kegelfurmiger I'apille, bei lev Onerwand stark eingeschüurt, mit gelbirauner, schwach leistenfürmiger Membran, $26-35 \mu$ lang, $14-18 \mu$ breit, erst im Frühjahre keimfähig. (Siehe Abb. 17., I.)

Vou April bis zum Winter auf

Chrysosplenium alternifolium: Radotín bei Prag (Velenorský im Herb. Th. Novák)! Herrnskretschen (Wagner)!

Sporen der Form persistens dienen zur Verbreitung des Pilzes während der Vegetationsperiode, diejenigen der Form fragilipes zur brhaltung der Art über den IVinter.

\section{Puccinia Virgaureae (De Candolle) Libert.}

'Teleutosporenlager hauptsächlich blattunterseits, seltener oberseits, auf gelben oder rötlichen, rundlichen Flecken, klein, schwarzhraun bis schwarz, dicht längs der Nerven grereiht, fast demiritische Gruppen bildend, tirf eingesenkt, von braunen Parafysen umgeben, endlich oft in fast zusammenhäugenle Überzuge zusammentliessend.

Sporen sehr ungleich, ellipsoidisch, leulenfirmig bis spindelformig, :35-55 "4 lang, $12-1$ is $\mu$ hreit, am scheitel ahgestutzt, ahgerundet orler verjüngt, zum Stiel rerschmatert, hei der (Querwand schwarh eingeschnür, mit glatter, hellgelbbrauner, am Scheitel stark rerdickter Membran; Stiel schwach hriunlich, so lang oder kürzer als die Spore. Oft kommen in den Lagern auch einzellige Teleutosporen vor.

Im August und September auf Blättern von

Solidago virugarea: Hannersdorf bei Görkau an Fusse des Erzgebirges (9. IX. 1896, Wiesbaur)!

\section{Familie. Gymnosporangieae.}

Teleutosporen zweizellig, in einer Gallertmasse eingehüllt oder mit stark aufquellenden Stielen. Aecidien mit Pseudoperidien versehen. 


\section{Gymnosporangium.}

Spermogonien flach oder krugförmig, mit kegelformiger Mündung.

A ecidien mit vollkommenen Pseuloperidien, dickwindig, lirugfurmig,

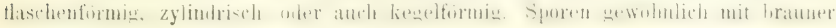
Membran und einigen Keimporen.

Tele utosporen zwei-, seltener mehrzellig, in gallertartige oder stark aufquellende, verschiedenartige Polster zusammengeklebt; in jeder Zelle einige lieimporen.

Uredosporen fehlen. Unsere einheimischen Arten sind alle heteroecisch und hilden ihre decidien atuf Pomaceen, Telentosporen auf Cupressineen aus. Thentusporen sind ron zweierlei Art: dirkwamlig. dunkler und diunwandig, heller. (Keimung siehe Abb. :3,3.)

\section{Gymnosporangium tremelloides R. Hartig.}

Spermogonien blattoberseits auf grossen, rotorangen Flecken, honigrötlichbraun, niedrig legelförmig.

Aecidien |Roestelia penicillata (Müller) Fries| blattunterseits auf stark verdicktem Gewebe; I'sendoperidien anfangs kegelformig, greschlossen, spriter offen. nedrig walzenfrirmig, weiss oder gelblich, ihr Rand bis zur liasis fadenförmig zer. schlitzt; sporen lughig bis lïnglich, manchmal etwas polycilrisch, 33-42 "1 lans, 28 -3.) " hreit, mit braner, 4-5 " dicker, zusammenesehrumpftwarziger Meuhran und 6-10 Keimporen.

'T'eleutosporen in schüsselförmige oder schalenförmige Fruchtkörver vereinigt, in reifen \%ustande oder tencht orange; Sporeu zweierlei Art, dickwandig

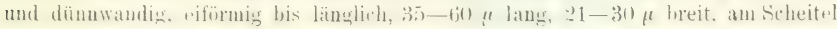

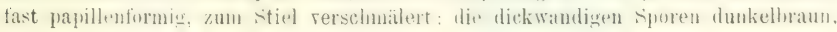
kürzer und breiter als die dünnwandigen.

Aecidien im August und September auf

P'irus II alus: Karlstein (Opiz 1837)!

Teleutosporen werden über den Winter gebildet auf Aesten von

Juniperus c o mu un i s: Roblinertal bei Karistein! Kladno (Velenovský)!

Der genetische Zusammenhang wurde zuerst von Rathay festgestellt. Die Aecidien kommen auch auf P'irus Aria vor; aus Böhmen sah ich sie aber bisher nicht. Was unter diesem Namen von ilturen bohmischen Simmlern anf Pirm Ariat ausgegeben wurde, sind nur Phytoptus-Gebilde.

\section{Gymmosporangium clavariiforme (Jacquin) Rees.}

Spermogonien in kleinen Gruppen auf orangefarbigen Flecken.

A ecidien auf der Unterseite derselben Flecke, auf verdicktem Gewebe, mit waluenformigen bis zur Basis zerschlitzten Psendoperidien; sporen lingli- bis

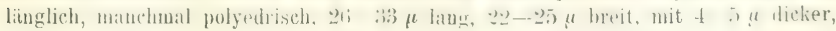
brauner, fein- und dichtwarziger Membran, mit undeutlichen Keimporen. 
Teleut os poren in lange, walzenförmige oder zungenförnige, hellrotorange Fruchtlörper vereinigt; dünmwandige Sporen 100-120 " lang, $10-18$ " breit, beiderseits verjüngt, dickwandige dunkler, $50-60 \mu$ ling, $15-21 \mu$ breit, am Scheitel abgerundet-verjüngt, zum Stiel verschmälert.
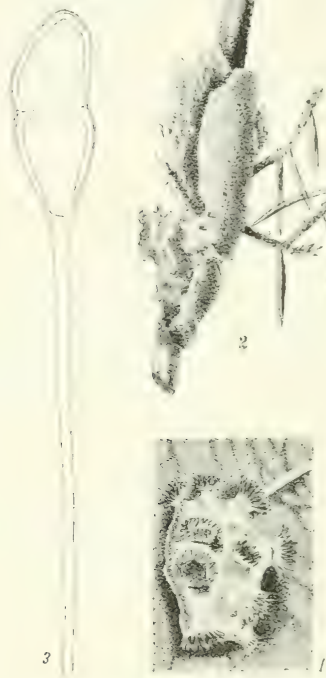

Abb. 30. Gymnosporangitum tremelloides. 1. Aecidien auf Pirus Aria. 2. Teleutosporenlager auf Juniperus communis. 3. Eine Teleutospore. (Nach Dietel.)

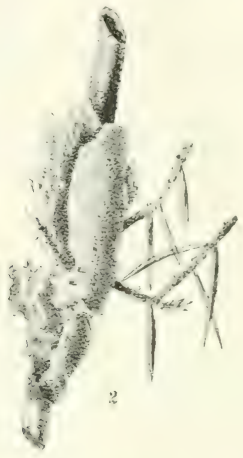

Aecidien im Juni auf Blättern von

Crataegus monogyna: bei Prag (Opiz)! Koda bei Tetín! Rovensko! Wittingau (Weidman)!

Sorbus torminalis: Kanalgarten bei Prag (Eck)!

Teleutosporen auf Aesten von Juniperus communis, J. oxycedrus und J. nana. Aus Böhmen sah ich sie noch nicht.

Die Aecidien liommen ausserdem auch auf Crataegus monogyna, oxyacantha, tomentosa, Dunglasii, nigra, tanacetifolia, grandiflora, sanguinea, Pirus communis,
Abb. 31. Dünn- und dickwandige Teleutosporen von Gymnosporangium clavariaeforme. (Nach Dietel.) 
Malus, Cydonia vulearis, Sorhus latifolia. Ancuparia, torminahs. Amelanchior canadensis, rulgaris.

Der genetische Zusammenhang wurde zuerst von Oerstedt festgestellt.

224. (jymnosporangium juniperinum (Limne) Fries. - Aceidium cornutum Gmelin.

Spermogonien auf der Oberseite orangefarbiger Flecke, in kleinen Gruppen, kegelförmig hervorragend.

A ecidien auf der Unterseite derselben Flecke, auf verdicktem Gewebe gruppenweise, mit langen, walzenfömigen I'seudoperidim, nur wente oder gar

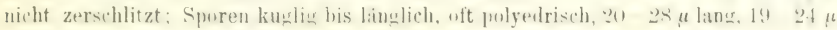

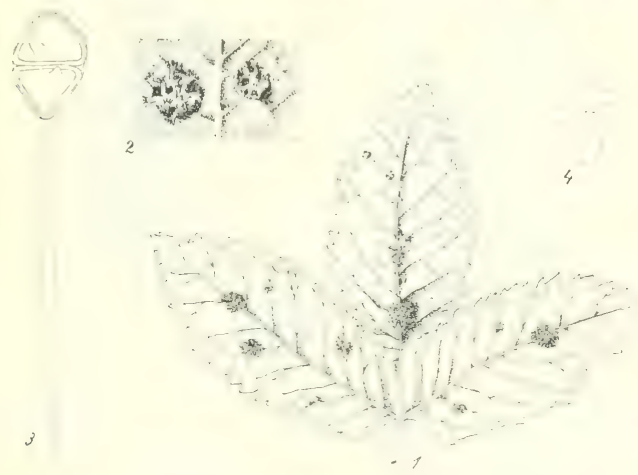

Abb. 32. Gymnosporangium juniperinum. 1. Aecidien auf Blätern von Sorbus Aucuparia. 2. Dieselben vergrössert. 3. Eine dickwandige und t. eine dünnwandige Teleutospore. (Nach Dietel.

hreit, mit dicker, bramer, dichtwarziger. Stellenweise flatter Membran und mit 6 Keimporen.

Teleutosporen in gelbrote Polster zusammengeklebt; Sporen beiderseits konisch abgerundet, 31-52 $\mu$ lang, $21-30 \mu$ breit, oft am. Scheitel mit breiter, farbloser Papille und mit dicker, gelbbrauner Membran.

Aecidien im Juli und August auf Blättern und Früchten von

Sorbus A ucuparia: Sehr verbreitet!

T'eleutosporen aut Nadeln und jungen Aestchen von

Juniperus communis: Ebeufalls verbreitet!

Die Aecidien kommen noch auf Amelanchier $\nabla u l g a r i s$ vor. Der gene. tische Zusammenhang wurde zuerst von Oerstedt festgestellt. 
225. (iymnosporangium Sabinae (Dickson) Winter. - Roestelia cancellat a Rebentisch.

Spermogonien rotorauge, kegelförmig, in kleinen Gruppen oberseits gelber oder rotoranger Flecke.

Aecidien unterseits derselben Flecke auf stark verdicktem Gewebe; Psendoperidien eiformin-kegelförmig, hellbram, am Scheitel geschlossen, nur an den Seiten gitterförmig sich öfneni. Sporen kuglig bis länglich, oft polyodrisch, 2:2 bis $40 \mu$ lang, 17-26 $\mu$ breit, mit brauner, feinwarziger Membran.

Teleuiosporen auf Aesten gruppenweise, unregelmässig kegelformige vier walzenfommige Fruhtkörper bildend; Sporen rifümig his spindelformig, düm- oder

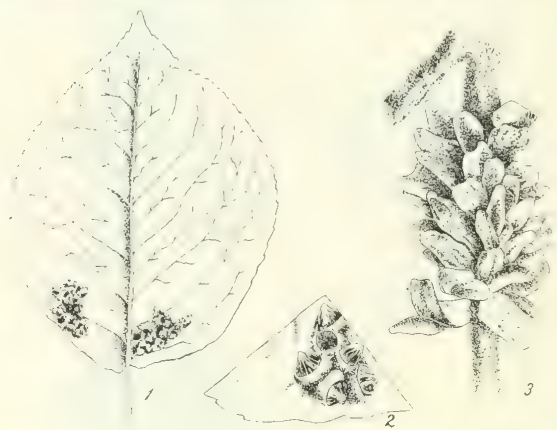

Abb. 33. Gymnosporangium Sabinae. 1. Aecidien auf Birnenblättern. 2. Dieselben vergrössert, 3 Telentosporen-Fruchtkörper auf Juniperus Sabina. (Nach Dietel).

dickwandig, 22-45 $\mu$ lang, 17-30 $\mu$ breit, beiderseits konisch verjüngt, bei der Querwand schwach eingeschnürt; Membran mehr oder weniger braun, in jeder Zelle 4 Keimporen.

Aecidien von Juli auf Blättern und seltener Früchten von

Pirus communis: Sehr verbreitet!

Teleutosporen auf Aesten von

Juniperus Sabina: Ebenfalls verbreitet.

Ias T'eleutosporemmycel überwintert in den Aesten, die dicker werden; jedes Jahr werden auf de.ı infizierten Stellen nene Fruchtkörper ansgebildet.

Der genetische Zusammenhang wurde zuerst von Oerstedt festgestellt.

\section{Familie. Phragmidieae.}

Teleutosporen zwei- bis vielzellig, untereinander frei; einzelne Zellen kettenformig oder in Form eint's Dreieckes verbunden. Aecidien obne Pseudoperidien, von Caeoma-Tyyus. Sporidien fast kuglig. 


\section{Gattungen.}

1. 'Teleutosporen drei- bis vielzellig, Zellen kettenförmig verbunien

2. Teleutosporen dreizellig, Kellen in form eines Dreieckes verbunilen Triphin!mmum.

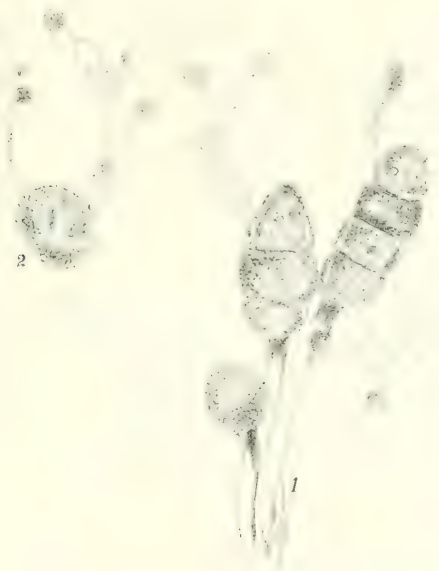

Abb. 34. Keimende Teleutosporen von 1. Phragmidium Rubi.

2. von Triphragmium Ulmariae. (Nach Tulasne.)

\section{Phragmidium Link.}

Spermogonien flach, von der Epidermis bedeckt.

A ecidien ohne Pseudoperidien, vom Caeoma-Typus, aussen gewöhnlich von einem Kranze nach innen gehngener l'arafisen umgeben; Sporen in kurzen Ketten, manchmal mit deutlichen interkalaren Zellen, gewöhnlich mit ti-s Keimporen.

Uredosporen gestielt, mit 6-8 Keimporen, mit Parafysen wie Caeoma.

Teleutosporen dreizellig bis vielzellig, Zellen kettenförmig verbunden, seltener $1-2$ zellig.

Sporidien kuglig. (Siehe Abb. 34, 1.)

Die Gattung Phragmidium kommt nur auf Rosaceen vor und alle Spezios sind :utoecisch. 
I. En-Plnagmidium. Alle Sporenformen auf derselben Planze entwickelt.

1. Teleutosporen erst im Frühjahre keimfähig.

a) Teleutosporenstiele an der Basis nicht aufgeblasen.

\section{Phragmidium Sanguisorbae (De Candolle) Schröter.}

Spermotronien gross, honigrelb, kreisformig oder in rudlichen Gruppen. blattbeiderseits auf dunkelpurpurroten Flecken.

Ca e omalager klein, rundlich bis länglich, gewöhnlich um die Spermogonien ringförmig stehend und zusammentliessend, auf Nerven und Biatt-tieleri verlingert, rotorange: sporen gewihnlich von keulenförmigsn. qebogenen, manchmal auch gelb gefübten Parafysen umgeben, kuglig bis länglich, 18-26 " lang. 14i his $22 \mu$ breit, ziemlich dichtwarzig, mit $6-8$ Keimporen.

Uredolager klein, rundlich bis elliptisch. hauptsächlich hlattuntrrseits,

von stark gehogenen, keulenfirmigen Parafysen ungeben; Sporen kuglig his ellipsoidisch, $16-22 \mu$ lang, $16-18 \mu$ hreit, mit entfernt stachliger Membran und 6-8 Keimporen.

Tele ut os porenlager klein, rundlich, bald nackt, schwarz, hauptsächlirh

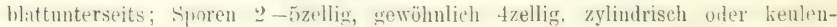
firmig, oben abgerundet oder verjüngt und damn mit einer Pajille versehen, an der Basis abgerundet, bei der Querwand schwach eingeschnürt, 44- io " lan», $2(1-24 \mu$ breit obere Zelle am lïnssten; Membran dunkelhraun, mit zerstreuten Wirzchen verseheu; Krimporen $2-3$ in jeder Zelle; Stiel 2)-2s $\mu$ lang, farhlos, Caeoma schon im März, Uredo von April, Telentosporen vou Juni auf $\mathrm{S}$ anguisorba minor: Ueberall verbreitet!

\section{Phragmidium Fragariastri (l)e ('andolle) Schrïter.}

Spermogonien kleiu, gelblich, in dichten, kleinen Gruppen auf der Oberseite der Flecke oder in der Mitte der Caeomagruppen

Caeomalager auf der Unterseite gelber oder rötlicher Flecke, auf den Blattspreiten in rundlichen bis länglichen oder anch ringformicen Gruppen, ant den Verreu und Blattstielen verlämgert, orange, von Parafy-en umueben; Sporen kuglig bis ellipsoilisch, oft polyedrisch, 17-28 $\mu$ lann, 14-20 " breit, ziemlich dichtwarzig, mit orangerotem Inhalt.

Uredolager auf der Unterseite gelblicher Flecke zerstreut, bald nackt, Ion zahlreichen, kopffirmigen Parafrsen durchsetzt und umgeben; Sporen liuglig bis ellipsoidisch, 17-24 $\mu$ lang, 14-20 $\mu$ breit, mit stachliger Membran und orangerotem Inhalt.

Teleutosporenlager blattunterseits, auf gelblichen Fleckchen, kleiu, schwarzhraun, bald nackt, staubig; sporen 2-5zellis. gewohnlich 4zellig. zyliudrisch his kenlenformig, heiderseits ahzerundet, ohne Papille, bei den Querwinden schwach eiugeschü̈rt, 45-70 4 lang. 2.2-2s $u$ breit, mit hellhraumer, wlatter oder zerstrent (am Scheitel dichter) warziger Membran: Keimproren 3 (seltener :) in jeder Zelle; Stiel 14-22 $\mu$ lang, farblos. 
Caeoma vou Ende Mai bis Mitte Juni, Uredosporen von Juni, Teleutosporen von Juli auf

Potentilla alba: Bei Prag öfters, z. B. St. P'rokop, Radotín! Stern

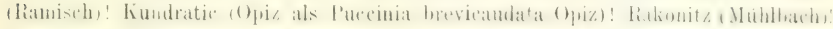

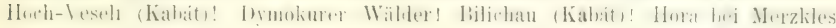
nächst Mileschan, Welbine und Skalic hei Leitmeritz, beim Dorfe Sedel nächst. Aussig!

\section{Pluagmidium Potentillae (P'ersoon) Winter.}

Spermogonien und Caeoma wie bei Phragmidium Fragariastri

Uredolager ebenfalls; Sporen von kopffömigen, bis $20 \mu$ breiten Parafysen umgeben, 20-24 $\mu$ lang, 18-20 $\mu$ breit, mit feinstacheliger Membran.

'́eleutosporenlager rundich, schwarz, bald nackt, blattunterseits zerstrent oder atuch dirht verteilt; sporen ; - bzellig, selten 1-zzellig, zylindrisch

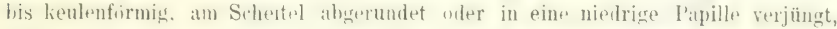
unten abgerundet und breit auf den Stiel aufgesetzt, $40-80 \mu$ lang, $22-28 \mu$ hreit, bei der Querwand gar nicht oder nu wenig eiuseschnüt, obere \%elle am lïnsten; Membran kastanienbram, glatt, in jeder Zelle nahe der Querwand mit 2-3 Keimporen; Stiel bis $150 \mu$ lang, farblos, fest, gleichmässig dick.

Caeoma schon Ende April und im Mai, Uredosporen von Mai, Teleutosporen von Juli auf

Potentilla opaca, verna, cinerea, argentea verbreitet.

Potentilla aurea: Im Riesengebirge und auf dem Glatzer Schneeberge in niedrigeren, wie auch höheren Lagen zerstreut.

b) Teleutosporenstiele an der Basis stark vertickt.

\section{Phragmidium subcorticinum (Schrauk) Winter.}

Spermogonien flach, subepidermal, gelblich.

Ca eomat auf Arstehen, Blattstielen, Blattmerven und jungèn linüchten in unregelmässigen, grosien Lazern, anf Bhatspreiten in kleineren oder grisseren, ringformigen (irmppen, orange, von kenlenformigen, farblosen, bis zo u langen Para. fysen umgehen; Sporen in kurzen Ketten, kuglig bis elipsoidisch, 18- „2. $\mu$ lan.r.

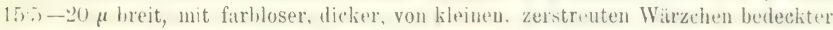
Membran und $6-8$ Keimporen.

Uredosporen klein, rundlich, blattunterseits zerstrent oder gruppiert, orange, von lieulenformign P'arafisen umgetren; soonen kuglig his ellipsoidisch, 1.'-26 und $6-8$ Keimporen.

T'eleutosporen anfangs in den Uredolagern, spïter in selbstïndigen Lagern, schwitz, blattunterseits zerstrent, oft schwarze l'eber/üge hillemi: - proreu

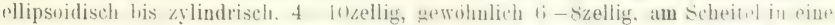
hyaline Papille ibbergehend, unten abgerumbet, hei den Querwinden nicht pingeschuirt, $50-120 \mu$ lang, $26-33 \mu$ breit, obere Zelle am lïngsten, mit kastanien- 
brauner, ungleichmissig warziger Membran; Keimporen $2-3$; in jeder Zelle; Stiel bis $130 \mu$ lang, hyalin, unten stark verdickt.

Caeoma von Mitte Mai, Uredosporen von Juni, Teleutosporen von Juli auf. verschiedenen Rosa-drten. hesonders anf kultivieten Rosen und aut Rosa can in a gemein.

Rosa alba: Teplitz (Thümen). Duppau bei Karlsbad (WViesbaur)!

Rosa cinerascens: Welhotten bei Gross-Priesen, Welhenitz bei Kostenblatt!

Rosa c oriifolia: Rovensko! Eisenbrod (Kabát)! Selčany (Th. Novák)!

Rosa turbinata: Welwarn (Kabát)!

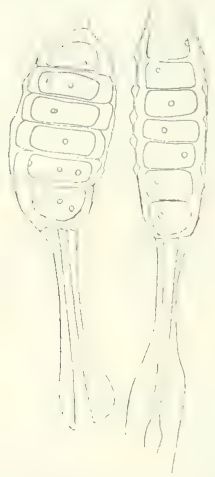

Abb. 35. Teleutosporen von Phragmidium subcorticinum von Rosa canina. (Nach E. Fischer.)
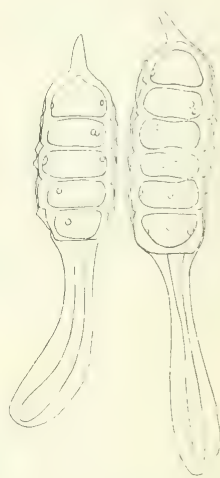

Abb. 36. Teleutosporen von Phragmidium tuberculatum von Rosa cinnamomea. (Nach E. Fischer.)

\section{Phragmidium Rosae pimpinellaefoliae (Rabenhorst) Dietel.}

Caeoma auf Nerven, Blattstielen, hauptsächlich junger Blätter, oder auf jungen Aesten und Früchten in ziemlich grossen, orangeroten. staubigen Lagern; Sporen kuglig oder eilormig, oft schwach polyedrisch, $17-2 \cdot 2 \mu$ lang, $15-20 \mu$ breit, mit farbloser, etwa $2 \mu$ dicker, feiuwarziger Membran; Inhalt orange.

Uredolager unterseits auf kleinen, gelben Fleckchen, sebr klein, orange, von stark gebonenen, walzenfürmigen oder bben schwach erweiterten, zahlreichen Parafysen umgeben; Sporen wie bei Caeoma, mit etwas stärkerer (2.5 $\mu)$ Membran. 
'I' eleutosporenlager blattunterseits, dunkelbraun, klein; Sporen wie bei der vorangehenden Spezies, aber liastanienhraun, $1 ;-8$ zellig. (i5)-87 u lang $28-30 \mu$ breit. Juli auf

Carma von Ende Mai, Ureilosporen von Iuni, Teleutosporen von Enile Rosa pimpinella ef olia: Ziegelschänke bei Trebnitz!

\section{¿331. Phragmidium tubereulatum J. Müller.}

Spermog onien in kleinen Gruppen blattoberseits, klein, honiggelb.

Ca eomalager unterseits auf gelben oder karminroten Flecken, einzeln oder in firuppen. später oft zusammenflessend, auf den Strngeln verlingrent, von einem Kranze farbloser. oben nur wenig oder gar nicht erweiterter Parafyseu umgeben; Sporen ellipsoidisch oder kuglig-polyedrisch, 18-;2 $\mu$ lang, 11 - $20 \mu$ breit: Membran farblos, mit würfelfoimigen oder prismatischen Warzen bedeckt: lieim. poren $6-8$, gewöhnlich beiderseits gewölbt; Inhalt orange.

Uredolager klein, unterseits auf gelben Flecken, rundlich, bald nackt,

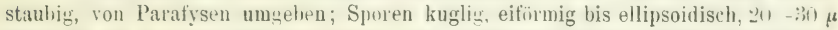
lang, 1s-20 " breit; Membran dick, mit kräftigen Stachelı besetat; Keimporen $6-8$, beiderseits gewölbt.

Teleutosporenlager zerstreut, auf der Unterseite von gelber oder karminroter Flecke; Sporen walzenformiz oder lïnglich ellipsoidisch, 4-tizellig, beiderseits abgerundet, am Scheitel mit gelblicher, bis $2+u$ hoher Papille, hei den Querwänden nicht eingeschnürt, 5j-100 " lang (ohne Papille), :33-37 $\mu$ breit, mit kastanienbrauner Membran; in jeder Zelle 2-:3 Keimporen; Stiel bis $130 \mu$ lang, unten stark verdickt. gust auf

Caeoma von Mai bis Juli, Uredosporen von Juni, Teleutosporen von Au-

Rosa canina: Podbaba bei Prag! Hedsebo bei Weltrus, Lešany bei Welwarn (Kabat)! Hoch Veseli (drerselbe)! Selian (Th. Noráli)! Taus (derselbe) Goldenkron bei Krumau!

Rosa cinnamomea fl. pl.: Rovensko! Turnau (Kabát)!

Rosa rubiginosa: Radotín bei Prag!

Rosa sepium: Zahořanertal bei Davle Taus (Th. Novák)!

Rosa trach y phylla: Hnojná Lhota bei Tábor!

Inn der voramehenden Art ist dieser Rostpilz durch die Form der Caeomasporen. deutlich und krifti stachlige Uredosporen, die mit 6-8, auf beide Seiten hervorgewïlbten Limporen versehen sind, wie auch durch die am Scheitel abgerundeten, daselbst mit langer und plötzlich aufgesetzter Papille versehenen Teleutosporen verschieden.

\section{2:32. Phragmidium Rosite alpinae (be ('andolle) Sichroeter} der Flecke.

Spermogonien klein, gelbbraun, in kleinen Gruppen auf der Oberseite 
Ca eomalager auf den Früchten gross, rundlich oder länglich, auf den Blattstielen und Blattnerven kleiner, verlingert, auf den Blattspreiten (auf gelhen oder purpurroten Flecken) klpine rundliche Po'ster bildend; Sporen von kenleafümigen Parafysen umgeben, rundlich bis lïuglich, oft polyedrisch, kettenförmig gehiluet, oft mit ziemlich langen interkalaren Zellen, 17-*8 u lang, 15-20 " breit, mit farbloser, dicker, entfernt stachliger Membran und $6-8$ nach innen stark gewölbten Keimporen; Inha!t orange.

Uredolager auf der Unterseite von geller bis purpuroter; oft zusammenHiessender Flecke, zerstreut, klein, runllich, wn einem dichten Kranze stark ge. hogener Parafysea umgeben; Sporen kuglig his ellipsoidisch, 18-气0 |" lang, 15)-18 $\mu$ breit, mit dünner, zerstrent stachliger Membran und $6-8$ wenig deutlichen Keimporen.

Teleutosporenlager anfangs in Uredolagern, später selbständig, in kleinen Gruppen; Sporen zylindrisch bs spindelformig, am Scheitel in eiue hornformige Papille übergehend, unten abgerundet, bei den querwänden nicht eiugeschüirt, $811-120 \mu$ lang. 20 - $25 \mu$ breit, 8 1:3zellig. ohere Zelle am längsten, die übrigen viel litirzer; Membran kistanienbraun, warzig, iu jeder Zelle mit 2 - :3 Keimporen; Stiel farblos, länger als die Spore, unten verdickt.

Caeoma von Juni, Uredosporen von Juli, Teleutosporen von Ende Juli auf

Rosa alpina: In höheren Lagen, besonders in Vorgebirgen verbreitet. Sonst auch am Jeschkenberge (Wagner)! Pintovka bei Tábor.

\section{Phragmidum Rubi Idaei (Persoon) Winter.}

Spermogonien klein, gelblich, blattoberseits.

Ca $\theta 0$ malager blattoberseits auf gelben Flecken, rundlich oder in kleinen, oft rimsformigen firuppen rings um die Spermogonien, von hyalinen, keulenförmigen Parafysen nmgeben, orange, hald nackt, fest, später etwas staubig; Sproren eiförmigr bis ellipsoidisch, 18-22 $\mu$ lang, 15-18 $\mu$ breit, mit $2-3 \mu$ dicker, entfernt stachliger Membran.

Vredolager blattunterseits auf kleinen, „nelblichen Flecken, mehr oder weniger zerstrent oder gruppiert, klein, rundlich, orange, bali staubig, umgeben ron gebozenen, keulenförmigen Parafysen; Sporen ellipsoidisch, 18-22 $u$ lang, 15-18 $\mu$ breit; Membran 2-3 $\mu$ dick, farblos, entfernt stachlig; Iuhalt orange.

Teleutosporenlager in lockeren Gruppen blattunterseits, 5-10zellig, gewöhnlich $\tau$-Szellig, zyliudrisch, an Scheitel abgerundet oder verjüngt, mit hyaliner oder gelblicher, bis 1:- $\mu$ hrher Papille, an der Basis ahgeruudet, bei den Querwänden nicht eingeschnürt, $62-132 "$ lang, $28-33 \mu$ breit, die oberste Zelle länger als die anderen, mit dicker, kastanienbrauner, wariger Membran und mit 3 Keimpren in jeder Zelle; Stiel bis $135 \mu$ lang, hyalin, unten stark verdickt.

Caeoma in Juni, Uredosporen von Ende Juni, Teleutosporen von Ende Juli auf

Rubus Idaeus: verbreitet. 


\section{Phragmidium Rubi (Persoon) Winter.}

Spermogonion auf der Oberseite der Flecke, sehr klein, gelblich.

C a eomalager hauptsächlich blattunterseits, seltener in kleinen, lockeren (iruppen blattoberseits, rundlich oder linglich, orangegelb, test, polstertomigs, spatter

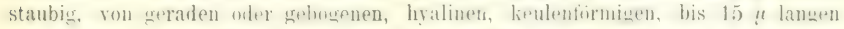

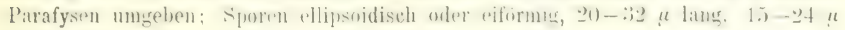
breit, mit hyaliner, ziemlich dicker, warziger Membran.

Uredolang hattuntereits auf pellun, oft karminrot umsiumten Fleclien, zerstreut oder manelumal dichter stehend, rumblich, helleclhorange, staubir. rum keulenformigen l'araphysen umgehen: Sporen ellipsoidisch oder eiforming, 20) :3n lang, 14-21 $\mu$ breit, ziemlich dünnwandig, locker stachlig.

Teleutosporenlager wie bei Uredosporen, klein, schwarz, oft zusammenfliessend, ball narkit, staubig; Sporen t Tzellig, meistens 5- fizellig, zylindrisch, an sicheitel ahugerundet und daselhst mit selblicher, his lo 2 hoher Papille

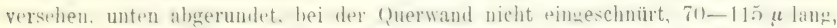
28-3:- $\mu$ breit, mit kastanienbrauner, dicker, feinwarziger Membran und in jeder Zelle mit 2 Keimporen; Stiel bis $120 \mu$ lang, unten stark verdickt. (Siehe Abb. 34, 1.)

Caeouna im Juni, Uredosporen Ende Juni, Teleutosporen von Juli auf verschiedenen Rubus-Arten gemein, z. B. auf Rubus caesius, nemorosus.

2.). Phragmidium perforang (lietrich) liro in Thedinear femnicate per 5st). Aecidium perforans Dietrich in Archiv f. Naturk. Liv-, Ehst- und Kurlandes, Ser. II, Vol. I (1859), p. 494. - Phragmidium Rubi saxatilis Liro I. c. p. 421 .

Ca 0 ma lager beiderseits, gelb, zerstreut, einzeln, rundlich, kaum $0.5 \mathrm{~mm}$

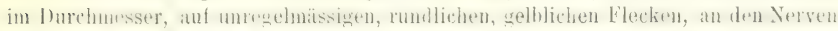
his 5 mm lang. Spren liettufümig zehildet, leirht trennbar, germulet oder kur\% und breit ellipsoidiscl, $15-23 \mu$ lang, 14-20 $\mu$ dick. Membran farblos, 1.5-25 $\mu$

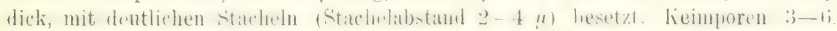
schwer sichtbar. I ager von reichlichen, farblosen, $50-70 \mu$ langen, $5-8 \mu$ dicken, oben abgerundeten, fadenförmigen Parafysen ungreben.

Uredolager klein, punktfömig, hellgelb, blattunterseits zerstreut, ohme Fleckenbildung; Sporen wie bei Caeoma, aber kurz gestielt.

Teleutosporenlager blattuntesseits, rundlich, zerstreut, auf winzigen, hellgrüuen ouler rosafarbigen Flecken. Paraphysen wie bei Caeoma. Sporen wie bei Phragmidium Rubi.

Caeoma Ende Juni uud aufangs Juli, Ureilosporen von Juli, T'eleutosporen von August aut

Rubus saxatilis: Vlĕi dûl hei T'íbor!

Die vorliegrende Spezies wurde von Liro erst in diesem Jahre (1908) aufgestellt. Die Diagnose verdanke ich dem Autor sellst. 


\section{Phragmidium violaceum (Schultz) Winter.}

Spermogonien halbkugelig, dicht gruppiert.

Caeomalager rundlich oder länglich, einzeln oder ringförmig oder verlängert nud dam bis I cm lang: Parafisen gerade oder wenig gehngen, lieulenfirmig; Sporen in liurzen Letten, kuslig his ellipsnidisch, $19-30 \mu$ laug, $17-24 \mu$ breit, mit farbloser, stachliger Membran und orangefarbigem Inhalt.

Uredolager auf der Unterseite von gelber, karminrot umsäuinter Flecke, rumilich, zerstreut o:ler gleichmilssiy und oft iber das ganze Blatt verteilt, bahl nackt und staubig, oft zusammentliessend, goldgclb, von zahlreichen, grehogenen, lieulenformigen orter kofffömigen, olen his :22 u breiten Parafysen umgeben; Sporen kuglig, eifurmis oder ellipsoidisch, 20-3n $\mu$ laug, 22-24 $\mu$ breit, mit $3-4 \mu$ dicker, stachliger, hyaliner Membran und orangefarbigem Inbalt.

Teleutosporenlager wie bei den Uredolagern, schwarz, gewölbt, ziemlich gross, nicht zusammentliessemt; sporen :3-izellig, zylindrisch. am scheitel abgerundet und mit niedriger, gelblicher Papille rersehen, unten abgerundet, bei den guerwänden schwach eingesthnürt. 52-110 " lang. :3;-37 "3 breit, mit kat. stanienbrauner, dichtwarziger Membran und in jeder Zelle mit ״ Keimporen; Stiel $90-130 \mu$ lang, unten stark verdickt.

Ca Rubus-Arten, hauptsächlich Rubus radula, thyrsoideus und villicaulis verbreitet. Bei Wittingau auf Rubus a moen us (Weidman)!

2. Teleutosporen keimen gleich nach der Reife.

2:37. Phragmidium Tormentillae Fuclel. - Phragmidium obtusum (Strauss) IVinter.

Spermogonien und $\mathrm{Ca}$ e $0 \mathrm{ma}$ wie bei Phragmidium Fragariastri.

Uredolager wie bei Phragmidium Potentillae, von dünnen $(7-9 \mu)$, keulenfirminen, nicht zihlreichen Parafysen umgehen; spocen kuglig oder eifurmin, 20-22 $\mu$ lang, $17-20 \mu$ breit, mit warziger Membran.

Teleutosporenlager klein, nackt, hellbraun, blattunterseits zerstretu; Syoren keuleuformig his spindelformig. am Scheitel kegelformig verjüugt, nach unten stark verjü口gt, bei den querwäuden wenig oder gar nicht eiuseschnürt, 2-8zellig, 50-160 $\mu$ lang, $18-28 \mu$ breit, mit hellbrauner, glatter, in jeder Zelle von unten nach ohen verdickter Membran: einzelne Zellen ungleich lang und breit, manchmal auch schief aufeinanler aufwesetzt, jede mit 1, dicht unterhalb der (Duerwand lienendem Keimporus. nur derjenige der obersten Zelle scheitelständig; Stiel farblos, verschieden (bis $100 \mu$ lang).

Caeoma (?), Uredosporen von Juli, Teleutosporen von September auf

Potentilla Tormentillat: Bodeubach! Teplitz (Thümen)! Johannesbad (Schroeter). Hoch Veselí Kabat)! Roreuslo! Turnau (Kabát)! Velenka bei Saldska! Vydrholec bei Ouval! Tábor! Wittingau (Weidman)!

Potentilla procumbens: Schumburg bei Tannwald!

Teleutosporen keimen sofort nach der Reife im Herbst. 
11. Brachyphragmidium. Caenmestadium fohlt.

9:8. Phragmidium albidum (kithm Ludwis. - ('h rysomy $x$ a a l bill a kihu. - Uredo aecidioides J. Müller. - Uredo Muelleri Schroeter. - K ï hneola albida Magnus.

Spermogonien blattoberzeits, honiggelbbraun, flach oter konkav, bis $250 \mu$ breit.

Uredosporen: l'imire Layer auf goldgelben, scliwach vorlickten Flerlien. meist hattunterseits, kreisformig um die Spermononien gruppiert, oft ringformig zusammentliessend, seltener auch blattunterseits, goldgell, von der Epirlermis an den Seiten bedeclit; seliundär Lager in grossen, dichten Gruppen blattunterseits. sehr selten hlattoherseits, auch auf den Kelchen und stengeln, hald nackt, dottergell, stiuling, später zitrongelh, im Alter weiss; beilerlei Sporen kuglig, eifrirmigs bis ellipsoidisch, 20-2s " lane, 18-21 $\mu$ breit, mit dïnner, fein- und ziemlich entferntstachliger Membran.

Teleutosporenlager entweder in Uredolagern oder auch selbständig einzeln oder in wrissen (xrupuen; Sporen keilformig, am Seheitrl at)gestutat orler umregelmïssig, manchmal fast mit kronentrtiren Ausläufern, ㄹ-13zenlig; vinzelne Zellen 17-47 $\mu$ laug, 19-21 $\mu$ breit, mit fiubloser, glatter Membran: querwinden von unten nach oben allmählich dicker; Keimprorus stets unterhalb der (gutrwand, in der siheitelzelle seitwäts liegend; Inhalt farhlos. - Sporidien kuglig, 8 . his $9 \cdot 5 \mu$ breit.

Primäre Uredo im Hochsonmer und im Herbst, sekunditre von Juli bis zum Winter, Teleutosporen von Mitte Juli bis September auf

Rubus glandulosus: Bora und Babylon bei Rovensko, Trosky! Turnau (Kabát)!

R u bus nem or os us: Bora bei Rovensko! Podháj bei Gross Skal, 'Turnau (Kabát)!

Rubus plicatus: Jirna bei Ouval! Friedstein bei Turnau (Kabát)!

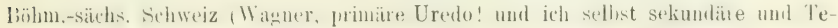

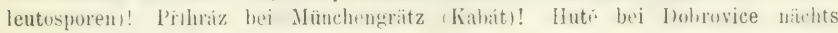
Tábor!

Schon J. Müller vermutete, dass seine Uredo a e cidioides mit Chrysomyxit albida zusammenhimgt. was experimentell erst ron Jacky bewiesen wurik. Teleutosporen keimen gleich nach der Reife.

III. Phragmidiopsis. Uredosporen nicht entwickelt.

2:39. Phragmidium carhonarium (Schlechtenial, Winter. Xenodor hus ca rbon arius Schlechtendal.

Ca eoma auf Blattstielen und Nerven in verlängerten, verschiedene Ḱrümmungen hervorrufenden Iagem, auf liatspreiten in rundlichen oder linglichen

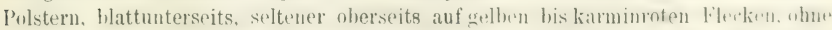

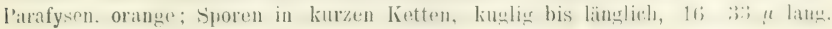
$16-22 \mu$ breit, feinwarzig, wit orangefarbigem Inhalt. 
T'eleut osporenlager blattbeiderseits, of mit Caeomalagern zusammenfliessend, „ewollt, rundlich bis länglich, sehwarz, bald nackt; Sporen viellzellig (;) bis 2.). lang walzenfoimig, oft gebogen, am Scheitel abgerundet, zum Stiel sehwach verjü॥gt, bei den Querwänden eingeschnürt, bis $300 \mu$ lang,

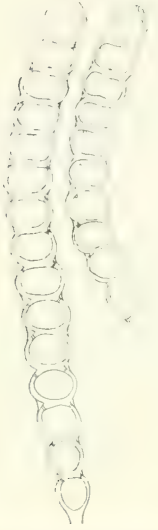

Abb. Teletutosporen von Phragmidium carbona. rinm (nach E. Fischer) 24-28 $\mu$ breit; einzelne Zellen 14-21 $\mu$ lang, von oben nach unten reifend, mit dunkelbrauner glatter Membran, in der Scheitelzelle mit einzigem oft mit einer Papille versehenem Keimporus, in den übrigen Zellen wit je zwei unterhalb der Querwand liegenden Keimporen; Stiel kurz, fest.

Caeoma von Mai, Teleutosporen Ende Juni auf

Sanguisorba officinalis: Habstein, Hoch Veseli (Kabát)! Teiche bei Roždalovic (I + III schon 20. VI.)! Korouhev bei Polička (Th. Novák)! Dobruška (Vodák)! Tábor !

\section{Triphragmium Link.}

Spermogonien flach, subepidermal.

Uredosporen (primäre und sekundäre) gestielt.

Teleutosporen dreizellig in dreieckiger Stellung, gestielt. (Die Keimung siehe Abb. 34, 2.)

I. Brachytriphragmium. Entwickelung wie oben angegeben. 240. Triphragmium Ulmariae (Schumacher) Winter.

Spermogonien ringförmig stehend, Hach, gelbrot; Sperinatien $4-6 \mu$ lang.

Uredosporen: Primäre Lager auf verbogenen Nerven und Blattstielen, gross, unregelmässig, rotorange; Sporen ellipsoidisch bis eiförmig, 25-28 $\mu$ lang, 18-21 breit, mit hyaliner, warziger Membran und orangefarhigem Inhalt; sehumdire Laner hlattunterseits zerstreut, klein, rundlich; Sporen wie bei primären Ligern.

Teleutosporenlager blattunterseits zerstrent, bald nackt, schwarzbraun, staubig, selbstindig ofler sporen nur in Lreslolagern entwickelt; sporen abgeflacht, auf der breiteren s'eite im Umrisse fast rundlich, auf der schmäleren Seite fast

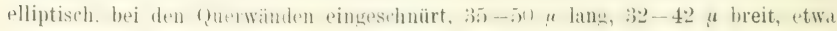
$28 \mu$ dick, 3 (seltener 2 oder $4-5$ ) zellig, mit brauner, um die Keimporen oder total warziger Membran; in jeder Zelle 1 Keimporus. (Siehe Abb. 34, 2.)

Primäre Uredo im Mai, sekundäre im Juni, Teleutosporen oft schon mit primären Uredosporen, sonst vom Juli anf

Ulmaria peutapetala: Cibulka bei Prag (Opiz)! Habstein (Kabát)! Hirschberg (Wagner), Teplitz (Thümen)! Tetschen (derselbe): Bohm. Leipa (sichiffner)! Reichenberer (Siegmund)! Rovensko! Svitkov bei Pardubic (Vorlik)! Teleci

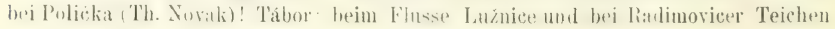
Kaplitz (Kirchner)! Eleonorenhain im Böhmerwalde! 
II. Microtriphragmium: Nur Teleutospoten entrickelt.

\section{Thriphragmium echinatum Léveillé.}

T'elentosporenlager auf einer oder auf beiden Blattseiten oder auf Blattstielen und Stengeln, klein, rundlich, bald nackt, schwarz, stanbig, in $1-2 \mathrm{~cm}$ lange Gruppen zusammenfliessend, auf den Seiten von silbergrauer Epidermis bedeckt, verschiedene Deformationen der befallenen Stellen hervorrufend; Sporen dreizellig, dreieckig abgerundet, von der Seite ellipsoidisch, bei den Querwänden eingeschnürt. 28-35 " lang, 25-28 $\mu$ breit, mit kastanienbrauner Membran, mit zahlreichen, $14 \mu$ langen, spitzigen, geraden oder an den Euden gebogenen, braunen Stacheln besetzt; Stiel hyalin, abfällig, so lang oder länger als die Spore; in jeder Zelle 2-3 Keimporen.

Von August bis zu Winter auf

Il eum athamanticum: Nur im Erzgebirge z. B. bei Zinnwald (Thümen, Wagner)! Moldau, Ullersdorf, Kalkofen, Yen. stadt!

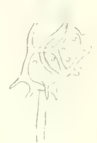

Alib. 38. Triphreigmium cchi. notiun. Teleuto sporen v. Neum athamanticum.

\section{Ordnung: Cronartiaceae.}

Teleutosporen stiellos, in vertikalen Reihen gebildet, untereinander frei oder

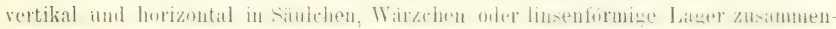
fliessend.

\section{Gattungen :}

1. Teleutosporen einzellig, in vertikal en Rei lo n enstehend, polsterförmig, verklebt, sofort nach der Reife lieimend. Chrysomyxu

2. Teleutosporen einzellig, läing und quer in Sïulchen z us am me fliessend, sofort nach der Reife keimend . . .

Cronartium

3. Teleutosporen einzellig, mit interkalaren, sterilen Zellen ket. tenfömig verbunden, bei der Reife sish loslösend, mit typischer P'seudoperidie . . . . . . . . . Endophyllum

\section{Chrysomyxa.}

Spermogonien kuglig.

A ecidien mit vollkommenen Pseudoperidien; Sporen kettenförmig ver-

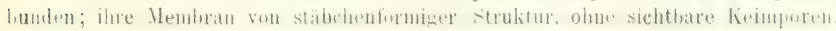

Uredosporen wie die Aecidiosporen aber ohne Pseudoperidie.

Teleutosporen in sammitarigen Polstern, in einfache oder verzweigte

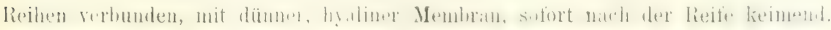

1. Euchrysomyxa. Alle Sporeuformen entwickelt.

242. Chrysomyxa Rhododendri (De Candolle) De Bary.

Spermogonien anf beiden Seiten der. Niuleln zerstreut, hall)kugelig. honigbraun. 
Aecidien unterseits auf den Nadeln anf gelben Flecken, 1-2reihig, mit sïchchenformigen oder zylinhrisch verlängerten, dünnwaudigen, von den Seiten stark zusammenguhürkten, unr.melmässig zerreissenden Psouduperidien; Pseudoperidienzellen schupjentormin ahgetlacht, auf der Innenseite konves. auf der Aussenseite

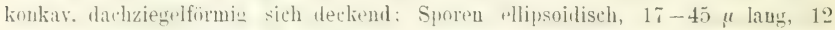
his "-. " hreit: Membran düun, farblus uml ausset viner kahlen schmalen Iängszone deatlich warzig; Inhalt orange.

Uredolager meistens blattunterseits auf violetten, gelben oder rötlichen Flerlien, rumblich bis lämlich, zerstreut ohter gruppenweise, manchmal auch auf den Arsten; Sporen mit interkalaren sterilen Zellen liettenweise gebillet, eiformig bis Jänglich oder auch unregelmïssig, 17-28 $\mu$ lang, 15-22 $\mu$ breit, mit warziger, farbloser Membran und orangerotem Inhalt.
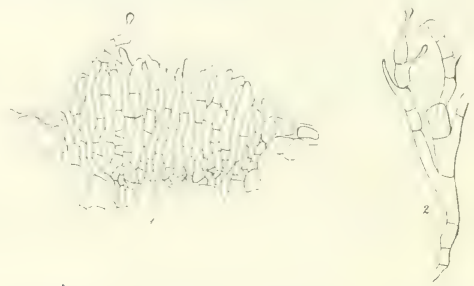

Abb. 39. Chrysomyxa Rhododendri. 1. Scbnitt durch ein Telentosporenlager.

2. Vergrösserte keimende Teleutosporen. (Nach de Bary.)

'leleutosporenlager rotbraun, bei der Keimung orange, rundlich bis limghch. mehr oder weniser dicht gruppiert; sporen prismatiseb, 20-30 "l lang, 10-14 " breit, in ter Mitte der Polster in 4 tizelligen Rieiluen: Yfembran hyalin. dünn, nur an Scheitel ringförmig verilickt. nicht. -

Aecidien im August auf Picea excelsa; aus Böhmen sah ich sie noch

Uredosporen und Teleutosporen von Mai auf

Rhododeudron hirsutum: Turnau in Glashäusern (Kabát)!

In den Alpen auch auf Rhododendron ferrugineum.

Der genetische Zusammenhang der Aecidien mit Chrysomyxa wurde von I) liary festresteht. In Iten Ghashiusern wher auf solchen Stellen, wo die Fichte fehlt, erhält sich dieser Pilz von einem Jahre zum anderen mittelst der Uredosporen.

243. Chrysomyxa Ledi (Whertini et Sihweintz) Winter. Aecidiun ahietinum Alhertini et Schweinitz.

Spermogonien auf einer oder beiden Seiten der Nadeln, honigbraun, schwach konisch hervorragend. 
A ecidien unterseits auf den Nadeln reihenteise, mit weissen, zylindrischen

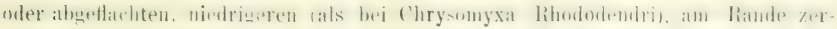
schlitzten Psoudoperidien; I'soudoperidienzellen stark aberflath, bridersents ar. wölbt; Sporen kuglig bis länglich, 17-45 " lang, 12-22 " breit, mit dichtwarziger Membran und orangerotem Inhalt.

Uredo lager klein, rundlich, blasenförmig, später nackt, oft ringförmig gruphiert und zusammentliessend, stauhig, orange ; sporen eifomin bis oflipsoidisch oft polyedrisch, 16-3;)" lang, 14-2.2 $\mu$ breit; Membran dick, farhlos, mit durch. sichtigen. stumpf abgerumdeten, leicht abfallenden Kirmehen besetzt: Inhalt orange.

Teleutosporenlager rotbraun bis blutrot, flach, zerstreut oder in klei-

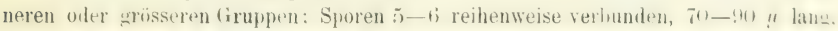
$13-15$ " breit, mit hyaliner, slatter Mrmbran: Inhalt oramoe; Sporidien rifirmig, $11 \mu$ lang, $7 \mu$ breit, mit orangefarbigem Inhalt.

Aecidien vou Juni bis zum August auf

A bies excelsa: Herrnskretschen (Wagner).

Uredosporen von Mai bis Cktober, Teleutosporen im Mai und Juni auf

Led um palustre: Habstein (Kabat)! Herruskretschen (Wagner). In den Kiefernwäldern auf den Moortlächen bei Zalšl und Mažic!

Der genetische Zusammenhang wurle von de Bary festgestellt. Chrysomyxa Ledi erbilt sich wie die vorangehende Art, mittelst des Tredosporenmycels, welches auf den überwinternden Blittern neue Lredolager ausbililet.

\section{Chrysomyxa Empetri (Persoon) Rostrup.}

Spermogonien und A eci dien nicht bekannt.

Uredolager blattunterseits, klein, rundlich oder in der Richtung der Blattachse verlingert, anfangs von aufgehlasener Epidermis bedeckt. später nackit, gelbrot. stanbig; Sporen eiformig his ellipsoidisch, manchmal polyedrisch, 26-35 (oft bis 45 ! " lang, 17 ...2 " " breit: Membran dünn, farhlos, von kurz-stäbchenförmigen, abfälligen Wärzchen bedeckt; Inhalt orange.

Von August bis Oktober auf Blättern von Empetrum nigrum: Riesengrehirge (Tausch, ohne nïhere Standortsangathe. (Belege dafiur im Herb) des bühm. Musenms in Prag und in den Sammlungen von Veselský, Iloffmann, Liratzminn u. a.)! - Am Gipfel des Arbers im Böhmerwalde (Krieger).

Aecidien unbekannt. Teleutosporen wurden von Rostrup.und L a ger heim beohachtet. dieselben linferten aber keine dieshezuliche beschreihung. Ins Buhmen sah ich nur Uredosporen.

\section{Chrysomyxa Pirolae (De C'andolle) Rostrup.}

Spermogonien und A ecidien bisher unbekaunt.

Uredolager klein. rundlich, über die ganze Plattunterseite sleichmä-rir verteilt, bald nackt, stauhig, ron der Epidermis an den siten umhïllt, gelhrut: Sinoren kuglig bis länglich, oft polyedrisch, 20-3:; " lang, 16-2.2 " breit, wn kriftigen. ziemlich entfernten Warzen besetzt. 
T'eleutosporenlager klein, etwa $\frac{1}{2} m m$ breit, rundlich bis länglich, gelbrot, spitter blutrot gefabt, trocken braun, gleichualssig blattunterscits verteilt Sporen 100-120 $\mu$ lang, etwa $8 \mu$ breit; Sporidien kuglig, $7-8 \mu$ im Durchmesser.

Uredosporen und Telentosporen von Mitte Juni bis August auf

Pirola secunda: Langenau bei Hohenelbe (Cypers)! Zwischen den Grenzbaulen und dur schwalen Koppe (Schroner). Rotrnhaus bei Komotau (Fuchs)! Teich "Puncocha" bei Kornhaus!

Pirola minor: Spitzberg im Böhmerwalde!

Die T'elentosporen werden nach Dietel selten gebildet.

II. Ieptochrysomyxa. Nur Teleutosporen, welche nach der Reife sofort lieimen.

\section{Chrysomyxa Abietis (Wallroth) Winter.}

T'eleutosporenlager fest, wachsartig, auf gelben Flecken auf der Unterseite der Varteln, mehr oiter weniger in der Richtung der Längsachse verlingert,

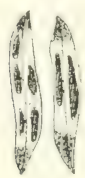

Alit). (11. (\%)! somity Abielis auf Fichtennadeln. rotbraun bis gelborange; Sporen $9-14 \mu$ breit, bis 12 reihen. törmig verbunden, Reihen bis $100 \mu$ lang; Membran hyalin, dünn, glatt, mit orangefarbigem Inhalt; Sporidien kuglig, $4-6 \mu$ im Durchmesser, mit orangerotem Inhalt.

Im Mai auf Nadeln von

Abies excelsa: Pelzdorf und Harta bei Hohenelbe $(\mathrm{Cy}$. pers)! Johanuesbad bei Trautenau (Schroeter). Herrnskretschen (Thümen, Wagner)! Rovensko! Sizava! Tábor! Eisensteiu (Krieger).

Die Teleutosporen kimen im Frühjahre, die Sporidien infizieren junge Nadeln, in welchen sich während der Vegetationsperiode das Mycel ausbildet; aus demselben bilden sich dann im Herbst dit jungen Lager, deren Sporen aber erst im Frühjahre reifen.

\section{Cronartium Fries.}

Sp ermog onien Hach, halbkugelig.

A ecidien (Peridermium) mit breiten, sackförmigen, unregelmässig zerreisenden Pseudoperilien; Sporen kettenfurmig, mit sterilen, interkalaren Zellen. Sporenmembran von stäbchenförmiger Struktur, ohne Keimporen.

Uredola@er ebafalls mit I’suloperidien, halbkugelig, später mit kleiner, rundlicher Öffuung; Sporen gestielt, stachlig, ohne Keimporen.

'Teleutosporen einzellig, lïngere Zeit hindurch aus einzelnen Hyphen liettruforming gebilitet, in walzenfömige oder fudenformige Süulchen verhunden, trocken hornatin sprörle. Keimung gleich nach der Reve Promycel in der Niahe des Scheitels heraustretenul. Sporidien kuglig oder fast kuglig. (Sielre Abb. 3 ๘.)

ㄴ.7. Cronartium asclepiadeum tWillenow) Fries. - ('ronartium flaceidum Albertini et Schweinitz. - Peridermium Cornui Klebahn

A ecidien in Form grosser, dicker, gelbroter Blasen und Säckchen, die ant der limde hervordringen und die Aste in ziemlich dichten oft weitliutigen 
Gruppen bedecken; Sporen kuglig-ellipsoidisch, oft polyetrisch, "2,-30 "u lang, 16-20 $\mu$ breit; Membran warzig, 3-4 $\mu$ dick, an einer Stelle von dichtstehenden, rröberen Warzen bedeckt, diselbst also netzförmig gefurcht.

Uredosporen: Psendoperidien klein, blasenförmig, ockergelb, mit kleiner.

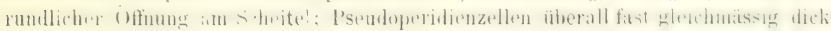
Sporen eiförnig bis ellipsoidisch, 21-24 $\mu$ lang, 17-21 " breit, mit farbloser; $15-2$ u dicker, entfernt $(3-4$ u) stachliger Membran.
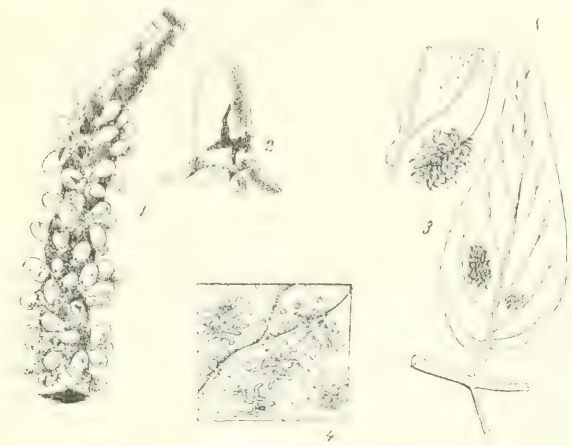

Abb. 41. 1-3. Cronartium asclepiadeum. Aecidien auf Kiefernaste. 2. Einzelnes Sückchen vergrussert. 8. Teleutosporensäulchen auf B.ättern von Vincetoxicum officinale. 4. Teleutosporensäulchen auf Ribes-Blättern. (Nach Dietel.)

Teleutosporen in länglichen Reihen, untereinander in walzenförmige, oft

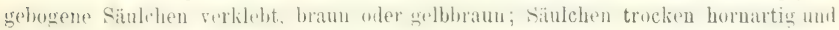
spröde, bis $1.5 \mathrm{~mm}$ lang, blattunterseits in kleineren oder grösseren Gruppen;

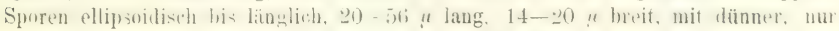
bei der obersten Spore an Scheitel verdickter Membran.

Aecidien im Jai und Juni auf Aesten von Pinus silvestris: Roztok bei Prag! In Wäldern zwischen Ričau und Mukaťov! Rovensko! Fugau (Karl)! Sebusein bei Leitmeritz (Wiesbaur)! Netolic (Hampl)! Pisek! 'Tábor! Krumau (Jungbauer)!

Uredosporen von Juni, Teleutosporen von Juli anf

Paeonia angustifolia: Holic (Čeněk)!

Paeonia officinalis: Harta bei Hohenelbe (Cypers)! Teplitz (Thümen). Kačina (Peyl)! Krumau (Jungbauer)!

In den Gïrtenanlagen bei Turnau wurde dieser Pilz von $\mathrm{K}$ a b át auf folgenden Arten gefunden:

Paeonia tenuifolia var. insignis, P. anomala, P. arietina, P. decora, P. peregrina! 
Vincetoxicum officinale: Prag (Corda). Zahoraner Schlucht bei Davle Trosky! Tumau (Kabat)! Kariua (Pryl)! Steinsthönu (Handschke)! Tahor! Plavo bei Budweis! Krumau (Jungbauer)!

Cronartium aselepiadeum ist biologisch dadurch interessant, dass es ausser den angefuihten Nihrphtanzen, weiter noch Impatiens Balsamina, Nemesia versicolor, Verbena teucrioiles, V. erinoides, also Pthanzen, die in ă „anz verschiedene Familien rehoiren, hefält. Durch ihnliche Pleophagie zeichnen sich nur die Aecidien von Puccinia Isiacae (Thümen) Winter aus.

Das Peridermiummycel überwintert in den Kiefern-

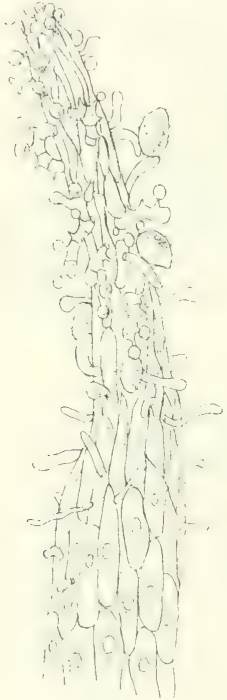

Abb. $4 *$. Fin Teleutosporen. säulchen von Cronartium ribicolum. Im oberen Teile keimende Teleutosporen. Rechts oben einige angeklebte Uredosporen. (Nach Tulasne.) ïsten, verursacht auf ihnen krebsartige Verdickungen, die oft bei $4 \mathrm{~cm}$ lang sind. Teleutosporen keimen sofort nach ihrer Reife.

\section{Cronartium ribicolum Dietrich. - Perider-} mium Strobi Klebahn.

Spermogonien in Form von unregelmässiger, gelber, blasenförmiger Verdickungen auf der Rinde, mit kleiner Oeffuung.

Aecidien blasenförmig aus der Rinde hervortretend; Pseudoperidien aus 2-3 Schichten isodiametrischer, $15-35 \mu$ breiter Zellen zusammengesetzt; Sporen kuglig-ellipsoidisch, oft polyedrisch, 22-30 $\mu$ lang, 18-20 $\mu$ breit, mit teilweise warziger, $2-2.5 \mu$ dicker, teilweise glatter und hier $3-3.5 \mu$ dicker Membran.

Uredolager wie bei der vorangehenden Art; Sporen ellipsoidisch oder eiförmig, 18-32 $\mu$ lang, 14 bis $22 \mu$ breit, mit farbloser, entfernt stachliger Membran und orangerotem Inhalt.

Teleutosporen: Säulchen verschiedenartig gebogen, gelbrot, später braun, bis $2 m m$ lang; Sporen bis $70 \mu$ lang und bis $21 \mu$ breit.

Aecidien von Mitte April bis zum Juni auf Aesten yon

Pinus Strobus: Turnau (Kabát)!, wo sie ausgedehnte junge Kulturen vernichteten. Reichenberg (Matouschek). In anderen Ländern auch auf $\mathrm{Pinus} \mathrm{Cem-}$ bra, P. Lambertiana und P. monticola.

Uredosporen von Juni, Teleutosporen von Juli anf verschiedenen Ribes-Arten. In Böhmen auf

Ribes a ureum: Turnau, Hoch Veseli, Welwarn (Kabát)! Tábor !

Ribes Gordonianum: Turnau (Kabát)!

Ribes grossularia: Vazorec bei Turnau (Kabát)!

Ribes nigrum: Welwarn, Turnau (Kabat)! Gross Skal! Friedrichstal im 


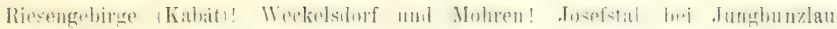
(Kíbát)!

Ribes rubrum: 'T'urnau (Kabát)!

Ribes sanguineum: 'Turnau (Kabát)!

Das Aecidiummycel perenniert in den Aesten uud jungen Stämmchen und rerursacht den bekannten Krehs der Weymouthskiefer: die wherhalh der intiziterten Stelle gelegenen Partien sterben ab.

\section{Endophyllum Léveillé.}

Teleutusporen in halbkugeligen Pseudoperilien, einzelliz, kettenformigr ate bildes, ohne dentliche Keimporen, staubir. Sporidien länglich (siehe Abh. :2, 4 ).

249. Endophyllum Sempervivi (Alhertini et Sehwoinitz) I) Bary.

Spermogonien kuglig, zwischen den Pseudoperidien zerstreut, braun, später konisch hervorracrend, dunkelbraun.

Teleutosporen: Pseudoperidien einasenkt, halbkugelier hervorgewoilbt, am Scheitel zuerst $n$ r mit rundlicher ()effuung, spaiter schüsselformig; Psendoperidimzellen abgerundet, nur lose gefügt; Sporen kuglig, eiformig bis ellipsoidiseh, wft polyedrisch, 18-3:3 " im I)urchmesner, mit hellgelbbrauner, 3--t " dicker, dicht-und feinwarziger Membran und orangerotem Inhalt: Sporidien lïnglich. (Siehe Abb. 3, 4.)

Im Mai auf verschiedenen Sempervivum-Arten. Das Mycel überwintert und durehdringt die ganze Nïhrptlanze. Die lilïter sind dann länerer, schmäler und bleicher.

Sempervixum soholiferum: Jaberlicher Kamm hei Reichenberg (Matouschek)! Raulbach bei Hohenelbe (Cypers)! Karlstein (Domin; ipse)!

(ypers)!

Sempervivum toctorum: Langengrund bei St. Peter im Riesengebirge

\section{Familie: Coleosporiaceae.}

Teleutosporen' in einfacher oder doppelter, wachsartiger Schicht, untercinander serkleht, stielos oder mit hreitem, zylindrischem Stiel und in diesem Falle anfangs zweizellig. Jede Zelle teilt sich dann quer in 4 Zellen, welche je eine grosse, gestielte Sporidie ausbilden.

\section{Gattungen :}

1. Aecidien mit blasenförmigen Pseudoperidien; Uredosporen kettenförmig verbunden; 'lelentosporen am Scheitel stark verdickt; Sporidien eiförmig . . . . . . . . . . . . Coleosporinm.

2. Aecidien mit schüsselförmiger Pseudoperidie; Uredosporen grestielt: Telentosporen dïnmwandig: Sporilien spindelformiz. Theropsora.

Dr. Bubik: Die Pilze Böhmens. 
1. Coleosporium Léveillè.

Spermogonien konisch abgeflacht.

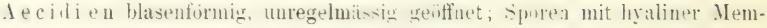
bran, ohne Keimporen, von stäbchenförmiger Struktur.

Uredosporen in kurzen Ketten, sonst wie bei den Aecidien.

Teleutosporen in flachen, wachsartigen Polstern, stiellos, mit farbloser, gelatinöser, am Scheitel stark verdickter. Membran. anfangs einzellig. bald quer vierzellig: Sterigmata labg, jedes mit einer arusen, einseitig abgeflarhter sporidie (siehe Abb. 3, כ).

Eimzelne Arten dieserGattung unterscheiden sich morpholocisch sehr wenig. Die Zugehörigkeit der Aecidien kann hei einir,n Spezies nu auf Grund ron Infektionsversuchen festgestellt werlen. Alle Arten siud heteröcisch und zwar hilden sich die Aecidien auf den Nadeln verschiedener Kiefern (P'inus) aus; die Telentosporen keimen im Herhst sofort nach ihrer Reife, die Sporidien infizieren die Kiefernnadeln und falls die Infektion noch zeitlich im Herbst stattgefunden hat su hilden sich noch in demselben Jahre Spermogonien aus; sonst erst im Frühjahre.

Lei den lieschreibungen einzelner Arten wurlen die Arbeiten fon E. F'isch"r und Klebahn benützt.

250. Coleosporium Inulae, Kunze) E i. Fischer. - Peridermium Wlehahni Ed. Fischer.

A ecidien: Pseudoperidien beilerseits auf den Nalm, flach blasenförmis, bis

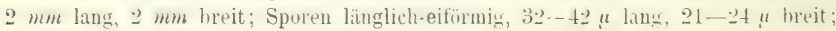
Membran 2 " dick, mit stïlohenfirmigen, 3 " langen Waren; an eiuer Stelle sind dieselben liürzer, tliessen zusammen, soitass diese Stelle glatt oder feinpunktiert erscheint.

Credola ger hlattunterseits Łerstreut. roturange: Syoren eiförmig his ellipsoidisch, 21-25 " lang, 18-21 " hreit; Memlıran düm. mit liräftigen Warzen hesetzt.

T'eleutosporenlager subepidermal, klein, rotbraun; Sporen bis $100 "$ " lang, 18-24 $u$ breit; Membran am Scheitel bis $18 \mu$ dick.

Aecidien im Mai auf den Naleln von Pinus silvestris. Aus Böhmen sah ich sie noch nicht.

Uredosporen von Juni, Teleutosporen von August auf Inula salicina: Kolin (Veselský)!

Der genetische Zusammenhang wurle ron E. F ischer festgestellt.

25) Coleosporium ('acaliae De Candolle) Wagner. - Peridermium Magnusianum E. Fischer. - Peridermium Magnusii Waguer:

decidien: Habituell wie in der Gattmoshlianose angegehen: detaile Beschreibung fehlt.

Lredulager blattunterseits in kleineren oder grösseren, von den Serven hererencten Gruppen, oft die ganze Blattliiche hedecliend, rundlich, bedeckt, später nackt, orange, stiubig; Sporen eiformig bis länglich, $24-35 \mu$ lang, 20-24" breit, mit düner, firbloser, wn kleineu. fast stibchenfürmigen Wärzchen hesetzter Membran. 
Teleutosporenlager wachsartig, rotbraun, in kleineren oder grisseren (iruppen blattunterseits; sporen prismatisch, bis 140 " lame. 18-2.5 " hreit, am Scheitel bis $28 \mu$ dick. bekannt.

Accidien auf den Nadeln von Pinus Pumilio; aus Böhmen bisher nicht

Uredosporen vou Juli, 'Telentosporen vou August auf

Adenostyles alhifrons: Aupaquellen, Elhgrund, Weisswassergrund im Riesengebirge!

Cacalia suaveolens: Ehemaliger alter botanischer Garten in Smichov (1848 leg. Hoffmaun)!

Der genetische Zusammenhang wurde zuerst von Wagner festgestellt.

2.:- Coleosporium T'ussilarinis I'ersoon) Klebahn. - l'eridermium Plowrightii Klebahn.

A ecidien habituell wie bei allen verwandten Arten; Sporen kuglig, eiförmig bis läuglich, 15-35 $\mu$ lang, 15-24, $\mu$ breit, mit $2-25 \mu$ dicker Membran.

I redolatwe blattunterseits auf rundichen oder umegelmais.igen, golblichen Flecken, gelbrot, bald verhleichend, staubig: Sporen kuglig his ellipsoidisch. 23-28 $u$ lang, 17-21 $\mu$ breit, mit warziger Membran.

Tele utosporenlager blattunterseits in den Intercellularen des sihwamm-

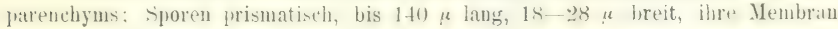
am Scheitel bis $25 \mu$ dick.

Aecidien auf den Nadeln von

Pinus silvestris im Frühjahre; Elbeleiten bei Tetschen (Wagner).

Uredosporen: von Juni, Teleutosporen von Juli auf

Tussilago farfara: Ueberall gemein.

Der genetische Zusammenhang wurde zuerst von $\mathrm{K}$ le ba $\mathrm{h}$ n festgestellt.

25:. Coleosporium Petasitidis De Bary. - P'eridermium Doudieri E. Fischer. - P'eridermium Dietelii Wagner.

A ecidien habituell wie bei den vorangehenden Arten; eine detaillierte Beschreibung fehlt.

Uredosporenlager wie bei der vorangehenden Art, orange; Sporen eiförmig bis länglich, 21-32 $\mu$ (selten bis $42 \mu$ ) lang, $14-21 \mu$ breit, mit lünner, hyaliuer, gleichmässig warziger Membran.

T'eleutosporen wie bei Coleosporium T'ussilaginis, bis $100 \mu$ lang, 18- $24 \mu$ breit, am Scheitel bis 14 « lick.

Aecidien im Frähahre auf Nadeln von Pinus silvestris; aus Böhmen bisher unbekannt.

Uredolager von Juli, Teleutosporenlager von August auf Pet a s it e s officin alis ziemlich verbreitet.

Der genetische Zusammenhang wurde zuerst ron $\mathrm{E}$. Fischer festgestellt. 
254. Coleosporium Sonchi (Persoon) Léveillé - Peri dermi um F is c heri Klebahn.

A ecidien halbituell wie bei den übrigen Arten; Sporen ellipsoidisch bis, polyedrisch, $25-32 \mu$ lang, 18-25 $\mu$ breit, mit farhloser, $2, \mu$ dicker, von stithcheuförmigen Wärchen besetzter Membran.

Ure d o la ger wie bei der vorangehenden Art; Sporen eiförmig, 18-25 $\mu$ lang, $15-21 \mu$ breit, dicht und deutlich warzig.

Teleutosporenlager wie hei der vorangehenden Art: Sporeu an Scheitel etwa $18 \mu$ dick.

Aecidien im Frühjahre auf Nadeln von Pin us silvestris: Aus Böhmen bisher unbekannt.

Uredosporen von Juni, Telentosporen von Ausust aut Sonch us arvensis, S. as per, S. oleraceus gemein.

Der genetische Zusammenhang wurde zuerst von $\mathrm{Kl} \mathrm{e} \mathrm{ba} \mathrm{hn} \mathrm{festgestellt.}$
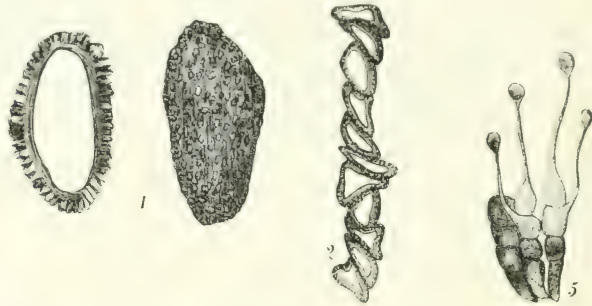

Abb. 43. Coleosporium Senecionis. 1. Aecidiosporen. 2- Radialer Schnitt durch eine Pseudoperidienwand. (Nach Klebabn). 3. Keimende Teleutosporen.

25). Coleosporium Senecionis (L'rsoon) Fries. - Peridermimm whlongisporum Klebahn.

A ecidien habituell wie bei anderen Arten; Sporen gewöhnlich länglich, selten kuglig, 25-35 $\mu$ (selten bis $50 \mu$ ) lang, 15-25 $\mu$ breit; Membran 35 bis 45 " dick, mit stäbchenformigen Warzen bedeckt: Pseudoperidienzellen auf der ganzen Oberfläche gleichmässig warzig.

Uredolager blattunterseits, rundlich bis länglich, bald nackt; Sporen eiförmig bis länglich, 26-31 $\mu$ lang, 14-17 $\mu$ breit.

T'ele utosporenlager klein, zusammenfliessend, rot: Sporen his 100 u lang. $18-24 \mu$ breit, am Scheitel bis $22 \mu$ dick.

Aecidien im Frühjahre auf Pinus silvestris und P. austriaca; aus Böhmen sah ich sie noch nicht.

Uredosporen von Juni, Teleutosporen von August auf Senecio silvaticus, S. viscosus und S. Fuchsii verbreitet: 
Senecio nemorensis: Niedergrund bei Tetschen, Hermskretschen (Wagner)! Tabor! Im Riesengebirge und im Böhmerwalde öfters.

Senecio Jacobaea: Teplitz (Thümen)! Turnau (Kabat)! Polsen (Maloch)!

Senecio vulgaris: Hoch Veself (Kabat)! Herruskretschen (Wagner); Soběslav (Stejskal)!

l)er genetische /usammenhang wurle von Wolfi, Cormu, Hartig und anderen festgestellt.

\section{Coleosporium Campanulae (Y'ersoon) Léreillé -}

Peridermium oblongisporum Rostrup - Peridermium Rostrupi Klebahn - Peridermium Kosmahlii Wagner.

Aecidien: Habituell wie die verwandten Arten; detaillierte Beschreibung fehlt.

Uredusporen blattuaterseits zerstreut oder gleichmissig verteilt, rundlich oder mmegelmässig, vou ler Epinlermis bedeckt, dann nackt, gelbrot, staubig; sporen riformig bis länglich, 17-35 " lang. 13-21 " breit, mit farbloser, ziemlich dichtwarziger Membran und orangerotem Inhalt.

Teleutosporenlager theh, wahsartig, gelbrot, spaiter blutrot bis brann; sporen kenlenfömig his prismatisch, his $110, \mu$ lang, 1K-2:2 $\mu$ lang; Membran farblos, am Scheitel bis $35 \mu$ dick; Inhalt rotorange.

Aecidien im Frühahre aut Nadeln von Pinus silvestris und Pinus mont ana.

Uredosporen von Juni, 'I'eleutosporen vou August auf Campanula, Phyteuma und Specularia.

In Böhmen sehr verbreitet auf Campanula patula, C. rotundifolia, C. rapunculoides, C. Trachelium, C. persicaefolia und Phyturma spicatum. Sonst noch auf

Campanula bononiens is: Rösselberg bei Brüx!

Campanula glomerata: Teplitz (Thümen)!

Campanula latifolia: Schluckenau (Karl)!

Campanula rapunculus: 'Tábor!

Campanula Scheuchzeri: Im Riesengebirge öfters!

Campanula sibirica: Prag (Hoffmann) !

Specularia Speculum: Reichenberg (Siegmund)! als Uredo Pris mat oc a r pa e Siegmund und Uredo S pecul u m Siegıund.

Der genetische Zusammenhang wurle zuerst von Rostruy vermutungsweist. ausgesprochen, später von E. I is $\mathrm{ch} \mathrm{he} \mathrm{und} \mathrm{W}$ a g a e r bestitigt. Spermononien bilden sich manchmal schon im Herbst; Tredosporen kimnen anch, falls dir Witterung mässig ist, auf den Blättern überwintern.

25̆. Coleosporium Melampyri (Rehentisch) Klebahn. -- P'eriderm in m Sor a u eri Klebahn.

A ecidien: Habituell wie bei verwandten Arten; detaillierte Beschreibung fehlt. 
Uredola g e r blattunterseits zerstreut oder dicht stehend, orange, bald narkt und rerhleichend, staubig: Sporen ellipsoidisch bis polyedrisch. "z- 3n $u$ lang. 21-28 $\mu$ breit, mit dünner, farbloser, ziemlich dichtwarziger Membran.

Teleutosporenlaøer anfanes gelbrot, dann rothraun, wachsartig: Sporen prismatisch, bis $115 \mu$ lang, $20-28 \mu$ breit, am Scheitel bis $28 \mu$ dick.

decidien auf Naleln von Pinus silvestris und Pinus montana; aus Böhmen sah ich sie noch nicht.

Uredosporen und Teleutosporen von Juli auf

II e I a m y r u m ar vense; Prag (Hennevogl)! Rovensko!

M el a m py rum cristatum: Dubitz bei Aussig (Sydow)!

If e l a m p y r um n e moros um : Stern bei Prag (Opiz)! Rovensko! Turnau

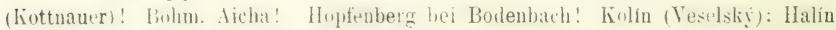
bei Dobruška (Vodáli)!

Melampyrum pratense: Sehr rerbreitet.

II el am p y r m silvaticum: Reichenberg (Siegmund)! Sclumburg, Venwelt, Harrachsitorf! Johanneshal ishoeter). Harta bei Hohenelbe (Cypers); Ober-Mohren bei Politz a./M.!

Der genetische Zusammenhaug der Aecidien mit dem Coleosporium wurde von $\mathrm{K}$ l e b a h $\mathrm{n}$ festgestellt.

\section{Coleosporium Euphrasiae (Schumacher) Winter.}

A e c i d i n habituell wie bei verwandten Arten; Sporen grösstenteils fast

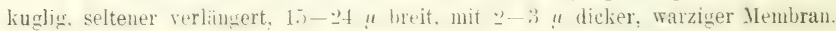

Uredolager wie bei vorangehender Art; Sporen $20-30 \mu$ (seltener bis $35 \mu)$ lang, 14-17 $\mu$ breit, mit dünner, grob-und dichtwarziger Membran.

Teleutosporenlager wie bei vorangehender Art; Sporen prismatisch, bis $105 \mu$ lang, $18-24 \mu$ breit, am Scheitel bis $14 \mu$ dick.

Aecidien auf Pinus silvestris, und P. montana; aus Böhmen sah ich sie noch uicht.

Uredosporen von Juli, T'eleutosporen von August auf

Alectorolophus alpinus: Am Riesengebirgskamm ziemlich häufig (Schroeter). Glatzer Schneeberg!

Alectorolophus hirsutus: Prag (Fischer)! Trebnitz! Zwischen Skalitz und Radelstein! Böhm. Aicha! Rovensko!

Alectoroloph us major: Elbeleiten bei Tetschen (Wagner). Johannesbad (Schröter). Vlkor bei Poděbrad (Th. Novák)! Krumau (Jungbauer)!

Alectorolophus minor: Auf dieser Nährpflanze ziemlich verbreitet!

Euphrasia officinalis: Ebenfalls.

Euphrasia nemorosa: Ebenfalls.

Euphrasia odontites: Prag (Kalmus)! IVelwarn (Kabát)! Raudnitz (Thümen)! Elbeleiten hei Tetschen (Wagner!. Rovenskn! Hoch leseli , Kabátı! Kačina (Peyl)! Selčan (Tb. Novák)! Krumau (Jungbauer)!

Euphrasia lutea: Rotenhaus bei Komotau (Sachs nach Thümen).

I)er genetische Znsmmenhang wurde zuerst von Klebahn festgestellt. 


\section{Auhang :}

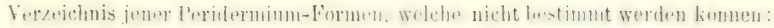

Pinus silvestris: Iorusic bei Č́słav ([’eyl)! Kolín (Veselský)! Grottau bei Reichenberg (Menzel)! Krumau (Jungbater)!

Pinus P'umilio: Melzergrund im Riesengebirge (Schröter)

\section{Ochropsora Dietel.}

Spermogonien halbkugelig, der Epidermis aufsitzend. A ecidien mit schüsselförmiger Pseudoperidie.

Uredos pore in einzeln gebildet, gestielt.

Teleutosporen in wachsartigen Polstern, nur lose vereinigt, nicht zusammengekleht, lieulenförmis bis zylindrisch, anfangs einzellig, spater in 4 nber1.inamber liegende Zelien geteilt; sterigmata kurz, aus jeder Z

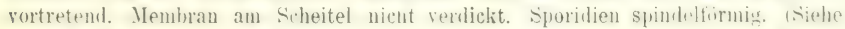
Abb. 3. 6).

259. Ochropsora Sorbi (Oudemans) Dietel. - Melampsora Sorbi Winter. - Aecidium leucospermum De Candolle.

Spermogonien blattoberseits und auf dem Perigon, weisslich.

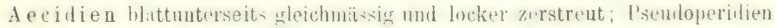

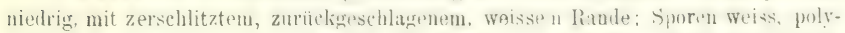

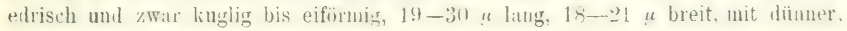
fein- und dichtwarziger Membrau.

Uredosporen blattunterseits in kleinen fruppen, rundlich. basenformin. sporen arhäuft, gelblich, won einem Parafysen-Kranze umgehen. P'arafysen an ler Basis dichtstehend und die Pseudoperidie nuchahmend, in ihrem oberen Teile aber frei, keulenformis, manchual mpougen, $14-17$ " lowet; Sporen linglig bis

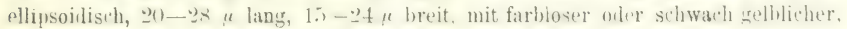
$1-15 \mu$ dicker, entferntstachliger Membran und farblosem Inhalt.

Teleutosporenlager in kleinen Gruppen blattunterseits, anfangs von der Epidermis bedeckt, gelblich, $2(0)-700) \mu$ breit, runilich oder linglich, flach: Sporen palissadenartig neben einander stehend, walzenfrirmig, lieiformig bis länglicls, am Scheitel abgerundet, abzostutzt oder verjüngt, zum Stiel lienlenformig verschmälert.

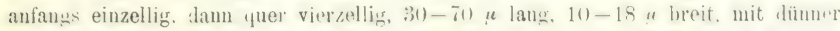
glatter Membran. Sporidien länglich bis spindelfirmig, 25 u lang, $7-8$ u lureit, farblus.

Aecidien im yai und anfangs Juni auf Anemone nemorosa ziemlich, verbreitet.

Uredosporen von Juli, Teleutosporen von August auf

Pirus a ucuparia: Stern bei Prag! Turnau (Kabát)! Rovensko! und gerviss auch anderwärts.

Pirus a cerbat: Roždialovie!

In anderen Ländern (und wahrscheinlich auch in Böhmen) kommt der Pilz noch auf Pirus aria, P. torminalis, P. scandica und Spiraea aruncus vor. Der genetische Zusammenhang wurde ron Tranzschel fostgestellt. 


\section{Familie. Melampsoraceae.}

T'eleutosporen stipllos, einzeln im Gewebe der Nïhrptlanze oder in Polster rerhunden, einzelliz oder vertilial mehrzellis. Promycelium typisch, mit kugligen Sporidien, welche auf Sterimmen sitzen: Uredosporen und Aecidien wit oder ohne Pseudoperidie.

\section{Gattungen:}

A) Teleutosporen mit vertilialen Querwänden.

a) Teleutosporen in Polstern und in den Epidermiszellen oder unterhalh, derselben.

«) Teleutosporen mit mehr oder weniger gebräunter Membran.

1) Teleutosporen in kleinen Polstern.

*) Teleutosporen unterhalb der Epidermis . . . . . . . 1. Pucciniastrum.

*) Telentosporen in den Epidermiszellen........ . 2. Thecopsora.

$\therefore$ Teleutosporen die Epidermiszellen fast der fanzen Sprosse

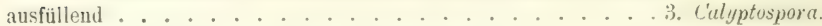

3) Teleutosporen mit farbloser Membran. . . . . . 4. Hyalopsora.

b) Teleutosporen einzeln im Mesophyll zerstreut ... 5. Uredinopsis.

B) Teleutosporen ohne Querwände.

a) Aecidien vom Caeomatypus, Uredolager ohno Psendoperidie . . . . . . . . . . . . . . . . . 6. Melampsorr.

b) Aecidien und Uredosporen mit Pseudoperidien.

a) Teleutosporen mit brauner Membran . . . . . . 7. Melampsoridium.

в) Teleutosporen mit farbloser Membran. . . . . 8. Melampsorella.

\section{Pucciniastrum Otth.}

Aecidien mit Pseudoperidien.

Uredosporen mit halbkugeliger Psendoperidie.

Teleutosporen in eiuschichtigen Lasern, suhepidermal, lurch vertikale oder etwas schief liegemle querwinde in "- + Zellen geteilt, falls 4 Zellen entstanden, dann kreuzweise stehend.

\section{Pucciniastrum Chamaenerii. Rostrup.}

A ecidien auf der Unterseite gelhlicher Xadeln, zweireihig, ziemlich dicht, (hisfo) stehend; Pseudoperidien lang walzenformig. etwa ${ }^{1}$ " $m m$ breit, in ihrem oberen Teile zorschlitzt: Pseutoperidienzellen unregrelmïssig polyædrisch, dünnwandig 25-4) " lane, 10-15 u hreit, an der inneren Vlïche feinwarzig. Sporen meistens länglich, seltener liugliur, 175-31 $u$ lang, 11-2.2 $u$ breit: Membran dünn, hie und da auch dieker ( $15 \overline{5}$ ) und daun von stäbchenfurmiger Strultur, daselbst infolgedessen warzig, sonst glatt und nur $1 \mu$ dick.

Lredolager blattunterseits auf gelblichen bis rötlichen Elecken, klein.

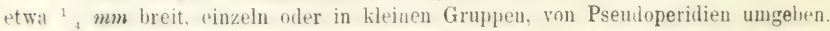
endich staubig; I'sendoperidieuzellen schief viereckig, etwa $10 \mu$ lang, $8 \mu$ breit, 


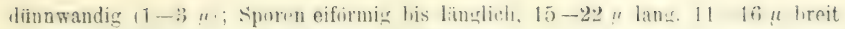
mit dünner, farbloser, entferntstachliger Nembran.

$\mathrm{T}$ el e u t o s p o r e n lag e r blattunterseits, von der Epidermis berleckt, klein, gruppenwise kleinere mier grössere Blattpartien krustenfurmig bedukenl, schwar. liraun; sporen kurz walkenformir oder prismatisch, 17 -35 " laus, $7-14$ " lreeit, in der Mitte der Polster palissadenförmig geträngt. an den Rändern getrennt, im Querschnitt rundlich oder keilförmig, 1- bis tzellig, mit hellbrauner, $1 \mu$ dicker, am Scheitel auf $2-3 \quad \mu$ verdickter Membran. Daselbst auch eine dünnere Stelle (Keimporus? ).

Aecidien im Juni und Juli auf

Abies pectinata: Herroskretschen (Wagner). Tábor!

Uredosporen von Mlitte Juni, 'Teleutosporen von August auf

Epilobium angustifolium: T'urnau (Kabát)! Rovensko! Katharinaberg bei Reichenberg (Kabát)! Langenau bei Hohenelbe (Cypers)! Chlum bei Dobruška (Vodák)! Glatzer Schneeberg (Schroeter). Geltschberg! Teplitz, Eulau hei 'T'etschen (Thümen) Bodenbach! Herrnskretschen (Wagner)! Schwarzer See im Böhmerwalde! und gewiss sonst viel verbreitet.

Der genetische Zusammenhang wurde von $\mathrm{Kl} \mathrm{e} \mathrm{bahn} \mathrm{festgestellt.}$

\section{Puceiniastrum Epilobii (Persoon) Otth.}

A ecidien bisher unbekannt.

Ur e d o s por e n blattunterseits, seltener blattoberseits, auf gelben oder rötlichen Fleckien. oder auch auf den Stengeln, suhepidermal, klein, etwa $0.2 \mathrm{~mm}$ breit, von Pseudoperidien umgehen, oft genährt und die Epidermis gemeinschaftlich emporhebend, endlich stanbig; Pseudoperidienzellen im ver-

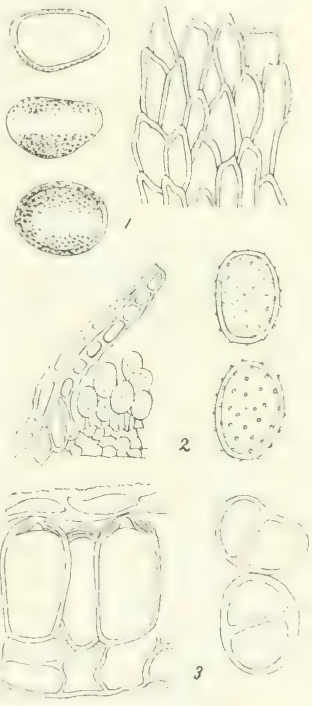

Abb. 44. Pueciniastrum Chamaenerii. 1. Aecidiosporen und P'seudoperidien. 2 Schnitt durch ein Teleutosporenlarer und isolierte Uredosporen. 3. Schnitt durch ein Teleutusporenlager und isolierte $\mathrm{Te}$ leutosporen. (Nach Klebahn). tikalen [urchschnitte viereckig oder schief, 10-18 "lang, (i-10 " breit; Sporen einfürmig oder ellipsoidisch, 17-22 $\mu$ lang. 12-15 $\mu$ breit, mit farhloser. dünner, entfernt warziger Membran.

Teleutosporenlager blattunterseits, selteuer hlattoberseits, oder auf den Stengeln, suhepidermal oder auch vereinzelte Sporen un Mesuphyl, klein. 1) $1-02 \mathrm{~mm}$ breit, in kleineren Gruppen, schwarzhraun: Sjuren walzenformig oder 
prismatisch, $15-28$ " lann, 6-28 " hreit, in der Mitte der Polster palissadenfurmig zusammengefügt, auf der Aussenseite entferut ron einander, auf dem Querschnitte rundlich oder rifrirmig, 1-tzellis. mit hauner. etwa $1 \%, \mu$, an Scheitel bis $2 \mu$ dicker Membran; Keimporus undeutlich.

Uredosporen von Juli, Teleutosporen von September auf

Epilobium alsinefolium: Hammermühl bei Ponmerndorf im Riesengebirge: (Cypers)!

Epilobium hirsutum: Chotěboř (Mühlbach)!

Epilobium roseum: Ziemlich rerbreitet.

Teleutosporen lihlen sich ziewlich spät aus, erst En le September. Meine Infelitionsversuche mit Spmidien dieser Art im 1905 auf Vadeln ron Piuns silresris, Abies Picea und Abies alba fielen negativ aus.

\section{Pucciniastrum Agrimoniae. (De Candolle) Lagerheim.}

A ecidien ubekannt.

Uredolager klein. auf kleinen, gelhen mler purpurnen Flecken blattunter-

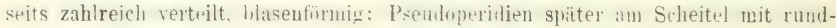
licher Oeffuung, gelhorange, staubig: Psendoperidienzellen dünnwandig. nur jene rings um die Oefinung liegenden dickwandig: Sporen luglig, eifomig his ellipsoidisch. 15-2. " lang, $11-14 \mu$ lreit, mit nicker, stachliger, orangegelber Nembran.

Teleutosporenlager hellhram: Teleutosporen interceilular, durch 2 sich kreuzende (curwäude in vier Zellen gretrilt, 30 "1 lang. 221-30 " breit. (Nach Tranzschel und Dietel).

Ureiblager von Mitte Juni bis zum Winter; Teleutosporenlager sab ich aus Böhmen noch nicht.

Agrimonia Eupatorium: Radotín (Kalmus)! Šáka (Opiz)! Teplitz (Thümenı! Trebnitz: Borese und Wopun arnertal hej Lohwsitc! Leitmeritz! , Wagnerı. Bühm. Leipa (Schiftuer)! Gross Skal! Rovensko! Langenan hei Hohenelbe (Cypers)! Tábor! Lomnic a. L. Weiđłman!

Vach neueren Untersuchungen von klehahn verlieren die im Freien überwinternden Uredosporen ihre Keimfähigkeit nicht.

\section{Pucciniastrum Circaeae. (Schumacher) Spegazzini.}

A ecidien bisher unbekannt.

Tredolagrer lilein. auf hleichen. unregelmissigen Fleckn b]attunterseits zerstreut: Pseurloperidien suiter am sibeitel geouffurt: Psaudoperidienzellen etwas strahleutirmig genrinet, dïnmandis, nur un die Oeffinung hrom dicker: Sporen unregelmässig kughig bis länglich, oft nach unten verschmälert, 15-20 $\mu$ lang, 11-14 $\mu$ breit. mit farbloser. entfernt warziner Yembran und oramserotem Inhalt.

Teleutos poren lager blattunterseits, sehr klein, gruppenweise zusammenHhessend. hellbraun: Sporen in lileineren oder grüsseren Gruppen. 2-tzellig. rmudlich oder durch wechselseitizen Druck ahwethacht. 15-25 $\mu$ hoh, 1:-25) $u$ breit. mit gleichmässig dicker ( $2 \mu)$, glatter, hellgelber Membran. 
Uredosporen von Angust, Teleutosporen ron September auf

Circaea alpi na: Herrnskretschen (Vagner)! Jagdhaus oberhalb Eichwald bei Teplitz! T'ábor! Wittingau (Weidman)!

Circaea intermedia: Baumgarten bei Prag (Opiz)! Kacina (Peyl)! Rovensko! Herrnskretschen (Wagner)! Schlackenwerth (Reuss)! Tábor!

Meine Infektionsversuche im J. 1905 mit Sporidien anf Nadeln von Pius silvestris, Abies Picea und Abies alba fielen negativ ans.

\section{Thekopsora Maguus.}

Wie Pucciniastrum, aber die Teleutosporen in den Epiderniszellen gebildet; Aecidien und Uredosporen mit Pseudoperidien.

264. Thekopsora Padi (Kunzo et Schmidt). - P'ucciniastrum Padi Dietel - Thecopsora a reolata (Wallroth) Magnus.

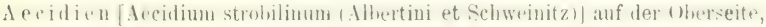

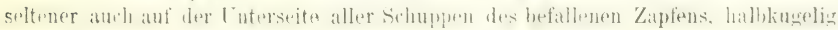
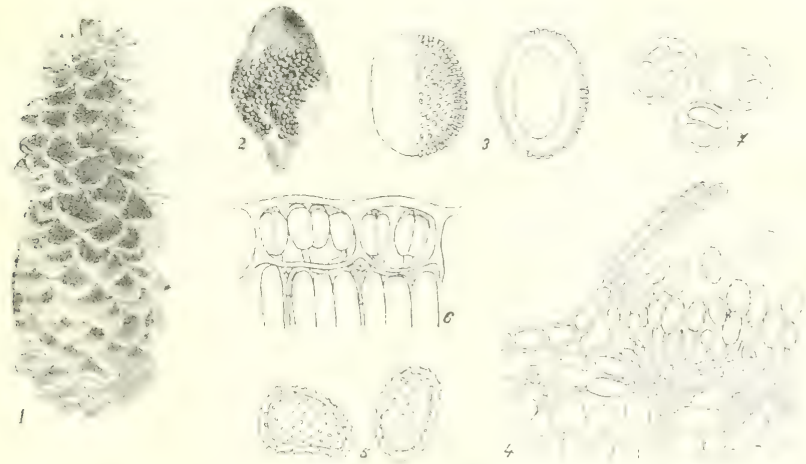

Abb. 45. Thekopsora Parli. 1. Aecidien auf Fichtennadeln. 2. Eine vergrösserte Zapfenschuppe mit Aecidien. (Nach Dietel). 3. Aecidiosporen. 4. Schnitt durch ein Uredolager. 5. Isolierte Uredosporen. 6. Schnitt durch ein Teleutosporenlager. 7 . Dieselben isoliert. (3-7 nach Klebahn).

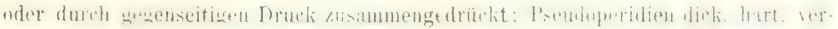

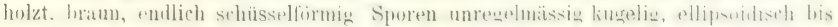
länglich, seltener polyedrisch, $18-35 \mu$ lang, 16-2. $\mu$ breit, Membran dick (6 $\boldsymbol{\mu}$, gelh, vou stäbchenformiger strulitur. Warzis, nur mit schmalem. kithlem and aneh dïnnerem Streifen. 
Uredosporen: Flecke blattoberseits, rotbraun, unten heller, $1-5 \mathrm{~mm}$ breit, scharf fon den Nerven begrenzt: Pseudoperidien klein, auf der Lnterseite der Flecke subepidermal, am Scheitel später mit rundlicher ()effnung versehen: Sporen kuglig-prismatisch bis lïnglich eiformig, 15-2:) " lang, 10-16 " breit, gelb, mit stachliger Membran.

Teleutosporenlager blattoberseits, Hach, glänzend, seltener blattunterseits; Sporen in llen Epiderniszellen, niedrig-walzenförmier oder prismatisch, 2 - -zellig, 22-30 $\mu$ lang, $8-14 \mu$ breit, mit dünner $(1 \mu)$, hellhrauner Membran.

decidien auf /apfen fon Ahies excels a in Nadelwiildern ziemlich verbreitet.

Der genetische Zusammenhang wurde ron 'Tuheuf festgestellt. Aecidiosporen keimen im Mai und infiziereu die Blätter von Prunus Padus. Teleutosporen keimen im Frühjahre und die Sporidien intizieren wahrscheiulich die weiblichen Blüten; es kïnnen auch junge Aestchen hefallen werden, aher die Aecidien werdon auf denselben nie gebillet.

2ỏ. Thekopsora (ialii (Liuk: De Toni. - Me lampsura liali i Winter.

A ecidieu bisher unbekannt.

Uredolager blattunterseits, orangenelb, klein, blasenfimig, ron Pseudoperidie umgeben; dieselbe am Scheitel später neölthet; Sporen eifürmig bis ellipsoidisch. $17-22 \mu$ lang, $11-16 \mu$ breit, orangerelh, mit farbloser. stachliger Membran.

Teleutosporenlager klein, dunkelbraun bis schwarz; Sporen in den Evidermiszellen, gewönlich zu einigen gruppiert, kuglig oder durch gregenseitigen Druck abgeflacht, $2-4 z e l l i g, 21-2 t$ " huch, $21-32 \mu$ breit, mit bräunlicher Membran.

Uredospuren von Mai, Teleutosporen zum Eude der Vegetationsperiode auf Galium mollugo: Roztok bei Prag! Kačina (Peyl)! Mühlhausen a. E. (Kabát)! Niedergrund bei Tetschen (Wagner). Rovensko!

Galium saxatile: Neuwelt im Riesengebirge!

Galium silvaticum: Radotin bei l'ras (Kalmus)! Uïhlhausen a. E. (Kahát)! Gross Wostray bei Aussig! Tábor!

Galium silvestre: Ondřiliovice bei Turuau (Kabát)!

iralium rerum: Wiesen bei V'setat! Welwarn (Kabát)! Teplitz (Thümen!!

Qriti. Thekopsora Vaceiniorum (De Candolle) Karsten. - L'ueciniastrum Vaccinii Dietel. - Melampsora Vaccinii Winter.

A ecidien bisher unbekannt.

Iredolager blattunterseits in kleinen Gruppen oder auch zerstreut, ron nrangegelber. am Scheitel spüter mit rundicher Oeffnung versehener Pseudoperidie. Sporen kuglig, eiförmig. ellipsoidisch his länglich, $19-28$ u lang. $13-18$ u breit. orangegelb, feiustachlig.

Teleutosporenlagrer sehr klein, braun, auf der Unterseite absterbender Blätter: Sporen in Epidermiszellen. 2-tzellig, hellbraun, 14-17 $\mu$ hoch.

Uredosporen von August, Teleutusporen erst zum Ende der Vecetationsperiode auf 
Vaccinium myrtillus: Ziemlich häufig und auch im Gebirge verbreitet.

Vaceinium uliginosum: Im Riesengebirge, an (ilatzer Schneeherge, in Erzgebirge und Böhmerwahde nicht selten. - Thamminhle bes Hirschberes (Kahits): Zâlší bei Veseli a. I.,!

Vaccinium Vitis id aea: Heruskretschen (Wagner) - Zwischen Aussergefild und Filippshütte im Böhmerwalde!

2tit. Thekopsora Pirolae (fimelin) Karten. Uredo Pirolae (Cimelin) Winter - Melampsora Pirolae (Gmelin) Schroeter.

A ecidien bisher unbekannt.

Lredolager blattunterseits auf welben oiler brannen Flecken, in kleinen, rundlichen Gruppen, von halbkugeliger, orangegelber Pseudoperidie umgeben, subepidermal, endlich am Scheitel mit rundlicher Oeftumns: Sporen eiformig, ellipsoidisch, lïnglich, oft einerseits schüiler, 20 -35, " laug, 12-18 " breit, orangegelh, feinstachelig.

T'eleutosporen bisher unbekannt.

Von Juli bis zum Winter, auf überwinternden Blätern auch im Winter auf

Pirola chlorantha: Bílá bei Böhm. Aicha! Reichenberg (Siegmund)! Pŕelouč (Peyl)! Krumau (Jungbauer);

Pirola rotun difolia. Bilichau (Kahát)! Altenbuch bei Trautenau ifiudernatsch)! Schïsselbauden in Riesengebirge (Kabát)!

Pirola secundiflora: Rotenhaus bei Komotau (Roth, Sachs)!

Pirola un iflora: Zwischea Tetschen und Kamnitz (Herb. d. k. k. Hofmuseums in Wien)! Riestngrund im Riesengebirge! (irenzbauden (Schroeter)! Spitzberg im Böhmerwalde!

Die ähnliche Chrysomy a Pirola e unterscheidet sich von der vorliegenden Art durch grössere, warzige Uredosporen.

\section{Calyptospora Kühn.}

Teleutusporen wie bei Thekopsora in den Epiderniszellen. aber nicht in kleinen P'olstern, sondern in der ganzen Epidermis ter befallenen Triebe: Iredosporen fehlen; Aecidien mit vollkommenen Pseudoperidien.

\section{Calyptospora Goeppertiana. Kühn.}

Spermogonien fehlen.

A ecidien mit langen, rohrenformigen, am Rande untegehmä-sig zerschlitzten ziemlich dicht stehemlen weissen Pseuhloperilien: Sporen kuglig bis ellipsoidisoh, 16-2f "t lang, $14-18 \mu$ breit, mit stachliger Membran und orangerotem Inhalt

Teleutosporenlager in den Epiderniszellen: die befallenen Triehe stak federkielartig verdickt und verlängert, anfangs rosafarbig, später braun: Sporen in den Zellen geilrängt und deshalb prismatisch, "2 -4zellig, bis 42 " hoh, mit hranuer, glatter Membran. Keimporen an den inneren Ecken der Tetraden. 
Aecidien im Juli anf Naleln von

A bies pectinata: Herruskretschen (Wagner). Harta bei Hohenelbe (Cypers). Tábor! Arber-See im Böhmerwalde (Krieger).

Teleutosposen im Herbst, Winter und Frühjahre auf

V a c cin i um Vitis ida ea: verbreitet, besoaders in kühleren, böheren Lagen, wo die Tanne gedeibt.
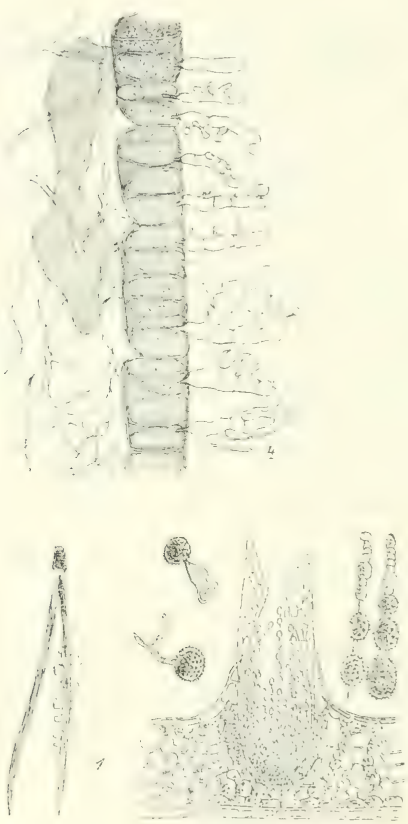
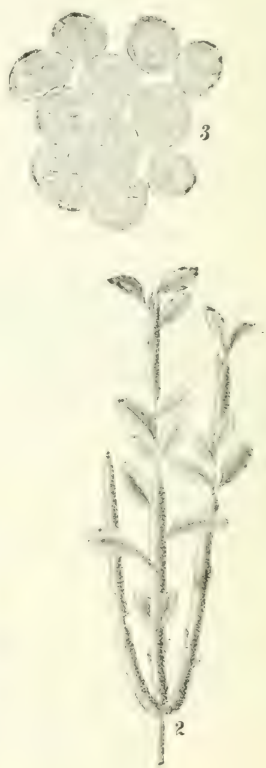

Abb. 46. Calyptospora Goeppertiana. 1. Aecidien auf Fichtenuadeln, Schnitt lureh eiue Pseudo. peridie, Sporenketten und keimende Sporen. (Nach Tubeuf und Hartig). 2. Eine Preiselbeerpflanze von Teleutosporen befallen. 3. Teleutosporen. 4. Radialer Schnitt durch einen befallenen Ast mit keimenden Teleutosporen. (Nach Hartig, Tubeuf und Dietel; 3 Original.

Der genetische Zusammenhang warde ron $\mathrm{H}$ a r t ig und $\mathrm{K}$ üh n festgestellt. Im Jahre 19u4 habe ich die Versuche mit den sporidien auf Tannennadeln wiederholt und zwar mit vollem Erfolge. 
Die intiziorten Preiselbeeren hahen ein rigentümliches Aussolsen, indem die befallenen Triebe verläusert, federkinlartig ardicht, braun, und wn straten Wuchse

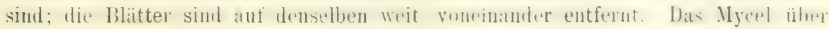

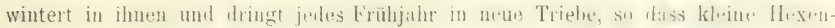
besen entstehen.

\section{Hyalopsora Maguus.}

'leleutosporen hyalin, in 1-2 Schichten in den Epidermiszellen gebildet, ilureh vertikale querwände in :- 4 \%ellen greteilt. Iredusporen mit oder ohne Pseudoperidien. Aecidien bisher unbekannt. Nur auf Farnptlanzen.

¿is. Ifyalopsora Polypodii dryopteridis (Mougeot et Nestler) Manuus. Melampsorella Aspidiotus (Peck) Maguus. - Hyalopsora Aspidiotus (Peck) Magnus.

A ecidien bisher unbekannt.

Credolager blattunterseits, seltener blattoherseits, blasenformigr, ohue l'semioperidie, nur ron der Epidermis bedeckt, "mallich nackit, staubigr, mangegrib. Sporen mit orangefarbigem Inhait und son zweirlei Art: 1) eiformig bis ellipsoidisch, $3:-4$ - $u$ lang, $16-26 u$ breit, mit dünner, futhloser, zerstreut warziger Membrau und 4 aequatorial gelegenen heimporen oder 2 ) oft polyedrisch, 36-7: " lang, $27-41)$ u breit, mit dieker, sehr feinwarziger Membran und ( -8 - heimporen.

Teleutosporen in den Epidermiszellen blattunterseits, rundlich oder auch unregelmässig, gersenseitip zusammengedrüclit, mamehmal anch in zwei schichten übereinander liegend, $201-42, \mu$ breit, bis $25, \mu$ hoch, $2-4$ (manchmal auch 5-) zellig; Membran dünn, hyalin.

Credosporen vom Frühjahre his zum Winter, Teleutosporen im Mai auf

Poly podium dry opteris: Zahorauertal bei Datle! Bublu. Leipa (Cypers)! Hermskretselien (Wamner)! Ellyrund im Riesengebirge (Kabit)! Oberbali, der Kratusebatuleu und im Weisswassergrund! 'Thbur! Krumau (dunghauer)! In der Vihte des T'eufelsees im Böhmerwalde! Eisenstein (Krieger).

Die Entwicklung unbekanut. Im J. 1905 habe ich mit den Sporidien auf deu Niuleln von Abies pectinati, Abies Picea, P'inus silvestris und Larix europaes Ausaten durchgeführt, aber ohne jeden Resultat. In ler Keimumgszeit der Teleutosporen sind die infizierten Pflanzen unterseits mit weissen Ueberzuge, welcher aus I'romycelien und Sporidien hesteht, hedeckt. Es scheint, dass das Mycel in den Rhizomen überwintert.

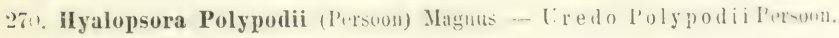

A ecidien bisher unbekannt.

Uredolager blattunterseits, sonst wie bei der vorangehenden Art; Sporeu orange, vou zweierlei Form: 1 , 2.2-3.) ". lang, 13-20 "2 breit, mit farbloser, ent.

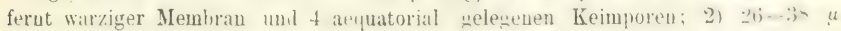
lang, 1s-29 "l breit; Memhran dick. mit Hachen Warzen hesetzt. farblos. mit $6-8$ Keimporen. 
Teleutosporen auf hrauneu Flecken in den Epidermiszellen blattuuterseits. dicht gedrängt. $14-18 \mu$ breit, mit sehr dünner, farbloser Membran.

Credospurea rom Frühjahre bis zum Winter. Telentosporen im Juli auf

Cystopteris fragilis: ziemlich verbreitet.

Iher Entwicklungsgang hisher unhekannt. Die befallenen Blatter sind hlejeh und durch die oft dichtstehenden, orangefärbigen Credolager sehr auffallend.

\section{Uredinopsis Magnus.}

Teleutosporen im Blattparenchym zerstreut, „--4ellig, farblos; Credolager mit Pseudoperidie; dieselbe aus sackförmig verlingerteu Zellen gehildet. Aecidien unbekannt.

\section{Uredinopsis filicina (Niessl) Magnus.}

A ecidien unbekannt.

Iredolager klein. subepidermal un 1 zwar immer unterhall eines Porus, in Form eines niedrigen, gelblichen orler grauen Wärzchens; Pseudoperidie unten

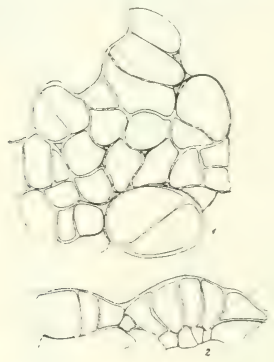

Obr. 47. Hi/alopsora Polypodii chrysopleridis. 1. Teleutosporen von oben gesehen. 2. Radialer Schnitt durch eine Teleutosporengruppe. (Nach E. Fischer.)
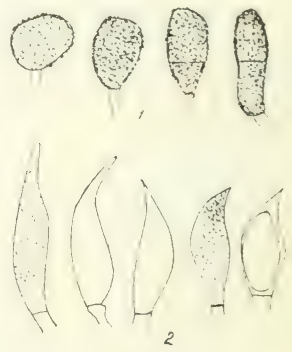

Abb. 48. Uredinopsis Alicina. Beide Formen der Uredosporen. (Nach F. Fischer.)

aus sackförmigen. oben polyedrischen Zellen. Sporen von zweierlei Art: 1) eifürmig his spindelföımig, ohen in eine lauge sipitze ühergehend, undeutlich warzig, 30-55 " lang, 7-15 Warzig, 1s-28 $\mu$ lang, $10-1$ s von kurzer Ranken herausgestossen.

Teleutosporenlager im Mesophyll zerstreut, kuglig bis länglich, 1-3. zellig, $17-21$ " breit. 28 " lang. mit dünner, glatter, farbloser Membran.

Uredolager von August, Teleutosporenlager etwas später auf

Phegopteris poly podioides in höheren Lagen: Reichenberg (Siegmund)! Herrnskretschen (Wasner)! In Riesengebirge bei Hackelstorf, im Elbgrumi. 


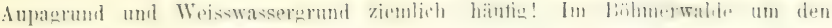
Teufelssee, bei Eisenstein, ron Deffernik zum Lakkasee! Am Wege von OherLipkit auf (fen Glatzer Schneeberg, im Marchtale oberbalb Gross Molnau!

\section{Melampsora Castagne.}

Pykniden flach, halbkugelig, subepidermal oder nur subliutikular.

Aecidien vom Caeoma-Typus, ohne Pseudoperidien und Parafysen.

Uredosporen einzeln auf Stielen gebildet, von Parafysen umgeben.

Teleutosporen einzellig, sehr selten quer geteilt, in Hache, wachsartige Polster verkleht.

I. Urealo- und Teleutosporen auf Salix.

1. Uredosporen länglich, am Scheitel glatt.

a) Tcleutosporen subepidermal.

a) Autoecische Arten.

\section{Melampsora Amygdalina Klebahn.}

Spermogonien wenig hervorragend mit konkaver Fruchtschicht.

Caeoma auf jungen Blättern und Aesten, auf Blättern meistens unterseits und $1 \mathrm{~mm}$ breit, auf Aesten bis $1 \mathrm{~cm}$ lang, mehr oder weniger zusammentliessend, intensiv orange; Sporen kuglig oder eiförmig, gewöhnlich polyedrisch, kettenfürmig gebildet, 18 bis $23 \mu$ lang, $14-19 " \mu$ breit, mit $2 \mu$ dicker, feinwarziger Membran.

Uredolager blattunserseits zerstreut, klein $(0.5 \mathrm{~mm})$, rundlich, intensiv orange, auf gelben Fleckchen sitzend; Sporen eiförmig bis keulenförmig, im oberen Teile dicker, 19-32 " lang, $11-15, "$ breit; Membran $15 \bar{y}$ dick, am Scheitel glatt, iibrigens entfernt $(2 \mu)$ stachlig; Parafysen kopfförmig, mit dünnem $(4-5 \mu)$ Stiel, 30 bis50 $\mu$ lang, oben $10-18 \mu$ breit oder lieulenfirmis, mit breiterem sitiel $(4-10 \mu)$, oben $10-15 \mu$ breit.

Teleutosporenlager blattunterseits, subepidermal, klein, $0 \% \mathrm{~mm}$ hreit,

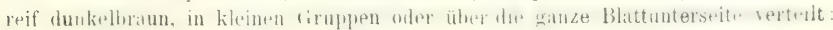

Dr. Ruhak, Die Pilze Rïhmens.

Abl. 49. Melamprora Ammatalinas. 1. Caeoua und Sivermogmiten ant Saliv amyad.t= lina, 2. Ketten ron Cacomasporen, Parafysen und vergrösserte Sporen. 3. Stark vergrösserte Caeomasporen. 4. Uredosporen. 5. Scbnitt durch ein Teleutosporenhaser. 6. Tine Partir dezcrlben stark ver. grössert. (Nach Klebabn.) 
Sporen prismatisch, oft unregelmässigr, heiderseits ahgerundet, $18-42 \mu$ lang $7-14 \mu$ breit, mit dünner, brauner, etwa $1 \mu$ dicker Membran.

Caeoma im Mai, Uredosporen von Juni, Teleutosporen von August auf

Salix a mydalina: Auf Bach- und Flussufern verbreitet.

Nach Klebahn's Versuchen soll diese Art auch auf Salix pentandra vorkommen.

Melampsora Amygdalinae ist durch seine Biologie von allen verwanden, auf Salix rorkmmmenien Art: n verschieden. Von der folgenden Art unterscheidet sie sich durch küzere fredosjoren. die auch dünnere, feinstachligere Membran besitzen.

ß) Heteroecische Arten.

\section{Melampsora minutissima (Opiz) Bubák.}

Melampsora Larici pentandrae Klebahn. - Uredo minutissima Opiz in Seznam 1852, yg. 152 et in schedis.

C'acoma intensix orange; Sporen linglig, eifirmig, immer towas polyedrisch,

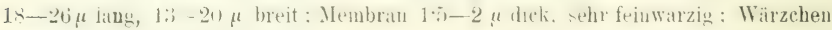
$1 \mu$ von einander entfernt.

Uredosporen iutensiv orange, bis $1 \mathrm{~mm}$ breit, hauptsächlich blattunterseits: vereinzelt auch blattoberseits; sporen lieulenfirmin, saltener linglich ellipso-

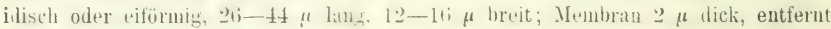
$\left(2-250\right.$ ) stachlig, in dem oheren ${ }^{1}$. glatt; P'arafysen his ju $\mu$ laug, oben $12-22 \mu$ dick, ihr Stiel $4-5 \mu$ breit.

T'eleutosporenlager wie bei der vorangehenden Art, oft zusammenfliessend, von Epidermisresten bertecht; sporen $2 x-38 \mu$ ling, $6-11 \mu$ breit.

Caeoma im Mai auf

Larix europaea: Aus Böhmen sah ich es noch nicht.

Uredosporen von Juni, Teleutosporen von Juli auf

Salix pentandra: Borek bei Cislas (Opiz als Uredo miuntissima Opiz)! Thammühle bei Habstein (Kabát)!

siehe die Bemerkung bei der rorangehenlen . Irt. Der genetische Zusammenhang wurde von Klebahn festgestellt.

\section{Melampsora Allii-Salicis albae Klebahn.}

Spermogonien mit flacher, wenig konvexer Fruchtschicht, $120 \mu$ hoch, 210 breit.

Caeomalager auf gelben Flecken auf Stengehn und Blättern. in kleinen Gruppen, etwa 1 mm breit, von deu Epidermisresten an den Seiten bedeckt, orange; Sporen unregelmässigr, selten kuslig, rewöbnlich polyedrisch, $17-26 \mu$ lang. $15-1 \times \mu$ breit, mit $1-15 \mu$ dicker, friu- und dichtwarziger iStachelentfernung $1 \mu$ ) Membran.

Uredolager anfangs auf jungen Aestchen, bis $5 \mathrm{~mm}$ lang, die Rinde durchbrechend, spriter auf jungen Blattern gruppiert, bis 2 mm breit, im Sommer und Herbst auf ausgebilieten Blittern um damn nur klein, ${ }_{2}{ }_{2}$ mm breit, meistens 
unterseits, seltener oberseits, auf gelblichen llecken; Sporen limelich, oft am Scheitel breiter und dann birnformig oder keulenformis, 20-3ti $\mu$ lang. $11-17 \mu$ hreit; Membran 2 " dick, an Scheitel glatt, im übrigen Teile entfernt stachlig (Stachelabstand ״-2.5 "I); Parafysen kopfförmig und diunnstielig oder keulenfïrmig, dickstielig, $50-70 \mu$ lang, oben 15-20 dick: Membran der Parafysen ;" "/ dick: Uredolager auf Aestchen ohne Larafysen.

Teleutosporenlager subepidermal, zerstreut oder blattbeilerseits gruppirt, blattoberseits gewöhnlich zahlrticher, dunkelbrauu, wenig ulänzend; Spoten umegelmässig prismatisch, beiderseits abgerundet, 25 - 4i) $\mu$ lang, $7-10 \mu$ breit; Membran etwa $1 \mu$ dick; Sporidien hyalin.

Caeoma im Mai, seltener sehon Ende April oder auch im Juni auf

Allium rotundum: Chotuc bei Kŕrinec!

Allium scorodoprasum: Daselbst zahlreich! Watislav bei Trebnitz!

A llium ursin um: Nymburk (Vštečka im Herbar des k. k. Gymmasiums in Jungbunzlau)!

Diese Lokalitïten kömnen aber auch zu der nächstfolgenden Art oder zu M elampsora Allii-populina Klebahn .gehören; ohne Infektionsversuche ist es unmöglich, dasselbe mit Sicherheit zu bestimmen.

Uredosporen von Mai, Teleutosporen von August auf

Sa lix alba: Prag (Opiz, Hennevogl)! Welwarn (Kabát)! Harta und Pelzdorf bei Hohenelbe (Cypers) und gewiss mehr verbreitet.

Diese Melampsora ist mit beiden vorangehenden Arten, wie auch mit den nächstfolgenden verwandt; sie unterscheidet sich von ihuen durch farblose Sporidien, von den zwei ersten ausser den biologischen Verhältuissen auch durch die blattoberseits gebildete Teleutosporenlager. Bei der folgenden Art werden die Teleutosporenlager subkutikular gebildet.

b) Teleutosporenlager zwischen der Epidermis und der Kutikula gebildet.

\section{Melampsora Allii-fragilis Klebahn.}

Spermogonien subepidermal, wenig gewïlbt, mit flacher Fruchtschicht, blass, etwa $200 \mu$ breit.

Ca $0 \mathrm{mal}$ a ger auf Stengeln, Blättern ouler Brutzwiebeln, auf gelben Flecken sitzend, klein, 05-1 mm breit oler bis $2 \mathrm{~mm}$ lang, von den Epidermisresten umgeben, orangegelb; Sporen unregelmässig. polyedrisch uud $z$ war isordiametrisch bis lïnglich, 18-25 $\mu$ lang, $12-19$ " breit; Membrau 1-2 $\mu$ dick, fein- und dichtwarzig (Stachelabstand $1 \mu$ ).

Uredol ager blattunterseits, seltener oberseits, klein, $1 / 2 \mathrm{~mm}$ breit, rundlich, rotorange, von Epidermisresten umgeben, auf rotgelben Flecken: Sporen länglich, am Scheitel breiter und daher länglich-eiförmig oder birnförmig, 22-3: lang, $13-1$ i) $\mu$ breit; Membrau :3 $\mu$ dick, entfernt $(2-3 \mu$ stachlig, nur am Scheitel glatt; Parafysen $50-70 \mu$ lang, kopfförmig, oben $15-20 \mu$ breit, ihr Stiel $3-5$, dick, oder keulenförmig, $10-15 \mu$ breit, Stiel $7 \mu$ dick; Membran der Parafysen $3-5 \mu$ dick.

Teleutosporenlager subkutikular, meistens blattoberseits, selfener 
unterseits, zerstreut oder mebr oder weniger gruppiert, gewölbt, $1 / 4-1^{1} / 2 \mathrm{~mm}$ breit, dunkelbraun, glänzend; Sporen unregelmissig prismatisch, beiderseits abgerundet. blattoberseits länger als blattunterseits, $30-48$ " lang. $7-14$ " breit, mit hellbrauner, etwa $1 \mu$ dicker Membran; Sporidien orange.

Caeoma auf verschiedenen Allium-Arten im Mai. Es ist möglich, dass hierher etliche Standorte. welche bei der vorangehenden Spezies aufgeführt sind, gehören.

Uredosporen von Juni, Teleutosporen von August auf
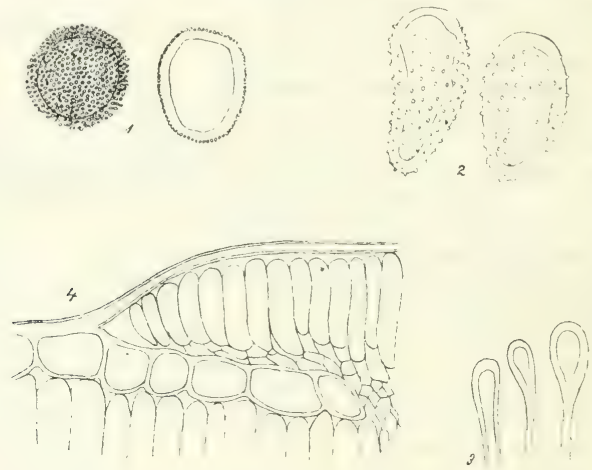

Alb. 50. Melamipsora Allii-fragilis. 1. Caeomasporen von Allium. 2. Uredosporen.

3. Parafysen. 4. Schnitt durch ein Teleutosporenlager (Nach Kilebahn).

Salix fragilis: Michle bei Prag (Opiz)! Sadská!

Roždalovic! Vazovec bei Turnau (Kabát)!

Rorensko! Bořkor hei Semil! Langenau bei Hohenelbe! Pustá liybna bei Polička (Novák)!

Siehe die Bemerkungen bei der vorangehenden und nïchsfolgenden dit. Der genetische Zusammenhang wurde ron Kle bahn festgestellt.

\section{Melampsora Galanthi-Fragilis Klebahu.}

Spermogonien flach, wenig hervorragend, $80-100 u$ hoch, 130 bis 160 " breit.

Cacomalager blattbeiderseits auf grösseren, gelblichen Flecken, zerstreut nler gruppiert, oft ringfürmig um die Spermogonien stehend, $1-2 \mathrm{~mm}$ breit, öfters zusammenfliessend, vou den Epidermisresten umgeben, orauge; Sporen polyedriseh und zwar kuglich bis eiförmig, $17-22$ " lang, 14-19 " breit, mit 1 " dicker, dicht- $(1, \mu)$ und feinwarziger Membran. 
Iredolager blattunterseits auf gelben Flecken, seltener blattobersents, zerstrent oiler gruppiert, ' $-1 \mathrm{~mm}$ gross, rundlich, von den lipidermisresten umgehen, orange; Sporen grisstenteils lïnglich, selten eiformig, oft birnformig oder keulenfürmig und dann an Scheitel breiter, 25-38 $\mu$ lang, $12-16 \mu$ breit; Membran 3 " dick, entfernt $-\left(\mathcal{B}_{-3}\right.$ "1) und feinstachlig, am Scheitel glatt, Parafysen gewöhnlich koptfirmig. 5()$-70), \mu$ lang, $17-23, u$ breit, ihr Stiel $2-5, u$ dick.

Teleutos porenlager subkutikular, $1 / 4-1$ man breit, sonst wie bei der vorangehenden Art; Sporen ebenfalls, $25-45 \mu$ lang, $8-15 \mu$ breit.

Caeoma von April auf

Ga lanthus nivalis: Im Schwarsenberg'scheu Gatten in Krumau (Jungbatuer nach Kirchuer; siehe Lotos 185ti, po. 179 als U redo $\mathrm{G}$ a lanth $\mathrm{i}$ Kirchner.

Uredo- und Teleutosporen sah ich aus Böhmen bisher nicht.

Von der vorangehenden Art nur biologisch verschieden.

2. Uredosporen kuglig, auch an Scheitel stachlig.

a) Teleutosporen am scheitel sturk verlickt, mit auffullendem hoimporws. sublitikular.

\section{Melampsora Larici-Capraearum Klebahn.}

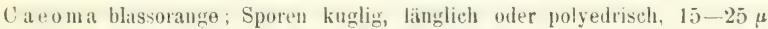
lanı, $12-17 \mu$ breit, mit $2 \mu$ dicker, ziemlich dicht- $(1, \mu)$ und feinwarziger Membran.

Uredol ager auf der Unterseite gelblicher filecke, zerstreut oder gruppiert,

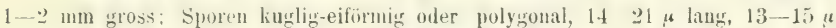
breit, mit 2-25 u lirker Membran; Parafysen 50-60 u lang, kopifformig, $18-26$ " breit, ihr Stiel $5-6 \mu$ breit, Membran $5 \mu$ dick.

T'eleutosporenlager subkutikular, $60 \mu$ hoch, $1 \mathrm{~mm}$ breit, oft ausgedehnt, litustentirmig, dunkelrotbraun; Sporen prismatisch, unten abgerundet, 30-4) " laug, $7-14$ " breit; Membriu hellbraun 1 " dick, an Scheitel bis $10 ~ " \iota$ dick und daselbst mit deutlichem, wenig seitwärts liesrendem Keimporus.

Caeoma nach Klebahn und Jacky auf

Larix europaea und L. oceidentalis.

Uredo und Teleutosporen auf Salix Capratea, seltener auf salix a u r ita verbreitet. Auf der letıtgenannten Nährptlanze bei Měsic nüchst Tibor !

\section{Melampsora Larici epitea (Klebahn) E. Fischer.}

Caeomalager unterseits auf gelben Flecken zerstreut oder ein- bis zweireihig, rundlich bis länglich, $1 / 2-1 \frac{1}{2}, \mathrm{~mm}$ lang; Sporen kuglig, eiformig ouler etwas polyedrisch, 15-25, 4 lang, $10-21$ " breit, mit foin- und dichtwarziger Membran (Warzenabstand etwa $1 \mu$ ).

Uredolager einerseits oder blattbeiderseits auf gelben Fleclitn, orangegelb, $1,-1 \frac{1}{2} \mathrm{~mm}$ breit; Sporen kuglig bis lïnglich, oft polyedrisch, 12-25 $\mu$ lang, $9-19 \mu$ breit: Membran 15-35 $\mu$ dick, entfernt $(2-3 \mu$ a stachlig: Parafysen kopfförmig, 35-80 " lang, 15- $44 \mu$ breit, mit $3-4$ " dicliem Stiel; ibre Membran 3-5 $\mu$, am Kopf oft bis $10 \mu$ dick. 
Teleutosporenlager subepidermal, blatbeiderseits, $1 / 4^{-1} \mathrm{~mm}$ breit, dicht gruppiert und oft zusammentliessen.1; Sporen prismatisch. seltener kenlenfurmig oiler unregelmässis. beiderseits ahgerundet oder am Scheitel vorgezogen, $20-50$ ulaum, $7-1+u$ breit; Membran hellbraum, nicht verdickt, ohue deutlichen Keimporus (nach Klebahn).

Gaeoma auf Larix europaea: Aus Böhmen sah ich sie noch nicht.
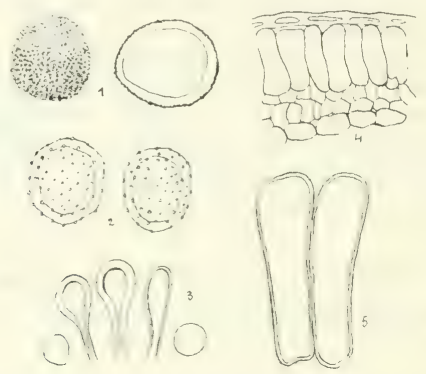

Abb. 51. Melampsora Lnivi-epitea. 1. Caeomasporen. 2., 3. Uredosporen und Parafysen. 5. Schnitt durch ein Teleutosporenlager. 5. Vergrösserte Teleutosporen. (Nach Klebahn).

Uredo- und Teleutosporen auf verschiedenen Salix-Arten und zwar: S a urita, cinerea, viminalis, hypophaifolia, Capraea, acutifolia, daphnoides, aurita $<$ viminalis, purpurea $X$ viminalis, dasyclados, Smithiana, retusa, herbacea, reticulata, serpyllifolia, nigricans, glabra, arbuscula, fragilis. purpurea. grandifolia. Aus Böhmen mit Sicherheit bisher nur auf

Salix viminalis: Turnau (Kabát)! Ždár bei Polic a M.!

Salix Capraea: Friedrichstal im Riesengebirge (Kabát)!

Salix aurita: Tábor!

Der genetische Zusammenhang wurde von Klebahn, E. Fischer und 0 . schneider bewiesen. Die genannten Autoren unterscheiden folgende biologische Formen:

1. f. sp. Larici-epitea typica (Mel, Larici-epitea Klebaho).

2. f. sp. Larici-daphnoidis (Klebahn) E. Fischer.

3. f. sp. Larici-retusae E. Fischer.

4. f. sp. Larici-nigricantis 0 . Schneider.

5. f. sp. Larici-purpureae 0 . Schneider.

Die Närptlanzen dieser hiologisehen Formen siehe in dem vorzüglichen Werke von E. Fischer, Die Uredineen der Schweiz, pg. 487. 
979. Melampsora repentis Plowrirht. Melamp<orat rehidi-r ppentes Klebahn.

Spermogonien eingesenkt, die Epidermis hervorwölbend, mit flachem Hymenium, etwa $170 \mu$ breit, $50 \mu$ hoch.

Caeomalager beiderseits auf grossen, gewïhnlich elliptischen, gelblichen Flecken, gruppiert oder ringfömigr, oft zusammentliessend, 1-2 mm gross, gelborange; Sporen gewöhnlich polyedrisch und zwar eiformig oder kuglig, $15-20 \mu$ lang, $11-15 \mu$ breit, mit dünner $(1-15 \mu)$, sehr fein- und dichtwarziger (1 $\mu)$ Membran.

Uredolager unterseits auf gelben Flecken, klein, $1 / 5-1 / 2 m m$ im Durchmesser, intensiv orange; Sporen kuglig bis eiförmig, $13-17 \mu$ lang, $12-14 \mu$ breit, mit $1.5 \mu$ licker, ziemlich dichtstachliger $\left(\begin{array}{lll}15 & \|\end{array}\right)$ Membran; Parafysen meistens kopfförmig, $40-70 \mu$ lang, $16-20 \mu$ breit; ihr Stiel $3-5 \mu$ dick; Nembran am Kopf $2-5 \mu$ dick.

Teleutosporenlaner blattunterseits, subepidermal, klein, dunkelloran; Sporen prismatisch, beiderseits absermulet. 16-4h " lampe, $7-14$ " breit, mit hellbrauner, $1 \mu$ dicker Membran.

Caeoma auf verschiedenen Orchideen, wie Orchis latifolia, maculata, incarnata. Kommt auch auf Platanthera chlorantha, Orchis militaris, sambucina, Gymnadenia conopea, Ophrys muscifera, Listera ovata vor. Aus Böhmen sah ich sie noch nicht.

Uredo und Telentosporen auf

Salix repens: Střebsko bei Pŕibram (Tił. Novák)!

Der genetische Zusammenhang wurde von Plowright und Klebahn festgestellt.

Kommt auch auf Salix a urita vor. Der vorangehenden Art ist sie sehr äbulich.

\section{Melapsora Evonymi-Capraearum Klebain.}

Spermog on ien in der Mitte der Lager, ziemlich zahlreich, oft beiderseits entwickelt, honighraun his rotbraun, mit schwach eingesmkenen Hymenium, :2(m) $\mu$ breit, $80 \mu$ hoch.

Ca e o m a af der Unterseite orangefarbiger. Flecke in dichten Gruppen,

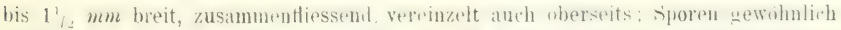
eiformis, auch liuslig. seltener lïnglich. 1s-2:3 " lans, 14-1!" "t hreit, mit diclier dicht- $(1 \boldsymbol{\mu})$ und feinwarziger Membran.

Uredolager auf der Unterseite gelber Flecke, etwa $1 / 2 m m$ breit, polster-

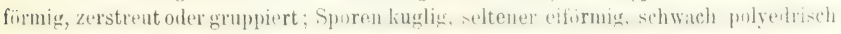
14-19 $\mu$ lang, 14-17 $\mu$ breit; Membran stellenweise $15 \mu$, stellenweise bis $4 \mu$ dick, entfernt $(2 \mu)$ stachlig; Parafysen koppförmig, $50-70 \mu$ lang, am Kopfe 18- $25 \mu$ breit, Stiel $4-5 \mu$ dick; Membran $2 \mu$, am Kopfe bis $8 \mu$ dick.

'Teleutosporenlager unterseits auf braunen Flecken, von der Èpidermis

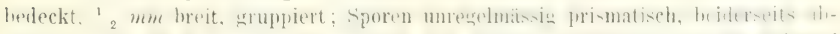
gerundet. 25-40 $\mu$ lang, $7-13 \mu$ breit, mit diunte, hellhramer, nu an sibe:tel schwach verdicliter Membran und daselbst mit wenig dentlichem Keimporus. 


\section{Caeoma im Juni auf}

Evonymus europaeus: Weltrus (Kabát)! Beim Dymokurer Teich!

Uredosporen von Juli, Teleutosporen von Ende August auf

Salix a r ita, cinerea, cinerea Xviminalis, incana. Aus Böhmen sah ich sie noch nicht.

Der genetische Zusammenhang wurde von Rostrup und Kleba h n festgestellt.

281. Melampsora Ribesii-Salicum Bubik nov. nom. - Nelampsoragribesi purpurea Klebahn et Melampsora Ribesii-auritae Klebahn,

Spermogonien mehr oder weniger kegelförmig gewölbt, $150-180 \mu$ breit, $60-80 \mu$ hoch.

Caeomalager blattunterseits oder seltener blattbeiderseits auf gelben Flecken vereinzelt oder in kleinen (iruppen, ${ }_{2}^{1}-1 \frac{1}{2} \mathrm{~mm}$ breit, oft zusammenHiessend, orange; Sporen kuglig, manchmal polyedrisch, selten lïnglich, 15-24 $\mu$ lau, 12-20 $\mu$ breit; Membran $3 \mu$ dick, ziemlicht dicht- $(1 \mu)$ und feinwarzig.

Uredolager unterseits auf gelben Fleckes, seltener oberseits, klein, und die ersten bis $1 \frac{1}{2} m m$ breit, die späteren nur $1 / 2-1 \mathrm{~mm}$, polsterfurmig, orauge; Sporen kuglig, selten polyedrisch, 15-2:" $"$ lang, $1420 \quad \mu$ breit; Membran $2 \cdot 5-3.5 \mu$ dick, entfernt $(2-2.5 \mu)$ und feinstachlig, Parafysen kopffirming oder keulenförmig, $40-70,4$ lang, oben 12-24 $"$ breit, Stiel $3-7 \mu$ breit, Membran $1.5-5 \mu$ dick.

Teleutosporeulager unterseits auf brauneu Flecken, seltener oberseits zorstreut oder gruppiert, 1/4 $1 / 2$ mm hreit, schwarzbraun; Sporen unregelmässig prismatisch, beiderseits abgerundet, 2()-35 $\mu$ lang, $7-11 \mu$ hreit; Membran liaum $1 \mu$ dick, hellbraun.

Caeoma auf verschiedenen Ribes-Arten Ende April und im Mai, in Böhmen auf

Ri bes grossularia: Mühlhausen a. E. (Kabát)! Raudnic (Procházka)! Turnau (Kabát)! beziehen.

Diese Standorte kimnen sich aber auch auf die nächtstolgende Spezies

Uredo- von Mai, Teleutosporen von August auf

salix anrita, Caprea, purpurea, purpurea $\times$ viminalis, selten Salix daph noides. In Böhmen an Bach- und Flussufern nicht selten auf

Salix purpurea: Roveusko; Boŕkov bei Semil! Turnau (Kabát)! Langenbruck bei Reichenherg (Matouschek)! Harta bei Hohenelbe (Cypers)! Tetscheu (Waguer)! Holice (Ćenék)! Kácina (Peylı! Kolín (Teselský)! I)uppau bei Karlsbad (Wiesbauer) !

Salix rubra (purpurea × vimiualis): Rovensko! Roždalovic! Wittingau (Weidman)!

Unter dem neuen Namen vereinige ich beide genannten Kl eba hn'schen Spezies, denn die Untersthiede zwischen beiden sind so gering und so relativ, dass sie nur für Spezialformen gehalten wurlen können. Die eine: f. sp. Ribesi i- 
a urita kommt uur auf Salix Cally a a und a $r$ it a vor, während die andere: f. sp. Ribesii purpure a e die übrigen Wirtspflanzen befallt.

ß) Teleutosporen zuischen Epidermis und Kutikula gebildet.

\section{Melampsora Kibesii-viminalis Klebahn.}

Spermogonien polsterförmig, $150 \mu$ breit, $70 \mu$ hoch, mit eingesunkenem Hymenium.

Ca eoma wie bei der vorangehenden Art; Sporen gewöhnlich kuglig, selten eiförmig, schwach polyedrisch, 18-23 $\mu$ lang, $14-17 \mu$ breit; Membran $2-3 \mu$ dick, ziemlich dicht- $(1, \mu)$ und feinwarzig.

Uredolager blattunterseits, 1/, mm breit, zerstreut oder gruppiert, blassorange; Sporen kuglig, seltener eiförmig, 15-19 $u$ lang, 14-16 $\mu$ breit; Membran $2 \mu$ dick, entfernt (2 $\mu$ ) stachlig; Parafysen koptförmig oder keulenförmig, 50 bis $70 \mu$ laug. $18-25 \mu$ breit, ihr Stiel $7-14 \mu$ breit, Membrau $1-2 \mu$ dick.

'Teleutosporenlager blattoberseits, subkutikular, $1 / 4-1 / 2 \mathrm{~mm}$ breit, zerstreut oder gruppiert, glinzeud, dunkelbraun; Sporen prismatisch, beiderseits abgerundet, 25 bis $40 \mu$ lang, $6-14 \mu$ breit, mit 1 " dicker, hellbrauner Membran.

Caeoma im Juni auf verschiedenen Ribes-Arten und zwar Ribes grossularia, rubrum, nigrum, seltener Ribes alpinum und aureum. In Böhmen bisher nur auf

Ribes rubrum: Turnau (Kabát)!
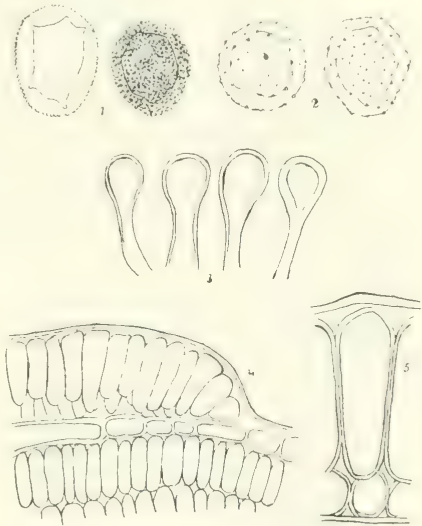

Abb. 52. Melampsora Ribesi-viminalis. 1. Caeoma. sporen. $\iota, 3$. Uredosporen und ihre Yarafysen. 4. Schnitt durch ein Teleutosporenlager. 5. Dieselben vargrössert. (Nach Klebahn.)

Uredo- und Teleutosporen auf

Salix viminalis: Kolin (Veselský)! Elbufer bei Sadska! Rovensko T'uruatu (Labit)! Pelzdorf bei Hohenelbe (Cypers)! (Wotébor (Mühlbarh)! Wittingan (Weidman)!

\section{Antıang:}

Jene Melampsora-Arten, welche von $\mathrm{Klebahn} \mathrm{und} \mathrm{anderen} \mathrm{auf} \mathrm{Grund} \mathrm{von}$ Infektionsversuchen aufgestellt wurden, sind oft einamler so thnlich, dass man sin nach mortologischen Charakteren nicht bestimm'n kamn. Nur diesbezüıliche Infektionsversuche könnten entscheiden, um welche Spezies es sich handelt. 
Ich führe deshalb hier auhangsweise jrne Exsiklkaten an, welche ans dem angeführten Grunde nicht bestimmbai sind :

Larix europaea: Bora bei Rovensko, zusammen mit Uredo auf Salix Capraea und Populus tremula.

Salix a urita: Rovensko! Tannwald, Schumburg, Př́chovic, Wurzelsulorf Neuwelt, Harachsdorf! Harta hei Hohenelbe (Cypers)! Ober Lipka bei (irulich, Tabor !

Salis Capratea: In Bihmen sehr verbreitet im Uredo- und Teleutosporenstadium

Salix c inerea: Mühlhaugen a. F. (Kabát)! Roźdalovic! Kúrinec! Táhor! (Schröter).

Salix La lponum: Kessel im Riesengebirge (Kabát)! Schlingelbaude

Salix silesiaca: Schlingelbaude, Grenzbaude (Schröter).

Salix viminalis: Beide Sporentornen in Böhmen sehr verbreitet.

II. Uredo- and Teleutosporen auf Populus.

1. Uredosporen kuglig, ïberall stachlig.

283. Melampsora Laricis R. Hartig. - Melam pora Larici-Tremulae Klebahn.

Ca eomalager vereinzelt oder in kleinen Gruppen auf gelblichen Flecken klein, etwa $1 \mathrm{~mm}$ lang oder breit, blassorange bis Heischrot; Sporen kugrlig, eifürmig oder polyedriseh, $14-17 "$ lang, 12-16 $\mu$ breit; Membran ziemlich dicht- $(1 \mu)$ nnd feinwarzig.

Uredolager blattunterseits, auf wenig auffallenden Flecken zerstreut, gewölbt, $1 / 2 m$ breit; Sporen ellipsoiłisch, lünglich, selten rundlich, $15-22 \mu$ lang, $10-15 \mu$ breit; Membran $2 \mu$ dick, entferntstachlig ( $2 \mu$; Parafysen keulenförmis, seltener koptformig, 40-4) $\mu$ lang, 8-17 $\mu$ breit, ihre Membran $3-5 \mu$ dick.

Teleutosporenlager blattunterseits, von der Epidermis bedeckt. dunkelbraun, etwa $1 \mathrm{~mm}$ breit: Sporen prismatisch, beiderseits abgerundet, 40 - $60 u$ lan.. 7-12 $\mu$ breit. Membran 1-2 $\mu$ dick. bratun, am Scheitel nicht verdickt.

Caeoma auf

Larix eu ropaea: Bisher nur im Lužnictale bei Tábor!

Uredo- und Teleutosporen auf

Populus tremula: Daselbst!

Diese Melampsora-Art, welche auch aut

Populus alba und P. balsamifera vorkommt ist gewiss in Böhmen riel verbreitet, leider kaun sie, wie auch die folgenden ;) Arten. nur mittelst der Infektionsversuche bestimmt werden.

Der genetische \%usmmenhang wurle zuerst son li. Hartig festurestellt, vou K lebahn und $\mathrm{E}$. F ischer später bestättigt.

2at. Melampsora pinitorgua linstrup - ('a es ma pi nit or qu um Al. Braun

Caeomalager unter der Rinde junger Triebe, später spaltenförıig geborsten, bis $2 \mathrm{~cm}$ lang und $3 \mathrm{~mm}$ breit, rotorange; Sporen kuglig oder ellipsoi- 
disch, $14-20 \mu$ lang, $13-17 \mu$ breit, seltener läuglich $(2 \% \times 10 \mu)$; Membran

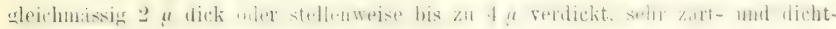
warzig $(1, \boldsymbol{t})$.

Uredolager unterseits auf gelben lilecken vereinzelt odler gruppiert, oft

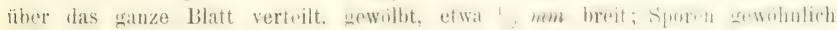

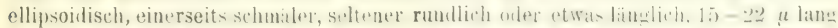
$11-16$ " breit: Menbran 2 u dick, anf zwei gegenüberliegenden str.len $5-6 ; \|$ dick, entfernt (2-3 $u$ ) stachlig; larafysen keulentiomig, $4(1-5)$ " lanz. Kupf 2()$-25 \mu$ lang, 12) 17 u breit, ihr Stiel $3-4$ " breit, Memban uleichmärig $3-7 \mu$ dick.

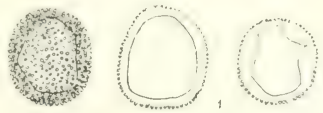

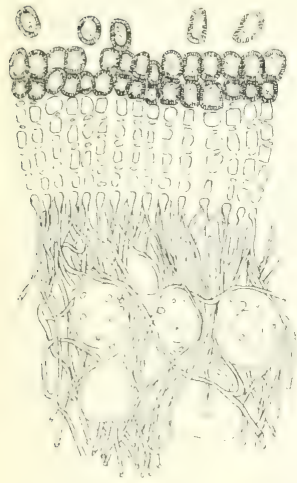

Abb. 53. Melampsora pinilorqua. Schnitt durch ein Caeomalager. (Nach Hartig.)
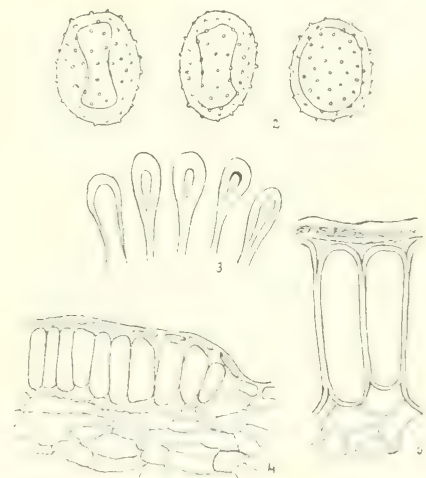

Abb. 5t. Melampsora pinilorqua. 1. ('aeomasporen. 2, 3. Uredosporen und ihre l'arafysen. 4. Schnitt durch ein Teleutosporenlager. 5. Eine Partie desselben vergrössert. (Nach Klebahn.)

Teleutosporenlager blattunterseits subepidermal, etwa $1 / 2 m m$ breit

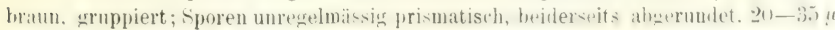
lang, $7-11 \mu$ dick; Membrau etwa 1 " dick, brïunlich.

\section{Caeoma auf}

Pin us silvestris: Bisher nur auf der Preisinglehne bei Rovenslio:

Uredo- und Teleutosporen auf

P'opulus tremu la: daselbst!

Diese Art kommt noch aut Populus alba und P. alba Xtremula vor: 
Die Spuridien infizieren im Fruhjahre junge Kieferntriebe. Thas Iycel perenniert im Rindenparenchym und in den Markstrahlen intercellular. Spermogonien entstehen nach der Infektion ende Mai und anfings Juni; Caeoma wird etwas später gr. bildet. Nachdem sich die Sporen verstiubt haben, stirbt die Rinde an dler infizierten Stelle bis zum Holze ab, aber während der übrigen Vegetationsperiode wird die Wunde wieder üherwallt. I ie hefallenen Triebe werden s-artig gekrümmt.

2*ò. Melampsora Magnusiana Wagner. - Melampsora Ḱ lebahn i Bubák.

Spermogonien subepidermal, wenig gewölbt.

Ca eomal ager auf gelben Flecken, oft ringförmig um die Spermogouien herum, später zusammentliessend, etwa $1 \mathrm{~mm}$ breit, orange; Sporen kuglig his ellipsoidisch, oft polyedrisch, $17-27 \mu \operatorname{lang}, 10-22 \mu$ breit; Membran $1-1^{1 /}{ }_{13} \mu$ dick, dichtwarzig $(1, \mu)$.

Eredolager hattunterseits, klein, etwa " ${ }_{2}$ mm breit, zerstreut, orangegell, ; Sporen viformig bis linglich, 17-28 " lang, 12-20 " breit; Membran 3 u dick, entferntstachlig (")-3 ") ; Parafysen gewöhnlich koptfömig, seltener keulenfömin, $40-57 \mu$ lang, $13-22 \mu$ breit, ihre Membran $3-5 \mu$ dick.

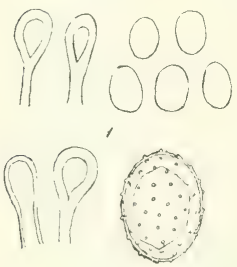

Abb. 55. Melampsora Maynusiana. 1. Uredosporen mit Parafysen. 2. Dieselben vergrössert. 3. Eine Partie ans dem Teleutosporenlager. (Nach Klebahn.)

T'e leutosporenlager blatt-

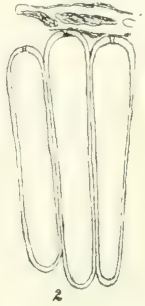
unterseits, subepidermal, etwa $1 \mathrm{~mm}$ breit, dunkelbraun; Sporen prismatisch, beiderseits ahgerundet, 40 bis $60 \mu$ lang, $7-10 \mu$ breit, Membrau $1-2 \mu$ dick.

Caeoma von Mitte April und im Mai auf

C he lido u i u m majus: Hermskretschen (Wagner, Krieger)!

Corydalis cava: Fasanerio bei Ćernoves nächst Raudnitz (Procházka)!

Uredo- und Teleutosporen auf Populus tremula: Herrnskretschen (Wagner)!

Caeoma kommt noch auf Corydalis digitata und C. fabacea vor.

Der genetische \%usammenhatng der Melampsora mit Cateoma auf Chelidonium wurde zuerst von Magnus festgestellt, später von Sydow, Wagner und Klebahn bestatigt: den Zusammenhang mit Crooma von Corydalis habe ich im J. 18!s entleckt und die betreffende Melampsora für selbständige Spezies gehalten. Später wurde aber von Klebahn bewiesen, dass meine Art mit Melampsora Magnusiana Wagner identisch ist.

\section{Melampsora Rostrupii Wagner}

Spermogonien in kleinen, lockeren Gruppen blattbeilerseits, honigbraun, balbkugelig gewölbt. 
Caeomalager blattunterseits, auf Blattstielen, seltener auf Stengeln und Infloresernzachen, ataf gelhlichen Flecken, oft rinzformig um die Sprmognien herum, 1-2 mm breit, oft zusammenfliesseme, orange: sporen liuglig his ellipsodidiseh 13-25 $\mu$ lang, 10-17 $\mu$ breit; Membran 1-25 $\mu$ dick, dichtwarzig (1 $\mu$ ).

U redolager blattunterseits, etwa $1 \mathrm{~mm}$ breit, ziemlich fest, auf gelblichen Flecken; Sporen hauptsiüblich ellipsoidiseh, atuch kuglig, seltuner polyedrisch.

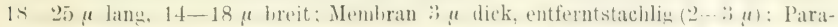

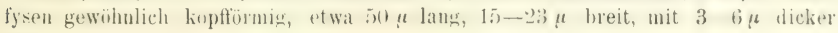
Membran.

Teleutosporen wie bei der vorangehenden Spezies.

Caeoma im Mai und in dẹt ersten Hälifte d. M. Juni auf

Mercurialis perennis: Karlstein (Th. Novák)! Mühlhausen, Bilichau (Kabit)! Chotuc bei Kínec ! Kratzau bei Reichenberg (Kratzmaun)! Turnau (Kabat)! P'elzdorf bei Hohenelbe (Cypers)! Inreikreuzberg bei Leitmerity! Solanerherg bei Trebnitz! Mache (Wagner) unl Berg Gross-Wostray bei Aussig? Königswald bed Teplitz (Thümen)! - Tábor !

Uredo- und Teleutosporen auf

Populus tremula: Mache bei Aussigg (Wagner); 'Tábor!

Der genetische Zusammenhang wurde zuerst von Rostrup und $\mathrm{Ni}$ is e n festgestellt und später von Plowright, Klebahn, Wagner und Jack y bestiitigt.

Die Uredo- und Teleutosporen kommen noch auf P'opulus alba, balsamifera, nigra, monilifera, italic a vor.

Wie schon früher bemerkt wurde, kann man die vier vorangehenden Arten im Stadium der Uredo- und Tolentosporen ron einander nicht unterscheiden. Aus diesem firunde kaun man dit I'ilze von folgenden Standorten nicht bestimmen:

Populus tremula: Auf dieser Nährptlanze sind die Uredo- und T'elentospuren in ganz Bohmen vorbreitet, hesonders auf nitrigen. strauchartigen Indivirluen.

Populus alba: Kačina (Peyl, Veselský)! Nové Dvory bei Kuttenherg (Veselský)! Welwarn (Kabat)! Veuber. bei funghunzlau (\%onplua)! Rad Wartenberg (Kabát)! Wittingau (Weidman)!

2. Uredosporen sturk verlängert, am Scheitel glatt.

a) Teleutosporenlager blattoberseits; Teleutosporen am Scheitel verdickt.

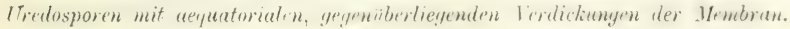

\section{Helampsora Larici-populina Klebahn.}

C a e omalager auf gelblichen Elecken, etwa $1 \mathrm{~mm}$ laug, intensiv orange:

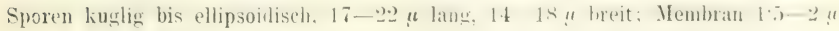
rlick, farblos, dichtwarzig $(1 \mu)$.

Uredolager blattunterseits, seltener oberseits, auf gelben Fleclion, etwa $1 \mathrm{~mm}$ hreit, anfaugs von einer pseudoparenchymatischer Hyphemderke und der Epidermis bedeckt, blasenformig, später nackit. staubin, gelboranee, zerstreut oder

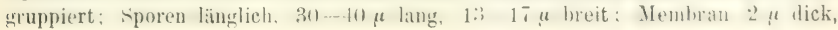


im Aequator auf zwei gercenüberliegenden Stellen innen $5-6 \mu$ dick, entferntstachlig $(2-25 \mu)$, nur am Scheitel glatt : P’arifysen keulenförmi” oder koptformie, $40-70 \mu$

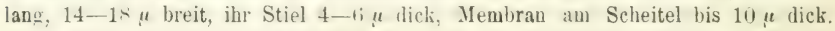

Teleutosporenlager blattobrrseits, subepidermal. anfangs gelbbraun, endlich schwarzhraun; klein, etwa $1 \mathrm{~mm}$ nross; zerstreut oder gruppiert, oft zusammentliessend; Sporen prismatisch, beiderseits abgerunclet, $40-70 u$ lang, $7-10 u$ breit: Membran dünn (1 1 ), nur am Scheitel $25-3 \mu$ rlick. schwach bräunlich.

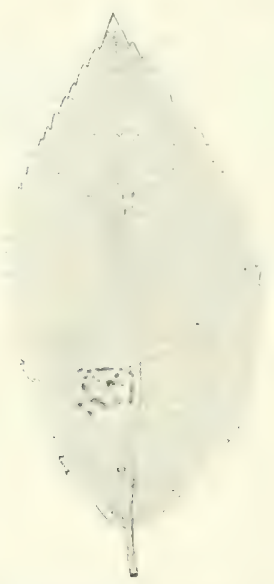

Abb. 56. Melampsora Rostrupii. Caeoma auf Blättern von Mercurialis pereunis.
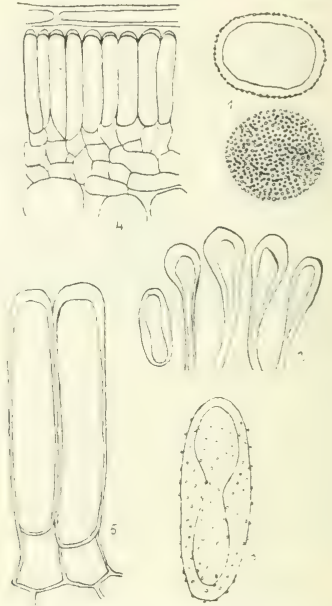

Abl. 57. Melampsora Larici-populina. 1. Caeomasporen, 2, 3. Uredosporen und ihre Parafysen. 4. Schnitt durch ein Teleutosporenlager. 5. Eine Partie desselben stark vergrössert. (Nach Klebahn.)

Caeoma auf Larix europaea: Aus Böhmen sah ich diese Sporenform noch nicht.

Uredo- und Teleutosporen auf

Populus niğra: Welwarn (hahat)! Stefansüberfuhr hei Mělafk! Hoch Veselí (Kabát)! Pardubic (Vodák)! Kuttenberg!

Populus balsa m ifera: Hoch Veself (Kabát)! Neuwelt im Isergebirge! Oher Mohren bei Polic a. M!

Populus pyramidal is: Tábor! Chýnov!

Diese Art kommt auch auf Populus canadensis ror. Der genetische 


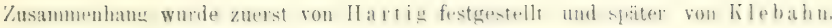
E. F ischer und $\mathrm{J}$ a $\mathrm{ck}$ y bestitigt.

b) Teleutosporenlager blattunterseits; Theutosporen an Scheitel fust gar nicht verdickt. Uredosporen ohne aequatorial Terdicknngen.

\section{Melampsora Allii populina Ḱlebahn.}

Spermogonien gewölbt, $100 \mu$ hoch, $140 "$ breit.

Caeomalager auf gelblichen lilecken gruppenweise, etwa 1 mm breit, von den lipideruistesten umgebn, orange, sporen kushin bis ellimoirliseh. meh oder weniger polyedrisch, 17-23 $\mu$ lang, $14-19 \mu$ breit; Membran $2 \mu$ dick, manchmal auch dicker, fein- und dichtwarzig $(1 \mu)$.

Uredolag er blattunterseits seltener blattoberseits, rundlich, $1 \mathrm{~mm}$ breit, gre-

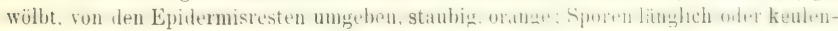
förmig, 2t-38 $\mu$ lang, $11-18 \mu$ breit; Membran $2-4 \mu$ dick, entferntstachlig $(2-3 \mu)$, nur am Scheitel glatt; Parafysen kopfförmig, $50-60 \mu$ lang, $14-22 \mu$ breit, Stiel $3-5 \mu$ breit; Membran $2-3 \mu$ dick.

'T eleutosporenlager blattunterseits, subepidermal, zerstreut oder gruppiert, schwach gewölbt, $1 / 4-1 \mathrm{~mm}$ breit, schwarzbraun, matt; Sporen unregelmä-sin prismatisch, heilerseits abgermudet, 3is- in " lang, ti-10 $\mu$ hreit; Memban $1-15 \mu$ dick, am Scheitel nur schwach $(2 \mu)$ dick;

Caeoma auf Allium ascalonicum, Schoenoprasum, vineale, Cepa, ursiunm, sat isum. Vielleicht gehort hierher irgentein standort von denjenicen. die bei Melampsora Allii-Salicis albae aufgeführt sind.

Uredo- und Teleutosporen auf Populus nigra, canadensis, balsa. mif era.

Der genetische Zusammenhaug wurde zuerst von schroeter entdeckt uni später von Klebahn bestätigt.

III. Uredo- und Teleutosporen auf Euphorbia-Arten.

\section{Melampsora IIelioscopiae (Persoon) Winter.}

Spermogonien hallkugelig abgeflacht. ohne. Parafysen in her ()effunng

Ca eomalager kleiu, auf Blättern ${ }^{1 / 4}-1 / 2 m$ breit, auf Stengeln $1-4 \mathrm{~mm}$ lann, gelbrot; Sporen in kurzen lietten, ohme l'arafysen, kurlig bis nlliparidisch, 21-28 $\mu$ lang. $19-24 \mu$ breit, mit dichtwarziger Membran (nach Dietel).

Uredolager rundlich bis länglich, bald nackt, staubig, orange und verblassend: Sporen kuglig hisellipsoidisch, 15-21 4 laug. 12-18 $\mu$ breit, mit hyalines

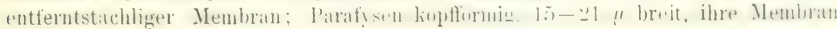
am Kopfe stark verdickt.

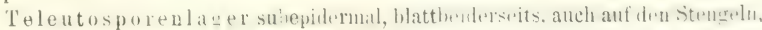

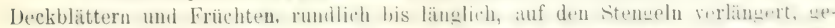
wiblbt, oft zusammenfliess'ml, anfaugs shwarzhraun. spaiter sehwarz; Spurru pris-

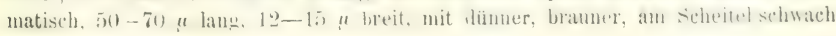
verdickter Membran. 
Caeoma im Frühjahre, Uredosporen von Juni, Teleutosporen ron Juli auf

Euphorbia Helioscopia: Sehr rerbreitet.

Euphorbia exigua: Prag (Opiz)! Kuchelbad (Bauer)! Welwarn (Kabát)!

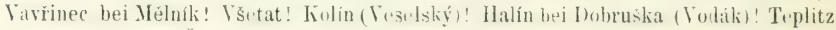
(Thümen)! Brïx (Štika)!

Euphorbia esula: Kaiserwiese bei Prag (Opiz)! Welwarn (Kabát)! Nové Strašeci! Hradisko bei Sarská! Dohruka (Vodik)! Teplitz, Graupeu, Tetschen (Thïmen)!

Euphorbia cyparissias: St. Prokop bei Prag (Opiz als Uredo biseriata Opiz. VII/1849)! Prowe (Drselle)! (iraupen, Teplitz (Thümen)!

Euphorbia peplus: Prag (Hrabal)! Lieben (Opiz)! Drorce (Kalmus)! Whwarn (Kabat)! ('hruilm (Kirizek)! Theresinfeld bei Mariaschein (Wiesbaur)!

Euplorbia platyphylla: Fuss des Berges Kostál bei Trebnitz!

\section{Melampsora Euphorbiae duleis Otth.}

Spermogonien auf gelben Flecken blattbeiderseits.

Cateo mal lager hauptsiuhlich blattunterseits. seltemer blattoberseits und auf Stengeln, auf roten, gelb umsämuten Flecken; Sporen olm. Parafysen, liettenformicr,

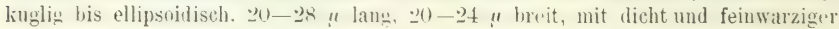
Membran.

Uredolager unterseits auf hellgelben, nicht deutlich begrenzten Flecken, pinzeln oder uruppenweise, manchmal kreisformig gestellt, etwa $1 / 2 m m$ im Durchmesser, orange-gelh, kuglig bis ellipsoidisch, 16-24 " lang, 16-20 " breit, mit hyaliner, stachliger Mrmbran; Parafysen zalulreich, koptfirmier verdicht, $14-2 i ; u$ breit.

T'e l e u o s p oren l a ger subepidermal, blattunterseits sehr dicht gruppiert, auch auf Strumln, anfangs hellhraun, später chokoladenbraun, niemals (wie bei der

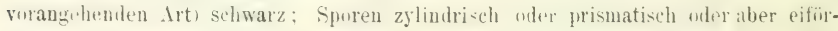
mig, 18-30 $\mu$ lang, $12-22 \mu$ breit; Nembran bis $3 \mu$ dick, gelbbraun.

Caeoma im Frühjalıre, Uredo im Juni, Teleutosporen von Juli auf 'Tíbor!

Euphorbia dule is: Radič bei Selčan (Th. Novák)! Pintovka bei

Diese Art kommt auch auf Euphorbia amygdaloides und E. car$\mathrm{n}$ i $01 \mathrm{j}$ c a ror.

Von der vorangehenden Spezies ist sie durch hellere Uredolager, durch die Gruppierung, Farbe und Grösse der Teleutosporenlager verschieden.

III. Uredo- und Telentosporenlager auf Limum-Arten.

291. Melampsora Lini. (Persoon) Desmaziéres.

Spermogoni en und Caeoma unbekannt.

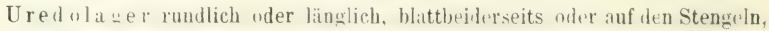
blasenfömig, balı nackt, staubig, orange; Sporen liuglig bis ellipsoidisch, manehmal polvedrisch, 15-24 $\mu$ lang, 14-21 $\mu$ breit, mit dicker, farbloser, entfernt stachliger Memhran; Parafyson zahlreich. kopfformig. 17-3: u breit, dicksandig. 
Telentos porenlager subepidermal, hauptsïblich auf Stengeln, anfangs rotbraun, endlich schwarz, unregehnässig, zusimmenfliessend; Sporen mismatisch, :5-60 $\mu$ lang, $7-16 \mu$ breit, mit dünner, brauner, gleichmïssigr dicker Membran.

Uredolager von April, Teleutosporenlager von Juli auf

L in um catharticum : Sehr verbreitet.

Die vorliegende. Art kommt auch auf kultiriertem Lin um us it a tis sim um vor und verursacht in manchen Ländern z. B. in Belwien, Frankreich sehr urossen Schaden.

\section{Auf Hypericum-Arten entwickelt.}

\subsection{Melampsora IIypericorum (De Candolle) Schroeter.}

( a e o m a l a ger klein, rundlich oder länglich, hauptsächlich unterseits auf gelben bis roten Flecken, blattunterseis zerstreut oder fast gleichmässig verteilt, bald nackt, orange, staubig: Sporen in kurzen fietten, polyeidrisch und zwar kuglig bis ellipsoidisch, $18-28 \mu$ lang, $10-18 \mu$ breit, mit $2 \mu$ dicker, hyaliner, ziemlich dichtwarziger Membran.

Teleutosporenlağer blattunterseits suhepidermal, klein, rundlich, rotbraun, später schwarzbraun; Sporen prismatisch, am Scheitel abgerundet, 28-40 $\mu$ lang, $10-17 \mu$ breit, mit brauner, am Scheitel bis $3 \mu$ dicker Membran.

Caeoma von Ende Juni, Teleutosporen erst zu Ende der Vegetationsperiode auf

Hypericum montanum: Bilichau (Kabát)! Wälder bei Roždalovic! Hoch Veseli (Kabát)! Tábor!

Hypericum perforatum: Friedstein bei Turnau (Kabát)! Reichenberg (Siegmund)! Chotěboř (Mühlbach)!

Hy pericum quadran (Waguer): Hořicky bei Böhm. Skalic (Kahat)! I'rovoz bej Dobruška (Vodak)! Zinnwald (Thümen)! lintenhaus bei Komotau (Roth)! Arber, Eisenstein, Veubrunn im Böhmerwalde!

Nach Tranzschel ist Melampsora Hypericorum eine Melampsoropsis. Das Caeoma wurde früher irrtümlicherweise für lredo gehalten.

\section{Auf Saxifraga-Arten entwickelt.}

\section{Melampsora Saxifragarum (De. Candolle) Scbroeter.}

Mela m p o ra vernalis Niessl.

Spermogonie n zerstrent, relb, stark gewilbt, honiggelt, später dunkler, $170-220 \mu$ breit.

C a e o m a 1 a g e r blattunterseits zerstreut oder gleichmäsig verteilt, auch auf Blumenblättern, rundlich oder elliptisch, anfangs subepidermal, dann nackt, staubig. gelborange: Sporen kettenförmig, rundlich his ellipsoidisch, mehr oder weniger polyedrisch, $20-29 \mu$ lans, $155-24 \mu$ breit, mit farbloser, $2-35 \mu$ dicker. dicht- und feipwarziger Membran und orangefarbigem Inhalt. 
Uredolager (nach Voglino) sehr klein, blattoberseits, rundlich; Sporen ellipsoidisch, goldgelb, $16-26 \mu$ lang, $15 \mu$ breit, feinstachlig.

Teleutosporeulager blattunterseits, subepidermal, klein, unregelmässig, ziemlich dichtstehend, dunkelbraun; Sporen keulenförmig bis länglich, $40-50 \mu$ lang, $14 \mu$ breit, Membran braun.

Caeoma schon Ende April, hauptsächlich aber im Mai, Teleutosporen am Ende der Vegetationsperiode auf

Saxifraga granulata: Prag (Forster)! Žalov bei Roztok! Zwischen Mnišek und Rıdká! Hrádek bei Eule (Th. Novák)! Plöschenberg bei Netluk nächst Trebuitz! Rovensko! Rakonitz (Mühlbach)! Rotenhaus bei Komotau (Roth)! Burgstadtl bei Duplau und Sollmus bei Buchau (Wieshaur)! "Na Pichcich" bei Přibram (Domin) ! Tábor !

\section{Saxifraga ca espitosa: Langerberg bei Solan!}

Uredo- und Teleutosporen habe ich aus Jöhmen bisher nicht gesehen. Es scheint mir, dass das (aeoma-Nycel perenniert, deun es dringt die ganze Pflanze hindurch.

\section{Melampsoridium Klebahn.}

Accidien mit blasenförmiger Pseudoperidie wie bei Peridermium. Uredolager mit halbkugeliger Pseudoperidie, an Scheitel geaffnet, ohne Parafysen; Uredosporen einzeln auf Stielen gebildet. Telentosporen einzellig, braun, kompakte Lager bildend (Die Keimung siehe Abb. 3, 8.)

294. Melampsoridium betulinum (Persoon) Klebahn. - M e l a m po r a b e t u li n a (Persoon) Tulasne.

A e cidien unterseits der Nadeln zerstreut oder längs des Nerven ein-oder zwei. reihig, kleiı. (1) $-15 \mathrm{~m} \mathrm{~m}$ lang, hellorange; Pseudoperidie blasenförmig, ungleichmässig sich off̈nend, lünuwandig: Pseudoperidienzellen 18-38 $\mu$ hoch, 10-17 $\mu$ breit. Sporen kurlig bis eiformis, 14-21 4 lang, $11-16$ u breit; Membran ungleich dick, von stäbchenförmiger Struktur.

Uredolayer blattunterseits auf gelben Flecken, klein, etra ${ }^{2}{ }_{2}, m m$ breit, von Pseudoperidie und Epidermis umgeben, später am Scheitel geöfnet, staubig, orangegelb; Sporen eiformi, , ellipsoidisch bis länglich, $22-38 \mu$ lang, $10-16 \mu$ breit, mit farbloser, sehr entfernt stachliger Membran,

Teleutos porenlager blattunterseits, subepidermal, klein, etwa ${ }^{1 / 2} \mathrm{~mm}$ breit, anfangs orange, mdlich braun; Sporen prismatisch, $30-50 \mu$ lang. $7-15 \mu$ breit; Membran dünn $(1 \mu)$, braun, am Scheitel nur schwach $(1.5 \mu)$ verdickt,

Aecidien in April und Mai auf Nadeln von Larix europaea; in Böhmen bisher nicht beobachtet.

Uredo von Juli, Telentosporen von August auf Betula alba und Betula pubescens in Böhmen verbreitet.

l)er genetisthe. Zus tmmenhang wurde zuerst ron PIowright festgestellt. 


\section{Melampsorella Schroeter.}

Teleutosporen in den Lipidermiszellen, mit düuner, hyaliner Mombran, einzellig oder selten geteilt; Uredosporen mit I'seudoperidie oder nur mit Parafysen. Aecidien mit typischer P'seudoperidie.

295. Helampsorella Caryophyllacearum (De Candolle). Schroeter. - M e l a mp sorella Cerastii (Persoon) Schroeter, - M ela m p s or a C e$r$ ast i i Winter.

Spermogonien auf der Oberseite der Nadeln, honiggelb.

A ecidien (A ecidium elatinum Albertini et Schweinitz) auf der Unterseite der Nadeln längs des Nerven zweireihig, tief im Gewebe eingesenkt, endlich in Form niedriger Becherchen hervorbrechend; Pseudoperidien mit zerschliztem, abfälligem Rande, orange; Sporen kuglig bis ellipsoidisch, gewöhnlich polyedrisch, $16-30 \mu$ lang, 14 bis 17 breit, mit hyaliner, dichtwarziger Membran und orangefarbigem Inhalte.

Uredolager klein, gelb, subepidermal und gowöhnlich unterbalb der Spaltöffnungen entstehend, mit Pseudoperidien, anfangs geschlossen, endlich mit runder Oeffnung, staubig; Sporen kuglig bis ellipsoidisch, $20-30 \mu$ lang, $16-21 \mu$ breit; Membran farblos, dünn, entferat stachlig; Inhalt orruge.

T'eleutosporen in den Epidermiszelleu gebildet, unterseits die ganze Epidermis erfüllend oder nur fleckenweise gebildet; die befallenen Stelleu weiss oder schwach rosenrot gefürbt; Sporen in kleinerer oder grösserer Anzahl in einzelnen Zellen, isoliert oder einander berührend und in diesem Falle von den Seiten zusammengedrückt, einzellig oder seltener mit Querwänden versehen, 14-21 $\mu$ breit; Membran dünn, hyaliu. - Sporidien kuglig, gelblich (geh:iuft), 7-9 $\iota \mathrm{im}$ Durchmesser.

Aecidien im Juni auf Abies pectinata: Harta bei Hohenelbe (Cypers)! Tetschner Schneeberg (Wagner)! Tábor! Arber und Eisenstein im Böhmerwalde (Krieger)! Zwischen Deffernik und Lakkasee, bei Schattawa!

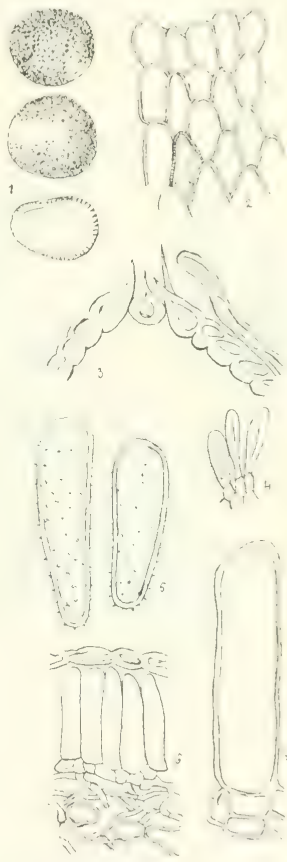

Abb. 58. Melampsoridium betulinum. 1. Aecidiosporen. ¿. Stück einer Pseudoperidienwand der Aecidien. 3. Oberer Teil einer Uredosporenpseudoperidie. 4. Typische und parafysenartige Uredosporen. 5. Yergrösserte Uredosporen. 6. Schnitt durch eiu Teleutosporenlager. 7. St:irk vergrösserte Teleutospore. (Nach Klebahn. 
Tredosporen durch die ganze Vegetationsperiode, manchmal noch im Winter. Teleutosporen im Mai auf

Cerastium arvense: Sehr verbreitet und zwar sind bisher nur Uredosporen von dieser Nährpflanze bekannt.

Stellaria Holostea: Ebenfalls nur Uredosporen und zwar häufig in Prager Gegend und in wärmeren Lagen des Böhm. Mittelgebirges: sonst nur bei Lešany nächst Welwarn (Kabát)! Pintorka bei Tábor!
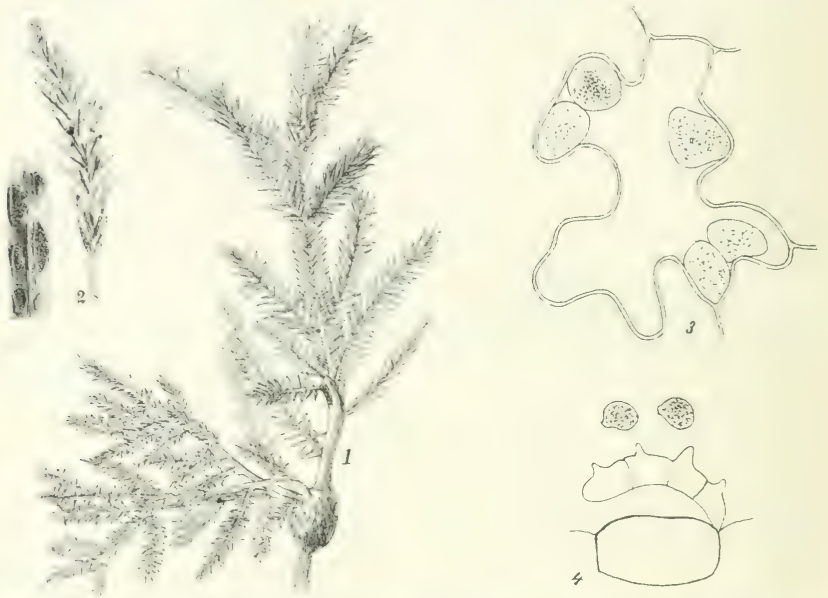

Abb. 59. Melamporella Caryophyllacearum, 1. Ein Hexenbesen. 2. Ein Hexenbesenästchen und eine Nadel mit Aecidien. 3. Teleutosporen in den Epidermiszellen. 4. Keimende Teleutospore mit Promycelium und Sporidien. (Nach E. Fischer.)

Stellaria nemorum: Gross Skal! Tábor! Auf beiden Standorten auch Teleutosporen.

In hiologischer Hinsicht ein sehr interessanter Rostpilz. Teleutosporen keimen im Mai und die Sporidien infizieren junge Tannenaestchen. lis zum Herbst bildet sich auf der Infelitionsstelle eine kleine Anschwellung, die im Laufe der Jahre zu einer mächtigen Beule anwächst. Aus dieser Beule wachsen dann senkrechte, stoife Aeste hervor und so entsteht der bekannte Hexenbesen. Auf den Nadeln der bofillenen Triehe billen sich die Aecidien nach der Infektion erst im Juui des nächstfoluenden Jahres aus, von hier ab dann alljïhrlich und fallen auch alljahrlich ab. Das Mycel überwintert in den Aesten les Hexenbesens und jedes Jahr dringt es in die neu sich bildenden Aeste ein Ebenfalls überwintert auch das Mycel der tredosporen und jeiles Jahr dringt es im Frühling in die neuen Triebe ein und 
bildet auf allen ihren Blittern zuerst Uredo, später 'leleutosporen (Stehlaria nemorums. Infolgedessen erhält sich dieser P'ilz auf Cerastium- und stellaria-Arten auch in solchen Gegenden, wo die 'Tanne gänzlich fehlt.

Bei künstlichen Infektionen gelang es Tubeuf, Fischer, Kle hath und mir (im J. 1904 und 1905) nicht, mittelst der Uredosporen von stellaria nemorum die Blitter von Cerastium arvense zu infizieren. so dass beile formen biologisch verschieden sind.

A ecidium Stellaria e Kirchuer in Lotos 1856, p. 180 von Stellaria graminea ist wahrscheinlich nur die Uredo dieses Rostpilzes.

\section{9ti. Melampsorella Symphyti (De (amlolle) Bubák. Lredo symphyti De Candolle.}

S permogonien hautsächlich auf der Unterseite der Niulelu, oft sehr zahlreich, gruppenweise oder die ganze Unterseite bedeckend, zientich dichtstehend. klein, halbkugelig oder auch etwas verlängert, orangegelb.

A ecidien unterseits auf den Nadelu, zweireihig lings des Nerven; l'seurloperidien von einander ziemlich entfernt, löchstens 16 in einer Reihe und gewöbnlich vicht alle entwickelt, kurz zylindrisch, $1 / 2-\%$ mm laus, am Scheitel durch einen Querriss geriffuet, endlich his zur Basis in $3-5$ lange, ungleiche, schief abstehend. oder gänzlich zurückgebogene, weisse Teile gespalten; Pseudoperidienzellen in Längsreihen, unremelmässig, längrlich-polygonal, :3-35 $u$ lang, 17-2.2 $\mu$ breit, hyalin, nit dünnwandiger, feinkörniger Jembran; Syoren mit sterilen Zwisclenzellen in Ketten, sewohnlich hurlig, seltener eiformig oder linglich, 20-39.5 " lang, 175-28\% "t breit, orange ; Membran vou stäbchenfurmiger Struktur, dichtwarzig oder stellenweise kahl.

I'redolager klein, über die ganze Blattunterseite ziemlich dicht verteilt, von einer Pseudoperidie umgeben, subepidermal, endlich an Scheitul geoffnet, staubı. orangegelb: Sporen eiförmigr bis ellipsoidisch, 24-35 $\mu$ lang, $22-28, " 2$ breit, mit dünuer, farbloser, entferntstachliger Membran.

'T'eleutosporenlager in den Epidermiszellen gebildet. die Blattunterseite total oder nur teilweise bedeckend und dieselbe weiss oder sciwach rosenrot verfitbend; Sporen in einzelnen Fidermiszellen in kleiner oder urosserer Anzahl. 11 - If $\mu$ lang, 9-15 $\mu$ breit, wit farbloser. glatter Membran; Sporidien tlachkugrelig, $655-8 \mu$ im Durchmesser.

Aecidien Ende Juni und anfangs Juli auf Nadeln von

A bies pectinata: Pintorka bei Tábor!

Uredo von Mitte Mai bis zum Herbst, Teleutospren im Mai und Juni aut Symphytum officinale (bisher nur Uredo): Baumgarten und Limutany bei Pras! Hoch Veselı (Kabat): Komairover Teich bes I)ymokur! hrüshtz und Srhünborn bei Bodenbach! Eulau bei Tetschen (Thümen)! Waltirsche, Klein Prirsen

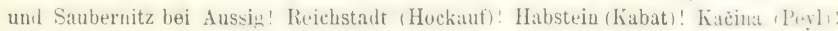
Tábor! Krumau (Jungbauer)!

Symphytum tuberosum: Roztoker Hain bei Pray: Elblehuen oberhalb Aussig vou Nestonitz bis zum Ziegenberge! Sehr hüutig im Leitmeritcer Mittel- 
gebirge über Skalitz, Babina, Tschersing, Malschen, Ober Sedlitz, Sedel, Nemschen, Gross Vostray bis zum Neudorf bei Aussig! Klein Priesen! - Pintovka bei Tábor !

Der genetische Zusammenhang der Aecilien mit den Ureilo- und Teleutosporen wurde ron mir im J. 1903 festgestellt.

Das Mycel der Uredo- und Teleutosporen perenniert in Rhizom und dringt im Frühahre in die neuen Triebe ein und hildet auf allen Blättern heide Sporenformen. Die befallenen Ptlanzen sind schmïchtiger und blasser als die gesunden. Die Teleutosporen keimen im Mai und ihre Sporilien infizieren die Tannenuadeln.

Die Infektionsversuche mit Aecidien auf Blättern schlugen alle fehl, so dass man die Infektion der Rhizomen annehmen muss.

297. Melampsorella Blechni Sylow. - Uredo Scolopendrii Schroeter p. p.

A ecidien bisher unbekannt.

Uredolager unterseits auf braun verfärbten Zipfelu, daselbst zerstreut, blasenförmig, gelblich, von einer l'seudoperilie umgeben, subepidermal, später am Scheitel geborsten und staubig; Sporen eiförmig bis ellipsoidisch, 27-42 $\mu$ lang, 18-24 breit; Membran warzig, hyalin.

Teleutosporen (nach Sydow) intracellular, hyalin.

Von August bis zum Winter auf

blechnum s̀ picant hauptsächlich im Gebirge und zwar in Riesengebirge am Wege ron der Pantschewiese läugs der Jummel bis zum Harrachsdorf! Elbfall (Kabát, ipse)! Friedrichstal am IVege zum Heidelberọ: Klokoě́ bei Turnau (Kabát)! - Stimmerslorf, Herrnskretschen (Wagner) - Bühmerwald: Arber! Klammerloch unterhalb Osser!

Die Teleutosporen sind noch bisher ungenügend bekannt.

\section{Melampsorella Dieteliana Sydow.}

A ecidien bisher unbekannt.

Uredolager wie bei der vorangehenden Art; Sporen sebr unregelmässig immer polyedrisch und zwar kuglig, meistens lïuglich-polyedrisch oder keulenförmig polyedrisch, $22-44 \mu$ lang, $13-28 \mu$ breit; Membran hyalin, warzig.

Teleutosporen wie bei Melampsorella Ble chni.

Von August auf Polypodium vulgare. Bisher nur in Wäldern bei Gross Skal! und bei Hermskretschen (Wagner)!

\section{Melampsorella Kriegeriana Magnus.}

A ecidien unbekannt.

Uredolagur wie bei den zwei vorangehenden Arten; Sporen eifürmg bis ellipsoidisch, 30 $-40 \mu$ lang, 15-17.5 $\mu$ breit; Membran byalin, entfernt stachlig.

Teleutosporen (nach Maguus) in den Epidermiszellen blattunterseits zu 4-8 (und rielleicht noch mehr)-zellig, hyalin, 1-2 schichtigr, die Sporen der Basalschicht viel niedriger. 
Uredosporen ron August, T'eleutosporen im November auf

Ispidium spinulosum: Gross-Skal und Yebákov bei Trosky (Kabit): Ilerrnskretschen (Wagner)! Am Wegre vom Spitzherge zum Teufelssen im Bühmerwalde!

\section{Anhang.}

I)iejenigen Uredineen, von welchen bisher nur Aecidien oder Uredosporen hekannt sind, werden vorläufig in die provisorischen Gattungen Aecidium und Ured o eingereiht.

\section{Aecidium.}

\section{Aecidium pseudocolumnare Kühn.}

Spermogonien zerstreut, mit schrach konkavem Hymenium.

A ecidien zweireihig auf der Unterseite gelbgrüner bis geller Nadeln; Pseudoperidien kuglig, eiformig oder kurz walzenförmig, weiss, mit unregelmässiger Oeffuunझ; Sporen kuglig, eiförmig oder ellipsoidisch, manchmal polyedrisch, 24 $33 \mu$ lang, weiss, dichtwarzig.

Im Juli und August auf Nadeln von

Abies pectinata: In der höhm--siachs. Schweiz auf einigen Stellen (Kriegrer, Sydow)!

\section{Aecidium Euphorbiae Gerardianae E. Fischer.}

A ecidien über die ganze Blattunterseite verteilt, schüsselförmig; I'seudoperidien mit fast nicht zurückgeschlagenem Rande; Pseudoperidienzellen in Längsreihen, auf der Aussenseite bis $10 \mu$, auf der Innenseite $3-4$ ! dick, auf radialem Schnitt fast rechteckig; Sporen orange, kuglig-polyedrisch, 16-21 $\|$ lueit; Menbran dünn, dicht- und feinwarzig.

Im Juni auf Euphorbia Gerardia na: Lihšc! Mühlhausen a/E. (Káát) !

Nach Müller's Versuchen gehört dieses Aecidium zu Uromyces Ononidis Passerini und ist deshalb) dort einzuschalten.

\section{Aecidium lampsanicolum Tranzschel}

Spermogonien fehlen (?).

A ecidien auf der Unterseite gelher, rundlicher, oft wenim riotlicher, heller umsäumter Flecke, in lockeren, mehr oder weniger kreisförmigen (irupjen; Psendoperidien kurz walzenförmig, mit reissem, zurückgehogenem, zerscblitztem Ranle ; Pseubloperidienzellen reihenfömig stehend, im ralialen Schnict rhomhisch, aussen 5-6 $\mu$ dick; Sporen kugligr-polyedrisch, 13-16 u lang; Membran hyalin, dichtund feinwarzig; Inhalt orange.

Im Juni auf Blättern von

Lampsana communis: Sebusein bei Leitmeritz ?

Gehört wahrscheinlich zu einer Puccinia von Carex. 


\section{2: Aecidium Petasitidis Sydow.}

Spermogonien auf heiden Seiten der Flecke, honiggell, später dunkler.

A ecidien unterseits grosser, gelher, violett umsäumter, rundlicher und oft zusammenfliessender Flecke, um die Spermogonien dicht gruppiert; Pseudoperidien 150-250 "u hreit, niedrig zylindrisch, mit grobzerschlitztem, zurücligebogenem Rande; Pseudoperidienzellen in zim mlich deutlichen Reiheu, aussen bis 11 "l dick ; Sporen orange, kuglig-polyedrisch, seltener ellipsoidisch, $20-25 \iota \mathbf{l a n g}, 15-2 \cdot 2 u$ breit: Membran dünn, dicht- und feinwarzig.

Im Juli im Vorgebirge und Gebirge auf

Petasites albus: Elbgrund! Pelzdorf bei Hohenelbe (Cypers)! Glatzer Schneeberg (Schroeter)!

Petasites officin alis: Schatzlar (Schroeter). Stěpanor bei Bilin!

\section{Aecidium Homogynes Schroeter.}

S permog onien beiderseits der Flecke, stark gervölbt.

A ecidien unterseits auf grelhen, spatter brannen Flechen, dicht kreisformig um die spermogonien gruppiert; Pseudoperidien walzenförmig, mit schmal zurückgebogenem. zerschlitztem Raude; I'seudoperidienzellen aussen 5- $7 \mu$ dick; Sporen kuglig-polyedrisch oder viformig, 14-24 4 lang. 14-21 breit, wit dünner, farhloser, dicht- und feinwarziger Membran und orangerotem Inhalt.

Im Juli und August im Gebirge auf

Homogye alpina: Weisswassergrund! Elbfallbaude, Prinz Heinrich. baude, Teufelsgarten, Grosser Kessel! - Glatzer Schneeberg!

Von E. Fischer wurde im Centralblatt für Bakteriol. und Parasitenkunde, II. Abt. XXII. B!. (19015). Heft $1 / 3$, Mr. $\$ 9$, bewiesen, dass dieses A e cidium zu Uromyces leratri gehort. Der Autur zerlegt auf Grund seiner Infektionsversuche Uromyces Veratri in 2 Spezialformen: f. sp. A denostylis und f. sp. Homogynes.

Ausser dem biologischen Verhalten siud beide Formen auch morphologisch gut unterscheidbar. Ich habe auf tiesen Lmstand in der bohmischen Ausgabe dieses Werkes aufmerksam gemacht, wo ich bei Cromyces Vexatri pg. 33 sage: „Die Exemplare vom Glatzer Schneeberge haben durchschnittlich liüzere Teleutosporen als diejenigen aus dem Riesengebirge."

Auch die Abbildung ron E. Fis $\mathrm{ch}$ e r l. c. zeigt sehr gut diesen Unterschied, in dem lei der Form Homogynes-Veratri kürzere Teleutosporen gezeichnet werden als bei jener von dilenustylis-Veratri. Meiner Meinung nach sind beide formen als gute Arten aufzufassen, denen am hesten die vorgeschlagenen Namen zutreffen.

\section{Aecidium Ligulariae Thümen.}

Spermogonien auf beiden Seiten der Flecke gruppiert oder zerstreut, honiggelb.

Aecidien blattunterseits auf gellen oiter rotrioletten, rundlichen Flecken, blattoherseits nur vereinzelt; Pseudoperidien breit, niedrig schüsselformig, mit zu. 


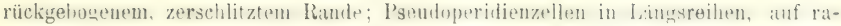
dialem Schnitt qualdatisch oder rumbisch, ausion his 11 u, aut den übrigensiden nur 4-6 $\mu$ dick; Sporen orange, kuglig oder eiförmig, manchmal polyerlrisch, $20-22 \mu$ lang, 17-20 $\mu$ breit; Membran fein- und dichtwarzig.

Im Juni und anfangs Juli aut

Ligularia sibirica: Habstein (Schiffner, Kabat)!

Dieses Aecidium kommt ausserdem nur in Sibirien vor.

\section{Aecidium Kabatianum Bubák.}

Spermogonien auf beiden Seiten der Flocke in ärmlichen Gruppen, honigbraun.

A ecidien unterseits auf gelben, undeutlich begrenzten Flecken, selten oberseits, zerstrent und mmer nur in kleiner Inzahlontwickelt; P'seudoperidien niedri: Watzenformir, anfangs blasenformis, mitbath abfallendem Rande; l'seudoperidiencellen

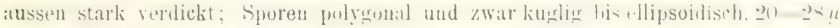
lang, 18-24 $\mu$ breit; Membran hyalin, dicht und feinwarzig, Inhalt orange.

Mitte Mai auf Myosotis stricta: Welwarn (Kabát)!

\section{Aecidium Lithospermi Thümen.}

Spermogonieu aut beiden Seiten der Flecke gruppiert, honigbraun, stark gewölbt.

A e c id i en unterseits auf braunen, rundlichen bis lïnglichen Flecken, selnt dicht pruppiert, niedrig walzenformig, unit schmal umgehogenem, nur wening zerschhtatem Rande; Pseudoperidienzellen in undentlicheu Reihen, aussen his $11 \mu$ dick; sporen kuglig, eiformig, sthe oft atuch ellipsoidisch bis linglich, of polyedrisch. 20-33 $\mu$ lang, $17-24 \mu$ breit; Membran 2-3 $\mu$ dick, dicht- und feinwarzig, hyalin; Inbalt orange.

Ende April und im Mai auf

Lithospermum arvense: Prag (Opiz 1851, als Aecidium Asperi. folii forma Rhytispermi Opiz)! Kačina (Peyl)! Kolín (Veselský)! Welwarm (Kabát)!

Von Aecidium Nonneae ist dieser Pilz durch grössere und längere Sporen verschieden.

\section{Aecidium Nonneae 'Thümen.}

Spermogonien stark gewölbt, auf beiden Seiten der Flecke zwischen den Aecidien gruppiert, honigbraun, oft das ganze Blatt bedeckend.

A ecidien auf gelben bis brannen, rundlichen Flecken, meistens blattunter-

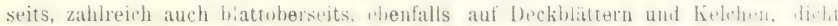

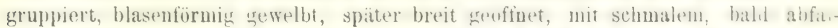

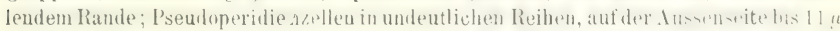

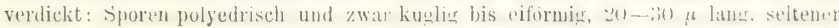


lïnger. $16-26 \mu$ breit; Membran 2-3 4 dick, dicht- und feinwarzig, hyalin; Inhalt orange.

Anfangs April auf Nonnea pulla: Welwaru (Kabát)! Kolín (Veselský)!

\section{Aecidium Pulmonariae Thümen.}

Spermogonien blattheiderseits in kleiner Gruppe, crewölbt, honigbraun.

A ecidien auf der Unterseite rundlicher, gelber, später brauner Flecke, in dichten Gruppen, seltener nur lireisförmig; Pseudoperidien niedrig walzenförmig, nit zuräckgeschlagenem und zerschlitztem Rande; Pseudoperidienzellen aussen bis 11 " dick, nicht reihenfömig; sporen orange, kuglim-polyedrisch oder eiförmig, $2(1-26 \mu$ lang, 18-24 hreit, mit ungleichmässig dicker, glatter Membran.

Ende Juni und anfangs Juli auf

Pulmonaria officiualis: Roteuhaus bei Komotau (Roth)! Tepl (Konrád)

\section{Aecidium Circaeae Cesati.}

Spermogonien auf biden Seiten der Flecke, honiggelb.

Aecidien auf der Unterseite gelber bis brauner, heller umsäunter, rundlicher Flecke, ziemlich locker gruppiert; Pseudoperidien niedrig walzenförmig, mit schmal zurückgebogenem, zerschlitztem Raude; Pseudoperidienzellen aussen 5-7 $\boldsymbol{\mu}$ dick; Sporen kuglig oder eifurmig, 12-16 $u$ lang, $9-14 \iota$ breit, mit düuner, hyaliner, dicht- und feinwarziger Membran und orangerotem Inbalt.

Im Mai und Juni auf

Circaea alpina: Herrnskretschen (Wagner).

Kommt auch auf Circaea lutetiana und C. intermedia vor.

\section{Uredo.}

\section{Uredo Airae Lagerheim.}

Uredolager zwischen den Nerven blattoherseits, unterseits durch gelbliche oder violettbraune Fleckchen markiert, zerstreut, rundlich bis kurz strichförmig, subepidermal und nur mittelst eines lïnglichen Risses sich iffnend, gelb, durchsetzt von zahlreichen, keulenförmigen, seltener kopfö̈rmigen, bis $100 \mu$ langen, $10-20 \mu$ breiten, geraden oder (manchmal sehr stark) gekrümmten, hyalinen, am Scheitel $2-3 \% \mu$ dicken Parafysen; Sporen kuglig bis ellipsoidisch, manchmal polyedrisch, $22-33 \mu$ lang, 17-24 $\boldsymbol{u}$ breit; Membran farblos, dick, ziemlich dichtwarzig (1.5 $и)$.

Im August auf Aira caespitosa: Wiesenhaule im Riesengebirge! Bisher nur aus Schweden und Finnland von Aira caespitosa, alpina und bottuica bekannt.

\section{Uredo anthoxanthina Bubák.}

Uredolager auf gelblichen oder schwach rötlichen Flecken blattoherseits, elliptisch oder lïnglich, zerstreut oder stellenweise gruppiert, manchmal zwischen den Nerven in kurzen Reihen und daun öters der Länge nach zusammentliessend, 


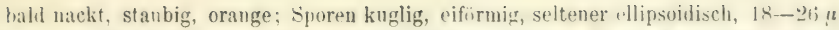
lang, $16-20 \mu$ breit, mit oxingefarbigem Inhalte, winigen (6-8) Krimporen; Parifysen zahlreich zwischen den Sporen entwickelt, gekrümmt odergebugen, zweimal ülıereinander aufgedunsen, keulenförmig oder kopttormig, bis 60 (1) lang. oben 11$)-15 u$ dick, hyalin oder schwach gelblich, dickwandig.

Von August auf A nthoxantum odoratum: Weisse Wiese im Riesengebirge (Kabát)!

\section{Anhang.}

Thümen gab in seinen, „Fungi a ustriaci" unter Nr. 402 einen Pilz rou Sta n hopea aus und zwar unter dem Namen Uredo Gynandrearum ('orda und führt denselben in seinem Verzeichnisse in den Verbandlungen il. zool. hot. Gesellschaft, Wien 1875 auch von $V$ anda sp. auf; beide Pilze wurilen von ihm in den Tetschner Glashäusern gesammelt.

Ich haibe das erste Exemplar untersucht (in Sammlungen d. bot. Abt. it biohm. Museums), konnte aber keinen Pilz finden. Corda beschreibt seinen Pilz folgendermassen :

\section{Uredo Gyuandrearum Corda.}

Flecken bleich, bräunlich, unregelmässig, zerstreut oder fehlend; Uredolayer blasenformig, elliptisch, zerstreut; Sporen kaffeebohnenartig, im Umrisse elliptisch, 16-22 $\boldsymbol{\text { b }}$ breit; Membran hyalin, feinwarzig; Inhalt weiss oder gelb.

Auf den Orchideen-Gattungen Stanhopea und Vanda in Glashäusern zu Tetschen (Thümen). 


\section{Vermeichnis der Wirtspflanzen.}

Abies excelsa . . . . 173, 174, 185, 188 - pectinata . . . . 190, 211, 213, 215

Actaea spicata

. 91

Achillea millefolium. . . . . . 150

- Ptarmica ........... 150

- setacea ......... 150

Adenostyles albifrons . . . . . 35, 179

- Alliariae ........ . . 52

Adoxa moschatellina . . . . . . 1241 146

Aegopodium Podagraria . . . . . 146

Aethusa cynapium . . . . . . 128

Agrimonia Eupatorium . . . . . . 186

Agropyrum repens . . . . . . . 86

Agrostis stolonifera . . . . . 98, 986

— vulgaris . . . . . 91, 98, 105, 106

Aira alpina. . . . . . . . . . 218

- bottnica. ........... 218

- caespitosa. . . . . . . . . . . . .

Alcbemilla fissa . . . . . . . . 5n

- vulgaris . . . . . . . . . . 50

Alectorolophus alpinus ...... . . 1 . 1 . .

- birsutus. . . . . . . . . 15ะ

- major . . . . . . . . . 18:

- minor ........... 1 . 1 2

Allium ascalonicum . . . . . . . . . . .

11ра . . . . . . . 2417

- tistulosum ..... . . . . 63

- oleraceum . . . . . . . . . 5:

- porrum . . . . . . . . . . 63

- rotundum . . . . . . 47.195

- sativum . . . . . . . . . 63.

- schoenoprasum . . . . . . . 6i:, u

- scorodoprasum . . . . . . 17,195

- sibiricun . . . . . . . . . . fi3

- ursinum . . . . . . . . 195, 20 \%

- vineale .......... . . 207

Alopecurus pratensis . . . . . 94, 107

Althaea officinalis. . . . . . . . 154

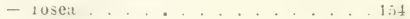

- rosea v. nigra. . . . . . . $15 t$
Amelanchier canadensis . . . . . . 154

— vulgaris . . . . . . . . . . . 159

Auchusa officinalis . . . . . . . . 83

Andropogon ischaemum . . . . . 105

Anemone nemorosa . . . . . . . 147, 183

- ranunculoides . . . . . . . 124, 148

- silvestris ........ . . 143

Angelica silvestris . . . . . 121, 12:1 127

Anthoxanthum odoratum . . . . 99, 219

Anthyllis vulneraria . . . . . . . 49

A pium graveolens . . . . . 58

Aquilegia rulgaris . . . . . . . . 91

Arabis hirsuta . . . . . . . . 15:

Arenaria serpyllifolia . . . . . . 153

Armeria vulgaris . . . . . . . . . 24

Arrhenatherum avenaceum . . . . . 90.307

Artemisia Abrotamum . . . . . . . . . 11!

- Absinthium . . . . . . . . . 141

- dracunculus ......... 111

- vuluaris ........ . . 1 . .

Arum maculatum . . . . . . 104

Asarum europaeum . . . . . . . . 111

Asparagus officiualis . . . . . . . . so

Asperula cynanchica . . . . . . tit

- galioides ........... . . t5?

- odorata ........... 151

Aspidium spinulosum . . . . . . . 215

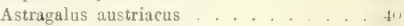

- eicer . . . . . . . 411

- exscapus .......... . to

- glycyphyllus .......... 4t

- onobrychis ........ 40

Astrantia major . . . . . . . 146

Avena fatua . . . . . . . . 98,107

- pubescens . . . . . . . . . 99

- sativa ... . . . . . 10

Barkhausia rhoeadifolia . . . . . . 0

Bellis perennis . . . . . . . 109

Berberis vulgaris . . . . . . . : 
Berula angustifolis ......... 3t

Beta vulyaris . . . . . . . . . . 04

Betula alba...........210

-. pubescens . . . . . . 2 210

Blechnum Spicant . . . . . . . .14

Brachypodium pinnatum. . . . . . 94

- silvaticum . . . . . . . . . . . . . 94

Bromus commutatus. . . . . . . . 84

- mollis . . . . . . . . . .4

- secalinus ........... 84

- sterilis ........... . . 84

- tectorum ......... . . 84

Bupleurum falcatum . . . . . . . 68

Cacalia suaveolens . . . . . . . . 179

Calamagrostis arundinacea.... 90, 90, 105

- epigeios . . . . . . . . . . . 88

- Halleriana . . . . . . . . . . $\$ 0$

- lanceolata . . . . . . . . . . . . .

Calsmintha Acinos . . . . . . 75,76

Caltha palustris . . . . . . 62, 76

Campanula bononiensis . . . . . . 181

- glomerata ........... . 181

- latifolia............. 381

- patula . . . . . . . . . . 181

- persicaefolia . . . . . . . 181

- rapunculoides ........... 181

- rapunculus ............. 181

- rotundifolia .............. 181

- Scheuchzeri . . . . . . . 145, 181

- sibirica ............ 181

- Trachelium ......... . . 181

Carduns acanthoides . . . . . . . 137

- crispus ............ 137

- nutans ............ . . 137

- personsta . . . . . . . . . 137

Carex acuta . . . . . . . 110,111

- acutiformis . . . . . . . 112

- brizoides ........... . 113

- caespitosa ........ 110, 111

- Davalliana. . . . . . . . . 117

- flava. . . . . . . . . 116

- fulva . . . . . . . . . . . 117

- glauca .............. 113

- birta . . . . . . . . . 110

- leporina........... . 113

- montana. . . . . . . . 115

- muricata ... . . . . . . 114

- pallescens . . . . . . . . . 113

- panicea.......... 113, 117

- pilosa........... . . 113

- Pseudocyperus......... . . 112

- rigida. . . . . . . . . . 113

- riparia ............. 111
Carex Schreberi . . . . . . . 113

- silvatica ............ . 113

- stricta. . . . . . . . 111, 117

- supina .......... . . 114

- vulgaris ........ 111, 117, 118

- vulpina . . . . . . . . 116

Carlina acaulis ...... . . . . 136

- vulgaris ........ . . 138

Carthamus tinctorius . . . . . 140

Carum carvi ... . . . . . . 121

Centaurea Cyanus. . . . . . . 139

- Jacea . . . . . . . 11:, 136

- montanit . . . . . . . 151

- Scabiosa ........ . . . . 136

Cerastium arrense . . . . . . . . . 212

- triviale .......... 153

Cerefolium silvestre... . . . . 81

Chaerophyllum aromaticum . . . . . 80

- hirsutum ........ . $\times 1$

- temulum . . . . . . . 81

Chelidonium majus . . . . . . . . . 201

Chondrilla juncea . . . . . . . 132

Chrysanthemum corymbosum. . . . . 141

- indicum ........... . . 142

- Leucanthemum . . . . . . . . . 115

Chrysosplenium alternifolium . . . 156

Cichorium Intybus . . . . . . . . 131

Cicuta virosa . . . . . . . . . . . 8:

Circaea alpina. . . . . 155, 187, 218

- intermedia . . . . . 155, 187, 218

- Lutetiana . . . . . . . 155, 218

Cirsium arvense .0 .0 .139

- canum . . . . . . . . 117,138

- canum $\times$ oleraceum . . . 117

- eriophorum ........ . . .

- heterophyllum. . . . . . . . 138

- Janceolatum . . . . . . . . . 77,78

- oleraceum . . . . 117. 138

- palustre . . . . . . . 117,138

- pannonicum . . . . . . . . 136

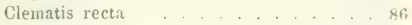

Clinopodium rulgare . . . . . . 75

Coninm maculatum . . . . . . . . . . 129

Convallaria majalis . . . . . . . . . . 103

Corydalis cava . . . . . . . . . . 204

- digitata. . . . . . . . . 204

- fabacea . . . . . . . . . . . .204

Crataegus Douglasii....... . . 158

— grandiflora. . . . . . . . . 158

- mono yyna. . . . . . . . . . . 158

- nigra . . . . . . . . . . . 158

- oxjacantha . . . . . . . . . . . 158

- songuinea . . . . . . . . . . . 158

- tanacetifolia ..... . . . . . . . 58 
Crataegus tomentosa. ....... 155

Crepis bienuis . . . . . . . . . 74, 112

- grandiflora ......... . 73

- paludo-a . . . . . . . . . . . . 72

- prsemorsa. . . . . . . . . . . $7 t$

- succisaefolia. . . . . . . . . 73

- tectorum ........... 6.4

- virens . . . . . . . . . . . . 69

Gononia vulgaris . . . . . . . . . 150

Cystopteris fragilis . . . . . . . 192

Cytisus litlorus . . . . . . . . . 50

- capitatus .......... 50

- Laburnum . . . . . . . . . . 51

- nigricans ........... . . 50

Dactylis glomerata . . . 31, $85,98,106$

Haucus carota . . . . . . . . . . 3t

Dentaria eaneaphyllos . . . . . . . 149

Deschampsia caespitosa ....... . . 95

Dianthus barbatus .......... 103

- caryophyllus........... 47

Echinops sphserocephalus . . . . . . 140

Elymus arenarius . . . . . . . . . . . . o

- europaeus.......... . . . 8i

Empetrum nigrum . . . . . . . . . 17 .

Epilobium alsinefolium . . . . . . . 186

- angustifolium ........... 18 . . . . . . .

- hirsutum ......... 67,186

- montanum .......... . . 67

- obscurum ............ 67

- roseum .........67, 674,186

Ervum hirsutum .......... . . 22

- leus . . . . . . . . . . . . . . . . . . .

Erythronium dens canis . . . . . . 45

Euphorbia amsgdaloides . . . . . . . 208

- carniolica . . . . . . . . . . 200

- cyparissias. . . 36, 37, 38, 39, 40,55, 208

- duleis............ . . 208

- esula......... . 36, 37, 55, 208

- exigria

- cerariliana

- heliosenpia

- peplus

- platypibill

- viret itit

Euphrasia lutea .... . . . . . . 182

- n.mornsit ........... 1n

- molontitr. . . . . . . . . . 1 . .

- othemalis. . . . . . . . . . 1-2

Evonymus europaeus ......... 200

Falcaria licini

125

Festuca arundinacea
Festuca duriuscula ......... 108

- gigantea . . . . . . . . . 107

- ovina ................ 30 108

- pratensis ........... . . 107

- rubra . . . . . . . $32,10 \mathrm{~s}$ silvatica. . . . . . . . . . . 1 4і

Ficuria verna. . . . . . . . . . 51

- verna v. calthaefolia ....... . . 5l

Frangula alnus . . . . . . . . 105

Gagea lutea ............ 51

- pratensis . . . . . . . . . 5 5

Galega ofticinalis . . . . . . . . 50

Galanthus nivalis . . . . . . . . . 197

Galium Aparine ......... . . 126

- Cruciata . . . . . . . . 126, 151

- mollugo . . . . . . . . 59, 151, 150

- palustre . . . . . . . . . . . 59

- saxatile .......... 151, 188

- silvaticum ........ . . 60, 151, 180

- silvestre . . . . . . . 59,150

- uliginusum _. . . . . . . . . 5:

- verum ............. $5 \%, 18 \%$

Genista tinctoria . . . . . . . . 50

Gentiana cruciata . . . . . . . . 64

Geranium columbinum . . . . . . . 96

- dissectum . . . . . . . . . 26

- palustre . . . . . . . . . 26,119

- pratense ......... 27, 119

- pusillum ........... . 118

- pyrenaicum . . . . . . . . . 27

- silvaticum ......... . 27,119

Glechoma hederaceum ....... . . 15\%

Globularia Willkommii . . . . . 152

Gljceris aquatica . . . . . . . . . . 10i

Gymuadenia conopea . . . . . . . 199

Hedysarum obscurum ......... 43

Helianthus anuuus . . . . . . . . . . . 5!

Herniaria glabra . . . . . . . . 154

Hieracium alpinum . . . . . . . . . 130

- aurantiacum . . . . . . . . . 130

- auricula . . . . . . . . . . T.4

- boreale ............ 130

- Fritzii ........... 130

- glanduloso-dentatum ....... . 130

- laevigatum ........... . 130

- murorum ........... . . 130

- nigrescens . . . . . . . . . 130

- Pilosella ........... . . 130

- praealtum .......... . . 130

- prenauthoides .......... . 130

- silvaticum ............ . . 130

- sudeticum ........... . 131 
Hitracium tridentatum . . . . . . 1:31

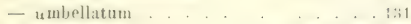

Holcus lamatus . . . . . . . 8-, 105, 10f, 11\%

- mollis.......... . 88, 106, 107

Homorgue alpina . . . . . . 115, 216

Hordeum distichum . . . . . . . . . 93

- hexastichum . . . . . . . . . 93

- vuleare . . . . . . . . . . . . . 9., zeorithon. . . . . . . . . . . . 93

Hypericum montanum . . . . . . . . . 209

- perforatum . . . . . . . . . . 207

- quadrangulum . . . . . . . . . 209

Hypochoeris glabra . . . . . . . . . 131

- radicata. . . . . . . . . . 134

- unitlorib.......... 131

Impatien; balsanina . . . . . . 17

- noli tangrere. . . . . . . . . 120

Inula salicina. . . . . . . . . . 178

Juniperus communis . . . . 157, 158, 159

- nana . . . . . . . . . . . . 158

- oxycedrus......... . . $15 \mathrm{x}$

- Sabina . . . . . . . . 14io

Koeleria cristata .......... 103

— glanca . . . . . . . . 103

- gracilis ........... 103

Lactuca muralis . . . . . . . . . 79, 111

- perennis ......... 78

- quercina........... . . 75

- scariolir . . . . . . . 11!

Lamplsana communis . . . . . . 71, 215

Lappa major . . . . . . . . . 130

— major $\times$ tomentosi ........ 135

- minor............ . . 135

- tomentosa............... 135

Larix europaea $.194,197,198,202,206, \pm 10$

- occidentalis . . . . . . . . . 197

Lathyrus pratensis . . . . . . . . . 37

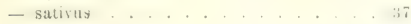

— silvestris . . . . . . . . . . 37

- tuberosus ............. . 26)

Ledum palustre . . . . . . . . . . . 17:3

Leontodon autumnalis . . . . . . . . 133

- hastilis ........... . . 132

- hispidus..... . . . . . 17.;

limularia sibiriea . . . . . . . . . . . . . . . . 45

Lilium candidum . . . . . . . . . 45

limum catharticum . . . . . . . . 269 usitatissimum . . . . . . . . . . . . . . . . . . . .

Listera ovata . . . . . . . 104, 199

Lithospermum arvense. . . . . . . . 217

Lolium perenue. . . . . . . . . 107

Lonicera xilosteum . . . . . . . . . . 1un
Lotus corniculate. . . . . . . : .

trunifolius . . . . . . . . . . . . . . . . .

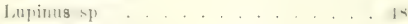

Luzula campestris . . . . . . . . 109

- maxima . . . . . . . . . . 1110

- pallescens .......... 110

- vernalis .......... 109, 110

Lychni- Jlos cuculi . . . . . . . 11:4

bycopsis arrensis . . . . . . . . . .

Mahonia aquifolium . . . . . . . . . 98

Malachium aquaticum . . . . . . . 153

Malva rotundifolia . . . . . . . . 154

- silvestris . . . . . . . . . 155

- rulgari . . . . . . . . . . 135

Medicago falcata ........ . . 30

- minina . . . . . . . . . . . .

- sativa. . . . . . . . . . in

Melampyrum arvense . . . . . . . 18:

- cristatum . . . . . . . . 182

- nemorosum . . . . . . . . . 18\% pratense . . . . . 111. 1 . . . . 14:

- sitraticum . . . . . . . . . 18:

Melandryum pratense ......... 66

- silve-tre. . . . . . . . . . . . 15is

Mrlica ciliata. . . . . . . . . 33

- nutans .. . . . . . . . . 100

Mentha aquatica .. . . . . . . . 76

_- arvensis. . . . . . . . . . . 76

- capitata . . . . . . . . . . 76

- lortensis. . . . . . . . . . . . . . .

- piperita .......... . . 76

- rotundifolia ......... . . 76

- silvestris . . . . . . . . . $7 t$

Mercurialis perennis. . . . . . . . 205

Meum athamanticum ........ . . 171

- mutellina . . . . . . . . . . 121

Moehringia triuervia . . . . . . . . . 153

Molinia coerulea . . . . . . . . 101

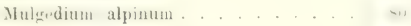

Muscari comosum . . . . . . . . . 5t

- tenuitlorum .......... . . 54

Myosotis stricta . . . . . . . . 217

Myrrhis odorata ........... 81

Nemesia versicolos . . . . . . . . 1 . 1 .

Nonnea pullit. . . . . . . . . . 11

Onobrychis viciaefolia . . . . . . . 4 ts

Unouis spinusit . . . . . 1

Ophrys muscifera. . . . . . . . . 199

Orchis incarnata ........ 104, 199

- latifolia ........... . . $19 y$

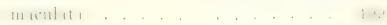


Orchis militaris. . . . . . . . . 199

- sambucina . . . . . . . . . . 199

Ornithogalum tenuifolium ....... 144

- umbellatum . . . . . . . . . 144

Orobus albus . . . . . . . . . . 20 20

- montanus............ . 21

- niger .. . . . . . . . . 21

- vernus ............. . . 21

Oxytropis pilosa . . . . . . . 40

Paeonia angustifolia. . . . . . . . . 175

- anomala. . . . . . . . . . 175

- arietina . . . . . . . . . 175

- decora ............ . 175

- insignis . . . . . . . . . 175

- officinalis . . . . . . . . 175

- peregrina .......... . . 175

- tenuifolia . . . . . . . . . 175

Paris quadrifolia . . . . . . . . . 103

Parnassia palustris ......... . . . 118

Pastinaca sativa. . . . . . . . . . 34

Pedicularis silvatica. . . . . . . . . 117

Petasites allus . . . . . . . . . 216

— officinalis . . . . . . . . 179, 216

Pencedanum Cervaria . . . . . . . . 129

- Oreoselinum . . . . . . . . 130

- palustre . . . . . . . . . 128

Phalaris arundinacea . . . . . 104, 106

Phaseolus vulgaris . . . . . . . . . 22

Phegopteris polypodioides. . . . . . 192

Phleum pratense . . . . . . . . . 99

Phragmites communis . . . . . . . 95, 96

Phyteuma spicatum ....... . . 53, 18 !

Picea excelsa. . . . . . . . . . 172

Picris hieracioides . . . . . . . . . 135

Pimpinella magna. . . . . . . . . . . 81

- Saxifrag ᄂ . . . . . . . . . . 82

Pinus anstriaca . . . . . . . . . 180

- cembra ........... . . 176

- Lambertiana. . . . . . . . . $17 \mathrm{t}$

- montana . . . . . . . 181, 182

- monticola . . . . . . . . . . 176

- Pumilio . . . . . . . . . . 179, 183

- silvestris $175,178,179,180,181,182,183,203$

- Strohus . . . . . . . . . 176

pirola chlorantha . . . . . . . . . 189

- minor . . . . . . . . . . 174

- rotundifolia . . . . . . . . . 189

- secunda........... . . . 174

- secunditlora ............ 189

- unitlora ............. 189

Pirus acerba . . . . . . . . . . . 183

- aria . . . . . . . . . . . 183

- aucuparia ............ 183
Pirus communis . . . . . . . 158, 160

— Malus . . . . . . . . 157,159

- scandica . . . . . . . 183

- torminalis .......... 183

Pisum sativum ..... . . . . 37

Platanthera chlorantha . . . . . . 199

Poa annua . . . . . . . . . . 32,94, 98

- compressa. . . . . . . . . 44

- nemoralis . . . . . . . . 32, 94,98

- pratensis . . . $32,94,98,106$

- trivialis ... . . . . . . 89,94

Podospernum Jacquinianum . . . . . 70

- laciniatum . . . . . . . . . . 70

Polygonatum multiflorum . . . . . . . 103

Polygonum amphibium . . . . . . . 119

- aviculare . . . . . . . . . 94

- Bistorta. . . . . . . . 121, 122

- Convolvulus . . . . . . . . . 118

- dumetorum . . . . . . . . . . 118

Polypodium dryopteris ... . . . . 191

- vulgare ... . . . . . . . 214

Populus alba . . . . . . . 202, 203, 205

- alba $\times$ tremula . . . . . . . . 203

- balsamifera . . . . 202, 205, 206, 207

- canadensis . . . . . . . 206, 207

- italica. . . . . . . . . . . 205

— monilifera. . . . . . . . . 205

- nigra . . . . . . . . $205, \geq 06,207$

- pyramidalis . . . . . . . 206

- tremula . . . . . 2012, $203.204,205$

Potentilla alba . . . . . . . . . 163

- argentea ............. 163

- aurea . . . . . . . . . . . . 163

- cinerea . . . . . . . . . . . . 163

- opaca. . . . . . . . . 1163

- procumbens ........... . . 16is

- Tormentilla . . . . . . . . . 16s

- vina. . . . . . . . . . 168

Prenanthes purpurea . . . . . . . 79

Primula minima . . . . . . . . . . . 54

Prunus armeniaca . . . . . . . . . 124

- domestica . . . . . . . . . . . 124

- insititia . . . . . . . . . . . 124

- Padrs . . . . . . . . . . 1ns

- spinosa .............. . . 124

Pulmonaria officinalis . . . . . . . . . 218

Pulsatilla alpins . . . . . . . . 143

- pratensis .......... . . 148

Ranuneulus acer . . . . . . . . . . . . . . . . . .

- auricomus . . . . . . . . . . . 32

- bulhosus . . . . . . . . .31, :82, 9.;

- ficaria . . . . . . . . . . 32, 34

- lanuginosus ......... . . 31 
lianunculus nemorosus . . . . . . 32

- repens . . . . . . . . 32, 95

lihamnus cathartica . . . . . . 107

-. saxatilis ............ . . 100

Rhododendron ferrugineum . . . . . 17:

- hirsutum . . . . . . . . . . 17:

Ribes alpinum . . . . . 111, 112, 201

- aureum . . . . . . 111, 11:, 176, 201

- Gordonianum . . . . . . . . . 170

- grossularia . . 111, 112, 176, 200,201

- nigrum . . . . . 111, 11:, 176, 201

- petraeum . . . . . . . . . . 149

- rubrum . . . . . 111, 149, 177, 201

- sanguineum....... 111, 112, 177

liosa alba............... 164

- alpina . . . . . . . . . . 160

- canina ........... 164,165

- cinerascens . . . . . . . . . 164

- cinnamomea........... 165

- corifolia . . . . . . 16it

- pimpinellaefolia . . . . . . . . 165

- rubiginosa. . . . . . . . . 165

- sepium ............ . . 165

- trachyphylla. . . . . . . . . 165

— turbinata ........... 164

Rubus amoenus. . . . . . . . . . 165

- cresius ............ . . 167

- glandulosus ............ 169

- Idaeus . . . . . . . 160

- nemorosus . . . . . . . . 167, 169

- plicatus ............. . . 169

- radula ............ . . 168

- saxatilis. . . . . . . . . 167

- thyrsoidens . . . . . . . . 168

- villicaulis . . . . . . . . . . 160

Rumex acetosa . . . . . . . \$0, 96, 123

- Acetosella. . . . . . . . . . 123

- alpians .......... . 56, 90

- aguaticus ......... 34, . 96

- arifolius . . . . . . . . . . 122, 123

- crispus . . . . . . . . . . . . 96

- Hydrolapathum . . . . . . . . 35,96

- maximus ............ . . 35

- obtusifolius . . . . . . . . 35,96

- scutatus............ . . 114

Sagina procumbens . . . . . . . . . . 153

Salix acntifolia ........... . . 198

- alha .............. 195

- amyrdalina ........... . . 194

- arbuscula . . . . . . . . . . 19s

- aurita . . . 197, 198, 199, $200,201,202$

- aurita viminalis. . . . . . $19 \mathrm{~s}$

- Capraea. . . . . 197, 195, $200,201,202$ Dr. Buták, Dìe Pilze Bühmens.
Salix cincrea

- cinerea viminalis

- daphnoides

- dasyclados.

- fragilis

- glabria

- grandifolia

- herliacea

- hypophaifolia

- incana

- Lapponum

- nigricans

- pentandra

- purpurea

- - viminalis repeus

- reticulatia

- retusa.

- rubra

- serpyllifolia

- silesiaca.

- Smithiana

- viminalis

Salvia silvestris .

- silvestris $\nless$ pratensis

- verticillata.

Sanguisorba minor

- officinalis

Saxifraga caespitosa

- granulata

Scirpus maritimus .

Scorzonera humilis

Scrophularia nodosit

Secale cereale

sedum acre

- boloniense.

Sempervivum soboliferum

- tectorum

Senecio Fuchsii.

- Jiteobae:

- nemorensis

- silvaticus.

- viscosus.

- vulgaris .

Serratula tinctoria

Seseli glaucum . .

- hippomarathrum

Sesleria coerulea

Silaus pratensis.

vilene inflata. nutans

Smilacina bitolia

Soldanella montana

Solidago virgaurea
$.198,200,202$

. . 200

$.198,200$

. 198

$.196,195$

.195

198

198

148

$\therefore 001$

.202

198

.194

198,200

$198, \geq 00$

.199

$.19 \mathrm{~s}$

.198

.200

.198

202

$19 \mathrm{~s}$

. $198,201,202$

. 102

. $10=$

65

. 162

.170

$\because 11$

. 150.210

34

135

42

$.83,85$

.103

. 111:;

.177

$17 \%$

113,180

. . 181

113, 151

.180

.180

$1 \div 1$

116,136

3:;

. $12 \mathrm{~s}$

1011

$1 \geq 8$ 
Solidago virgaurea $\mathrm{v}$, alpesti is . . . . . 5: Funchus anvensis . . . . . . . . 1s

- aspir........ . . . . . . . . .

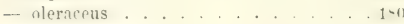

Sorbus ancuparia . . . . . . . 15:

- latifolia . . . . . . . . . 159

- torminalis ......... 158,159

Specularia Speculum . . . . . . 181

Spergula arrensis. . . . . . . 15t

Spiraea aruncus . . . . . . . . . . . 183

Stanhopea . . . . . . . . . 219

Statice Limonium . . . . . . . . 25

Stellaria graminea. . . . . . . 153, $21:$

- holoster.......... 153,212

- media. . . . . . . . . . 153

- nemorum . . . . . . . 15:3, $21 \%$

Stipa capillata. . . . . . . . . . 102

sweertia peremic. . . . . fit

Symphytum ofticinale . . . . . $\$ 4,213$

- tuberosum ........... 213

Tanacetum 13alsamita . . . . . 142

- vulgare ........... . . 140

Taraxacum leptocephalum ..... . . 132

- officinale......... . 113,132

- palustre . . . . . . . . . . 15z

Teucrium chamaedrys. . . . . . . 152

Thalictrum minus. . . . . . . . s6

Thesimm ebrateatum . . . . . . 1:5

- linophyllam .......... in

- pritense ...... . . . 5

Ihlaspi alpestre . . . . . . . 15;

Thymus alpestris . . . . 14:

- angustifolius .......... 102

- chamaedrys . . . . . . . . . 145

- ovatus . . . . . . . . 102

- pannonicus .......... 101

- praecox .......... . . 102

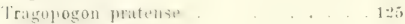

Iritolium agrarium ....... . . 38

- arvense ........... 38
Trifoliun: fragiferum ........ fit

- hybridum .......... 41 . .

- montanum . . . . . . . . 44

- pratense .. . . . . . . 4t

- repens ............. . . . .

Trisetum flarescens . . . . . . . . .

Triticum caninum . . . . . . 88, 91, 98

- repens . . . . $86,88,98,106$

- vulgare . . . . . . . . 84,88

Tussilago farfara . . . . 94, 179

Ulmaria pentapetala . . . . . . . 170

Urtica dioica .... . . . . 110

Vaccinium myrtillus. . . . . . 189

- nliginosum. . . . . . . . 18!

— Vitis idaes .... . . . 189, 190

Valeriana dioica ............

一officinalis . . . . . . . . . \pm 8

Vanda sp. . . . . . . . . . . 219

Veratrum Lohelianum . . . . . . 3i

Verbascum Thapsus . . . . . . . 42

Verbena crinoides. . . . . . 176

- teucrioides . . . . . . . . 1iti

Veronica Anagallis . . . . . . . ti

- montana . . . . . 1:il

Vicia cracea . . . . . .

- Faba . . .

- sativa . . . . . . .

- sepium .......... . . .

Vincetoxicum officinale . . . . 17i

Yinla canina . . . . . . . . tit;

- collina ... . . t titi

- hirta ........... thit

- mirabilis ...... . . (bi

- odorata.......... . . tit

- Riviniana .......... . bit

- silvestris ............ (tit

Willemetia hieracioides . . . . . . . .

Zea Mays .......... . 11m 


\section{Verzeichniss der Familien und hatmmeen.}

(Syonyma kursiv, Diagnosen fette Ziffern.

Aecidium . . . . . . . 21:

C'acoma (Siche Verzeichnis der Arten).

Calyptospora . . . . . . 181, 1S!)

('apitularia (Siehe Verzcichnis der Arten).

Chrysomyxa . . . . . . . 171, 171

1. Euchrysomyxa ....... 171

II. Leptochrysomyxa . . . . . 174

Colcosporiaceas . . . . . . . . . 177

Colcosporium . . . . . . . 177, 17s

ironartiacean . . . . . . . . . . .

Cronartium . . . . . . . 171, 174

Dicaeoma (Siehe Verzeichnis der Arten.

Endophyllum . . . . . . . 171, 175

(ivmnosporangiene . . . . . . . 156

fiymnosporangium . . . . . . 157

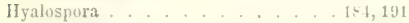

Külncola (Siehe Verzeichnis der Arten) . . 163

Melampsora . . . . . . . . 184, 193

Melamporaceae ............ 181

Melampsorella . . . . . . . 1\$1,211

Melampsoridium . . . . . . 184, 210

Ochropsora . . . . . . . 177, 15:3

l'crilcminm (Siehe Verzeichnis der Arten).

l'hragmidieae . . . . . . . . 1(i)

Phragmidium . . . . . . . 161, 161

1. Kupbragmidium ....... 162

II. Brachyphragmidium . . . . . 1699

111. Phragmidiopsis . . . . . . . 169

Pucuinir . . . . . . 19. 56
1. Eupuccinia . . . . . . . 5

1. Auteupuccinia ....... . . 5i

¿. Heteropuccinia . . . . . . . \$2

II. Pucciniopsis . . . . . . . 1世4

1II. Brachypuccinia . . . . . 12:

IV. Micropuccinia . . . . . . 11 1:3

V. Leptopuccinia . . . . . . . 150

Pucciniaceas .......... 19

Pucciniastrum . . . . . . . . 144, 154

Pluccinieac . . . . . . . . 19

Rocstelia (Siche Verzeichnis der Arten).

Schroeteriaster . . . . . . 19,53

Thecopsora . . . . . . . 1s1, 187

Trachyspora (Siehe Verzeichnis der Irten)

'Iriphragmiun . . . . . . . 161, 170

I liashytriphatamens. . . Lin

II. Nicrotriphragmium . . . . . 17t

Uredinopsis . . . . . . . 1s1, 1!!2

Uredo . . . . . . 215, 21s

Ureilo (Siehe Verzeiclunis der Artem.

Uromyces . . . . . . . . 19, 20

1. Euuromyes . . . . . . . 20

1. Auteumomyces . . . . . . 21

2. Heteruromyces . . . . . . 30

II. Uromycopsis . . . . . . . . 40

III. Brachyuromyces . . . . . . 16

IV. Hemiuromyces . . . . . . . 415

V. Microuromyes . . . . . .

VI. Leptouromyces . . . . . . . . . . .

Tenolochus iSjehe Verzeichnis der Arten! 


\section{Verzeichnis der Arten.}

(Artendiagnosen durch fette Ziftern liervorgehoben.)

Aecidium abietinum .11\%, et Schr. . . . 172

- Actaeae Opiz. . . . . . . . . 91

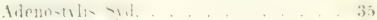

- Inagallidir liarl .... . . . nit

- Aquilegiae Pers. . . . . . . . su

- Asperifulii forma libytispermi Opiz . .217

- Rehenis DC. . . . . . . . . 40 Melieridis Pes . . . 97

- Berulae Bubák . . . . . . . . . . 34

- Bubálianum Juel. . . . . . . . . . .128 Bupleuri Opiz. . . . . . . . . 68

- Cacaliae Thüm. . . . . . . . 35

- carotinum Bubák. . . . . . . . . . 34 ('irnate linati ..2.21s

— Clematidis DC . . . . . . . S5

- Convallariate Schum. . . . . . . 103

- cornumum limel. . . . . . . . . . . . . . . . .

- Ervi Wallr. . . . . . . . . 21 Firtimuii $[x$. . . . It

— Etiphorbiae Yers. p. p. . . . . . 35, 38, 89

- Euphorbiac Gerardiana E. Fischer 49, 215

- Ficariae Pers. p. p. . . . . . . . 34 - fit-cim l'er. . . . . . 117

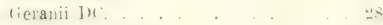

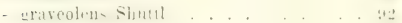
Homogynes Schroet. . . . . . 216

- Kilıatianum Bulrk . ....... 217

- lactucinum Lagerh. et Lindr. . . . . . 113

- Lampsanicolum Tranz. . . . . . 72,215

- Lencanthemi DC . . . . . . 111 Lencospunam I)C... . 1-3

- Ligulariae Thïm. . . . . . . . 216

- Lithospermi 'Thum. . . . . . . 217

-. Yei - hroet. .... 1 .

- Yei mutellinae Wint. . . . . . . . 121

- Melampyri Kunze et Sclimidt. . . . . 100

-. Nonneae Thum. . . . . . . . 217

- Orchidearum Dulyy . . . . . . . 101

- Parnassiae Gravis . . . . . . 117
Aecidium l'astiuacae Rostrup. . . . . . 34

- l'edicularis Libosch . . . . . . 117

-- perforans Dietrich . . . . . . . . 167

- P'ericlymeni Sehum. . . . . . . 108 l'etasitidis Syd. . . . . . 216

- Pimpinellae Kirclner. . . . . . . 81

- praecox Bubák ......... . 74

- pseudocolumnare Küh . . . . . 215

- l'ulmonariae Thüm. . . . . . . 21s

- punctatum P'ers. . . . . . . . . . 123

- Ranunculacearum DC. p. p. . . 30, 31, 32

- Einguinolentum Lindr. . . . . . . . 119

- Serophulariae DC. . . . . . . . . 41

- Sedi Schroet. . . . . . . . . 102

— Seseli Niessl. . . . . . . . . 3ะ

- Stellariae kirchner........ . . 13

- Thapsi Opiz ........... 42

- Thymi Fuckel . . . . . . . . 101

- 'Trifolii repentis Cast. . . . . . . 25

- Valerianae Kirchner . . . . . . . 28

Caeoma Armeriae schlecht. ... . . . . 24

- Errthronii Corda. . . . . . . 44

- Lilii Link. . . . . . . . 45

- pinitorquum 11. 13r. . . . . . . 202

- ptychospermum Opiz ....... . 21

- Silenes Schlecht. ......... 22

- Solidaginis Sommt. . . . . . . 53

Calyptospora Goeppertiana Küln. . . . 189

Capitularia graminis Niessl. . . . . . . 32

(hrysomyxa Abietis (Wallr.) Wint. . . 174

- albida Kühn. . . . . . . . 169

- Empetri (P'ers.) Rostrup . . . . . . 173 - Ledi (Alb. et Schw.) Wint. . . . 172, 173

- Pirolae (DC.) Rostrup . . . . . 173, 189

- Rhododendri (DC) De Bary . . . . 171

Coleosporium Caraliae (DC.) Vianer. . 17s

- Campanulae (Pers.) Lér. . . . . . 181

- Euphrasiae (Schum.) Wint. . . . . . 182 
Coleosporium Inulae (Kunze) F.-Fischer . 176

- Melampyri (Reb.) lileb. . . . . . . 181

- l'etasitidis De Bary . . . . . . . . 179

- Senecionis (Pers.) Fries. . . . . . 150

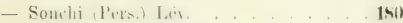

- I'ussilaginis (Y'ers.) Kileb. . . . . . 179)

Cropartium asclepiadeum (Willd) liries 174, 176

— flaceidum Alh. et Schw. . . . . . 174

- ribicolum Dietrich . . . . . . $\mathbf{1 7 6}$

Dicaeoma Carthami Hìtzelmann . . . . 140

- Epilobii Opiz ......... . 67

- Lupini Hotlm. . . . . . . . 48

- Pulsatillac Opiz . . . . . . . . 117

Endophyllum Sedi (DC.) Lév. . . . . 102

- Sempervivi (Alb. et Schw.) De Bary . .177

Gymnosporangium clavariitorme (Jacq.) liees, $\mathbf{1 5 7}$

- juniperinum (L.) Fries. . . . . . . 159

- Sabinae (Diks.) Wint. . . . . . 160

- tremelloides li. Hartig. . . . . . . 157

Hyalonsora Aspidiotus (Peck.) Maguus . . 191

- Polypodii (Pers.) Marnus. . . . . . 191

- Polypotii dryopteridis (Moug. et Nesti.) Ma $a$ nus

191

Kühncolia albida Magnus. . . . . . 169

Lycoperdon caryophyllinum Schrank . . 47

- scutellatum Schrank

Melampsora Allii fragilis Kleb.

195

- Allii-populina Kileb.

195,207

- Allii-Salicis albae Kleb.

194,207

- Amygdalinae Kleh. .

193,191

- betulina (Pers.) Tul.

.210

- Cerastii Wint.

$\because 11$

- Euphorbiae dulcis Otth.

208

- Evonymi-capraearum Kileb.

199

- Galanthi fragilis Kleb.

$19 \mathrm{i}$

- Galii Wint.

188

- Ielioscopiae (Pers.) Wint.

207

- Ispericorum (1)C.) Schroet.

209

- Klebałni Bubák

204

- Larici-capraearum Kleb.

197

- Larici-daphnoidis (Kleb.) E. Fischer . . 198

- Larici-epitea (Kleb.) E. Fischer . . 197, 198

- Larici-epitea forma typica . . . . . . 198

- Larici-nigricantis 0. Schneider . . . . 198

- Larici-pentandrae Kleb. . . . . . . . 194

- Larici-populina Kleb . . . . . . . . 205

— Larici-purpureae 0. Sclnneider . . . 198
Nelampsora Larici-retusae F. Fischer . . 198

- Larici-tremulae Kleb.... . . . . . . 202

- Laricis R. Hartig . . . . . . . . . . 202

- Lini (Pers.) Desm. . . . . . . . . . 20s

- Maguusiana Wagner . . . . . . . . 204

Melampsora minutissima (Opiz) Bubak . 194

- Orchidi-repentis Kleb. . . . . . . . 199

- pinitorqua lostrup ... . . . . . 202 l'irolae (imel.) >lorou. . . . . . 1s!

- repeutis 1'uwr. . . . . . . . 19!

- Fibesii-auritae Kleb. . . . . . . . . 200

- Ribesii purpureae Klcb. . . . . . 200,201

- Ribesii-Salicum Bubik . . . . . . . . 200

- Ribesii-viminalis Iíleb. . . . . . . 201

- Rostrupii Wagner . . . . . . . . . . 204

— Saxifragarum (1)C.) Schroet. . . . . . 209

- Sorbi IVint. . . . . . . . . . . 183

- Vaccinii Wint. . . . . . . . 185

- vernalis Niessl . . . . . . . . . 20!

Melampsorella Aspidiotus (Peck.) Magnus . 1!1

- Blechni Sydow. . . . . . . . . 214

- Caryophyllacearum (DC) Schroet. . . 211

- Cerastii ('Pers.) Schroet. . . . . . 211 Dieteliana Sydow. . . . . . . . . 214

- Kriegeriana Magnus. . . . . . . . 214

- Symphti (DC.) Bubik . . . . . . .213

II lampsoridium betulinum (Pers.) Kleb. . 210

Ochropsora Sorbi (Oud.) Dictel . . . . 158

Peridermium Boudieri E. Kischer. . . . 179

- Cinruui kleb. . . . . . . . . . . . . . . .

— Dietelii Waguer . . . . . . . . . 179

- Fischeri Kleb. . . . . . . . . . 180

- Klehabni Ed. Fisther. . . . . 17

- Kosmablii Wagner. . . . . . 1s

- Magnusianum E. Fischer . . . . . . . 178

- Magnusii Wagner . . . . . . . . . 178

- oblongisporum Kleb. . . . . . . . 150

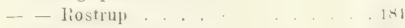

- I'lum rightii Kleb... . . . . . 17: Rostrupii kleh. . . . . . . . . . . .

- Soraueri Klm..... 1-1

- Strobi Kleb............ . . 176

Phragmidium albidum (Kühn.) Lutw. . . 169

- carbonarium (Schlecht.) Wint. . . . 169

- Fragariastri (DC.) Schroet. . . 162, 163, 168

- obtusum (Strauss.) Wint. . . . . . 168

- perforans (Dietrich) Liro . . . . . . 167

- Potentillae (Pers.) Wint. . . . . 163, 168

- Rosae-alpinae (DC.) Schroet. . . . . 165

- Rosae pimpinellaefoliae (Rabh.) Dietel. . 164

- Riubi (Per-1 IV int. . . . . . . . 167

- Rubi Idaei (Pers.) Wint. . . . . . 166 
Puccinia Rubi saxatilis Liro.

- Sanguisorbae (DC.) Schroet.

- subcorticinum (Schrank.) Wint.

- Tormentillae Fuckel.

tuberculatum .T. Müller.

- riolaceum (Schultz) Wint. .

Absinthii $1 \mathrm{C}$.

- Acetosae (Schum.) Körn.

- Actaeae-Agropyri E. Fischer

- Adoxae Autt p. p.

- Hedw. fil.

- Aecidii-Lencanthemi k. Fischer

- Aegopodii Link.

- - (Schum.) Link. .

- Agropyri Ell. et Ev.

- Agrostidis Plowr.

- albescens (Grév) Hlowr.

- ambigua (Alb. et Schw.) Lagerh.

- Angelicae (Schum.) Fuckel

- Angelicae-Bistortae Kleb.

- Angelicae mammillata Kílcb.

- Anemones virginianae Wint.

annularis (Strauss) Wint.

- Anthoxanthi Fuckel

- Apii Desm.

- Aquilegiac ('ers.) Lagerh. Arenariae (Schum.) Wiut.

- argentata (Schulz.) Wint

- Ari-Phalaridis Kleb.

- aromatica Bubák. .

- Arrhenatheri (Kleb.) Eriks

- asarina Kunze.

- Asvaragi DC.

- Asperulae-cynanchicae Winth Asperulae-odoratac Wurth

- Astrantiac Kalchbr.

- astrantiicola Bubik

- Athamanthae (DC.) Lindr.

- Arenae pubescentis Bubák

- Balsamitae (Stranss) Wiot.

- Bardanae Corda.

- Barklıausiae-rhoeadifoliae Bubák

- Baryi (Berk. et Br.) Wint.

- Bäumleri Lagerheim .

- Betonicae .

- Bistortae (Strauss.) DC.

- bromina Eriks.

- bullata (Pers.) Wint. .

- _ Autt. p. p.

- Bupleuri talcati (DC.) W'int

- Cacaliae DC.

- Calthae Link.

- Campanulae Carm.
.165

.165

. 1 tis

$140,1+1$

. 30, 122

411

145

145

114

.146

146

9.5

90

.146

. 126

127

.120

122

.143

.143

152

98

67

30

153

120, 146

. 104

s)

92

144

57

(60)

(i1

146

. 146

129

4) 99

142

135

69

94

145

(6)

120)

8:3

127

tir

$6 \mathrm{~S}$

6.) 3

62, i⿱

.144
P'uccinia Carduorum Jacky ...... 137

- Cari-Bistortae Kleb. . . . . . . . 120

- caricicola Fuckel . . . . . . . 11t

- Caricis (Schum.) liebent. . . . . . . 110

- Caricis montanae E. Fischer . . . . 115

- Carlinae Jacky .......... 138

- Carthami (Hutzelm) Corda . . . . 140

- caulincola Schneider....... . 145

- Celakorskýana Bubak . . . . . . 126

- Centaurea DC. . . . . . . 136

- Cesatii Schroet. . . . . . . 104

- Chaerophylli Purt. . . . . . . . 80 Chondrillae Corda . . . . 78, 114

- Chondrillina Bubak et Sydow. . . . 131

- Clirysanthemi Roze. . . . . . . . 142

- Chrysosplenii Grev. . . . . . . 156

- Cicutre Lasch. . . . . . . . . 82

- Cichorii (DC.) Bell. . . . . . . 131

- Circacae l'ers. . . . . . . . 155

-. Cirsii Lasch. . . . . . . . . . 137

- Cirsii eriophori Jacky . . . . . . . 77

- Cirsii lanceolati Schroet. . . . . . . 77

- Clematidis Lagerb. . . . . . . . . 85

- coaetanea Bubák. . . . . . . . \$1

- compacta De Bary . . . . . . . . 143

- conglomerata (Strass.) Schum, et liunze $\mathbf{1 4 5}$

- Conii (Strauss.) Fuckel . . . . . . . 128

- coronata Corda . . . . . 105, 108

- coronifera Kleb. . . . . . . . 106

- Crepidis Schroet. . . . . . 69, 70

- Crepidis grandiflorae Ilasler. . . . 72, 73 Crucheti IIasler ... . . . . . 73

- Cyani (Schleich.) Pass. . . . . . . 139

- dactylidina Bubak . . . . . . . 85

- De Baryana Thüm. . . . . . . 143

- Dentariae (Alb. et Schw.) Fuclicl. . . . 149

- dioicae Maguus . . . . . . . . . 116

- dispersa liriks. . . . . . $\mathbf{s 2}, 83,81,85$

- - Eriks. et Henn. . . . . . . 82

— divergens Bubák . . . . . . . . 138

- Echinopis DC. . . . . . . . 139

- Epilobii DC. . . . . . . . . 67,148

- Kpilobii tetragoni (DC.) Wint. . . . . 67

- Erikssonii Bubák . . . . . . 107

- Ervi Opiz ......... 21, 22

- Falcariae (Pers.) Fuckel. . . . . . . 125

- Festncae 1'lowr. ......... 10s

- fusea (Pers.) Wint....... 147,118

- Galii Antt. non Pers. . . . . . . . 59

- Galii silvatici Otth. . . . . . . 60

- Gentianae Strauss. . . . . . . . 63

- Geranii Corda .......... 28

- Glechomatis DC. . . . . . . 151 
P'uccinia glumarum (Schmidt.) Friks. et Uenn. $82,8 \overline{7}, 88,89$
.$\quad 57$

- graminis Pers.

- grisea (Stranss.) Wint. 152

- IJelianthi Schweinitz

- Herniariae Kirchuer is

- Unger 154

- Hieracii (Schum.) Mart.

154

- holcina Eriks.

130

- Iypochoeridis Oudem Intybi (Juel.) Sydow. .

- Isiacae (Thúm) Wint.

- Jaceae Otth.

- Lactucarum Sydow. .

- Lampsanae (Schultz.) Fuckel

- Leontodontis Jacky

- Liliacearum Duhy

- Lolii Niels.

- Inngissima Schroet.

- Loti Kirchner.

- Maguusiana Koern.

- Magnusii Kleb.

- major Dietel.

- Malvacearum Mont.

- Mammillata Schroet.

- Maydis Bér. . . .

- Mei-manmillata Semadeni

-. Melicae Bubik

- $\quad$ - Eriks.) Syidow.

- Menthae Pers. . . . . .

- Millefolii Fuctel.

- Moliniae Tul.

- montivaga Bubák

- Mulgedii Sydow.

- Mycelis Opiz .

- nemoralis $\mathrm{J}_{n \mathrm{el}}$.

- nigrèscens Kirchner.

- oblongata (Link.) Wint

- obscura Schroet. . . . .

- obtegens (Link.) 'Tul. . .

- obtusa Schroet.

- Opizii Bubák

- Orchidearum-Phalaridis Kleb.

- Oreoselini (Strauss,) Fuckel.

- Oroli Kirchner.

- paludosa Plowr.

- Passerinii Schroct.

- perplexans Plowr. .

- persistens Plowr.

- Petroselini (DC.) Lindr.

- Phalaridis Plowr.

- Phaseoli Opiz.

- Phlei pratensis Eriks.

- Phragmitis (Schum.) Kürn.
Puccinia phyteumarum DC: 53

- Picrilis Haszl. . . . . . . . 1:34

- Pimpinellae (Strauss.) Mart. _. 81

- Poae trivialis Bubrik . . . . . . \$! Poarum Niels ... . . 93 Podospermi DC. . . . . . . . . .

- Polggoni Pers. .... . . . 23

- Alb. et Schw. . . . 11s

Polygoni amphibii l'ers. . . . . 119

Porri (Sow.) Wint. . . (i:3

- praecox lubák . . . . . . I4

- Prenanthis (Yers.) Lindr. . . . . . . . is Prenantbis purpureae (Pers.) Lindr. 79, 80

- I'ringsheimiana Kleb. . . . . . 110

- Pruni spinosae Pers. . . . . . . 12:3

- Ptarmicae Karsten. . . . . . . 150

- Pulsatillae (Opiz) Rostr. . . . 11:

- punctata Link. . . . . . . . 59, 127 pygmaea Eriks. . . . . . . . !1

- Pyrethri Rabl.. . . . . . 110, 141

- Ribesii Pseudocyperi Kleb. . . . . . 112

- Ribi IH . . . . . . . 11!

- Rumicis Lasch. . . . . . . . . . . .

litumicis scutati (DC) Wint. . . . 11!

Saxifragae Schlecht. . . . . 14!

scorzopericola Tranzschel. . . . . . 1:is

Sehneideri Schroet. . . . . . 14:

- Schroeteriana Kleh. . . . . . 111; serialis 0 piz . . . . . . . . . . . . .

Sesleriae Reichardt. . . . . . . 99 sessilis Schneider. . . . 10:3, 104

- Silenes Schroet. . . . . . . . tifi

silvatica Schroet. . . . . . . 111, 112

simplex (Koern.) Eriks. ct Henn. . . . !2?

singularis Magnus . . . . . . 145

Smilacearum-Digraphidis Kleb. . . . . . . . .

Soldanellae (DC.) Fuckel . . . . . 6.

Sorghi Schweinitz .. . . IIII

Spergulae DC.......... 1.5

- Kirchner. . . . . . 154

Stipae (Opiz.) Hora . . . . IIII

suaveolens (Pers.) Rostr. . . . 1:is

101, 164 - - subfusca Holway. . . . . . . . 1 1: lit

Symphyti-Bromorum Fritz Miiller . . . \$3

117 - Tanaceti DC. . . . . . 140,141

124 - Taraxaci (Reb.) Plorr ... . . 1:32

s9 - tenuistipes Opiz ... . . . . ii

S6 - Thesii (1)esv.) Chaill. . . . . . . is

125 - Thlaspeos Schub. . . . . 152

104 - tinctoriicola Magnas . . . . . 13i;

22 - Tragopogi (Pers.) Corda . . . . 125

99 - Trailii Plowr. . . . . . 50.94\%

$95 \quad$ - Trifolii Hedw, . . . . . . . . 4 4i 
Puecinia 'lriseti Eriks. . . . . . . 88

- triticina liriks. . . . . . . . $\$: \$, \mathbf{S 4}$

- uliginosa Juel. . . . . . . 117

- Valantiae Pers. . . . . . . . . 151

- Veronicae Schroet. . . . . . . 151

- Verruca Thim. . . . . . . . . . 150

- Violae (Schum.) DC. . . . . . . . 665

- Virgaurea (DC.) Lib. . . . . . . . 156

- Willemetiae Bubak . . . . . . . . $\tau_{5}$

- Zoptii Wint........... 76

Pucciniastrum Agrimoniae (DC.) Lagerh. . 186;

- Chamaenerii Rostrup. . . . . . . 184

- Circaeae (Schum.) Speg. . . . . . 156;

- Epilobii (Pers.) Otth. . . . . . . . 155

- Padi Dietel. . . . . . . . . . . 187

- Vaccinii Dietel. ... . . . . 188

Roestelia cancellata Reb........ 160

- pennicillata (Müller) Fıies. . . . . . 157

Schroeteriaster alpinus (Schroet) Magnus $\mathbf{5 5}$

Thecopsora areolata (Wallr.) Magnus . . 187

- Galii (Link, De T'oni . . . . . . . 15s

- Padi (Kunze et Schmidt) . . . . . 157

- Pirolae (Gmel.) Karst. . . . . . . . 189

- Vacciniorum (DC) Ḱarst. . . . . . Iss

Trachyspora Alchemillae Fuckel . . . . 50

'friphragmium echinatum Léx. . . . . 171

- Ulmariae (Schum.) Wint. . . . . . 170

Uredinopsis filicina (Niessl) Magnus . . 192

Uredo Acetosae Schum. . . . . . 12:

- acuminata Kirchner . . . . . . 39

- aecidioides J. Muller . . . . . . . 169

- Aegopodii Schum. . . . . . . 14t

- Airae Lagerb. . . . . . . . . . 218

- Alchemilla pers. ........ 54

- ambigua DC. . . . . . . . . . 47

- annularis Stranss . . . . . . 152 anthoxanthina Bubik. . . . . .9, 218

- Anthyllidis Grev. . . . . . . . . 49 Apii $\theta_{\text {piz }} \ldots . . . . . .6 .67$

- appendiculata var. Cenistae tinctoriae pers. . . . . . . . . 49

- appendiculata var. Phaseoli l'ers. . . . 22

- - var. Pisi Pers. . . . . . . . 35

- Astragali Opiz . . . . . . . . . 39

- Betae Pers. . . . . . . . . . . 98

- biseriata Opiz ......... . 20s

- Brachypodii Opiz . . . . . . . 94 Chondrillae Opiz . . . . . . . 131

- Dianthi Hariot... . . . . . . 4i

- Fabae Pers........... 20
Uredo liabae var. Medicaginis falcatae DC. 38 Ficariae Schum. . . . . . . . . . Galanthi Kirchner . . . . . . . 197

- Galegae Opiz . . . . . . . . . . 50 Geranii DC. . . . . . . . . 26

- Gynandrearum Corda . . . . . . . 219

- Hedysari obscuri DC. . . . . . . 4. Hyacinthi Opiz . . . . . . . . . 53

— Limonii Autt p. p. . . . . . . . . 24 minutissima Opiz . . . . . . . $1: 44$ Muelleri Schroet. . . . . . . . . 169 Onobrychii Desm. . . . . . . 48 Pirolae (Gmel.) Wint. . . . . . . In! Polypodii Pers. . . . . . . 191 Prismatocarpae Siegm. . . . . . . 1s1 Rumicis Schum. . . . . . . . . . 34 Scillarum Grev. . . . . . . . . 53

Scirpi Cast. . . . . . . . . . . . 33

Scolopendrii Schroet. . . . . . . . 14

Speculum Siegm. . . . . . . . . 1s1

Symphyti DC. . . . . . . . . . 13

Thapsi Opiz . . . . . . . . 42

Valerianae Schum. . . . . . . . . . .

Iromyces Acetosae Schroet. . . . . . . 2y acutatus Fuckel . . . . . . . . 5

Alchemillae (Pers.) Schroet. . . . . 50

-. alpinus Schroet. . . . . . . . . 5i ambiguus (DC.) Fuckel. . . . . \$7 Anthyllidis (Grer.) Schroet. . . . . 49

- Ilariot. p. p. . . . . . 1s apiosporus Haszl. . . . . . . . . 5t

— appendiculatus Link. . . . . . . 22

Armeriae (Schlecht) Lév. . . . . . 24 Lév. . . . . . . . . . . .

Astragali $\langle$ Opiz) Sace. . . . . . . 39

- Jordi nec Opiz . . . . . . . 411

- Behenis (DC.) Unger. . . . . . . 40

ISetae (Pers.) T'ul. . . . . . . . 2s

- 'Tul. . . . . . . . . . . .

- Cacaliae (DC.) Unger . . . . . . . 52

- Unger . . . . . . . . . . . . .

caryophyllinus (Schrank.) Schroet. . . 47

Dactylidis 0 tth. . . . . . 30, 31

- Schroet. p. p........ 30, 31

- Wint. . . . . . . . 32

Dianthi Niessl. . . . . . . . 47

Ervi (Wallr.) Plowr. . . . . 21, 뽀

- Erythronii (DC.) Pass. . . . . . . . H

- Autt. p. p. . . . . . . . 15

- (Wint.) De T'oni p. p. . . . . 14, 45

Euphorbiae-Astragali Jordi . . . . . : 39 Euphorbiae-corniculati Jordi . . . . 39!

- Fabae (Yers.) De Bary . . . . . 20, 2ע

lestucat sydow. . . . . . . . 32 
Uromyces Ficariae (Schum.) Lév. . . . . 51

- Lév. . . . . . . . . . . . is

- Fischeri Eduardi Magnus . . . . . . . 37

- Gageae Beck.

- Genistae tinctoriae (Pers.) Wint. . . . 49

- - - Wint. p. p. . . . . 48, 4 - (Wint) De Toni et alii p. p. . . 48

- Geranii (DC) Otth. et Wartm. . . . 2fi

- Beck. . . . . . . . . . 27

- (Wint.) Sacc. . . . . . . . . . 27

- graminis (Niessl.) Dietel. . . . . . . . 34

- Hedysari Fuckel. . . . . . . . . . 42

- Hedysari obscuri (DC.) Carest et Piec, 42

_ - - Wint. . . . . . . . 49 49

- inaeyuialtus Lasch , . . . . . . . . . . . .

- Jordianus Bubák. . . . . . . . . . . 40

- Magnus nec lBubák . . . . . . . . 37

- Kabatianus Bubák ....... 27 Kalmusii Sace. . . . . 5t, 55

- Lilii Fuekel. . . . . . . . . 45

-

- Limunii (DC) Lév. . . . . . . . . . 25

- lineolatus. (Desm.) Wint . . . . . . 33

- lupinicolus Bubák . . . . . . . 48

- Medicaginis falcatae (DC) Wint. 38, 39, 55

- minor Schroet. . . . . . . 43

- Onobrychidis (Desm) Lév. . . . . 48

- Onobrychii Desm. ........ 48

- Ononidis Passer........ 45, 215

- Ornithogali Lév. . . . . . . . . 52

- - Wint. Schroet. ete. non Lév. . . . . n1
Uromyces Orobi Wint. . . . . . . . 20

- - (Pers.) Hlowr. . . . . . . . 21

- Phaseoli (Pers.) Wint. . . . . . . . 22

- Phyteumatum (DC.) Unger ...... . 53

- Pisi Autt. p. p. . . . . . . . . . 37

- - (Pers.) De Bary . . . . . 21, 35, 55

- Poae Rabh. . . . . . . . . . . . . 31

- Polygoni (Pers.) Fuckel . . . . . . 23

- Primulae Sebroet p. p. . . . . . . . 54

- Primulae integrifoliae Wint. p. p. . . . 54

- Primulae minimae E. Fischer . . . . 54

- Ranunculi-Festucae Jaap. . . . . . . . 32

- Rumicis (Schum.) Wint. . . . . . . . 34

- Seirpi (Cast.) Lagerh. . . . . . . . 33, 34

- Scillarum (Grew.) Wint. . . . . . . . 53

- Scrophulariar (DC.) Wint . . . 41, 42

- scutellatus. (Schrank.) Lév . . . . \$4, 55

- Silenes (Schlecht) Fuckel . . . . . . 22

- Solidaginis (Sommf.) Niessl. . . . . . . 53

- striatus Schroet. . . . . . . . . 35

- Thapsi (Opiz.) Bubák . . . . . . . . 42 Trifolii Autt. p. p. . . . . . . . . . . .

- - (Hedw.) Lév. . . . . . . . . 46, 48

- - Wint. p. p. . . . . . . . . 43

- Trifolii repeutis (Cast.) Lindr. ... . . 25

- Valerianae (Schum.) Fuckel . . . . . . 25

- Veratri 1C. . . . . . 35, 52, 216

- Verbasci Nie.sl. . . . . . . . . $4 \%$

- Viciae craccae Const. . . . . . . 36, 39

Xenodochus carbonarius Schlecht. . . . 169 


\section{Verzeichniss der wichtigeren Literatur.}

Saccardo P. A.: Sylloge fungorum Padua 188:-1906. Bd. I.-XVIII. (Uredineen in VII., IX., XI., XIV., XVI. und XVIII. Band.)

Sydow P. und II.: Monographia Uredinearum. Berlin 1904. Bd. I. Genus Puccinia.

Fischer E.: Uredineen der Schweiz. Bern 1904.

Liro I. J.: Uredineae fennicae. Helsingfors 1908.

Winter $G$.: Die Pilze. Leipzig 188t. (Die Uredineen in I. Abt. Ihre Bearbeitung veraltet.)

Schroeter J.: Die Pilze von Schlesien. Breslau 1889. (Die Uredineenim III. B., 1. Hälfte; ebenfalls veraltet.

Jacky E.: Die Kompositenbewobnenden Puccinien vom Typus der Puccinia Hieracii. Zeitschr. f. Pflanzenkrankheiten, Bd. IX, Stuttgart 1 r99.

Lindroth (Liro) I. J.: Die Umbelliferen-Uredineen. Helsingfors 1902.

Plowright Ch. S.: A monograph of the british Uredineae and Ustilagineae. London 1889.

Klebahn H.: Die wirtswechselnden Rostpilze. Berlin 1904.

Eriksson J.: Die Getreideroste. Stockholm 1896.

\section{Neine Publikationen üher die Rostpilze Böhmens.}

1. Fin Beitrag zur Kenntnis der böhmischen Peronosporeen, Ustilagineen und Uredineen. Verhandlungen d. zool. bot. Gesellschaft in Wien 1×97.)

2. Zweiter Beitrag zur Pilzflora von Böhmen und Nordmähren. (Daselbst 1898.)

3. Über die Uredineen, welche in Europa auf Crepis-Arten vorkommen. (Verhandlungen d. naturforsch. Vereines, Brünn 18.48.)

4. Caeoma Fumariae Link im genetischen Zusammenhange mit eine $i$ Nelampsora auf Populus tremula. (Zeitschrift f. Pflanzenkranheiten, Stuttgart 1899.)

5. 0 rezich, které cizopasí na nẻkterých Rubiaceich. (Sitzungsberichte d. königl. böbm. Gesell. d. Wiss., Prag 1s98.)

6. Resultate der mykologisehen Durchforschung Böhmens im J. 1898. (Daselbst 1898.)

7. Ueber einige Umbelliferen berwohnende Puccinien. (Daselbst 1900.)

8. Ueber die Puccinien vom Typus der Puccinia Anemones virginianae. (Daselbst 1901.)

9. Ueber einige Compositen bewohnenden Puccinien. (Oesterr. botan. Zeitschr., Wien, 1902.)

10. Einige neue oder kritische Uromyces-Arten. (Sitzungsberichte d. kōnigl. böhm. Gesell. d. Wiss. Prag 1902.)

1i. Bemerkungen über einige Puccinien. (Hedwigia, Bd. XLII, Dresden 1903.)

12. Beitrag zur Kentnis einiger Uredineen. (Annales mycologici, Vol. III., Berlin, 1905.)

13. Neue oder kritische Pilze. (Daselbst, Vol. VI., 1906.)

14. Infektionsversuche mit einigen Uredineen. I. Bericht. (Centralblatt f. Bakteriol. und Parasitenkunde II. Abt, Bd. IX, Jena 1902.)

15. Dasselbe. II. Bericht. (Bd XII, Jena 1904.)

16. Dasselbe. III. Bericht. (Bd. XVI., Jena 1906.)

17. Dasselbe. IV. Bericht. (Bd. XVIII., Jena 1908.) 
ARCHIV DER NATURWISSENSCHAFTLICHEN LANDES-

DURCHFORSCHUNG VON BÖHMEN.

XV. Band. Nr. 3.

\title{
DIE PILZE BÖHMENS.
}

\author{
II. TEIL. \\ BRANDPILZE (HEMIBASIDII).
}

MIT 24 TEXTFIGUREN.

BEARBEITET VON

PH. DR. FRANZ BUBÁK,

ORD. PROFESSOR DER BOTANIK UND DER PFLANZENKRANKHEITEN

AN DER KONNIGL. LANDWIRTSCHAFTLICHEN

AKADEMIE IN TABOR.

PRAG 1916.

KOMMISSIONSVERLAG VON FR. R̈IVNÁČ. - BUCHDRUCKEREI DR. ED. GREGR A SYN. 


\section{VORWORT.}

Der vorliegende zweite Teil der Pilzflora von B̈̈hmen enthält die Brandpilze (Hemibasidii), eine in landwirtschaftlicher Hinsicht sehr wichtige Pilzgruppe, denn viele hierher gehörigen Pilze, wie z. B. diejenigen aus den (iattungen L'stilago und Tilletiu sind gefïhrliche Parasiten der Kulturpflanzen und verursachen jedes Jahr eineu enormen, in Millionen reichenden Schaden.

Der grösste Teil der Brandpilze gehört aber zu seltenen Pilzen, manche sogar zu den seltensten. Ausserdem kommen sie oft nur in sehr geringen Mengen vor oder sind so versteckt, dass man sie sehr leicht iibersieht. Deshalb nahm ich auch solche Arten auf, welche zwar in Bühmen bisher nicht aufgefunden wurden, doch gewiss später noch entdeckt werden können.

Seit der Ausgahe des böhmischen Textes der Hemibasidien (1912) wurden von mir folgende Arten in Bühmen gefunden: Ustilago dura, Ustilago Vaillantii, Thecaphora deformans, Tilletia levis, Tilletia aculeata. Von E. Bau dy š: Ustilago ('ardni, Tilletia Airae (aespitosae, Melanotaenium Ari, Melanotaenium ringens, Fntyloma veronicicola. Von Čelakovský fil.: C'intractia subinclusa. Von Kavin a: Tilletia sphamni. Die Gesammtzahl der aus Böhmen hekaunten Hemibasidien beträgt jetzt also 93 Arten. Im ganzen sind hier aber 161 Spezies beschrieben.

Die Abbildungen sind durchwegs (Originale, welehe nach den böhmischen Exemplaren meines Herbariums von meinen Assistenten verfertigt wurden.

Tábor, Ende April 1916. 



\section{HEMIBASIDII.}

Parasitische Pilze, welche verschiedene Pflanzenteile der Phanerogamen befallen.*)

Das Myzel sehr zart, nur 2-5 $\mu$ breit, septiert, mehr oder weniger verzweigt, farblos, interzellular, seltener intrazellular (L'stilago hypodytes, U. echinata u. A.), gewöhnlich mit lappigen oder traubenartigen Haustorien, vermittelst welcher sie die Nahrung der Wirtspplanze entnehmen.

Die Sporen bilden sich aus dicht verflochtenen oder parallel, wie auch senkrecht zum Substrate orientierten Hyphen. Bei den meisten Arten quellen die Hyphenmembranen gallertartig auf, der innere plasmatische Inhalt zerfällt in kleine Portionen, die sich allmählich vergrisserm und endlich aussen eine feste Membran ausbilden. Zugleich wird die gallertartige Hülle immer dinner, bis sie bei der Sporenreife gänzlich verschwindet. Fewöhnlich wird das ganze Myzel zur Sporenbildung verbraucht, so dass sich dann auf solehen Stellen, wo die Sporifikation stattfindet, nur die Sporen befinden. Die Sporenmembran ist doppelt: die innere dinne, hyaline, die äussere dickere, mehr oder weniger verfärbte, glatte, warzige, stachlige oder netzförmige. Bei der (rattung Entyloma entstehen die Sporen interkalar, so dass sich immer zwischen zwei Sporen ein kurzer, steriler Hyphenstiick befindet. Bei der (rattung Tilletia bilden sich die Sporen an den Hyphenenden oder auch interkalar. Reife Sporen verhalten sich verschiedenartig: entweder sind sie einzeln frei oder zu zwei bis mehreren in Knäuel verbunden und in beiden Fïillen verstäuben sie oder aber bleiben sie im Nïhrgewehe cingeschlowsen olne zu verstäuben. In den Knäueln sind die Sporen entweder alle keimfähing oder - wie bei Urocystis - sind sie oben von nicht keimfïhigen sporen (Nebensporen) umhiillt. Eigentimlieh ausgebildet sind die Knäutel hei der Gattung Doassansia, wo die Nebenzellen in eine feste, kontinuierlich.. Hiille au den Hauptsporen verwachsen sind, wie anch hei der (iattung

*) Die Zugehörigkeit jener Pilze, welche die Mooskapseln belallen (wie z. B. Tilletia Sphagni Nawaschin), zu den Brandpilzen ist immer noch sehr fraglich. 
I oassansiopsis, wo umgekehrt die Hauptsporen einen Mantel an der Oberfläche der Knaiuel hilden, die Nebensporen im Innern sich befinden und die Kuinel au der Oberfläche von einem dickeren Hyphengeflechte bedeckt sind. Bei der Gattung Tracya sind die inneren sterilen Sporen durch ein lockeres Hyphennetz ersetzt. Die Sporen der Hemibasidien sind ('hlam y dosporen, aus welchen sich erst bei der Keimung auf cinem Promyzel die eigentlichen Sporen - Sporidien bilden.

Die Keimung geht vor sich entweder in feuchter Erde, im Wrasser oder in kiustlichen Nährflissigkeiten. Sporen mancher Brandvilze keimen sehr schwierig und dann hilft man sich, dass man in das zur Keimung dargehotenes Wasser Extrakt der Wirtspflanze zugiebt, auf welcher der Pilz parasitiert. I)ie Brandsporen besitzen keine Keimsporen und deshalb muss das auswachsende Promycelium die Sporenmembran irgendwo durchbrechen. Das Promyzel ist von zweierlei Art: 1. Bei der (iruppe der Ustilagineen ist es 1-5zellig und bildet im TVasser nur eine sehr kurze Zeit, im kiinstlichen Nährboden ziemlich lange die sporidien. l)ieselhen entstehen am Scheitel und an den ( sung zu vermehren. Die Promyzelien, wie auch die Sporidien können sich manchmal zu zwei brickenweise verbinden.

2. Bei der Gruppe der Tilletiineen ist das Promyzel einzellig und bildet die Sporidien nur am Scheitel, gewöhnlich 4-12, nur bei der Gattung Neovossia 30-50, ja noch mehr, immer quirlig. Auf feuchtem Substrate oder in Fliissigkeiten, keint die Sporidie in ein Myzel aus, auf welchem sich dann sekundäre Sporidien ausbilden, die mehr oder weniger sichelartig gebogen sind. Bei Neorossia sind sie entweder sichelartig oder auch fadenförmig. Dit Sporidien kïnnen sich auch hier zu zwei brickenweine verbiuden. Bei einigen Gattungen z. B. Entyloma, Tuburcinia bilden sich aus dem parasitierenden Myzel auch Konidien, welche auf den Blättern kleine oder ausgedehntè Anflïge hervorbringen.

Die Infektion kann bei den Hemibasidien auf dreierlei Weise geschehen:

1. Das Keimptlinz hen wird infiziert und dann wächst das Myzel his in die Gewebe, wo es sporifizieren soll (Aehren, Bliiten) und ältere Iyzelpartien werden gewöhnlich resorbiert. Manchmal bleiben aber auch in den infizierten (ietreidehalmen, in den unteren Teilen hier und da, hesonders in deu Knoten Ifrzelreste erhalten, bilden aber daselbst keine Sporen (Ustilago Avenae, U. Hordei, Tilletia Tritici).

2. Es wird nur ein bestimmtes Organ der Nährpflanze infiziert und dort hilden sich auch die Sporen aus, wie bei Tstilago Zeae Mays, wo die Wurzeln, der Halm, die Blitter, die weiblichen und männlichen Bliiten infiziert werden kïnnen - aber nur solange sie noch jugendlich sind.

3. Es wird die Samenanlage infiziert und dann bildet sich der Brandpilz erst in der nächsten Vegetationsperiode, bei der Keimung des 


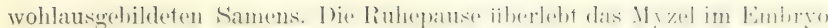
mol in der wathenden l'llanze drinet es bis dorthin, wo es - yorilizieren soll (Ustilago Tritici, U. nuda).

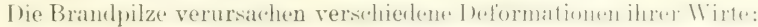

Die Nährpflanze verkriippelt oder seine Achsen schwellen an

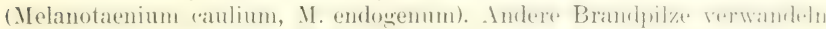
wieder einzelne oder alle Bliiten in 'T'uberkeln oder es bilden sich ant

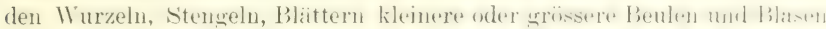
oft werden ganze Intloreszenzen heulenartig. Il ieder andere limandpilze

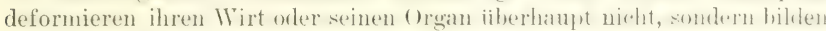
nur z. B. in den Blittern und Stengeh sehmale, stauhige stroilen (T'illetia

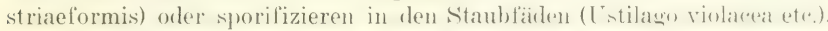

Der Scharlen, welchen manche Brandpilze verursachen, heosmeler die Getreidebrambilze, ist oft sehr gross. So kimn z. B. Tilletia 'Tritioi $50-75^{0 \prime}$ aller dehren vernichten. Wir haben in .J. 1911 hed Babive nurl Lesná nïchst Pacov in Böhmen Tilletia Seralis entdeckt, wo sic .j1" " ler Kornähren in weiter Umgegend vernichtete.

Die Hemibasidien teilt man nach der Form der Promyzelien in zwei Gruppen:

\section{Ustilagineae. 2. Tilletiineae.}

\section{Ustilagineae.}

Die Sporen keimen in ein quergeteiltes, 1-5 zelliges Promyzel ans, und die sporidien entstehen am scheitel wnd an den (2uerwinden; orler die Promyzelzellen wachsen zu Färden atus, die auch eine lutektion hervorrufen können.

A. Sporen einzeln.

(1) Promyzelium 1-5 zellig; Simoridien am Soheitel und an den (2nerwänden gebildet.

1. Hülle der Sporenlager nur aus dem Gewehe der Nührpflanze gebildet; Kolumella fehlt . . 1. Ustilago.

2. Hiille auch aus sterilen Hyphen des Piizes gebildet; Kolumella echt oder unecht

2. Sphacelotheca.

b) Promyzel 2 zellig; beide Zellen bilden am Eude eines Sterigmas die Sporidien.

3. Cintractia.

c) Promyzel 1 zellig, in der Spore ganz eingesenkt; die Sporidien bilden sich an seinem Scheitel. . 4. Elateromyces.

$B$. Sporen zu zwei verbunden

5. Schizonella.

C. Sporen mehr als zwei knäuelartig verbunden.

a) Promyzel mit scheitel- und seitenstiundigen Sporidien. 
1. Sporenknäuel mehr oder weniger locker gefügt, unreif mit gallertartiger Hülle

6. Sorosporium.

2. Sporenknïuel fest, ohne Hiille.

7. Tolyposporium.

b) Promyzel 1 zellig, mit einer einzigen Scheitelsporidie.

\section{Thecaphora.}

\section{Gatt. Ustilago Persoon.}

Sporen einzeln oder manchmal verklebt, staubig, aus ganzem, stark gallertartig gequollenem Myzel enstehend. Sporenmembran glatt, warzig, stachlig oder netzförmig. Promyzel $1-5$ zellig, am Scheitel und an den Querwänden Sporidien bildend oder nur in Infektionsfäden auswachsend. Sporidien oft sprossend.

Eine sehr reiche Gattung, derer Arten verschiedene Organe der Pflanzen angreifen: Wurzeln, Stengel, Blätter, Infloreszenzen, Samen, Samenanlagen, Staubfäden, dieselben verschiedenartig deformieren, kleinere oder grössere Tuberkeln auf ihnen hervorrufen oder aber die Nährpflanze und ihre Organe unverändert lassen.

Die Sporen verstäuben nach der Reife.

\section{A. Sporen glatt.}

a) Sporenmasseschwarzbraun is schwarz.

a) In Infloreszenzen oder Blüten.

\section{Ustilago Digitariae (Kunze) Rabenhorst - Uredo Digitariae Kunze.}

Sporenmasse in den Aehrehen oder ganzen Rispen, dieselben in lange, walzenförmige Gebilde umwandelnd, anfags mit einer granen Hülle, später nackt, dunkelolivenbraun, staubig; Sporen kuglig oder kurz eiförmig, oft eckig, 55-9.5 $\mu$ breit, mit hellolivenbrauner, glatter Membran.

Von Juli auf Panicum glabrum und Panicum sanguinale in Italien uud Deutschland. Vielleicht auch in Böhmen. Von Ustilago Rabenhorstiana durch kleinere, glatte Sporen verschieden.

\section{Ustilago Crameri Körnicke.}

Sporenmasse in Fruchtknoten, die in kleine Tuberkeln verwandelt werden, ziemlich lange bedeckt, dann nackt, stäubend, schwarzbraun; Sporen verschieden geformt, gewöhnlich mehr oder weniger eckig, kuglig, 7\%-115 " im Durchmesser, oder eiförmig bis länglich, bis $14 \mu$ lang, hellkastanienbraun, glatt, mit wabenförmigem, oelartigem Inhalte.

In den Fruchtknoten von Setaria-Arten von Juli bis Oktober: Setaria germanica: Im botanischen Garten zu Tábor! Setaria italica var. breviseta und var. longiseta: Daselbst!

Die Hiillspelzen sind eng mit dem brandigen Fruchtknoten verwachsen. 
2. Ustilago levis (Kellerman et Swingle) Magnus. - L vilunn Armu var. levis Kellerman et Swingle.

Sporenmasse in den Aehrohen, die Bliiten last gainzlich vernirhtemul, anf den Hiillspelzen nur in der Basis und etwas höher entwickelt, kieine,

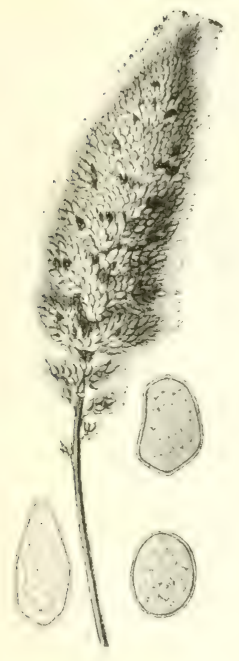

Abb. 1. Ustilago Crameri auf Setaria italiea. Habitusbild und isolierte Sporen. (Original.)

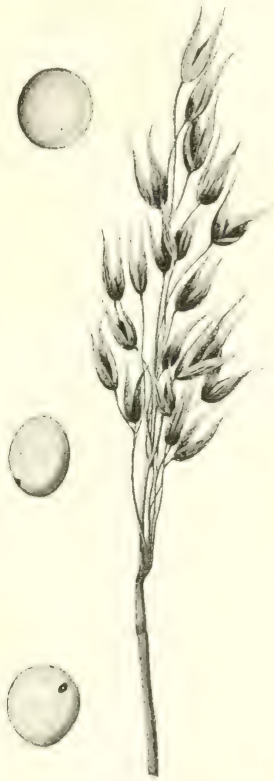

Abb. 2. Ustilago levis. Habitusbild des Pilzes im Hafer und isolierte Sporen. (Original.)
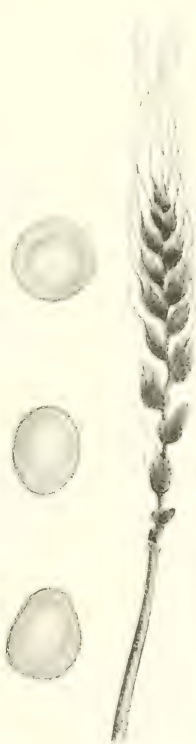

Abb. 3. Ustilago Hordei. Habitusbild des Pilzes auf Hordeum distichum und isolierte Sporen. (Original.)

harte Tuberkel bildend, wenig staulig, Sporen kuglig, 5-95 " im l)urhmesser oder eiförmig, his 11 "lang, Membran dunkelolirenbrann, whtt.

In den Haferährchen (Avena sativa) von Juli bis September zwar verbreitet, doch seltener als Ustilago Avenae.

Ustilago levis sehört zu den Hartbrandarten. Die sporen verunreinigen die Körner erst beim I)reschen. I)ie Keimung unl Entwicklung 
sind dieselben wie bei Ustilago Avenae und I'stilago Hordei. Sie zerstört alle Aehrehen der infizierten Pflanze.

Von Estilago Avenae unterseheidet sie sich auch dadurch, dass die Hiillipelzen teilweise erhalten bleiben; oft anch die Deck- und Torspelze.

3. Ustilago Hordei (Persoon) Kellerman et Swingle.

Uredo segetum a) Hordei Persoon. - Ustilago Hordei Kellerm. et Sw. Ustilago Jenseni Rostrup.

Sporenmanse in den Aehrehen, ein festes, hartes, an der Oberfläche höckeriges Korn bildend, schwarz, von den spelzenresten bederkt. Sporen kuglig, 5-9 ", im Durchmesser, orler eiförmig, ellipsoidisch, bis 11 "l lang, dunkelkastanienbraun, glatt.

Im Juni und Juli in den Gerstenähren (Hordeum distichum) verbreitet.

Sie zerstört alle Bliten der infizierten Pflanzen. Die Sporen zerstäuben nicht, und deshall, gehört sie zn den Hartbrandarten. Erst beim Dreschen werden die Sporen isoliert, verunreinigen die Kö̈ner, mit welchen sie damn auf die Felder kommen. Dort keimen sie in ein $4-5$ zelliges Promyzel aus und an diesem bildeu sich dann die Sporidien, welche in güngstigen Verhïltnissen auch sprossen kömnen. Auf diese Weise vermehrt sich das Infektionsmaterial. Es können nur junge Nährpflänzchen infiziert werden. Dit ganze Entwicklung dieser Brandart verläuft in einer Vegetationsperiode.

\section{Ustilago dura Appel et Gassner. - Ustilago Arrhenatheri Schellenberg.}

Sporenmasse in den Bliiten an der Basis eine kleine, harte Tuberkel verursachend, so dass in jedtem dehrchen 3 Tuherkel entstehen, schwarzbraun, ni rht stan hig; Sporen kuglig, eiförmig, ellipsoidisch, 55-75 " breit mit dunkelolivenbrauner, glatter Membran.

In den Rispen von Arrhenatherum avenaceum von Mai bis September: Prag (Opiz 1852)! Podbaba (derselbe)! Troja (Bozdèch)! Weisser Berg (Baulyš)! Karlstein (I)omin)! Kornhaus bei Schlan! Liebshausen und Saidschitz bei Bilin! Anssig (Thiimen)! Tetsehen (Wagner); Zinkenstein!

Eine Hartbrandart, die mit Ustilago peremans friher vermengt wurde. Sie stimht nicht, so dass die Spelzen glänzend weiss bleiben. Sie befiallt hauptsiichlich die Basis der Bliiten, und die Deckspelzen umhiillen die kleinen Tuberkeln. Die Aehrehenachse bleibt pilzfrei. Die Sporen sind glatt mol bilden hei der Keimung am Promyzel keine Sporidien, sondern nur Seitenzweige. Myzel perenniert in dem Rhizom. 
B) In den Stengeln und Blättern.

\section{Ustilago grandis Fries.}

Sporenmasse in den Internodien oder in Blittern in schmalen, langen Streifen, auf den Halmen zu langen, schwarzen, periphericehen, schwach aufgedunsenen, von der Épidermis bedeckten I'eberziigen zusammenfliessend; Sporen staubig, kuglig orler eiförmig, oft eckig, 75-1.2 ". breit, mit dunkelolivenbrauner, glatter Membran.
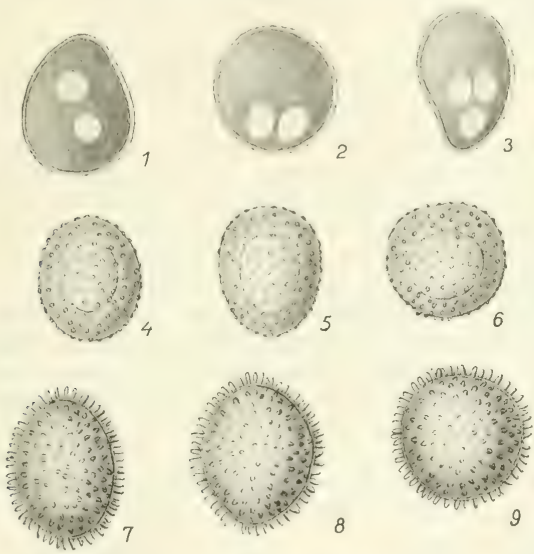

Abb. 4. 1-3 Sporen von Ustilago hypodytes aus den Blättern von Triticum repens; $4 \rightarrow 6$ Sporen von Ustilugo Zeae Mays; 7-9 Sporen von Ustilago echinata aus den Blättern von Phalaris arundinacea. (Original.)

Von August bis in die Wintermonate auf Phragmites communis: Kačina (Peyl; siehe Veselský, Oesterr, botan. Z. 1859, pg. 387 sub nom. "Ustilago hypodytes"). Belegexemplare fand ich weder in P e y's Herbar, noch in den Sammlungen des böhm. Museums in Prag.

Dieser Brandpilz ergreift inmer einige Internodien, welele verdicken, auf den Knoten eingesehniirrt sind, so dass sie an Typha-Infloreszenzen erinnern.

6. Ustilago hypodytes (Sehlechtendal) Fries. - (Caeoma huppodytes Schlechtendal.)

Sporenmasse an der Oberfläche der Interuodien ohne hesondere Hiille, teilweise oder manchmal ganz in den Blattscheiden verhorgen, 
schwarzbraun bis schwarz, stark stäubend; Sporen kuglig bis eiförmig, hier und da eckig, $4-6 \mu$, seltener bis $7 "$ breit, mit dunkelolivenbrauner, glatter Membran.

Vou Jumi bis zum Winter auf den Halmen verschiedener Gräser; hei uns auf Agropyrum repens: Sct. Prokopius u. Záběhlice bei Prag (Baudyš)! Welwarn (Kabát)! Kačina bei Kuttenberg (Peyl)! Pürglitz (Domin)! Lány, Rinholetz bei Neu-Straschitz (Baudyš); Lenešic (Houska)! Steinteinitz bei Laun! Ziegelschänke bei Trebnitz! Stipa capillata: Sct. Prokopius und Slivenec bei Prag (Baudyš); Kuchelbad bei Prag! Karlstein (Domin)! Kožover Berg bei Laun!

\section{Ustilago Ornithogali (Schmidt et Kunze) Kiihn. - Uredo Ormithogali Schmidt et Kunze.}

Sporenlager rundlich oder sehmal, bis $1 \mathrm{~cm}$ lang, von grauer Epidermis bedeckt, mit einem Längsrisse berstend; Sporenmasse schwarzbraun, leicht zerstiubend. Sporen gewöhnlich polyedrisch, seltener kuglig oder eiförmig, oft einerseits oder beiderseits gugespitzt, 13-22 $\mu$ lang (seltener bis 25 ı), $11-20 \mu$ breit, mit dunkelkastanienbrauner, glatter Membran.

Im April und Mai in Blättern verschiedener Ornithogalum- und (iagea-Arten; bei uns auf (iagea bohemica: Letná bei Prag (Kalmus, 19. IV. 1653)! Gayea lutea: Kbelnice bei Jičín (Baudyš)! Veltrus (Kabát)! Kgl. Weinberge im Havlíček Anlagen (Baudyš)! Gagea minima: Karlstein! Hradisko bei Sadská! Ciagea pratensis: Radotín bei Prag! Velenka bei Sadská! Rovensko! Tábor!

Ustilago Tulipae (Rabenhorst) 1 inter. - I stilago pompholygodes f) Tulipae Rabenhorst.

Sporenlager verlängert, von grauer Epidermis bedeckt, dann geborsten, schwarz, stäubend. Sporen kuglig oder eiförmig, 15-21 $\mu$ breit, kastanienbraun, mit doppelter Membran: die äussere heller, durch Kalilauge stark aufquellend und mit dunkleren Kanälchen versehen, die innere dunkler, oft ziemlich dick.

In den Blättern von Tulipa silvestris im Mai und Juni. Die Art kiinnte vielleicht auch in Böhmen vorkommen, da die Nährpflanze hier ziemlich verbreitet ist.

Dic Sporen scheinen warzig zu sein; wenn man aber Kalilauge heniitzt, so quillt die äussere Membran stark auf und dann sieht man nur dunklere und hellere Stellen in derselben.

b) Sporenmasse olivenbraun.

8. Ustilago Iongissima (Sowerby) Tulasne. - Uredo longissima Sowerby.

Sporeulager schmal strichförmig, lang, parallel, oft der Länge nach zusammenfliesend, anfangs von der Epidermis bedeckt, später der Länge 
nach gespalten, stäubend. Sporenmasse dunkelolivenbraun. Sinren kuglig oder eiförmig, $4-75$ " breit, mit dimner, hellolivenbritunlicher, glatter Membran.

Von Mai bis zum Winter in Blittern und Blattscheiden, seltener in Bliten von Cilyceria aquatica: Allgemein verbreitet. (ilyceria fluitun: Ebenfalls. Glyceria nemoralis: Asch (Thümen)! Glyceria plicata: Koda bei Tetín! Květná bei Příbram! Kornhaus bei Schlan! Dollanken im Bielatale!

Der Pilz bildet in den Blättern und Blattscheiden lange, olivenbraune Streifen. Das Myzel perenniert im Rhizom und jedes Jahr dringt es in alle neue Triebe ein, die verkriippeln und keine Rispen ausbilden.

\section{$B$. Sporen warzig.}

a) Sporenmasse schwarzbraun oder sehwarz.

\section{Ustilago perennans Rostrup.}

Sporenmasse in den Bliiten, Ahrchenachsen, Hüll- und Deckspelzen, schwarzbraun, zuerst bedeckt, dann frei, stäubend. Sporen kuglig, eiförmig, seltener ellipsoidisch, 55-7.5 $\mu$ breit, mit dunkelolivenbrauner, feinwarziger Membran.

In den Rispen von Arrhenatherum avenaceum bei Kbelnice nächst Jičín (Baudyš)! Welwarn (Kabát)! Mariaschein (Wiesbaur)! und gewiss noch anderwärts.

Von Ustilago dura unterscheidet sich diese Staubbrandart hauptsächlich durch feinwarzige Sporen und das Promyzel, welches Sporidien bildet. Das Myzel uberwintert auch bei dieser Spezies.

10. Ustilago bromivora (Tulasne) Fischer de Waldheim. Lredo ('arbo a) vulgaris d) bromivora T'ulasne.

Sporenmasse in den Fruchtknoten, kleine, kug-

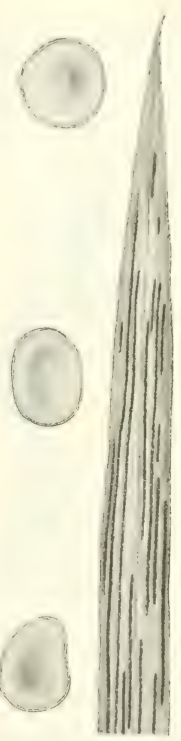

Abb. 5. Blattstiick von Glyceria aquatica mit L stilago longissima und isolierte Sp ren. (Original.) lige oder eiförmige, von der Epidermis umhüllte Körperchen bildend, später nackt, schwarz, stäubend; Sporen kuglig, $75-11 \%$ " breit oder eiförmig, bis $135 \%$ lang, oft eekig, mit dunkelolivenhanumer, glatter oder feinwarziger Membran.

In Ahrchen verschiedener Bromu-Arten vou Mai his Sejtember: Bromus mollis: Tábor! Bromus secalinus: Kaưina hei Kuttenberg (Peyl)! 


\section{Ustilago Vaillantii Tulasne.}

Sporenmasse in deu Bliiten eingeschlossen, in den Staubfäden und den Fruchknoten entstehend, olivenschwarzbraun; Sporen kuglig, $75-10 u$ breit, oder eiförmig, ellipsoidisch bis länglich, manchmal einerseits oder beiderstits verjügt, bis $15 \mu$ lang,

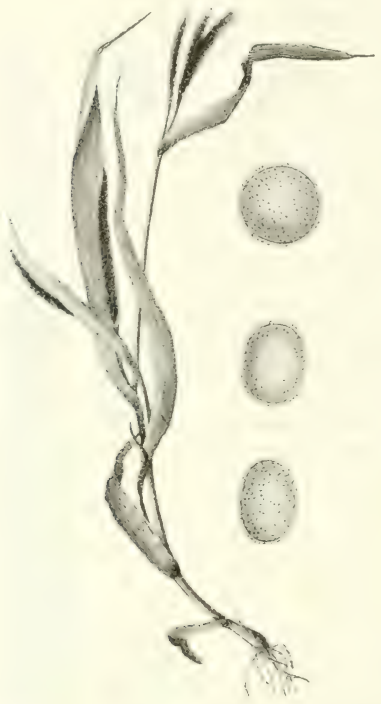

Abb. 6. Ustilago Rabenhorstiana. Eine vom Pilze befallene Pflanze und isolierte Sporen. (Original.) mit kastanienbrauner, sehr feinwarziger Membran.

Im Mai und Juni in Bliiten verschiedener Muscari-Arten.

Muscari alpinum: Tábor, im botanischen Garten, eingeschleppt!

Die befallenen Bliiten verkiimmern und nehmen eine kuglige oder ellipsoide Form an. gelb.

b) Sporenmasse ocker-

Ustilago Thlaspeos (Beck) Lagerheim. Tilletia Thlaspeos Beck.

Sporenmasse in den Schötchen, in den Samen entstanden; ockergelb; Sporen kuglig oder eiförmig, 13-17 $\mu$ breit, mit ockergelber, deutlich warziger Membran.

In Schötchen von Thlaspi alpestre, Arabis hirsuta, A. petraea von Juni bis August in Schweden, Nieder Oesterreich und Tirol. Könnte auch bei uns gefunden werden.

\section{Sporen feinstachlig.}

(a) Sporenmasse schwarzbraun bis schwarz.

\section{Ustilago Rabenhorstiana Kiihn.}

Sporenmasse schwarzbraun, in den Rispen entwickelt. Sporen kuglig, 10 15 "n breit oder eiförmig bis ellipsoidisch, oft polyedrisch, 11-17 " lang. 9 $9-15$ " breit, mit dunkelkastanienbrauner, feinstachliger Membran.

Ton Juli zum Winter auf Panicum glabrum: Auf den Sandfluren zwischen Hradisko und Př́vilaky bei Sadská! Panicum sanguinale (sativum): Kačina (Peyl)! 
1)ie inlizierten Rispen sind anfangs in den Soheiden der obersten

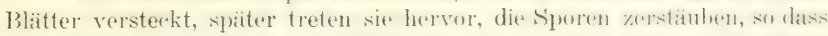

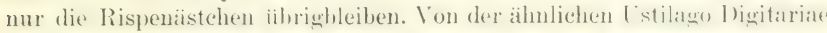
ist die vorliegende Art durch stachlige Sporen verschieden.

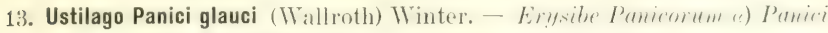
miliacei 1 Vallroth. - Ustilago neglecta Niessl.

Sporenmasse in den Fruchtknoten, anlangs eingeschlosien, spriater stäbend, schwarzhraun; Sporen oft polyedrisch und zwar kuglig, 9-1:3 !" breit orer eifömig his ellipsoidisch, 11-15 " lang, 85-11 " hreit, mit dunkelkastanienbrauner, feinstachliger Membran.

In August und september in allen Fruchtknoten einer und derselben Rispe.

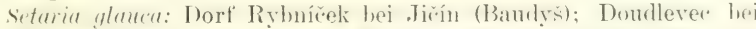
I'ilsen (Hora); Karbitz bei 'Teplitz (Thimen, Fungi austriace 340, nath Angabe des Sammlers auf Sotaria verticillata, sicher aber aut Setaria glauca)! Habstein (Čelakovský fil.)!

Die befallenen Bliitenstande weichen von den gesunden dur.h graue Farbe und hetriahtlichere Dicke ah. Ille Rispen der hefallenen Ptlanzen sind brandig.

14. Ustilago Avenae (Persomil) Jensen. Credo segetum ;) Areme Persoon. Ustilago Avenae. Jensen.

sporenmasse in den Shrchen, antings von den ebentialls infizierten Hiill- mol Deckspelzen hedeckt, spaiter staubend, schwarzbram; Sporen kuglig, 5\%-75 " hreit oder eifurmin, his 95 u lang, mit dunkelolivenbrauner, feinstachliger Membran.

In den Ahrchen verschiedener Avena-Arten von Mitte Juni bis zum September.

Avena sativa: Ueberall gemein! Avena strigosa: Im botanischen Garten zu Tábor!

Eine Staubbrandart, bei welcher sich die Sporen schon am Felde verstiuben, auf den Boden oder auf die Bliten fallen oder mit gesunden Chren geerntet werden, so dass die Kïrner erst heim Ireschen von ihmen verunreinigt werden. Im Boden keimen sie mit einem 4-5 zelligem I'romyzel, welches sporidien bildet. Die sporidien vermägen zu sprosin. Dit Infektion lindet auf dieselbe Weise wit bei I'stilago Hordei statt.

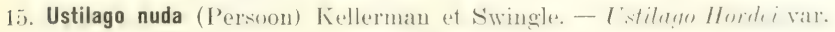
muda Pers.

Sporemmasse in den Throhen, alles bis auf die ciefiasshimdel und die Epidermis der Hiilteile vernichtend, hakl nackt, stiuhrud, schmar\%- 
braun; Sporen kuglig, 55-75 u breit oder eiförmig, ellipsoidisch, bis 95 " lang, mit kastanienbrauner, feimstachliger Membran.

Im Juni und anfangs Juli in Gerstenähren, besonders auf Hordeum distichum gemein.

Eine Stauhbrandart bei welcher die Entwicklung und Infektion wie bei Ustilago Tritici vor sich geht.

16. Ustilago Tritici (Persoon) Jensen. - Tredo segetum 3 Tritici Persoon. Ustilago Carbo Aut. p. p.

Sporemmasse in den Ihrchen, anfangs ron den Hiilteilen bedeckt, dann nackt, stäubeud, kuglig, $55-7 \% 5$ " breit oder eiförmig, oft auch einerseits abgeflacht, $55-950$ lang, $45-65$, breit, mit schwarzbrauner, sehr fein und locker, manchmal nur stellenweise stachliger Membran.

In den Ahren verschiedener Triticum-Sorten im Juli gemein; selten in den Blättern.

Eine Staubbrandart. Die Sporen zerstituben schon am Felde, so dass nur die Ahrenachse, Reste der Hiillteile und die Borsten übrigbleiben. Die Sporen keimen nur an den Narben. Der Keimschlauch dringt durch den Griffel in das junge Korn und das Mrzel macht mit dem Samen die Ruheperiode im latenten Zustande durch. Erst nach der Keimung des Kornes wächst es gleichzeitig mit dem Halme und dringt in die Ahre, in welcher es gewöhnlich alle Ahrchen vernichtet. Lstilago Tritici braucht also zu seiner vollen Entwickelung zwei Vegetationsperioden.

17. Ustilago Zeae Mays (De ('andolle) Winter. - Tredo segetum var. Zeae Mays De Candolle. - Ustilago Maydis Corda.

Tuberkeln und Beulen auf allen Orgauen der Pflanze, klein oder bis die Grösse des Kindeskopfes erreichend, anfangs saftig, von silbergrauer, aus dem (ierrebe des Wirtes und spärlichen, gallertartigen Hyphen des Pilzes gefügter Memhran bedeckt, später trocken, berstend, schwarzhraun, stark stäuhend: Sporen kuglig, 8-13 " breit, oder ellipsoidisch. bis 15 "l lang, mit sehr dicker, dunkelbrauner, feinstachliger Membran. (Siehe die Abb. Nr. 4, Fig. 4-6).

Ton August bis zum Winter auf Wurzeln, Halmen, Blättern, weiblichen und männlichen Bliten des Maises.

Zea Mays: Kol. Weinberge in Havlícek Anlagen (Baudyš); Künigssaal (Bracht)! Böhmisch Brod! Pečky a. d. Bahn! Martiněves bei Budyně a. Eger ('éskoslor. Hospodář 1890, S. 69). Miinchengrätz (Sekera)! Kačina (Peyl)!

Diese Brandart wird zu uns allïhrlich mit fremden Samen eingeschleppt. Die Infektion weicht von jener der Getreidebrandarten gänzlich ab, da alle Organe des Maises infiziert werden köunen, wenn sie nur jung sind. 
b) Sporenmasse schwarzviolett.

1s. Ustilago marginalis (I)e Candolle) Léveille. - Iredo Bistortarum $\beta$ marginalis De Candolle. - Caeoma marginalis Link.

(Abb. 7.)

Sporenmasse in den Blatträndern, in blasenförmigen Beulchen und Polsterchen, zusammenfliessend und den ganzen Blattrand einnehmend, schwarzviolett; Sporen kuglig, 11-17 $\mu$ breit, oder eiförmig, 13-19 $\mu$ lang, $11-15 \mu$ breit, mit dunkelviolettbrauner, feinstachliger Membran. Im Juli nur im Riesengebirge.

Polygonum Bistorta: Peterbaude, Schlingelbaude, Spindlerbaude (Schröter); Mittagsteine und Prinz Heinrichbaude!

19. Ustilago pustulata (De Candolle) Bubák in Vestergren, Micromycetes rariores selecti Nr. 336 (1901). Uredo Bistortarum a pustulata De Candolle. - Ustilago Bistortarum. Körnicke p. p.

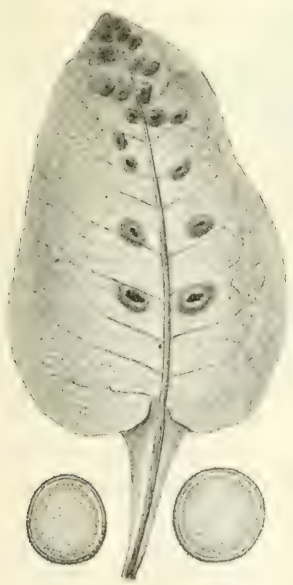

Abb. 8. Ustilago pustulata auf Polygonum bistorta und isolierte Sporen, projektiert. (Original.)

Sporenmasse blattbeiderseits, in halbkugligen, 2-5 mm breiten Blasen, anfangs von rötlicher Epidermis bedeckt, später berstend, schwarzviolett, stäubend; Sporen durchschnittlich grösser als bei vori-

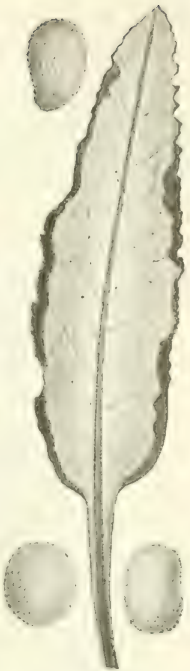

Abb. 7.Ustilagomarginalis auf Blättern von Polygonum Bistorta und isolierte Sporen, trocken gezeicbnet. (Original.) ger Art, mehr kuglig, 13-21 $\mu$ breit, oder eiförmig, 15-23 $\mu$ lang, 15-19 $\iota$ breit, mit dunkelviolettbrauner, feinstachliger Membran.

In niedrigeren Lagen im Mai und Juni, im Gebirge von Juli bis August in Blättern von Polygonum Bistorta: Prinz Heinrichbaude, Mittagsteine, Elbfallbaude im Riesengebirge! Keilberg im Erzgebirge (Wagner); Taschow und Malschen bei Lewin! Herrnskretschen (IVagner).

Diese und die vorige Brandart wurden früher unter dem Namen Ustilago Bistortarum (D) Körnicke zusammengezogen. Beile sind aber voneinander biologisch und morfologisch verschieden. 


\section{Sporen langstachlig.}

20. Ustilago echinata Schroeter. - Istilago remucosa Vestergren.

Sporenmasse in den obersten Blättern und jungen Rispen in schmalen, auf den Blattspreiten und Blattscheiden einige $\mathrm{cm}$ langen, parallelen, bald lïngs geborstemen, stäubenden Streifen, schwarzbraun; Sporen kuglig, 15-19 " breit, oder eiförmig his länglich, 19-26 " lang, 13-17 " breit, mit dunkelkastanienhrauner, von 2 " hohen, konischen, dichtstehenden Stacheln besetzter Membran. (Siehe Abb. Nr. 4, Fig. 7-9.)

Ton . Juli his September aut Phalaris arundinacea: Brandeis a $\mathrm{E}$. (Opiz 1 355)! Elhufer ron Tetsehen bis zu Leitmeritz (Tagner).

\section{E. Sporen mit netzartigen Leisten.}

a) Sporenmasse gelb.

Ustilago Vuyckii Oudemans et Beijerinck.

Sporenmasise in deu Fruchtkapseln, aus deu Samenanlagen entstanden, nach Berstumg der Kapseln staiuhend, gelb; Sporen kuglig, 15-22 " breit, mit - je nach dem Reifestadium - hyaliner, gelber oder hellgelbbramer, von 15-2 " hohen, netzartig verbundenen Leisten besetzter Membran. Maschen eckig, 2-2\% $\mu$ breit.

In den Fruchtkapseln von Luzula iernalis und $L$. campestris von Juni bis August.

Tielleicht wird auch diese Brandart später in Böhmen gefunden. Sie ist besonders durch die gelbe Sporenmasse charakterisiert.

b) Sporenmasse hell- bis dunkelviolett.

\section{Ustilago anomala Kunze.}

(Abb. 9., 4-6.)

Sporenmasse rotviolett, in den Bliiten aus den Staulffiden und den Fruchtknoten gebildet, von den Perigonblättern bedeckt, stark stäubend; Sporen kuglig oder kurz eiförmig, 95-135 " breit, mit rötlichbrauner, von $1-15$ " hohen, netzartig verbundenen Leisten besetzter Membran; Maschen eckig, 15-3 4 breit. (Siehe Abb. 9, Fig. 4-6).

Von Juni bis Oktober in den Bliiten vou Polvgonum-Arten aus der Sektion Tiniaria.

Polygonum (rmcolvulus: źlábek bei Rovensko! Olšinky und Butoves bei Jič́n (Baudy̌s); Písfan bei Leitmeritz! Polygonum dumetorum: Im Tale des Lužnice-Flusses bei Tábor!

2-2. Ustilago utriculosa (Nees) Tulasne. - C'apoma utriculs:um Nees. (Abb. 9., 7-8.)

Siprenmasse in den Fruchthuoten und der Basis ron Staubfäden, in den Bliiten eingeschlossen, violettbraun, später stiubend; Sporen kuglig, 
9-13 $u$ breit, mit violetter, von $155-2 \mu$ hohen, diinnen, netzartig verbundenen Leisten besetzter. Membran; Marchen 5- fieckig uler rundlicheckig, 2-3 и breit. (Siehe Abb. 9, Fig. 7, 8.)

In den Bliiten verschiedener Polygonum-Arten von Juli bis zum

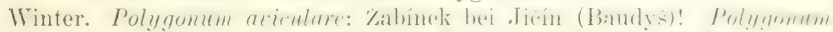

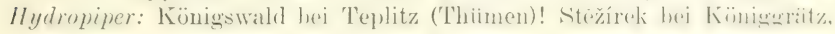
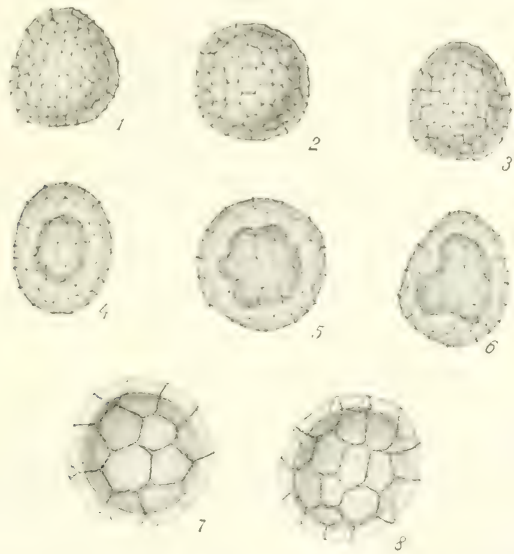

Abb. 9. 1-3 Sporen von Ustilago major von Silene otites; 4-fi Sporen von $I_{\text {sti. }}$ lago anomala von Polygonum dumetorum; 7-s Sporen ron Lstilago utriculosu von Polygonum lapathifolium. (Original.)

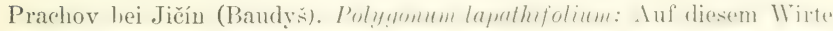
ziemlich verbreitet! Polygumum trum ntestum: T'áhor, im botanisehen (iarten seit 1912 alljährlich.

Ton der ïhnlichen siphuretothea Ilydropiperis durch hellere sporenmasse, hauptsählich aber dureh die netzlörmige sporenmemhan verschieden.

\section{Ustilago Goeppertiana Schroeter.}

Sporenmasse in den Blittstielen, Blattspreiten, seltener in den stengeln und Bliiten, hyalin, hel]- oder dunklerhraun, oft die ganz. Mlattspreite unterhalb der Epidermis fiillend, danermi herleckt und unr dureh entstandene Risse stiubend; sporen kuglig oder eilormig, 1::--21 " hreit. mit hyaliner oder mehr minder violetter, ron 1 " hohen, netzatie verbundenen Leisten besetzter Memhran. Matschen eckig, 1-1\% "hreit. 
Im Juli auf Rumex Acetosa in Deutschland (Schlesien, Hamburg) und Schweden. Vielleicht auch bei uns in Böhmen.

Die Blattspreiteu sind oft unterhalb der Epidermis von einer kontinuirlichen: Sporenmasse gefüllt und daun sind sie verdickt und hellfarbig. Ton der folgenden Art unterscheidet sie sich durch hellere Sporen.

\section{Ustilago Kuehneana Wolf.}

Sporeumasse in den Bliten, dunkelviolett, von einer aus dem Gerrebe der. Nïhrpflanze und des Pilzes gebildeter Membran umgeben; Sporen luglig, seltener eiförmig, $13-19 u$ (seltener bis $22 \mu$ ) breit, mit dunkelvioletter, von $1-1 \%$ " hohen, netzartig verbundenen Leisten besetzter Membran; Maschen $1-2 \mu$ breit.

In den Bliten ron Rumex Acetosa und $R$. Acetosella in England, l)entschlaud und Italien. Am nächsten bei Königstein a'E. und deshalb wohl auch in Böhmen.

Winter und Saccardo geben an, dass diese Brandart auch die Stengel und die Blitter befällt. Wabrscheinlich handelt es sich in diesen Fällen um die vorangehende Art.

\section{Ustilago Parlatorei Fischer de Waldheim.}

Sporenmasse duukelviolett, in den Steugeln, Blattstielen und den Hauptnerven in langen, die hefallenen Partien verschiedenartig krïmmenden Schwielen, anfangs von der Epidermis bedeckt; später der Länge nach geborsten, stäuhend; Sporen kuglig oder kurz eiförmig, 115-17." breit, mit hellvioletthrauner, vou 1.5-2 " hohen, netzartig verbundenen Leisten besetzter Membran; Maschen $1{ }^{\prime} 5-2 \mu$ breit.

Im Juli und August auf Rumex alpinus, R. maritimus, R. obtusifolius. Die Art kïnnte auch in Böhmen vorkommen. Sie ist bisher nur alus Russiand, Italien, Deutschland und aus der Schweiz bekannt.

Ton den zwei vorangehenden Arten weicht sie durch kleinere Sporen, höhere und breitere Maschen ab.

23. Ustilago Scabiosae (Sowerhy) Winter. - Farinaria Scabiosae Sowerby.

Sporenmasse in den Stauhfäiden, hellrosenrot; Sporen kuglig, 8.5 bis $11 \%$ " breit, oder eiförmig, seltener ellipsoidisch, 11-15 $/$ lang, 8. $5-11.5$ " hreit, mit fast hyaliner, ron niedrigen (etwa $1 u$ ), netzartig verbundenen Leisten besetzter Membran; Maschen etwa $1 \mu$ breit.

Ton Ende Juni bis September in den Staubfäden von Knautia arvensis: Ziemlich verbreitet.

Das Mrzel perenniert, dringt in alle Infloreszenzen, welche immer stärker gewölh, sind wie die gesunden. Sie soll auch auf Knautia silvatica vorkommen. 


\section{Ustilago intermedia Schroeter.}

Sporemmasse in den Stauhfälen, dunkelviolett; Spuren kuglie, 11 17"

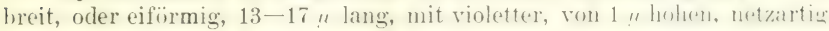
verbundenen Leisten besetzter Membran; Maschen $1.5-3 \mu$ breit.

Im Juli und August in den Staubfäden von Scabiosa columbaria in Deutschland, Frankreich und Fugland. Kann auch hei uns gefumben werten.

Von $L$ stilago Scabinsae weicht dieser P'ilz durch dunkelviolette, weitmaschige sporen, vou Tstilago flosculorum durch kleinere, mit niedrigen Leisten besetzte und weitmaschige Sporen ab.

\section{Ustilago Succisae Magnus.}

Sporenmasse in den staubfïlen, sehr hellviolett; Sporen kuglig orler eiförmig, 13-19 " breit, mit schwach hellvioletter, von 1 " holen, netzartig verbundenen Leisten hesetzter Membran; Mas.hen 15--3 " hreit. Im Juli und August in den Infloreszenzen von Succisa pratensis.

1)iese Brandart nimmt durch ihre ('haraktere die Mittestelle zwischen Ustilago floseulorum und Ustilago intermedia ein. Sie ist durch sehr helle Sporen charakterisiert.

Ustilago flosculorum (De ('andolle) IVinter emend. - Tredo flosculorum De Candolle.

Sporenmasse in den Staubfäden, dunkelviolett: Sporeu kuglin, 13 bis 19 " breit, oder eiförmiu bis ellipsoidisch, his 21 ", lang, mit vinletten, vov $15-2$ " hohen, netzartig verbundenen Leisten besetzter Membran: Maschen $1-2 \mu$ breit.

Im Juli und August in den Infloreszenzen von Knautia arvensis. Vielleicht auch bei uns.

Von Ustilago Scabiosat ist diese Brandart durch dunkelviolette sunren, von Lstilago intermedia durch hellere, mit hiheren und breiteren Maschen versehene Sporen verschieden.

Die Beschreibung von Uredo flosculorum De r'andolle bezicht sich nur auf den Brandpilz von Kinautia arvensis ("la scabieuse de champs).

\section{Ustilago Pinguiculae Rostrup.}

Sporenmasse in den Staubtiiden, hellviolettbraum; Sporen knglig, 4-6 " breit, oder eiförmig, $7-8$ " laug, 4 $5-6$ " breit, mit rotvioletter, von sehr niedrigen, netzartig verbundenen Leisten besetztey Membran: Maschen $1-15 \mu$ breit.

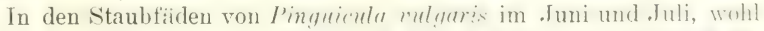
auch bei uns. Bisher mur in Dinemark und aut der Tusel fotland uesammelt. Auf Pinguirula alpina im nördlichen Norwegen und in ren Tiroler Alpen. 


\section{Ustilago pallida Lagerheim.}

Sporenmasse in deu Staubbenteln, hellviolettrötlich; Sporen kuglig oder eifömig, 5\%-is "/ loreit, mit riolettrïtlicher, von sehr niedrigen (etwa "2 "hohen), netzartig verbundenen Leisten besetzter Membran; Maschen 1-2

Im .Juni in deu Staubbeuteln von Tisearia rulgaris: Friedstein bei Klein-Skal (Kabát)! Welbine bei Leitmeritz! Prosseln bei Tetschen (Magnus)! Branischowerberg bei Pilsen (Maloch).

Die Entwickelung wie bei Ustilago violacea, von welcher Art sie durch kleinere und hellere Sporen verschieden ist. Die hefallenen Bliten sind kiirzer und etwas aufgedunsen.

\section{Ustilago maior Schroeter.}

(Abb. 9., 1-3.)

Sporenmasse in den Staubbeuteln der verkrümmten Blüten, dunkelviolett. Sporen kuglig, 7-95 " breit, oder eifürmig bis ellipsoidisch, 9 bis 13 " lang, mit violetter, vou 1 " hohen, netzartig verbundenen Leisten besetzter Membran; Masehen $1 \mu$ breit. (Siehe Abb. 9, Fig. 1-3.)

Von Juni bis September in den Blüten von Silene Otites: Prag (Opiz)! Straschnitz, Keje, Podhoř (Bandy̌s); Kolín (Teselský)! Welwarn (Kahát)! Libočan bei Saaz (Člakorský fil.), Teplitz (Thimen in Rabh.Winter, Fungi eur. Nr. 3202)! Lobosch hei Lobositz! Radobyl bei Leitmeritz! Schreckenstein bei Aussig (Wagner)! Junghunzlau (Bandyš).

Die Entwickelung wie bei Lstilano pallida und Ust. violacea, ron welchen sich die vorliegende Art durch grössere und dunklere Sporen unterscheidet.

\section{Ustilago violacea (Persoon) (iray. - Tredo riwlacea Persoon. Ustilago antherarum Fries.}

Sporeumasse in den Stanhhenteln, hell- oder dunkel-riolett, stäubend. Sporen kuglig oder ellinsoidisch, $65-950$ breit; Membran in verschiedenen Abtimungen violett, von ${ }^{2}-1$ " hohen netzartig verbundenen Leisten besetzt; Maschen $1 / 2-1$ "

In den Staubbenteln verschiedener ('aryophyllaceen von Mai bis September: Dianthus: (urthusianmm: Porthor hei Prag, Smichow ([Tel); Hloubětín bei Prag (Domin)! Telenka bei Sadská (C'elakovský fil.)! Teplitz (Thiimen)! Anhöhe „Perě zwischen Saaz und Welledit/ (Celakorský fil.). Dianthus deltoides: Eisenstein (Krieger)! Lychnis flos cuculi: Auf dieser Wirtspllanze ziemlich verbreitet. Saponuria officinalis: Zwischen Karlstein und Srbsko! Elbufer bei Bodenbach! silene influta: Auf dieser Nïhrpflanze ziemlich verbreitet, anch im Riesengebirge! Silene nutan: Prag (Herzig, im Herb. des böhm. Museums)!

Das Myzel durchelringt die wanze Nihrpflanze, veruichtet gewöhnlich alle Staubfäden und iiberwintert im Rhizom. Die Staubfäden sind durch 
ihre violette Verfairbmng auftaillig. Besonders in weissen orler hellyefäbten Bliten ist die Sporenmasse schon makroskopisch gut zu sehen.

\section{Ustilago Holostei De Bary.}

Sporenmasse in den Samenkapseln aus den Samenanlagen entstehend, dunkelviolett; Sporen kuglig oder (iförmig, 11-15 "/ lireit, dunkelviolett; Membran von $1-15 \mu$ hohen, netzartig verbundenen Leisten besetzt; Maschen $1-2 \mu$ breit.

$1 \mathrm{~m}$ April und Mai in den Samenkapseln von Holosteum umbellatum. WVird wahrscheinlich auch in Böhmen gefunden.

Ustilago Duriaeana Tulasne.

Sporenmasse in den Samenkapseln, dunkelviolett; Sporen kuglig oder kurzeiförmig, 11-15 $\mu$ breit, mit braunvioletter, von $1-15 \mu$ hohen, netzartig verbundenen Leisten besetzter Membran; Maschen 2-4 $\mu$ breit, eckig.

In den Samenkapseln verschiedener Cerastium-Arten, besonders Cer. glutinosum, Cer. semidecandrum und Arenaria serpyllifolia. Kommt auch in Böhmen gewiss vor.

Die Sporen entstehen in den Samenanlagen; der Kelch und die Krone sind ganz normal, die Staubfäden mehr oder weniger verkiimmert. Von den verwandten Arten weicht die vorliegende durch die grossmaschigen Sporen ab.

c) Sporenmasse schwarzviolett.

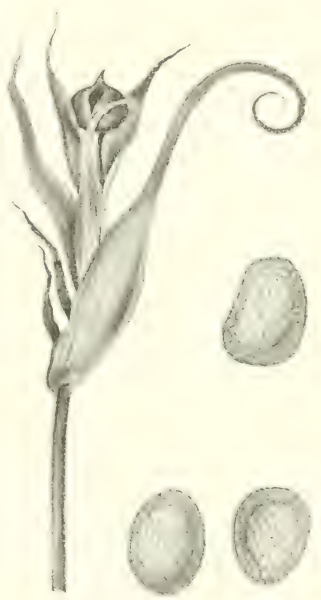

Abb. 10. Ustilago Trat,opogonis pratensis. Habitusbild des Pilzes auf Tragopogon pratensis und isolierteSporen.(Original.)

27. Ustilago Tragopogonis pratensis (Persoon) Irinter. - Iredo Tragomo!ni pratensis Persoon.

(Abb. 10.)

Sporenmasse in den Bliitenköpfen, anfangs von dem Involucrum bedeckt, später stäubend, schwarzviolett: Sporen kuglig, 13-17 " breit oder eiförmig, his 19 "lang, oft unregehmassig; Memhran schwar\%violett, von sehr niedrigen $\left({ }^{\prime}, u\right)$, netzartig verbundenen Leisten besctz: Maschen $1-15 \mu$ breit.

Fnde Mai bis Ende Juli in den Bliitenkïpten von Trugnumem mrimtalis: Lukow bei Bilin! Tragopogon matensis: Aut dieser Yihrpllanze sehr verbreitet. 
Das Mrzel durchdringt die ganze Nährpflanze und sporifiziert in allen ihren Bliitenköpfen, welche fast total vernichtet werden. Die Bliitenkïpfe verkiimmern und nehmen eine knopfartige Form an. Die Involucralhiatter bedecken die Sporenmasse, bald vertrocknen sie aber, schrumpfen zusammen und die Sporen fallen dann leicht heraus.

28. Ustilago Scorzonerae (Albertini et Schweinitz) Schroeter. - I'redo Tragopogi $\beta \beta$ Scorzonerae Albertini et Schweinitz.

Sporenmasse wie bei der vorigen Art; Sporen ebenfalls, doch kleiner, 9-13 " breit; Membran schwarzviolett, von 1 " hohen, netzartig verbundenen Leisten besetzt; Maschen $1-2 \mu$ breit.

Von Mitte Mai bis Eude Juni in den Bliitenköpfen von Scorzonera humilis: Gutwasser bei Hartmanitz (Baudyš)! Welbine und Babina bei Leitmeritz! Nemschen bei Aussig! Plzenec (Maloch)! Náchod, Svrabov und ('hỵnov bei Tábor! Scorzonera purpurea: Chlumee bei Wittingau (Weidmann)!

Die Entwickelung wie hei der vorangehenden Art, von weleher sich die vorliegende durch kleinere Sporen, höhere Leisten und breitere Maschen unterscheidet.

29. Ustilago Cardui Fischer de Waldheim.

Sporenmasse in den Fruchtknoten, schwarzviolett; Sporen kuglig, 16-19 " breit oder eiförmig bis 21 " lang; Membran violett, von 2-4" hohen, netzartig verbundenen Leisten besetzt; Maschen $2-4$ " breit, eckig.

In den Bliitenküpfeu von Silybum. Marianum, Carduus acanthoides, C. defloratus und C. mutans in Deutschland.

('ardus: acanthoides: "Stromka" a. d. Kol. Weinbergen, Radotín bei Prag (Baudyš)!

Sphacelotheca De Bary.

Sporenmasse vou einer Membrau umgeben, die aus dem Myzel des Brandpilzes und dem Gewebe der Nährpflanze gebildet ist. In der Mitte der Sporenmasse eine Kolumella, welche nur aus dem Wirtsgewebe oder auch aus dem Myzel des Pilzes hesteht. Sporenbildung wie bei der Gattung ('intractia. Zwischen den Sporen Gruppen von sterilen Zellen. Keimung wie bei Ustilago.

Bei einizen Arten statt der Kolumella Reste der Gefässbündel von den Rispenästen.

\section{A. Kolumella nur aus dem Gewebe der Nährpflanze gebildet.}

a) Sporen glatt. 
30. Sphacelotheca Andropogonis (Opiz) Bubák. - Lredo (L stilango) Andropogi ()piz.*) - Tstilago Ischarmi Fuchel. - Sphacelothera lscharmi ('linton.

Sporenmasse in der Infloreszenz, dieselbe in kurze oder längere, walzenförmige oder gelappte, $1-3 \mathrm{~cm}$ lange, $1-3 \mathrm{~mm}$ hreite fiebilde umwandeln, von einer ledergelhen, aus dem Myzel gebildeten Ifembran bedeckt, später stäubend, schwarzhraun; Sporen kuglig bis eiförmig, 7-11\%̆!" breit oder lang, mit kastanienbramer, glatter Membran. Zwischen den Sporen Gruppen diunwandiger, kuglig-eckiger, steriler Zellen. Kolumella unecht, in Form von Resten der Infloreszenzaeste.

Von Juni bis Oetober in den Infloreszenzen vou Andropryon Ischurmum: Bei Prag: Smíchov, Sct. Prokop, Kuchelbad, Radotín, Kosor̆, Modřan, Dáblice, Troja, Lysoleje, Roztoky! Miihlhausen a/Elhe, Welwarn, ('hry̌ín, Uha, Jabín (Kabát)! Zwischen Míkov und Záhoři bei Neratovie! Jungbunzlau (Baudyš); Rösselberg hei Briix! Teplitz (Thiimen)! Schlossberg daselbst (Magnus)! - Caské údolí bei Pilsen (Maloch)!

Dieser Brandpilz wurde schon vor Fuckel von Opiz beschrieben, Die Rispenäste bleiben erhalten und ahmen in den missgebildeten, brandigen Infloreszenzen die Kolumella nach. Die äussere Membran besteht aus kleinzelligen Hyphen. Die Sporen entstehen aus den einzelnen Myzelhyphen reihenweise, basipetal. Die befallenen Rispen bleiben gewöhnlich in den Blattscheiden verborgen.

\section{Sphacelotheca vallesiaca Schellenberg.}

Sporenmasse in langen, sehwarzen, die Halme an den Internodien oder am Scheitel umhiillend, von dem Wirtsgewebe durch ein dickes Myzelgeflecht ahgetreunt; Sporen schwarz, zusammenhängend, nicht stiiuheud, kuglig bis ellipsoidisch, $4-6$ " l, reit, mit hellkastanienbrauner, glatter Membran. (Nach dem Autor.)

Auf sterilen Trieben von Stipa pennata bisher nur aus der Schweiz bekannt.

Diese Brandart erimuert sehr an L'stilago hypodytes, weicht aber von derselben mikroskopisch gïuzlich ab. Sie könnte auch in Böhmen gefunden werden.

\section{Sphacelotheca Sorghi (Link) ('linton. - I'stilano Sorghi Passerini.}

Sporenmasse in den Fruchtknoten, dieselhen zu kugligen oder hornförmigen, glatten Tuberkeln umwandeln; Tuberkeln 3-10 $\mathrm{mm}$ lang, von

*) Opiz F. M.: Naturalientausch 1823 24. pag. 43. Die Diagnose lautet: "Uredo (Ustilago) Andropogi Opiz. ['ulvere tenuissimo, fuscopurpureo, loco spicis, e membrana utriculosa, eylindrica, apice attenuata, erumpente. Opiz. Statt der Aelren in Andropogon angustifolius Sib. et Sm. (= Andr. Ischaemum) auf dem Dablitzerberg bei Prag. 
einer hellbraunen, pseudoparenchymatischen, dicken, festen, teilweise aus dem Wirtsgewebe gebildeten Hiille umgeben, spaiter berstend, stänbend; Sporen schwarzbraun, mit Gruppen steriler Zellen vermischt, kuglig oder eiförmig, 55-75 u lang, dunkelkastanienbraun, glatt. Kolumella unecht, aus dem Gewebe des Fruchtknotens gebildet.

Von Juli bis Oktober in den Rispen vou Sorghum vulgare: Im botanischen Garten der königl. böhm. landwirtschaftlichen Akademie zu Tábor!

Sphacelotheea Sorghi ist iiberall, wo die Wirtspflanze kultiviert mird zu finden und verbreitet sich durch die Sporen. In wärmeren Gegenden werden alle Fruchtknoten deformiert und die Rispe ist gedrängt, bei uns in Mitteleuropa gewöhnlich nur einzelne Fruchtknoten und die Rispe bleibt dann normal.

\section{Sphacelotheca cruenta (Kiihn) Bubák. - I'stilago cruenta Kïhn.}

Tuberkeln unregelmässig, mehr oder weniger verlängert, furchig, alle Rispenteile befallend, seltener auch am Halme unterhalb der Rispe entwickelt, an den Aestchenenden oft zusammenfliessend oder verästelt. bis $1 \mathrm{~cm}$ lang, von einer rotbrauner, ziemlich fester, pseudoparenchymatischer, aus dem (iewebe des Wirtes und dem Pilzmyzel gebildeter Membran umschlossen, später berstend, stäuljend; Sporen mit Gruppen steriler Zellen gemischt, kuglig, $755-9{ }^{\circ} 5$ u breit oder eiförmig $9{ }^{\circ}-115 \mu$ laug, 75 " breit, glatt. Kolumella unecht, aus den befallenen Geweben gebildet.

Im August auf Sorghum rulgare. Könnte auch bei uns gefunden werden, da die Wirtpflanze in Böhmen öfters als Futterpflanze gebaut wird. Da das Saatgut aus fremden Lïndern eingefuihrt werden muss, weil es hier nicht reift, so kann auch der Pilz leicht eingeschleppt werden.

Clinton vereinigt diese Brandart mit der vorigen, was entschieden unrichtig ist.

32. Sphacelotheca Panici miliacel (Persoon) Bubák. - L'redo (L'stilago) segetum. of Panici miliacei Persoou. - L'stilago Panici miliacei Winter. Ustilago destruens Schlechtendal.

(Abb. 11.)

Sporenmasse in den Infloreszenzen, dieselben zu eiförmigen oder länglichen, beiderseits verjüngten, oft auch walzenförmigen, bis $3 \mathrm{~cm}$ langen Beulchen umwandelnd; die Deckmembran teilweise auch aus dem Myzel gebildet; Sporen schwarzbraun, später verstäuhend, gewöhnlich polygonal und zwar kuglig, 8-12 " breit, oder eiförmig, seltener länglich, bis 15 " lang; Membran hellkastauienbraun, glatt. Kolumella durch Gefässbiindelreste der Aeste, welche stellenweise vom Myzel bedeckt sind, vertreten.

In den Rispeu der Hirse im August und September überall, wo die Pflanze im Grossen kultiviert wird. 


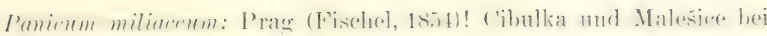

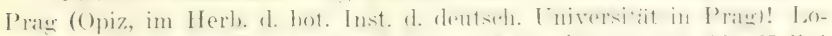

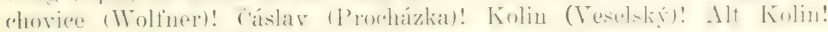
Kuttenberg (Domin)! Platz bei Neuhaus (Weidmann)! 'Tábor, im botan. Garten auf der weissamigen Varietät!

Alle Rispen der befallenen Pflanzen werden brandig und verwandeln sich in dicke, spindelförmige Beulchen, die anfangs bedeckt und in den Blattscheiden eingeschlossen sind. Später zerreisst die Hiille, die Beulen werden breiter, indem sich die Rispenäste lockern, so dass die Sporen herausfallen können. Aus den Scheiden treten die Beulen nur wenig hervor.

Friher, wo die Hirse bei uns mehr kultiviert wurde, war auch der Pilz häufiger, deshalb wurde er von den älteren Sammlern (Opiz, Fischel, Wolfner, Veselský) öfters gefunden.

b) Sporen stachlig.

Sphacelotheca Reiliana (Kiihn) Clinton. Ustilago Reiliana Kiihn.

Brandbeulchen entweder aus einzelnen Fruchtknoten und männlichen Bliiten entstehend oder ganze Rispen werden in grosse kuglige oder eiförmige, manchmal his 15 cm lange Beulen verwandelt; Hiillmembran psendoparenchymatisch, teils auch aus dem Pilzmyel gehildet, anfangx weiss,

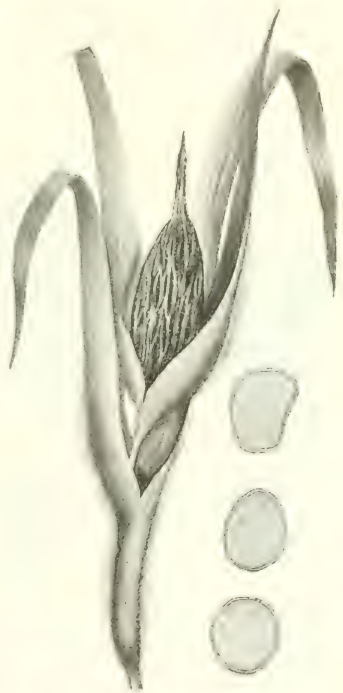

1bb. 11. Syllacelotheca Panici miliucei. Eine infuzierte Rispe, sehon mit zerstiorter Hiille und isolierte Sporeu. (Original.) später gelbbraun, fest, später rissig; Sporenmasse stiubend, schwarzhraun, mit firuppen steriler, gelbbramer Zellen vermischt; Sporen kuglig orter kurz eiförmig. 9-1i "l breit, mit kastanienbrauner, feinstachliger. Memban. Kolumella dureh fictasshimblreste der Rispenästen vertreten.

In den Infloreszenzen von Zea Mays und Sorghum vulgare im August und September. Könnte auch in Böhmen gefunden werden.

Die Sporen verstäuben gänzlich, so dass nur die Faser-Reste der Aeste zurüickbleiben.

I. Kolumella aus dem Gewebe der Nährpflanze und aus dem Pilzmyzel 
33. Sphacelotheca Hydropiperis (Schuhmacher) De Bary. - Uredo Hydropiperis Schuhmacher. - Ustilago Hydropiperis Schroeter p. p.

Brandbeuteln aus den Fruchtkuoten gebildet, kuglig oder länglich, 3-5 " lang, vou dem Perigon hedeckt; Hiillmembran pseudoparenchymaiisch, teilweise auch aus dem Pilzmyzel hestehend, braun, bald am Scheitel berstend; Sporenmasse schwarzviolett, mit Gruppen steriler, hyaliner

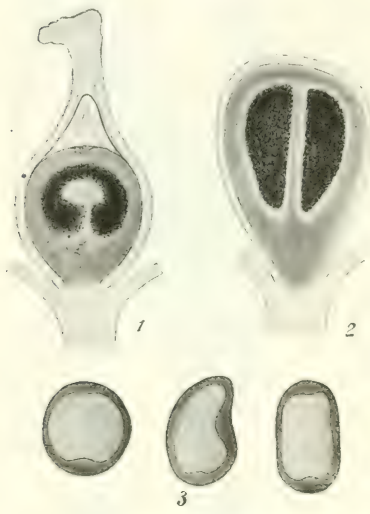

Abb. 12. Sphacelotheca Hydropiperis. 1. Schnitt durch einen jungen Brandbeutel, 2. durch einen ilteren; in beiden sieht man die Kolumella und die äussere vom II yzel gebildete Hïile; 3. isolierte Sporen. (Original.) oder schwach violetter Zellen vermischt; Sporen kuglig, $11-15 \mu$ breit oder eiförmig, 13-17 $\mu$ lang, 11-13 $\mu$ dick, mit violettbrauner, feinwarziger Membran. Kolumella zentral, dick, fest, aus dem Gewebe der Nährpflanze und dem Pilzmyzel gebildet.

In den Infloreszenzen verschiedener Polygonum-Arten von Juli bis zum Winter; in Böhmen nur auf Polygonum Hydropiper: Ziemlich verbreitet.

Der Sporeninhalt ist oft zusammengeschrumpft und von der Sporenmembran entfernt. Das Myzel ist einjährig. Die Sporen keimen erst nach längerer Ruheperiode.

Von der ähnlichen Ustilago utriculosa weicht sie, ausser der Entwickluug, hauptsächlich durch ganz verschiedene Skulptur der Sporenmembran ab.

34. Sphacelotheca borealis (Clinton) Schellenberg. - Sph. Hydropiperis Autt. p. p. - Sph. Hydropiperis var, borealis Clinton.

Brandbeuteln aus deu Fruchtknoten entstehend, kuglig oder kurzeiförmig, braun, glïnzend, rom Perigon bedeckt; Huillmembran hauptsäehlich aus dem F'ruchtknotengewebe und nur spärlichem Pilzmyzel gebildet, braun, bald berstend; Sporenmasse stiubend, violettschwarz; sterile Zellen einzeln oder gruppenweise, hyalin, dickwandig; Sporen kuglig, 11-17 " breit oder eifürmig, 11-19 " lang, 95 brauner, deutlich feinwarziger Membran; Kolumella dick, fest, aus dem Gewebe der Nährpflanze und aus dem Pilzmyzel gebildet.

Im Riesengebirge: im Juni in den Infloreszenzen von Polygonum Bistorta: Schlingelbaude, Petersbaude (Schroeter)! Schüsselbauden, 
Riesengrund, Kileiner und Grosser Kesselgrund! Harta (Cypers)! Gilatzer Schneeberg (Schroeter).

Diese Brandart wurde friiher mit der vorangehenden vermengt, erst C'linton und Schellenberg haben sie von derselben abgetrennt.

Die Beutelchen sind kïrzer als bei Sphacelotheca Hydropiperis, die Sporen grösser und deutlich warzig. Die Kolumella ist dicker, aber an ihrer Ausbildung beteiligt sich das Myzel nur sehr wenig. Das Myzel perenniert im Rhizom, dringt jedes Jahr in die neuen Triebe ein und infiziert alle Fruchtknoten derselben Aehre. Die Sporen keimen sofort nach der Reife. Das Promyzel ist - nach Schellenberg - kräftiger als bei Sph. Hydropiperis, die Sporidien bilden sich an den Querwänden und am Scheitel wirtelig.

\section{Cintractia Cornu. - (Anthracoidea} Brefeld.)

Sporen aus einem zentralen, kompakten Gewebe (Stroma) basipetal aus gallertartig verquollenen Hyphen gebildet, anfangs fest verbunden, später stäubend; Promyzel zweizellig; die obere Zelle bildet am Scheitel, die basale unterhalb der Querwand ein Sterigma, welches nach einander und neben einander Sporidien erzeugt.

Bei den einheimischen Arten bilden sich die Sporen hauptsichlich in den Fruchtknoten, bei fremden Arten auch in den Blïten- und vegetativen Achsen.

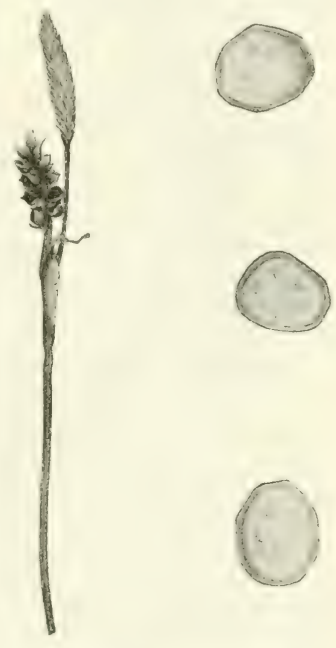

Abb. 13. Cintractia Caricis von Carex vaginata. Habitus des Pilzes und isolierte Sporen. (Original.)

35. Cintractia Caricis (Persoon) Magnus. - Uredo Caricis Persoon. Ustilago Caricis Fuckel, - Anthracoidea Caricis Brefeld.

Tuberkeln aus den Fruehtknoten gebildet, kuglig oder eiförmig, hart, 2-4 $\mathrm{mm}$ breit, anfaugs von einer grauen Hiillmembran bedeckt, daun nackt, an der Oberfläche stänbend; Sporen sehr variabel: kuglig, eilïrmig, ellipsoidisch bis länglich, of polyedrisch, verschieden gross, 15-3* " lang, 15-28 " breit, mit ziemlich dicker, schwarzkastanienbrauner, feinwarziger Membran. 
In den weiblichen Bluten verschiedener ('arex-Arten von Mai (Carex praecox) bis zum Winter: Carex brizoides: Wälder bei Žehušic nächst Cáslav (Peyl)! Wittingau (Weidmann)! Kaplitz (Kirchner)! Steindlberg, Lakkasee und rou hier ab bis zum Deffernik im Böhmerwalde! Carex currata: Teichründer bei Padrf nächst Rožmital! Carex echinata: Weisswassergrund, Teufelsgrund und bei der Spindlerbaude im Riesengebirge (Schroeter)! Carex glauca: Valdice hei Jičín (Baudyš); Rovensko, Böhm. Aicha! Klein Skal (Kahát)! Potrosowitz bei Liebenau (Baudyš); Karlsbad (Reuss)! ('arex humilis: Kuchelbad (Schiffner)! Carex Michelii: Kuchelbad (Opiz)! ('arex pallescens: Rehhorn bei Schatzlar (Domin)! Carex pilulifera: Modřaner Schlucht bei Prag! Teleuka bei Sadská! C'arex praecox: Lissowa bei Staab (Maloch)! ('arex vaginata (C. sparsiflora): Kessel der Kesselkoppe (Schroeter); Brumnenberg (Domiu)! Teufelsgarten (Wilhelm)! Carex vulgaris: Brada bei Jičín (Baudyš)!

Die Sporengrösse variert je nach den Wirtspflanzen sehr. Am grössten fand ich sie auf Carex vaginatil und ('. glauca, wo sie bis 38 " lang, $28 \mu$ breit sind; die kleinsten faud ich auf Carex curvata, oft nur 15 " im Diameter. Wahrscheinlich ist ( intractia Caricis in jetziger Auffassung eine Kollektivart.

Cintractia Scirpi (Kühn) Schellenherg. - Lstilago scirpi Kïhn.

Tuberkeln aus den Fruchtknoten gebildet, kuglig oder eiförmig, 2-25 " laug, sonst wie bei der vorangehenden Art; Sporen kuglig, eiförmig, seltener länglich, 18-28 „ lang orler breit, mit dunkelkastauienbrauner, feinwarziger Membran.

In den Fruchtknoten von S'cirpus carspitosus: in Gebirgen, z. B. in Schtreden, Deutsehland (Harz), in der Schweiz und vielleicht auch in Bühmen.

Von der vorangehenden Art weicht sie durch deutlichere Warzen ab. Ihre Selbständigkeit muss noch durch Infektionsversuche bestättigt werden. Die Diagnose wurde nach Sydow's Exemplaren aus dem Harze (Sydow, Ustilagineen Nr. 362) entwerfen.

36. Cintractia Montagnei (Tulasue) Magnus. - Estilago Montagnei Tulasne.

Tuberkeln aus den Fruchtknoten gebildet, länglich oder eiförmig, 1-2 $\mathrm{mm}$ lang, hart, anfangs bedeckt und in den Spelzen rerborgen, spiter nackt, schwarz und aus den Spelzen die schwarze Sporenmasse verstitubend; Sporen variahel, kuglig, eiförmig bis ellipsoidisch, 9-15 " breit oder 9-17 " lang, 55-13 " breit, mit diinuer, dunkelkastanienbrauner, undeutlich warziger Membran.

Von Juli bis September in den Fruchtkuoten von Rhynchospora alba: Reichenherg (Siegmund 1853! als Lstilago Rhynchosporei Siegm. in schedis)! Teich Bolevec bei Pilsen (Hora).

Ton C. Seirpi hauptsäichlich dureh kleinere Sporen abweichend. 
37. Cintractia subinclusa (Köruicke) Magnus. - L'stilugo subinclusa Körnicke: - Anthracoidea subinclusa Brefeld.

Tuherkeln aus den Fruchtknoten entstehend, anfangs von dem Schlauche bedeckt, nach dessen Zerreissen bröckelig, schwarzbraun; Sporen kuglig oder eiförmig, 13-20 " breit, schwarzkastanienbraun, mit starken, ziemlich langen Stachelchen besetzt.

Von Juni bis Angust in den Schläuchen von (arex acutu, ampullucea, filiformis, riparia. resicaria. C'arex riparia: Skáčov bei Dolní Bonsov (Celakovský fil.)!

38. Cintractia Luzulae (Saceardo) ('linton. - L'stilayo Luzulue Saceardo.

Sporenmasse in den Fruchtknoten ziemlich fest verklebt, manchmal auch an der Basis der Perigonbliitter, schwarz, wenig stiubend; Sporen kuglig, 20-30 " im Durchmesser oder eiförmig, 24-32 "lang, 19-27 " breit, mit schwarzbrauner, undurchsichtiger, seltever durchscheinenter, mit porenartigen Vertiefungen (nach Maire dureh Faltung entstandeneu) versehener Membran.

Ton Juni bis September in den Fruchtknoten verschiedener LuzulaArten und zwar Luzula albida. campestris, spicata, irrmalis. Aus Böhmen führt Opiz diesen Pilz an und zwar in Lotos, Jahrg. V. (185̌5), pag. 217 als Lredo C'aricis var. Luzulue aus dem Böhmerwalde, wo sie im J. 1854 von Em. Purkymè gesammelt sein sollte. Ich sah sie nicht.

Luzula vernalis: Převyšina bei Jiěín (Baudyš)!

Die befallenen Pflanzen sind immer kleiner als gesunde, was besonders von den Aehrehen und Bliiten gilt. Alle Fruchtknoten der erkrankten Pflanzen werden brandig.

Cintractia Junci (Schweinitz) Trelease. - C'aeoma . Iunci Sehweinitz. Ustilago Junci Curtis. - Ustilago Liebmanni P. Hennings.

Brandpolstem flach, ziemlich ausgedehnt, zwixchen dem Halme und den Blattscheiden gebildet, fest, schwarzhram. Sporen ellipsoidisch oder eiförmig, oft unregelmässig, polyedrisch, 10-20 "lang, mit schwarzbrauner glatter Membran.

Auf verschiedenen Juncus-Arten, hesonders auf Juncus bufonius. Von dem ähnlichen Tolyposporium Junci weicht er durch einzellige Sporen ab.

Elateromyces Bubák, novum genus.

Hiille der Tuberkeln aus dem (iewehe der Nährpflanze und dem Pilzmyzel gebildet. Sporen kettenförmig aus mehr oder weniger parallelen Hyphen auf dieselbe Weise wie bei Ustilago entstehend. Zwisehen den Sporen sterile, strangartig verklebte, wellenförmig gekrimmte Hyphen, 
welche sich nach der Reife der Sporen strecken und dieselben herausstreuen. Keimung der Sporen mit einem einzelligen, in der Spore eingegeschlossenen Promyzel, welches auf einem kurzen Sterigma kettenförmig die Sporidien produziert.

39. Elateromyces olivaceus Bubák (De Candolle). - Uredo olivacea De Candolle. - Ustilago olivacea Tulasne.

Sporen in einzeluen Fruchtknoten, welche in kuglige, $2-5 \mathrm{~mm}$ breite Tuberkeln verwaudelt werden; Hiille teils aus dem Wirtsgewebe, teils aus dem Pilzmyzel gebildet; Sporenmasse dunkelolivenbraun, mit strangartig verklebten, wellenförmig gekriimmten Hyphen vermischt, die sich später strecken und weit aus den Tuberkeln hervorragen; Sporen klumpenweise oder rosenkranzartig verbunden, später einzeln, sehr ungleich, kuglig, 4-9 " breit oder eiförmig, ellipsoidisch, unregelmässig, biskuitartig oder gebogen, 6-15 " lang, 4-6 " dick, hellolivenbraun, feinwarzig.

In einzelnen Fruchtknoten verschiedener Carex-Arten im Juli und August, in Böhmen auf Carex riparia: Welwarn (Kabát)!

Diese Brandart besitzt eine ithnliche Hiille wie die Gattung Sphacelotheca. Weiterhin zeichnen sie die strangartig verklebten Hyphen aus, welche, nachdem die Tuberkelu am Scheitel geborsten sind, sich strecken und die Sporen ausstreuen; sie fungieren also wie die Elateren der Myxomyzeten. Zu dieser neuen Gattung gehört auch sicher Ustilago Treubii, die also Elateromyces Treubii (Solms) Bubák genannt werden muss.

\section{Schizonella Schroeter.}

Sporen zu zwei locker mit einander verluuden, aus einer Mutterzelle durch Zweiteilung entstanden, kettenweise aus den Myzelhyphen gebildet. Keimung wie bei der Gattung Ustilago. Die Sporidien vermögen zu sprossen.

40. Schizonella melanogramma (De Candolle) Schroeter. - Uredo melanogramma De Candolle. - Geminella foliicola Schroeter.

Brandpolster rundlich oder strichförmig, oft der Länge nach zusammenfliessend, schmal, schwarz, lange bedeckt, erst spät geöffnet, schwarz, wenig stäubend; Sporen zu zwei, nur mit kleinen Flächen sich berihrend; einzelne Zellen 7-11 " breit, an der Innenseite abgerundet, diinnwandig, gelbbraun, an der Aussenseite polyedrisch oder sphaerisch, dickwandig, zweischichtig, äussere Schicht schwarzbraun, innere gelbbraun. (Siehe Abb. 14, Fig. 1-4.)

In den Blätteru verschiedener Carex-Arten von Mai bis September: Carex digitata: Set. Procopius bei Prag (Baudyš); Berg "Hora " bei Se- 
mice nächst Lysá! Carex Michelii: Kuchelbad (E. Vávra, 4. V. 1851 im Herb. d. böhm. Museums in Prag)! Daselhst sammelte ich den P'ilz auch selbst und zwar oberhalb des ersten Wichterhauses hinter dem Paahmhote in der Richtung gegen Radotín! Radotín! Botanischer (iarten in Tábor! Carex montana: Karlstein! Carex praecox: Závist, Homole bei Vran a. d. Mold. (Baudyš)! Zahořanertal bei Davle (Velenovský)! Plešivec bei Karlstein (Baudyš). Carex rigida: Oberhalb des Kleinen Teiches im Riesengebirge bis zur Wiesenbaude (Schroeter).

Durch die schwarzen Blattstreifchen sehr auffallend.

\section{Gatt. Sorosporium Rudolphi.}

Sporen an den Enden von einwärts gekrümmten Hyphen gebildet, später ballenartig verbunden. Unreife Ballen mit einer aus gallertartig verquollenen Hyphen gebildeter Hülle, reif nackt, nur locker verbunden. Promyzel einzellig, schlauchartig, bei fremden Arten auch mit Querwänden und apikalen, wie seitenständigen Sporidien.

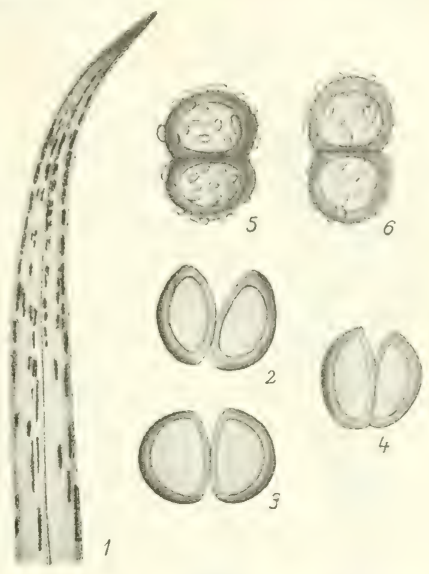

Abb. 14. 1-4 Schizonella melanogramma auf Carex Michelii: 1. Hahitus des Pilzes; $2-4$ isolierte Sporenzwillinge. - 5-6 Sporen vou Schroeteria delastrina. (Original.)

41. Sorosporium Saponariae Rudolphi. - L'stilago Rudolphii T'ulasne. (Abb. 15.)

Sporenmasse in total vernichteter Blïte oder nur im Fruchtknoten, oder aber in der Basis der Bliiten, Staubfäden, wie auch der Kronenblätter, schon in der Knospe entstehend, rotbraun; Ballen kuglig, 50-90" breit oder sehwach verlängert, his 120 " lang, leicht zerfallend, vielsporig; Sporen kuglig, 15-19 „ im Durehmesser, eiförmig, 17-19 " lang. 13-17 „ breit oder länglich, bis 26 " lang, an den Berihrungstlichen flach, Ifembran an der freien Seite von feinen Stachelchen und kurzen Leistchen besetzt.

Von Mai bis September in den Bliiten der Caryophyllacen: Cirstium arvense: Bei Měchenic nächst Davle! Zwischen Voskovreh und dem Dorfe Odřepsy bei Poděbrad! Bílý mlỵn und Rỵbnícek bei Ticín (Baudyš); Herrnskretschen (Waguer)! Chýnov bei Tábor! Dianthus armeria: 
Jičinères hei .Tičn (Baudy̌s)! Dianthus carthusianorum: Podhoř und Bohdaluw hei Ifichle, Sele bei Prag(Baudyš)! Dianthus deltoides: Eisenstein (Krie-

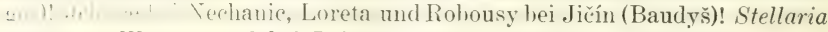
IIolosten: Woparuertal bei Lobositz! Popovice bei Jičín (Baudyš).

Die wefallenen Pflanzen zeigen entweder

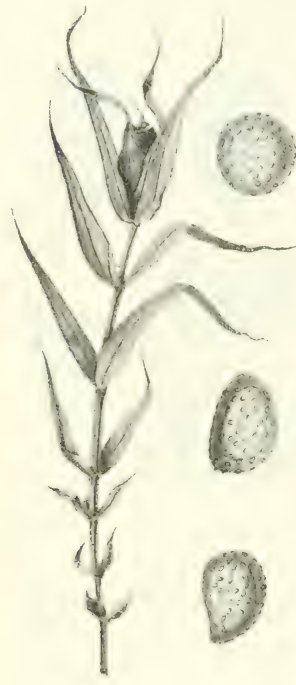

Abb. 15. Sorosporium Saponariae. Iufizierte. St ilitia Holostea und isolierte Sporen. (Original.) einen normalen Habitus, die Blüten sind ziemlich gut entwickelt oder die oberen Internodien, welche die Blüten tragen, sehr verkiirzt, so dass sich, wie z. B. bei Cerastium und Stellaria, am Scheitel der Triebe kleinere nder grössere Beulen bilden. Sie bestehen aus den verkiirzten Stengelinternodien, aus den brandigen Bliiten und den Deckblättern.

\section{Sorosporium Montiae Rostrup.}

Ballen schwarzbraun bis schwarz, in den Blättern und Stengeln gebildet, kuglig oder länglich, $30-80 \mu$ lang, vielsporig, fest; Sporen kuglig, eiförmig, an den Berührungsflächen flach, fest verbunden, $5-8 \mu$ breit, schwarzbraun, wenig durchsichtig, glatt.

Im Juli in Montia fontana und M. minor, bisher nur aus Dänemark und Norwegen bekannt. Vielleicht auch in Böhmen.

Unter der Lupe sind die befallenen Blätter und Stengel sehwarzwarzig, was von den im Gewebe versteckten Ballen herriihrt. Myzel stark entwickelt, hyalin, die Blätter allseitig durehdringend.

\section{7. (iatt. Tolyposporium Woronin.}

Sporen in unregelmässige Ballen verklebt, aus knäuelartig verflochtenen Hyphen entstehent. Keimung wie bei L'stilago. Auf Stengeln, Blättern, Blitenstielen, Samenkapseln und in den Fruchtknoten bilden die Tolyposporium-Arten kleine oder grössere Tuberkeln.

42. Tolyposporium Junci (Schroeter) Woronin, - Sorosporium Junci Schroeter. (Abb. 16.)

'Tuherkeln auf Halmen, Blättern, Bliitenstielen und Samenkapseln, klein, $1-t \mathrm{~mm}$ hreit oder lang, von grauer, glänzender Epidermis bederkt, spaiter nackt, schwarz, wenig stauhig. Ballen kuglig bis länglich, gewöhnlich unregelmäissig, 20-80 
Tenig durchsichtig, aus 2-50 oder noch mehreren Syoren hestelend; dieselben kuglig his ellipsoidisch, an den Beriihrungsflichen flach, 12-17! lang, dunkelkastanienbraun, undeutlich höckerig.

Von Ende .Juni bis September auf Juncus bufonius: Auf feuchten Feldern bei Radkov und Balkova Lhota nächst Tábor!

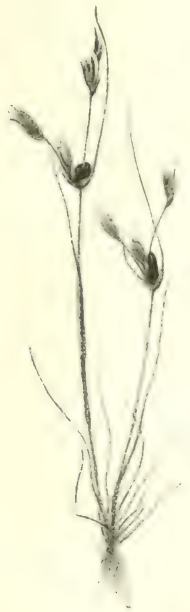

Abb. 16. Tolyposporium Junci. Eine kranke Pflanze und isolierte Sporenballen. (Original.)
Tolyposporium bullatum Schroeter.

Einzelne Fruchtknoten stark aufgedunsen, 2-4 $\mathrm{mm}$ lang, ziemlich lange geschlossen, später berstend und die Sporenballen verstäubend; dieselben kuglig bis länglich, oft ziemlich unregelmässig, $65-250 \mu$ lang, schwarzbraun bis schwarz, wenig durchsichtig, aus einer grossen Zahl von Sporen bestehend; Sporen kuglig oder kurz ellipsoidisch, an den Beriihrungsflächen flach, 7.5-12 $\mu$ lang, entfernt höckerig.

Im August in den Fruchtknoten von Panicum crus galli. Aus Schlesien, Sachsen und Bulgarien (hier ron mir im J. 1907 gefunden) bekannt. Am nächsten bei Königsberg a. E., so dass die Art auch bei uns vorkommen könnte. In den Rispen sind nur einzelne, wenige Fruchtknoten befallen; ihre Deck- und Torspelzen sind stark rergrössert.

Tolyposporium leptideum Sydow.

Ánorenmasse in den Fruchtknoten aus den Samenanlagen entwickelt, zimmtbrauu; Sporenballen kuglig, 35-65 u breit, oder ellipsoidisch his lïnglich, bis 75 , lang, vielsporig, fest; Sporen an den Berihrungflärhen eckig, anssen sphaerisch, 9-16 " in Durchmesser, mit hellbramer, f'einwarziger Membran.

In den Friichten ron ('henopodium album bisher nur aus I)eutschland bekannt.

Ob diese Brandart wirklich hierher oder zu Théaphora gebürt, muss noch auf Grund ihrer Entwicklung entschieden werden.

Die befallenen Pflanzen sind kleiner als die gesunden und haben eimen dichteren $\mathbb{T}$ uchs. Die Blitter sind schmäler und die ganze Pflanze 
hat ein hexenbesenartiges Aussehen. Kleine Pflanzen sind (nach dem Autor) oft ganz infiziert, grössere nur teilweise, gewöhnlich nur die unteren Aeste.

\section{Gatt. Thecaphora Fingerhut.}

Sporen in Ballen fest verklebt; Promyzel fadenförmig, manchmal verzweigt, mit einer einzigen spindelförmiger Konidie an den Astenden.

\section{Thecaphora aterrima Tulasne.}

Sporenmasse hinter den Spelzen versteckt, aus weiblichen oder männlichen Fruchtblättern entstanden; Sporenballen kuglig oder länglich, 19
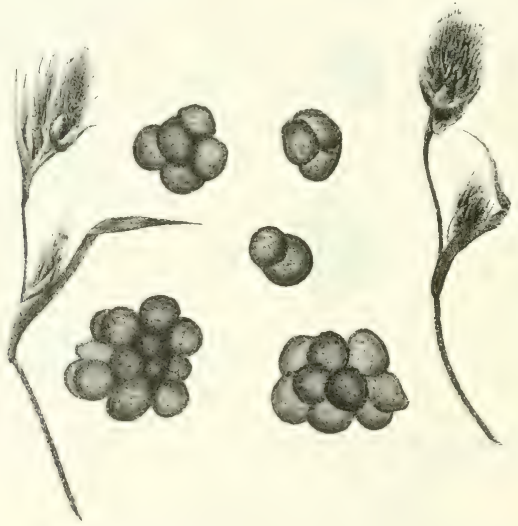

Abb. 17. Thecaphora aterrima: Brandige Ährchen und isolierte Sporenballen. (Original.)

bis 57 " breit, sehwarzbraun, selten 1-2zellig, gewöhnlich 3-20zellig; Sporen kuglig bis ellipsoidisch, an den Berihrungsseiten flach, 755-15 $\mu$ breit, mit kastanienbramer, undentlich warziger Nembran.

In weiblichen und männlichen Aehren verschiedener Carex-Arten: ('arex Michelii: Ton Ende Mal bis zum Anfang Juli bei Radotín nächst Prag! ('arex praecox: Von Ende April und im Mai bei Stěchovic (Podpěra)! 
44. Thecaphora Traillii C'ooke. - Therethora ('irsii Bonrlier.

Sporenmasse dunkelolivenbraun, in den mehr oler weniger verkiimmerten Blütenköpfehen versteckt; Sporenballen kuglig lis ellipsoidisch oder unregelmässig, 19-32 " lang, 2-4, seltener 5-6zellig; Sporen kucliw bis ellipsoidisch, an den Berihrungsseiten flach, 12-19 "hreit, aussen gewölbt, netzförmig-warzig.

Im Juni und August in verkiimmerten und manchmal verk riimmten Blütenköpfen von

Cirsium heterophyllum: Zechgrund am Fichtelherge bei (Oher Wiesental (Wagner, Sydow)!

\section{Thecaphora capsularum (Fries) Desmazières. - Thecaphora hyalina Fingerhut.}

Sporenmasse chokoladenbraun, in den Fruchtkapseln eingeschlossen, aus den Samen entstanden; Sporenballen kuglig bis ellipsoidisch, 24 bi. 64 " lang, hell bis kastanienbraun, 2-12sporig; Sporen kuglig bis linglich, hellkastanienbraun, an den Berihrungsseiten flach, an der Aussenseite sphaerisch. 13-22 " breit, mit abgerundeten Wirzchen besetzt.

In den Fruchtkapseln von ('oncolvulus areensis und ('. sepium von Juli bis zum Fruihjahre. Gewiss auch in Böhmen!

\section{Thecaphora deformans I)urieu et Montagne. - Thecaphora affinis Schneider. - Thecaphora Lathyri Kühn.}

Sporenmasse chokoladenbraun, in verkiimmerten Hiilsen versteckt, aus den Samen entstanden; Sporenballen kuglig bis länglich, 28 his 6i " lang, hellkastanienbraun, 3-20sporig, gewöhnlich 6-15sporig; sporen kuglig bis kurz ellipsoidisch, an den Beriihrungsseiten flach, 15 bis 223 ". breit; Membran gelbbraun, an der freien Seite mit 3-5 " langen, konischen oder prismatischen Stacheln besetzt.

In den Hiilsen verschiedener Papilionaceen: Astragalus alycyphyllu. und Lathyrus silvestris in Europa; in Amerika in den Hiilsen von Lotus, Desmodium, Hosackia, Lupinus, Trifolium, Vicia; im Algerien auf Medicago tribuloides.

Astragalus glycyphyllus: Tábor! Slatina bei Jiěín (Baudy̌s)!

Ich bin iiberzeugt, dass der Pilz in dieser Umgrenzung eine sammelspezies ist. Leider konnte ich ausser der Astragalu:-Form nur noch lie Form von Vicia trifida aus Amerika untersuchen. Sie untersheidet sirh von der ersten durch vielsporige Ballen - bis .2s sporen - wie aurh durch das warzige, also nicht stachlige Epispor. Ich nenne sie Thecaphora Viciae Bubák. 


\section{Tilletiineae.}

Promyzel einzellig; Sporidien scheitelständig, wirtelig oder köpfenartig verbunden.

A) Sporen einzeln.

a) Sporidien $30-50$, auch mehr am Scheitel des Promyzels im Köpfehen stehend. . . . . . 9. Neovossia.

b) Sporidien 4-12 am Ende des Promyzels wirtelig angeordnet.

1. Sporen dunkel gefärbt, stäubend, in den Fruchtknoten eingeschlossen oder in den Blättern Streifen bildend. . . . . 10. Tilletia.

2. Sporen dunkel, in Tuberkeln oder in ausgedehnten Verdickungen in den Blättern und Stengeln . . . . . . . . . 11. Melanotaenium.

3. Sporen gewöhnlich hellgefärbt, nesterweise im Gewebe eingeschlossen . . . . . . 12. Entyloma.

4. Sporen hellgefärbt, in knollenförmig verdickten Wurzeln . . . . . . . 13. Schinzia.

B) Sporen zu zwei verbunden .......... 14. Schroeteria.

C) Drei bis mehrere Sporen zu Ballen verbunden.

a) Sporenballen nur aus keimfähigen Sporen zusammengesetzt . . . . . . . 15. Tuburcinia.

b) Sporenballen auch aus sterilen Zellen bestehend.

1. Sterile Zellen an der Oberfläche der Ballen.

a) Sterile Zellen isoliert oder nur lose bei einanderstehend . . . . . . . 16. Urocystis.

ß) Sterile Zellen eine dicht zusammenhängende Schicht bildend . . . . . 17. Doassansia.

2. Sterile Zellen innerhalb der Ballen; Ballen an der Oberfläche mit einer Hyphenschicht umgeben

18. Doassansiopsis

c) Sporenballen innerlich mit einem Hyphennetz . 19. Tracya.

\section{Gatt. Neovossia Körnicke.}

Sporen an den Hyphenenden, gestielt, von einer hyalinen, gallertartigen Masse umgeben. Promyzel kurz, säulchenartig, oben köpfchenförmig verdickt, mit 30 - 50, oft noch mehr Sporidien. Sporidien gerade oder schwach gebogen, bei der Keimung sekundäre Sporidien derselben Form oder sichelförmige hervorbringend. Sporenstiel fest. 
Neovossia Moliniae (Thümen) Koernicke. - Tossia Molinin' 'T'hiimen. Tilletia Moliniae Winter.

Einzelne F'mehtkurten zu lïnglichen Tuherkein verwandelt, von

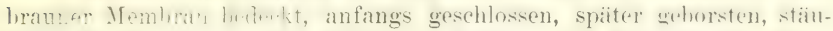

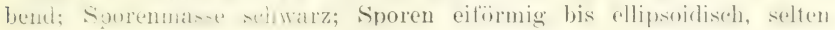

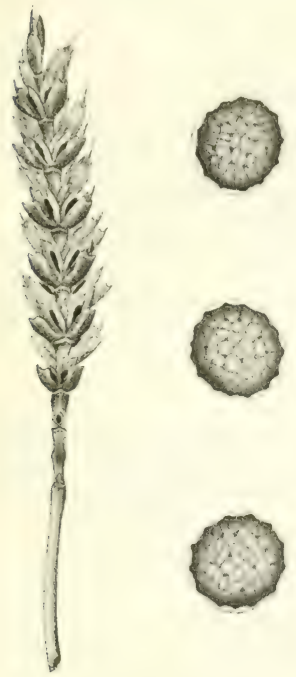

Ahb. 18. Tilletia Tritici: Eine infizierte Weizenäbre und isolierte Sporen. (Original.) kuglig, 24-38 $\mu$ lang, 17-23 $\mu$ breit; Membran kastanienbraun, mit netzförmig verbundenen Leisten besetzt und dariiber noch mit einer kontinuierlichen, hyalinen Schicht; Sporenstielchen oben gelblich, unten hyalin, mehr oder weniger zusammengeschrumpft.

In einzelnen Ovarien von Molinia coemulea im September. Bisher nur aus Italien und Krain bekannt.

Die Sporen werden aus einfachen oder verzweigten (ipse vidi!) Fruchthyphen, welche den Fruchtwänden anliegen, gebildet. Die Hyphen bleiben dann als Stielchen an den Sporen hängen.

\section{Gatt. Tilletia Tulasne.}

Sporen einzeln an den Hyphenenden des Myzels aus gallertartig verquollenen Zellen gebildet, später frei, stäubend. Promyzel einzellig, mit 4-12 scheitelständigen, faden- oder spindelförmigen Sporidien. Sporidien brïckenweise zu zwei zusammen verbunden, fadenförmig auskeimend und auf den Hyphenästen sekundäre, sichelförmige Sporidien bildend, welche wieder ebensolche tertiäre produzieren können.

\section{1) In dẹn Fruchtknoten, nach Trimethylamin stinkend.}

a) Sporenmasse schwarz oder sehwarzbraun.

a) Sporen an der Oberfläche netzig.

46. Tilletia Tritici (Bjerkander) Winter. - Lycoperdon Tritiri Bjerkamler. (Abb. 18.)

Sporenmasse schwarzolivenbraun, alle Fruchtkuoten fiillent; Sporen kuglig, 19-24 " breit, oder eiförmig, 24-26 " lang, 24 " breit, mit hellolivenbrauner, mit 2-4 " hohen, netzförmig zusammenfliessenden leisten besetzter Membran; Maschen $2-7 \mu$ breit, 
In den Fruchtknoten verschiedener Triticum-Arten von Ende Juni und im Juli:

Triticum vulgare: Anf allen Sorten weit verbreitet!

Triticum compactum: Botanischer Garten zu Tábor:

Die Sporen stinken nach Trimethylamin. Die Brandkörner sind kurz und breit und spreizen die Spelzen ziemlich stark. Die infizierten Aehren sind bleich und stehen gerade. Oft werden 50-80\% aller Aehren infiziert.

\section{Tilletia separata J. Kunze.}

Sporenmasse schwarz, alle Fruchtknoten füllend; Sporen kuglig, seltener eiförmig, 24-305 " breit; Membran dunkelkastanienbraun, mit niedrigen, nur $2-3 \|$ hohen, netzförmig zusammenfliessenden Leisten besetzt; Maschen rundlich oder eckig, $25-5.5 \mu$ breit.

Im Juli in den Fruchtkuoten von Aira spica venti: Stěpánovice bei Klattau (prof. Dr. K. Holý)!

Diese seltene Brandart vernichtet alle Fruchtknoten der infizierten Pflanzen.

\section{Tilletia Airae Blytt.}

Sporenmasse in allen Fruehtknoten, schwarzbraun; Sporen kuglig bis eiförmig, 24-30 " breit; Membran kastanienbraun, besetzt mit niedrigen, 1-25 " hohen, netzartig zusammenfliessenden Leisten; Maschen unregelmässig, $4 \mu$ breit.

In den Fruchtknoten von Deschampsia caespitosa in Norwegen und Nordamerika. Vielleicht auch bei uns.

\section{Tilletia Anthoxanthi Blytt.}

Sporenmasse in allen Fruchtknoten, schwarz; Sporen kuglig, 28 bis 32 " breit oder eiförmig, 28-35 " lang. 26-30 " breit; Membran dunkelkastanienbraun, besetzt mit $2-3$ " hohen, netzartig zusammenfliessenden Leisten; Maschen gross, $35-6,4$ breit, rundlich oder eckig.

Im August in den Fruchtknoten von Anthoxanthum odoratum in Norwegen, Schweden und Nord Amerika. Wohl auch bei uns.

Tilletia Holci (Westendorp) Rostrup. - T. Rauuenhoffii Fischer de Waldheim.

Sporen in allen Fruchtknoten, schwarz; Sporen kuglig, 28-33 $\mu$ breit oder kurz eiförmig; 32-36 " lang, 28-33 " breit, dunkelkastanienbraun; Membran mit $3-45, "$ hohen, netzartig verbundenen Leisten besetzt; Maschen polygonal, meistens sechseckig, gross, 3-6 $\mu$ breit. 
Im Juli und August in den Fruchtknoten von Holcus mollis und II. lanatus in Belgien, Dïnemark und England. Vielleicht auch in Bähmen.

ß) Sporen glatt.

48. Tilletia levis Kuihn. - I'stilago foetens Berkeley et Curtis nom. nurlum.

Sporenmasse in allen Fruchtknoten, schwarz; Sporen sehr variabel, kuglig, 19- $24 \mu$ breit, oder eiförmig, ellipsoidisch, länglich, keulenförmig, polyedrisch oder gebogen, 24-38 $\mu$ lang, 17-21 " breit, mit dunkelkastanienbrauner, $2 \mu$ dicker, glatter Membran.

In den Fruchtknoten von Triticum vulgare und zwar meistens in den borstigen Sommersorten: Malešice bei Prag (Baudyš); Mečeřiž bei Benátek! Chleby bei Poděbrad! Vokšice bei Jičín (Baudyš)!

Tilletia levis ist hauptsächlich in Siideuropa verbreitet. Ich fand sie öfters in Bulgarien und Montenegro. Sie stinkt ebenfalls nach Trimethylamin.

b) Sporenmasse violettbraun.

49. Tilletia Secalis (Corda) Kühn. - Uredo Secalis Corda.

Sporenmasse in allen Fruchtknoten, violettbraun; Sporen kuglig, $18-245 \mu$ breit, oder eiförmig, $22.5-245 \mu$ lang, $18.5-22.5 \mu$ breit, oft auch polyedrisch; Membrau violettbraun, besetzt mit 2-2"5 " hohen, netzartig zusammenfliessenden Leisten; Maschen 2-5 " breit.

In den Fruchtknoten von Secale cereale: Lesná und Babice bei Pacov!

Eine seltene Brandart, die mir nur aus Sachsen, Schlesien, Mähren, Bulgarien bekannt ist. In Mähren sammelte sie der Apotheker J. P a ul bei Mähr. Schönberg, in Bulgarien bei Boikovo in den Rhodopen ich selbst und der † Malkow. Aus Böhmen führt den Pilz schon Corda als Uredo Sccalis in $\mathrm{H} l$ u bek's "Oekonomischen Neuigkeiten" an. Ich konnte diese Zeitschrift leider nirgends finden und deshalb ist mir Corda's Standort unbekannt.

Bei den obengenannten zwei Dörfern erschien dieser Brand im J. 1910 Mitte Juli und vernichtete daselbst weit und breit bis $50 \%$ der Ähren. Die Sporenmasse stinkt stark nach Trimethylamin.

Volkart hält sie für identisch mit Tilletia Tritici. was entschieden falsch ist. Schon die Farbe der Sporenmasse ist gänzlich verschieden. Es gelang mir bei meinen Infektionsversuchen in den J. 1911-1913 nie mit Sporen von Tilletia Secalis Triticum und Hordeum zu infizieren.

\section{Tilletia Panćicii Bubák et Ranojevié.}

Sporenmasse dunkelviolettbraun, alle Fruchtknoten erfiillend; Sporen kuglig, $20-24 \mu$ breit oder eiförmig bis ellipsoidisch, $22-28 \mu$ lang, 
18-22 u breit; Membran violettbraun, besetzt mit $2-3^{*} 2 \mu$ hohen, netzartig verbundenen Leisten; Maschen $2-6 \mu$ breit.

In den Fruchtknoten verschiedener Hordeum-Arten (in Serbien und Bulgarien auf Hordeum tetrastichon) Ende Juni und im Juli.

In Böhmen im Juli auf Hordeum distichum: Ober Počernic, nach Angabe des Herrn Nolč. Hordeum tetrastichon: Im botanischen Garten zu Tábor! Hordeum hexastichon: Ebendort!

Das Vorkommen dieser Brandart im botanischen Garten zu Tábor, lïsst sich auf die Versuche nit derselben, die ich daselbst im J. 1910 bis 1912 durchgefiuhrt habe zurïkführen. Bei diesen Versuchen gelang es mir zahlreiche Sorten der vier- und sechszeiligen Gerste zu infizieren. Die Versuche mit Roggen und Weizen verliefen immer negativ.

Mit Tilletiu Hordei Körnicke, welche auf Hordeum murinum, fragile, bulbosum vorkommt, hat die vorliegende Art nichts zu tun.

\section{Tilletia controversa Kühn.}

Sporenmasse violettbraun, in allen Fruchtknoten entwickelt; Sporen kuglig, 22-28 " breit, oder eiförmig, 22-30 " lang, 22-26.5 " breit; Membran hellviollettbraun, mit 2--3 $\mu$ hohen, netzartig zusammenfliessenden Leisten besetzt; Maschen $355-755 \mu$ breit.

In den Fruchtknoten von Agropyrum-Arten. In Böhmen auf Agropyrum repens: Letná bei Prag (Opiz im Herb. d. böhm. Museums in Prag)! Schwarzerberg bei Brixx! Wostray bei Lobositz (Čelakovský fil.)!

Durch hellere, violette Sporenmasse, das uberwinternde Myzel, grössere Sporen von Tilletia Tritici verschieden.

\section{Tilletia Lolii Auerswald.}

Sporen hellolivenbraun, in allen Fruchtknoten entwickelt; Sporen kuglig bis eiförmig, 20-29 " breit; Membran gelbbraun, mit $2 \mu$ hohen, netzartig verbundeuen Leisten besetzt; Maschen 2-4 " breit, rundlich oder eckig.

Im Juli und September in den Fruchtknoten verschiedener LoliumArten, z. B. Lolium perenne, L. remotum, L. temulentum. Wird gewiss auch in Böhmen gefunden.

\section{Tilletia Menierii Hariot et Patouillard.}

Sporenmasse alle Fruchtknoten füllend, violettbraun; Sporen kuglig bis eiförmig, 19-28 " breit; Membran hellviolettbraun, besetzt mit 2 bis 3 " hohen, netzartig verbundenen Leisten; Maschen rundlich oder eckig, $3-6 \mu$ breit.

Im Juli in den Fruchtknoten ron Phalaris arundinacea var. picta in Frankreich. Könnte auch bei uns gefunden werden. 
Tilletia Guyotiana Hariot 1900. - T. Trlemorslýi Bubák 1903. - T. belgradensis Magnus 1908.

Sporenmasse in allen Fruchtknoten entwickelt, violetthraun; Sporen kughig oder kurz eiförmig, 22-285 " hreit; Membran hellviolethraun, besetzt mit nur 1 " hohen, netzförmig zusammenfliesseulen Leisten; Maschen eckig, $2-4 \mu$ breit.

Im Mai und Juni in den Fruchtknoten verschiedener BromusArten (z. B. Bromus arvensis, erectus, secalinus). Aus Frankreich, Russland, Ingarn, Serbien, Bulgarien bekannt. Wird gewiss auch in Böhnen später gefunden.

\section{Tilletia decipiens (Persoon) Körnicke.}

Sporeumasse hellviolettbraun, in allen Fruchtkuoten entwickelt; Sporen kuglig, 28-32 " breit, oder eiförmig, 28-38 $\mu$ lang, 28-32 ") breit;

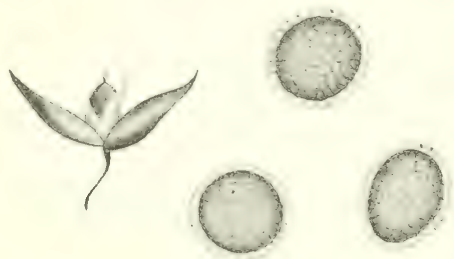

Abb. 19. Tilletia decipiens: Ein infiziertes Aehrchen von Agrostis vulgaris und isolierte Sporen. (Original.)

Membran hellvioletthraun, hesetzt mit 35-55 " hohen, netzförmig verbundeneu Leisten; Maschen rumdlich oler eckig, 25-4 " breit.

Im Juli und August in den Fruchtknoten von Agrostis vulgaris: Riesengebirge (Kablik, im Herb. d. böhm. Museums in Prag)! Raschen im Jeschkengebirge (Baudyš); Isergehirge (Opiz)! Fugau (Karl)! Fuss des Berges Třemošná bei Př́lbram! Mašovice bei ('hýnov! Bzí bei Wesselí a. L. (Celakovský fil.) Budweis (.Jechl)! Rosental, Vrsee bei Kopidlno, Jičíněves und Zebín bei Jiěín (Baudyš).

Das Myzel durchdringt alle Triebe der befallenen Pflanzen, iiherwintert im Rhizom und in den Wurzeln. Die infizierten Pflanzen verkiimmern, die Rispen sind gedrungen, so dass solche Pflanzen von den älteren Samlern (Kablik, ()piz, Karl ete.) als eine auffallende Form ron Agrostis alba! gesammelt wurden.

\section{$B$. Sporenmasse in den Blättern.}

a) Sporen an der Oberflächenetzig. 


\section{Tilletia olida (Riess) Winter. - T. endophylla De Bary.}

Streifen lang, schmal, die ganze Blattspreite durchlaufend, von grauer Epidermis bedeckt, später nackt, schwarz, stäubend; die Spreite wird faserförmig zersehlitzt; Sporen kuglig, 21-27 $\mu$ breit oder eiförmig, länglich, oft polygonal, 20-30 lang, 19-25 " breit; Membran kastanienbraun, besetzt mit $1-15$ u hohen, netzartig verbundenen Leisten oder nur mit meändrischen Rippen; Maschen rundlich oder eckig, 2-4 $\mu$ breit.

Von Ende Mai bis August in den Blättern von Brachypodium silvaticum: Teplitz (Thümen)! Krumau (Gerhardt)!

Kommt auch auf Brachypodium pinnatum vor. Sie zeichnet sich durch zweierlei Struktur des Epispors aus; die meändrische ist seltener.

\section{Tilletia flectens Lagerheim.}

Brandpolster kurz, höchstens $2 \mathrm{~cm}$ lang, das ganze Mesophyll füllend, von grauer Epidermis bedeckt, dann geborsten, stäubend, schwarz; Sporen kuglig, 28--32 $\mu$ breit, oder eiförmig, 32-40 $\mu$ lang, 26-34 " breit; Membran dunkelkastanienbraun, besetzt mit $1 \frac{1 / 2}{2} 2 \mu$ hohen, netzförmig verbundenen Leisten; Maschen $1^{\circ} 5-3 \mu$ breit.

In den Blättern von Aira flexuosa bisher nur in Schweden. Die befallenen Blätter sind mehr oder weniger verbogen und gewöhnlich rot verfärbt.

Sie ist mit T. Sesleriae verwandt, von derselben aber durch kleinere Sporen und Maschen verschieden. Auf Aira flexuosa kommt auch Tilletia striaeformis vor.

\section{Tilletia Sesleriae Juel.}

Brandstreifen schmal, bis einige $\mathrm{cm}$ lang, von grauer Epidermis bedeckt, später berstend, schwarz, stäubend; Sporen kuglig, $32-36 \mu$ breit, eiförmig oder polyedrisch, 32-42 $\mu$ lang, 28-34 breit; Membran dunkelkastanienbraun, mit 1-1.5 $\mu$ hohen, netzartig verbundenen Leisten bedeckt; Maschen $2-4 \mu$ breit, rundlich oder eckig.

In den Blättern von Sesleria coerulea von Mitte Mai bis Juli auf den schwedischen Inseln Gotland und Oeland. Vielleicht auch bei uns, wo die Nährpflanze verbreitet ist.

Von allen verwandten Arten durch die grossen Sporen abweichend.

Die Diagnose habe ich nach Juel's Originalen entworfen.

b) Sporen warzig.

\section{Tilletia Airae caespitosae Lindroth.}

Brandpolster kurz, schmal, der Länge nach zusammenfliessend, von grauer Epidermis bedeckt, später berstend, schwarz, stäubend; Sporen 
kuglig, $95-135$ " breit, oder eiförmig bis länglich, oft auch polyedrisch, 11-16 "lang, 95-11\% " breit, mit kastanienbrauner, fein warziger Membran.

Finnland.

In den Bliittern von Aira caespitosa im August, hisher nur, in

\section{Deschampsia caespitosa: Vokšic bei Jičín (Baudyš)!}

Die Diagnose entwarf ich nach den Origiualen. Ton Tilletia striaeformis und den verwandten Arten durch feinwarzige Sporen verschieden.

c) Sporen stachlig.

55. Tilletia striaeformis (Westendorp) Oudemans. - T. Brizae Ule. T. Milii Fuckel.

Brandpolster schmal, bis einige $\mathrm{cm}$ lang, von grauer Epidermis bedeckt, später berstend, schwarz, stäubend; endlich zerreisst die Blattspreite faserförmig; Sporen kuglig, 95-135 $"$ breit, oder eiförmig bis ellijssoidisch und of t polyedrisch, $115-14^{\circ} 5 u \operatorname{lang}, 95-115 \%$ breit, hellkastanienbraun, mit warzig-stachliger Membran.

In den Blättern verschiedener Gräser: Agrostis, Arrhenatherum, Briza, Bromus, Calamagrostis, Dactylis, Festuca, Holeus, Lolium, Milium, Phleum, Poa.

In Böhmen von Mai bis August in deu Blättern von Agrostis vulgaris: Rybníček bei Jičín (Baudyš)! Dactylis glomerata: Zwisehen Babka und Solopisky nüchst Cernošic! Tetschen (Thümen)! Holcus lanatus: Harta bei Hohenelbe (Cypers)! Herrnskretschen (Wagner)! Tal Jezírka bei Kacanova näehst Gross-Skal, zwischen Kbelnice und Dílce bei Jičín (Baudyš). Holcus mollis: Tetschen (Thiimen)! Herrnskretschen (Wagner). Horní Lochov bei Jičín, Kundratice bei Prag (Baudyš)!

Es war mir möglich die vorliegende Brandart fast von allen oben angeführten Grasgattungen zu untersuchen. Ich fand zwischen den einzelnen Formen nur unbedeutende Unterschiede, welche die Form und Grösse der Sporen und die Höhe der Stachelchen betreffen. Diese Unterschiede sind sehr relativ und reichen zur Bildung neuer Arten nicht aus. So fand ich z. B., dass die Sporen auf Dactylis, Milium und Phleum grösser und deutlicher warzig sind als bei der Form auf Holcus. Am meisten weicht die Form auf Agropyrum repens ab, so dass ich sie fiir eine gute Art halte.

Ule hat eine Reihe von Tilletia-Arten (siehe Hedwigia 1886, pg. 112-114) von verschiedenen Gräsern aufgestellt. Dieselbeu sind ungenuigend beschrieben. Alle seine von mir untersuchten Arten gehören sicher zu der vorliegenden Spezies. Ich sah nicht: T. Acenar Tle aut' Avena pratensis, $T$. alopecurivora Ule auf' Alopecurus pratensis und T. steritis Ule auf Koeleria cristata. Ich zweifle aber nicht, dass anch sie zu T. striaeformis gehören. 
Tilletia Calamagrostidis Fuckel.

Brandstreifen kurz oder einige ( $m$ lang, der Länge nach zusammenfliessend, ron grawer Epidermis bedeckt, später nackt, schwarz, stäubend; Sporen kuglig, 13-17 " breit oder eiförmig, ellipsoidisch oder unregelmässig, oft auch polyedrisch, 17-19 "lang, 11-17 $\mu$ breit, dunkelkastanienbraun, mit $1 \mu$ hohen Stacheln besetzt.

In den Blattspreiten und Blattscheiden verschiedener Calamagrostis-Arten. Wahrscheinlich auch in Böhmen.

T. ('alamagrostis ist sicher eine gute Art, durch die grosen Sporen und lange Stacheln ausgezeichnet. Friiher war sie mit T. striaeformis, welche auch auf C'alamagrostis-Arteu rorkommt, konfundiert. Die Tilletia auf Calamarrostis Halleriana weicht von T. striaeformis und T. Calamagrostidis gänzlich ab.

\section{Tilletia corcontica Bubák n. sp.}

Brandstreifen bis einige $\mathrm{cm}$ lang, schmal, parallel zwischen den Nerven verlaufend, von grauer Epidermis bedeckt, später nackt, schwarz, stäubend; Sporeu sehr variabel, kuglig. 11 bis länglich, manchmal polyedrisch, 13-17 " lang, 9`5-13 " breit; Membran dunkelkastanienbraun, mit feinen, ': ", hohen, diinnen Stachelı besetzt.

Im Juli und August in den Blättern von Calamagrostis Halleriana: Schneegrubenbaude (Schroeter); Riesengebirgskamm (ohne nähere Standortangabe, leg. Gerhardt)! Birnai bei Aussig (Wagner).

Diese Brandart ähuelt in der Bestachelung der vorangehenden, hat aber konstant kleinere sporen. Die närhstfolgende Spezies hat wieder grössere sporen und laingere Stacheh. Schon Wi n te r (Pilz= flora v. Deutschland I, pg. 108) macht auf diese Unterschiede aufmerksam.

\section{Tilletia aculeata Ule.}

Braudstreifen schmal, bis einige $\mathrm{cm}$ lang, von grauer Epidermis bedeckt, später berstend. schwarz, stiubend, die Blattspreite faserförmig zerschlitzt; Sporeu kuglig, 115-17 " breit, oder eiförmig, ellipsoidisch, länglich, 13-17 " lang, 9`5-13 " breit; Membran dunkelkastanienbraun, mit $1 / 2-3 / 4 \mu$ Stacheln besetzt.

Von Mitte Mai bis August in den Blättern von Agropyrum repens: Ostufer des Teiches Jordan hei Tábor (zuerst 19./T. 1914)! Liebenau (Baudyš, 7./VI. 1915)!

In der Bestachelung steht sie in der Mitte zwischen T. striaefor. mis und T. Calamagrostidis. Sch r o eter reiht sie in Pilze Schlesiens I, pg. $279 \mathrm{zu}$ der letzteren, gewiss mit Unrecht.

\section{C) Sporen in den Kapseln der Torfmoose.}




\section{Tilletia Sphagni Nawaschin.}

Sporemmasse in den Kapseln, gethorange, stäuhend: Sporen kughig, seltener eiförmig, 11-15 u breit; Membran gelblich, 1-1:5 $u$ dick, mit sehr niedrigen, netzformig verbundenten Leisten hesetzt; Maschen 3-4 "I breit, eckig.

In den Kayseln von S'phagnum-Arten. In Böhmen auf siphanmum eymbifolium: Lomnitz a./L. (Kavina nach Baudyš).

Die befallenen Kapseln sind kuglig und etwas grösser als die gesunden. Friber wurden diese syoren fiir die "Mikrosporen" der Torfmoose gehalten.

Die Zugehörigkeit des Pilzes zu den Hemibasidien ist sehr unsirher.

\section{Gatt. Melanotaenium de Bary.}

Sporen interkalar aus nicht gallertartig verquollenen Hyphen gebildet, nicht stiubend. Promyzel dichotom verzweignt; der eine Ast verkiimmert und bleibt steril, der andere wird läuser und bildet am scheitel Sporidien, welche fest anhaften und oft zu zwei fusionieren.

Myzel entweder flichtig und lokal (M. Ari) oder ausdauerud und damn dringt es alljährlich in die newen Triebe ein, die auf verschiedene Weise deformiert werden.

\section{A) Myzel lokalisiert.}

a) Sporen mit doppelter Membran.

59. Melanotaenium Ari (('ooke) Lagerheim. - Protomyces Ari Cooke. Lstilago plumbea Rostrup. - Melunotanium plumbeum Rostrup.

Sporenmasise in den Blittern, kleine 'Tuberkeln bildend; dieselben in kleinere oder grössere meändrische (imppen zusammenfliessend, von grauer Epidermis dauerud bedeckt; Sporen kuglig, 13-17 u breit, oder eiförmig, seltener ellipsoidisch, of t unregelmässig, 19-26 "lang, 13-17 " hreit: Membran doppelt: die innere dick, gleichmäsig verdickt, intensiv gelbbraun, die aussere unregelmaissig dick, stellenweise hyaliu.

Ton Mai bis. Juli in den Blattstielen und Blattspreiten von Arum maculatum: Wiesenmühle bei Liebenau (Baudyš)!

b) Sporen miteinfacher Membran.

Melanotaenium hypogaeum ('T'ulasne) Schellenberg. - C stila!y" h!lpumum T'ulasne.

Sporenmasse in Wurzeln oder im Hypokotyl, in knollenartigen, unregelmässigen, anfangs geschlossenen, später rissigen Intumezunzu, schwarz; Sporen unregelmäsig kuglig oder eifömig, oft polyedrisch, 
14-22 " breit oder bis $25 \mu$ lang; Membran einfach, schwarzbraun, dick, glatt.

Auf Linaria spuria bisher nur in der Schweiz und in Frankreich. Vielleicht auch bei uns. Die Diagnose wurde auf Grund des französischen Materials (von Hariot) entworfen.

\section{$B)$ Myzel perennierend; Sporenmembran einfach.}

60. Melanotaenium cingens (Beck) Maguus. Ustilago cingens Beck 1881. Melanotaenium caulium Schneider 1887.

Sporeumasse in federkielartig verdickten Stengeln und Aesten, oder auch in Blättern, von der Epidermis bedeckt, nur schwarzblau durchschimmernd; Sporen kuglig, 17-23 $\iota$ breit, oder eiförmig, 19-23 $\mu$ lang, 13-17 $\mu$ breit, mit intensiv kastanienbrauner, glatter Membran.

Von Juni bis september in Linaria vulgaris: Ceřovka bei Jičín (Baudyš)!

Das Myzel iberwintert im Rhizom, durchdringt in der Vegetationsperiode gewöhnlich die ganze Nährpflanze, welche einen gedrungenen, thyrsoiden Wuchs aufweist; die Stengel und Aeste sind federkielartig verdickt.

\section{Melanotaenium endogenum (Unger) De Bary. - Proto- myces endogenus Unger.}

Sporenmasse in den Stengeln, Aesten und Blättern, von der Epidermis bedeckt, nur schwarzblau durchscheinend; Sporen eiförmig oder ellipsoidisch, selten kuglig, $20-28 \mu$ lang, $13-22 \mu$ breit, schwarzkastanienbraun, glatt.

Von Mai bis September in verschiedenen Stellateen. Asperula galioides: Sct. Procopius bei Prag! Galium mollugo: Korno bei Karlstein (Schiffner)! Galium

Abb. 20. Melanotaenium endogenum auf Galium verum: Habitus der infizierten Pflanze. (Original.) verum: Tschersing bei Leitmeritz! Tábor! 
Diese seltene Brandart durehdringt mit ihrem Myzel dir ganze Niihrpllinze, welche entweder verkimmert, wobei die Internodien verkiirzt und rerdickt sind mul die infizierte. Pflanze jumen Konfferenkeimpflanzen ähnelt, orter manchnal auch ganz normal sind. lats Myzel iuberwintert im Rhizom.

\section{Gatt. Entyloma De Bary.}

Flache oder verdickte Blattlereke oder Tuherkeln auf den Stengehn und Wurzeln, seltener auf Blittern und Blattstielen. Sporen im (irmulgewebe einzeh oder nesterweise, interkalar im Verlaufe der einzelnen Ifyphen whe gallertartige Verfuellung entstanden. Nembran gewöhnlieh glatt, seltener fein- wder grobwarzig, shleichmässig orler ungleichmissig dick, gelblich, gelbbräunlich, seltener schwarzbram. Promyzel cinzellig. Sporidien am Scheitel sruppiert, länglich his fadenförmig, sekundäre sporidien bildend oder mit sterilem Faden keimend. Finige Arten bilden auch Konidien, welche den Sporidien ähnlich sind; sie dringen durch die Poren hervor und bilden gewïhnlich an der Tnterseite der Flecke weisse Gruppen oder Anfliige.

\section{A) Sporen in Flecken.}

a) Sporen von groben, stumpfen Warzen besetzt.

Entyloma urocystoides Bubák nov. nomen - Trooystis Corydalis Niessl.

Blattflecke rundlich oder elliptisch, 1-4 $\mathrm{mm}$ breit, beiderseits schwach gewïlbt, anfangs weiss, spiter ganz hraun, hesleckt, endlich rissiz; Sporen kuglig oder ellipsoidisch, 15-2.2 " breit, gefhbraun: Membran mit hreiten prismen- oder pyramidenartigen Terdickmngen, deren Breite ea $1 / 4$ des Sporendurchmessers beträgt.

In Blättern von Corydalis cava im Mai, bisher nur bei Brünn und Leipzig gesammelt. Vielleicht auch bei uns.

Auf firund einer eingehenden I'ntersuchung des Pilzes halte ich ihu (mit Winter) für eine Entylomu-Art. Da der Spezieswame Nies.s's schon vergeben ist (Siehe Ent. ('orydalis De Bary), so musste ich einen neuen Namen schaffen. Die Verdickungen auf der Sporenmembran sind keine Nebensporen, sondern kompakte, lumenlose Verdickungen.

b) Sporen mit Höckern besetzt.

\section{Entyloma verruculosum Passerini.}

Blattflecke unregelmässig, gewöhnlich verlängert, bis 1 ('m lang. gelb, spaiter in der Mitte brimulich; Sporen kuglig, 11-17" breit; Mem- 
bran gelbbraun, gleichmässig 3 " dick, mit niedrigen, flachen, ungleichmässigen Höckern besetzt.

Von Mai auf Rauunculus-Blïttern. In Böhmen auf Ramunculus lanuginusu: Pelsdorf bei Hohenelbe (Cypers). Belegeexemplare habe ich nicht gesehen!

\section{Entyloma Corydalis De Bary.}

Flecke rundlich oder lïnglich, bis $3 \mathrm{~mm}$ breit, anfangs an der Interseite weiss, von den Konidien bedeckt, an der Oberfläche gelblich oder mit schwach weisslichem Anfluge, später beiderseits braun. Sporen eiförmig oder kuglig, 13-17 " breit, oder bis 21 "lang; Membran gelbbrann, besetzt mit kurzen, dicken und lïngeren, verbogenen Höckern; Konidien zylindrisch, bis $30 \mu$ lang, $25 \%$ dick, hyalin.

Im Mai und in der ersten Hialtte Juni in Bliattern von CorydalisArten. In Böhmen auf corydalis cura: Am Wege von Karlstein zu Sct. Ivan! Klecaner Wiildchen! IIihlhausen a./E. (Kabát)! Chotuc bei Křnec!

Die Angabeu der Sporengrïsse sind bei Saccardo, Schroeter und Winter unrichtig.

c) Sporen glatt.

a) Membran hellgelb oder gelbbraun.

\section{Entyloma Ranunculi (Bonorden) Schroeter. - Fusidium Ranunculi Bonorden.}

Blattflecken rundlich oder lïnglich, 1-5 $\mathrm{mm}$ lang, von den Konidien anfangs bedeckt und weiss, spïter gelb und braun; Sporen kuglig oder eiförmig, 11-17 " breit, im Zusammenhange polyedrisch und oft verschiedenartig zusammengedriickt, mit hellgelbbrauner, glatter, gleichmäissig 2-27 " dicker Membran; Konidien von zweierlei Form: spindelförmig, 15-20 $\mu$ lang, 25-35 $\mu$ breit oder fadenförmig, bis $45 \mu$ lang.

Von Mai bis zum Wrinter auf verschiedenen Ranunculaceen: Ficaria rerna: Auf dieser Nihnpflanze verbreitet. Ranunculus auricomus: Ǩbelnice bei .Jičín (Baudyš)! Teplitz (Thiimen); 'Tábor! Ranunculus nemorosus: Radelstein im Böhm. Mittelgebirge! Ranunculus repens: Auf dieser Nährpflanze ziemlich oft! Ranunculuss scelerutus: ('hržín bei Welwarn (Kabát)! Parduhitz (Vodák)! Die Blätter siud oft von den Flecken wie besäet.

\section{(ii). Entyloma Thalictri (Thiimen) Schroeter. - Fusidium Thalictri Thiimen.}

Flecke auf beiden Blattseiten, un regelmässig, eckig, gewöhnlich von den Nerven begrenzt, $1-2 \mathrm{~mm}$ hreit, gelb bis braun; Sporen kuglig oder eiförmig, 75-13 " breit, im Zusammenhange polyedrisch, mit gleich- 
mässig 2-35 " dicker, gelbbrauner, glatter Membran; Konidienanfliige an der Unterseite der Flecke, weisslich.

Von Mai auf Blättern vou Thalictim-Arten. Thalictrum minus: Aussig (Thümen).

\section{Entyloma fuscum Sehroeter. - Entyloma bicolor Zopf.}

Flecke rundlich oder länglich, graubraun, braun bis schwarz, manchmal rot umsäumt, $1-10 \mathrm{~mm}$ breit; Sporen kuglig oder eiförmig, im Zusammenhange polyedrisch, 11-23 " hreit; Membran 2-6 " dick, zweischichtig: die äussere hyalin bis gelh)hraun, ungleichmäissig dick, glatt, die innere hell kastanienbraun, glatt; Konidien cylindrisch, 20-22 $\mu$ lang, 3 " dick, gebogen, an der Basis verjuingt, am Scheitel abgerundet, ein- melirzellig.

Von Juni bis August in Bliattern von Papater Argemone, P. dubium, $P$. rhoeas, $P$. somniferum. Sicher auch in Böhmen.

Zwisehen Ent. fuscum und Ent. bicolor kann ieh keine Unterschiede feststellen. Deshalb ziehe ich heicle, wie es auch ('linto n getan hat, zusammen.

\section{Entyloma Glaucii Dangeard.}

Flecke auf beiden Blattseiten, rundlich oder fiust rundlich, anfangs schmutzigweiss, später duukelgrau, 2-5 $\mathrm{mm}$ breit; Sporen kuglig oder eiförmig, im Zusammenhange unregelmässig und schwach polyedrisch, 10-16 " breit; Membran aufangs gelblich, reif hellbraun, glatt, $1 \%$ bis $2 \mu$ dick.

Von Juli bis September auf Glaucium luteum und Gl. flavum. Könnte auch in Böhmen vorkommen.

\section{Entyloma Feurichii Krieger.}

Flecke blattbeiderseits, rundlich oder lïnglich, $1-3 \mathrm{~mm}$ breit, hram, späiter in der Mitte graubraun, mamchmal zusammenfliessend. Sporen

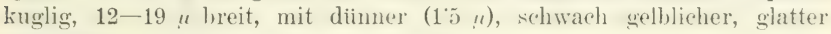
Membran.

In Blättern von Lathyrus silvestris im September, bisher nur aus Sachsen bekannt. Könnte auch bei uns gefunden werden.

\section{Entyloma Chrysosplenii Schroeter.}

Flecke blattunterseits, mehr oder weniger regelmässig rundlich, his $7 \mathrm{~mm}$ breit, anfangs weiss, später in der Mitte gelblich bis briumlich, anf der Oberseite nur dureh vergilbtes Gewetre markiert; Sporen kuglig oder fast kuglig, 7-12 $\mu$ breit, mit diumer, schwach gelblicher, glatter Membran. 
Von Mai bis zum Winter auf Blättern von Chrysosplenium alternifolium: Neuwelt im Riesengebirge. Bratlec bei Jičín (Baudyš)!

\section{Entyloma Mágocsyanum Bubák.}

Flecke klein, nur 1-3 mm breit, eckig, von den Nerven begrenzt, ledergelh, spitter blasser, blattbeiderseits sichtbar, flach; Sporen kuglig oder fast kuglig, 9-13 " breit, im Zusammenhange polyedrisch, hell-

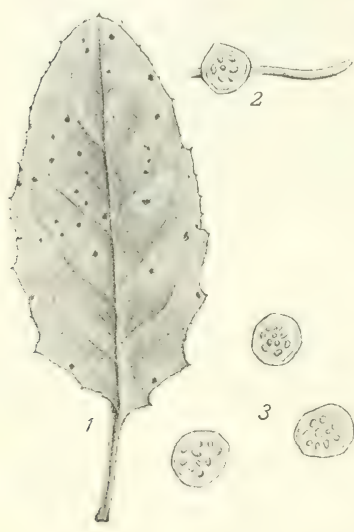

Abb. 21. Entyloma Calendulae: $1=$ Ein Blatt von Hieracium murorum mit dem Pilze; $2=$ eine interkalar gebildete Spore; $3=$ isolierte Sporen. (Original.) gelbbraun, mit glatter, $1-15 \mu$ dicker Membran.

Von Juni auf Blättern von Tordylium maximum. Bisher nur aus Ungarn bekannt.

\section{Entyloma Helosciadii Magnus.}

Flecke blattbeiderseits, rundlich oder unregelmässig, klein, nur etwa $1 \mathrm{~mm}$ breit, weiss. Sporen im Zusammenhange polyedrisch, 8-11 $\mu$ breit, mit hellgelber, glatter, überall gleichmässig $1 \mu$ dicker Membran.

Von Juni bis September auf Blättern von Berula angustifolia und Sium latifolium. Gewiss auch in Böhmen.

67. Entyloma Calendulae (Oudemans) De Bary. - Protomyces Calendulae Oudemans.

Flecke rundlich, bis $5 \mathrm{~mm}$ breit, griinlich oder weiss, später braun, oft mit rotbraunem oder karminrotem Saume; Sporen kuglig, 10-15 $\mu$ breit, hellgelb bis hellgelbbraun, mit doppelter, 2-3 $\mu$ dicker, glatter Membran.

In Blittern verschiedener Compositen von Mai bis zum Winter: Arnoseris musilla: Záholice bei Turuau (Kabát)! Arnica montana: Keilberg im Frzgelirge (WVagner, Krieger)! Calendula officinalis: Herrnskretschen, Tetschen (Wagner); Welwarn (Kabát). Hieracium murorum: Auf dieser Wirtispflanze in der Ehene und im Gebirge verbreitet. So z. B. im Riesengebirge bei cier Bergschmiede und im Riesengrund! Hieracium siliaticum: Jesserkenberg bei Trebnitz! An der Mummel am TTege von der Elbfallbaude! Hieracium sudeticum: Riesengebirge (Schroeter). Hieracium laevigatum: Dvorce bei Jičn (Baudyš)! 
Entyloma Cichorii Wróblewski

in Spraw. Kom. fizyogr. Akad. Tmiej. Krakow, T. XI.VII (1913), pag. 153 und 178.

Flecke auf gelhlich oder bräunlich verfürbten Blatfpartien, flarh, anfangs hellgriin, später braun, $1 \frac{1}{2}-2 \mathrm{~mm}$ breit; Sporen kugelig bis ellipsoidisch, im Zusammenhange polyedrisch, 10-14 " breit oder bis 15 " lang, mit hellgelber, glatter, gleichmiissig $1 \%$ " dicker Membran.

Auf Blättern von (ichorium Intybu: bisher nur aus (ializien hekannt. Die Diagnose wurde nach den Originalen, aus der Hand des Autors, entworfen.

\section{Entyloma Picridis Rostrup.}

Flecke klein, 1-2 mm breit, beiderseits gewällt, gelb umsäumt; Sporen kuglig oder eiförmig, im Zusammenhange polyedrisch oder zusammeugedriickt, $11-15 \mu$ breit oder bis $17 \mu$ lang, mit gelbbrauner, glatter, zweischichtiger, gleichmaissig 2 "dicker Membran; Konidien (nach Rostrup) nadelförmig.

Von August bis zum Oktober auf Blättern von Picris hieracioides: Tschöppern bei Brüx!

Entyloma Tragopogi Lagerheim. - Ent. Tragopononis Wróhlewski 1. ค. T. XLVIII (1914), pg. 5 et 15.

Flecke blattheiderseits, klein, ${ }^{1 / 2}-3 \mathrm{~mm}$ hreit, gelhlich; Sporen kuglig oder eiförmig, im Zusammenhange polyedrisch, 9-15 " breit, mit hellgelbbriunlicher, glatter, doppelter, gleichmissig oder ungleichmässig 2-3 $\mu$ dicker Membran.

Im August auf Blättern von Tragopoyom orientalis. Pisher uur aus Frankreich und Galizien bekannt. La gerheim heschreiht die Flecke bis 11 "lang, 1-2 " breit. Mir liegen die galizischen Fxemplare vor, nach welchen die Diagnose entworfen ist. Ich zweifle gar nicht, dass beide Pilze identisch sind.

\section{Entyloma Bellidis Krieger.}

Flecke weiss oder gelb, rumdlich, nicht hegrenzt, $1-2^{1}{ }_{2} \mathrm{~mm}$ breit, manchmal auch zusammenfliessend; sporen kuglig, (9-15 ") hreit, mit $1 \frac{1}{2}-2^{1 / 2}$ " dicker, gelblicher, glatter Membran; Konidien nadelförmig, 20-40 $\mu$ lang, $15 \mu$ breit, fast gerade, hyalin.

Von Mai bis August in Blatteru von Bellis perenmis: Herrnskretschen (Krieger, Wagner)! Eisenstein im Böhmerwalde (Krieger)!

\section{Entyloma Matricariae Rostrup.}

Flecke auf den Fiederblïttchen, klein, rundlich oder lïn lich, schwach verdickt, anfangs weisslich, snïter gelb bis braun; Sporen kuglig 
oder eiförmig, 13-17 " breit, im Zusammenhange polyedrisch, mit hellgelber, 15-2 " gleichmässig dicker, glatter Membran; Konidien (nach Rostrup) eiförmig, 4-6 $\mu$ lang, 2-2*5 $\mu$ breit.

Auf Blittern von Matricaria inodora vou Juni bis September. Vielleicht auch in Böhmen.

\section{Entyloma Achilleae Magnus.}

Sporen in den gebräunten und mehr oder weniger rerdickten Blattzipfeln, kuglig oder eiförmig, 12-15 "/ breit, mit goldgelber, gleichmässig, manchmal auch ungleichmässig 1\%-20 ".

In den Blättern von Achillea Millefolium im August in Finnland Schweden, Dänemark, Deutschland, Calizien. Sicher auch bei uns. Ein sehr unauffalliger Pilz, der deshalb iibersehen wird. Es sind immer nur sehr wenige Blattzipfeln inficiert.

\section{Entyloma serotinum Schroeter.}

Flecke rundlich, 2-5 $\mathrm{mm}$ breit, anfangs von den Konidien bedeckt, ganz weiss, später braun; Sporen kuglig, 11-15 " breit, mit hellgelbbrauner, glatter, gleichmässig $2-2.5$ u dicker Membran; Konidien fadenförmig, 25-40 $\mu$ lang, $2-3 \mu$ breit, hyalin.

Von Mai his zum Winter auf Symphytum-Arten, Borrago officinalis und Pulmonaria officinalis. Tu Bühmen auf Symphytum officinale: Baumgarten und (ibulka hei Prag! Sadská! Pardubitz (Vodák)! Welwarn (Kabát)! Wopurarnertal bei Lohositz (Kahát)! (iross Skal! Harta (Cypers); Herruskretschen (Waguer)! Tábor! Symuluytum tuberosum: Komorany, Závist, Roztok bei Prag! Welhíne bei Leitmeritz! Mache daselbst (Tagner); Rybuícek und Weisse Miihle hei Jičín, Bohdánkor bei Liebenau (Bandrš) Pintorka bei Tábor! Die Blätter sind gewöhnlich von den Flecken dicht besäet.

71. Entyloma Fergussoni (Berkeley et Broome) Plowright. - Protomyces Fergussoni Berkeley et Broome. - Entyloma canescens Schroeter.

Flecke blattheiderseits orler uur blattunterseits, rundlich, 1-2 $\mathrm{mm}$ breit, weiss, später in der Mitte bräumlich: Sporen kuglig, 11-13 " breit, mit $1-1$ : " dicker, hellgelber, slatter Membran; Konidien zylindrisch, 25-40 " lang, 25-3 u breit.

Von Juli his (1) ktober anf Blattern verschiedener Myosotis-Arten. In Böhmen auf' Mynsotix palustris: Welwarn, Turnau (Kabát)! Eisenstadtl bei Jičín (Bandyš)! Myosutis arrensis: Kbelnice bei Jiěín (Baudyš)!

I)iese Brandart ist in den sammlungen gewöhnlich steril, denn die Sporen bilden sich erst in älteren Blättern. 


\section{Entyloma Linariae Schroeter.}

Flecke gelblich, später weiss, rundlich orter länglicts, 1-2 mm hreit,

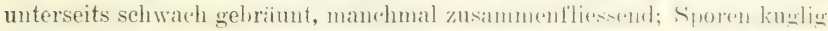
oder eiformig, 11-15 ", breit, slatt, mit doppelter Mrmbran: die anssur. gelblich, die innere hyalin, beide gleichmässig je 1 " dick.

Von Juni bis Oktober in den Blättern von Linaria vulgaris: Turnau (Kabát)! Butoves und Rybniček bei Jičín, Těsin bei Fisenstault (Bauḍ̣s); Herrnskretschen (Wagner).

\section{Entyloma veronicicola Lindroth.}

Flecke blattheiderseits, rundlich, schwach verdickt, 't -1 mm lireit, anfangs yrau, später braun; Sporen kuglig, $13-175$ "l lieit, exler 175 bis 21 " lang, 155-175 " breit, mit hellgelher, doppelter Membran: dif innere $15 \%$, die äussere $25 \mu$ dick, glatt.

Von August bis Oktober auf Blättern von Veronica serpyllifolia und $\mathrm{T}$. acinifolia bisher nur in Finnland, Deutschland und Montenegro. Bei uns auf Veronica serpyllifolia: Bei Liebenau (Baudyš)!

Entyloma Henningsianum Sydow. - Ent. Talerandi Rostrup manuser.

Flecke blattbeiderseits, rundlich oder liunglich, 4--8 $\mathrm{mm}$ hroit, anfangs gelblich, später gelhbraun, schwach verdickt; Sporen kuglig, 10 bis 15 " breit, oder eiförmig, bis 18 , lang, mit hellgelber, glatter, 2-27 " dicker Membran.

Von Juli bis September in den Blaittern von Stamolus. T'alerandi in Dänemark und Deutschland. Vielleicht auch in Böhmen.

\section{Entyloma Plantaginis Blytt.}

Flecke blattbeiderseits, gelblich, undentlich, nicht begrenzt, unregelmässig; Sporen kuglig bis eifömig, im Zusammenhange eckig, 10-1々 "I breit, mit doppelter, gelbbrauner, 2-25 " dicker Mtumbran, glatt.

Auf Blättern von Plantago media in Norwegen und Pl. lanceolata in Galizien, vielleicht auch hei uns, denn der Pilz ist sehr unansehnlich und deshalb wohl bisher ibersehen worden. Die Diamnse worde nach dem galizischen Material (gesammelt rom IT roblews ki) von mir (ntworfen.

\section{Entyloma Brefeldi Krieger.}

Sporen in Blittern in gelhlichen, langen und ausgerlehnten sitreitim. kuglig oder eifömig, im Zusammenhange polyedrisch, $11-19$ "I hreit, mit hellgelber bis hellgelbhrauner, zweischichtiger, 2- + " dicker, ulatter Membran. 
Von Juli bis August in Blattspreiten und Blattscheiden von Holcus mollis: Fichtelherg im Erzgebirge (Krieger)! Phalaris arundinacea: Polenztal in der böhm.-sächs. Schweiz (Krieger)!

Kommt auch in den Blïttern von Irrhenatherum avenaceum, Holcus lanatus und Poa pratensis vor. Die befallenen Blätter sind gelb verfärbt, sonst fallen sie gar nicht auf, da keine begrenzte Flecke gebildet werden.

в) Sporenmembran dunkelbraun.

\section{Entyloma crastophilum Saceardo.}

Flecke blattbeiderseits, zwischen den Nerven dichtstehend, rundlich oder kurz strichförmig, bis $2 \mathrm{~mm}$ lang, manchmal quer oder der Länge nach zusammenfliessend, schwarz; Sporen kuglig oder eiförmig, 8-14 " breit, dicht verklebt, deshalb polyedrisch; Membran dunkelbraun, in den Ecken dicker, glatt.

In den Blättern von Dactylis glomerata, Holcus lanatus, H. mollis, Phleum pratense von Juli bis zum Winter. Holcus mollis: Kuhstall in der böhm.-sächs. Schweiz (Krieger)! und gewiss noch anderwärts.

\section{Entyloma irregulare Johanson.}

Flecke blattbeiderseits, rundlich oder länglich, etwa $0.25-1.8 \mathrm{~mm}$ breit, oft quer oder der Länge nach zusammenfliessend, anfangs grau, später schrarz; Sporen nicht verklebt, kuglig, eiförmig, 8-14 $u$ breit, oder lünglich, oft auch unregelmässig, bis $19 "$ lang, glatt, mit hellkastanienbrauner, 1-1 ${ }^{\prime \prime}$, "l dicker, stellenweise dickerer Jembran; Konidien verlängert, spindelfürmig, oft am Scheitel dicker, wenig gebogen, $10 \mu$ lang, $175-3 \mu$ dick, hyalin.

Von August his Oktober in den Blättern von Poa pratensis. Wohl auch in Böhmen. Durch freie, hellere, weniger regelmässige Sporen von der vorangehenden Art verschieden.

\section{$B$. Sporen in Tuberkeln gebildet.}

a) In den Blattspreiten und Blattstielen.

\section{Entyloma microsporum (L'nger) Schroeter. - Protomyces:} microsporus Unger.

Tuberkeln halbkugelig, länglich bis verlängert, 2-10 $m$ m gross, anfangs weiss, später lederbraun, innen weiss, dann herstend, schwach stäubend; Sporen kuglig, eiförmig oder lïnglich, 15-25 " lang, 12-18 " breit, im Zusammenhange polyedrisch oder zusammengedriickt, mit sehr hellgelber, ungleichmässig bis $7 \mu$ dicker, glatter Membran.

Von August bis Oktober auf Blattspreiten und Blattstielen von Ranun ulus acris: Dráěov bei Rovensko! Teue stiihle bei Liebenau (Ban- 
dyš). Renunculus r pens: Ková, Novğ mlýn, (iross skal bei Rovensko! Nechanice, Zehín, Kolín, Butoves bei Jiěn, Eisenstadtl, Liehenau (Bamdyš); Eisenstein im Böhmerwalde (Krieger).

77. Entyloma Eryngii (Corda) De Bary. - Phyysoderma Erymgii ('orda.

Tuberkelu blattbeiderseits, wenig gewölht, anfangs schwach violett, später braun, $1-3 \mathrm{~mm}$ breit, oft zusammenfliessend, unregelmaissig berstend, stäubend; Sporen in senkrechteu Reihen, kuglig bs lïnglich, $10-15$ " breit oder bis 22 " lang, stark polyedrisch, mit hellgelbhrauner, doppelter Membran: die innere gleichmässig, die iussere ungleichmäissig dick, im Wasser leicht aufquellend, glatt.

Eryngium campestre: In der nächsten Umgegend von Prag ïfterw, hier schon von ('orda und Opiz gesammelt! Unter Krě (Opiz)! Vysočan! Kuchelbad! Koda bei Beraun! Kolín (Veselský); Kačina (Peyl)! Budohostice bei Welwarn (Kabát)! (ešov hei Kopidluo, Velíš hei Jičín (Bandyš). Brüx (Stika)! Teplitz (Thümen, Eichler)! Aussig!

b) Auf dem Stengel und Hypokotyl.

Entyloma Aschersonii (Ule) Woronin. - Sorosporium Aschersonii Ule. Ustilago Magnusii Winter p. p.

Beulen auf dem Stengel und Hypokotyl, fast kuglig, manchmal bis $1 \mathrm{~cm}$ hreit, oft gehäuft, anfangs innen hellgelb, später katstanienbraun; Sporen kuglig oder eiförmig, 11-21 " hreit, im Zusammenhange wenig zusammengedriickt, mit mehrschichtiger, $4-7 \mu$ dicker, hellkastanienbrauner, glatter Membran.

Auf Gnaphalium arenarium von Juli bis zum Winter in Deutschland. Vielleicht auch bei uns. I)ie befallenen Pflanzen oder ihre Triebe gehen zu Grunde.

Entyloma Magnusii (Ule) Woronin. - Sorosporium Magnusii Ule. - Tstilago Magnusii Winter p. p.

Beulen auf den Stengeln und auf dem Hypokotyl, fast kuglig, 3-10 $\mathrm{mm}$ dick, oft gehäuft, anfangs inuen hellbraun, später dunkelhraun; Sporen kuglig oder eifürmig, 13-25 " breit, im Zusammenhange oft polyedrisch, mit mehrschichtiger, 4-6 " dicker, hellgelher, glatter Hembran.

Auf (inaphalium luteo-album vou Juli bis zum Winter in Deutsehland. Vielleicht auch bei uns.

Vou der vorangehenden Art durch grüssere, hellere Sporen verschieden. 


\section{Gatt. Schinzia Naegeli (Entorrhiza C. Weber).}

Myzel im Rindenparenchym der Wurzeln, verzweigt. Sporen dickwandig, intrazellular an den Enden bischelig verzweigter Hyphenaeste gebildet. Ein bis mehrere, manchmal wenig verzweigte Promyzelien. Sporidien klein, sichelförmig, am Ende des Promyzels und seiner Aeste entstehend, seltener ein wenig herabgeruickt.

78. Schinzia Aschersoniana Magnus. -- Entorrhiza cypericola Schroeter. E. Aschersoniana Lagerheim.

Tuberkeln auf den Turzeln, eiförmig bis ellipsoidisch, bis $1 \mathrm{~cm}$ lang, his $5 \mathrm{~mm}$ breit, hellbraun; Sporen in den Zellen der Tuberkeln, kuglig, 15-24 " breit, oder eiförmig, manchmal auch zugespitzt, 19-28 "॥ lang, 17-25 " breit; Membran dick, gelb oder hellkastanienbraun, mit zahlreichen, groben, abgerundeten Warzen besetzt.

Von Juni bis September auf Turzeln von Juncus bufonius: Láz bei Přibram! Herrnskretschen (IVagner).

Saccardo, Schroeter und Schellenberg geben die Sporen viel kleiner an. Ich finde sie aber so, wie oben angegeben.

Schinzia Casparyana Magnus. - Entorrhiza Casparyana De Toni.

Tuberkeh wie bei der vorangehenden Art; Sporen kuglig, 17-22 u breit, hellgelb, mit grossen, unregelmässigen, stark gewölbten, bis j u breiten Warzen bedeckt.

In den Trurzeln von Juncus Tenageia in Deutschland und auf der Insel Sardinien. Vielleicht auch in Böhmen.

Die Diagnose wurde aus den Angaben ron Magnus zusammengestellt. (Berichte d. deutsch. bot. Ges. 1888, pg. 103.)

79. Schinzia digitata (Lagerheim) Maguus. - Entorrhiza digitata Lagerheim.

Tuberkeln wie bei den vorangehenden Arten, handförmig geteilt; Sporen kuglig, 17-30 " breit, hellkastanienbraun, mit פrossen, zerstreut stehenden Warzen.

In den Wurzeln von Juncus lamprocarpus, J. arcticus. Auf der ersten Nährpflauze: Zwischen Rỵbníček und Brada bei Jičín (Baudy̌)!

Ton der vorangehenden Species ist die vorliegende durch die Form der Tuberkeln und grössere Sporen, deren Membran von weniger zahlreichen, zerstreut stehenden und grösseren Warzen besetzt ist, verschieden.

Schinzia cypericola Magnus. - Entorrhiza cypericola De Toni.

Tuberkeln wie bei Schinzia Aschersoniana; Sporen eiförmig-länglich. 20-28 "lang, 13-21 " breit, hellbraun, mit doppelter Membran: die in- 
nere gefïrht, undeutlich eingesehrumplt netzig, seltener warzig, die äussere hyalin. Böhmen.

Von Juli in den Wurzeln von Cyperus flavescens. Wohl auch in

Schinzia scirpicola c'orrens. - Entorrhiza scirpicola Sace. et Syd.

Tuberkeln wie hei Sehinzia Aschersoniana, 1-1.5 mm dick; Sporen ellipsoidisch orler eifürmig, 16-20 " lang, 11-14"/ hreit; Membran gelb, mit spiralig aufsteigenden Leisten besetzt.

In den Trurzeln von S'cirpus pauciflorus in der Schweiz, vielleicht auch in Böhmen.

Die Ilagnose wurde aus der Abhandlung des Autors in Hedwigia 1897, pag. 40 entnommen.

\section{Gatt. Schroeteria.}

Sporen zu zwei oder drei verbunden, mit einer breiten Fläche sich berihhrend. Keimung im Wasser mit einem fadenförmigen Promyzel, an dessen Scheitel winzige, kuglige Sporidien entstehen, im Nïhrboden nur mit einem fadenförmigen Promyzel, ohne Sporidien.

Der ganze habitus des Pilzes zeigt auf die Hemibasidien.

80. Schroeteria Delastrina (Tulasue) Winter. - Thecaphora delastrina Tulasne. - Geminella delastrina Schroeter.

Sporenmasse in den Kapsehn eingeschlossen, in den Eianlagen, Funikulen und Plazenten entwickelt, schwarzbläulich; Sporen zu 2, seltener zu 3 fest verbunden, kuglig orler eifürmig, an den Beriihrungsseiten abgeflacht; Doppelsporen ellipsoidisch, 20-30 " lang, 12-17 " breit, in der Nitte mehr oder weniger eingeschniirt; Membran schwarzbraun, schwach bliiulich, besetzt mit groben, 1-1.5 " hoheu, unregelmässigen Warzeu. (Siehe Abb. 14, Fig. 5, 6.)

In den Kapseln verschiedener Veronica-Arten, gewöhnlich im Mai aber auch im Juni und Juli. Teronica arcensis: Teplitz (Thïmen, Mye. univ. Nr. 21 und Fungi austr. Nr. 344)! Holín bei Jirín, Keje hei Pran (Baudyss)! Tábor! Feronica triphyllos: Uha bei Welwarn (Kabát)! 'T'áloor! Veronica verna: Tábor!

Schroeteria Decaisneana (Boudier) De Toni. - Cieminella Decaisnema Boudier.

Sporenmasse in den Kapseln, nur aus den Funikulen entstanden, olivenschwarzhraun; Sporen zu zwei locker verbunden, an den Berihlrungsseiten abgeflacht, bald zerfallend; einfache Sporen kuglig, seltener eiförmig, 755-15 $\mu$ breit; Membran hellbraun, von lïngeren Leisten hesetzt. 
Im Mai und Juni in den Kapseln von Teronica hederifolia. Gewiss auch in Böhmen.

Diese Brandart befällt nur die Funikulen, so dass die Samen zwar entwickelt sind, die Keimfähigkeit aber verbiisst haben. In den Diagnosen werden die Sporen als warzig angegeben; ich fand sie mit längeren Leisten besetzt.

\section{Gatt. Tuburcinia (Fries) Woronin emend.}

Sporenballen ohne Nebenzellen, vielsporig, in einem Hyphenknänel entstehend. Promyzel kurz, mit $4-8$ scheitelstäurligen, länglichen, öfters zu zrei verbundenen Sporidien. Sporidien bildeu sekundäre und diese wieder tertiäre Sporidien. Konidien entweder eiförmig oder birnförmig, auf langen Hyphen zwischen den Epidermiszellen hervorbrechend und meisse Anfliige bildend (Tubureinia Trientalis) oder kuglig, kettenweise entstehend, auf den Staubfäden und Fruchtknoten entwickelt (Tuburcinia primulicola).

\section{Tuburcinia Trientalis Berkeley et Broome - Sorosporium Trientalis Woronin.}

Brandtuberkeln auf den Blattspreiten, hauptsächlich auf den Nerven, auf Blattstielen und Stengeln, rundlich, verlängert oder unregelmässig, manchmal bis einige $\mathrm{c} m$ lang, von grauer Epidermis bedeckt, an der Oberfläche runzlig-körnig, dann berstend; Sporenmasse grobkörnig, schwarz; Sporenballen kuglig bis länglich, gewühnlich unregelmässig, 30-100 "lang, schwarzbraun, mit mehr oder weniger deutlicher, gelblicher, steriler Hiille, bis 100sporig; Sporen kuglig bis ellipsoidisch, durch gegenseitigen Druck verschiedenartig zusammengedriickt, 13-22 " lang, dunkelkastanienbraun, glatt.

Konidien (Ascomyces Trientalis Berkeley): Myzel durehdringt die ganze Nährpflanze, die schlanker ist als die gesunde; Blätter schmäler, oft gekrimmt und auf der ganzen Unterseite mit weissem Sporidienanfluge. Konidien eiförmig bis länglich, nach oben verjüngt, 11-14 «lang, $5-\tau \mu$ breit, mit diunner, hyaliner Membran, auf langen, fadenförmigen Stielen.

Konidien Ende Mai und im Juni, Chlamydosporen im Juni und Juli auf Trientalis europaea: Am Wege aus dem Elbgrunde zur Elbfallbaude, ca $1275 \mathrm{~m}$ (Kiihn); im Elbtale nächst Spindelmiihle (J. Kunze, Fungi selecti Nr. 212).

\section{Tuburcinia schizocaulon (Cesati) Maire.}

In den Stengeln diinnere oder dickere, federkielartige Intumeszenzen, oft bis $1 \mathrm{dm}$ lang, auf den Blättern kïrzer, anfangs geschlossen 
später der Länge nach herstend, stiuhend; Siporenmasse schwarz; Sporenballen kuglig bis binglich, 32-7*2 " lang, schwarzhram, mit steriler, velblicher, oft an Nebenzellen erimernder Hiille, 6-30sporig; Sporen kuglig bis ellipsoidisch, dureh gegenseitigen I)ruck polyedrisch, 9-16 " breit, dunkelkastanienbraun, undeutlich höckerig.

Im Juli und August in den Stengeln und Blattern von Euphrasia luter. Myzel durchdringt wohl die ganze Nïhrpflanze, die schlank, gestreckt und tederkielartig verdickt ist. Konidienstadium fohlt. Wohl anch in Böhmen.

Tuburcinia primulicola (Magnus) Kithn. - Erocystis primulicola Magnus. Paipalopsis Irmischice Kühn.

Konidien auf den Staubfiden und Fruchtknoten in weissen, kontinuierlichen Anflügen, zuerst schmierig, spïter trocken, stïubend; Sporen kuglig, 3-8 von einander getrennt, hyalin.

('hlamydosporen daselbst gebildet, knäuelartig, schwarzbraun, stiubend, aus 5-vielen Sporen zusammengesetzt, kuglig bis eiformig, 20-50 breit; einzelne Syoren kuglig-polyedrisch, $9-15$ „ breit, kastanienbraun, wlatt.

In den Bliten von Primula officinalis und $P$. elatior, wohl auch in Böhmen.

Tuburcinia Paridis (Lnger) Vestergren. - Protomyces Paridis Unger. Sorosporium Paridis Winter p. p.

Brandtuberkeln auf den Blïttern ruudlich bis läuglich, fast dendritisch, beiderseits gewölbt; auf den Stengeln verlïngert, bis $1^{1 / 2} \mathrm{~cm}$ lang, schmal oder dieselben ganz umhiillend, glatt; beide von grauer Epidermis lange beleckt, später herstend, narkt, schwarz, stiubend; Sporenballen kuglig his liuglich, $32-110$ " lang, schwarzhraun, mit steriler Hiille, 6-30sporig; Sporen kuglig bis elipsoidisch, polyedrisch, 13-20 "u lang, dunkelkastanienbraun, glatt.

Im Mai und Juni auf Paris quadrifolia. Bisher aus der Schweiz, I)inemark, baltischen russischen Provinzen und den nahe liegenden Inseln bekannt. Vielleicht auch in Böhmen.

\section{Gatt. Urocystis Rabenhorst.}

Sporen uur in kleinerer Anzahl (1-15) zu Siprenballen vereinigt, dieselben mit sterilen, helleren, kleinen Zellen, so genannten v, benzell $n$ besetzt. Die Keimung wie bei 'Tilletia, mit cinem Promyzel, anl' lessen Scheitel die Sporidien entstehen, oder das Promyzel ist ohen verzweigt und die Iste wachsen zu Keimschlänchen aus. Die Tehenzellen sind als Flugapparate anzusehen. 
82. Urocystls occulta (Wallr.) Rabenhorst. - Ur. Agropyri Wallr. p. p.

Brandpolster auf allen griinen Teilen, länglich oder strichförmig, oft sehr lang, der Länge nach und quer zusammenfliessend, von silbergrauer Fpidermis bedeckt, in der Längsrichtung berstend; Sporenmasse schwarz, stäubend; Sporenballen kuglig bis länglich, oft unregelmässig, 16-38 "lang, 16-32 " breit; Hauptsporen 1-2, seltener 3-4, einschichtig oder - falls 4 - ibereinander, 10-18 " gross, kuglig bis länglich an deu Beriihrungsseiten flach oder auch sphärisch, hellkastanien-
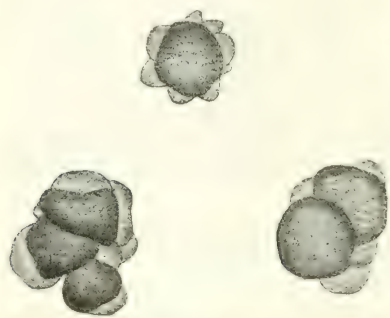

Abb. 22. Sporenballen von Urocystis occulta aus Roggen. (Original.) braun; Nebensporen gelbbraun, halbkugelig oder abgeflacht, selten den ganzen Ballen bedeckend, oft nur hie und da entwickelt, auch vereinzelt, $7-16 \mu$ breit.

Im Juni und anfangs Juli auf Secale cereale in ganz Böhmen.

Diese Brandart ist dem Roggen sehr schädlich. Gewöhnlich ist der ganze Halm befallen, bleibt kurz, kriimmt sich im oberen Teile verschiedenartig, berstet der länge nach, so dass der inuere, von Sporeu schwarz bestiubte Raum völlig geöffnet ist. Die Ähren verkümmern, sind mehrfach um ihre Achse gedreht, schiessen gewöhnlich nicht aus und nur ihr zugehöriger Stengelteil drängt sich bogenförmig an der Seite ans der Scheide hervor. Die Köruer entwickeln sich überhaupt nicht. Gewöhnlich kommt der Pilz nur zerstrent und selten vernichtet er bis $2 / 3$ aller Halme.

83. Urocystis Agropyri (Preuss) Schröter. - Ur. Llei Magnus. - Ur. Festucae Ule.

Brandpolster auf den Blattscheiden und Blattspreiten, strichförmig, verschieden lang und hreit, anfangs ron grauer Epidermis bedeckt, später geborsten, schwarz, stiiubend; Sporenknäuel kuglig, ellipsoidisch bis lïnglich, regelmässig oder öfters unregelmässig, 16-34 $\mu$ lang, 19-28 " breit; Hauptsporen 1-3, seltener 4, einschichtig, 10-18 " lang, kuglig bis ellipsoidisch, an den Beriihrungsstellen mehr oder weniger abgeflacht, hellkastanienbraun; Nebensporen hyalin bis gelblichlraum, flach, halbkugelig oder fast kuglig, die Hauptsporen gä̈nzlich bedeckend, 5-13 ı breit.

Auf Agropyrum repens, Alopecurus pratensis, Arrhenaterum avenaceum, Bromus inermis, Dactylis glomerata, Festuca rubra, F. ovina, Holeus mollis, Melica nutans, Poa annua, P. trivialis u. A. vom Frihjahre bis zum Winter. In Böhmen bisher nur auf Agropyrum repens: Teplitz 
(Thiimen, Myc. univ. 419; Fung. austr. 1229)! Leitmeritz (Wieshaur)! Herruskretschen (Krieger), Lana, Vokšice und Khelnice bẹ Jiěn, Získalí und Jílové bei Liebenau (Baudyš). Alopecurus fratensis: Sellovice bei Sichrow, Wieseumiihle bei Liebeuau, Herrmannstal (Baudyš)!

\section{Urocystis Fischeri Körnicke.}

Brandpolster auf den Blattspreiten, seltener auch auf den Scheiden, blasenförmig oder strichförmig, verlängert, reiheuweise, der Länge nach zusammenfliessend, von grauer Epidermis bedeckt, dann mittelst eimes Längsrisses berstend; Sporenmasse schwarzbraun, stäubend; Sporeuballen kuglig, ellipsoidisch bis lïnglich, 23-48 " laug, 23-30 " breit; Hauptsporeu $1-2$, seltener 3 (und dann die Ballen bis 42 " breit), einschichtig, 16-20 " gross, kuglig bis ellipsoidisch, an den Beriihrungstellen mehr oder weniger abgeflacht, dunkelkastanienbraun; Nebensporen gelbbraun, flach bis halbkugelig, die Hauptsporen gänzlich deckend, 5-13 " hreit.

Auf verschiedenen Carex-Arten ( $C$. acuta, hirta, muricata, vulgaris u. A.) von Mitte Mai bis August. In Böhmen auf Carex acuta: Auf den Wiesen unterhalb Kuldanov nächst Tábor (13. Mai 1914)! Carex rulguris: Wiesen bei_Welwarn (Ḱahát)! C'arex glauca: Nächst Liebenau (Baudy̌š)!

Von Urocrstis Agropyri hauptsächlich durch grössere Sporenballen und Sporen, wie auch intensivere Verfärbung derselben verschieden.

\section{Urocystis Junci Lagerheim.}

Sporenmasse in den Halmen versteckt und erst, nachdem dieselben geborsten sind sichtbar, massenhaft entwickelt, schwarzbraun, stäubend; Sporenballen kuglig bis stark verlïngert, $34-65$ " (manchmal bis $85 ~ ")$ gross, 4-15zellig, seltener 1-3zellig; Hauptsporen kuglig, eiförmig bis ellipsoidisch, 11-16 "lang, hellkastanienbraun; Nebensporen niedrig, wenig gewölbt, seltener halbkugelig, 4-13 u breit, gelblich, eine kontinuierliche Hiille bildend.

Im Juni im Innern der Halme von Juncus: filiformis: Tábor! Lhota Stoklasná daselbst!

\section{Urocystis Lagerheimii Bubák n. sp.}

Brandpolster stark verlängert, bis $3 \mathrm{~mm}$ lang, das ganze Blatt umschliessend, von silbergrauer Epidermis bedeckt, dann nackt, schwarz, stäubend; Sporenballen kuglig, eiförmig, ellipsoidisch, länglich, $28-48, "$ lang, gewöhnlich $1-4$ sporig, einsehichtig, oder 5-7sporig und dann zweischichtig; Hauptsporen kuglig, eiförmig, ellipsoidisch, 13-2.t " lang, dunkelkastanienbraun; Nebensporen stark abgeflacht, manchmal nur als ein Leistennetz entwickelt, 4-10 « breit, gelblich, eine kontinuierliche Decke bildend. 
Die vorliegende Brandart wurde von $\mathrm{L}$ a ger heim auf der Insel Bornholm (Schreden) gefunden und in Sydow's Ustilagineeu Nr. 247 als Urocystis Junci ausgegeben. Von dieser Art ist sie aber durch folgende Merkmale verschieden: Die Sporeuballen sind kleiner und aus einer kleineren Zahl von Hauptsporen zusammengesetzt; die Hauptsporen sind grösser, die Nebensporen sehr flach und fast nur als ein Leistennetz entwickelt.

Urocystis Johansoni (Lagerheim) Magnus 1895. - Urr. Junci var. Johansoni Lagerheim. - Ur. Johansoni Bubák 1912.

Blasen ${ }^{2}=3 / 4 m m$ lang, an der Blatthasis, vou silbergraner Epidermis bedeckt, später nackt, schwarz, stüubend; Sporenballen kuglig, eiförmig, ellipsoidisch, $19-38$ " gross, $1-4$ sporig, oder seltener $5-6$ sporig; Hauptsporen kuglig oder eiförmig, 8-13 " lang, schwarzbraun; Nebensporen niedrig, wenig gewölbt, $4-10$ u breit, gelbhraun, die Hauptsporen gänzlich bedeckend.

Auf der Basis der Blätter von Juncus bufonius in Schweden und Norwegen. Ton den zwei vorangehenden Arten durch kleinere Sporenballen und Hauptsporen verschieden. Ton Lrocystis Junci ausserdem noch durch wenigsporige Ballen, von Ur. Lagerheimii durch mehr gewölbte Nebensporen. Die Kontureu der Hauptsporen sind oft undeutlich, denn sie werden von der intensiv braun verfürbten Basis der Nebensporen verdunkelt.

\section{Urocystis Luzulae Schroeter.}

Brandpolster auf den Blattspreiten und Blattscheiden, schmal, strichförmig, oft einige 'm lang, nicht selten dicht neheneinander liegend und quer zusammenfliessend, ron graner Epidermis bedeckt, dann nackt, schwarz, stäubend; Sporenballen kuglig bis ellipsoidisch, 29-48 " lang, gewöhnlich 3-5sporig, oder auch 1-2, seltener 6sporig; Hauptsporen kuglig oder eifïrmig, 9-15 " lang, schwarzbraun; Nebensporen ziemlich gewïlbt, 6-11 " breit, die Hauptsporen gïnzlich bedeckend, kastanienbraun.

Im Juni auf Luzula pilosa. Wohl auch in Böhmen.

\section{Urocystis Colchici (Schlechtendal) Rabenhorst. - C'aeoma Colchici Schlechtendal.}

Brandsporen in den Blättern, kurz oder verlängert, reihenförmig geordnet, von der Epidermis bedeckt, später in der Längsrichtung berstend, zu langen Streifen zusammenfliessend, sehwarz, stäubend; Sporenballen unregelmäisig kuglig bis lïnglich, 26-42 $\mu$ gross, 1-2 sporig, oft auch 3-4sporig; Hauptsporen kuglig oder eiförmig, kastanienbraun, 11-19 " gross; Nebensporen sehr zahlreich, $7-19 u$ breit, flach gewölbt, 


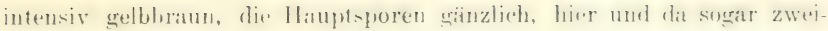
sehichtig deckend.

Im Mai und Juni, seltener später auf Blättern von Colchicum au-

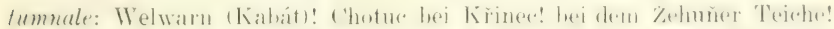

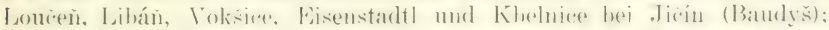

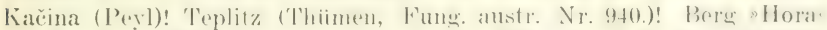
hei Merzkles! Strižowitzerlure hei Aussig (Wieshaur)! Mosern daselhst! Levín! Duppau bei Karlsbad (WViesbaur)!

\section{Urocystis Leucoji Bubák.}

Brandstreifen hasentörmig, 1-11 mm lang, im l'mrisse elliptisch, blattbeiderseits gewolbt, oft zusammenfliessend, von graner Fpidermis bederkt, später nakkt, stanhend. Sjurenballen ziemlich regelmässig, kuglig bis länglich, 24-3s u wrosis, 1sporig, seltener 2sporig; Hanptsporen kuglig bis ellipsoidisch, schwer sichthar, dunkelkastanienhraun: Xohensporen wie bei Ur. Colchici, aber immer nur einschichtig.

Im Juni in den Blittern von Leucojum vermum: 'T'eplitz (Dr. G. Eichler in Petrak's, Fungi Eichleriani Nr. 1.)!

Die vorliegende neue Art, die ich im J. 1912 in Houby české, T'eil II (Hemihasidii), pr. fit heschrieh, weicht von I'r. ('olehici durch folgende Merkmale ab: Jic sporenballen sind fast regelmässig, gewöhnich nur 1sporig; die Hauptsporen sind grösser. Anch habituell ist sie von Ur. Colchici verschieden.

\section{Urocystis Cepulae Frost.}

Brandblasen auf Blattern und /wiehelschuppen, länelich oder strichlïmig, verschiedenartig zusammenfliessend. umb dann bis 8 cm lang, von silhergrauer Hudermis hedeckt, spiter herstend, uarkt, schwarz, stiubeud; Sporenhallen riemlich remelmaissig, kuglig oder oiförmig, 17 his $2 x$ " gross, gewöhnlich 1sporig, selten 2-3sporig; Hauptsporen kuglig

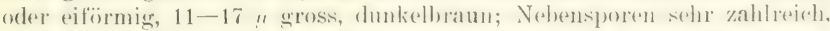

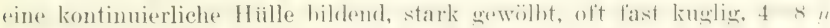
breit, gelbbraum.

Von Mai bis Juli auf Allimm Cepa: Tábor, in den Mistbeeten hiesiger Gärtner alljährlich! Allium Porrum: Daselbst!

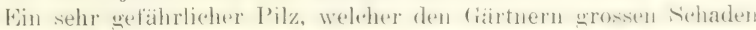
vorursacht, indem er in matudent . Tahren einf Iussat mach der andem vernichtet.

Die Art ist sehr typisch unter den verwandten und zeichnet sich durch kleine sporenballen und kleine, stark gewolhte Vubensuoren aus. Sie wurde nach Europa wahrseheinlieh aus. Imerika eingeschleppt. 


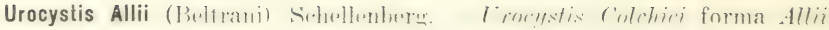
subhirsuti Beltrani.

Brandblasen 2-3 $m m$ lang, 1-2 mm breit, in der Längsrichtung

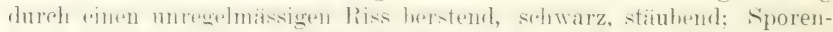

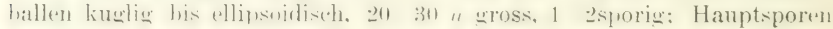

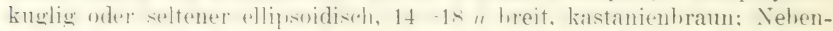

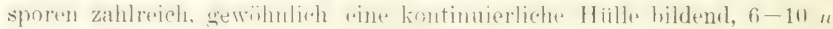
breit, gelbbraun. (Nach Sehellenherg).

Auf Bliittern von Allium-Arten, besonders von Allium oleraceum. Wohl auch in Böhmen.

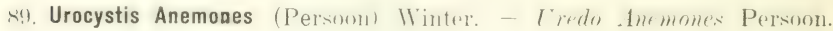

Brandblasen auf Blättern und Stengeln, klein oder gross, kuglig his länglich orler anch ferlerkielartig, -ron graner oder hrauner Fpidermis hederkt, später herstend, nackt, stiubenrl; siporenhallen sehr ungleich, kuglig his langlich, 20 3x " lang, 19--25 " hreit; Hauptsporen kuglig

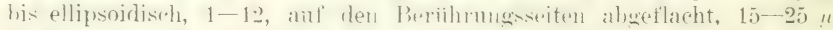

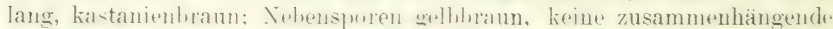

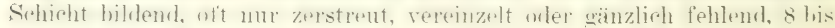
19 « lang, flach oder halhkugelig.

Auf verschiedenen Ranumeulaceen, in Böhmen auf: Anemone nemorosa von Ende April bis Ende Mai sehr verbreitet. Anemone ranunculoides: Sct Prokopius hei Prag (Baudyš). Ficaria verna im Mai: Krě hei Prag (太. Prit); Lithenau (Pandys)! Hermsketsehen (Wagner)! Hepatica triloba*) im Mai und .Juni: (In der löhmischen Ausgabe der Hemihasidien aus Jersthen nicht aufuetiihrt)! Záhoramerschlucht bei Davle.

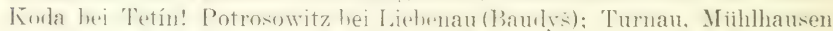
a Fi., Barl sternherg bei smeino (Kabit)! 'Teplitz (Thimen, Fichler)!

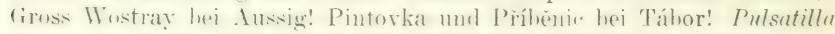
yaten: im .Juni: Kahlerherer her Laitmeritz! lianumeulus anricomms im Mai und Juni: 'Tábor! Chýnov! Ranunculus bulbosus im Juni: Teplitz

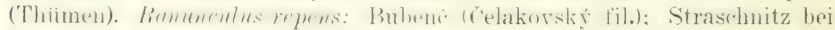
Pran (Baurly). Aussiu ('takorski fil.); Bodenhach (Waguer); Mariasohein (IViesaur)! Teplitz (Thiimen); (iross skal! Havatice bej Turnau,

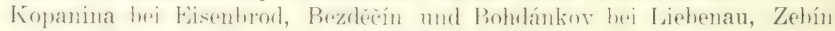
bei Jičn (Baudyš)! Von Juni bis Oktober.

Urocystis Anemones ist in jetziger Auffassung eine Kollektivart. Es ist aber sehr schwer einzelne Formen morphologisch auseinander

*) Hierher gehört auch Uredo syncocca Kirehner in Lotos 1856, pg. 179: „Sporen schön dunkelblau, undurehsichtig. sehr gross, kugelrund, stiellos, in rundlichen. grossen. stark erhabenen und tief unter der Epidermis sitzenden Haufen . An der unteren Blattflache von Hepatica triloha ; albiflora Opiz. Im Pohnholz bei Kaplitz. 
zu halten und deshalh ist es nötig dureh diesbeziigliche Infektionsver-

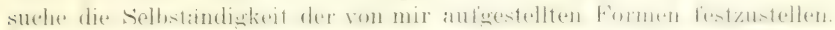

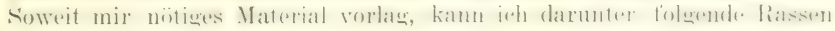
unterscheiden:

1. typica m. Sporenballen iiberwiegend 1sporig, öfters anch 2-3spo-

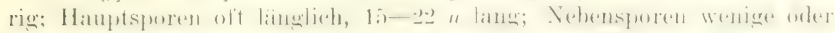

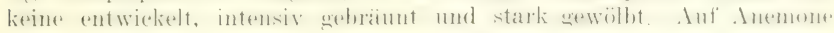
nemorosa, ranuneuloides, silvestris und Helleborus-Arten.

2. Pulsatillu m. Sporenballen 1. Bsporige, seltener t ssporig: Hauphsporen kuglig his limglich, mit zahlrevohren, zimmlich gewiolhten, welhbraunen Nebensporeu.

3. Ramunculi repentis $m$. Sporenballen 1-3sporig, seltener 4-5sporig; Hauptsporen iiberwiegend kuglig oder eiförmig, 16-19 " breit; Nebensporen wenige oder lieine entwickelt. Von der Forma typica besonders durch kleinere Hauptsporen verschieden.

4. Ranunculi auricomi m. Sporenballen 4-6sporig, seltener 1-3spo-

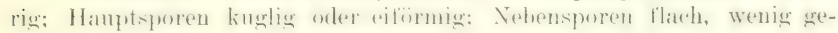
wölbt, nur wenige oder keine vorhanden.

5. Hepaticae m. Finsporige Sporenballen sehr selten, gewöhnlich nur 2-5sporige, oft auch 6-12sporige vorhanden, oft bis 50 "l lang;

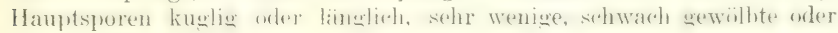
keine Nebensporen.

6. Firarior m. Sporenbatlen 3-mehrsporig; Hauptsporen kughig lis

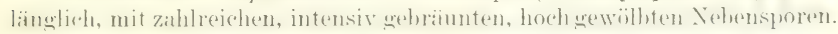

Die Form von Ranunculus bulbosus konnte ich nicht untersuchen. Schroeter fiihrt sie in Pilze Schlesiens I, pg. 280 falseh als Uro"rstis sorosporioides anf, welche ron fr. Anemones dureh vielsporige ind grössere Sporenballen ahweicht.

\section{Urocystis Leimbachii Körnicke.}

Brandbeulen kuglig, bis $1 \mathrm{~cm}$ gross, oder spindelförmig, auf dem Hypokotyl und der Hauptwurzel entwickelt, orler kleinere benkhen aut Basalhlaittern vorhanden, lange hedeckt, spiiter herstend, nackt, selwarz,

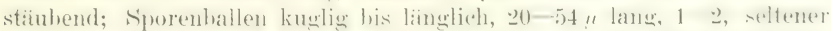

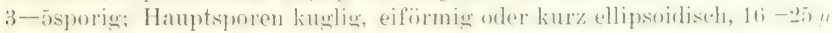
lang; Sehensporen s-19 " hreit, dunkelgellimaum, stark gewrilht, zahlreich, zerstreut oder eine kontinuierliehe Hiille bildend.

Von Mitte Juni his Mitte. Juli auf Adomis aestinalis: Srbsko bei Karlstein (Domin)!

Die Selhstindigkeit dieser . Irt, welehe mit der vomangehenden naht. verwandt ist, muss noch durch Infektionsversuche hewiesen werden. 
Urocystis carcinodes (Berkeley of ('urtis) Fischer de Waldheim. - Theraphora carcinodes Berkeley et Curtis.

Syorenmasse in schwielenartigen Verdickungen der sitengel und Bläter, anfangs beleckt, spatter staubend, schwarz; Sporenhallen kuglig bis ellipsoilisch, 25 45" hreit; Hauptsporen 1-4, selten bis 6, dunkelhraun, 1:2-15" breit: Jebensporen eine kontimuierliche Hiille bildend, galbbraun, derbwandig, $6-12 \mu$ breit. (Nach Schellenberg.)

Auf Actaea spicata in der Schweiz, auf versehiedenen Actaea- und Cimicifuga-Arten in Nordamerika.

Sie steht in der Mitte zwischen Lr. Inemones und Tr. sorosporioides. Ton der ersten weicht sie durch derbwandigere Nebensporen, von der letzteren dureh die geringe Zahl der Hauptsporen in den Sporenballen.

\section{Urocystis sorosporioides Körnicke.}

Praudblasen hattunterseits, rumllich oder verlangert, $1-5 \mathrm{~mm}$ lang, anf den Plattstielen unl Stengelı his $1 \mathrm{~cm}$ lang. von grauer Epidermis lange bedeckt, dann herstend, schwary, staubig: Sporenballen kuglig bis lïnglich, 28-60 " lang, seltener langer, t-1jsporig, manchmal auch 1-3sporig; Hauptsporen kuglig his kurz ellipsoidisch, 9-19 " lang, dunkelbraun: Vebensporen $7-16 \|$ lang, qelhbrann, stark gewiilbt, den Ballen ganz oder nur stellenweise bedeckend.

Im .Juli in Europa auf rersehiedenen Thalictrum-Arten. Wohl auch in Bohmen. Sie zeichnet sirh hesonders durch die grossen, vielsporigen Ballen aus.

In Amerika soll dieselbe Art auch auf Aconitum, Aquilegia und Delphinium vorkommen.

91. Urocystis Violae (Kowerhy) Fischer de Waldheim. - Cirmuluria Tiolae Sowerby.

(Abb. 23.)

Bramltuberkeln auf den Blattspreiten und Bliiten, blasenförmig, rundlich bis linglich; auf den Blattstielen und stengeln verlängerte, oft his einige cm lange, ferlerkielartige Intumeszenzen; hedide lange von der Epidermis hedeckt, spater gehorsten, schwarz, stiubend; śporenballen fast

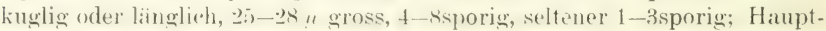
spquren kuglig his eifümigr, 11-19 "l heit, hellbraun; Nebensporen 7-15 " hreit, wenig gewilht, sohwarh gehräunt, eine liontinuierliche Hiille bildend.

Von Juni bis September auf verschiedenen Viola-Arten (ausser $V$. tricolor und verwandten Spezies). In Böhmen auf: Viola cyanea: Botau. (iarten d. bihm. Universitat (Kavina). Fiola Kerneri (V. austriaca $\because$ hirta): Iuppau hei Karlsbad (Wiesbaur)! J inla lilacina Rossm.: Mariawhein bei Teplitz (Wieshaur)! T iolı mbroto: Liehenau (Raudșis)! Sohislav (Rybák)! 
Urocystis Kmetiana Magnus.

Von Trocestis Violate morpholngiseh wenigr verschieden. Kumm konstant nur in den Fruehtkapseln von Viola tricolor var. arvensis von Juni bis zum Winter vor. Bisher nur aus Ungarn und Schweden bekinnt. Gewiss auch bei uns in Böhmen.

Die Infektion findet bei der Keimung statt, so dass das Myzel die ganze Pflanze durehdringt und in den Fruchtkapseln aller Triebe sporifiziert.

Urocystis Filipendulae ('T'ulasue) F'uckel. - Polycystis Filipendulae Tulasne.

Verlängerte Intumeszenzen auf den Blattstielen und Nerven, lange bedeckt, endlich berstend, schwarz, staiubend; Sporenballen sehr unregelmässig, bis 45 " lang, gewöhnlich 2-5sporig, aber auch 1sporig, oder bis 7sporig; Hauptsporen kuglig bis stark verliugert, 15-26 "! lang, gelbbraun, hier und da höckerig; Nebensporen sehr ungleich, manchmal den Hauptsporen ähnlich, zerstreut, oft auch gesehichtet, 7-13" breit, gelbbraun.

Besonders auf den Basalbliittern von spiraen Filipendula im . Ifai und . Juni. Sicher auch in Böhmen.

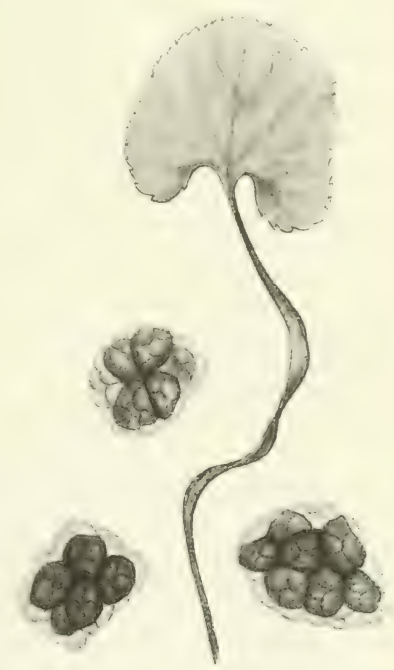

Abb. 23. Crocystis Jiolat. Ein IBatt von Viola odorata vou dem Brandpilze befallen und isolierte Sporenballen. (Original.)

\section{7. (iatt. Doassansia Cornul.}

Sporenballen auf der ()bertlache mit einer kontinuterlieden, fester Haille. von sterilen Zellen. Promyzel mit scheitelstandigem Wirtel von Sporidien, die öfters an der Basis hriickenweise zusammentliessen. In kiinstlichen Nährboden bilden die sporidien sekundare und diese wienter tertiare Sporidien.

Die äussere, aus sturilen, leeren \%ellen gebildete. Hiille fomerert als Sichwimmapparat, so dass sich die Sporen leicht an der Wiaseroherfliche halten und im Frihgahre die jungen Pllanzenteile intizicren kinnen. 
92. Doassansia punctiformis (Niussl) Schroeter. - Irotomyess munctiformi: Niessl. - Setchellia punctiformis Magnus.

Flecke selhlich, rerliangert, wenix deutlich: sporenballen im Mesophyll, kuglig oder verflacht, wenig emporragend, his ${ }^{1 /}+1 / m$ breit; sterile Zellen eiformig oder verläugert, 10-20 "/ lang, 7-12 breit, oft wenig vom den Sporen abweichend, manchmal auch geschichtet oder an der Fyidermis gänzlich fehlend, kastanienhraun; einzelne Syoren kuglig oder eiförmig, oft polyedrisch, $7-15$ ", breit, kastanienbraun.

Von Juli bis Oktober in den Blättern von Butomus umbellatus: Lužnice bei 'Tábor!

Doassansia Alismatis (Nees) ('ornu. - Silerotium Alismatis Nees.

Flecke rundlich orler ellipsindisch, $0 \%-1, \mathrm{rm}$ breit, manchmal auch zusammenfliessend, mit breitem, gelhem Saume; Aporenballen bis 300 u bruit, kuglig orler wtwas ahgeflacht, blattheiderseits emporragend; sterile Zellen in radialer Richtumg verlingert, 11-20 " laug, is -10 "1 hreit, hellkastanienhraum: Syoren dicht zusammongefiigt, ungleichmaissig kuglig. bis eiförmig, oft polyedriseh, 4-13 " breit, hellgelbbraun, glatt.

Von Juni bis September im Mesophyll der Blätter von Alisma Plantago. Sicher auch in Böhmen.

\section{Doassansia Sagittariae (Westendorp) Tulasne. - Uredo Sagittariae Westendorp.}

Flecke rundlich, welb, spiter hraun, bis $1 \%$ in m hreit, welb umsiumt; sporenballen kuglig oder weniw abgeflacht, bis ${ }^{+}+$mm hreit, nur blattunterseits halh kugelig emporragend: sterile Zellen ellipsoidisch his länglieh, dureh gewenseitigen Druck oft unregelmissig. his os " lang, bis 15 " hreit, hellbraun; Sporen unremelmassig kuglig his eiformig, oft polvedrisch, 6-20 $\mu$ lang, $75-13$ " breit, hellgelbbraun, glatt.

Von Juli bis Oktober im Mesophyll der Blätter von Sagittaria safiffa folia: Teich "Zabokor" hei Miuchengrätz (Kabát)! Filhtimpel bei Bard Porlèrad (Kahát)! Nezlíver Teich hej Rokycan (Maloch)! Teich im botan. Garten zu Tábor!

Von der vorangehenden Alt weicht die vorliegende durch kleinere Sporenballen, die Form und Farbe der sterilen Zellen.

Doassansia Hottoniae (limllup) De T'oui. Entylomer Hottomine Rostrup).

Sporenballen in den Blattzipteln, blattheiderseits gewoilbt, rothraun, kuglig oder wenig ahgeflareht, 100 - 200 u breit; sterile Zellen durch gegenseitigen Drurk zusammengeprest, unregelmissigr polyerliseh oder schwach 
verlängert, bis $20 "$ lang, bis $14 \mu$ breit, hellkastanienbraun; Sporen kuglig-polyedrisch, 8-15 " breit, hellgelbbraun.

Von Juli bis Oktober in den Blättern von Ilottonia palustris. Promyzel zylindrisch, am Scheitel mit 4 lïnglichen Sporidien.

\section{8. (iatt. Doassansiopsis Setchell.}

Sporenballen von einer Hiille aus verllochtenen Hyphen ungeben

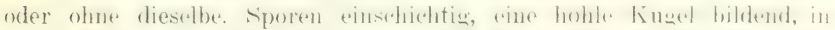
deren Mitt ein pseudoparenehymatisches steriles Hyphengellecht ausgebildet ist. Promyzel mit i-10 scheitelstandigen fiporidien. Ansserdem

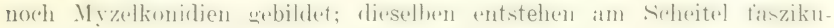
lierter Hyphen, welche aus den Spaltöffnungen durchbrechen.

Das diinnwandige, leere, pareuchymatische innere (iewebe macht die Sporenballen zum Schwimmen geeignet.

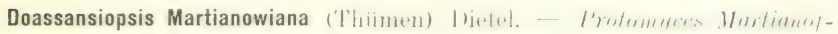
fianus 'Thimen. - Doassansia Martianoffina Schroeter.

Sporenballeu in Schwammparenchym der Blaitter in gelben oder

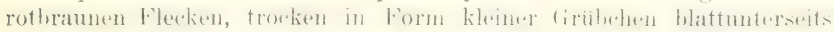

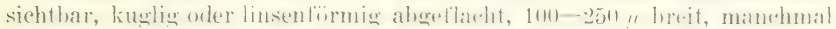
dureh gegenseitigen Druck auch unregelmässig, von einer dicken, aus

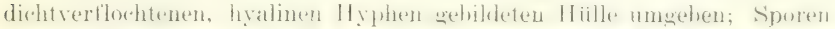

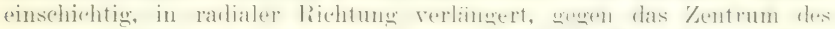

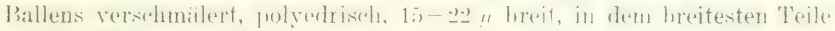

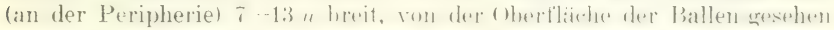

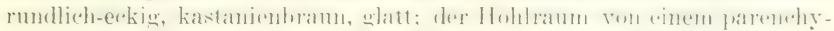

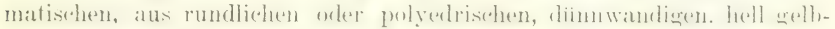
braunen leeren Zellen gebildetem Gewebe ausgefüllt.

Von Juni bis September in Blattern verschiedener PotamogetonArten, am häufigsten in Potamogeton natans.

Gewiss auch in Böhmen. Die Transskription "Martianoffiana" ist unrichtig!

\section{9. (iatt. Tracya Sydow.}

Sporenballen in den Blättern. Sporen einsehichtig, eine hohle Kugrel hildend, derer Mitte von tinem Iorkeren, hrammon Hyphenuetz ausgefiillt ist. Keimung wie bei Doassansia.

Die hohlen und nur mit einem lockeren Hyphennetz versehenen Sporenballen sind zum Schwimmen sehr gut angepasst. 
Tracya Hydrocharidis Lagerheim.

Sporenballen in den Blittern in crelben, unbestimmten Flecken, blattbeiderseits, mehr aber hlattunterseits emporqewölbt, kugligr oder abveflacht, 12(1)-2.20 " breit, dunkellraun, leicht ausfallend; Sporen einschichtig, in radialer Richtumer verlingert, gergen lie Mitte verjiingt, poIredrisch, 15-2.2 " laug, in dem hreitesten Teile (an der Peripherie) 7 .. 13 " breit, von der ()bertaiche der Ballen gesehen rundlich-erkig, kastanienbraun, wlatt, mit gramuliertem Inhalt: Hohlraum ron einem sehr lockeren, hellhraunen Hyphemuetz ausgefiillt: Hyphen $15-2$ "1 dick.

In den Blättern von Hydrocharis morsus ranae von Juli bis September. Könnte auch in Böhmen vorkommen.

In Anerika kommt in Lemu pulyirhiza Tracya Lemnae (Setehell) Sydow vor.

Zu den Hemibasidien wird auch die (iattung Graphiola gestellt. Hhw Zugehorigkeit zu den Brandpilzen ist aher noch unsicher.

l)iv (iattun. Tuberculina, welche friiher auch als ein Brandpilz. gedeutet wurde, gehört zu den Fungi imperfecti.

\section{Graphiola Poiteau.}

Myzel in lebenden Blättern. śporengehaust subepidermal augelegt, spater durchbrechend, oherflichlich, halbkugeligr oder abgetlacht, aus piner iusseren, harten, schwarzen und einer inneren, zarten, hyalinen, verwinglichen Peridie gebildet. In dem sporengehiuse sind sterile und sporifizierente Hyphen entwickelt: liese hestehen aus kuglig-polyedrischen, reihenfirmig angeordueten \%ellen, aus welchen sich an den Seiten $3-6$ kuslige, ellipsoirlische oder zylindrische Initialen bilden. Durch eint" (querteilung der Initialen entstehen : Sporen, die sich von einander ahtrenuen. Sit sind kuglig oter eifurmia und keimen entweder mit einer Hyphe wher as bilden sich an einem kurzen stielchen spindelfürmige Sporidien.

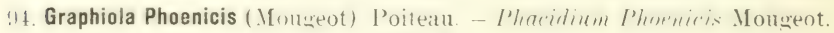
(Abb. 24.)

Sporengehäuse unterhalb der Epidermis, später oberflächlich, 1-15 " hreit. schwarz, kunlig oder abgeflarht, "ins siheitel mit rundem, hreitem Porus geniffuet und dann daselbst mit einer, aus wellhen, - - $3 \mathrm{~mm}$ weit hervorragenden Bursten zusammentesetzten Säule verschen: I'uridiu zweischichtig: die aussere hart, schwarz, glituzend, die innere diinu, hyalin. bald versehwindend: Siporen kuglig his . llipsoidisch, à-6 u lireit, hellgelh. glatt. Auf den Blattern verschiedener Phoenis-Arten in den fiewiachshäusern das ganze Jahr hindurch. 
Phoenix dactylifere: Košíre bei Prag (Kabát)! Cervené Pečky (Pleštil)! Koclérov bei Köni grinhof (Rákos)!

Fine eingehende Beschreibung dieses Pilzes lieferte mein chemaliger Assistent Prof. Dr. .J. Smolák in der Zeitsehrift "Vesmír 1906, pg. 136, woher anch die Abbildung entnommen wurde.

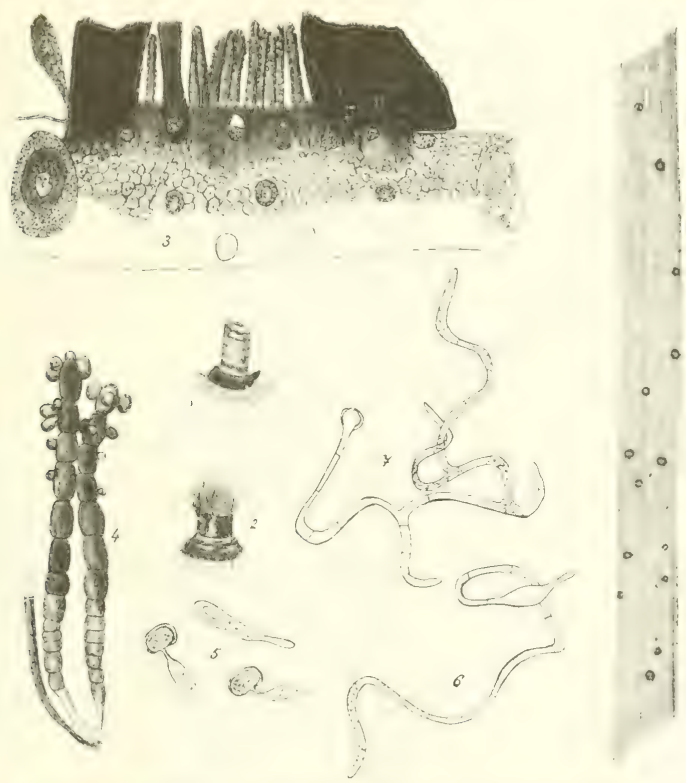

Abb. 24. Graphiola Phoenicis: Habitus des Pilzes aul einem Stiockluen des Blättrbenvoll Phoenix canariensis: 1 - Sporengebause von verschiedenem Alter, hei 2 . sterile Hyplien schon gestreckt; 3. Schnitt durch ein Gehaiuse; 4. sporenbildendr. Hyphen mit Initialen; 5-7. keimende Sporen. (Original.)

Die sterileu Hyphen verlingern sich bei der Sporenreife und

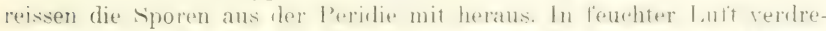
hen sie sich und kimmen in ihre lrihere Lage nicht mehr zuriarkehren. Vachdem die Sporen anseretrocknet sind, so fallen sie von den sterilem Hyphen $a b$, oder werden durch die luftbewegung weggeblasen und verbreitet. 


\section{Verzeichnis der Abbildungen.}

Cintractia Caricis

Entyloma Calendulae

Graphiola Phoenicis -

Melanotaenium endogenum

Schizonella melanogramma

Schroeteria delastrina

Sorosporium Saponariae

Sphacelotheca Hydropiperis

- Panici miliacei

'Theeaphora aterrima

Tilletia decipiens

- Tritici

Tolvposporium Junei

Urocystis occulta

- Violae
Ustilago anomala . . . . . . . . 19

- Crameri . . . . . . . . 9

- echinata . . . . . . . . 11

- Hordei . . . . . . . . 9

- hypodytes . . . . . . . . . 11

- levis . . . . . . . . . 9

- longissima . . . . . . . . 13

- major . . . . . . . . 19

- marginalis . . . . . . . 17

- pustulata . . . . . . 17

- Rabenhorstiana . . . . . 14

- Tragopogonis pratensis . . . . .

- ntriculosa . . . . . . . . . . 19

- Zeae Mays . . . . . . . 11

\section{Verzeichnis der Wirtspflanzen.}

Achillea Millefolimm

Aconitum

Actaea

- spicata

Adonis aestivalis

Agroprrum

- repens

Agrostis

- alba

- vulgaris

Aira caespitosa . . . . . . . .45

— flexuosa . . . . . . . 44

- spica venti . . . . . . . . 40

Alisma Plantago . . . . . . . . 70

Allium . . . . . . . . . 66

— Сepa . . . . . . . . 65

- oleracenm . . . . . . . 66

- Porrum . . . . . . . . . . 6.

Alopecurus pratensis . . 4.5. ti. 6.3

Andropogon Ischaemum
Anemone nemorosa . . . . . . bil

- ramuneuloides . . . . . . bifi

Anthoxanthum odoratum . . . . . 4h

Aquilegia . . . . . . . lis

Arabis hirsuta . . . . . . 14

- petraea . . . . . . . . . 11

Arenaria serpollifolia . . . . . . :

Arnica montana . . . . . . . . .

Arnoseris pusilla . . . . . . . . .

Arrhenatherum . . . . . . . t.

- avenaceum . . . . 10, 13, 56, 62

Arum maeulatum . . . . . . . . 47

Asperula galioides . . . . . . . ts

Astragalus glyerphyllus . . . . . 3i

Avena pratensis. . . . . . 4.

— sativa . . . . . . . . .

Avena strigosa . . . . . . . . . .

Bellis perennis . . . . . . . . .

Berula angustifolia . . . . . . . . . .

Borrago officinalis . it 
Brachypodium pinnatum . . . . 44

_ silvaticum

Briza

Bromus

- arrensis

- ereetus

- inermis

- mollis

- secalinus

Butomus umbellatu.

Calamagrostis

- Halleriana

Calendula officinalis

Carduus acanthoides

- defloratus

- nutans

Cares

- aeuta

- ampullacea

- brizoides

- eurvata

- digitata

- echinata

- filiformis

- glanea

- hirta

- humilis

- Michelii

- montana

- murjeata

- pallescens

- pilulifera

- praecox

-. ricida

- riparia .

- vaginata

- vesicaria

- vulgaris

Caryophyllaceae

Cerastium

- arvense

- glutinosum

- semidecandrum

Chenopodium album

Chrrsosplenium alternifolim

Cichorium Intrbus.

Cimicifuga

Cirsium heterophyllum

Colehieum antummale

Compositae

Convolvulus arvensis

- sepium

Corvolalis
13. 43,45

. 43

. 43

(62)

13

13. $4: 3$

70

45,46

. 46

.52

. 24

24

. 24

$.30,32,36,63$

31. 633

$$
\text { . } 31
$$

. 30

.30

32

. 311

. 31

30,63

63

. 30

30. 333, 36

. 33

63

.30

.311

311, 33, 366

. 33)

31,32

. 30

.31

30. 63

. 3:

. $2: 3$

. 333

23

3

35

52

.53

68

.37

(6.)

52

37

37

50
Corydalis cava

49,50

Crperus flavescens . . . . . . . i?

Dactylis

.45

- glomerata

$45,56,62$

Delphinium

68

Deschampsia caespitosa. . . 4i, 4.

Desmodiuma

4h. 4.

Dianthus armeria

.33

- Carthusianorum

22, 34

- deltoides

2.2. 34

Eryngium campestre . . . . . 5

Euphrasia lutea . . . . . . . . 61

Festuca . . . . . . . . 45

- ovina . . . . . . . (6)

- rubra . . . . . . . . . . . 62

Ficaria verna . . . . . . 5ll. 66

Gagea . . . . . . . . 12

- bohemica. . . . . . 1"

- Intea . . . . . . . . 19

- minima . . . . . . . . 12

- pratensis . . . . . . . 19

Galium mollugo . . . . . . . . . th

- verum . . . . . . . . . th

Glaneim flavum . . . . . . . 51

- Jutem . . . . . . . . . . .

Glyceria aquatica . . . . . . . 13

- fluitans . . . . . . . . 13

- nemoralis . . . . . . . . 13

- plicata . . . . . . . . . 13

Gnaphalium arenarium . . . . . . .57

- luten-album . . . . . . . . .57

Hellehorus . . . . . . . . .67

Hepatica triloba . . . . . . . 56

Hieracium laeviqatmu . . . . . . .

— murorum . . . . . . . . 52

- silvatiem . . . . . . . . 52

— sudeticum . . . . . . . .52

Holens . . . . . . . . 45

- lanatus . . . . . . 41, 45, 56

- mollis . . . . 41, 45. 56, 62

[folostemm umbellatum . . . . . . . .

Horterm . . . . . . 4.

- distiehum . . . . 111. 16. 4?

- hexastichmm . . . . . . 4.

- tetrastichmul . . . . . .42

Hosackia . . . . . . . . . . 37

Iottonia palustris . . . . . . . . 71

Hydrocharis morsus ranas . . . . . .2

.

- aretiens . . . . . . . . .

- bufonius. . . . 31. 35. 35. 64

— filiformis . . . . . (6:3

- lamprocarpus. . . . . . . 5s 
Juneus Tenageja

58

Knautia arvensis

Keeleria eristata

Lathyrus silvestris

Lemna polyrrhiza

Lencojum vermum

Linaria spuria

- vulgaris

Lolium

- peremue

- remotum

- temulentum

Lotus

Lupims

Luzula allida

- campestris

- pilosa

- spicata

- vernalis

Lychnis flos cuculi

Matricaria inodora

Medieago tribuloides

Melica mutans.

Milinm

Molinia coerulea

Nontia fontana

- minor

Muscarj

- alpinum

Mrosotis

- arvensis

- palustris

Ornithogalum

Panieum erus galli

- glabrum

- miliaceum

- sanguinale

Papaver Argemone

- dubium

- rhoeas

- somniferum

Paris quadrifolia

Phalaris arundinacea

- v. picta

Phleum

- pratense

Phoenix

- dactrlifera

Phragmites communis

Pieris hieracioides

Pinguicula alpina

- vulgaris

Plantage lanceolata
Plantago media . . . . . . . .55

20. 21 Poa . . . . . . . . . 4.

.4 - ammua . . . . . . 62

37.51 - pratensis _. . . . . . . . . . . .

. 2 - trivialis . . . . . . . 62

(6.) Polygonum . . . . . . . . . . . .

. 45 - aviculare . . . . . . . . . . 19

45. 5. - Bistorta . . . . . 19. $2 \mathrm{~s}$

4.2 4. - Convolvulus . . . . . 16

.. - dumetorum . . . . . . 18

. $4^{2}$ - Hrdropiper . . . 19. 28

4.) - lapathifolium . . . . . . 19

37 - tomentosum . . . . . . . . . 19

.37 Potamogeton . . . . . . . . . . 1

.31 - natans . . . . . . . . . . . .

1.. 31 Primula elatior . . . . . . . . . . . .

. it -officinalis . . . . . . . . . 61

.31 Pulmonaria officinalis . . . . . . . it

18. :31 Pulsatilla patens . . . . . . . 66

..".) Ranmeulaceae . . . . . . 66

it Ramunculus acris . . . . . . . if

.37 - auricomus . . . . . 50, 66i

62- - bulbosus . . . . . 666

$.45-$ lanuginosus . . . . . . . . .0

$.39-$ nemorosus . . . . . . . . 50

.34 - repens. . . . . 50, 57, 66

.34 - sceleratus . . . . . . . . . .

.14 Rhsnchospora alba . . . . . . 30

14 Rumex Acetosa . . . . . . 20

.5 - Acetosella . . . . . . 20

it - alpinus . . . . . . . 20

.54 - maritimus . . . . . . . . .

12 - obtusifolius. . . . . . . . . .

3.) Sagittaria sagittaefolia . . . . it

s. 14 Samolus Valerandi . . . . . . . .

.7 Samonaria officinalis . . . . . . . .2.

s. 14 Scabiosa columbaria . . . . . . 1

.11 Scirpus eaespitosus . . . . . . . . . . . .

.1 - pauciflorus . . . . . . . . . . . .99

.51 Scorzonera humilis . . . . . . 24

il - purpurea . . . . . . . . 24

61 Secale cereale . . . . 41. 62

1. is Sesleria coerulea . . . . . . . . . . . . .

4.2 Setaria germanica . . . . . . 8

4.5 - glanca. . . . . . . . . . 15

.56 - italiea $v$. breviseta . . . . 8

$72-\ldots$ longisela . . . . s

in - verticillata . . . . . . . . . . . .

11 Silene inflata . . . . . . . . . 2?

.3 - mutans . . . . . . . . .

210 Otite 20

¿1 Silybum Marianum . . . . . . . .4

j.) Simm Iatifolium . . . . . . . . . . 
Sirrelum vulwark

$26,2 \pi$

Sphagnum . . . . . . . . 47

- cymbifolium . . ... . . . 47

Spiraea filipendula . . . . . . 69

Stellaria Holostea . . . . . . . 34

Stipa capillata . . . . . . . 12

- pennata . . . . . . . . 25

Succisa pratensis . . . . . . . 21

Symphytum . . . . . . . .54

—officinale . . . . . . . . 54

— tuberosumı . . . . . . . . . .

Thalictrum . . . . 51, 68

- minus . . . . . . . . . 51

Thlaspi alpestre . . . . . . . . 14

Tiniaria . . . . . . 18

Tordylium maximum . . . . . . .52

Tragopogon orientalis . . . . 23,53

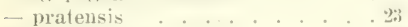

Trientalis enropaea . . . . . . 60

Trifolium . . . . . . . . 37

Triticum compactum . . . . . . . 40
Triticum vulgare . . . . 40. 41

'T'ulipa silvestris. . . . . . . 12

Voronica acinifolia . . . . . . . . . . . .

— arvensis... . . . . . . . . . . .

- hederifolia . . . . . . . 60

— serpyllifolia . . . . . . . 55

- tripligllos . . . . . . . . .59

- vernar . . . . . . . . . . 54

Vicia . . . . . . . 35

- trifida . . . . . . . . . . 37

Viola . . . . . . . . 68

- austriaea $x$ hirtat . . . . . 68

- eyanea . . . . . . . 68

- Kerneri . . . . . . . . 68

- lilacina ...... . . 68

- odorata . . . . . . . 68

- tricolor . . . . . . . 68

- - varvensis . . . . . . . . 69

Viscaria vulgaris . . . . . . . .2.

Kea Mays . . . . . . 16, 27

\section{Verzeichnis der Familien und Gattungen.}

(Synonyma kursiv, Diarnosen fette Ziffern.)

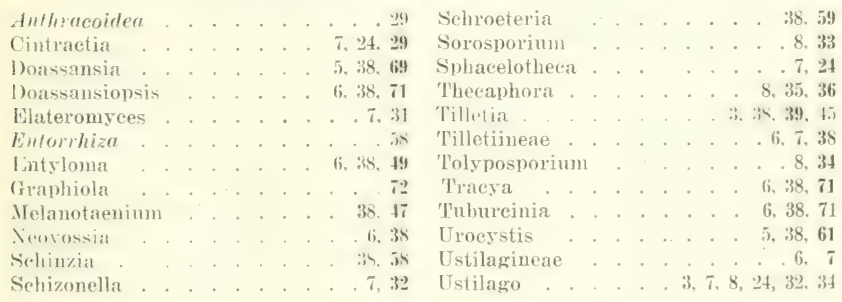

\section{Verzeichnis der Arten.}

(Artendiagnosen durch fette Ziffern hervorgehoben.)

Anthracoilea Caricis Brefeld

- subinclusa Brefelel

Ascomyces Trientalis Berkeley

Caeoma Colchici Sohlechtendal

- hypodytes Schlechtendal

- Junei Schweinit\%

- marginalis Link

- utriculosum Nees

Cintractia Carieis (Persoon) Magnus 29
.29) Cintractia Junei (Sehweinitz) Tre-

.31 lease . . . . . . . 31

.60 - Luzulae (Saccardo) Clinton . . . il

tif. ti. - Montagnei (Tulasne) Magnus . " 0

.11 - Scirpi (Kiihn) Schellenberg . . . 311

.31 - subinelusa (Körnicke) Magnus 3. 31

17 Doassansia Alismatis (Nees) Cornu i0

- Hottoniae (Rostrup) De T'oni . . -

- Martianoffiana Schroeter . il 
Doassansia muetiformis (Nies-l) Sehroeter . . . . . . . .

- Sagittariae (Westendorp) Tulasne

Doassansiopsis Martianowiana (Thïmen) Dietel

Elateromyces olivacens (De Candolle) Bubák

- Treubii (Solus) Bubák. . . . . 32

Entorrhiza Aschersoniana Lagerheim

- Casparyana De Toni .58

- cypericola Schroeter.

.58

- - De Toni

- digitata Lagerheim

- seirpicola Sace. et Syd.

Entyloma Achilleae Magmus.

- Aschersonii (Ule) Woronin

- Bellidis Krieger

- bicolor Zopf

- Brefeldi Krieger

- Calendulae (Oudemans) De Jary 52

- canescens Sidroeter.

- Chrysosplenii Schroeter

- Cichorii Wróblewski.

- Corydalis De Bary

- crastophilum Saccardo

-. Eryngii (Corda) De Bars . 57

- Fergussoni (Berkeley et Broome) Plowright

- Feurichii Krieger.

- fuscum Seliroeter

- Glaucii Dangeard

- Helosciadii Magnus

- Henningsianum Sydow

- Hottoniae Rostrup

- irregulare Johanson

- Linariae Sehroeter

- Magmusii (Ule) Woronin . . . . 57

- Mágoesyauum Bubák . . . . . 52

- Matricariae Rostrup . . . . 5:

- microsporum (Unger) Schroeter . 56

- Picridis Rostrup . . . . . . .53

- Plantaginis Blytt . . . . . . .5.

- Ranunculi (Bonorden) Schroeter . 50

- serotinum Schroeter . . . . . . 54

- Thalictri (Thümen) Schroeler . . 50

- Tragopogonis Wróblewski . . .53

— Tragopogi Lagerheim . . . . . 53

- urocrstoides Bubák n. nomen. . 49

- Valerandi Rostrup manuser. . . 55

— veronicicola Lindroth . . . 3, 55

- verrueulosum Passerini ... 49
Erysibe Pauicorum a) Panici miliacei Wallroth . . . . . . 15

Farinaria Scabiosae Sowerby . . . 20 Fusidium Ranuneuli Bonorden . . . . — Thalietri Thümen . . . . . . . .50 Geminella Decaisneana Boudier . 59 — delastrina Schroeter . . . . . . 59

- foliicola Sehroeter . . . . . . 32 Granularia Violae Sowerby . . . . 68 Graphiola Phoenicis (Mougeot) Poiteau . . . . . . 72

Lycoperdon Tritici Bjerkander . . 39

Melanotaenimu Ari (Cooke) Lagerleim . . . . . . . 3, ti

— eaulium Sehneider . . . . . 7, 48

- cingens (Besk) Magnus . . 3, ts

- endogenum Unger (De Bary) 7, 18

- hypogaenm (T'ulasne) Sehellenberg . . . . . . . . . 47

- plumberm Rostrup . . . . . . 47

Neorossia Moliniae (Thümen) Koernicke . . . . . . . . . . 39

Paipalopsis Irmischiae Kühn . . .61

Phacidium Phoenicis Mougeot. . .72

Physoderma Eryngii Corda . . . . 57

Polyeystis Filipendulae Tulasne . .69

Protonyces Ari Cooke . . . . . . 47

- Calendulae Oudemans . . . . . . 52

- endogenus Unger . . . . . . . 48

- Fergussoni Berkeles et Broome ist

- Martianoffianus Thimen . . . . 71

- microsporus Unger . . . . . 56

- Paridis Unger . . . . . . . (61

- pumetiformis Niessl . . . . . 70

Schinzia Aschersoniana Magnus . . 58

- Casparyana Magnus . . . . . 8

- cruericola Magnus . . . . . 58

- digitata (Lagerheim) Magnus . .58

— scirpicola Correns . . . . . . . 59

Schizonella melanogramma (De Candolle) Schroeter . . . . . . . 32

Schroeteria Decaisneana (Boudier) De Toni . . . . . . . . . 59

- Delastrina (Tulasne) Winter . .59

Sclerotium Alismatis Nees . . . . 70

Setehellia punetiformis Magnus . . 70

Sorosporium Aschersonii Ule . . . 5i

— Jumei Schroeter . . . . . . . . 34

- Magnusii Ule . . . . . . . 57

- Montiae Rostrup . . . . . . 34

- Paridis Winter p. p. . . . . . 61

- Saponariae Rudolphi . . . . 33

- Trientalis Woronin ....60 
Sphacelotheea Andropogonis (Oviz) Bubák

- borealis (Clinton) Schellenberg. Is exuenta (Kühn) Bubák . . . . . 6 i

- Hydropiperis Autt. p p. . . 19, 28

- - (Schuhmacher) De Bary . . . 28

- - . borealis Clinton . . . . . 88

- Ischaemi Clinton . . . . . 25

- Panici miliacei (Persoon) Bubák 26

- Reiliana (Kühn) Clinton . . . .

- Sorghi (Link) Clinton . . . . 25

- vallesiaca Schellenberg. . . . . . 25

Thecaphora affinis Sehneider . . . . .37

- aterrima 'Tulasne . . . . . . . 36

- capsularum (Fries) Desmaziéres . 37

- earcinodes Berkeley et Curtis . . (is

- Cirsii Boudier . . . . . . . . 37

- deformans Durieu et Montague . 37

- delastrina Thlasne . . . . . . .59

- hyalina Fingerhut . . . . . 37

- Lathyri Kühn . . . . . . . . 37

- Traillii Cooke . . . . . . . . \$i

- Viciae Bubák. . . . . . .37

Tilletia aculeata Ule . . . . 3. 16

- Airae Blytt . . . . . . . 40

- Airae caespitosae Lindroth . . 3, 44

- Anthoxanthi Blyti . . . . .40

- Avenae Ule . . . . . . 45

- belgradensis Magnus . . . . . 43

- Brizae Ule . . . . . . . . 45

- Calamagrostidis Fuckel . . .46

- controversa Kiiln _.... .42

- corcontica Bubák n. sp. . . . 46

- decipiens (Persoon) Körnicke. . 43

- endophylla De Bary . . . . . 44

- flectens Lagerheim . . . . . .44

-. Guyotiana Hariot . . . . . . . 43

- Holei (Westendorp) Rostrup . .40

- Hordei Körnicke . . . . . 42

- levis Kühn . . . . 3,41

- Lolii Anerswald . . . . . . 42

- Menierii Hariot et Patouilard. 42

— Milii Fuekel . . . . . . 45

- Moliniae Winter. . . . . . . 39

- olida (Riess) Winter. . . . 44

- Panćiéii Bubák of Ranojevic . 11

- Ranwenhoffii Fischor do Waldheim

40

- Secalis (Corda) Kühn . . . . 7, 41

— separata .J. Kunze . . . . . .40

- Sesleriae Juel . . . . . . . 44

- Sphagni Nawaschin . . . 3, 5.47
T'illetia striaeformis (IVostonctorio) Oulemans 7. 14, 1.). 16

- Thlaspeos Beck . . . . . . . . 14

- Tritici (Bjerkauder) Winter 6. 7 .

39, +1, 4\%

Velenovskyi Bubák . . . . . . 43

Tolyposjorium bullatum Schroeter . 35

- Junci (Schroeter) Woronin . 31, 34

- leptideum Sydow . . . . . . 35

Tracya Hydrocharidis Lagerheim . 72

- Lemuae (Setchell) Sydow . . . 72

'Tubureinia Paridis (Unger) Vestergren . . . . . . . . 61

- primulicola (Magnus) Kühn . . 61

- schizocanlon (Cesati) Maire. . . 60

Trientalis Berkeley et Broome , (ill

Uredo Andropogi Opiz . . . . . 25

- Anemones Persoon . . . . . . 66t

- Bistortarum "marginalis De Candolle . . . . . . . . . 17

- - a pustulata De Candolle . . 17

- Carbo e) vulgaris d bromivora T'ulasne . . . . . . . 13

- Caricis Persoon . . . . . . . . 29

- Digitariae Kunze . . . . . . . 8

- floseulorum De Candolle . . . . 21

- Hordei var. nuda Pers. . . . . . 15

- Hydropiperis Schuhmacher . . . 28

- Iongissima Sowerby . . . . . . 12

- melanogramma De Candolle . . 32

- olivacea De Candolle . . . . . . 32

- Oruithogali Schmidt et Kunze . . 12

- Sagittariae Westendory . . . . 70

- Secalis Corda. . . . . . . . 41

- segetum A) Avenae Persoou . . 15

— - c) Hordei Persoon . . . . . 10

- d) Panici miliacei Persoon . . 26

- 3) Tritici Persoon. . . . . . 16

- - var. Zeae Mays De Candolle . 16

_ srneocea Kirchner . . . . . .66

- Tragopogi pratensis Persoon . .2:

- -3) Seorzonerae Albertini o1 Schweinitz . . . . . . . . . 24

- violacea Persoon . . . . . . . 2.

Urocystis Agropyri Wallr. 1) 1) . .62 — - (Preuss) Sehröter . . . 62,63

- Allii (Beltrani) Schellenberg . . 66

- Anemones (Persoon) Winter 66, 67, 69

- - forma Ficariae Bubák . . . 6i

- - Hepaticae Bubák . . . . . .67

- - Pulsatillae Bubák . . . .67

- - Ramuneuli auricomi Bubák . 67

_- - repentis Bubák . . . . 67 
Urocystis Anemones forma typica Bubák .17

- carcinodes (Berkeley et Curtis) Fischer de Waldheim . . . . 68

- Cepulae Frost . . . . . . . 65

- Colchici (Schlechtendal) Rahenhorst . 64

_ - forma Allii subhirsuti Beltrani 66

- Corydalis Niessl . . . . 49

- Festueae Ule . . . . . . . 6*2

- Filipendulae (Tulasue) Fuckel . .69

— Fischeri Körnieke . . . . . 63

- Johansoni Bubák. . . . . 64

_ - (Lagerheim) Magmus . . . . 64

— Junci Lagerlieim . . . . . 63,64

- - var. Johansoni Lagerheim . .64

- Kmetiana Magnus . . . . . . 69

- Lagerheimii Bubák n. sp). . 63, 64

- Leimbachii Körnicke . . . . 6 67

— Leneoji Bubák n. sp. . . . . . .65

- Luzulae Schroeter . . . . . . .61

- occulta (Wallr.) Rabenhorst . . 62

- primulicola Maguus . . . . . 61

— sorosporioides Körnicke . . 67, 68

- Ulei Magnus . . . . . . . . 162

- Violae (Sowerby) Fiseber de Waldheim . $6 \mathrm{~S}$

Ustilago anomala Kunze . . . . . 18

- antherarum Fries. . . . . . . 29

- Arrhenatheri Schellenberg . . . 10

- Avenae (Persoon) Jensen 6. 10. 15

- - var. levis Kellermann ef Swingle . . . . . . . . . . 9

- Bistortarum Körnicke . . . . . 17

- momivora (Tulasne) Fiseher de Waldheim 13

- Carbo Autt. . . . . . . . . . 16 Cardui Fischer de Waldheim . 3, 24 Caricis Fuckel . . . . . . . 39

- cingens Beck. . . . . . . . . 48 Crameri Körnicke. . . . . . S Umenta Kühn . . . . . . 26 destruens Schlechtendal . . . . 26 Digitariae (Kunze) Rabenhorst o s dura Appel et Gassner . . 3, 10, 13 Duriaeana Thlasne . . . . . . 23 echinata Schroeter . . . . 5, 18 flosenlorum (De Candolle) Winter 21 foetens Berkeley et Curtis . . . 41 Goepertiana Schroeter . . . 19 grandis Fries . . . . . . . 11 Holostei De Barry
Uotilago Hordei (Persoon) Kellermann et Swingle . . . . , 6. 10

- - var, nuda Pers. . . . . . . 15

- Hydropiperis Schroeter . . . . 28

- liypodytes (Schlechtendal) Fries

5. 11, 28

- hypogaea I'ulasne . . . . . . 47

- intermedia Schroeter . . . . 21

- Ischaemi Fuckel . . . . . . 25

- Jenseni Rostrup . . . . . 10

- Junci Curtis . . . . . . . . . 31

- Kuehneana Wolf . . . . . . 20

- levis (Kellermann et Swingle) Magnus . . . . . . . . . . 9

- Liebmanni P. Hennings . . . . 31

- Jongissima (Sowerby) Tulasne .12

- Luzulae Saceardo . . . . . . . 31

- Magnusii Winter p. p. . . . . . 57 maior Schroeter . . . . . . 22

- marginalis (De Candolle) Léveille 17

- Maydis Corda . . . . . . . 16

-. Montagnei Tulasne . . . . . 30

- neglecta Niessl . . . . . . 15

- mula (Persoon) Kellermann et swingle. . . . . . . . . . 15

— olivacea 'lulasne . . . . . . . 32

- Ornithogali (Schmidt et Kunze) Külın . . . . . . . . . 12

- pallida Lagerheim . . . . . . . 22

- Panici glauci (Wallroth) Winter 15

- - miliacei Winter . . . . . 26

- Parlatorei Fischer de Waldheim . 20

- perennans Rostrup . . . 10, 13

- Pinguieulae Rostrup . . . . 21

- plumbea Rostrup . . . . . . 47

- pompholygodes f. Tulipae Rabenlhorst . . . . . . 12

- pustulata (De Candolle) Bubák . 17

- Rabentorstiaua Kühn . . . . 8, 14

- Reiliana Kiilı. . . . . . . 27

_. Rhynchosporei Siegm. . . . . . 30

- liudolphi T'ulasne . . . . . . . 33

- Seabiosae (Sowerby) Winter 20,21

- Scirpi Kühn . . . . . . . 30

- Seorzonerae (Albertini et Schweinitz) Schroeter . . . . . . . 24

- segetum d) Panici miliacei Persoon . . . . . . . 26

- Paniei miliacei Winter . . . . 26

- Sorghi Passerini . . . . . . 25

— subinelusa Körnicke . . . . . 31

- Suceisae Magnus . . . . . . .21

- Thlaspeos (Beck) Lagerheim . . 14 
Ustilago Tragopogonis pratensis Ustilago Vaillantii T'ulasne. . . \$, 14 (Persoon) Winter . . . . . $\mathbf{2 3}$ - verrucosa Vestergren . . . . . 18

- 'Treubii Solms . . . . . . . 32 - violacea (Persoon) Gray . . . 7, 22

- Tritici (Persoon) Jensen . . 7, 16 - Vuyekii Oudemans et Beijerinck 18

- Thulipae (Rabenhorst) Winter . .12 - Zeae Mays (De Candolle) Winter 6, 16

- utriculosa (Nees) Tulasne. 18, 28 Vossia Moliniae Thïmen . . . . 34

\section{Verzeichnis der wichtigeren Literatur.}

Saccarlo P. A.: Sylloge Fungrorum. Padua 1883-1911. Band I-XX. (Hemibasidii in VII., 1X., XI., XIV., XVI. und XVII. Band.)

Schellenberg H. C.: Die Brandpilze der Sehweiz. Bern 1911.

Winter (i.: I)ie Pilze. Leipzig 1884. (Die Brandpilze in I. Abt. Ihre Bearbeitun veraltet.)

Schroeter J.: Pilze von Schlesien. Breslau 1889. (Die Brandpilze im I. Teil.)

Plouright Ch. S.: A monorraph of the british Eredineae and I'stilagineat. London 1889.

Clinton G. P.: North american Ustilagineae Boston 1904.

Fischer von II aldheim H.: Les L'stilarineae et leurs plautes nourricieres. Pari1877. (Annal. sc. nat. 6. S. T. IV)

Brefeld O.: Untersuchungen aus dem Gestmt-Gebiete der Iryologie. Heft V. (Leipzig 1883), Heft XI. (Miinster in IV. 1895), Heft XII. (Daselbst 1895), Heft XIII. (Easelbst 1905).

Lindau G.: Ustilagineen in Kryptogamenfl. 1. Mark Brandenburg. Band Va. Pilze 1II., pg. 1-68.

\section{Meine Publikationen über die Brandpilze Böhmens.}

1. Ein Beitrag zur Kenntnis der böhmischen Peronosporeen, Istilagineen uml Uredineen (Verhandl. d. zool.-bot. Gesellseh. Wien 1897).

2. '/weiter Beitras zur Pilzflora von Böhnen und Nordmiitren. (I)aselbst 1895.)

3. Resultate der mykologischen Durchforschung Böhmens im J. 189S. (Sitzungberichte d. königl. böhm. Gesellsch. d. Wiss. Prag, 1902.)

4 Zweiter Beitrag zur Pilzflora von Bosnien und Bulgarien. (Oesterr bot. Zeitschrift, Wien 1903.)

5. Ein Beitrag zur Pilzflora vou Ingarn. Nöivénytani Közleméuyek, Burlapest 1907.)

1. Eine neue Tilletia-Art. (Zeitschr. f. d. landw. Tersurhswesen in ()esterreith. Wien 1909.) 


PLEASE dO NOT REMOVE CARDS OR SLIPS FROM THIS POCKET

\section{UNIVERSITY OF TORONTO LIBRARY}

EsoMed 


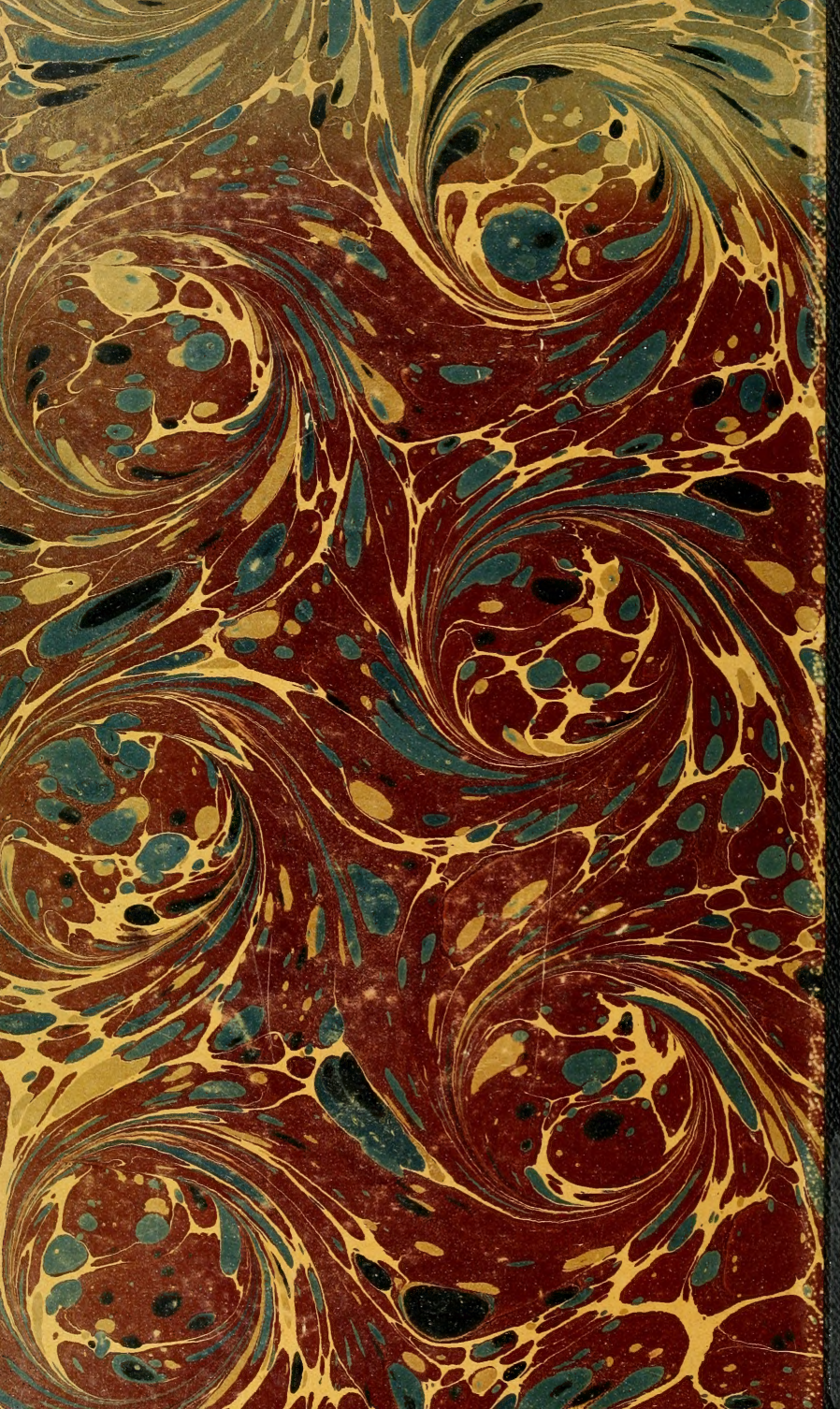

